Carl Joleijel 


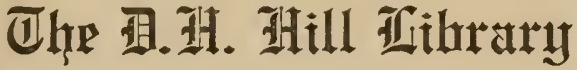

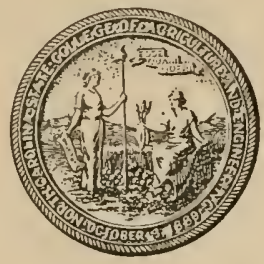

Ãnrth Caralina State Collene

SPECIAL COLLECTIONS

$$
\begin{aligned}
& \text { QK } 91 \\
& \text { S6 } \\
& \mathrm{v} .1
\end{aligned}
$$




\section{0}

This book must not $b$. taken from the Librar building.

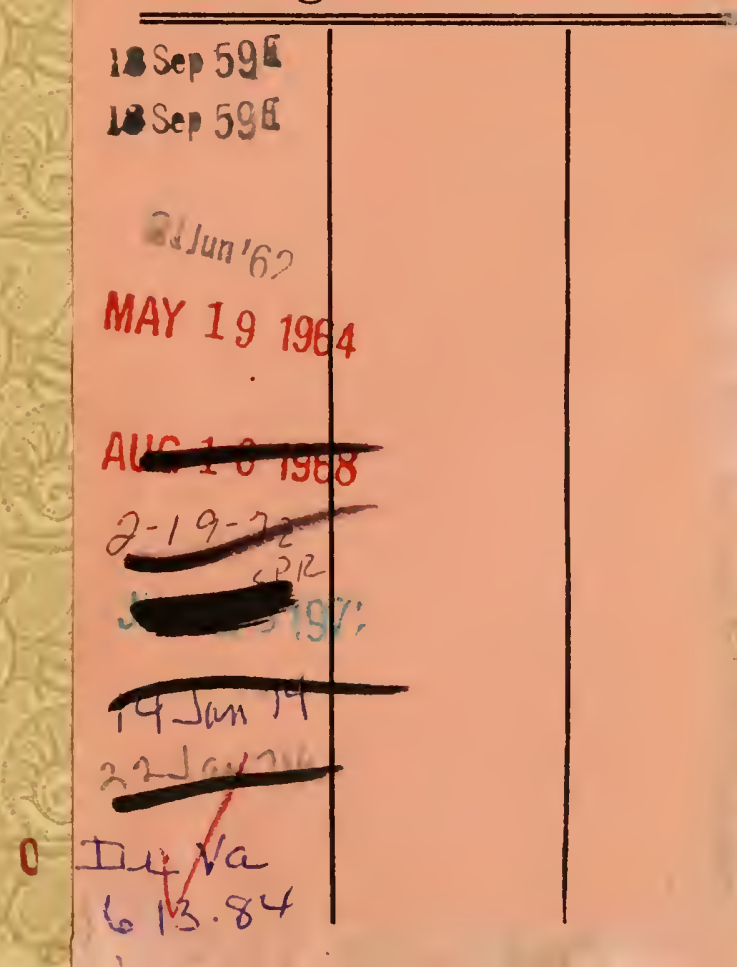


$m=3$

$\$ 17$ 195 


\section{CAROLI LINNÆI}

Si R:gie Mitis Svecie Archiatri; Medic, \& Botan.

Profess. Upsal: Equitis aur. de Stella Polars, nec non acad. Imper. Monspel. Berol. Tolos.

UPSAL. STOGKH. SOC. \& PARIS. CORESP.
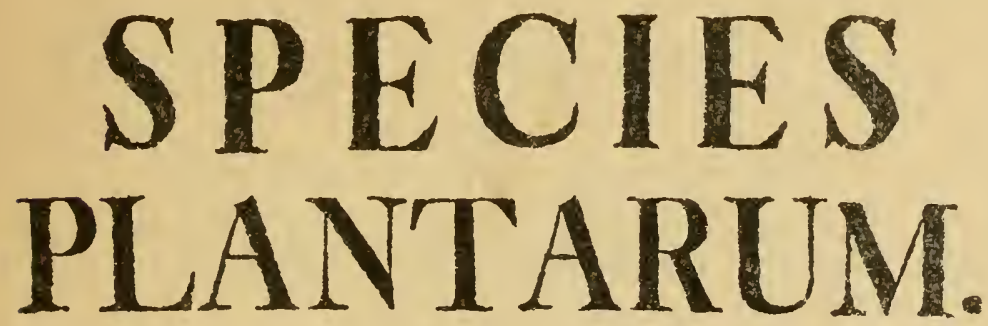

EXHIBENTES

PLANTAS RITE COGNITAS.

$A D$

GENERA RELATAS.

CUM

Differentils Specificis,

Nominibus Trivialibus,

SyNONYMIS SELECTIS,

Locis Natalibus,

SECUNDUM

SYSTEMA SEXUALE

DIGESTAS.

TOMUS $\mathbf{I}$.

Cum Priviligio S. R. Mitis Suecia ts S, R. M:tis Polonira ac Elentoris Soxon.

HOLMIE.

IMPENSIS LA URENTII SALVII.

I 753 . 
Ignoto Genere proprio nulla defcriptio, quis accurata tradita, certam demonitrat, fed plerumque fallit. CASALP. profai. 
STORMAGTIGSTE ALLERNALDIGSTE

\section{KONUNG OCH DROTTNING} ADOLPH FRIDERIC, LOVISA ULRICA,

Sveriges Gíthes och Vendes

KONUNG OCH DROTTNING!

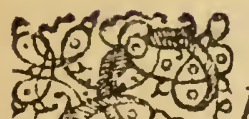

DRA MAYESTETER ar jag 6) allerunderdinig/t fkyldig detta verk,

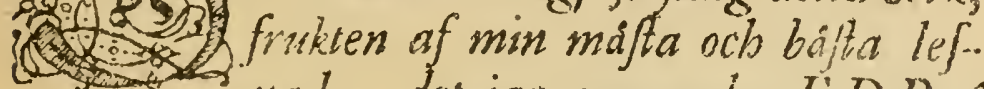
nad, det jag nu under EDR A $M A \mathcal{E}$ STETERS milda regering fats med noggdt och roligstinne fullbordt. 
EDRE MAJESTETER bafva, ifrin förtha lyckeliga ankomaten til riket, fádse anfett mig med blida fralar, kallat migfom ofiaglit til $S_{i t}$ Hof, och betygat emot mig all K.ongelig nad.

EDRE MAFESTETER bafva ock gifrit den Veten/kapen, fom jag idkat ljus och anfeende i Sit Rike, di EDRE MAFESTE$T E R$ ej allenaft allernidig/t latit Skaparens anderverk for fig befkrifvas, utan ock bopkallat allehanda jordenes inbyggare af alla tre Naturens riken, famt befalt dem inlogeras uti fina prikktiga luft-Jott Ulriksdabl och Drottningholm, der deffe, likfom deputerade fran bela vida verlden, fo dageligt forretride for MAJESTE. $T E N S$ igon.

Tror mig altfa ej fága fór mycket, da jag rent ut bekanner, at ifran den visa Konung $S a-$ lomons tid ocb Drotningens af rika Arabien, inga Potentater g jordt pâ den Alsmágtiga. Skaparens underserk ftorre aktning.

Ty bór och /kal demna Vetenfkapen táfla med alla andra minnesmairken, at góra EDRA MAYESTETERS namn ododeliya, da den in. 
inpraglar demi Naturens egen bolk, fom arligen d nyo uplagges, at blifua med Fordklotet lika. beftindig.

Himmelen gore EDRAMAFESTE$T E R S$ dagar ocb regering lang och lyckelig. Sa viff jag lefuer ocb dor

EDRA KONG. MAJESTETERS

allerunderdänigfte och tropliktigfte

tjănare och underfäte

CARL LINN EUS. 


\section{LECTORI EQUO.}

Homo fui confcius obfervat MUNDUM effe omnipofcize fapientiz miraculis, fe vero in hunc, tamquam Hofpitem introductum, ut hifce deliciis fefe delectando magnificentiam Domini agnolcat. Indigmus profecto is cenfendus hofpes, qui, pecoris inftar, tantum gula infervit, nec magnalia poffefforis intueri atque æuttimare novit.

HOSPITES ut digni evadamus orbis, opera hæc Creatoris fcrutari nobis neceffe clt, quae ita cum noftris commodis combinavit fummum Ens, ut eis, unde omnia noftra bona defumimus, carere nulla ratione quxamus; \& quo magis hæc intelligimus, co etjam plura in ufum generis humani cedunt.

COGNITIONEM horum ut rite acquiramus, fingula diftincta Idea \& diftincto Nomine complecti oportet, quibus fepofitis copia rerum nos obruat necefte eft, \& com. mercium omne, deficiente comnuni lingua, ceftabir.

SCIENTIA NATUR $£$ inde inter Homines nata eft, quæ comprehendit fub phyfica \& Chemia Elementa, fub Zoologia, Botanica, Lithologia tria Naturæ regna.

REM HERBARIAM heic libare lubet, qux quondam paucarum plantarum erat Scientia; hodie vero copia delectorum evafit omnium amplifima.

INVENTORUM recentioris zvi indefefis laboribus notitiam debenus plurium Plantarum, nuam omnibus prifcorum temporum eruditis, inter quos imprimis nominandi Clufuss, Columna, Baubini, Hermannus, Rhecde, Sherardus, Rajus, Plukenetius, Toutrnefortius, Plumierus, Vaillantius, Dillerius, Gmelinus. E'c. 


\section{LECT ORI.}

NOTITIA plantarum conftabat quondam Nominibus arbitraris, memoria tabula infixis, quam vacillantem Icones fiblevabant.

SYSTEMATICORUM fapientia indagavit ordinem qui memorix fuccurrerct, \& Icientiam folidis fundzmentis inadificaret, quem debemus Principibus Viris Gefnero, Cafalpino, Baubino, Morilono, Hermanno, Tourmefortio, Vaillantro, Dillenio, aliisque.

ARIADNEUM hoc filum Syftematicorum terminabatur Generibus, quod tentavi ad Species usque extendere, confectis legitimis harum differentiis, ut erjam in hilce lia fibi confturet certitudo, quum omnis vera cognitio cognitione fpecierum innitatur; hac enim dificiente vacillat \& hiftoria, ut in plerisque Peregrinatorum diariis.

SPECIES plantarum ue mihi familiares redderem, peragravi Alpes Lapporicas: totam Suciam: partem Norvegia, Dania, Germania, Belgii, Anglia', Galiia: perquitivi deinde HORTOS Botanicos: Parifinum, $O$ xorienfem, Cibelfcianum, Hartecampenfem, Leidenfem, Ul-

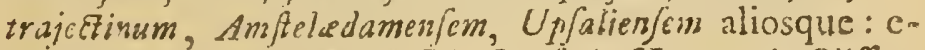
volvi etjan HERBARIA Burferi, Hermanni, Cliffortii, Burnanni, Gronovii, Royeni, Sloanei, Sberardi, Bobarti, Mi!leri, Suriani, Tournefortii, Vhillantii, Fufiai, Backii \&c. Meo fuafu DISCIDULT quondam dileEtiffimi: P. Kalmius Canadam, F. Hafjelguilt IEgyptum, P. Osbeck Chinam, P. Leefling Hifpaniam, Montin Lapponiam adire, plantasque lectas mecum communicarunt. E variis terris demum mifere Amici BOT ANICI femina plantasque ficcas non paucas, uti B. Jufreu, Ravenus, 7. Gefnerus, WWacbendorfus, Sibtorpius, Montius, Gleditfchius, Krafcbeninnikoffirs, Minuartius, Velezius, nec non $Q$. Muncbbaujen L. B, S. C. Bielke L. B, F. Ratbgeb Eqü. Demi)० 4

doff 


\section{LECTORI.}

Wojf Nob. Collinfon, Toren, Braan, aliisque Cififordo: mines quas in duplo habuit: Lagerftrom india orientalis plurimas: Gronovius plerasque Virginicas \& Gmelinus Sibericas facile cmnes, at Snavagcfius integrum fuum thefaurum plantarum dedit, exemplo raro \& inaudito, ande factum, ut copiam plantarum obtinuerim non mediocrem.

DIFFERENTIAS Specificas antehac Plantis non pallcis impofui in Flora Lapponica, Suecica, Zeylanica, in Horto Cliffortiono, Uplalienfi. lisdem principris infticere praitancifimi Botanici Gronovizs, Royenus, HVacbendorff, Gorrer, B. Fuffreus, Le Menier, Gvettard, Dalibard, Snuvages, Colden, Hill, inque non paucis Hullerus. Gmelinus aliique, quorum opera plurima Species evafere ratæ \& evidentes.

NOMIN A hec pallim difperfa in gratiam ftudioforum confujtum duxi colligere, acquifras dein plantas addere, inque unum Sylterna reducere; at vero pluribus Speciebus obfervatis, prxitantioribus noris detectis, aptioribus Terminis cufis, debui interdum differentias emendare, antea quamyis oprimas,

Characteres efientiales pro NOMINE SPECIFICO conftituere non levidenfe opus eft; requirit enim Species wm plurium accuratam cognitionem, harum attentisfimam portium indagationem, differentium felectionem, Terminorum denique artis propriam applicationem, ut evadant compendiofifimi tutistimique.

NON VISAS plantas heic omifi, toties elufus $a b a u$. Atoribus, ne dubia certiffmis mifcerem, fi vero aliquando contigerit non fufficienter infpexiffe plantam, val lpecimen imperfectum obtinuife, figno thoc notavi, ut alii eandem accuratius examinent. 


\section{LECTORI.}

Non nominatas in hoc Libello plantas, fi quis ad me mittere velit, eas in proxima editione V.D. recenfebo cum honorifica recenfione datoris.

NUMERUM plantarum totius orbis longe parciorem effe, quam vulgo creditur, fatis certo calculo inteliexi, utpote qui vix ac ne vix 10000 attingat.

TRIVIALIA nomina in margine appofti, ut miffis ambagibus, uno quamlibet Herbam nomine complecti queamus; hæc vero absque felectu polui, quippe quem alius dies pofcit. Caveant autem quam fanetiffme omnes fani Botanici, umquam proponere nomen triviale fine ifflicienti differentia fpecifica, ne ruat in priftinam barbariem fcientia.

SYNONYNA paucirtima in EUROPIEIS plantis adhibui, contentus C. Baubino \& lcorograpbo preitantiore; in EXOTICIS vero plura, quum difficiliora minusque trita fint.

DESCRIPTIONES tantum in obfcuris adhibere necesfum fuit, easque fine ambagibus, ut obtinerem compendium tironibus gratum.

LOCA natalia more meo adjeci, inque notifimis Fruti cantes 7 , Perennes 4 , Biennes ơ, Annuas $\odot$ notavi.

GENERA nonnulla nova, nonnulla imrutata adhibui, qux in nova editione Generum plantarum gropedien filtere animus eft.

ADVERSARIORUM tela nunquam retorfi: acerrima convitia, infimulationes, cavillationes, buccinationes, (præitantiorum longe Virorum, omni xvo, laboris præmia) tranquillo animo fuftinui, nec fuis audtoribus hac invideo, fi inde iphis apud vulgus gloria ma- 


\section{ECTORI.}

yor. Fero hxc, qux in me ne capilium qquidem mu. tant, \& cur non ferrem iniquos, qui a veris Botanicis \& quidem confummatifimis, quibus affurgere debent illi, fummis cumulatus fum encomiis. Parem deinde adverfariis referre gratiam, nec anni ingravefcentes, nec munus, quo fungor, nec mci mores patiuntur. Quod mihi fupereft brevioris avi, tranquillus utilioribus oblervationibus impemdam. Res naturales enim proprio privilegio munitæ perfiftunt, ut quemadmodum errores in his comrnifi a nullo defendi, ita nec veritates obfervationibus innixa 2 toto e"uditorum orbe conculcari poffint; judices itaque pro. vuco Reros Nicpotes:

Pafcitur in vivis livor, foft fasa gaiefict, Tum fuus ex merize quemque thetsy bonos.

Dabam 1753 d. 2 Maji. Upfaliz.. 


\section{AUCTORES}

REFORMATORES.

Propkia Genera plantarum. Lagdb. I752. nef. Philofophia Botanica. Ha?mior. 1751 . of. Hortus Cliffortianus. Amafte!. 173\% fol. Hortus Upfalienlis. Holmise 1748 . of Flora Sueclca. Holmin 1745. of?. Flosa Lappunica. Amfepl. 1737. oft. Fiors Zeylanica. Helmix 174\% oet. Viridarium Cliffortian. Am/sel. 1737. oef. Mareria Medica. Holmior 1749. off. Amoenitdi. Academ.1. Lipfre. 1749. of?. Amcenitat. Academ.2. IJulmix 175\%, oft. Iter Oelandicum. Holmia 1745. ofe. Suer. Iter Gotlandicun. Holmice 1745. oft. Puss. Iter Weitrogothicum. Holmia 1747 . net. Swer. Iter Scanicum Holmiae 175i. ofl. Juet. A da Upfalienf. R foc.tlolmio 1740. Esc. quart. Ada Stockh. R. foc. Holmis 1739. E36. on feser.

$$
\text { * * }
$$

KALM FETR. Plantz catadenes propediem ederda. HASSELQUIST FR. Pl. ayjpti in act, upf. É suilzols. OSBECK PETR. Pl. chinenfes in licuris, Mfc. L.OEFLING PETR. Pl. hifpance in giflolis Mffe.

$$
\text { * * * }
$$

Gronovius J. F. Flora virginics \& z. Leida 1739 of?. ROYEN ADR. Flora leidentis. Leida 1740. oit. GORTER DAY. Flore geiro-zulphan. Harderv. $1 \%+5$ or?. JUSSIEU $B$. GUETTARD M. DALIBAKJ M. SAUVAGES Fr. COLDEN CONR. Pl. rarrores vatias in lit. Es nall. parif. Obfervations fur les plantes. Parif.ry47. wa?. Flora parifienfis. Parif. 1799. duud. Flora inonfpelientis. Haga 175 ' od. Plantz coidinghamix. ad. wy5. 1743. quart. WACHENDORFFE.J. Fiot tus Ultrajectinus. Trajeit. 1747. oft. HALLER ALB. LuUVig. C.G. GMELIN J. G. Stirpes belyetic a Gorsing. I 742 . Fol. Genera Aptiorismi, Lipf, 173 oct.

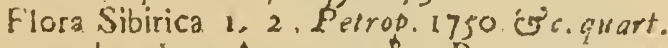
Moniek. Lud.Gun., cat, des pl.en Auvergne \&c. Par. 1745 . $p$.

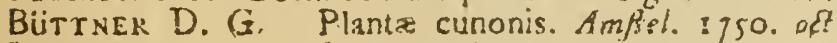
HuL $\mathrm{JOH}$, MITCHEL JOH. Monti Cajet Hiftoris of plants. Lond. ryst. fol. Genera pl: virglnic. E. $N, C^{\prime}$. Seslerus Leonh. Epiftola de vitaliana. Venct. a 750 fol. 


\section{USITATIORES.}

Bauhin: pinax.

Bauhini Hifloria pl.

Camerarii epitome.

Columna ecplornfis.

Clufil biforia.

Dodonxi pemptades.

Fuchfii bilturia.

Dalechampii biftoria.

Marcgravii brajilia.

Alpinus exotica.

Lalelii prujuca.

Lobelii Lcores.

Brunsfelfi Hifuria.

Tabernamontani Hiftoria.

Cornuti Canaderfes

Renealini Specimen.

Morifoni hiftoria. 2. 3.

Raji

Plukenerii

Potiveri

Sloani

Hermiann:

Rheede

hiforis. 1. 2. Supplementum 3. Symofis 3:tia

Almagefium, Pbytographia.

gazapbylacium.

Famaica.

Hort. lugdbat. Paradifus.

Hort. malab.

Commelini Hort amftel. I 2 Preludia.

Breynii Centuria.

Dodarti menzoires.

Prodromus a filio.

Rivini Ordines.

Tournefortii infitutiones.

Plumierii. Genera, Species, Amiricana, Filaces.

Fewillxi

Ifnard

Bocconis

Barrelieri

peruviana.

aEla parifina.

Lineum,

Sicula planta.

Irones.

* * *

Boerhavii

Kəmpferi

Hortus lugd-batavus.

Amonitates exoticx.

Scheuchzeri Gramina; Itinera alpina.

Michelii Genere nova.

Vaillantii Asta parifina. Flora parifina.

Monti

Gramina.

Tilli Hortus pifanus.

Buxbaum.

Catesby

Burmanni

Amanni

Dillenii

Seguieri

Centurió.

Carolisisa 1. 2. 3.

Zcylanica, africanarum decades.

Martyni Centuria،

Rutbsisica, Herbarium.

Eltibamenses, Musci.

Verona.

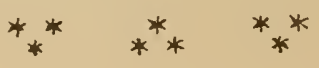

Clas - 


\section{Clasfis \\ Pag 1 . \\ MONANDRIA \\ MONOGTNIA. \\ $C A N N A$.}

I CANNA foliis oratis utrinque acuminatis nervolis fiatica.

Roy. ikgdb. II. Fl zeyl. I. Hurt. asp'. i

Cantua fpatulis billoris. Hort. cliff. 1.

Arundes indica larifolia. Bauth.pin. Ig.

Hisitat inter tropicos Afix, Atrica, Americx. If

2. CANNA foliis lanceolatis petiolatis nervoris.

Canna ioliis lanceolatis petiolatis. Hori. sliff. 1 .

Arundo indica tiorida anguftifolia. Noris niji. $3 . p \cdot 250$.

f.S. t. 14. f. 6 .

Habitat ivier tropicas America: Uimbrofüs fonngintas. 4

3. CANNA foliis ianceolatis petiolatis enervibus Ruy glasuir. lugdl. II.

Canna foliis enervibus. Tirid. cliff. 104.

Cannodes. Hort. cliff. 488.

CannaAcorus glaucophyllus, ampliore tore, uridis paluftris facic. Dill. elth. 69. t. 59. f. 69 .

llabitat i,a Carolina?

\section{AMOMUM,}

AMOMUM fcapo nudo, ipica ovata. Hort. cliff. 3. Zingiber. Hurt upS. I. Flor. zeyl. 3. Mat. ined. I. Roy. lugdio. 12 .

Zingiber. Baub. pin. 35 .

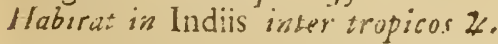

2. AMOMUM fcapo nudo, fpica oblonga obtura. Hort. Zerumbel cliff. 3 Hort. upl. I. Fl. zeyl. 2. Roy. liggdb. 12.

Zingiber Jatifulium fylveftre. Merm.lugdb.636. t.6,37. IIabit $2 \%$ is. India. 2

3 AMOMUM feapo brąeis alternis laxis caule bre-Cardamom. viore. Fl. zey. 4. Nat. med. 2.

Elettari 2. Rbied. mal. I1. p. 9. t. 6.

Habitat in India. $Z$

D. H. HILL LIBRARY

North Carolina State Colleg. 
Gran.peras. 4. AMOMUM f́apo veftito racemofo.

Amomum caule racemolo. Mat. med. 3 .

Grana paradifi ofticinatum. Baub. pin. 4I3.

Habitat in Madagafcar, Guinea.

COSTUS,

abien \& COSTUS. Hort cliff. 2. Hort. upf. 2. Fl. 2.egl. 5. Mat. med, 4. Roy. lugdb. is.

Coftus arabicus. Basb. pin. 36. Mar. Jurin. 36. s. $3^{6 .}$ Habitat in India abrague. 2

\section{AI.PINIA.}

remasa, 1. ALPINIA Roy. lugdb. 12.

Alpina racemola alba, cannacori foliis. Plum. Gen, 26 Paco feroca Marcgr. braf. $4 \$$.

Habitat in America calidiore. 25

MARANTA.

rundinseso 1. MARANTA. Hort. cliff. 2* Roy. lugdb. It. Maranta arundinacea, callnacori folio. Plum. gen. io Mart. cent. 39. () Habitat in America calidiore. 2

\section{CURCUMA.}

ratund. 1. CURCUMA foliis lanceolato-ovatis; nervis laterali. bus rarifimis.

Curcuma foliis ovatis utrinque acuminatis: nervis lateralibus pauciffimis. Roy. lugdb. I2. Fl. zey\%. 6 . Manja-kua. Rbeed. mal. 11.p.19. t. 10." Habitat in India. 2

longs. 2. CURCUMA foliis lanceolatis : nervis lateralibus numerofiffimis.

Curcuma foliis lanceolatis utrinque acuminatis: nervis lateralibus numerofifimis. Koy. lugdb. I 2. Fl. zey/. 7 . Mat. med. r.

Curcuma radice longa. Herm. lugdb. 208. t. 20\%. Habitat in India. 2

\section{KAEMPEERIA.}

Salostg, 1. KAEMPFERIA foliis ovatis feffilibus. Fl. zeyl. 8. Mat. med. ว. Kaempferia. Hori. cliff. 2. t. 3. Roy. lugdb. I2. 
Wantom. Kaempf. rmioen. gor, t. 902.

Ilabitat in lndia. $z$

2. KAE.MPFERIA folits lanceolatis petiolatis. Fl. zeyi. rotndz. 9. Mat. med. $?$

Zedoaria motunda. Baub. pin. $3^{\mathrm{r}}$

Habitat in India.

\section{BOERHAVIA.}

BOERHAVIA caule ereáo.

orgtia.

Boerhavia, jollni fojio, erefta glabra. Amm. herbi $24 \pi$.

Mabitat in Vera Crucc. *

2. BOFRHAVIA canle diffuro.

Bocrinavia diffilid. Fl. acyi. ro. IJort. wpf. 4 .

Boerhavia folis ovatis. Hort. cliff. $x 7$. Koy. lagdb.234.

Talu-dama. Rheed. mal. 7. p. 105. ¿. jö:

liabitat in India. 2

3. BOERHAVIA caule fondente.

Solanum baccifenm americanum, fruetu corymbofo. Pluk. alm. 3+4. t. 226. f. 7 .

Valerianella, alfines folio, feandens. Sloan:flor 91 . hift. I. p. 210. Raj. Fuppl. 244 .

Antanifophyllum icandens, alfines majoris folio. Faill: ast. $1722 . p \cdot 258$.

Habitut in Jamaica ad urbem jagn de la vega. z

4. BOERHAVIA caule repente.

Boerhavia nubica ininor. V rill. eex: 53 .

B Boerhavia nubica minina. Vail! fex. 55.

Mabitat in Nubia inter Mocbo Ev Tizngos.

diff $\mathrm{x} / \mathrm{s}$.

$$
\text { SALICORIIA. }
$$

1. SALICORNIA articulis apice craffioribus obtufis. esropies. Mat. meá. 8 .

Salicornia herbacea. Fl. frec.l.

Salicornia annud. Sauv. mon $\iint_{2} 7$.

Salicornia. Hort. cliff. 450. Roy. lugdb. 205

3 Salicornia fempervivers. Sauv. monip. 7.

Kali geniculatum majus. Bauh.pix. 280.

repeni

fandens.

Habitat in Europx litoribus maritimis. 50

Conferantur annua \& fempervirells utruin $\int p e c i c d$ fincte?

4. SALICORNIA articulis ubrulis bafi incrafiatis, fpicis arabicr. ovatis.

A : 
Kali geniculatom majus. Baub. pin. 289. Morif. bift.

p. 610. $\int .5 . t .33$ f. 7. Raj. bift. 211 .

Habitat in Arabia.

virginia. 3. SALJCORNIA articulis apice compreflis emarginatis bifidis.

Salicornia caulium ramorumque articulis apice bicorni-

bus Gron. virg. 129.

Habivat in Virginia, of ad Salinas Saxonix. $\odot$

raspici. $\quad$ SALICORNIA articulis cylindricis, Spicis filiformibus.

Kali arborefcens, tamarifci facie. Buxb.cext. 1.t. II.f.।

Hatitat an fqualidis maris Cafpii Ev Medix 5 .

\section{HIPPURIS.}

vuigaris

6. HIPPTIRIS. Fl. lapp. 1. Fl. Juec. 2. Hort. cliff: ;. Kuy. iugdb. 205. Dalib. parif. $\mathbf{1}$.

Equiletum paluftre, brevioribus foliis, polyfpermum. Baub. pin. 35 .

Habizat in Europa fontibus. $z$

\section{DIGTNIA.}

\section{CORISPERMUM.}

byfopifol. 1. CORISPERMUMM floribus lateralibus. Hort. ups. 2. Corifpermum fioribus alternis. Hort cliff. 3. Ft. gotl. 316. Roy.lugdb. 205. Sauv. monsp. 52 .

Corifpermum hyffopifolium. Fuff. act, 1712. p. 244. Habitat aáVolgam 'Tastarix, Gillau Borufix, Monfpelii arcrofis

figutrofum, 2. CORISPERMUM fpicis fquarrofis. Hort. ups. 3. * Rhagron is foliis arundinaceis. Buxb.cent. $3 \cdot p \cdot 30 . t 55$. Habitat ad Wolgam Tartarix, inque defertis Coffacoruni. $\odot$.

\section{BLITUM.}

cupiratum. I. BLITUM capitellis fpicatis terminalibus. Hort.up $5 \cdot 3$. Biitum foliis triangularibus dentatis, calycibus baccatis, capitulis furmis nudis. Virid. cliff. 1. Rby. lugdb.206. Bitum foliis triangularibus dentatis. Hort. cliff. 28. Atriplex baccifer3. Ray. biff. 197.

Hucitat in Europa: prajertion in comit. Fyrolenfi. ()

wargin..3. 2. BLI'TUM capitellis fparfis lateralibus. Hort. upf. 3 . Blitum folis triangularibus dematis, calycibus bacca- 
tis, caprulis funmis foliolis. Hort. cliff. 195. Roy. ingab. 206.

Atriplex fylveftris, mori fructu. Baub. fin. x19.

Haoitat is Tataria, Hifpania. $\odot$

\section{CINNA.}

1. CINNA.

Habitat in Canada, rince feinina per D. Kalm. $z$

arkndinaced.

Gramen magnitudinge Avence fative. Folia fere arundinacea, lieviufcula. Panicuia denfa, flaccida. F lores conferti, Jecundi, latersbus calycis \&o petalo majore Scabri. Arila onfra apicem Glume majoris petali brevis. fima. Gramen inamanum ftamine unico spectabile. 


\section{Claffis 11 . \\ D I A N D R IA \\ $M O N O G R I A$.}

\section{NYCTANTHES.}

arion stiftis. 1. NYCTANTHES caule tetragono, foliis ovatis acuminatis, rericarpiis membxanaceis conpreftis. Fl.2eyl il.

Arbor triftis myrto fimilis. Ban bin 469

Manja-plimeram. Rbeed mal. 1. p. 35.t. 21 . Fiabrat in India. b

Sombat 2. NYCTANTHES folic inferioribus cordatis obtufis, fuperioribus ovatis acutis. Hort. upf. 4.

Nyctanthes caule volubili, foliis Irbovutis acutis. Hort. "liff. 5. Hart. uff. +."Flas. zoyl. 12. Koy. lngat. 395.

faiminum arabicum. C'kf, csr. 3.t. 3, Aingl. bort.t. 27. Habriat is India. 5

undulat 3. NYCTANTHFS foliis ovatis acuminatic undulatis, ramis teretibus.

Jafninum indicum, fore poiypetalo exelbido, fruetu minori, Ray. bijt. I 601.

Tfieregain-inuila. Rbeed. mal. 6. p.97.t.55.

Ifohitut in Malabaria. t

hiryte, 4. NYCTANTHES petiolis peodunculisque villofis. $\odot$ Rava-pou. Rbced. mai. i. p. ryg. t. 48 .

Habitat in India. b.

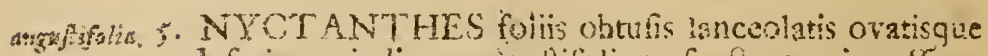
Jafminas indicum argut: foliam, friens gemino. 'Tour. $32 f .73$. 538 .

Kati-pitfe. man mulla. Kkek. mal. 5. 5.93.t. 53.Ray. bili. Itoz.

Hubiat in Malabariz arewofis. b; 


\section{JASMINUM.}

I. JASMINUM foliis oppofitis pinnatis. Hort. cliff. 5 . affirinale.

Hort. ups. 5. Mat. med. 9. Roy. Lugdb. 397. Jafininum vulgatius, flo:e albo. Baub.per. 397 . Habitat in India. B

2. JASMINUM foliis oppofitis ternatis. Hort. cliff. 5. azorisam. Fl. ₹ey!. 13.Roy. lagdb. 397.

Jalininum azoricumtritoliatum. Comm, hork, 1. p. s ro. t. 82 .

Habitat in India.

3. JASMINUM foliis alternis ternatis fimplicibusque, froticarts ramis angulatis. Hort. sliff. 5. Hort. ups. 5. Roy. lugdb. 397. Sauv. monsp. 174 .

Jafminuni luteum vulgo diktumbacciferum. Bsab.pin. 398.

Habitat in Europa auftrali.

4. IASMINUM. foliis alternis ternatis pinnatisque, ra- harili,. mis angulatis. Hort. $u p$. 5 .

Jafminum follis alternis ternatis acuminatis. Hort. chiff. 6. Roy. lugdb. 398 .

Jasminum humile luteum. Baub. pin. 397. Habitat - . -

5. JASMINUM foliis alternis ternatis pinnatisque, s2-odorafifim. mis teretibus. Hort. ups. 5 . Jafminum foliis alternis ternatis obtufs. Hort. sliff. 5 . Rog. lugdb. 397. Jafminum indicum flavam odoratiffinum. Ferr. cult. 93 . Habitat in India? b

\section{L.IGUSTRUM.}

1. LIGUSTRUM. Hort.cliff. 6, Fl, svec.4.Ruy. lagdb. vilgars, 398. Dalib. parif. 2. Liguftrum germanicum. Basb. pin. 475 Habirat in Europacallibus glareofis. $\hbar$

PHILLYREA.

1. PHILLYREA foliis lanceolatis fubintegerrimis. Hort. angnfifol. upS. 5 .
A 4
Phil- 
Phillyren foliis ovato-lanceolatis vis a culatis. Hort. sliff. 4. Ruy. lugdb.. 398.

Phillyrea liguttri folio. Bauh.pin. 476 .

Q.Phillyrea foliis lanceolatis integerrimis, Hort. cliff. 4 . Roy. lugdb. 398.

Phillyrea angutifolia r. 2. Bauh. pin. 476.

Habitat in Europe anftralioris collibus. b

iarifotid, 2. PHILLYREA foliis cordato-oratis ferratis. Hort.cliff. 4. Hort. ups. 6. Roy. lugdb. 398.

Phillyrea latifolia fpinofa. Baub. pin. 476 .

Phillyrea folio leviter ferrato. Baús. pin. 476

Halstat in Europa auftrali. 5

\section{OLEA.}

-xropes. 2, CI.EA foliis lanceolatis.

Olea foliis lanceolatis, ramis teretiufculis. Hort.cliff.4. Mat. med. 10. Koy. lugdb. 398.

Olea fativa. Bauh. pin. 472.

Q. Olea foliis lanceolatis, ramis tetragonis. Hort, cilff. 4 . Roy. lugdb. 399.

Olea fylveftris, folio duro fubtus incano. Ba:sh, pin. 472. Habitat in Europa auftrals. b

sapenfis, 2. OLEA foliis ovatis. Hort. cliff. 4. Roy. lugdb. 399. liguftrum capenfe fempervirens, folio craffo lubrotul. do. Dill. elth. 193.t. 170. f. 194. Habitat ad Cap. b. Spei. $b$

\section{CHIONANTHUS.}

virginica. I. CHIONANTHUS pedunculis trifidis trifloris.

Chionantnus. Hort. sliff. i? Grorz. virg. 10. Roy. lugdb. 17.

Amelanchier virginiana, lanrocerant folin. Pet.. fice. 241. Catefo. carol. 1. p. 68 . t. 68. Habitat in America Jeptentrionali. 5

*eylonicu, 2. CHIONANTHUS pedunculis paniculatis multifloris. Fl. zeyl. I4:

Arbor zeylanica, cotini foliis fubtus lanugine villofis. Burm. zeyl. 31 .

Habitat in Zeylonis. 5 


\section{S YRINGA.}

1. SYRINGA foliis ovato cordatis. Hort. cliff. 6. Hort. whigaris. upf. 6. Roy. lugdb. 397. Dalib. parif. 2.

Syringa carulea. Bauh. pin. 398.

Habitat verfus Pertiam. 5

¿. SYRINGA foliis lanceolatis.

perfica.

a. Syringa foliis lanceolaiis integris. Hort cliff. 6. Hort. upf. 6. Roy. lugdb. 397.

B.Syringa foliis lanceolatis integris diffedisque laciniata. Hort. cliff. 6. Hort. upf. 6. Roy. lugdb 397.

Liguftrum foliis laciniatis. Baub. p:n. 476 .

Hatitat in Perfia? b

\section{ERANTHEMUM.}

ERANTHEMUM.Fl.zeyl. I5.* Amans. acad.385. "apense. Ephemerum ly chnidis Hore africanum. Herm. parad.1 53 . Amm. berk. 232.

Labitat in Ethiopia.

\section{CIRC $Æ A$.}

I. CIRCFA caule erećto, racemis pluribus.

Circæa. Fl. Suec. 5. Hort cliff. 7. Koy. lugdb. 303. Dalib. parif. 3.

Solanifolia Circæa dicta major. Barsh. pin. I68. It. wgoth. 213.

3. Circaa canadenfis latifolia, flore albo. Tournef. inft. canadenfis. 301.

Habitat in Europæ EF Americ borealis ncmoribus. $*$ Hiec Sefquipedalis caule erecio, Racemis terminali Eo lateralibus; Perianthiam confiftertia calycina, $\int$ curolla longe crafius, rudiusque, nee corolle concolor.

$\therefore$ CIRCEA caule adrcendente, racemo unico.

alpins.

Circæa cillyce colorato. Fl. lapp. 3.

Solanifolia Circea alpina. Bash. pin. I 68.

Hakitat ad radices montium in frigidis Europx. 4

Planta vix digiti longitudine, magis procumbens, calyce coloratu, uts corolla; differt quidem a priori, attamen ivirits affi is.

\section{VERONICA. \\ * Spicate.}

. VERONICA fpicis terminalibus, foliis quaternis qui- virginita. nisve. 
Veronica foliis quaternis quinisve. Hort. cliff. 7 * Gron. virg. 4. Roy. lugdb. 30r. Ciold. roveb. 3.

Veronica virgíniana procerior, foliis ternis, quaternis \& ctiain quinis caulem amplezantibus, fpicis floram candidiffmis. Pluk. alm. $38_{3}$. t. 70 . f. 2 .

Habitat in Virginia. 2 .

ipuris. 2. VERONICA rpicis rerminalibus, folis ternis rquali ter ferratis. Hort. appl. 7 . *

Veronica picata anguflifolia. Baub. pin 246.

Veronica mas lurtecta elatior. Barr. rar. I55. 2. 391. Liabitat in Europa aufrniore, Sibiria. 2"

masitma. 3. VERONICA fpicisterminaibus, foliis ternis inaqua* liter ferratis.

Veronica floribus fpicatis, foliis ternis. Fl. fuec. 6.

Vercitica foliis taptus ternis. Lirid, cliff. 2. Hort. cliff. 7. Ray. lastáb. 301 .

Veronica caule erecto, fpicis pluribus, foliis lanceolatis ferratis. Fil. lapp. 4 .

Ilabilat in martsmis Europa masrs aprisis. 2

torgejolin, 4. VERONICA ipicis terminalibus, foliis oppofitis lan* ccolatis ferratis acuminatis. Hort. upf. 7 .

Veronica lpichta latifolia. Barb. pin 246.

Veronica I ercetior latifolia. Cinf. biff. s. p. 346 .

B. Veronica ipicata longifolia aitera. Amm. ruth. 26. $2 \%$ Veronica ficicata, urticæ folio. Amm. ruth. 26. Halitat in Tataria, Autria, Suecia. 2

nccina, 5. VERONICA fpicis terminalibus, foliis oppofitis crenatis obrutis, caule eredo tomentofo. Hort. up. $\%$.

Veroụca caule fruticofo, tolis oblongis: inferiaribus crenatis petiolatis: Cuperioribus lefilibus integerrimis. Rov. lingds. 530 .

Veronica fvicata lanuginofa \& incana, Horibus cxruleis. Aram. rutis. 30.

Labitat in Ucrania, Samara. 4

fursta 6. VERONICA fpica terminali, foliis oppofitis erenatis obtufis, chule adfcerdente fimplicifimo.

Veronica Horibus fpicatis, foliis oppofitis, canie erceto. Fi. faec. 7. Dalib. parif: 3 .

Veronica folits oppofitis, caule foica terminato. Hort cliff. 8. Roy. lugdls. 302 .

Veronica picata minor. Bawh. pin. 247.

Viahiat in Europa Lorealis cavipis. 2 
7. VERONICA rpicis terminalibus, foliis opporitis ob- bybrids. ture ferraris fcabris, caule erecto.

Veronica foicata cambrobritannica, bugula fubhirfito folio. Raj. Jyn. 3.p. 278.t.11.f. 1.

Habizat in Europa rarius.

Obf. Folia veronica fequentis, Caulis precedentis, fed Spice majores pallidiores. 2

8. VERONICA fpicis lateralibus yedunculatis, foliis op." offinglis. politis, caule procumbente. Mat. med. 2 I.

Veronica floribus ficatis, foliis oppofitis, caule procumbenec. Fl.suec. 8. Dalsb. parif, 3 .

Veronica caule repente, fcapis fpicatis, foliis oppofitis ovais Atrigofis. F\%. lapp. 5. Hort. rliff. 8. Ray. lugdb. 302.

$V$ eronica mas fupina \& vulgatifima. Baub. pin. 246. Habitat in Europx fylwejtribus fersilibus. 2o

$$
\text { * Corymliofo-racemofa. }
$$

9. VERONICA corymbo terminali, feapo nudo.

Veronica foliis ovatis radicalibus, caule nudo. Roy. lugaib. 302.

Veronica alpina pumila, caule aphyllo. Borc. muf. 2. p. 17. t. 1 .

Veronica parua faxatilis, cauliculis nudis. Plak.alm.384.

t. II 4 . f. 3. Sega. zier. $241 . t$. 3r.f. 2.

Chamadrys alpina minima hirfuts. Baub. pin. 247.

Ifabitat in alpibus Europa auftralionis. 2 .

10. VERONICA corymbo terminali, caule adfcendente bellidivides. diphyllo.

Veronica caule non ramofo, follis obtulis crenatis, fioribus congeftis terminato, foliis ovatis lubalperis. Hall. belv. 53 I. t. I2. f. 1 .

Veronica aipina, bellidis folio. Banb.pin. $24 \%$ prod. I16 Burf. XII?: 27.

Habitut ins Helvecia, Pyrenais. 2

11. VERONICA corymbo terminali, foliis oppofitis Eonarata. ferrato dentaris, calycibus linearibus.

Bonarota. Micb. gen. Ig. t. I5. f., I2.

Padcrota Gest. 0 ?. I I.

Chamxdrys alpina faxarilis. Buzk, fiss. 248.

Habitut in alnibus lialicis. \&

12. VEFCNICA conymbo terminali, folits oppofitis, ca- nipine lycibus hilpidis. 
Veronica floritius corymbofis terminalibus, caiycibus hippiciis $\mathrm{Fl}$ juec. 13 .

Vcronic: caule Horibus terminato, foliis ovatis crena. tis. F. lapp. "i. t. 9. f. 4 .

$V$ eronica caule inferne procumbenta fruticolo, folis ovatis oppofitis. racemo terminali. Roy. lugdb. 302.

Veronica alpina frutefcens. Bauh. pix. 247.

Habitat in alpibus Europæ. 2

ferpyllifolia. I3. VERONICA racemo terminali fubfpicato, foliis ovatis glabris crenatis.

Veronica floribus folitarïs fubcorymbolis, foliis ovatis glabris crenatis. Fl. Suec. 14. Dalib. parif. 4.

Veronica foliis inferioribus oppotitis ovatis. fuperioribus alternis lanceolatıs, floribus folitariis. Hort. cliff. 9 . Gron. virg. 4. Roy. lugdú. 302. Ciolá. novéo. 1.

Veronica floribus fparfis, foliis ovatis crenatis glabris. Fl. lapp. 6.

Veronica pratenfis ferpyllifolia. Baub. pin. 247.

Habitat in Europa E' America Septentrionali ad vias, agros. 2

Beccabryga. 14. VERONICA racemis lateralibus, foliis ovatis planis, caule repente. Fl. Suec. II. Dalib. parif. 7.

$\checkmark$ eronica foliis oppolitis lævibus crenitis, tloribus racemofis lateralibus. Rov. lugdb. 302.

$V$ eronica foliis oppofitis lavibus crenatis, floribus laxe fpicatis ex alis Hort. cliff. 8. Gron. virg. 4.

Aliagallis aquatica major (minorque), folio fubrotundo. Bual. pin. $2 j 2$.

Habitut in Europa ad rivulos. \#

Amouil. $\nabla$ is. VERONICA racemis lateralibus, foliis lanceolatis ferratis, caule erecto. Fl. Suec. Io. Dalib. parif. 7 .

Veronica foliis oppolitis lavibus creliatis, floribus laxe fpicatis ex alis. Gron. virg. 4.

Veronica aquatica najor, foliw oblongo. Baub. pin. 252. Hiwitat in Europa ad follas. $(5$

fcutellata. 16. VERONICA racemis lateralibus pedicellis pendulis, foliis linearibus integerrimis. Fl. Suec. 9. Dalib. parif. 7 .

Veronica foliis linear-lanceolatis integris, tacemis laxe Horiteris Fl. lapp.9. Hort. cliff. 10. Roy. lugdt. 302.

Veronica aquatica alygutiolia fcutellata. Baub. Fin. 252.

Habiat in Eurcpe inkndatio. 26 
17. VERONICA racemis lateralibus, foliis multifidis. multifda

Verorica montana, rolio vario. Buxb. cent. I. p. 24. t. $3 \delta$.

Habitat in Armenix, Iberia graminofis. 2

18. VERONICA racemis lateralibus, foliis ovatis rugo-Chamadrys. fis dentaris, caule debili. Fl. Suec. 12. Dalib. parif. 4.

Veromica toliis oppofitis plicatis dentatis, fcapis ex alis inferioribus laxe fpicatis. Hort. cliff. S. Roy. lugdb. 303 .

Veronica foliis cordatis felfilibus oppolitis, raccmis laxe floriferis. rl.lapt. 8.

Chamedrys tpuria minor rotundifolia. Bat:k. pin. 249. Mabistat in Europie pratis. 2

19 VERON!CA racenns Iateraibus, follis cordatis ru- Intifoin.

gofis dentatis, caule fricto.

Veronica fo!lis oppofitis plicatis dentatis, fcapis $\mathrm{cx}$ alis fuperioribus laxe ficicatis. Hort. c!.ff?.?. Roj. lugdh. 303.

Veronica praterfis omnium maxima. Buxb. cont. I. p. $23 . t .34$.

Chamædrys fpuria major latifolia Bauh. pin. 248.

Habitat in Helvetia, Bithynia. $z$.

\section{*** Pedunculis unifloris.}

20. VERONICA floribus folitariis, foliis cordatis incilis agrefis. pedunculo brevioribus. Fl. Suec. 17. Dalib. par if. 6.

Veronica foliis cordatis crenatis, floribus folitariis pedunculatis. Roy. lugdb. 303.

Veronica foliis alternis cordatis crenatis, foribus folitariis. Hurt. cliff. 9 .

Alfine chamxdryfolia, flofculis pediculis oblongis infidentibus. Baub. pin. 250.

Habitat in Europe cultis, arvis. $\odot$

21. VERONICA floribus folitariis, follis cordatis inci-arven/is fis pedunculo longioribus. Fl. Succ, : 6. Dalib.paril.5.

$V$ cronica foliis oppofitis cordatis crenatis, floribus folitariis feffilibus. Hort. cliff. 9. Gron. virg. 4. Roy. $\operatorname{lng} 26.303$.

Aitine veronicæ foliis, flofculis cauliculis adhærentibus. Bauh. pin. 250.

Mabitat in Europæ arvic, cullis.

22. VFRONICA floribus folitariis, foliis cordatis pianis sencirictiz. quinquelobis. Fl. fvec. IS. Dalib. parif. 6 . 
Veronica foliis alternis cordatis quinguelobis, floribus folitariis. Hort. cliff. 2. Roy. Iagdis. 303.

Alfine hederulx folio. Baub. fin. 250.

B. Veronica chia, cymbaiarix folio, verna, flore albo: umbilico virefcente. Tournef. car. 7 . Buxbo c cmt. $x \cdot p \cdot 25$. t. 39. f. 1 .

Habitat in Europx ruderatis. $\odot$

* Obr. Semina umbilicata funt buic propria.

sriphyllos. 23. VERONICA floribus folitariis, foliis, digitato-par titis pedunculo orevioribus. Fl. fusec 99 . Dalib. parif. 6

Veronica foliis alternis: inferioribus quinquepartitis; $f u$. perioribus tripartitis, floribus folitariis. Hor: cliff. 9 . Roy. lugdb. 302.

Veronica triphyllos cæruica. B.inh. pin: 250.

Habitat in Europe agris. ()

3cru. 24. VERONICA floribus folitariis, foliis digitato-partitis pedunculo longioribus. Fl. fuec. 20.

Veronica humiis ereda montana, flore parvo caruleo. Dill. app. 39 .

Habitat in Suecix, Gemanix, Hifpanix aridis apricis. $\odot$

эмman. 25. VERONICA floribus folitariis fubfeffilibus, foliis oblongis fubdentatis, caule erecto.

Veronica minima, clinopodii minoris folio glabro, romana. Bocc. muf. 2. p. 29.t. 102. Vaill. parif. 201. t. 23. f. 3. Raj. Jappl. 423.

Veronica erecta, acini folio glabro, floribus cæruleis. Dill. app. 39.

Habitat in Europæ anftralioris agris. $\odot$ Planta noftra gerit folia magis oblonga, quam illa a $V a$ lantio pieta.

peregrin:, 26. VERONICA floribus folitariis feflilibus, foilis lanceolato-linearibus glabris obtufis integerrimis, caule erecto. Fl. .jec. I5. *

Veronica terreftris annua, folio polygoni, flore albo. Morif. bift. 2. p. 322. f. 3. t. 24. f. 19.

Habitat in Europæ bortis, arvisque. $\odot$

marilandica.2\%. VERONICA floribus folitariis feffilibus, folits linearibus, caulibus diffufis.

Veronica caulibus procumbentibus, folitis linearibus, flo. ribus feffilibus lateralibus. Gron. virg. 4.

Habitat in Virginia. 


\section{JUSTICIA.}

IUSTICIA arborea, tolis Ianccolato-ovatis, bracteis Allkitods. ovatis perfiftentibic, corollarum galea concava. Il zeyl. 16. Hort upf. 7.

junicia foliis ovato-lanceoiatis, fpicis foliolis, florum galea concava. Hort clifi. y. Roy. lugah', agi.

Adhatoda zeylanenfium. Herm. lagib. 642. 1. 643. Pluk. alm. 9. t. I 73. f. 3 .

Habitat is Zeylona. 5

2. JUSTICIA arborea, ioliis lanceolato-ovatis, bradteis Eckolinn. ovatis deciduis mucronaris, corollarum galea reficxa.

Fl. zeyl. 17 .

Adhatoda, fpica longiffima, fore refexo. Burm. agol.

7. A. 4. f. I.

Carim-curini. Rheed. ma!. 2. p. 37. t. 20. Plak. alm.

I26. t. 17 I f. 4 .

Hábstas in Malabaria, Zeylona. 5

3. JUSTICIA frutico [3, foliis lanceolato-ovatis, bracteis Betonice

o:aris acuminatis venofo-reticulatis coloratis. Fl. zeyl.

:8. *

Betonica frutefcens. Bont. jas. 146.

Bem curini. Rfeed. mal. 2. p. I26. t. 21.

Habitat in India. 5

4. IUSTICIA fruticofa, foliis lanccolatis integerrimis, pe- by fopifolia. dunculis trifloris ancipitibus, bracteis calyce breviosibus.

fufticia foliis linear--lanceolatis, fforibus 〔xpius folitarïs. Hort. cliff. 10. Roy. lugdb. 291.

Ecbolii indici f. Adhatodæcucullatis floribus aemuia, hyffopifulia planta ex infulis fortunatis. Pluk. alm. 132. t. $280 . f$. 1.

Habitat in infulis Fortunatis. 5

5. JUSTICIA procumbens, foliis lanceolatis integerri- procumbens. mis, fpicis terminalibus lateralibusque alternis, braQeis fetaceis. Fl. zeyl. 19. *

Euphralia, alfines anguftiore folio, rubix modo fpicath, golcondea. Pluk. alm. 142. t.56. f. 3 .

1labitat in Zeylona. 4

6. IUSTICIA repens, foliis ovatis fubcrenatis, fpicis ter-repens. minalibus, bracteis lanceolatis. Fl. zeyl. 20.

Adhatoda ficata, flolculos ex foliolis membranaceis. Burm. zeyl. 7..t. 3. f. 2.

Habitat in Zeylona. $z$

7. JU- 
dirnenfis. 7. JUSTIClA herbacea, folits ovatic, for bus lateralibus, pedunculis tuifloris brafteis ovalibus.

Habitat in Chillat

Caules angulati, pedales, inferne ramofi. folia oppofita, petiolnta, oriaia, acuminat a, obtufiufcule, vix crenata. Ex alis pedunculi duo f. tres, finguli brewes apice trifleri, invoiucro diphyllo, feracco, nudo, bradeis ovatis, obtufis, longitudine foris, minimis.

ecbroides

8. JUSTICIA foliis linceolato-linearibus obtufis feffili. bus racemis adfcendenti-iecundis, bracteis fetaceis. Fl. zeyl. 21. *

Euphrafix affinis indica echioides. Herr. $\operatorname{lng}$ db.668.t.663 Peetumba. Rheed. mal. 9. p. 87 t. to.

Habitat in India.

Fexmgulav, 9. JUSTICIA foliis ovatis integerrinis, braeteis cuneiformibus, ramis fexingularibus.

JuRicia annua, hexangulari canle, blis circxe coningatis, Hore miniato. Amm. berb. 27\%. Iiorl cliff. 10.

Euphratia, allines majori folio, flore galeato pallide luceo, jamaicenlis. Pluk. alm. I42. t. 279. f. 6.

Habitat in Vera cruce, Jamaica. $\odot$

nufutg

10. JUSTICIA foliis lanceolato-oratis integctrimis. pe dunculis dichoromis.

Pulcolli. Rheed. mal. 9. p. 135. t. óy.

Haitat in India Toren.

Rrini obfolete angulati. Folia lato-lanceolataf. lanieola trovata, obtufe ainininata, integerrima, minus gla. bra. Pedunculi dichotomi, longitudine foliorsm. Flores feffiles, brateis minimis, lineatis. Calyces minim: Corclio tubus filiformis, longus. Limbi labium Superi. 3us lineare, anguftum, brevius, refiexum; L. inferius "quale, trifidum. Stamina extra fauces prominevia. Stylus capillaris, ferfifterzs.

purpuren. 1:. JUSTICIA foliis ovatis utrinque mucronatis integerrimis glabris, caule geniculato, fpicis fecundis.

Habitat in China. Osbeck.

Caulis berbaceus, brachiatus. Folia lato-ovatu, apice E" baf mucronota, glabra, petiolata, iniegerrima. Arti. culi coulis of rami fupra hafin Gericulo twimilo, gnod jupra anzuftius evadit, notantur. Spica ad latera ${ }^{\circ} a^{-}$ pices ramurum, fecunda. Bractere angufite, lanceolatae, longitudine capfularurn. Corolls purpuree: labiis crectis; allero lineari anguftiffirno; aliero lato trilsbo. Staminu dxo, purpuree, longitudine corollic. 


\section{GRATIOLA.}

- GRATIOLA floribus pedunculatis, foliis lanceolatis officinalis, ferraris. Mat. med. 8 .

Gratiola. Riv.mos. 157. Hort.cliff.9. Roy.lugdb. 292. Dulib. parif. S. Sauz. monjp. 13 T.

Gratiola centuruicies. Baub. pin. 279 .

Habiat in Lufatia, Gallia Eे arfitulioribus Europx bamidiufculis. 2

2. GRATIOLA floribus pedunculatis, foliis ovatis cre-dubia natis. Grun. virg. 12,9.

Ruellia pedunculis Dolitariis unifloris longitudine foliorum. Gron. virg. T3. *.

Habitat in Virginia aquolis.

Fuliala diso ifta floralia, qu.e in procedente Es sequente, in bac dejunt.

3. GRATIOLA foliis lanceolatis obtufis fubdentatis. virginim. Gron. virg. 6. *.

Habitat in Virginia.

4. GRATIOLA floribus fubfefilibus.

Gratiola latiore folio, flore albo. Fewill. peruv. 3.t. 47 .

pernvians

Habitat in Peru.

\section{PING VICULA.}

1. PINGVICULA nectarii apice incraffato.

Viola paluftris, Pinguicula diea, lufitanica. Grif. Iufst.

Habitat in Lufitania. 2 .

2. PINGVICULA nectario cylindraceo longitudine pe- vnigaris. tali. Fl. lapp. I1. Fl. Juec. 21. Roy. lugdb. 304.

Sanicula montada, Hore calcari donato. Baub. tim. $24 \hat{\jmath}$. litabitat in Europa uliginofis $\%$.

3. PINGUICULA neetario conico petalo breviore. Fl. alpins: lapp. I2. t. I2. f. .. *. Fl. Svec. 22.

Pingvicula tore albo minore, calcari brevifimo. $R a j$. bift. 752 .

Havitat in Alpibus Lapponicis. Z

4. PINGVICULA fcapo villofo. Fl.Japp. I 3.t.12. f. 2. villofa. Fl. Iuec. 23 .

Ilabitas in Lapponia, Sibiria. z 
UTRICULARIA.

*ulgaris. 1. UTRICULARIA neetario conico. Fl. lapp. I4. Fl. fuec. 24. Fl. $\approx c y l .22$. Roy. $\mid$ ugdb. 304.

Lentibularia. Riv. mon. 78 .

Millefolium aquaticum lenticulatum. Bauh. pin. I 4 I.

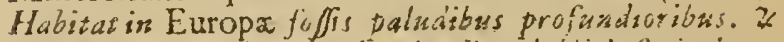

NedFarium fubulatum, longitudine lnbii isfersoris; cui approximatum; faxix clauja palato gibbo. Planta nobis drelex: altera MAYOR a Rivino delineala, calyce poftice rotundato. Altera $M I N U K$ calyce pofice transverfo, E' quafi truncato; crefcunt conjunitim

mirsor.

2. UTRICULARIA necario carinato. Fl. Suecn 25. * Millefolium paluftre galericulatum minus. Plsk. alm. 25x.t.99. f. 6.

Aparine aquis innatans trevifana, foliis perchepier capreolis doniata. Bocc. muf. I. p. 23.t. 4 .

Habitat in Europa folfis rarius.

Nectarium obfoletum, deorfum Spectans; fawis absque sibbo palato, pervia E' bians.

fuswlats. 3. UTRICULARIA netario fubulato. Gros, virg. 6. Habitat in Virginia.

gibsa. 4. UTRICULARIA nectario gibboro.

Utricularia florum nectario gibbofo, fcapo nunc uniforo nunc bifloro. Gron. virg. I29.

Habitat in Virginia.

bifis. 5. UTRICULARIA fcapo nudo bitido.

Habitat in China. Osbeck.

Caulis filiformis, digiti longitudine, bifidus $\int$. duplici racerrio, nadus. Flores alterni, lutei: labio fuperiore lateribus acuto.

carries. 6. UTRICULARIA fcapo nudo, fquamis aiternis vagis fubulatis. Fl. zeyl. 23 .

Nelipu. Kheed. mal.. 9.p. 137. t. 70.

Habitat in Zeylona.

foliofa. 7. UTRICULARIA caule foliofo. $\dagger$

Linaria paluftris, foniculi folio. Plum. spec. 6.

Habitat in Americes Gallia requinodtiali.

\section{VERBENA. \\ * Diandrue ciefpermie.}

orubica.

I. VERBENA diandra, ipicis longiflimis foliofis. 
Vertena roliis ovatis acuminatis; ipica foliofa. Hort. ciaff. 10.

Verbena orubica, tencrii folio, primula veris Aore, filiquis \& feminibus longiffimis. Pluk. alma. $383, t .228$. f. $4.8 g^{2}+.327 \cdot f \cdot 7$.

Sherardia urtica folio fubtus incano, floribus violaceis. Eibret. pitt. t. 5. f. 1.

Hialisat in Oruba injula americes Septemtrionalis.

2. VERBENA Jiandra, fpicis longiflimis carnofis fubnu- jamaicenfito dis.

Verbena foliis cobtufe ovalibus, fpica carnofa nuda. Hort. clis: 10 . Koy. lugilo. $32 \%$.

Verbena folio fubrolundo ferrato, flare cæruleo. Slaan. hif 171 . 6. 107. f. $\mathrm{r}$.

Hebirat in Jamaica E Caribeis. 1 (2)

3. VERBENA diandra, fpicis ovatis, foliis lanceolatis frecabajol. ferrato-plicatis, caule fruticolo. Roy. lugdób. 327.

Sherardia nodiflora, Itochadis ferratifolii folio. Vaill. sex. 49 .

Lavandula, foliis crenatis latioribus, americana frutefcerrs. plum. Spec. 6.

Habiial in America Gallia aquinoctialis.

4. VERBENA diandra, fpicis laxis, calycibus alternis prifmatica. primaticis truncatis arittatis, foliis ovatis obtufis.

Verbend minima, chamedryos folio, Sloam. jarn. 64.

Habitat in Jamaica.

5. Verbena diandra, fpicis laxis, calycibus fruetus reflexo-mexicana. penculis fubglobofis hilpidis.

Verbena mexicana, trachelii folio, fructu aparines: Dill. elth. $407 . t .302$. f. 389 .

Habitat in Mexico.

6. VERBENA diandta, calycibus fubrotundis eretiufcr-lappnlisees, lis, feminibus echinatis.

Scorodinia fioribus fpicatis purpurafcentibus pentapetaloidibus. Slsan. jakz. 66.

Blairia Honft. Aimm. berb. 277.

Habitat in Jamaica.

7. VERBENA diandra, fpicis longis, calycibus aritatt's, curalavisa. foliis ovatis argute ferratis.

Veronicæ fimilis fruticofa curaffavica. Herm. parad.240.

Kempfera. Houft. m. II:

Habitat in Curaftao Americes.

B 2

- $\tau_{2-}$ 


\section{* Tetrandre Tetralperme.}

sodifora. 8. VERBENA tetrandra, fpicis rapitatc-conicis, folis ferratis, caule reponte. F!. zey!. 390 .

Verbena foliis verticaliter ovatis, fpicis globolis. Kort. cliff. II.

Verbena foliis verticaliter ovatis, fpicis Colitariis ovatis. Roy. lagdk. 327.

$V$ erbena caule repente, foliis oblongis fuperne crenatis, pedunculis folitariis capitatis. Gros. virg. 7.

Vcrbena nodiflord. Baub. pin. 269. prodr. 125

Halitut in Virginia. $\odot$

bonarienfis, 9. VERBENA tetrandra, fpicis faiciculatis, foliis lanceoiatis amplexicaulibus. Hort. sps. 8.

Verbena foliis lanceolatis, foribus congentis fafligiatis. Hort. cliff. II. Roy. lugdi. 326..

$V$ crbena bonarientis aitifima, laveindula canarienfis folio, fpica lavendula. Dill. elth. 406. t. $300 . \int .38 \%$

Habitat in agro Bonarienf. z

Goniuta. IO. VERBENA tetrandra, fpicis longis acuminatis, foliis haltatis. Hori. ups. 8.

Verbena foliis lanceolatis fermits, fpicis filiformibus paniculatis. Roy. $\operatorname{lug} d 6.327$.

Verbena americana altifima, fpica multiplici, urtica foliis angutis, floribus cæruleis. Herm. parad. 242. $t$. 242 .

thabitat in Canada buinidis. $z$

articifolia, II. VERBENA tetrandra, fpicis filiformibus paniculatis. foliis indivitis ferratis petiolatis. Horl. upf:?

Verbena foliis oratis, caule erecto, fpicis filiformibus paniculatis. hort. cliff. II. Gron.virg. i. Roy. ludb. 327.

Verbena recta canadenfis, urtica foliis. Morif. bift. $\hat{z}$. p. 418 . S. II. t. $25 \cdot$ f. 3 .

Habitat in Virginiz, Canades aridis. $z$

(5wrie. 12. VERBENA tetrandra, fpicis filitormibus, foliis multifido-laciniatis, caulibus numerolis. Hort. up $\int .8$.

$\checkmark$ eronica humilior, folis incilis. Clayt. virg. 8.

llabitat in Canada, Virginia. 3

Jffiralis. 13. VERBENA tetrandra, fpicis filiformibus paniculatis, foliis multificlo-laciniatis, caule folitario.

$V$ erbena foliis nultindo-laciniatis, fpicis filiformibus 
Hort. cliff. I1. Fl. Svec. 26. Roy. lugdb. 32\%. Dalib. parif. 9. Sauv. monsp. 279.

Verbena communis, flore cxruleo. Baub. pis. 269.

Habitat in Europe mediterranere ruderatis. ()

14. VERBENA tetrandra, Ppicis filiformibus folitariis, , fupina.

foliis bipinnatifidis.

$V$ crbena tenuitolia. Bauh. pin. 269.

Verbena fupina. Cluf. bift. 2. p. 46.

Habitat in Hifpania.

\section{LICOPUS}

1. LYCOPUS foliis finuato-ferratis.

Lycopus foliis indivifis. Fl. fvec. 27. Dalib. parif. 9.

єиropanc.

Iyycopus. Hort. cliff. Ix. Rog. lugdb. 326.

Marrubiun palulte glabrum. Baub. pin. 230.

Habitat in Europx ripis burrent:bus. 2

2. LYCOPUS foliis xqualiter ferratis.

Lycopus foliis lanceolatis tenuilime ferratis. Grons. virg. 8.

Habivat in Virginia. 2

\section{AMETHYSTEA.}

I. AMETHYSTEA. Hort. upS. 9. Ainon. ocad. 386 . *armlea. Amerhyftin montana erecta, folis exiguis digitaris trifidis ferratis, floiculis cum coma e cxrulco-janthinis. Anm. ruth. 4. Hall. aet. upf. I $742, p .51 . f . I$.

Habitat in Sibirix montộs. $\odot$

\section{ZIZIPHORA.}

1. ZIZIPHORA capitulis terminalibus, foliis oratis. supison, Ziziphora foliis lanceolatis, floribus terminatricibus. Hort. cliff. 30r. Roy. lugdb. ji $\hat{j}$.

Clinopodium fiftulofum pumilum indix occidentalis, lummo caule tloridum. Pluk. alm. I I I. t. .64. f.4. $\odot$ Habitat in Sy ria.

2. ZIZIPHORA floribus lateralibus, foliis lanceolatis. zennior. Ziziphora foliis lanceolatis, floribus ex alis. Hort. cliff: 305.

Ziziphora foliis lanceolatis, floribus lateralibus. Roy. lugdb. 3 I3. Hort. ups. 9 .

Acinos fyriaca, folio mucronato, capfulis hirfutis. Miorif. bift. 3. p. 404. S. II. t. 19. f. 3. 4 .

Ilabitat in Syria? 
acineides. 3. ZIZIPHORA floribus lateralibus, follis ovatis. Cinopodiam fupinum incanum. Anrm. psth. 66?

Habitat in Sibiria. $\odot$

Habitus 'ibymi Acinos, fed majora quintaplo omnia. Fotsa 7. capicatio: Flores latcrales ut in Z. tenusore 2, jed sotiufiores. Calyces fimiliter bijpidi; ntamina extraco-

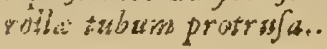

\section{MONARDA.}

fflthefr. I. MONARDA capitulis terminalibas, caule obtuf-angulo. Hort. $x p f .72$.

Monarda floribus capiratis, saule obtufo. Vit. cliff, 30 Ro1. Jugdb. 313.

Moriarda. Hort. cliffir. 11.

Origanum fitulolum canadenfe. Corn. ranak. 13.t. If, Habitat in Canada. 2

didym: 2. MONARDA foribus capitatis fub-didynamis, caule acuranguio.

Monarda caule acute angulato, capitulis terminalibus. Hort. cliff. 495 . Cold soveb. 7.

Monarda Horibus capitatis verticillatisque, caule acute angulato, foliis lanceolato ferratis glabris. Batin. cun. 236.

Ilabitat in Penfilvania, Noveboraco.

climopolia, 3. MONARDA floribus capitatis, foliis lavibus ferratis: Monardia folis ovato-lanceolatis, verticillis lateralibus dichotomis corymbofis, follis inæq̨ualiter ferratis. Gron. virg. 9.

Habitat in Virginia. I:

Radix repens. Facios p'ante precedentis quoad fistrram, at foliv uerit Clinopodid incani omnino; neque bate foica rubra, mee fiores tetrandri; foliesque gla-

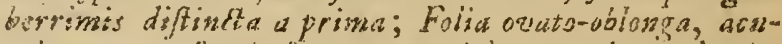
minata prolunde ferrata, petialata, atringute levia. Coulis quadrangzlaris, mag is quam in prina, minzs: argate quast sin jecunda. Flores in capiostum brateis ridiatsm, fallicis.

puntetard. 4. MONARDA floribus verticillatis, corollis punetacis. Hort. aps. 12.

Monarda floribus verticillatis. Hort. cliff. 495. Gron. virg. 9. Roy. Lud ly. 313 .

Clinopodium virginianum angufifolium, quovis vericillo 
cillo duodecim foliolis rubentibus cincto. Pluk.atm. ill. t. $24 . f .1$.

Habitat in Virginia. $\odot$

5. MONARDA foribus verticillatis, corollis involucro cilinta. longioribus.

Monarda fpica interrupta, involucris longitudine verticillorum lanceolatis: Gron. virg.9.

Clinopodium anguftifolimm non ramofum, flore caruleo: labio trifidis atropurpureis maculis ornaro. $P / x k$. abm. IC. t. 164. f. 3. Morif. bijt. 3. p. 374. S. d k.t. 8. f. 6.

Ilabitat in Virginia.

\section{ROSMARINUS。}

3. ROSMARINUS. Hort. cliff. I4. Hort, upf. Ix. Mat. offcinalis, med. i6. Roy. $\operatorname{lig} d b .3$ io.

Rofmarnus fpontanens, latiore folio. Bazh piss. 217.

B. Rolinarinus hortenlis, angultiore folio. Baub. pir. 217 . Ifabitat in Hifpania, G. narbonenfi, Galilxa. b

\section{SALYIA.}

ร. SALVIA foliis lineari-lanceolatis denticulatis, flori-agyptiasa. bas petiolatis. Hort. cliff. 13. * Roy. iugdb. 309.

Horminum agypium minimum ramofifimum. Lippi,

Boerib. lugds. 1. p. 66.

Hacitut in 王erypto.

2. SALVIA foliis ianceolatis, calycibus diphyllis. Habitat in Creia.

cretica

3. SALVIA foliis radicalibus lyratis dentatis, corollarum lyata. galea breviffima.

Salvia corollarum labio fuperiore breviore; fauce patente. Gron. virg. 8.

Horminum virginianum ereetun, urticx foliis, fore minore; Morif bijt. 3.p. 395. S. I1. t. I3. f. $3 \mathbf{i}$.

Habitat in Virginia.

4. SALYIA folitis lanceolato-ovatis integris cremulatis, offsinalis. fioribus rpicatis, calycibus acutis. Hort. cliff. I2. Hort.

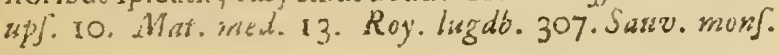
343.

Salvia major. Maub. pin. $23 \%$.

Q.Salvia minor aurita \& non aurita. Baub. pin. $23 \%$.

Habisut in Europa auftrali. b

$$
\text { B } 4 \text { 5. SAL" }
$$


pumifura.

5. SALVIA foliis Janceolato-ovatis integris crenulatis, floribus fpicatis, calycibus obtulis. Hort. clitf. 12. Roy, lisidi: 307.

Salvia cretica frutefcels pomifera, foliis longioribus incanis \& crifpis. Tournef. com. 10. itin. 1.p.92.1.92.

Salvia baccifera. Baub. pir. 237.

Mabiatut in Creta.

urticifolia. 6. SALVIA foliis ovato-oblong is duplicato-ferratis, coly cibles tridentatis: lacinia fumma tridentatd. Gron. zirg. 8 Hominum rirginianum ercenum, urica foliis, flore minore. Morif. bift. 3. p. 395. S. Ir. t. 13. f. 3 I. Inbitat in Virginia.

viridis. 7. SALVIA foliis oblongis crenatis, corollarum galea fe. mi-orbiculata, calycibus fructiferis reflexis.

Saivia foliis ovaio-oblongis obtulis zqualiter crenatis. corollarum galea femi-orbiculata. Hort. upf. 11. * Horminum coma viridi. Tournef. inft. 178.

Habitat - - - O

Horminum. 8. SALVIA foliis obtufis crentitis, bracteis fummis ne1 ilibus majoribus coloratis. Vir. cliff. 4. Hort. cliff. 12. Mat. med. I4. Koy. lugdb. 310. Horminum fativum. Batib. pis. 238 .

Hubitat in Gracia, Apulia. (-)

fyleftris. 9. SiLVIA foliis cordato-lanceolatis acutis, bracteis coloratis flore brevioribus.

Horminum fylvefle falvifolium majus maculatum. Baub. pin. 239.

Horminum fylveftre v. Clus. bift. 2. p. 31 .

Horminum fylvefte falvifolium ininus. Bauh. pin. z 39 .

I'ibitat in Aultrix inferioris, Bohemix agrorum marginibus, vineis. 4

hemmedes. 10. SALIVA follis cordato-ovatis rugofis tomentofis, calycibus hifpidis, radice tuberora. $†$

Iforminum fanguineum, afphodeli radice. Triumf. obf. 69. $t .69$.

Hurminum fivefte maculatum tubcrofum. Honspbr. Horminum fylveltre majus h:mmatodes glabrum, flore caruleo, italicum. Barr. rar. $234 . \pm 185$.

ISciuitat in J talia.

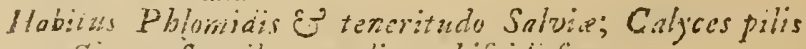
rcotis, exflantibus undiuge bifpidifunt. 
1) SALVIA foliis cordatc-oblongis crenatis: fummis pratenfis. amplexicaulibus, verticillis fubnudis, corollis galea glutinofis.

Salvia foliis ovatis incifo-crenatis, verticillis fubnudis. Hurt. cliff. 12. Flor. Suec. 28. Hort. wpf. I0. Roy. ligutb, 310. Dalib. parif. Io.

Horninum pratenfe, foliis ferratis. Baub. Pin. 238.

B. Gallitrichum fylveftre, flore majore albo. Baub. bift. $3 \cdot p \cdot 312$.

Varictas $Q$ differt foliis latioribus, obtufioribus, magis canefcentibus; floribus albis galea dimidio minore, ferius ficrenibus.

i2. SALVIA foliis cordatis obtufis crenatis fubtomen-dorainica. tofis, corullis calyce anguftioribus.

Ilalitat in Domingo.

13. SALVIA foliis ferratis finuatis, corollis calyce an-verbenack. guttioribus. Virid, cliff. 17. Gron. virg. 8. Roy.lugdb. 30\%. Dalib. parif. 9: Sazu. mousp. 278 .

Salvia folis pinnatim incilis glabris. Hort. cliff. 12. Horninum fylvefre, lavendulx flore. Buzh́ tin. 239?

itorminum frivefte, incifo folio, parvo flore, italicum. Burr. ic. $220.20 \delta$.

Horminum verberac laciniis angultifolium. Triumf.obf. бó. $t .66$.

Iabitat is Europæ pafcuis. 7

14. S. ILVIA foliis obtufis erofis, ftaminibus corolla du-pyienaica. plo longioribus. Roy. longdí. 309 .

Horminum pyrenacum glutinofum angurix folio. Herm.

parad. I $87 . t .187$.

Helitat in Pyrenxis.

5). S/LVIA foliis ovatis utrinque acuminatis ferratis. mexicama, flort. cliti. 13. Roy. lugdb. 308.

So area mexicana altinima tacic heliotropii, Dill. $e l t h$. 339. $t$ : 254 . f. 330.

Flabitat in Mexicx bumentibus. 古

SAI.VIA foliis ovatis bafibus mucronato-tuberofis, fpi- bijonica. cis imbricatis, calvcibus trifidis.

Horminum fylveftre, lavendulx flore. Baub. pia, 239 ?

Sclarea hifpanica. Tauern. bift. 764. ic. $37+$.

Mcinitat in Italia. D. Rathgeb; in Hifpunia. Lafling. (P)

Ciaslis fefquipedalos, tetragonus, obturser, quadrifulcatss,

$$
\text { B } 5 \text { faper- }
$$


juperne pilis reflexis albis veftitus. Foliaovata, acula, rugofa, ferraza, baficacuajpetiolis bafi utringue obturo mucrone prominentibus. spaca telragona, imbricata Braateis ovatis, longitudine calycum, ciliatis. Calyces fub fingula fquama Jepe 5, ore triacntati, acuti, deste fuperiore folitario, inferioribus dnobus. Corollacarnilea: limbo longitudine calycis: galea brevisore fubvillofo; labis inferiore trifido, obtujo, instegerrimo, ball mackllis 2.pallitiss.

Indica. 17. SALVIA foliis cordatis acute crenatis: fummis feffilibus, verricillis fubnudis remotifiniss. Roy. lagdb. Is" Sclarea indica, floribus variegatis. Tournef. infl. 170.

liabitat in India.

verticillats. 18. SALVIA foliis cordatis crenato-dentatis, verticillis fubnudis, ftylo corollarum labio inferiorc incuribentibus. Hart. aps. II.

Salvia foliis cordato-fagitatis dentatis. Hort. cliff. 495 . Roy. lugdb. 309

Horminum fylveltre latifolium verticillatun. Bawh.join. 238.

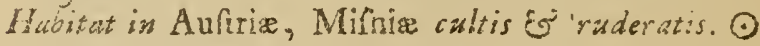

giutinẹa. 19. SALVIA foliis cordato-1agittatis ferratis acutis. Hort. cliff. :3. Hort. wh. Ix. Roy.lizgdb. 308. Saui. inanjp. 1.46.

Horminum luteum glutinorum. Bauh. pin. 238 .

ilabitut in Europa lutofis. 2

scantienfis. 20. SALVIA foliis haftato-triangularibus oblongis crenatis obtufis. Hort. cliff. 13. Liort. upf. 10. Roy.lagds. 308.

Yorminum canarienfe tomentolim, haftato folio. Morif. kist. 3. p. 394. f. I1. t. I3. f. 17.

Habitat in Canarijs. 5

nfr. earklen. 21. SALVIA foliis fubrotundis ferratis: bali truncatis dentatis. Hort. cliff. 13. Ray. lngdb. 308.

Salvia africana fruteicens; folio fcorodonia, flore violaceo. Cumm. burt. 2. P. J81. t. 91 .

Habitat ad Cap. b. fpei, locis argillofis. to

afr.lutea 22. SALVIA folis fubrotuidis integerrinis: bafi tmucatis dentatis. Hort. cliff. 13 . Ruy. lingdb. $30 \%$.

Salvia africana trutefens, folio fubrotundo glauco, fore

magno aureo. Comm. bort. 2. p. 183. t. 92.

Irabitat ad Cap. b. Ipei juxta rivulos b 
23. SAL,VIA foliis rugofis oblongo-cordatis ferratis, fo-Sines, ralibus calyce longioribus concavis acuminatis. Hort. cliff. 12. Hort. yp 30. Mat. med. 15. Roy. lagab. 309. Dalib. parif. 9 .

Salvia folis cordato-ovatis obferre undulatis, foliolis floralibus lancelato-concavis. Guett. Anmp. $26_{3}$.

Horminum Sclarea dielum. Baub. pin. 239.

Habilat is: Syria, Italia. 8

24. SAL,VIA foliis rugolis pinnatifidis lanatis.

Sal ria foliis fimplicibus Jentato-pinnatis afperis. Hort, secotophyilid. cliff. I3. Roy. lagdb. 30 S.

Salvia foliis timplicibus dentato-pinnatis rugofiş verru* colis. Hort. upf. 10.

Hominum rugofo verrucofoque folio cornin cerviexprimente. Pluk. alm, I86. 5. 99. f. 5. Herm. peo rad. 1 \&6. t. 1860.

Mabitat in Perina. ()

25. SALVIA foliis oblongis dentatomangulatis hirfutis, Aibisgis. verticillis lanasis, corollarum labio taceatu.

Salvia foliis lanceolatis finuato-dentatis: flocalibus verticillos comprimentibus. Hort. cliff. I 3. Ray.lugdt. 308.

Athiopis folis finuofis. Bamb. pin. 24 I.

B. Ethiopis laciniatis foliis. Barr. rar. 24. t. 188.

\%. Marum agypticum. Pell. alp. 212. t. 212.

Habitat in Illyria, Grxcia, Africa. ()

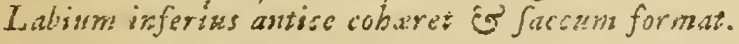

26. SALVIA foliis compofitis pinnalis. Hort. cliff. 13. pinnatso Roy. lugdb. 309.

Salva orientalis latifolia hirfutifina vifcofa pinnata, flore \& calyce purpuseis, inodora. Boerb. liggdb. I. p. 167. t. 167.

Horminim arabicum, alatis folis, llore rubello. Piks. alm. I\$6. t. 194. $f$, 6.

Habitat in Oriente Es Arabia.

2\%. SALY IA foliis cordatis inxqualiter bafi excigs, caule nutns. fubmudo, fpicis ante foreficentiam cernuis.

Habitat in Impcris Rutheno. 2*

\section{DIANTHERA}

1. DIANTHERA. Gron. irg, 6. * americana. Wabitat in Virginià. 
cmadufis. ¿. COLLINSONIA. HInt. diff. 14.t.5.Coid.noveb.8. Habutat in Virginix, Canada/jlvis. 2

\section{MORINA.}

revfica. T. MORINA Hort. cliff. 1.4. Rog. lugdb. 236.

Morina orientalis, carlinx tolio. Iournef. cor. 48 . itin 3. p. I32. t. I 32 .

Habitat in Perfia ad Hispabam. 2

\section{DIG $I N I A$.}

\section{ANTHOXANTHUM.}

odoratum. 5. ANTHOXANTHUM fpica ovato-oblongan, holculis fubpedunculatis arifta longioribus.

Anthoxanthum florculis diandris. Hort cliff. 25. Roy. lizgdb. 58 .

Anchoxanthum Fl. Succ. 29. Dalib. parif. 10.

Gramen pratente, fpica fiarefcente. Baub.jin. 3. Sche. uckz. grain. 83.

Habitat in Europx pratis. 2

iruticam a Anthoxanthum fpica lineari, flofculis feflilibus arifla brevioribus. Fl. zeyl. 25 .

Habitat in India.

paniculatum 3 ANTHOKANTHUM floribus paniculatis. Anzan. acad. 145 .

Gramen ipartcum, panicula tiavefcente. Rall. ely. I, $f . x_{4}$.

Habitat in Eniopa aultraliore.

\section{TRIGTNIA.}

\section{PI'ER.}

nigyan. I PIPER foliis ovatis fubfeptemncrviis glabris, petiolis firnicicifimis. Fl. zeyl. 2\%. * Mat. med. 26.

Piper rorundum nigrum. Basb. pirs. 4IY. Pluk. alm. 297. $1.437 . f . \mathrm{I}$.

Malaigu-codi. Rlised. mal. 7.p. 23.t. 12.

Habitat in India. 万

Betle. 2. PIPER foliis cratis oblongitifculis acuminatis feptinerviis, petiols bidentatis. $F \% . z c y l .27$. 
Piper qui Saururus foliis feptinerviis oblongo-atuninatis.

Burrz. ze\%l. 193. t. 82. f. 2.

Bectla-codi. Rbeed. mal. 7. p. 29. t. Is.

Habitat in India.

3. PIPER foliis ovatis acutiufculis fubtus fiabris: nervis Malnmiris. quinque fibtus eleratis. Fl. zcyl. 26.

Frutex americanus, fpica longagracili. Pluk. alm. 297.

t. $215 . f .2$.

Amalago. Rbeed. mal. 7.p. ... t. I6

Havitat in India utrayue.

4. PIPER foliis cordatis fubleptinervis venofis. Fl. zcyl. Siribo.z 29. *

Berela quem Sirii-boa vocant: Bont. jav. 9i. t. gir.

Iubitat in India.

5. PIPER foliis cordatis petiolatis feflilibusque. Fl. seyl. longum 30. * Mai. med. 20.

Piper longum orientale. Bazh. pin. $4[2$

Piper longum, piftolochir folis absque pediculis, maderafpatanum. Pluk. alm. 29\%. t. 104. $\int .4$.

Cattu-tirpali. Rbeed. mal. $7.9 .2 \%$. . I4.

Habitat in India.

6. PIPER foliis lanceolato-ovatis quinquenervis rugofis. Amaitg.

Piper longum arboreum altius, folio nervolo minore, fpica gracili \& breviore. $510 a n$. biff. I. t. I37.t. 87.f. I.

Pipcr trutex, fpica longa gracili. P!ak. alm.297. 2.215 . f. 2 .

Saururus folits lanceolato-ovatis guinquencrvis rugolis. Hort. cliff. 140.

Habitat in Jamaic:l.

7. PIPER foliis cordatis quinquenerviis reticulatis.

Saururus botryoides major arborefcens, foliis plantagineis. Plurn. arner. $57 . t .75$.

Jaborandi. Marcgr. braf. 37. Pif. braf. 97.

Habitat in Martinica, Brafilia.

8. PIPER foliis ovato-lanceolatis : nervis alternis, fpicis aimachns uncillatis.

Piper longum, folio ncrvolo pallide viridi, humilius. Sloan. hit?. I. p. 1 $35 . t .87 . f .2$.

Saururus foliis ovato-lanceolatis: nervis alternis. Hort. cliff. I 40. Ruj. lugdb. 9.

Saururus arborefcens, fruteuadunco.P lum asmer.j8.t.-77. Habitet in famaica. 
pelixcidun. 9. PIPER folis cordatis petiolatis, caule herbaceo.

Piper foliis cordatis, caule procumbente. Hart. cliff. 6. t. 4. *Ray'. laigdb. 8.

Saururus minor procumbens botryitis, folio crafro cotdato. Pl:sm. amer. 54. t. 72 .

Habitat si; Amcrica calidiore. ()

mexrinatum 10. PIPER foliis lanceolato-ovatis nervofis carnofis.

Saururus alius humilis, folio carnolo \& acuminazo. Plum. amer. 5.4. $t$. 71 .

Habitat in Anerica calidiore.

obruffolism. II. PIPER foliis obverfe ovatis enerviis.

Saururus humilis, folio carnofo lubrotundo. Plum amer. 53. $t .70$

Habitat in America calidioie.

notxudifol. I2. PIPER foliis orbiculatis folitariis carnofis.

Saururus repens, folio orbiculari nummularix facie. Plkm. anzer. 52. $t$. 69 .

Habitat in America calidiore.

macnlofm. I3. PIPER foliis peltatis ovatis.

Saururus hederaceus, caulibus maculofis, major. Plum. amer. 60. t. 66.

Habitat is Domingo.

pelatum. 14. PIPER foliis peltatis orbiculato-cordatis obtufis repandis, fpicis umbellatis.

Sanrurus arborefcens, foliis amplis rotundis \& umbilicatis. Pium. amer. 56. t. 74 .

Habitat in America calidiore.

diftachyon. I5. PIPER foliis ovatis, fpicis conjugatis.

Saururus hederaceus, caulibus maculofis, minor. Plam. amer. 51. 2.67.

Habitat in Americes Gallia æquinodiali.

umbellatam. 16. PIPER foliis cordatis fubrotundis acutis venofis, fpicis umbellatis.

Saururus arborefcens, foliis amplis cordatis non umbilicacatis. Pluin. amoer. 53. t. 73 .

Habitat in Domingo.

trifolium. 17. PIPER foliis ternis fubrotundis.

Saururus hederaceus triphyllus, folio rotundo. Plum. anter. 52. t. 68.

Habitat in Americes Gallia requinotiali. 


\section{Claffis III.}

\section{TR IA NDR IA} MONOGRNIA.

VALERIANA.

I. VALERIANA fioribus monanchis candatis, fclitis lan- rabra, ceolatis integerrimis. Mort. cliff: r s. Hort. upp. It. Roy. lugatb. 235. Dalsb. parif. 12.

Valeriana u ubra. Bawb. pin. IO5.

Habitat in Gallix, Helvetix, Iralix ruderatis. Z

2. VALERIANA foribus monandris, foliis pinnatifidis. ealcitrspas. Hort. ups. 14.

Valcriana folis pinnato-laciniatis, foribus monandris. l'irid. cliff. 4. Hort. cliff. IG. Kuy.lugalb. 235. Sauv. monsp. 275 .

Valeriana foliis calcitrapx. Baub. pin. I 64 .

Valeriana fylveftris, foliis tenuifime divilis. Baub. pin. 165.

Habitat in Lufitania. $\odot$

3. VALERIANA floribus diandris ringentibus, foliis o- cornucopia. vatis feffilibus. Hurt. cliff. I5. Itsrt. upf. 13. Ray. lugith. 235 .

Valeriana peregrina purpurea albave. Bak:b. pin. 164. prodr. 87:

Halitat in Americx, Mauritanix, Sicilix, Hilpaniæ arvis. $\odot$

4. VALERIANA floribus triandris dioicis, foliis pinnatis, dicies.

Valeriana dioica. It. œl. 46. Fl. juec. 3r. Dalib.parif. I I.

Valeriana, foliis caulinis pinnatis, iexu diftincta. Hort. cliff. I6.

Valeriana, foliis caulinis pinnutis, polyganıa. Vir. cliff. 5. Koy. lugdb. 235 .

Valeriana paluftris mincr \& Valeriana paluntris inodora parum laciniata, Bauh. pin.86.

Valeriana alpina minor. Bawh. pin, 165 . frodr. 87. llabitat in Europre campis uligisoufis. \&

5. VALERIANA foribus triandris, foliis ornnibus pin- officinulis. nats. Mat. med. 21. Mlort. cliff. I5. Fl. S3ec. 3 C. Koy. luydlb. 234. Dalib. parif. II. 
Valeriana fylveftris major. Baub. pzn. ró4. Fl. lapp. 14 Habitat in Europe nemoribus paludofis. 2.

Pbu。

6. VALERIANA floribus triandris, foliis caulinis pin natis; radicalibus indivifis. Jort. 2 . $\int .13$. Mat.med. 22.

Valeriana foliis infinis integris; proximis laciniatis; caulinis pinnatis. Hort cliff. J5. Roy. lugdb. 234.

Valeriana hortenfis. Bawb. piz. xó4.

Habitat in Alfaria. 2

Ciasle non julcato ô foliolie exiersoriuzus majorsbus a.V. officivali etjar differt.

sripteris. 7. VALERIANA floribus triandris, foliis "adicalibus cordatis; caulinis ternatis lanceolatis ferratis.

Valeriana floribus triandris, oliis radicalibus cordatis, aliis laciniatis. Saur, monfp. 276.

Valeriana alpina prima. Baub pin. Ís, prodr. 86. ¿.86

Valeriana alpina altera. Bush. pir. ibs.

Valeriana alpina minor, planta pislmaris. Pluḱ. alm. $380 . t .231 . f .7$.

Valeriana minima, planta uncialis. Pluk. alm. $380 . t$. 23 I. $f .8$.

Habitat in alpibus Helvetix.

Involucra propria funt atpoylia, fetaced. *

montana. 8. VALERIANA floribus triandris, foliis ovatc-oblongis fibdentatis, caule fimplici.

$T$ aleriana folis omnibus integris ex ovatomacuminatis levitur dentatis. Hall. belv. 664. it. 8.

Valcrianla muritana, fubiotundo folio. Baub. pin 165 .

Valeriana alpina, fcrophularix folio. Bakh. jin. 164 . prodr. 87 .

Valeriana alpina, nardo celticre fimilis, inodora. Pisk. alir. 380. t. 232 . f. 2.

Nardo celice fimilis inodora. Bazh. pin. 105.

Habitat inalpilus Helreticis, Rheticis, Pyrenxis. ?

celtice. $\quad$ V VALERIANA floribus triandris, foliis ovato-oblongis obtufis integerrimis. Mat. med. 23.

Valeriana tolis ovatis obturis minime dentatis. Hall. belv. 664.

Nardus ex apulia. Baub. pin. 165.

Nardus celtica diofcoridis. Baub. pz:n. I6.5.

Nardus celtica altera. Baub. pizz. 166.

Nardus celtica. Bazh. hift. 3.p. 205.

Spica celtica faltigio flof culortm ordine differens. Cam. epit. 14.

Habitat in alpibus Hclvetix, Valefix. 2

10. 
1. VALERIANA notibus triandris, foliis lanceolatis tubrersa. integerrinis: caulinis bafi pinratis.

Nardus montana, sadice olivari. Baub. pin. 165.

6. Nardus montans, isdice oblonga. Bauk. pin. 165.

Nardus montana, iongus radicata. Cam. epit. 16.

Mabitat in Dalmatia, Sicitia, Galloprovinicia. 2

1r. VALFRIANA fonibus triandris, foliis fribdentatis; ra- faxatilis. dicalibus ovatis, pedunculis comnnunibus elongatis.

Valeriana alpina nardo celticic fímilis. Bainh, pin. I65. Valeriana fyiveltris alpina 2 fasatilis. Claf. hift. I. p. 50. bina.

Nardo Celtica rimilisinodora. Bauh. pin. 165. prodr. 88. Berf $1 / 1 /$ : 122

Habilut in alpibus Styrix, Auitrix: $z$

12 VALERIANA Horibus triandris, foliis cordatis fer-pyrenaica. raris periolatis: fummis termatis. Hurt. cliff. 15. Roy. ingdib. 235 .

Valeriana maxima pyrenaica, cacaliae folio. Tumef. inft. 131.

Valeriana canadeınis. Riv. mon. 6.

Valeriana crientslis alliariz folio, flore albo. Buxb. cent. 2. p. 19. t. 31 .

Haititat in Pyrenais? 4

13. T'ALERIANA foribus trimaliris, follis omnibus cor-Chinenfis. datis repando-lobatis.

Habitat in China. Orbick.

Caules berhacei, erivit, plus quair pedales, ramis foriferis oppofitis; Lolid oppofita, petiolata, glubra, cordata. ncuth, lobis luteralións uirinque binis oistufis. Rariti ef caules termirati: uinbellulis involusclls circtis. Jemina nisidis.

i4. VALERIANA Hotibus triandris, cauie dichoromo, Lochfta toliis lineuribus. F\% fuec. j2. Hork. ups. I4. Dalib: tiril. I2.

$V$ aleriana caule dichotomo, foliis lanceolatis integris. Vir. cliff. 5 .

a. Valeriana ceale dichotomo foliis lanceolutis integris, olitoria. fruQu finplici. Hort. cliff. I6 Ror. lurdi. 235 .

Valeriana campeftris inodora major. Bazib. pin $16 \%$.

B. Valeriana caule dichoromo, foliis lanceolatis ferratis, veficaria.

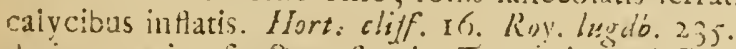

Vateriama cretica, fructu veficario. Toursef. ror. 6. Boerb. vis.db. I. P. $75 \cdot t \cdot 75$.

C $\quad y \cdot \mathrm{Va}-$ 
rornuta. $\gamma$. Valeriana caule dichotomo, foliis lanceolatis denratis, fruetu fexdentato. Hort. cliff. 16. Roy. lingd6. 235.

Valeriana femine ftellato. Bazh. pin. 105.

dertats. 8. Valcriana caule dichotomo. foliis oblongis fubrerratis, feminis corona tridentata. Hall, belv. 666. Dalib. parij. 12.

Loculta major. Riv. mox. 6.

radicta. $\varepsilon$. Valcriana caule dichotomo, capitulis terminalibus involucro cinctis. Gron. virg. 10.

Valeriana marilandica, follis oblongis obtufis. Raj.Suppl 3. p. 244 .

Habitat a. in Europx , B. Creta, $\gamma$. Lufitanix, of Europ $x$ aufralioris, $\varepsilon$. Marilandiæ arvis. $\odot$

mixta.

I5 VALERIANA floribus trandris, cauie quadrifido foliis imis bipinnatifidis, ferminis pappo plumofo. Saure monsp. 275 . t.

Valeriantla femine umbilicato hiríuto minore. Morif. umb.

Habitat Monfpelii.

Sibirica. 16. VALERIANA foribus tetrandris æqualibus, foliis pinnatifidis, feminibus palca ovali adnatis. Hort. ups: I3.

Valeriana lutca humilis, Amm. ruth. 18. $\% .25, t .3$. Hubitat in Sibirix campis. ().

HIRTELLA.

oncricarn, r. HIR TELLA, Hort. cliff. $17 .{ }^{*}$ Habitat in America rateridionali. 5.

\section{OLAX.}

xeylanica.

I. OLAX. Fl. zeyl. 34. * Amon. acad. I.p.387. Arbor ftercoraria zeylanica glandifera. Burm. zeyl. 26. Habitat in Zeylona. क

\section{TAMARINDUS.}

iqrdica.

I. TAMARINDUS. Hort. cliff. 18. Mat. med. 28. Hort. apf. 15. Fl. zeyl. 14. Roy. lugdb. 465.

Siliqua arabica, qux Tamarindus. Bazb. pin. 403. Balam-pulli. Rbeed mal. I. p. 39. t. 23.

Habitat in India, America, Agypto, Arabia. b

$$
\text { CNEORUM. }
$$

triccess". I. CNEORUM. Llort. cliff. I8. Roy. lugdb. I I9. 
Chamæiea tricoccos. Bauk. pin. 462.

Chamælea. Cam. epit, 973 .

Habitat in Hifpanix, Naibonx glareofis. 5 .

\section{MELOTHRIA.}

1. MELOTHRIA. Hort. cliff. 490, * Hort. "pS. Is. perdula. Gron. virg. 10. Roy. lug dh. 518.

Cucumis parva repens virginiana, fruetu minimo. Pluk. alm. 123. t. 85. fi. 5 .

Cucumis minima, fruetu ovali nigro lævi. Sloan. bift. 1; p. 227 . t. I $42 . f .1$.

Habitat in Catiada, Virginia, Jamaica. 0

\section{LOEFLINGIA.}

I. LOEFLINGIA.

Illecebrum procumbens ramofun, floribus lateralibus imbrieatis. Lat. defer: VI. 34.

Habitat in Hifpanix collibus apricis. $\odot$

Caules profufi Schler:antbi f. Herniaria, wifcidi. Folia

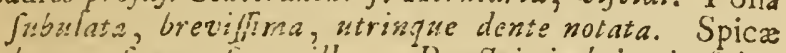
breves, fquarroj ", axillares, Bractsis imbricatis, Jubulatis, destatis:

\section{POLYCNEMUM.}

1. POLYCNF.MUM Sast. mansp. 45.

Salfola caule repente, foliis \& ftipulis feffilibus fubulahißpanis.,.

tis cartilaginess. Dalib. perif. So.

Chenopodium foliis fubulatis pritmaticis, floribus folitariis feffilibus axillaribus. Givett. ftamp. I4.

Chenopodium annum humitufum, folio breviori o $\mathrm{ca}=$ pillacco. Tournef. inft. 506 .

Camphorata vaginis finofis. H.zll. belv. 183 .

Camplacratid congener. Bazb. pin. 486.

Herniaria foliis longis angufis acuminatis \& glabris, Magn char. $5 \mathrm{I}$.

Habitat in Gallix, Italix, Cermanix arvis.

\section{CASSYTHA;}

1. CASSYTHA Osbeck.

Cuicuta altera f. major. Camel. Inz. I. p. I. n. 1. Pe:. arvers?

Cufcuta baccifer: barbadenfum a maritimis. Plak. alin. I26. t. I\%2. $\int .2$.

Acatia-valli. Rbeed mal. $T$ f.83.t.44.Raj. Suppl.55I

$\mathrm{C}_{2} \mathrm{H}_{\mathrm{Ha}}$ 
Habitat in India.

Habitus है umniaCufouta, at iructificatio a'iverfifima.

\section{CROCUS.}

fatsus. 1. CROCUS fpatha univalvi radicall, corollx tubo longillimo.

Crocus floribus fructui impofitis: tubo longifimo. Roy. lighb. 41. Hort. upf. 15 . Mat. med. 27.

Crocus fiore fructui imponto. Hort. cliti. 18.

officinalis. a. Crocus autumnalis lativus. Morif. bifi.2. $p \cdot 335 \cdot \int \cdot 4$ t. $2 . f .1$.

Crocus fativus. Baub. pin. 65 .

vernus. 6. Crocus vernus latifolius. I-XI. \& I-VI. Banb. pin. 65.66.

Habitat in Alpibus Helvericis, Pyrenæis, Lutitanicis, Tracicis. 2

Bulbocodism: 2. CROCUS fpatha diphylla fiori approximata, tuboco. rollx brevi.

Crocus flore fructui impofitn: tabo brevi. Roy. lugulb. 4l

Sifyrinchium minus anguftitolium, flore majore varicgato. Busb. pin. 4 r.

Sifyrinchium afpren!tum, angufo folio, alterum. Col ecjkr. 2. p. 5. t. . f. 1 .

Bulbocodium crocifolium, flore magito albo fundo luton. Tournef: cor. so.

Havitas ist alpibus Italicis. 2:

\section{IXIA.}

africms. I. IXIA foribus capitatis, fpathis laceris.

Ixira. Hort. cliff. 490.* Roy. lagetb. 20.

Ixia folits ad radiccm nervolis grämineis, floribus ac fruetu convolutis. Burm. afric. 191. t. 70. f́. 2.

Bermudiana capenfis, capitulis ianuginolis. Pet.ficc. 242.

Gramen eriophorum africanmin, fiore lanato. Pluk. ratant. 98.

Hlabitat ad Cap. b. Spei. 2

sbiner:is. 2. IXIA folis enfiformibus, floribus remotis. Hort. ups. 16. Bermudiana, iridis folio majori, fiore croceo cleganter punctato. Krauf. bort. 25.t. 25 .

Balencanda-Schularmandi. Rbeed. mal. II.P. 7j.t. 3i. liavitat in India. $z^{\circ}$

$$
\text { G. ADIOLUS. }
$$

-mmuni: I. C.LADIO LUS toliis enfiformibus, fortbus diftantibus. 
Gladiolus foliis enfitormibus. Hort. cliff. 20. Hort. "pps. 16.

Gladiolus caule finsplicifimo, foliis enfifurmibus. Roy. lugdb. 19.

Gladiolus floribus uno verfii הilpofitis. Banb. pin. 41.

Habitat is Europa azu?trali. 2

2. GLADIOLU S foliis enfiformibus, fioribus imbricatis, :mbricatus, Habitat in Kuffia citeriore. :

Flores parvi verfus unum latus inhluicati.

3. GLADIOLUS foliis lincaribus, caule fimpliciffimo, Jptesus. floriblis lipicatis. Roy. lugdth. 19.

Habitat in Africa. $\psi$

4. GLADIOLUS foliis lincaribus, foribus diftantibus, angufuis. coroliarum nubo limbis longiore.

Gladiolus caule umpicifimo, foliis lincaribus, floribus altcrnis. Roy. lakgdo. 19.

Gladiolus foliis linearibus. Hort. cliff. 20. * t. 6.

Habitat in Africa. 2

5. GLADIOLUS caule ramofo, foliis linearibus. Roy. vamofirs. lugdb. 19.

Habital in Atrica. 2

- GI,ADIOLUS caule ramoro, capitulis pedanculatis, capitatus. radice tuberofa.

Habitat in Africa. 2

Planta eft maxima; floribus ceruless.

\section{ANTHOLYZA.}

1. ANTHOLYZA famine unico declinato.

ringens.

Gladiolo $x$ thiopico fimilis planta anguft:folia. Comm. hort. 1. t. 4l. Rudb. elyj: 2. p. 237.

Gladiolus floridns rictum referens coccineus: fuprema lacinia ereeta \& fïltulora. Brejn. ic. 21.t. \&. f. I. llabitat in Ethiopia. 2

2. ANTHOLYZA ftaminibus omnibus adfcendentibus. Cunanis. Cunonia floribus feffilibus, fpathis maximis. Burtn. cun. $211 . t$. I.

Gladiolus zthiopicus, flore coccinco. Corn. canad. 78 . t. 79. Morif. bift. 2. p. 421. S. 4. t. 23. f. I.

Habitat ad Cap. b. Spei. $z$

Utrum hac fit diflinet i generis planta, tum primumelucefcat; cum precedentis flores examinentur ulterius.

C 3

IRIS 


\section{TRIANDRIA MONOGYNIA}

\section{IRIS}

* Barbaze neelariis petalorum reflexaram.

rufiams. I. IRIS corollis barbatis, cauic foliis longiore unifloro. Hart. cliff: i8. Koy. lugdb. I7.

Iris fufiana, flore maxinno ex albo nigricante. Bauh. pin. 31. theat.r. 579

Habitat in Oriente; enent conftantinopali in Betgium $157 \hat{3} .2$

Caulis teres; Germen trigoszo-teretiufculum; Petala 3 inieriora majora reflexa.

\&ermanica. 2. IRIS corollis barbatis, caule foliis longiore multitloro. Hort. cliff. 18. Hort. ups. 16, Mat. med. 24. Roy. lugdb. I7:

Iris valgaris germanicaf. fylve?tis. Baub, pin. 30.

Iris hortenfis latifolia. Banb. pir. $3 \mathbf{I}$,

Habitat in Germanix edins. 2

phylla. 3. IRIS corollis barbatis, fcapo nudo longitudine foliorum multiforo. Roy. lugdb. 17.

Iris latifolia, caule aphyllo. Baub. pin. 32 ,

Huabitat - - 2

arriegata. 4. IRIS corollis barbatis, caule fubfoliofo longitudine foliorun multitloro. Roy. lugab. I 7. Hort. upf. I6.

Iris corollis barbatis, caule altitudine caulis multiflori. IIort. cliff. I9.

Iris latifolia pannonica, colore multiplici, Bauh.pin. $3^{\text {r }}$. Ilabitat in Hungaria. 2

bifora. $\quad$. IRIS corollis barbatis, canle foliis breviore multiforo. Jortus, ups. 17 .

Iris corollis barbatis, foliis caulem muitiforum fuperautibus. Hort. cliff. 19. Roy. ingdb 17.

Chamæiris major faturate purpurea binora. Baub. tis.

II ilitat in Lufitanix rupibus. *

6u mita. IRIS corollis barbatis, caule foliis breviore uniforo.

lris corolis barbatis, foliis caulem uniflorum fupcrantibus. liort. cliff: 39. Roy. lisgib. I7.

Chamxiris minor, flore purpureo. Baub. pin. 33

Habitat in Auftrix, Pannonise, collibus apricis. 2

* * Imberbes: petalis deflexis levitius

presclacoves. 7. IRIS corollis imberbibus, petafis interioribus tigmate ninoribus, foliis enliformibus. Hort. cliff. 19. Fl fuci. 33. mat. med: $2 f$ : 
Acorus adulterinus. Baub. pis. 34. theatr. 634.

Habir at in Europa ad ripes palidum folfarum. is

8. IRIS corollis imberbibus, petalis internis longitudine fatudiffms ftigmatis, folis enfiformibus. Hort. cliff. I9. Ray. lugdb. 18. Dalib. paiti. I3. Sant. monfp. 41.

Gladiolus foetidus. Biauls. pin. 30.

Spathula foctida X yris. Bass.hifl. 2.p. 73 . Dod. pernpt. 247.

Habitat in Gallia, Anglia, Hetruria. 2

9. IRIS corollis imberbibus, germinibus rrigonis, caule fibirien. tereti, toliis linearibus. Hort. eliff. 19. Hori. ssf. 17. Roy. ingd6. 78. Hall belv. 2So. Gmel. Sibir. 1.p. 28. Iris pratenlis anguflíolia non foetida altior. liaub. pin. 32 , theatr. 597 .

Habitat in Auftria, Helvetix, Sibirix pratis. 2

10. IRIS corollis imberbibus, germinibus fubtrigonis, can- verficoler. le tereti, tolis enfiformibus.

Iris americana verficolor, ftylo crenato. Dill. elth. 188. 5. $155 . \int .188$.

Iris americana verficolor, ftylo non crenaro. Dill. elth. $187 . t .155 . f .187$.

Iris iatifolid virginiana, florum petalis repandis purpureis, Ebret. pial. t. 6. f. 2.

Mabial in Virginia, Marilandia, Henfylvia. 4

11. TRIS corollis imberbibus, genninibus trigonis, caule virginiea ancipiti. Gron. wirg. I1.

Habilat in Virginia. *

12. IRIS corollis imberbibus, germinibus fexangularibus, [prita. caule tereti, folis fublinearibus. Liorl. ciiff. 19. Hert.

ups. 17. Roj. lugdb. 16.

Iris pratenfis anguflifolia, folia fatido, Baub. pin. 32.

Habilat in Germanize pratis. 2

13. IRIS corollis imberbibus, germinibus fexangularibus, graminen, caule ancipiti, foliis linearibus. Hort. cliff. 19. Hort. upf. 17. Roy. Iugdh. 18

Iris anguflifolia prunum redolens minior Baub.pin. 33 .

Habital in Auftria ad radices monitum is

14. IRIS corollis imberbibus, cauleunifloro foliis breviore, verna radice fibrofa. Gron. virg. 10.

fris virginiana pumila $r$. Chamæiris verna angultifolia,

flore 
fiore purpuro cærules cdorato. Plak. alin. 199. ! $196, f .6$.

Inibutat in Virginia. \#

tuherera. I5: IRIS corollis imberbibus, foliis tetragonis. I'ir. cliff. 6. Hort cliff. 20. Mut. med. 26. Ro: $\operatorname{lug}$ db. 13 . lris tuberoia, foliu angulufo. Baub. pis. 40. Hermodactylus folio quadrangulo. Tournef. cor. 50. Ilabitat in Arabia é Oriente. 2

Sipbinm: I6. IRIS corollis imberbibus, foliis fubulato-canaliculatis caule brevioribus. Hort. upf. 17.

Iris foliis margine conniventibus, corollis imberbibus. Hort. cliff. 20.

Iris mulefcens, foliis margine conniventibus, corollis imberbibus. Roy.lugdb. I8.

Iris bulbofa latifotia, caule donata. Bawh. pin. 38 .

B. Iris bulwola crrulco-violacea. Banb. pin. 4 \%.

Habitat in Hifpunia. 3

perica: IY: IRIS corollis imberbitus, foliis fubuiato-cana!iculatis canle longioribus.

Iris scaulis, fuliis margine connilentibus, corollis imbrbious. kov'. lagdb. Is.

$X$ iphion perficum præcox, fore variegato. Tournef. injl. 363 .

Ilalitat in Perfia. $\mathbb{Z}$

S: friqclium 18 . IRIS corollis imberbibus, foliis canaliculatis, bulbis germinis finperimpolitis.

Sifyrinchimm majus. Baub. pin. 4n Cluf. hift. 1.p. 216. B. Sifyrinchium medium. Bauh.pin. $4 \mathrm{r}$.

Sifyrinchium minus. Cluf. bilt. 210.

Habitat in Hilpania, Luliania. 26

Colore ef petalorum purpurco mecula lutea locobarbe; bulhis (ron turicatis fimplicibus ut inbulloglis Xiphiis 16 . 17, Jed) ex gemino bulbo altero alteri impofito, ut in Gladjolo, Círoco.

\section{COMMEI.TNA. \\ * Dipetale dicte.}

commuris. I, COMMELINA corollis inxqualibus, foliis ovato-lanceolatis acutis, caule procumbente glabro, Hort. upf.1 $\$$. Commelina folis ovato-lanceolatis, caule procumbente glabro, petalis duobus majoribus. L'irid. cleft. 6 . fiort. cliff. 21. Koy. Ixgdb.17. Gron. virg. 130.

Com- 
Commelina procumbens innua, faponaria tolio. D:!l. clab. 93. t. 78 . f.o 0 .

Licibitut in Americà. $\odot$

2. COMMIELINA corollis inæaunlibus, folits lanceola- "ficana. tis glauris obtufis, caule rcpenti.

Commelia radice perenni, foliis linceolatis, canle reperite glabro, petalis duobus majoitus. $\|$ arb. whr. $3=3$

Commclina procumbens, flore luten. Roy. lugab. 539 . Heibitat in Finion. 2 ?

Ciffert a priata peislis iftis majoribus resiformibur latcis, tertio oratn jilamentir longiorihns whuli, vaginis folioruin ciliatis, inzolucro zon riliculito.

3. COMMMLIN i corollis inxqualibus, foliis ovatis ob-bengbalenfis. ralis, caule tepente.

Ephemenum benghalenfe rerpens, folio fobrotundo brevi, phalangoides. Pluk. aim. 130. t. 27. f. 3.

Habit.ut in Benghala.

1. COMMELINA corollis mxqualibus foliis orator-erax. Innceciatis: caule crecto licabro timpliciffmo. Hort. woj. If

Commelina foliis ovato-lancenlatis, caule ercetiurculo fabro, petali duobus majoribus. l'irial eliff. 16. Linrt. cliff. 495. Gron. virg. 11. Koy. Ingen. $3^{3}$.

Commeiula erecta, amplione libcrerulco Hore. Dill. elth. $94 \cdot p \cdot 77 . t .88$.

llabitat in Virginia, ?

$$
\text { * Tripelala Zanonicr Pl. }
$$

5. COMMELINA corollis ayualibus, foliis ovato-lan- tabuofa. ceolaris fubciliatis. Hort. ups. İे.

Commelina foliis ovato lanceolaris, petalis tribus majoribus xqualibus. Hort. cliff. 21 . Roy. lugdb. 38 .

Commelina ravice anacamplerotidis. Dill. elth. 94. t. 79. j. 90.

Habitat in Merico. 2

6. COMMELIN 4 corollis aqualibus, pedunculis incras- Zanoria. fatic, loliis lincarii-ianceolatis. $\dagger$

Zanonia graminea perfoliata. Plum gen. $3^{8 .}$

Habialt in America Gallix cyninoctiais.

7. COMMELINA corollis xqualibus, peduneulis capi i- nudifora, iaribus, foliis lineari-lauceolatis, involucro nullo. $F \%$ zej!. 31 .

Ephe- 
Ephemerum phalangoldes madera!patenfe minimum, foliis perangufis, peroliatuin. Plak. alm, 135.t. 27.f.4. Hiabitat in India.

sxilaris.

8. COMMIELINA corollis wqualibus, floribus feffilibus, foliis linearibus.

Ephencrum phalangoides maderafpatanum minimum, fecundum caulem quati cx utriculis foridum. Pluk. alm. $135 . t$. 174. $\therefore$. 3 .

Ephemerum malabaricum. flore tripetalo in foliorum alis fetiili. Raj. Jizpol. 567.

Nir-pulli. Rheed. mal. 10, p. 28, t. 13.

Habitat in India.

cripata. 9. COMMIELINA corollis xqualibus, involucris fpica. tim imbricitis, Fl. zeyl. 32 .

Ephomerum zeylanicum procumbens inflatum. Herm. parid. 143 . R.aj. bift. 566 .

Habitat in Leỵloni?

\section{XYRIS.}

indiea. 1, XYRIS.

X.yris foliis gladiatis. Gron. virg. I1. Fl. ziyl. 35.

Gladiolo lacultri accedens malabarica, e capitulo botryoidco florifera. Iluk. alm. I jo. t. $416 . f .4$. Katfiletti-pullu. Rbeed, mal. o. p. I 39, t. 7 . Habitat in lndiis,

\section{SCHOENUS.}

Etuiticus. 1. SCHOENUS culmo tereti, foliis margine dorfoque aculeatis. Fl.fuec. 35. It gor?. x $70 .{ }^{*}$ Dalib. parif. I 4 . Pfeudo-cyperus paluftris, foliis \& carina ferratis. Scbeachz. gram. 375 .

Cyperus longus inodorus germanicus. Bash. pin. 14. Hrabitat in Europe paludibms, ix

ncritatus. 2. SCHOENUS culmo tereti ramofo, capitulis terminaiibus, involucro Iriphyllo breviftimo rigido patentc.

Gramen album, capitulis aculeatis, italicum. Baxh.pin. 7. theatr. 108. Siberith gram. 85. Morif. bift. 3. p. ios. f. S.t. $5 . f .3$.

Gramen fpicatum, fpicis in capitulum foliatum congeftis. Tournef. infl. 517.

Ciramen aculearum. Cam. cpit. $7+5$.

Habitat in Italia, Narbona. Lufitania, Archipclagi injulis.?

smacromalus. 3. SCHOENUS culmo tereti nudo, rpicis-fafciculatis divaricatis, involucro triphyllo tubulato, "Scir- 
Scirpus culmo tercti, foliis tribus patulis thofculisque ag. geitis terminato. Sawi' mon/p. 9 .

Scirpus maritimus, caplte glomerato. Tournef. inft.46, Scheschz. gram. $36 \%$.

Gramen Cyperoides maritimum. Baub.pix. 6. theatr. gr.

Gramen junceum maritimum, capite fquamofo foliaceo, Morif. hift. 3. p. 227. S. 8, t. 9. f. 6.

Habitat in Gallia, Narbonx, Tyrrheni, Smyrnx maritimis. 2

Foliz et inor involucri apice pungunt. Soica ablong ge, fefliles, apscibus diftanies; Involucruin triphyllum, interian diphylluss.

4. SCHOFNUS culmo tereti rudo., capitulo ovato: in- nigricane. volucri diphylli valvula altera fúbulata longa. Fl. Suec. 36. is gotl. 234. Dalic parif. 113.

Scirpns flofculis feicatis. Act. flockh. 174 x. p. 182.

Juncus lievis minor, panicuila glomerata nigricantc. Morif biff. 3. p. 233. f. 8. t. 10. f. 28 ,

Junca affinis capitulo glomerato nitricante. Scheuch. gram. 349 .

Insbitat in Europx palrdibus aftate, exficcatis. 2

5. SCHOENUS culmo tereti nudo, fpica duplici, invo- farruginems. lucri vaivul majore fpicam æquante.

Gramen Cyperoides minimum, caryophylli proifferi capitulo fimplici fquamato. Morif. bijt. 3.p. 245. $\int$. 8. t. 12 . f. 40 .

Habitat in Gotlandix, Anglix paludibus. 2

$$
\text { * * Culmo triquetro. }
$$

6. SCHOENUS cuimo iriquetro, capitulo fubrotundo, colorats: iurolucro longifinno plano variegato.

Schnenus florun capitulis involucro longiffimo radiatis. Hort. cliff. 495 .

Gramen Cyperodes fpica compacta alba, foliis ad fpicam, partim albis partim viridibus. Sloan. bifit.1. p.110.t,78.f.r.

Itabitat in Janaica, Bahama.

7. SCHOENUS culmo fubtriquetro nudo, fpica difti- comprchus. cha, involucro monophyllo.

Cyperclla montalla fpicata, radice renente, caule totun-. do triquetro, fipica fuica compreffa difticha, femine cinereo. Mick. gen. 53 .

Gramen Cyperoides tpica timplici compreffa diaticha. Pluk. alm. 173. t. 34. f. 9 . Scheuch. gram. 490. Raj. hift. 1910. Mioris. hift. 3. p. 245 .

Habitat in Anglia, Hcivctia, Italia:

8. 
s'omeratus. S. SCHOENUS culmo triquetro foliolo, floribus fafciculatis, foliis planis, pedunculis lateralibus geminis. Schanus culnio triquetio, pedunculis geminis lateralibus, Horibus conglomeralis. Gran. virg. 131 .

Ilabitat in Ving:ria.

albus. 2. SCHOENUS cuimo fubrriquetro foliofo, foritus fafciculatis, toliis fetaceis. Fl. frec. 34. Dalib. parif. 14 Schcenus Hofculis fafciculatis. Hort cliff. 22. Roy. lagdb $4^{8 .}$

Cyperus paluftris hirfutus minor, paniculis albis. Morif bilt. 3.5.8.t. 9. f. 39. Fl. lapp. 17.

Gramen Cyperoides palufte leucanthemum. Scheucbz. Gram. 503.

Ihabitar in Europæ borcalis paluabus ficcaris. 2

\section{CYPERLS. \\ * Culmo tereti.}

orticulatus. I. CYPERUS culmo tereti nudo articulato.

Cyperus culmo nudo articulolo. Koy. ingab. $5 \mathrm{r}$.

Juncus Cyperoides creberrime geniculatus medulla farEus aquaticus, radice rubra tuberofa odorata. Sluan. jam. 36. bift. I. p. 121.t.81. f. 1.

Habitat in Jamaica rivulis 2 .

minimus. 2. CYPERUS culmo tereti nudo, fpicis fub apice.

Cyperus culmo tcreti, fpicas fub apice ferente. Hort. cliff. 21. Roy. Iugdl. 49.

Gramen junceum perpufillum, capillaceis foliis, $x$ thiopicum. Pluk. alin. 179.t. 300. f.5.

Gramen Cyperoides minimum, fpicis pluribus compzEtis ex oblongo-rotundis. Slaan. jam. 36. bift. 1. p. 1 20. t. 79. f. 3. Raj. bift. 3.p.625.

Habitat in Jamaica, Atrica.

aryndinaces. 3. CYPFRUS culmo tereti foliofo articulato, racemis lateralibus, fplcis alternis patentibus.

Cyperus racentis fimplicibus lateratious folitariis dittichis, fuicis alternis patentibus. Ciron virg. I3 I.

Gramen junceum elatius, caule articulato, virginianum, cyperi paniculis inter folia prope fummitatem prodeuntibus. Pluk. alm. I $7 \%$ t. $301 . f .1$.

Gramen fuviatile geniculatum, panicula foliacea: locuftis tenuibus oblongis, virginianurn. Morif. bifi. $3 \cdot p$. $183 . f .8 . t .3$.

Habitat in Virginia. 


\section{* Culmo triquetro.}

4. CYPFRUS culmo triquetro foliofo, umbella fupra-bafpan.

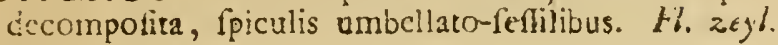
37.

Gramen Cyperoides madcrafparaium, panicula magis fárfa \& lpeciota. Pluk. alm 179. t.192. f. 2.

Habitat in India, Ethopia. 2

5. CYPERUS culmo triquetro foliofo, unbella foliofa longw. fupradecompofita, pedunculis nudis fpicis aiternis. Roy. lugrab. 50. Mat. med. 29 Dalib.parif. 14.

Cyperus odoratus radice longa $f$. Cyperus officinarum. i3aub. pin. 14. Schisuch. gram. 378. Moris. bift. j. fag. 237 . . . 8. t. II. . 13 .

Habitat in Italiz, Gallia paludibus. 2

j. CYPERUS culmo triquetro fubnudo, umbella de- roturduso compolita : fpicis alternis linearibus. Fl. zeyl.36. Mat. med. 30 .

Cyperus orientaiis, radice olivarii, fpicis longis e fpadiceo purpurafcentibus. Scbeuch. gram. 391 .

Hahitat in India.

7. CYPERUS culmo triquetro nudo, umbella foliofa, efculent's. radicum tuberibus ovatis: zonis imbricatis. Roy. lugdb. 5r.

Cyperus rotundus efculentus anguftifolius. Baub. pin. 14. theatr. 222. Sibuth, gram. 382. Morif. bift 3. p. $2 \hat{j}$ 6. S. 8. t. II. f. 10.

Thrafi. Bauh. bift. 2. p. 504 .

liabitat Monfipeii, inque ltalia, Oriente. $2 \%$

8. CYPERUS cuimo triquetro feminudo, umbella fo- Iria. liosa decompofita, ficiculis alternis granis diftinetis.

Gramen Cyperoides Indix orientalis elatius; panticula fparla pallefcente. Plik. alim. I79. t. I91. $f .7$.

Iria f. Balari. Rbeed. mal. I 2. p. I05. t. 56 .

llabitat in India. Osbeck.

Pedunculi in umbellic plurimi, apice umbelluliferi; nirsbella ex tribus quatuarve radiis, qui alternation spiculas gerunt ex granis triquetris, obtufifirmis, vix manifejta palea reflitis, parum dijtantibus.

9. CYPERUS cnlmo triquetro nudo, umbella foliofa, elegrnto pedunculis nudis proifferis, lipicis confertis. Roy. lugdb. jI.

Cyperus panicula maxime fparla ferruginea compreffa elegati- 
eiegantifimi. Sloan. jaim. 35. bift. 1.p. II7.t.75.f. 1. Kai. Suppl. 6io .

Habitat in Jamaicæ paladofis maritimis.

iorsins. 10. CYPERUS culmo triquetro nudo, umbella decompolita fimpliciter foliofa, pedicellis diftiche fpicatis.

Cyperus culmo triquetro nudo, umbella duplicata foliofa, pedunculis propriis diftiche fpicatis. Roy. latzdb. 5o. Gron. virg. 131.

Cyperus longus odoratus, panicula fparfa, fpicis ftrigofioribus viridibus. Sloun. jam. 35 . bijt: $1: p .116 . t$. 74. f. 1 .

Habitat in America ad fuviorum ripas.

smprefsis. II. CYPERUS culmo triquetro nudo, umbella triphylla, pedunculis fimplicitus, fpicis alterno-digitatis ıanceolatis diftichis.

Cyperus culmo triquctro nudo, panicula foliofa, pedunculis limplicibus, fpicis alternis fubulatis ditichis. Roy'. lugab. 51. Gron. virg. I3I.

Cyperus rotundus gramineus fere inodorus, panicula fparla comprella viridi. Slocn. jarn. 35. bift. I.p.117.t. 76. f. 1. Raj. Stppl. 623.

Habitat in America feptentrionalis pratis arenofis.

Ravefcuss. 12. CYPERUS culmo triquetro nudo, umbella triphylia, pcdunculis fimplicibus inæqualibus, fpicis contertis lanceolatis.

Cyperus culmo triquetro nudo, panicula foliofa fupradecompoíta, fpicis confertis dittiche compreflis. Dalib. parij. 14 .

Cyperus minimus, panicula fparfa flavefcente. $T$. Scbeuch. gram. $3^{85}$. Hall. belv. 246.

Cyperus minor pulcher, panicula lati compreffa fubflavefcentc: Morif. hift. 3. p. 239. $\int$. 8. t. II. $f .37$.

Gramen Cyperoides minus, panicula lparda lubflava. Baub. pin. 6. theatr. 88. t. 88.

Habitat in Germanix, Helvetix, Gallix paludofis.

fufcus, 13. CYYERUS culmo triquetro nudo, umbella trifida, pedunculis fimplicibus inæqualibus, fpicis contertis 3 nearibus.

Cyperus culmo triquetro nudo, panicula diphylla fupradccompolita, fpicis 1trigotioribus confertis dittiche compreffis. Dalib. parif. is.

Cyperus minimus, panicula lparfo nigricante. $\mathcal{Z}$. Scbewho. gram. 384. 
Cypertis minor pulcher, panicula compreffa nigricante. Worif. bift. 3. p. 239. . . 8. t. 9. f. 38.

Gramen Cyporoides minus, panicula fparfa nigricante. Baun. pin. 6.

Habitat in Gallix, Germanix, Helvetix pratis basmidis. Differt a $C$. fiavefcente vix manifefte, Spiculis anguftioribus fufcis of folits magis foabris.

14. CYPERUS culmo triquetro nudo, umbella fimplici, frigofns. fpiculis linearibus confertiflinis horizontalibus.

Cyperus rotmindus, panicula farta, fpicis ftrigofis terrugineis. Sloan. jarn. 35. bift. x. p. I i6.t. 74. f.23. Habitat io palsdibus Jamaice, Virginia.

Radix fubrotunda. Umbelle radif jimplices, erectiuscuin, inflrust: spicillis linearibus, longiufoulis, ferrugine is, conferitjionis, nurnerofisfimis, horizontaliter a pedunchlo commun patentibus rel etjon deorjum flexis.

85. CYPERUS culmo triquetro nudo, umbella fimplici Papyrys foliofa, pedunculis fimpliciffimis ditiche fpicatis. Ruy. lugdb. 50.

Cyperus omnium maximus Papyrus dictus. (Mont. gram. I 4 ), locuftis minimis. Mich. gen. 44. i. I9.

Cyperus enodis nudus, culmis e vaginis brevibus prodeuntibus, fpicis tenuioribus. Scheuch. gram. 387.

Cyperus niloticus vel fyriacus naximus papjeraceus. Moref. bift. 3. p. 239. f. 8. t. 11. f. 41 .

Papyrus fyriaca \& Jiciliana. Baubpin. I 2. theatr. 333. Habitat in Calabria, Sicilia, Syria, Ægypto.

\section{SCIRPUS.$$
\text { * * Spica unica. }
$$

afticulatws.

1. Seirpus culmo tereri nudiufcuio femigeniculato, capituJo glomerato laterali.

Thieli. Rteed. mal. i2. p. I35. t. 71.

Ifabitat in Malabarixe aquojis arenofis.

Culnus cavus, geniculis cindus, at non undique. Spica laterales in capitulum femiverticillut um collecta.

¿. SCIRPUS culmo teretinudo, fpica fubovata imbricapaluftris. ta. Fl. Suec. 41. Dalib. parif: 16.

Scirpus culino nudo, fpica terminali lubovata. Roy. lagdb. 48.

Scirpus equileti capitulo majore. T. Scheuchz gram, jóo. Fl. lapp. 19.

Juncis paluftris, capitulo equifeti, major. Bawh pin. I2.

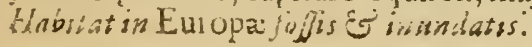

3. SCIR. 
geniculatks. 3. SCIRPUS culmo tereti nudo, fpica fubgiobóa termirali

Scirpus culno nudo, fpica terminali fubrotunda. Ior cliff. 21 . * Roy. lugdlb. 48 .

Juncus aquaticus geniculatus, capitulis equileto major \& minor. Siwan. jam. 37. hif. 1. p. 122. 6. $75 \cdot f \cdot 2$. É t. 81. f. 3. Raj. juppl. 628.

Habitat in Jamaica.

copitofis. 4. SCIRPU S culmo ftriato nudo, fpica bivalvi terminali lonyitudine calycis, radicibus fquanula interntinctis. Fi. Juec. 42. Lulib. parij: 17.

Scifpus toiro cuhni unico. Fl. imp. 20. Rov. lugdb. 49.

Scirfus nuntanus, capitulo breviore. Scbexck, gram. 363. $\therefore$. $7 . f .18$.

Habitat in Europæ paludibus cefpitofis fylvaticis. 4

sapiata. 5. SCIRPUS atho tereti nudo futiformi, fpica fulghlo. bofa.

Scirpus culino fitaceo sudo, fpica fubglobora. Gros. 3irg. 52.

llabiziat in Virginia.

cocularis. 6. SCIRPUS culmo tereti nudo fetirormi, fpica ovata biva!vi, fominibus nudis. F! juec. 42 Dalib. par. :. 17.

Scirpus inapnitudine acicule. $1 \%$ lapp. 21 . Roy. lngdu. 49 Juncellus mininus, capitulis equileti. Mlak. alm. 2or. t. 40. f. 7. Morif: bitt. 3.p. 234. 5. 8. t. 10:f. 37. Hahitat in Europafis squis puriorious. fuitams. 7 SCIRPUS eumis teretibus nudis alternis, caule foli-
ofo Haccido.

Scirpus foliis lincaribus planis alternatim fafciculatis, loica terminali. Guett. Aamp. I 41 .

Scirpus caule toliofo faccido, fcapis alternis capitatis. Ray. izgdb. 49. Saur. monip. ?.

Scirpus cquifeti capitulo ininori.T. Scbencis. ram. jos t. $7 . t .20$.

Juncellus, capitulis equifeti, minor fluitans. Bauh pi:s. 12. prour. 23 . theatr. 187.

Granien iunceum clavatum minimum. Raj. hilt. 1310.

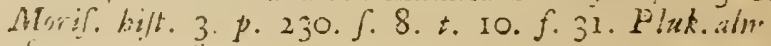
1so. t. 35. I.

Hulitut inglix, Gallix udis.

$$
\text { * * Culmo tereti polyptacbio. }
$$

lacifiris. 8. SCIRPUS cumo teretinudo, Rpicis ovatis plurious, pecinculatis terminalibas. Fi. Joet. 40. Daltb parif Io. 
Scirpus fpicis copiolis. Roy. lugdtb. 48 .

Juncus maximus $\mathrm{C}$. fcirpus inajor. Baub. pin. 12, theatr. 178.

Habitat in Europ aquis puris fragnantibus Ev fluviatio lives.

9. SCIRPUS culmo tereti nudo, fpicis fubglobofis g!oma- Folo/fcem ratis pedunculatis, involucro diphyllo inaequali mucronato.

Scirpus panicula folum foliotá, fipicis globolis peduncu. latis iateralibus. Sanv. monjp. 8.

funcus acutus maritimus, capitulis rotundis. Baub pin. II. theatr. 17 .

Scirpoides maritimum, capitulis fparfis glomeratis. Scbes uch. grain. 371 .

Holorchœnus Dalech. bift. 987

Habitat in Europa anftrali

10. SCIRPUS culmu teren nudo, capituio taterali con" romanus. giobato, bracica refexa.

Scirpus capitulo fingrulari, radice tomentofa Barr. rar . I249. t. $255 \cdot f \cdot 3$.

Scirpoides acutum maritimum, capitulo glomerato folitario. Scheusb. gram. 373. Micb. gen. 52.

Habitat in Galloprovincia s

11. SCIRPUS culmo nudo feraceo, ficicis lateralibus fub- Setacent , folitariis feffilibus, it. fcan. 227.

Scirpus culmo nudo fetaceo, ficis pedunculatis. Roy. lugab. 49 .

Scirpus omnium minimus, capitulo breviorc.. T. Scheutch. gram. 359.

Juncellus omniuru minimus. Morij. bift. 3. p. 232. fo S. t. ro. f. 23 .

Habitat in Europe litoribus maritimis.

12. SCIRPUS culmo tereni nudo, fpicis feffilibus in me-supinuit. dio culmo glomeratis. Dalib. parif. 16 . $t$

Scirpus fupinus minimus, capitulis conglobatis, foliis rotundo-teretibus. Tournef. inft. 528 .

Habitat Parifiis.

13 SCIRPUS culmo nudo capillari, fpicis pedunculatis sapillatis. feffilibusque lateralibus.

Scirpus culmo teretiufculo feminudo, fpicis capitatis fefflibus, involucro diphyllo fetaceo. $\mathrm{Fl}$. zeyl. 39 .

Cyperus culmo tereti fpicas infra apicem ferente. Hort. rliff. $2 \mathrm{I}$.

D

Gra. 
Gramer junceun perpufillum, capillaceis fodiis, $x$ thiopicum. Pluk. alm. I 79. t. 300. f. 5 :

Gramen putillum, junci capitulis minimis, ad batin foliolis binis acutis. Burm. zecyl. IOS. t. 47. f. 2.

Habitat in Virginia, Athiopia, Zeylona.

$$
\text { * * Culno triquetre, panicula nuda. }
$$

mueronatus. 14. SCIRPUS culmo triquetro nudo acuminato, panicula conglomerata nuda.

Scirpo-Cyperus maritinus. Mich. gen. 47. ord. r. 2. 3. Juncus acutus maritimus, caule triangulo. Banh. pirt. II. prodr. 22. Morif. hilt. 3.p. 232. f. 8. t. 10.f. 20 , Juncus acutus maritimus, caule triquetru rigido \& mol1i. Pluk. alm. 200. t. 40. f. 1. 3 .

Habitat in Anglix, Italix, Helvetix, Virginix fagnis maritimis.

diehotonus. I\%. SCIRPUS culmo triquetro nudo, umbella decompofita, ficicis dichotomiæ fefilibus. Fl. zeyl. 40.

Gramen Cyperoides maderalpatanum, juncelli gefneri capitulis iparfis. Pluk. alm. I 79. t. I I9. $f .3$.

Habitat in India.

ethinatks. I6. SCIRPUS culmo triquetro nudo, umbella fimplici, fpicis ovatis. Fl zeyl. 38 . *

Cyperus floribus capitatıs ereetis pedunculatis. Gron. virg 12.

Gramen Cyperoides americanum, fpicis grandioribus oblongo-rotundis, fparganii in modum echinatis, ad fun! . mum caulem pediculis longis innitentibus. Pluk.talm 1 79. $t .91 . f .4$.

Habitat is India utraqs".

retrofratus. 17. SCIRPUS culmo triquetro, umbella fimplici:fpicarum flofculis retrofractis.

Cyperi genus indianum, panicula fpeciofa, rpiculis propendentibus atris. Pluk. pbyt. $4 \mathrm{I} 5 . f .4$.

Habitat in Virginia. $z$

ferrmianens. 18. SCIRPUS culmo triquetro fubnudo, pedunculis nudis numerofis, fpicis ovatis folitariis.

Cyperus culmo triquetro nudo, panicula diphylla, pedunculis quibusdam fubdivifis, fipicis ovatis folitariis. Roy. Iugdb. 50.

Gramen Cyperoides majus fpicis ex oblongo-rotundis compa dis ferrugineis. Sloan. jain. 36. bift. I .p. j6. $t$. 77. $f .2$.

Habitat in Januaicæ paiudibus moritimis.

19. 
(9. SCIRPUS culmo triquetro nudo, umbella fubliuda, fosdiceus. fpicis oblongis feffilibus terninalibusque.

Scirpus culmo triquetro nudo, panicula laxa, fpicis alternis fubferlilibus, pedunculis longis terminalibus, Gron. virg. 132.

Gramen Cyperoides majus aquaticum, paniculis plurimis junceis fparfis, fpicis ex oblonga-rotundis padiceis. Sloan. jam. 36. bift. 1. p. I1 . t. 76. f. 2 ,

Habitat in Jamaicæ fuviiss

* * * Culmo triquetro paricula foliacea.

20. SCIRPUS culmo triquetro, panicula conglobata fo- maritinus. liacc:a, fpicularum fquamis trifidis: intermedia fubulata. Fl. Suec. 39. Dabib. parif. Is.

Cyperus culmo triquetro, panicula foliacea, pedunculis fimpliflimis, Spicis confertis. Roy.lugdb. 50

Cyperus panicula fubleflili, capitulis fubovatis, Gzetb. tharp. 2. p. 414.

Cyperus rotundus inodorus germanicus. Bash. pin. I 4 . theatr. 215.

B. Cyperus rotuindus inodorus anglicus. Baub. pin. I4. $\gamma$. Cypcrus panicula compacta e fpicis teretibus craftionbus compolita. Scbeuch. bifis. 400 .

\$. Gramen Cyperoides nanicula iparfa majus, Bauh.pin. 6. $\varepsilon$. Scirpo-Cyperus paluitrís, radice repente nodofa inodora, panicula firarta , capitulis majoribus. Mich.gen. 48 .

Habitat in Europx litoribus maritimis. 2

Anatome partium fruetijication is conjundionem $\beta . \gamma . \delta . E$. jujit.

21. SCIRPUS culmo triquetro foliofo, panicula folia tithojpermss cea, feminibus offeis.

Kaden-pullu. Rheed. mal, 12.p.89. t. 43.

Habitut in Irdia.

Culmus nudui, triqueter, craffitie fil:. Panicula fimplex; ramzlis alternis. Foliwm Jub panisula ejuscem langitudinis. Spicie parvie, ovatre, fubjecto Folio fitaceo vix spica longiore. Semina magna, nivea; fubcuata nitida, nuda, prominentia, diverfilfima a C'vpero watximo americano, litbolpermi femine. Morif. bifl. 3 . p. 237. . 8. t. 11. f. I6.

22. SCIRPUS culir a triquetro foliofo, umbeila foliacea, fylvaticu: fedunculis nudis fupra-decompofitis, fipicis confertis. Hi. Juec. 38. Dalis. parif. Is.

Cyperus culno triquetro, panicula foliofa, poduncu- 
lis nudis fupra-decompofitis, fpicis confertis. Rog. lugd6. 49.

Gramen cyperoidss miliaceum. Baub. pir. 6.

Gramen arundinaceum, foliis acutiffimis, panicula mur. tiplici, cyperi facie. Lxe. p:ulJ. Iiy. t. 33 .

Havitat in Europe glvis. 2

elomeratus. 23. SCIRPUS culmo triquetro foliofo, capitulo glomerato, involucro foliofo.

Cyperus calmo triquetro foliofo, capitulo glometate triphyllo, fpicis teretibus. Gros. virg. I 1 I?

Pee-mottenga. Rheed. mal. 2. p. 99. t. 53 .

Habitat in Virginia, India.

Culmus Subnudus, triqueter, Semipedalis. Involucrunz nutaxs foliis 3. S. 4 , longitudine culmi. Syiculic plurime, ovatonoblongre, jefiles, in capitulum jribrotundum congefthe.

mickeliaxus. 24. SCIRPUS cuImo triquetro, capitulo globolo, inro. lucro polyphyllo longo.

Cyperus italicis ominium minimus. Till.pis. 5 1.t.20.f.5. Habitat in Italia rarius.

\section{ERIOPHORUM.}

ozginatsm. I. ERIOPHORUM culmis vaginatis teretibus, fpica paleacea. Fl. fvec. 45. Dalib. parif. I8.

Eriophorum fpica erecta, caule tereti. Fl. lapp. 23. Roy. lug $d 6.51$.

Gramen tomentofum alpinum \& minus. Bawh. pin. 5 . prodr. IO. Burf. I: 43.

Juncus alpinus capitulo lanuginoro r. Schønolagurus. Baut. pin. 12.prodr. 23.theatr. 188. Schewsh. gram. 302. t. $7 . f$. I.

Habitat in Europæ frigidis ferilibus. 2

pciyfathlon.2. ERIOPHORUM culmis teretibus, foliis planis fpicatis pedunculatis. Fl. Suec. 44. Dalib. parif. i8.

Eriophorum fpicis pendulis. Fl. lapp. 28. Hort. cliff. 22. Roy. lugdb. SI.

Gramen pratenfe tomentofum, panicula fparfa. Buut. pin. 4.

Habitat in Europx uliginofis, turfofis. 2 virginicsm. 3. ERIOPHORUM culmis foliolis teretibus, foliis pla-
nis, fpica erecta.

Eriophorum ipica compacta ereeta foliacea, caule com. piello. Gron. virg. 132.

Gra- 
Gramen tomentofum virginianum, panicula magis compacta aureo colore pertufa. Ploke. alm. 179. t. 299. f. 4 .

Gramen tomentofum, capitulo ampliore fufco \& foliaceo. Morif. bift. 3. p. 224 f. 8. t. 9. f. 2.

Havitat in Virginia. 2

4. ERIOPHORUM culmis nudis triquctris, fpica pappo slpinum breviore. Fl. fisec. 46.

Eriophorum fpica erecta, caule triquetro. Fl. lapp. 2.4. Linagrontis juncea alpina, capitulo parvo: tomento rariore. Scbezch. gram. 305. t. 7. f. 4 .

Juncus alpinus bombycinus. Bash. pin. 12. prodr. 6. llatitat in Europx alpibus, locisque affibibus. 2

\section{NARDUS}

1. NARDUS f́pics fetacea recla. F\%. Juec. 47. Dalib. firitu. parif. 18.

Nardus fpica lineari. Fl. lapp. 40. Fort. cliff. 42

Gramen sparteum juncifolium. Baih. pin. 5. Scbeucb. gram. 90.

Gramen fparteum hollandicum, capilluceo folio, \& minus. Bauh. pin. 5. frodr. xI. MTorif. hift. 3. p.217 f. 8. t. 7. f. 8 .

Habitat in Europx afperis, fterilibus, duris. Z

2. NARDUS fpica recurva. $\dagger$

Nardus fpuria narbonenfis. Baub. pin. I3.

Nardus gangitis fpuria narbonenfis. Lob. ic. 84. Morif. bift. 3. p. $257 . \int .8$. t. 13. f. ult. Raj. bijt. 1911. llabitat in $\mathrm{G}$. Narbonenfi.

3. NitRDUS fpica incurva ciliata.

Habitat in India.

Folia graminea, plana. Culmus jpitameus, Spica dimidiata $\int$ altero latere tantum Flofculis alternis, eredtis, I2 a 15: valiula exteriore ovato-oblonga, mutica, riargine ciliata palis fabris, numerofis. Calyx proprie $3 u l l u s$, fed ad alterum latus flofculorwm Seta, brevior ipsa gluma.

4. NARDUS fpica cylindrica articulata.

Nardus fpica fibulata difticha. Roy. Ingdb. $5^{8}$.

Gramen loliaceum, fpicis articulofis erectis. T. Scbeuch. gi: 43 . 43 .

Gramen loliaceum maritimum, fpicis articulatis. Morif. bif. . . p. 182. . 8. t.5. f.

gangiric.

ciliaris. 
Gramen myuros erectuin minimum arundinaceum. Boec. muj. 70. t. 59.

Habitat in Italia, Hifpania, G, Narbonenfi.

\section{DIGTNIA. \\ BOBARTIA.}

indics. I, BOBARTIA.

Bobartia fpicis capitatis, involucro foliofo. Fl. zeyl.41.* Amocn. acad. I. p. 3\$S. *

Scirpus maderafpatanus, capitulo fquamofo fubrotundo. Scheuch, gram. 369.

Hakitat in India.

Refert ita Schanum nucronatum, ut ejus firuraprobujus abique vessditari poljit.

\section{CORNUCOPIF.}

cucullsum, I. CORNUCOPIE. Hort. cliff. 490. Roy. lugdb. 52. Juncus clavatus vaginatus polycephalus. Pet, zaz. $t, ; 3$. $f .5$.

Gramen orientale vernum in udis proveniens, caçitulo inflexo. Scheuch. gram. II 7 .

Habitat Smyrn.e. D, Rinfelquift.

\section{SACCHARUM.}

officinaram. I, SACCHARUM floribus paniculatis. Hort. cliff. 26. Mat. med. 33. Roy. lugdb. 52 .

- Arundo faccharifera. Baub, pin, 18. Sioar. jam. 3 I. hif. r. p. ios. t. 66.

Habitat in India wtriusque locis inundatis.

fpicatsm 2. SACCHARUM foribus fpicatis.

Framen indicum alopecuroides holofericeum majus, fpi-

ca longa pappefcente. Pluk. aim. i77.t. 92 . f.5.

Tjeria-kuren-pullu. Rheed. mal. i2. p. $117 . t .62$.

Hakitat in Indix petrofis.

\section{PHALARIS}

eanarienfis. I. PHALARIS panicula fubnyata fpiciformi, glumis cariuatis. Fort. upf. Ig.

Phalaris radice annua, Iort. cliff. 23. Roy. lugdb. 63 Dalib. parif. 20.

Phalaris major fomine alion. Bath yin. 28. Alor:foif? 3. . . 186. f. 8. t. 3. f. 1 . 
Q. Fhalaris majoi, femine nigro. Bash. pin. 28.

\%. Phalaris radice pcrenni. Roy. Iugdb. 63 .

Phalaris bulbofa, femine albo. Kaj. hiff. a 249 . Schescb.

gram. 53 .

Hauttat in Europa axfirali, Canariis.

2. PHALARIS panicula cylindrica fpiciformf.

Phalaris fpica cylindrica Fl. fsec. 49. Dalib. parif. 19.

Gramell typhoides afperum primum. Baub.pin.4. Scho-

phleoider. uch. gram. 6r. Hall. beiv. 232.

Habitat in Europe verfuris.

3. PHALARIS panicula oblonga ventricofa.

armnilinacss.

Phalaris panicula oblonga. Fl. fvec. 48. Dalib. parif. 99.

Arundo foliis planis, panicula (picata, (piculis confettis. Hort. cliff. 26. Roy. lagdb.66.

Gramen aquaticum paniculatum, phalaridis femine. $T$. Schesech. grain. 126 .

Gramen :trundinaceum fpicatum. Baub. pin. 6. theasr.94. Gramen aquaticum paniculanm latifolium. Baub. pin.6. Gramen arundinaceum, acerofa gluma, jerferianum. Kaj. asgl. 3. P. 400.

B. Gramen paniculatum, folio variegato. Baub. pir. 3. pisa. Habita in Europre fubbumidis ad ripas lacuum.

4. PHALARIS panicula lineari fecunda, calycibus bifo-erwuxformis. ris.

Dantylis fpicis numerofis alternis culmo adpreftis longitudine internodiorum, caly cibus bifloris. Ray. lugdb.

57. Gmel. Jibir. I F. T.30. t. 29.

Gramen paluftre, locuftis erucaformibus. Barr. rar. J158. $t .2$.

Habitat in Sibiria, Ruffia, Europa auftrali.

5. PHALARIS panicula effufa, glumarum carinis ciliatis. cryzoidss.

Oryza glumis carina hifpidis. Gron. virg. 153 .

Habitat in Virginia paludibus nemorofis.

\section{PANICUM.}

* S'pecata.

1. PANICUM fpica tereti, involucris fetaceis fafcicula-ulopenvoir tis unifloris, flofculo quadruplo longionbus.

Gramen geniculaturn brevifolium crifpum, fpica purpuro-ferices. Plisk, alin. $\mathrm{s} ; \%$. t. s ro. f. 1 .

Habitat in China

Spica longa, ferragivea, Flofeuli fparfi, pedunculis bice D $f$ 
vibus, cincti fetis longis, erects; Scapus infru fpicarn parum villojus; pedicelli omnes zinifür:

sanswi. 2. PANICUM fpica tereti, involucellis bitioris fafcica. lat(r-pilofis. Fl. zeyl. 44 .

Gramen alopecuroides maderafpatanum, fpica quafi ge viculati molli. Plrek. alm. 177. t. 15,0. f. 6.

R. Gramen paniceum f. Panicum fylvefte, fimplici fpicas Schguch. grain. 46.

\%.Pninicum fijea limplici, ariftis aggregatis fojculo tub jectis. Gron. virg. I 34 .

Panicum indicum altillimun?, tpicis fimplicibus molli bus in foliorum alis, pediculis longiffmis inlidentibus. Tournef.inft. Sis.

Habitat in Indiis. $\odot$

Scte in jpica longitudine flofculorum. Foliorum vagin.t uris filoga. Dum ficica recens prodist Flolculi in Jeries difpofiti ublervianisr.

amerzonum 3. PANICUM fipica fimplici requali, pedunculis bifforis. Koy. lugdi. 54 .

Fanicum indicum, fpica obtufa cxrulea. Baxh. pin. 7 . theatr. 522.

Panicum ancricanum. Ciuf. bift. 2, $p$. 215.

Habitat in America,

italicum. 4. PANICUM fpica compofita, fpiculis glometatis fetis immixtis, pedunculo hirtito.

Panicum 1pica compofita, ariftis thofculo brevioribus. $V$ ir cliff. \%. Hurt. upf. 19. Roy. lugdb. 54. Gron. virg. I 34 .

Panicum italicum r. panicula majorc. Bauh. pin. 27. thiair. 519.

Hubitat in Indiis. $\odot$

Cru:gaili, 5. PANICUM fpicis alternis conjugatisque, fpiculis fubdivifis, flumis ariftatis hifpidis.

Panicum licis alternis remotis declinatis compolitis. Vir. liff. 7. Roy, lugdb. 55. Dalib. parif. 22.

Panicum fpicis alternis remotis laxis. Hort. cliff. 27.

G Gamen paniceum, lpica divifa. Baub. pin.8.

B.Gramen paniceum, ipica divifa, arifis longis armata. Bash. pin. 8.

llabitat in Furopa, Virginix cultis. $\odot$

$V$ ariat ariftis, in alies longitudine glumarwin, in aliis de. sioslonziuribus. 
6. P.NICUM fpiculis alternis; achi lineari membra- lifectuin. nacea extrorfum imbricato-florirera.

Us clylis ipicis alternis numciotis patulls, calycibus uniHoils. Roy. lngdb. gro.

Gramen paniceum, fpica fimpliciad caulcm intervallata binis granorum ordinibus uno verfu conflante, americanum. Plish. mant. 94. t. 350 . f. 2.

Gramen dactylon majus, fanceula longa, fpicis plurimis nudis craflis. Sloais, jam. $34.6 i f$. I, p. i12.t.69,j.2. Hobitat in Indiis.

7. PANICUM fpica dimidiato-fecunda, rachi lineari dimidintum. membranacea cxtrorfum iloiculis aggregatis.

Gramen bermudenfe frumentaceum, tolits brevibus obtutis, fpica craffiufcula compreffa antrorfum gemine verlu granifera. Pluk. plyt. 244. f. 9 .

Ilúvitat in India.

Folin laiblima vaginis latis. Spica ex frapi apice nembrasaceo, plano, cui ad alierzirb tantuin latus Flores alcunation conferti diverowites.

૪. PANICUM fpicis aggreyatis, bafi interiore nodofis, fangtzme flofeulis geminis muticis, raginis foliorum punctatis. Inanicum fpicis alternis onpolitisque linearibus patentifimis muticis, flofculis alternatim biris: altero pedunculato. Roy. ligdb. 55. Gron. virg. I st. Dalib. parij. 22.

Gramen datylon, folio latiore. Baub. pix. 8. theatr. II 4. Scheuch. gram, IOI.

Gramen dactylon majus, panicula longa e fpicis plurimis gracilioribus purpureis \& viridibus mollibus conflate. Sloan. jam. 3. bift. I. p. I I3. t. .0. f, 2, *

Hab:tat in America, Europa auftrali. ()

9. PANICUM Spicis fubdigitatis approximatis erestis fi-fiformat.

liformious: rachi fiexuola, dentibus bitoris: altero feflili.

Habiat in America leptentrignali. Kaim.

Folia lanceslata. Culmi pedales filiformes, fuperne nudi, c* redti; Spica filifarmis, rara, flexsof as racbi, alternasim utrinque ad destes Flofculi :: altera felfli, aliero pedicellato; Spice tinues, primun valde appraximote quafi in unurl, quarzis alternu.

10 PANICUM fpica compofita, fpiculis linearibus fe-compofitmon. cundis flofculis geminis remotis, calycibus aiftatis. Fl. $\approx e v / .42$.

Habitat in Zeylona. 
* Paniculata.

dichotoman II. PANICUM paniculis fimplicibus, culmo ramofo d:chotomo. Gran. rirg. 133 .

Habitat in Virginia.

Staiura refert urluificulam inferne fimplicem, superne fow fciculatarn.

elandefa- 12. PANICUM racemis occultatis intra foliorum va$n * t s$. ginas.

Gramen cyperoides folyttachyon, fpicis ad nodos ex fo. liorum alis prodeuntibus. Sloan. jam. 36. bifs. x. p. I20. t. 80 .

Habitat in Jamaica, Penfylvania. Kalm.

Culmi aichoiomi, ramofi; Folia ovato-lanceolata, vagisis prinkitatis, piigfis, intra quas Racomi finctificationum orraino occuliastur, wt exths ne veftigium eorum appareat.

enillare. 3. PANICUMI panicula capillari ereeta, foliis pilofits. Gros. surs. I3.

Pancum milisceum viride, folis latis brevibus, panicula capillacca, Sloan.jam. 35. hift. 1. p. $115 \cdot t \cdot 72 . f \cdot 3 \cdot$ Hacustut in Virginia, Jamaica.

patews. 4. PAIVICUM panicula oblonga patente, calycibus biforis, foliis lineari-lanceolatis.

Thiana-pullu. Rbeed. mal. 12, p. 75.t. 4 I. Habitat in Inda; fomilis e Lufitania.

dnitylox, I5. PANICUM fpicis digitatis patentibus: bafi interiose villofis, floribus folitariis, farmentis repentibus.

Gramen dactylon, folio arundinaceo, majus aculeatum. Baub. pirs. 7 .

Gramen dakylon, radice repente. f. officinarum. Scbeuch. gram. 104 .

Gramen legitimuin Clus. bifz. 2. p. $21 \%$.

Ilabisat in Europa auftrali. 2

milincsam. 16. PANICUM panicuia laxa fiaccida, foliorum vaginis putefcentbus. Hort. cliff. 27. Hort. upS. 20. Mat med. 34. Roy. lugdb. 5j. Dalib. parif. 22.

Milium femine luteo \& alto. Baub.pin. 26. theatr. 502. Habtat is India.

Intifolium. 17. PANICUM panicula raccmis lateralibus frmplicibus, folis urato-lanceolatis coilo pilofis. 
Gramen virginianum, lato brevique folio, panicula rariore. Morif. bift. 3.p. s96. f. 8. t. 5. f. 4 .

Gramen miliaceum fylvaticum maximum, femine albo. Sloon. jam. 34. bift. I. p. I14. t. i1. f. 3.

Habitat in America.

Folia latioudine Commelina, ad fauces amplexicanlis; extur collo circum fauces villofo, etiam bafs foliorum miargine pilofa. Paniculs valde rnediocris ex racemis lateralibus, non Jubdivilis, fed peäicellos proprios, nec fubdivilos proferentes. Flores mutici, majufculi.

Is PANICUM paniculatum, foliorun vaginis longitu-brevifoliur. disaliter ciliatis.

Panicum miliaceum, latiore folio, maderafpatanum. Pluk. alin. 176. t. 189 . f. 4 .

Habitat in India.

Granen pedale vel bipedale. Folia ovata, amplexicaulia; Panicula tenxifjma, folio jupremo Es majore compredjo. Variat foliis angut? is E lanceolatis.

19. PANICUM paniculatum ramofifimum, foliis ov 2- arborefcens. to-oblongis acuminatis. Fl. zeyl. 43 .

Panicum panicula laxa fipara, follorum vaginis glabris. Hort. cliff. 27.

Habitat in India.

Alritudine certat cum altifimis arboribus; Culmus vix perna anferina lietior.

20. PANICUM panicula virgata, glumis acuminatis lz-vagatrm. vibus extima denlf́cente.

PANICUM paniculatum, glumis acutis Gron. virg.I 33 .

Habitat in Virginia,

\section{PHLEUM.}

1. PHLEUM fpica cylindrica longiffima. Fl, lapp. 26. Fl, praterfe. fuec. 50. Hort cliff. 2.2. Roy. lugdb. 53. Dalib. parif. 20.

Gramen typhoidas maximum, fpica longifima. Bauh. pin. 4. Scheuch. gram. 6o,

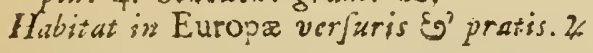

2. PLLEUM fpica ovato-cylindracea. Fl. latp. 25. Fl. alpimum. feec. 5!. Lulib. parif. 20.

Gramen typhoides alpinum, fpica brexi denfa \& veiar villofa. Jibeuch gram, 6q.

llabitat ir: Alpibus it 
*"enum 3. PHLEUM fpica ovata ciliata, caule ramoio. Hort. cliff. 23. it. form. 109. Koy. lagdb. 54.

Gramen lypilinnm maritimum milus. R. Pluk. alm. I 77. t. 33. $f: 8$.

Habitat in Europe locis arenojs. (c)

Spica vix abfoiute e vagıra folit esit.

scheroities. 4. PHLEUM Ípicis ovatis obvolutis foliis brevisfimis nucronat's amplexicaulibus.

Gramen maritimum typhinum, brevi \& cralfori fpica ad fingula genicula prodeunte i. fecundum. Scbeuch. gram. 86.

Tiatint in Italia, Smyrna, inque Hippania. Lxfing.

Mavisus Scbasi aculeati folizs flordions anplexicaulibus, brevibus nucronatis.

\section{AL OPECURUS.}

bratifio. 1. ALOPECURUS culmo fpicato ereato. Rog. Ingrib 54. Fl. Juec. 52. Dalib. parif. $2 \mathrm{I}$.

Gramen phalaroides majus $\mathrm{C}$ italicum. Baub. pin. 4 ibautr. 55 .

Giansen alopecuro fimileglabrum cum piiis-longiufcu. lis in fpica Onocordon. Baxh. bif. 2. p. 475 .

B. Ciramen typhoides fpica anguftiore. Baub pin. 4.

Hubitat in Europa pratis. 2

geniculatus, 2. ALOPECURUS culmo fpicato infrafto. F\%. Suec. 53: Daliv, parif. 20.

Alopecurtus culmo infracto, ariftis gluma longioribus. Kuy. lugaib. 54.

Alopecurus ariltis gluma longioribus, Fl. lapp. 37.

Gramen aquaticum geniculatum fpicatum. Bazb.pin.3. Sibeuch. gram. 72 .

B. A iopecurus ariftis gluma xqualibus. Fl. lapp. $3^{8}$. Habitat in Europx uliginofis. 2.

bardeiformis 3, ALOPECURUS racemo fimplici, flofculis ariftis circumvallatis.

Hahitat in India,

Habitus omrino Hordei murini. Culmus pedalis. Folia plano- canaliculata, zervofa, culmo fepius longiora. Spica racemofa, longa. Flores numerofi, pedicelli Florim brevilyim:, fimplicilfimi. Calyces obvallat: Tetis arifijormibus, numerofis, floriuss trijlo longiarious, gluma bivivi, atera minore. Corolla bivalu'is glumias oblongs, acuminatis. I'itrilluin flore longius. Stamilia tria. 
4. ALOPECURUS panicula villoía oblonga folio in- 1:onfpe'ienf. voluta. Samz?. monjp. 37. t

Gramen alopecurum minus, spica iongiore. Baub.pis. 4. theatr. 57. Schesch. graim. I54.

Gramen alopecurum minus, fpica virefcens divulfa. Barr. ic. IIs. J. I.

Canda vulpis monlpelienfium, Alopecurus theophrafti. Lab. ic. 4 r.

Ilabitat Monfpeini.

\section{IUM.}

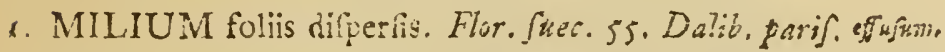
23.

Milium clumis diphylis. Mort cliff. $2{ }^{7}$.

Gramen fylvaticum, panicula miliacea fparfa. Batah.Pin. 8. theatr. 141. Jobench. gram. I3j. Norif. hifl. 3. f.8. t. 5. f. IO.

Habitat in Europx nemoribus ninbrofis. $\%$

2. MILIUM foribus confertis. Roy. Ingdb. 57.

Gramen pailicuiatum alpinum latifolium, panicula miliacea fparla. Scheuch. gram. 134. Hall. belw. 220.

Habitat in Helvetixe fyluis.

\section{A GROSTIS.}

\section{* Ariftotre.}

1. AGROSTIS petalo cxteriore exferente ariftam re- fpica ventì. ctain frictam iongifimam. Roy. lugdb. 59. Fl. fucr. 58.

Gramen fegetum altrifimun, panicuis fparfa. C. B. Scheush. gram. I44.

Gramen capillatum. Bruh. bift. $3 \cdot p \cdot 462$.

Habitat in Europa inter Segetes. (5)

2. AGROSTIS calycum fquama exteriore ariftata lon- miliacen. giore; interiore acuminata mutica. Roy. lagdb. 59. Hatizat in Europ:.

3. AGROSTIS panicula oblonga, petalo exteriore bafi orkwituiern. villofo, arifta torta calyce longore. $i$. frec. $59 .{ }^{*}$ Agroftis culmo enodi, panicuia contactia. Fi. lapp. 44 . Gramcn avenaccum montanum, panicula anguita e di: lutifimo fufco albicante \& pappora. Scbencl, granz. 57

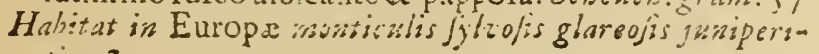
tis. 2 
rubra, 4. AGROSTIS paniculx parte florente patentiffims, petalo exteriore glabro terminato arifta tortili recurva. Fl. Suet. 60. Dalib. parif. 24.

Agroftis panicula inferiore verticillatim laza; fuperiore contracta. Fl. lapp. 46.

Gramen ferotinum arvenfe, panicula contracta pyramidali. Scheuch. grain. I 48 .

Habitat in Europia arenojis jubbuinidis.

єпniv, 5. AGROSTJS calycibus coloratis, petalorum arifta dorfali recurva. $F l$. Suec. II 38 .

Gramen fupinum caninum. paniculatum, folio varians. Bauh. pin. I. theatr. I2.

Gramen paniculatum fupinum ad infima culmorum genicula foliorum capillarium geniculis fafciculatis donatum. Scheuch. gramen. I 41 .

Habitat in Europa pafcuis humidiufculis. 4

Fैaradoxa. 6. AGROSTIS flolculis ariftatis gemellis: altero fterili, terminalibus ternis. Sauv. monfp. 35. t

Grancn avenaceum paniculatum galloprovinciale, aquilegiæ femine. T. Morif. bift. 3. p. 214. n. 29. Pluk. alm. I 74. t. 32. $f: 2$.

Gramen paniculatum latifolium, locuftis craffioribus, femine nigro aquilegia fimili. Tournef. in/t. 522 .

Habitat in Galloprovincia, G. Narbonenfi.

\section{* Mutice.}

folonifon. 7. AGROSTIS paniculx ramulis divaricatis muticis, culmo repente, calycibus æqualibus.

Agroftis culmo repente foliis radicalibus breviore, folii fuprema vagina ventricofa, Ho fculis muticis. Roy. lugdh. 59. Fl. Suec. 62.

Agroftis culmo repente, ragina fupremi folii ventricoTa. Roy. lugab. 59. Dalib. parif. 23.

Gramen caninum fupinum minus. Sheuch. gram. 128. Habitat in Europa. 2

wallaris. 8. AGROSTIS panicula capillari patente, calvcibus fubulatis æqualibus hipipidiufculis coloratis, flofculis mutícis. Roy.lngdb. 59. Dalib. parif. 23 .

Agrotis panicula tenuiflima. Fl. lapp. 45.

Gramen montanum, panicula fpadicea delicatiore. $B$ auh. pin. 3. prodr. 12. Sicheuch. grain, 29.

Habitat in Europac pratis.

Panicula were capillar s, tenuiffirisque peäicallis fingularis. 
9. AGROSTIS panicula taxa, caiycibus muticis cqua-alka.

libus. Rov. lugdb. 59 .

Halistat in Europae nersoribus.

1c. AGROSTIS panicula mutica filiformi.

жіміна.

Nardus panicula ipicata, floribus folitariis alternis.

Guet?. Atamp, 155 . Dalib. parif: 155 .

Gramen miaimum paniculis elegantifimis. Baub. pin.

2. Scheuth. gram. 40. Morif. bifl. 3.p. 200. f. 8.t.2.f.10.

Gramen minimum. Baub, bift. 2.p.465. Dalech. bifi. 425.

Habitat in Gallia.

11. AGROSTIS panicula contracta mutica, foliis invo- virginica. luto-fubulatis rigidis exftantibus. C'layt. virg. 507.

Habitat in Virginia.

I2. AGROSTIS panicula contraeta mutica, racemis la - indica. teralibus erectis alternis.

Gramen pratenfe panicula \& foliis anguftifimis, fpicis brevibus muticis, locultis minimis. Sloan. jam. 35 . bift. I. P. IIs. t. 73, f. I.

Habitat in India.

Culmus erectus. Folia plana, angu!fa. Panicula oblonga e racemislateralibus, alternis, racbi approximatis; $\mathrm{l}_{\mathrm{h}}$ mis brevidimis, acutis.

\section{A IRA.}

\section{* Mutica.}

1. AIR A fpica fubovata fecunda, flofculis obtufis muti-spicata. cis, foliis planis.

llabitat in lindia.

Gramen procumbens, digiti longitudine. Folia plana. Spica fecunda, conglomerata. vvato-ablonga. Gibumie ob:ufe, mutica.

2. AIRA pancula fpicata, floribus muticis pedunculo crifrats. longioribus, glumis acuminatis inæqualibus. Roy. lugab. 6r. Dalib. parif. 27.

Gramen, fpica crittata fubhirfutum. Bast. pin. 2.frodr. 8. Morif. bift. 3. p. 194. S. S. t. 4. f. 7. Sicheuch. gram. I66.

Habitat in Anglix, Gallix, Heivetix facciaribus.

3. AIRA foliis planis, panicula coarctata, floribus pedun-cain'ea. culatis mut:cis convoluto lubulatis. Fl.jüec. $71 . D . G-$ 1.6. paris. 26. 
Poa fpiculis fubulatis, pancula rara contraEs. Fl lapp. 29. Roy. lugdb. 6r.

Gramen aruncinaceum enode minus iylvaticum. Baub. pin. 7. theatr. 97. Scheuch. gram. 209.

Gramen pratenfe lerotinum, panicula rara purpurafcen. te. Murif. bit. 3. p. 201. 5.8 . t. 5 f 2.2 .

Habitat in Europæ pufcuis aquofis. 2

armialincen. 4. AIRA panicula oblonga fecunda mutica imbricata, fo liis planis.

Gramen orientale paniculatum, portulacae femine. Tournef. cor: 39 .

Ilabitat in Oriente.

minuta. 5. AIRA panicula laxa fubraftigiata ramofifima; flofcu lis muticis. Loefl.

Gramen paniculatum arvenfe minimum. Buxbacent. S p. 35. t. 67 ?

Habitat in Hifpania Laffing. $\odot$

Differt tantum a Buxbaumiano, quod longe minus, vix polliccm transterfum alitum.

untratici. 6. AIR A foliis planis, panicula patente, floribus muticis lavibus calyce longioribus. Fl. Juec. 60. Dalib.parif 26.

Aira culmo inferiore repente, forculis muticis calyce longioribus: altero pedunculato. Roy. lasgdb. 60 .

Gramen aquaticum miliace!nn. Scbeasch.gram. 218 . Vaill parif. 89. t. 17. f. 7 .

Gramen caninum fupinum pániculatum duice. Baub, pin. 2 :

Hibitiat in Europx pascuis aquofis. \#

$$
\text { * * Ariltatie. }
$$

fuiciatr 7. AIRA foliis planis, panicula fpicata, forculis medio atiftatis: arilia reflexa laxiore. Fl. juec. 6r. *

Aira panicula fpicata, peúiceilis fiofculo brevioribus. $F$. lapp. 47.

Gramen arenaceum paniculatum alpinum humile, locuIt is in ficam collectis varicoloribus arifatis. Scbeuch. gram. 22I. prodr. 24. t. 6.

H:tivat in Lapponiz alpibus. 2

céfitafas. S. AIRA foliis planis, panicula patente, petalis bafi villofis ariftatisque: arilta reeta brevi. Fl. fucc. 63 .

Aira panicula patentifima, flofculis fubariltatis feffilibus bafi villolis, foliis planis. Mor. ant. Jiockh. J742. $p \cdot 30$.

Aira 
Aira panicula longilima tenui. Fl. lapp. so.

Gramen fegetum, panicula arundinacea, Baub. pin. 3 . theatr. 35. Scibcuch. grain. 244.

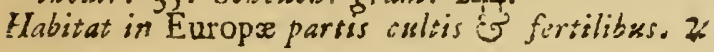

9. AIRA foliis retaceis, culmis fubnudis, panicula divari-ftexuofa, cata, peduncillis flexuofis. Fl.fucc. 64. Dalib.parif. 26.

Aira panicula rara, calycibus albis. Fl. lapp. 43 .

Gramen alpinum nemorofum paniculatum, toliis anguftiflimis, locuftis fplendenlibus ariftatis. Schcuch. gram. 2I8. t. 6. f. I,

Gramen nemorofum, vaniculis sibis, capillaceo folio. Baub pin. 7. proir. I4. Moris. bifto 3. p. 300 . S. 8. $t .7 . f .9$.

Habitat in Europx petris, rupibus. $z$

Io AIRA foliis fetaces, panicula anguftata, flofculis ba- montanc, fi pilofis ariftatis: aritta tortili longiore. Fl. Suec. 69,

Aira panicula rara, calycibus furcis. Fl. lapp. 49.

Gramen avenaceum paniculatum alpinum, foliis capil. laceis brevibus, locuftis purpuro-argenteis \& ariltatis. Scbeucb. gram. 216, t. $4 . j .4$.

Gramen avenaceurn capillaceum, minoribus' glumis. Bauh. pin. 10.

Hebitat in Europ alpinis.

11. AIR A foliis fubulatis, panicula denfa, fforculis bafi pi- alptna. lofis ariftatts: arifa brevi.

Gramein avenaceum capillaceum, minoribus glumis argenteis vix ariftatis, foliis angultioribus. Sebeucb. gram. 222.

Habitat in alpibus Lapponicis, Germania.

12. AIR A foliis fetaceis: funmo paniculain inferne ob-canefren. volvente. Roy. lizgdb. 6o. Fl. Juec. 72. Dalib. parif. 25 .

Aira foliis fetaceis, ariftis e bafi glumarum calyecm $x-$ quantibus. Hort. dilff. 495 .

Gramen foliis junceis, radice jubata. Bash, pin. 5. Scbeuch. gr:sm. 243 .

Habitat in Scania $\sigma^{\sigma}$ anftraliuris Europæ arvis $\odot$ Arifta in modio cincta denticulis, infra crafior fufaca, Supra tentuior Subclavata albida. Panicula anto florefcentianz Spicata.

13. AIRA foliis fetaceis: vaginis angulatis, foribus panj- preevor. culato-ipicatis, flolculis bafi ariftatis. $1 t$. fcan. 226 . 
Gramen ninimum, fica brevihabitione, nofrum. Scbeuch. gram. 219.

Gramen parvum precox, panicula laya canelcente. Rrj. angl. 3. p. 407. t. 22. f. 2. Pluk. alm. 177.: 33 . f, 9 .

Habilat in Euspé auftralioris cuinp:s arenufis insndatis. $\odot$

roryopbyllea. 14. AIRA follis retaceis, panicula diraricata, floribus ariftatis diftantibus.

Aira foliis fubulatis, ariftis a bafi forculorum tortilibus, flofculo altero peduncularo. Koy, ingido. 6o. Dalib parif. 26.

Gramen phalaroides Sparfa panicula minimum angaltifolium. Barr. rar r2r8. t. 44. f. $r$.

Gramen paniculatum, locuftis purpuro-argenteis. anmuuin. Raj. angl. 3. p. 407. Alurij. hijt. 3. p. 200.j: 8. t. 5. f. L 2 .

Gramen patuculatum minimum molle Magn. monfp. 296. Scbeuch. gram, 215.

Caryophyllus avenfis glaber minimus. Baub.prodr. Ior. Habitat in Anglix, (iermanix. Galliz glareojis. (c)

\section{MELICA.}

clsab. 1. AELICA petalis exterioribus ciliatis. It. gotl. 291 . Fl. jiec. 56.

Melica Horibus horizontaliter patentibns. Roy.lugdb. $5 \%$ Gramen avenaceum inuntanum lanuginofum. I3auh. pim. Io.

Gramen avenaceum, ipica fimplici, locuftis denfifumis candicantibus $r$ ! xumginofis. Scbeuch. grain. 174.

Ilabitat in Europx cullibus Jterilibus jaxofis. 2

whans. 2. MELICA petalis imberbibus, panicula nutante fimplici.

Melica petalis imberbibus. Fl. faec. 57. Malit. parif. 23. Melica Aoribus fub culmo pendulis. Fl. Iapp. 36. Roy. linglit. 57

Gramcn montanum avenaceum, iocultis, rubris. Bauh. pin. ro. prodr. 20.

Giamen montanum ayenaccisin fpicatum B.auh. ₹zи. 10. (i) amen a yenacenm, locuttis raricribus. Banb. pin. 10 Hubitat ia Europaj frigidior:s rugibus.

nisionls. 3. MELlCA petalis imberbibus, panicula ramofifima. Horn II) 20. 
Mclic? floícuis glabris; fummo urcenlari. Gmel. fib. I. p. 98. t. 20.

Gramen avenaccum, locuftis rarinrihus muicis, virginianum majus. Morif hift. 3. p. 216. f. . t. 7.f.51.

Habitat in Sibiria, Cansia. 2

\section{POA.}

1. POA panicula diffufa, fpiculis fexforis linearibus. $7 \%$ a aquricn. liuce. 73 . Dalis. parif. 29.

$P A C$ panicula diffufa, ipiculis fexforis linearibus muticis compreflis. Act. Itnckb. 174t.p. 1S5.

Poa panicula contraeta, fipicis ovatis tireriufulis. Ilort. clitt. 494. Ro\%. lugdb. ór.

Gramen paluftre paniculatum altifimum. Baub. p:n. 2. theatr. 39. Scheucib. gram. I9l.

Grainen aquaticum paniculatum latifolium. Morif. bilt. 3. p. 201. f: 8. i. 6. f. 25 .

Havitat in Europa ad ripas fifcinarsim, fiationum. 2"

2. POA panicuia diffúa tamofiffima, Spiculis textoris n'pira. cordatis. Fl. fuec. 79. Dalib. parif. 28.

Gramell alpinum paniculatum majus, pánicula fpeciora variegata. Scbeuch grara. 186. Hall. be.v. $21+$.

B. Grameir alpinum latifolium, panicula laxa follacea, to- vivipara. liolis ia panicula paucioribus \& magis crifpis. Scbench. grim. $2 \times 2$.

Habstat in aipibus Lapponicis, Helveticis. 2

An hace a. B. Sequentis tantum virbietas.

j. POA panicula diffura, (piculis quinquefioris bafi pa- trivillis, beficentibus, culmo erecto tercti. Fi. fuec. 78 . Dalib. parif. 28.

Gramcil pratenfe paniculatum medium. Baub.pin. 2 Scbeuch. gram. 180.

Habitat in Europae pafcuis.

4. POA panicula diffifa, fpiculis quadrifloris pubefcenti- anguffifolia. bus, culmo ereeto tereti. Fl. Suec. 77. Dalib. paril. 29 .

Po: fpiculis ovaro-oblongis, foliis fubulatis. H.lapp.52.

Gramen pratenic pariculatum majts, angufiiore folio.

1saub. par. 2. proar. 5. Scbewch. grasi. 178.

Hahitat in Luropa ad agrorum verjuras. 2

P. POA panicula diffura, fpiculis trifloris glabris, cuimo pratenfiro. erecto tercti. Fl. Juec. 76. Dalib. pariz. 27.

$$
\text { E: Tra }
$$


Poa fpiculis ovatis compreffis muticis. Fl. lapp. rt. Hort. cliff. 27. Row. iugdb. $6 \mathrm{t}$.

Gramen prateúf yaniculatum majus (12tiore folio. Barh pis. 2.) Scheach. gram. 177 .

Habitat in: Europae pratis fertilifimis.

Limites projpeciebus 2. 3. 4. 5-rite difcernendis $\pi / 3$ dum perspicue evicti funt.

амиนa. 6. POA panicula diffura angulis reetis, fpiculis obtufis : culmo obliquo comprefio. Fl. fuec. 75 . Dalio. parif.28. Gramen pratenfe panicuiatum minus. Busb. pin. 2. theatr. 31 .

2. Gramen pratenfe paniculatum minus rubrum. Lournef init. 522 .

Habitat in Europa ad vias. $\odot$

Raik. 7. POA panicula diffura, fpiculis ovato-oblongis nitidis Gron. virg. 13.

Gramen pratenfe majus virginlanuin. Fen: $m a k$. 23?.

Habitat in Virginia.

pilusa. 8. POA panicula patente ftricta; ramificationibus frima riis pilotis.

Gramen, paniculis elegantinmis, majus, locunis pur. puro- fpadiceis minoribus. S'cheuch. gram. 193 .

Habitat in Italia.

mmbilis, 9. POA panicula patente, ipiculis odtiforis linearibus. Fl. zevl. 4 \%."

Gramen paniculatum ex oris malabaricis, panicula de. licatiore. Pluk. alm. 176. t. $300 . \mathrm{f} .3$.

Habitat in India.

Eragrofit: ro. POA panicula patente, pedicellis flexuofis, fpiculis ferratis decemfloris.

Gramen, paniculis elegantifimis, minimum. Sclsench. iram. 192.

Gramen Halaroides, fparfa brizæ panicula, minus. Barr. ic. .t. 44.52.

Mabitat in Italia Jupra maros. D. Back.

capillaris. \&. POA panicuia laxa patentifima capillari, foliis pilofis, culmo ramofiffimo.

Poa panicula laxa ereeta fricta, fpiculis ereetis oblongis. Grott. virg. I 36 .

Gramen paniculatum virginianum, locuftis minimis. Morif. bift. 3. p. 202. f. 8.r. $6 . f .33$. 
Habitat in Virginia, Canada. D. Kaim.

Panicula capillacea, Aricti/lina, par entiffima, ramofisfima. Spiculce ex flofculis $4,5 f .6$, minimu. Folia ad bafin pilis longis raris. Culmus ramofus.

i2. POA paniculre ramis fimpliciffimis, foribus feffilibus, malabarica. Ieminibus diftantibus, culmo repente.

Tfiama-pullu. Rhced. mal. 12. p.83. t. 45 .

Habitat in India arenofis.

13. POA panicula ramis fimplicifimis, foribus feffilibus thinenfis. femintbus intricatis, culmo erecto.

Habitat in India. Osbeck.

Rami ponicularimpliciflimi, ut in axtecedente, magis conferti, Flores ininores; Flofculi 4 aec feptem.

I4. $\mathrm{POA}$ panicula oblonga tubverticillata, flofculis fex-tenella. floris.

Habiatat in Incia.

Gramen bipedale, Foliis longis. Panicula anguftata, ramulis confertifirnis, fubramofis of fere verticillata apparent; Flores tam parvi, ut nudis oculis vix flofouli mumescintur.

Ir. POA panicula coaretata fecunda, culmo obliquo com- rompresa. preffo. Fl. faec. 74. L*. gotl. 178 . Daiib.parif. 28.

Poa fipiculis ovatis compresfis muticis, panicuia fecunda coaretata. Act. ftockb. $1741 . p .184$.

Gramen murorum, radice repente. Bash. pin. 2. prodr. 2.

Gramen paniculatum, radice repente, culmo compreffo, locultis dittichis pulchellis. Scheuch z. gram. 199.

Havisat in Europac Eo Americac feptentrionalis ficcis. muris, tcetis. 2;

Americana thefoulis fopiats ternis, Europica vero Senis,

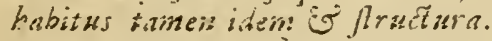

16. POA panicula attenuata, fpiculis fub-bifloris mucrona-nemoralis. tis icabris, culmo incurvo.

(iramen fylvaticum, panicula tenui e raris locuftis compofita. Di:ll. Speci. 57 .

Gramen paniculaum anguntioilum alpinum, locuftis rarioribus 2 anguftioribus son arfltatis. Sckicuch. grum. 1b.t. t. 2 .

Gramen loliaceum alpinum, pariculis ex rarioribus \& exiguis locullis compolitum. Mlont. gram. 39 .

Q. Gamen cirrhofa \& villora lpongia ad lingula genicuI 3 
in donatum, pariculatum minimum alpinum. Bore. inuf. 2. H. 70. t. 50.

Habitat in Europa adradices montium umbrofas

kulbja, 17. 'OO panicula iecunda protentiufcula, fpiculis quadrinums.

Pou culmorum bati tuberoft. Guet. framb. I p. 163. Dalib. purif. 25.

a. Gramen xeramplinum, miliacea pratenui ramoraque 1 parta panicula $t^{\circ}$. Xerampelino congener acvenfe $x$ ftivum, Gramen minutistimo femine Lob. illufir. 1.4. Scheuch. gram ids.

B. Giramen arventic, panicula crifpa. Bauls pin. 3 Barr. ic. 703 .

Gramen arvenie anguftifolium, paricula denfa foliacea: toliolis in panicula anguntistimis. Srobub. gram 211. y. Giamen vornum, radice alcalonica. I'al. purif. gr. ¿. 17. $f: 8$.

Inobitat in Ga!ia.

In a. calmi jemper inclinat; in y. Gluma inscuales;

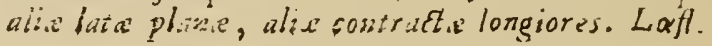

\section{BRILA.}

mivor. 1. BRIZA rpiculis triangulis, caiyce flofculis (7) longiore. Flurt. clift. 23 . Roj. lugd6. 53 .

Gamen tremulum minus, nanicula parva. Baub. pin. 2. prodr. 4.

liobitat in Helvetia, Italia.

media. 2. BRIZA fpiculis ovatis, calyce flofculis (7) brevicac. llort. clitt. 23. Fl. Suer. 80. Roy. lugáb. 63.

Gramen tremulum majus. Baub.pin. 2. Schexsh.gram. 204.

Habitat in Europapartis ficiccoribus.

masima. 3. BRIZA fpiculis cordatis, flofculis feptendecim. Hort. cliff. 23. Hort. uff. 20. Rov. ingab. 63.

Gramcn tremulum naximum $B a z b$. pin. 2. Scheuck. nivin. 204.

Habiat i: Ialia, Iufitania.

Eragrofis. 4. BRIZA fpiculis lanmentatis, flofeulis viginti.

Briza panicnla fivata, idculis lanccolatis. Guett.ftamp. 1. p. 163 .

Lnola calycibus ciphyllis, fpiculys ovato-tanceolatis. Gires. 269.136. 
Gramen paniculis elegatifrmis. Beub. pin. 2. Scheuch. grain. 1y4. Morif. bifl. 3. p. 204. j. 8. t. 6. f. 52 . Gramen Eranthemum f. Eragroftis. Borr. rar. t. 4 . Habitat in Europa asf frali ad agrorum verfuras.

\section{UNIOLA.}

I. UNIOLA pariculata.

Uniola calycious polyphyllis. Gron. virg. I 36

Uninla. Hort. cliff. 23. Roy. lagdo. 6?

Gramen nyloicophorum osyphyllon cárolinianusi. P':k. alm. I 73. t. 32. f. G. Catefb. car 1. p. j2. t. 32 .

Habitat in Carolina.

2. UNIOLA fubficicata, foliis in:outis rigidis.

Gramen parvum maritimum fpicatum, foliis anguntis rigidis. Clayt. 507.

Habitat in Anericx borealis maritimis.

Culmus Spithameus, Folizi alternis rigidis inzolu!n-mucronctis. Paniculaminima, coarctata ut vix fignum pedicellorum, Secunda; calyx E gluma carinatie flofoulis quainor.

\section{DA CTYLIS.}

I. D 4CTYLIS fpicis fparfis fecundis fabris numerofis. cynofureides.

Gramen unaritinum, fpica craffa dal yloide terminaii,odore rancido, culmo albo. Gron. zirg. I35.

E. Ditetylis picis alternis fecundis incilis ereetis approx:inatis, calycibus unifloris fubulats. Gron. virg. I34. Haúitut in Virginia, Canada, Lutitania. 2

Culmus bipedalis, arundinaccus. Foliu in culmo fex, latu, culirbo longiora, lavisfima margine fcabra, incurva, pagina interiori glauciore. Spica jex f. plurime, fecundue divergentes, paleacen: Hof culis imbricatis latere polizco jcalbis. Calycibus minficiris cario a fonbris, mucronatis, flofoulo longioribus, febilibus, fecundis. 1'ifillis villofis longinitious.

2. DACTYLIS panicula fecunda glomerata.

Cynofurus panicula fecund.r glomerata. Fl. fuec. 85 .

Jpicatw.

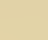




\section{CYNOSURUS.}

crifatw, 2. CYNOSURUS braeteis pinnatifidis, Hort. cliff. 493. Fl. Suec. 8r. Roy, lugdb. 64 .

Gramen pratenfe criftatum, f. fpica criftata lævi. Baub. pin. 2. prodr. 8. Scbeuch gram. 79.

Habitat in Europx pratis.

echinatus, 2. CYNOSURUS bracteis pinnato-palcaceis ariftatis. Roy. $\operatorname{lug} d 6.64$.

Gramen alopecuroides, fpica afpera. Baub.pin. 4. Scbeuch. gram. 80.

Gramen alopecurum, fpica afpera. Barr, rar t. 123. Habitat in Europa auftraliori.

Lima, 3 . CYNOSURUS fpica fecunda, calycis gluma interiore fpiculis fubjeets. Loefi.

Habitat in Hifpania. $\odot$

Grainen wix spithameurn. Foliorum vagine tumidiuf cula, folin ipfo pario. Spica lecunda, areze imbricata, oblonga, ex floribus fecterdis, fefilibus, duplici ferie, cumpreffo carinatis: calicina calvula exteriore comprefla, majore; flores finguli conftant fiofoulis 5 .

duru, 4. CYNOSURUS fpiculis alternis fecundis feffilibus rigidis pedicellatis.

Gramen arvenfe, polypodii panicula crafliore. Barr. rar. I2I3. t. 50.

Halitat in Europa anfrali.

ceruleus, 5. CYNOSURUS bracteis integris. Hort. cliff. 495. Fl. Suec. 82. Roy. leid. 64.

Gramen glumis variis. Bauh. pin. 10. prodr. 21. Scbeuch. gram. $8_{\hat{3}}$.

Habitat in Furopa pafcuis uliginofis. 4

azyptius, 6. CYNOSURUS fpicis quaternis obtufis dimidiatis, calycibus mucronatis.

Cynofurus fpicis quaternis terminalibus horizontalibus. Roy. logdb. 64.

Gramen ifchxmum maiabaricum fpeciofus, longioribus mucronatis foliis. Pluk. alm. 775. t. $300 . \mathrm{f} .8$.

Gramen 1)actylon agyptiacum. Bazh. pin. 7. theatr. го. Koy. lugdb. Iog. Morif. bift. j. p. I84. f. 8. t. 3. f. T. Scheuch. gram. Iog.

Habitat in Africa, Alia, America.

idicks. $\quad \%$ CYNOSURUS fpicis diziratis lincaribus, floribusovato-lanccolatis.

Cyno- 
Cynofnrus ficis aggregatis terminalibus deorfumariftatis. Roy. luglb. 65.

Gramen Dactyloides fpicis deorfun arifratis. Burm. zzyl. 106. i. $47 . f$. 1 .

Gramen dacylon americanum minus. Scbeach. gram. 107.

Habitat in Indiis.

8. CYNOSURUS panicula fubfpicata, flofculis fimpli-paniens. cibus biarifatis.

Panicum floribus congjomerato-fpicatis lævibus arifta dimidio brevioribus. Fl. fucc, 54 .

Panicnm fpica compolitz, arittis ficica longioribus. Virid. cliff. 7. Roy. lugdb. 55.

Panicum fpiculis ficatis fcabritie adharentibus. Hor.cl.27. Gramen paniceun, fpica afpera. Bauls. pin.8. Scbencb. gram. 47.

Ilabitat in Europe agris cultis. $\odot$

9. CYNOSURUS paniculx fpiculis fteriibus pendulis aurcys. ternatis, Horibus ariltatis.

Gramen barcinonenle, panicula denfa aurea. Tournef. inflit. iz.

Gramen panicula pendula aurea. Bauh. pin. 3. theatr. 3j. Scherich. $5 \mathrm{ram}$. 149 .

Gramen fciurumir. alopecurum minus, hcteromalla panicula. Barr. rar. I180. t. 4.

Habitat in Europia aufiali.

Spiculx terzatae, feriles; Calyce bivalwi, lineari, acuminato, involvente Glunas folitarias, alternas, ovatas, obtufos, concuias, absque valuula minore, ftaminibus aut piffillis; nequeunt corrreode dici flores, fed potius pro involucris baberi; Flores bini ad bafin $\int p$ icxlarum, Calyse lineari, longitudine flofoulorum, bifloro; Flofculo inferiori felfili: Gluma exteriore ovata, infra apicim arifa longa recta; interiore angufiffirna. Florculus alter, pedunculo longitudine flofculi prioris, mivor, finiliomsu; tertii flof culi folum rudimentum apparet.

\section{FESTUCA. \\ * Panieula fecunda.}

I. FESTUCA panicula fecunda coaretata ariftata, cul-ovira. mo tetragono nudiufculo, foliis retaceis. Fl. $\int u e c .95$. Poa foliis fetaceis comprellis: caulino latiore, panicula 
contracta fecunda, corollis acuminato-arittatis. Act. floskib. i 743 . p. 184.

Pia foliis fetacois, paricula ramofa, foribis petiolatis antrorfim fpcctantibus, glumis lubulatis. Roy. lkxgdb. 62 .

Poa fpiculis ovato-angufti: ariftato-acuminats. Fl.lapp. 55 .

Gramen foliis junceis brevibus, majus, radice nigra. Bauh. pin. 5. prodr. 34 . Scheucn. gran. 279.

Hubitat in Eurupx colibrs apricis aridis vulgatifimum. 2

B. Feltuca ipiculis viviparis. Fl. laec. 94.

Gramen panicuiatum 1parteum alpinum, panicula angufo-lpadiceo viridi, proliferum. Scbeuch gram. 2 I3. t. 1 .

Habitat in Aipibus I,apponix, Helvetix, Scotix. \#

iurinftula. 2. FESTUCA panicula mutante inferne jamufa, fpicis adfcendentibus hitipidis, foliis letaceis. Roy. lngdb.68.

Gramen pratenfe, panicula duriore laxa mam nartem fpectante. Raj. bift. 1 86 . Schezch. gram. 285.

Gramen tenue duriufculnm \& pene jarceurn. Bash. bift. 2. $p .463$.

Haútat in Europx pratis ficcis.

rubra 3. FESTUCA panicula lecunda fcabra, lpiculis fexflo$r$ is ariftatis: Hofculo ulimo inutico, culmo lemitcreti. I\%. Jiec. 93 .

Gramen alpinum pratente, panicula duriore laxa fpadicea: locultis niajoribus. Scbeuch. gram. 287.

Habitat in Europx fterilibus ficcis.

Magnitusivic, colore maturitatis rubro, culmo teretised altero iatere planiufculo, difingaitur a $F$. ovina.

eme?ajfira. 4. FESTUCA panicula fpicata, Epiculis uno verfu inclinatis fubmaticis. Koy. Inyau. 69 .

Gramen montanum, foliis capillaribus longioribus, panicula heteromalla fpadicea. \& velut ametinyfina. sebeuch. gram. 276 .

Cramen paniculatum elatius, fpicis jongis muticis fqua: molis. Raj. bift. 1286 . angl. 3. p. 4 it.

Habitat in Itali:i, Gallia, 4 nglia.

myso: 5. FESTUCA panicula rpicata nutante, calycibus minutiflimis muticis, floribus 1cabris. Roy. leid. 68 .

Gimen teftuceum mvarm, minori fpica heteromalla. Burr. ic.t. 99 . f. r. 
Gramen murorun', fpica longifima. Raj. anql. 3.p. 415. bift. 28G. Muris. balf. j. p. 215.1 .7 t. +3 .

Iiabitat in Angria, tralia.

๑. FESTUCA panicula fubnntane iecunda, pcdunculis incruffata. incrallatis, arittis calycinis longitudine flofculorum. Gramen reftuceum myurum ciacias, ipica hetcromalia, graciti. Barr. ic. t. 99. f. 2. Sc.2 uch. gram. 293?

Jiablitut in Hípantia.

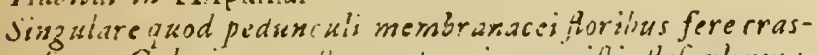

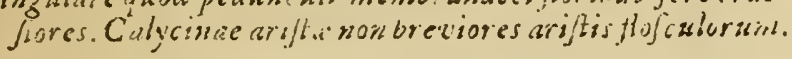

7. FESTUCA paniruia ceunda: fipiculis ercetis: calycis bromithes. altcra valvula intcgra; altera acuminata.

Fefuza lpicis ereatis a unum lans, paiea altera calycina minima, a:terii acuminata. Rov. ingab. 68.

Gramen paitculatum bromoides minus, paniculis arithatis unam parten fpectanibus. Kaj. angl. 3. P.415. bifi. 1297 . Plikk. alm. 174. t. 33. f. IC. Scbeuch. gram. 2.97.

Habitat in Anglia, Gallia.

\section{* Panicula equiari.}

8. FESTUCA panicula erecia, fpiculis fubovatis muti- dew: nbencis, calyce forculis majore, cauic decumbent. $F l$. 92. It. jcain. 226.

Gramen montanum avenaceum, locuftis muticis tumentijus, piloium. S'cbezuch. grim 170.

Gramen avenaceum parvum procumbens, paniculis no: aritaris. Raj. angl. 3. p. 408. bill. 1289 . Pluk alm: 174. t. 34. f. I. Mlont proar. 53. t. 2. f. I.

ilavitat in Europa pafouis liccis flerilious.

9. FESTUCA panicu'a fecunda el cèa, lipiculis fubarifta- elntier. tis exterioribus teretibus. Fl. Sut, gt.

Feltuca panicula fícara, ipiculis uro verfu inclinatis übmuticis. Roy. lugd's. OS.

Grame!n pratenfe majus, locultis tumidis. Buxb, cent. 5.p. $4 \mathrm{I} \cdot t \cdot 16$.

Habitat in Europe pratis jertiliflemis.

10. FESTUCA panicula ramofa erecta. Spiculis fubfcs-finitans. liibus teretibus muticis. $1 \%$ livec. 90.

Poa fpiculis ob!ongis eicet is !ort, cliff. 28. Roy.lugdb.62, G:amen aquaticum Hutitans, multiplici (pica. Barb.pin.

2. theatr. 41. Schench gram. 199.

dabitat in Europex jollis ơ pulnaisus.

1. IE- 
crifata, I1. FESTUCA panicula fipicata lobata, fpiculis ovatis latis fextoris hirfutis. Isafi.

Itabiat in I ufitanix collibus ferilibus.

Culmi c radice thami, vix digiti Inngitudine. Pawicuia Jubfpicuta, fereovata, diverfach Aira crifiatafinfoulis pluribus iisque birfutis, culino breviore, facie antem accedit.

\section{BROMUS.}

fecalins. . BROMTS panicula patente, fpiculis ovaris: ariftis reel is. Fl. fuec. 84 .

Fefucat culmo paniculato, fpicis compreflo-ovatis. Fl. lapp. 28. Roy. lugdb. 6\%.

B. Feltuca graminea, glumis hirfutis. Baub.pin.9. theatr. $\mathrm{I}+3$. Srbeuch. rark. 250.

Gramen avenaceum regerale majus, gluma turgidiore.

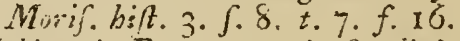

Habitat in Europx agris feralinis arenolis. $\odot$

fquarrofus, 2. BROMUS panicula patula fpicis ovatis: ariftis divaricatis.

Felluca graminca, glumis vacuis. Scheuch. gram. $25 \mathrm{r}$. t. 5. f. II.

Gramen avenaccum, locuftis amplioribus candicantibus glabus \& ariltatis. Tournef. injt. 535 .

Gramen phalaroides aceroíum, nutanie fpica. Barr.ic. 2.4. $f .1$.

Halitat in Gallia, Helvetia, Sibiria.

purgnus. 3. BROMUS panicula nutante crifpa, foliis utrinque nudis: vaginis pilofis, olumis villotis.

Gramen bromoides catharticum. Few. perav. 705. t. $x$ ?

Habitiat in Canada. Kalm. 2

Culnus fesquipedalis, firmus. Folia latitudine aruadiris, carinata, viridia, fuprafers nuda, fublus omninoglabra. Vaginae folioruin retrorfum pilujac. Panicula cripa, Acxuofa, nutans. Spiculae frofoulis 8 ad it oblongare. Glumac pilis breviflonis undique extus ritlojat. Griflu fub apice glumice exterioris. Differt nofera o Fewillaei ráaicibus fibrojis nec fqualrofis; Joiculis angufingribus.

ciliatz. 4. DROMUS panicula nutante, foliis utrinque vaginisque libpilons, glumis ciliatis.

Ilabitut in Canada cx femine. D. Kalm.

Culmitcnues. Folia utrinque $\mathrm{\omega}$ raginc vix manifefre pubefcentes. Panicula valde nutans, non crifpis pedinculis. 
culss. Spioulic oblonga, compreffe, petalorum marginibus (xon dorfo) valdo pilojis qua notafacile difting aritur. Floforli 8 , jub apice ariftati: calyces nudi. Glubme corollae banceolulise.

5. BROMUS panicula patula, fpiculis oblongis diftichis, fitrilis. glumis fubulato-ariftatis.

Feltuca avenacea ferilis elatior. Baub. pan 9. Múris. biff. 3. p. 212. . . 8. t. T. f 11 .

Gramen avenaceum, panicula foarfa, locultis majoribus \& ariftatis. T. Scheush. gram. 258 .

Habitat in Europæ waftralioris agris, fylvis.

6. BROMUS panicula nutante, fpiculis ovats-oblongis. arvenfis. Fl. SHes. 8 .

Bromus culmo paniculato, fpicis comprefts. Fl. lapp. 2\%. Hort. cliff. 25 .

Feftucr graminea, juba affufa. Baub. pin. 192.

Feftuca avenacea fterilis clatior circa Upfaliam. Rudb. elyf. r. p. 87.f. 7. upt.

Gramen avenaceum villofum, locuftis amplioribus virjdantibus margine argenteo cinctis ariftatis. T. Scbeuch. gram. 253

Egilops major, catule \& foliis arundinaceis, locuftis giabrioribus \& angultioribus e fufco verampelinis. Dill, app. Go.

Habitat in Europa ad verfuras agrorum. $\odot$

7. LROMUS panicula nutante, fpiculis linearibus. Fl. tectorum. frec. 96.

Gramen avenaceum, locuftis villolis angultis candicanrious \& ariltatis. Tournefort. init. 526.

Gramen avenaceum, locultis villofis anguftis candicaniibus \& arifatis. Tे. Scheuch. gram. 254.

Habitat in Europa collibus ficcis "ن tectis terreftribus of

8. BROMUS panicula crceta coaretata. Fl. fiec. 8\%. bordeccens.

Feituca avenacea fterilis hunilior. Baub. pin. 10.

Gramen avenaceum pratenfe, panicula fquamata or villora. Morif. bift. $3 ., f \cdot 213 \cdot f .9 ., t .7 . f .18$.?

Milbitat in Eurnpe collibas aridifimis fabulojis. o)

9. SROMUS panicula nutante, fipicul:s quadrifloris ariftis gigntens. brevioribus.

Gramen fylraticum glabrum, panicula $x$ curva, Faill. B prorif. 93. t. IS. f. 3 . Fittu- 
Tefuca foliis digiti latitudine iongisfimis, panicula laxa. Roy. Iugdl. 60.

Gramen bromoides aquaticum latifolium, panicua fparfa tenuifima aritati?. Scineuch. gram. 264.

Habitat in Europic Sylvis fuicis. 2"

pinsunites.

10. BROMUS culmo indivifo, fpirulis niternis fubfeffilibus terctibus. Fl. fuec. \$9. it. go:l. 180.

Feftrca culmo alteriatim foicato, fpicis teretibus. $\mathrm{Fl}$. lapp. 29. Roy.lugdt. 67.

Cramen, Spica briza, majus. Bauh. pin. 9. prodr. 19. 1 biatr. 133 .

Hatitent in Europa folluij moniofis uperis. 2

criflatus.

It. FROMLis fpiculis difliche imbricatis fefillibus depreflis. ilant. caist thb. I. *

Felluca cumo ípicato, lpiculis muttitoris. Gmel fibir. 1. \%. II5. t. 22.

Gramen triticum, jila latiore compacta, crifatum. Buxb. cext. . p. $3^{2}$. t. 50. f. 3 .

fiabitat in Sibiria, Tataria. 2

\section{STIIA.}

frnus'A,

I. STIP A arittis lanatis.

Fetica aritis panicule circiter longitudine plumofis. Kev. lizgio. 63.

Granien picatum, ariftis pennatis. Tournef. inft. 518. Scheuchz.gram. 1 53 .

Gramen foarteum pennatum. Baub. pin. 5. theatr. 70. Spartum aultriacum. Ciuf. bijk. 2. p. 221.

Habitat in Auftia, Gallia.

innces.

2. STIPA ariftis rudis, calycibus remine longioribus.

Fefluca ariftis circiter longitudine panicule nudis. Roy. lugdb. 6x.

Feftuca junceo iolio. Baub. pin. 9. Theatr. 145. Scheuch. gram. 151.

Feituca longifimis arifis. 13amb. pin. 10. theatr 153. Habitat ix Helvetia, Gallia.

o:enacen.

3. STIPA ariftis nudis, calycibus femen xquantibus. Andropogon folio fuperiore fpathaceo, pedunculis lateralibus oppolitis uniftoris, arillis fleruolis. Gran.virg. 133.

Habitat in Virginia.

Culini texuej. Folium Summurn ventricofum longitudine 
paniculae. Paticuia pedunculis conjugatis, wrifloris. Caly cis gluma winifurn, pallida, bizalis, we yualss. Corollne srifta terminaibs, contorta bafi articulatu, ruda, lorgitudine pedunculorum. Grome" hoc Aienafasivaminuseft.

\section{A VENA.}

I. AVENA paniculata calycibus uniforis, leninibus hir-fibirisa. lutis, arittis calyce trip!o longioribus.

Feftuca glumis villons, aritis calyce triplo longiorious. Gricel. isirir. I. p. II3. t. 2.2 .

Mabitat in Sibiria.

2. AVENA calycibus biforis. flofculo hermaphrodito claiver. mutico, malculo ariftato. Fl. Suec. 98.

Avena calycibus bifioris, panicula laxe fpicata: fedunculis prioribus faiciculatis. Gzett. Jtamp. 1. p. I 22 .

Giamen avenaceum, nanicula acerofa, temine paporo. Dill. atp. 43 .

Gramen arenaceum elatius, juba longa fflendente. Kaj. meth. 179. ungl. 3. p. 406. Mor if. hift. 3. f. 214. f: 8. t. $7.3 \%$. Scheuch.gram. 239. Hall nolv.225. B. Avena panicnia nutunte, calycibus bifloris: altero 1!ufculo ariftato. $R \cdot \%$. lugdb. 60.

Gramen mudofun, avelice: panicula, radice tubuibus pradita. Bauh. pin. 2. prodr. j. theatr. IS. Jobeuch. gram. 23 ?

Mhbiat in Eurcpa maritimis E apricis.

3. AVENA panicula attenuata, calycibus bitoris femini-penfylunica bus villolis, arifitis calyce duplo longioribus.

tiabiat in Penfylvania. Kalm.

+. AVINal panicula contracta, flofculis binis apice bi-lafiugian. ariftaris, dorfo arifta reflexa. Lofl.

Habitat in Hitpania.

Gramen ix digiti longitudine; culmi plures ex radice. Folia planiufcula: Summum ventricofum latius. Panicu'a coarctata, crafja. Calyx floficulis longiur. Arittze terminales, fetacene, longituline corollarum: dorfalis duplo lingeior: turta.

5. AVFNA calycibu's difpermis, feminibus lavibus. Hort. fativa. cliff. 35 . Hort. wps. 20. Miat. rned. $3 \delta$. Koy. lugd's. 65.

Alena nigra. Bask. viz. 23.

B. Arena aliba. Barb.pin. 23

Hobilui - - C

6. AVE, 
farno 6. AVENA panicula patente, calycibus trifioris, nofculis bafi pilctis. $5 \%$. Juec. 97.

Avena leminibus hirfutis. Fl. lapp. 30. Roy. lsgdb. 65. Feftuca utriculis lanugine thavefcentibus. Bauh pin. 10.

Gramen avenaceum, locultis lanugine favefcentibus. Scherich. gram. 239.

Habitat in Europe agris inter fegetes. ()

faeffiers. 7. AVENA panicula laxa, calycibus trifloris brevibns, Hofculis oinnibus aritatis. Rov. lugdh. 66.

Gramen avenaceim pratente elatius, panicula flavelcente, locuftis parvis. Raj. angl. 3. p. 407. hift. 1284 . Scheucb. gram. 223 .

Gramen avenaccum, pica fparfa tavefcente, locultis parvis Morif. bift. 3. p. 215 . . . 8. t. 7. f. 42.

Habitat in Germania, Anglia, Gallia.

frogitis. 8. AYENA fpicata, Hofculis fubquaternis calyce lon gioribus.

Gramen loliaceum lanuginofum fpica fragili articulata . g!umis pilofis aritatum. Sabcucls. gram. 32 .

Gramen loliaceum fpurium hirfutum, ariftis geniculatis. Barr. ic. 905. f. 1. 2. 3 .

Habitat in Lulitania, Hifpania. Loefl.

praters. 9. AVENA calycibus quinquefioris, panicula fpicata.

Avena panicuia fpicata, fpiculis cylindricis culmo oppreffis. Gisett. fiamp. I p. ISz.

Avena fpicis eretis, calyce fpiculis breviore. Fl. lupp. 31 . Fl. juec. 96.

Avena calycibus trifloris, panicula nutante, foliis planis. Gmel. fibir. I. p. 12 g.

Gramen avenaceum montanum, fpica fimplici, ariftis recurvis Raj. angl. 3. \$. 252. t. 21. f.I. Sibench. gram. 226.

6. Granch avenacenm glabrum $\mathrm{f}$. potius hirfutum, panicula purpuro-aigentca fplendente. Kaj.angl. 3.p. 406. t. 2 I. f. 2 .

Habiatin Europxpafurs Jiccis apricis.

Spicats.

10. AVENA fpicata, calycibus fpiculis fexfloris longioribus: tenlo cxteriore apice ariftato fircatoque.

Habitat in Ponfilvania.

Gramen argy firm; Folia linearia. Spica compofita ex Jpiculis 3. S. 4, remotis, erectis: Spicula $\int u b p e d u n c u$. latce: Jiresiles Calyx diployllus. Júbulatus, uequalis, fpicula longior; Flofculi 6, feljiles, ereda: Petalo exreri- 
reciore apice bifido in apices duos felaceos, e quarum divifura arifts orticulaia, longitudise fpuculac. Fa. cies Fefurae decumbentis.

\section{LA GURUS.}

1. LAGURUS ipica ovata. Hort. cliff. 25 .

Gramen alopecuroides fpica rocundiore. Baxb. pm.4. tbeasr 50.

Gramen fpicatum tomentofum Iongitimis ariftis dona. tum. T. Sheach. gram. 58

Hobitat in Iralia, Gallia. Sicilia, Lufitania.

\section{ARUNDO.}

ARUNDO arbor, Bash. pin. 18. Hort. sliff. 25. Fl. Ramb $2 c y l: 47$. Koy - lingd6. 67 .

Tabaxir \& Mombu arbor. Baub bift. 1. p. 222.

Ily. Rbeed. mal 1.p.25. t. 16.

Habilit in India utraque. b

AR.UNDO calycibus trifloris, panicula diffula. Roy. Donmu. litgdb. 66

Arindu rativa. Virid. cliff. 7. Hort. claff. 26.

Arundo fativa, quæ Donax dioicoridis. Bash. pir. i7. theatr. 271 .

$B$ Arundo indica laconica verficolor. Morif. bift $3 \cdot p$. 219. 5. 8. t. 8. f. 9. Hort. cliff. 26.

Habitat in Hipania, Galloprovincia.

3 ARUNDO calycibus quinqueftoris, panicula 12xa. phrogniter, Roy. lagd's 66. Gron. vire 37.

A runcu paricula laxa, folculis quinis, Fl. fuee. 99.

Arundo panicula laxa, calycibus fubbitloris. Sauv. monsp. 38.

Arundo vulgaris is phragmites diofcoridis, Bamb. pin. I7. Scheuch. grain. IOt.

Habitat in Europx lacabus finviis. 2

4. ARUNDO calycibus unifloris, panicuia ereeta, folïs epigajos. subtus glabris.

Aruudo panicula coarctata erecta integra, foliis inferne glabris. Fl. Suec. Ior.

Gramen arundinaceum paniculatum montanum, panicula fpadiceo viridi, femine pappofo. Scbeuch. gram, 124.

Habitat in Europa collibus arialis. 4 
Ceinmagro- 5. ARUNDO calycibus unittoris, culmo ramóo. Fl. fits. lapp. 42. Fl. fuec. 100. Rेoy. lugdb. 66.

Gramen arusdiuaceum, panicula molli fpadicea, majus. Bawh. pin. 7. tbeatr. 94. Ssbeutb. gram. 122 t. 3. f. 5 .

Habitat 2 Europe palibaibis graminufis. \#

renaria.

6. ARUNDO calyribus unifloris, folitis involutis mucronato-pungentibus.

Arundo folionum lateribus convolutis acumine pungen. te. Fl. $\operatorname{lntp} .4 j$. Fl. juer. roz.

Gramen tparteum fpicatum, folits mucronatis longioribus. Ballb. pin. 5 .

Granen fpicatum lecalinum maritimum maximum, foica longiont. 'T'. Sebeach. gram, I 38 .

Hobitat in Europa ad maris litura arenofa. $z$.

\section{ARISTIDA.}

Ad ceniposus. 1. ARISTIDA.

Gramen avenaccum, panicula minus fparfa, cujus fingula grana tres arittas longitlimas habent. Sioare. jain. 35. bijt. $3 . p \cdot 16 . t .2 . f .56$.

Gramen avanaceum maderafparanum, panicula fparfazriftis lonzioribus ornata. Plus. alm. $174, t$. ig1. f. 3 ?

Habirat in Infula Adfcentionis sna ex quatuor iftius fiasperrime Flow plantis, quarmm I. Sberardia fruticajie 2. Eupboritia origancides, 3 . Portulaca. Osbeck. 3.

Habins Feftusa or'in a' Sed paulo major. Radix cefpitem cenftitucris. Culmi inferne rabnofi. Folia e bafi latioie fenfism anguftista, plano-canaliculata, jubuloitas: $\mathrm{Pa}$ nicula oblongaz diftin. fliformitus, horgibadinabier cenvulutis, triplici arifla terminatis.

\section{APLUDA.}

imatien. I. APLUDDA.

Schonanthus ayenaceis procumbens maderafparanus, bupleuri folio. P Schemch. gram. 1ig?

Habitat in India.

Culni longifjuri, bipedales 8 ultra, debiles, glabri. genicalis trmidus. Folia langa, plana, lanceolato, pe-

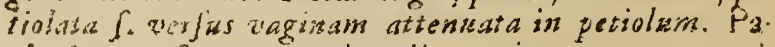
nicula angutis, parza, clateribus exiens, e vaginas mi

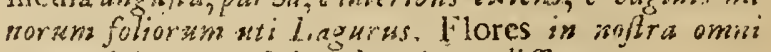
zo murici, qua a Schisicberiona differunt. 


\section{LOLIUM.}

1. LOLIUM fpica mutica.

Lolium ficis muticis, radice perenni. Hort. cliff. 24-pereten. Fl. Suec. 104. R2y: lugdb. 69.

Lolivin fpicis compreffis, radice perenni. F\%. lapp. 32.

Gramen loliaceum, angutiore folio \& lpica. Bawh. pin.

9: theatr. 127. Scbeuch. grart. 25.

Habitat in Europa ad agrorwin verfuras fols fertili:

2. LOLIUUM fpica ariftata.

Lolium fpicis ariltatis, radice annua. Hort. cliff. 23. F\%, tomulencum. fuer. $10_{3}$. Koy lugdib. 69 .

Gramen loilaceum, fipica longiore, r. Loliun diofcoridis.

Eaub. pir. 9. thiatr. I21. Sibezeh. gram. 31 .

Habitat in Europe agris inter Hordewin, Linum: 7

\section{ELYMUS.}

r. ELYMUS foliis mucronato-pungentibus. It. fian 336 ; arenariss:

Gen. nov. 1074:

Secaic fpiculis geminatis. Fl. Suer. 106.

Triticum foliis acuminatis pungentibus. Ro\%. lugdb.. $7 \mathrm{i}$.

Gramen caniuum maritinum, fpica triticea, noltıas. $R a j$. bit. I 256 . Sichench. gram. 6.

Habitat ad Europa litora inarina in arena mobili. 2

2. EL YMUS fica flaccido pendula fpiculis binatis. Hort: Siviricus. ups. 22.* Gez. nov. 1004.

Triticum radice perenti, fpiculis binis longifime arifl-tis, Greel. Fibir. I: po i23. t. 29.

Habitat in Sibiria. 2

3. ELIMUS fpica tlaccido-pendula, ipiculis inferioribus canadenfir: ternatis; fuperioribus binatis. Gen. nov. 1094.

Gramen fecslinum majus altilfinuin virginianum $\mathrm{Mo-}$ rif. bift. 3. p. I Sc. $\int$. S. t. 10. f. 2. Kaj. fuppl. 599.

Habitat in Canada. Kalia. 2.

Convenit in plurimis cum E. Sioirice, a quo tamen differt I. Spiculis villotts, aec nutit: 2 . involucris in ariftarn excuntibus longioribus ip aspicula, demtis ariftis; at in fibirica involucrian minus fubulatum, fed jere larceolatum in ariftum definens, quale longe orcuior Sza fpicula. 3. Spicae inferne termat, quum Sibirica femper duar obtineat. 4. Spiculae, duin florent, de'n:fiunt afcapopatulo, in fibiricaverojpiculae opproximatae font foapo: Variat hrec fpicis ineurvis है pend it:

bis: 
lis. Arifiz corolline cxin maturefoit fructus patcutireflexae funt contra ac in Siburion.

wirginicus. 4. ELY YMUSS fpica crecta, fuicula involucro longiore. Hort. upf. 22.

Hordeun fiofcuis onnibus hemephroditis, involucris for $z$ ilos cratite \& longitudine liperautibus. Grox. virg. I3.

Habitat in Virginia. \#

capt medus. 5, ELYMUS fpiculis uniforis involucris fetaceis matentisfimis.

Eiymus involucris refcro-patentibus. Gex. noz?. I094, A vena luntanica foicati, caput medufa referens. Morif. bilt. 3. p. 210. Rai. Suppl. 6:I.

Gramen hordeaceun, fpica ariftis longifinis circumvallata. S'bescì. gram. 20?

labibat iw Luftania, Hijania matritimis.

\section{SECALE.}

sereale. I. SECALE glumarum ciliis fcabris. Hort up $f, 22$.

hybernun. Secale hybernm vel majus. Bauh. pin. 22. theatr. $42 \xi$. vernuka.

B. Sevale vernum 1. minus. Bask. pin. 23 . Habitat - . -

oillofwm.

2. SECALE glumarum cilis villoris, fquamis calycinis cuncirormibus.

Gramen fipicatum fecalinum, glumis villofis in ariftas longistinas definentibus Tumrnef. injt. 518.

Gramen fecalinum maximum. Park. theatr. 1144.

2. Gramen creticum tpicaun fecalinum, glumis ciliaribu. Tuurnef. cor. 39. Ensto. cest. 5. p. 2I. t. 4I.

Habitat in Europa asfirali, $G$ in orieste.

erwata. 3: SECALE giumis hirfutis, fquamis calycinis fubulatis. Gramen orientale fecalinum, fpica brevi \& lara. Tukrnef. cor. 39.

Habitat ad Archipelagum.

treitum. 4. SECALE giumis extrorfum ciliatis.

Gramen creticum ipicatum fecalium altifimum, tube ror radice. Tournef. cor. 39 . Scheach. grim. 22. Habitut in Creta.

\section{HORDELAN.}

valgave. I. HORDEUM flofculis omnibus hermaphroditis ariftatis; ordinibus duobus erectioribus.

Hordeum folculis omnibus hermaphroditis, feminibus corticatis. Hort. upf. 22. Mat. med. 35. Her- 
Hordeum fof culis omnibus hermaphrecitis. Hort. shat 24. Roy.lugab. 69.

Hordeun polyitichon vernum. Bawh.pin. 22. theatr. 439 .

B. Hordeum fotculis omnibus hermaphroditis, feminious coetefte. decorticatis. Ilort. ups. 23 . Habitat - - - 6

3. HORDEUM fiorculis ommibus hermaphroditis ariftatis, bexifficken. feminibus fexfarian requalitur pontis. Hort. ups. $2 \hat{\jmath}$. Habitat - - - 2

3. HORDEUM forculis lateralibus mafculis muticis, fe- difichors. minibus angularibus imbricatis. 12ort. $\approx p$. 23

Hordeum diftichon. Bush. pin. 22.

G. Hordeum flofculis lateralibus máculis muticis, femini- dift,nudum bus angularibus imbricatis deco:ticatis

liabitat

4. IORDEUM forculis laterglibus mafculis muticis, fe- rexritelie minibus angularibus patentibus corricatis. Hort. upfo 23. n. 5 .

Zeocriton f. oryza germanica. Bakb. pin. 22. Habitat - - : 0

5. HORDEUM flofculis lateralibus mafculis ariftatis, 7tarintam, Hort. cliff: 24. Fl. Suec. 10\%. Roy. Isrgdt. 60.

Gramen hordcaceum ninus \& vulgare. Bawh. pim. 8. theatr. 134. Scheuch. gran. 54 .

B. Gramen foicatum fecalinum minus. Schesch. gram. 17. Vaill parif, 83: $: 17 . \hat{f} .6$.

Habitat in Europe locis rideratis. $\odot$

6. HORDEUM ariftis involucrisgue fetaceis longiffimis. inuastsm. Habitat in Canada. Kalm.

Habitus hordei murini, Sed inzolucra co arifte fetacese

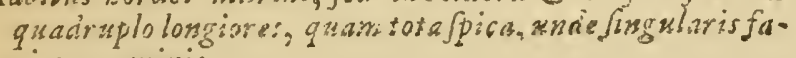
reis graminis.

\section{TRITICA.}

\section{* Anrua.}

3. TRITICUM glumis rentricofis glabris imbrieatis offiwim, ariftatis. Hors. wp. 21 .

Triticum radice annua, fpica glabra ariftata Hort cliff. 24. Roy. lugdb. 1 70 .

Triticum entivum Baub. pix. as,

Haúitat $\cdots . \cdot \odot$

F $₹$ 2. TRS. 
byteint:n. 2: TRITICUM glunis ventricolis lavibus imbricatis fubmuticis. Hort. upf. 21. Wat. mea. 36 .

Triticum radice annua. Spica mutica. Hort. cliff. 24 . Koy. lagdb. 70.

Triticum hybernum, aritis carens. Baub. pin. $2 \mathrm{I}$. Ilcábitut

ixprifun: 3. TRITICUM glumis ventricofis villofis imbricatis obtufis. Hort. aDf. $2 \mathrm{~T}$.

Triticum radice snnua, glumis villofis. Hort. cliff. 24. Roy. lugdb. 70.

Triticum ipica viliofa quadrata breviore \& turgidure. Morif. hift. 3. F. I -6. 5. 8. t. 1. . . 14.

Habitat - - - $\odot$

Speitu: 4. TRITICUM calycibus truncstis guadriforis, flofculis ariftatis hermaphroditis: intermedio neutro: Hort. up: $2 \mathrm{I}$,

Hordeum flofculis lateralibus mafculis muticis involucro deftitutis. Saur. moisp. 39.

7.er dicoccos vel Spelta major. Bauh. pin. 22. theatr. tri2. $t, 414$.

Habiat $-\cdots-\odot$

monocessm 5: TRITICUM involucris uniforis, floribus ariftatis, Spica difticha. Suzv. mousp. 30. t"

Fordcum diftichum fpica nitida 1 . Briza nuncupatum. Tournef. in/t. $5 \$ 3$.

'Za Briza dieta 1. monococcos germanica. Banb. pin. $2 \mathrm{I}$.

Briza moncococcos dodonxi. Lab. ic. $3^{1}$ :

Habitat .. - - .

\section{* Perennia.}

repens 6. TRITICUM ralycibus fubulatis trifioris acuminatis. Triticum sadice repente, foliis viridibus. $f l$. lapp. 3.3 . Fl. Sues. I05. Hort. cliff: 24. LIat. med. 37. Roy: lugdb. 70 .

Gramen caninum arvenfe f. Gramen diofcoridis. $B a z b$. in. I. Scheuch grain. 5 .

Hobriatin Furopx caltis. 4 .

comizrsm?

7. TRITICUM calycibus libbulatis quadrifloris anuia. tis.

Gramen caninum non repens ciatius, epica arifala. Morif bif. 3.p. I77.f. \&, l. I. . 2. Buxú. cent. 4. p. 29. t. 50 . 
Gramen loliaceum sadice refente C. Gramen officinarum, longioribus ariltis donaturn. T. L aill. parij. 81. ใ. 17. f. 2 .

Graminis fpica triticea repentis vulgaris varietas cum fpica ariftata. Scbiucb. gram. 9.

Habitat in Europe fepilos \&

\section{TRIGTNIA}

ERIOCAULON.

1. FRIOCA ULON calno quinquangulari, calyce uni-quinguanguverfali pertiaphyilo. $F$ l. zcyl 43 .

Sratiofa gramined mudiczulis, capitulis argenteis $[$. Stztice minima macicrafparana. Plak, a/m 306.t. 221.f.7.

Haibitat in iudia. 2

2. ERIOCAULON culmo iexangulari, foliis enfiformi- sexangunare. bus. Fl. zeyl. 49.

Gramen junceum indixe orientalis minus, capitulo totundo ex paleaceis fpiculis in cacumine caulis glonerato. Flus. mani. 48 .

Habitat in India. 2

3- FRIOCAULON culmo fexangulari, foliis fetaceis. Setaceum. 1i. zeyl. jo.

Randalia malabarica, capillaceo folio. Pesiv. topic. 344

Itieru-kotijellcti-pollu. Rheed. mal. 12 . p. I29.1.63.

Halitat in India.

4. ERIOCAULON cuimo decangulari, foliis enfifor- dechngylare. mibus.

Eriocaulon noveboracenfe, capitulo albo globofo $f$. Globularia americana ftarices haud abfimilis, cauliculis lana atro-nitente refertis. Pluk. umalth. t. 409. f. 5

Randalia americana procerior. Pet. gaz. t. b. f. 2 .

Globularix affinis aquatica, caulc tenui aphyllo gramineo, capitulis albicaltibus parvis giobofis, toliis paucis humiftratis gramineis. Gron. z'irg. 13.

Habitat in Americx lepientrionalis paludibus.

\section{MONTIA.}

1. MONTIA. Fl. lapp. 30. Fl. Suec. 108. Roy. lugdt, foutons: 199.

Montia aquatica minor. Mich. gen. 18.t. J3. f. 2.

Cameraria arvenfis minor. Dill. gi 2 l: 46

$$
{ }_{i}{ }_{4} \text { Alfi. }
$$


Alfinoides annua verna. Vall. paryl. 1. 3. f. 4. Alfine paluftris, portulaco aquatica fimilis. Raj. ij/s. I035 Pet.berb.t. 10. f. 12.

Portulace arvenfis. Basb.pin. 288 .

Habitat in Europa ad fraiurigines. $\odot$

PROSERIINACA.

pustutris. I. PRCISERPINACA. Aci. ups. I741,p. \&.

Trixis. Mitch. E. $N, C$. 1748. n, 23.

Habitat in Virginix paludibus.

Radix repens. Caules pedales, terctiufculi. Folia altere $n_{a}$, lanceolata, ferruta, in petiolos definexita: demerfis f. ime in lacinias lineares pennatifida. Florcs axill.sres, folitari. Fructus figura Poligon:.

\section{HOLOSTEUM.}

"rdam 1. HOLOSTEUM folits fubcordatis. Gen. nov. 10g5. Alfine folits fubcordatis, ftipulis utringue quaternis Hort: up $: 24$.

Alfine americana, nummularia folio. Horm. parad. II. t. $1 \mathrm{i}$.

Habivat in Jamaica, Surinama.

isculswm 2. HOLCISTEUM foliis ellpticis carnolis, Gers. sov. 1095 .

Alfine folis ellioticis fucculentis, Cold.noreb. 9. Hulitat in Noveboraco.

Girfum. 3. HOLOSTEUM foliis orbiculatis hirfitis. Gen. stov. 1095.

A!fine foliis orbiculatis hirfutis, floribus feffilbus. Roy. ins?

Hobitat in Malabaria.

umbellusuen. 4. HOLOSTEUM horibus umbellat's.

Spergula foliis oppofitis, pedunculis umbeilatis Guert. famp. 298. Dalib. parif. 134.

Holofteum caryophyllæum arvenfe. Taberm. 233. Lychnis graminea hirfuta umbelitera. Moraj: bift, 2, f. 546. .5. 5. t. 22. f. 46.

Caryophyllus arvenfis umbellatus, folio glabra. Bask, pin, 210.

Caryophyllus arvenfis Baub. bift. 3. p. 361 . Habitat in Germaniz, Gallix arzis. 


\section{MOLLUGO.}

1. MOLLUGO foliis oppolitis ianceolatis, ramis alter-oppefitfolit. nis, pedunculis lateralibus confertis uniforis. Fl. zevl 52.

Habiat in Zeylona.

2. MOLLUGO folits quaternis obovatis, panicula tetraphysios dichotoma. Hort. diff 28. Roy. lugdb. 21 y. Saur. monsp. I64.

Anthyliis marina alfinefolin. Baub. pix. 28\%.

Anthyllis allinefolia poivgonoides maior, Barr.rar. 103. f. 534 .

Habitat in Iralia, Narbona rineis, (9)

Hiric petala 4, coata, calyce breitiora.

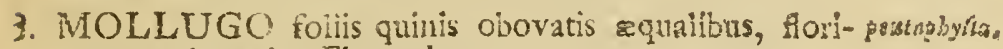
bus paniculatis. Fl. 2eyl. 5 T.

Alfine ramofa procumbens quadrifolia, ad radicem por

lyphylla. Burrie. zeyl. 13. \$. 8. f. 12.

Habitat in Zeylona.

4. MOLLUGO foliis verticillatis cunciformibus acutis, ventiolhats caule fub divifo decumbente, peduncuis uniforis. Hort 3pj: 24.

Mollugo toliis fapius feptenis lanceolatis. Gron. virg. 14 Aline Spergula mariana, lationi folio, floribus ad nodos pediculis curtis circa caulem infidentibus, calycibus eleganter punctatis. Pluk, rant. 9. t, 332. $f .5$.

B. Mollugo foliis feptenis linearibus. Hort. cliff. 28.

Alfine procumbens, gallii facie, africana. Herm, iugdo. ig. t. 21. Ebret. pict. t. 6. f. 3.

Habitat in Africa, Virginia. $\odot$

\section{MINUARTIA.}

MINUARTIA Lefl.

hispanite.

Habitat in Hirpania. ()

Piantula rigida, dar a, tenax, fapias fimpiex. Folia oppofite, $\int$ ctacca. Flores cymofi in capitziclun quadratum, ardfe dicbotomum, faftigiatum, caxle fepius majus, fesflles Bradtex fetacer, flore longiorcs, apice recto. Semina quingue ad oito, fubrotunda, reniformia. Colos plante Jubfufcus. Laef.

\section{GUEREZIA.}

r. GUEREZIA foribus capltatis. Lx.e. 
Mubitat in Hilpalla. $\odot$

Anecedente ininor, $f:$ agilior. Capitulum for um objoirtiun teiragorum, jaciline a raule difcedens. Bracles sctacen, erece, apice extrorfum kamata, veltibus adburentes. Semen I, comprelfum, fubrotusidum. Colou plant albidus. Leff. Habitus antecedentis o ftruatura fioris eadem; at Seminafolitaria É plura con. Aitulin genera diverfiffima.

camalebis. 2. GUEREZIA Horibus folitariis, caule dichotomo.

Mollugo foljis oppofitis, flipulis quaternis, cale dichotomo. Gron. virg. '4?

Hubitat in Canada, Virginia.

Radix furofa. Caulis ftritus; dichotomus, fpithame: us teres, filiformis, ciedus, Herba lini catbartui. Fuila oppofital. lanceolato-avota, integerrima, adfperga utringus punctis fufcis. Stipula gemine utrinque, aluta, membranace. Flores folitarii, $\int u b-$ pedunculati, parvi, virides, ex füzula dichotomia. Calyx quinquepartitus joinolis obiufiufoulis, fubfornicatis Petala nulla. Stamina 3, Antheris flavis. Germen Jubrotundum. Styli tres Spontanca plarta nitior caule rapillari; culta crafior Eै foliis minime punstatis.

\section{LECHEA.}

minor. 1. LECHEA foliis lineari-lanceolatis, floribus paniculatis. Gen. now. 1074.

Capraria foliis integerrimis, Gron. virg. 75.

Scoparia foliis tenuifimis in plurimos \& retuiffimos $12-$ mulos divifa \& lubdivifa. Raj. Suppl. 132.

Habitat in Canadx fylvis glarenfis. 4

major 2. LECHEA foliis ovati-lanceolatis, foribus lateralibus vagis. Gea. nov. 1074. S. 4. *

Habitat in Canade aridis. 


\section{Clagis $I V$.}

\section{TETRANDRIA MONOGRNIA.}

LEUCADENDRON.

1. LEUCADFNDRON foliis fetaccis, fofculis difjun- rncemornm. Etis racemolis.

Protea foliis fetaceis, foribus racemolis. Hort, cliff.496.

Liabiat in Ethiopia. b

2. LEUCADENDRCN foliis fubularis, ramis detcr-proteozd:s. minatis, toribus terninalibus.

Protea foliis linearibus fimpliciffimis, ramis determinatis, floribus terminaibus. Koy. lugdb. 186.

Habicat ad Caput b. fpei. 5

Folia conferta. Rami ad áeterminata fortia conforti,ce. terum nulli, Calyces fubrotundi, pubefienter.

3. LEUCADENDRON foliis fubulatis, ramis fparfis, sancoliatum. floribus lateralibas.

Lepidocarpodendron foliis anguftifimis gramines, fruEtu cancellato, femine coronato. Boerb. logdb. 2. $p$ I93. 5. 193 .

Habitat ad Caput b. Spei.

4. LEUCADENDRON foliis ianceolatis, floribus ob-Legidocarpolongis, calycum fquamis fummis hir'utis: deridrons.

Protei foliis lanccolatis integerrimis ghabris, calycinis fuperne villofis. Roy. lugib. 186.

Lepidocarpodendron foiiis anguftis longioribus falignis, calycis fquamis elegantiflime ex fiayo fufco albonigro variegatis, florum piumis atropurpurcis. Boerb ingdb. 2. p. 188. t. 188 .

R Protea foliis lanceolatis integerrimis glabris, calycem fuccingentibus hirfutis. Roy, prodr. I $\$ 8$.

Lepidocarpodendron folio faligno viridi: nervo \& margine flavo, cono longo fuperiore parte maxime claufo Boerh. Ingdb. 2. p. 189. t. 189.

Habizat ad Cap. b. Ipei. 5

r. LEUCADENDRON foli's lanceolatis, floribus ob-repers. longis, calycum lquamis glabris. 
Protea caule multiforo, calycibus oblongis, follis lanceolatis integerrimis. Roy. lag it. 185 .

Lepidocarpodendron tolis ang unt brevioribus talignis, cafycis fundis clegantilime ex rofeo sureo albo a-

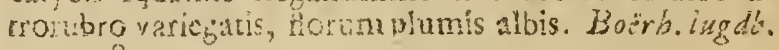
2. f. 187 .

3. Leticalandron folis Inngilimis obture trigonis, longitudine torem fuperanibus. II ach. ultraj. 204.

Protea caule anifloro, calyce oblongo, foliis lineribus

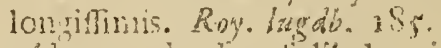

Levidocarpodendron tolis longisfmis anguftisfmits, fru. tum elegantistime ex rub;o tavo \& albo variegatum ficcingsntibus, adice repente. Boerb. iugdb. 2. F. rpo. t. 190 .

Habiiat ad Caput. in. lipel.

abuilias.

Sedyranee. phal:ski.

6. JIUUCADENDKON follis hanceolatis, horibus fúb. rolundis, canle fuffuticolo uniftoro.

Leacidendron acaiton. Wach. whitraj. 204.

Froted canle unitioro, follis lanceolatis. Roy. ingde 186.

Lepiducarpodenaron acululon, folís paucis latis, nervo \& marginibus rubrís ornatis, fruetu paryo. Boerh. lugdk. 2. p. 19r. t. 191.

Habitat us Caput b. fpei. o

7. LEUCADENDRON foliis lanceolatis, fioribus fubrotundis, caule fruticofo ramofo.

Lepidocarpodendron acaulon, ramis numerofis e terra excrefcens, calyce foris immaturo extus ex rubro \& fiavo variegsio, intus flavo. Bocrb. lag dh. 2. p. 192. i. I92.

Habitat al Caput b. fpei, in erisetis mont. Tigradis. 5.

Cltarontes. 8. LEUCADENDRON foliis integris, floribus depresfis, corollarum limbis cylindricis.

Lencadendron foliis fubrotundis paicntifimis petiolatis, foliolis calycinis carinatis. Wach. ultraj. 204.

Lepidocarpodendren follo fubrotundo rigido, in pedunculo longo crafro, fore maximo purpureo. Barb.lugdit. 2. $p, 184.5,1 \varepsilon_{4}$.

Cinaroides fruter, tolio finbrotundo rigido, e nonte an bulari. Petiv. muf. 37.4.

6. Protea foliis lanceolatis integerrims, flore patente gla bro, ftylis longifimis. Roy. luydb. I86.

Hubitat ad Capit $b$. tpei in busmidis mont. Tabularis. fariat folias sordatis ${ }_{2}$ ov at is, lanceolatis. 
9. LEUCADENDRONi tolis calloro-tricupidatis in- ckstintkm. volventibus tores iaserales.

Lencadendron foliis cututitormibus apice tridentato-callofis, lummis tilra fiosem protenfis. Whash, sltraj. 203.

Prote: foliis lanecclatis obtulis Raes involventibus: 2pice tridentato-callolis, Roy. Iugdb. I 34 .

Hypophyllocarpodentron folis interioribus apice trifico rubro; fiperioribis penitus rubris glabris. Burb. lagdó. 2. p. 206 . t. 206 .

Habitat ad Cap. b. Ipej bosis isliginofis. 5

10. LEUCADENDROM folis callolo-tricufidatis, ca- Hypoplyila. lycibus turbinatis indis.

Leucadeudros aficana f. Scoly moceptalus fulio angutiori: apicibus tridentutis. Plak, alm. 2r\%.

Proter foliis lanceoluto-linearibus apice micientato-calloits, capituils aphyllis. Roy. lagrab. i 84 .

Protea foliis lanciolato-linearibus: spice tridentato-cailofis. Hort. cliff. 29.

Conocarpodendron folio rigidio angufto: apice tridentato rubro, fore aurantio. Barb. Iugdb. 2. $5.19 \$$. iog. 8.

Habitat ad Cap. b. foei in campis fabulofis. b

11. LEUCADENDRON foliis calloio-quinquedentatis. Con ana per,

Leucadendron foliis obverfe ovatis oblongis: zhargine callolo-timbriatis: ad apicem crenatis. Wach. uliraj. 203.

Lencadendron africana arbor argentea, fummo folio crenato. Pluk. airn. 212. t. 200. $f$. 2.

Protea foliis oblongo-ovatis apice quinquedentato-callofis. Roy. laggd6. Is 4 .

Comocarpodendron folio craffo nervo lanuginofo fupra crenato ibigne limbo rubro, flore aureo, cono facile deciduo. Bawh. Iugdb. 2. p. 196. t. I96.

Scolymocephalus africanus latifolius lanuginorus, foliis in funmitaie crenatis. Merra afr. 20. Raj. dendr. 9 .

Habitat in Ethiopia. 5

12. LEUCADENDROS foliis feraceis fivnitrifidis.

Protea follis linearibus ramolis. Roy. bugdb. r\&6. corpodertis.

Cyanus rthiopicus, rigidis capillaceis tenuisfinis tolits tritidis. Fluk. mant. GI. t. $345 \cdot f$. 6 .

Mabialat cat. Cap. b. Ipei. b

13. LEUCADENDROS foliis fetaceis multifidis.

Abrotanvides arooreum monomatapenfe, floribus in $\mathrm{ra}$ nulorum cymis. Plmi. rant. I. ¿. 329.f. I. 
Serraria foliis tenuiffime divifis, foribus rubris apetalis. Burm. afr. 264 , t. 99. f. 1 .

B. Serraria toliis tenuifime divifis, capitulis tomentofis. Burn. afr. $265 . t .99 . f .2$.

$\gamma$. Anethifolius fratex africanus, flore fericco. Seb. thef.2. t. 43 . $f .6$.

Ilabitat in Ethiopia. b

\section{PROTFA.}

uggented.

I. PROTEA foliis lanccolatis obliquis acuris fparfis, floralibus verticillatis.

Protea foliis lanceolatis integerrimis hirfutis mitidis. liort. cliffi 29.

Leucadendros africana aroor tota ingentea ferica, foliis integris. Pluk, alm. 2 I2. t. $200 \mathrm{f} .1$.

Argyrodendros africana, foliis fericeis \& argenteis.Comm. bort. 2. p. 51. Raj. dendr. 9 .

Conocarpodendron follis argenteis fericcis latiffimis. Boerh. Ingi's. 2. p. 195. t. 195.

frute: 2 hiopicus coniter, toiiis cneori ianuginofis falici remulis. Breyn prodr. 2.p. 49.

Arbor ferens folia argentea. Zanon. bit. 24.

B Protea foliis lineari-lanceulatis iategerimis acutis. Hort. cliff. 29.

Ptotea foliis lineari-lanceolatis integerrinis: fuperiozibus hirfutis nitidis. Rov. lugrib. i8.

Globularia africana frutercens, thymelea folio Januginofo. Tournef. inti. 467 .

Frutex xthiopicus conifer, foliis cneori falici æmulis. Brayn. cent. al. t. o.

$\gamma$. Prote foliis linearj-lanceolatis giabris, capitulis fquammofis: corona foliacea fuccinct:s. Foy. luzalb. is5.

Conocarpodendron folio rigido citilo anguíto, conolaricis parvo Boerb. lugdía. 2. p. 197. t. 197.

f. Protea foliis lincari-lanceolatis glabris, capirulis ad bafin fquaminotis. Roy. lagá. I8r.

Conocarpodendron folio angulto rigido brevi, cuno parvoaureo: coinona Eoliacia fucchiloto. Bcerhilugdb. 2. p. 200.

๕. Protea foliis lineari-lanceolatis giabris, canle inferne radicato. Rov. Iugdh. 195.

Conocarpodendron folio tenuifimo anguftifimo fal:gno, cono calyculato. Boerb. log $46.2 .8 \cdot 203 \cdot t \cdot 203$.

?. Proted foliis lanceolatis acuminatis Bexuolis, capiralis corona toliacea fuccinetis. Roy, lagedb. 185 .

Cono- 
Conocarprodenáron folio terui angufto falignto. cono calyculato corona foliucea fucciucto. Buerh. lagdh. 2. p. 204. t. 204.

Habitat aa Cap. b. Ipei. b

Plunta naturilis, in patria. argentea excellit fronde, in..

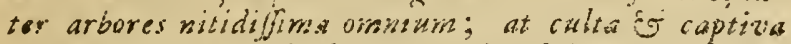
extra patriam exuit decks; variat dein ttjan domi mille modis vere Protea.

3. PROTEA folis ovatis obtufis imbricatis, capituiis glo- fusca. bolis.

Coworarpodendron folin fubrotundo brevifimo, capituli immaturi globoti parte inferiore fuica, media aurca, fuprema riridi. Bocrb. laglb. 2. p. 202. t. 202.

B. Protea foliis oblongo-ovatis lana obvolutis. Roy. ingdb. i87.

$\gamma$. Chry fanthemum fruticofum, polygon folis, africanum, caulibus fcabiis, flore minore, Pluk. mant. $47: t \cdot 343$. f. 9 .

Habitat in Ethiopia. b

\section{CEPHALANTHUS.}

1. CEPHALANTHUS foliis oppofitis. Fl. zeyl. 53. drientaiis. Platanocephalos cirni follis bijugis, capite majore. $V$ aill. a.t. 1722.13 .259$.

Katu-Thaca. Kbeed. mal. 3. p. 29. . 33.

Haisitat in India \& Africa. b

Capjulas babet limas monopernas; fipulas quibus folia uniuntur, diverfas gerit a fequents. B. julfiem.

2. CEPHALANTHUS foliis oppofitis rernisque. Grove occidentids virg. 15.

Cephalantlus folits ternis. Hort. aliff. 73. Roy. iugdb. 197.

Scabiola dendroides americara, ternis foliis caluem ambientibus, toribus ochroleucis: Hink. alm. $336 . t .77$. t. 4 .

Havitut in Amcrica feptentrionali.

Caplalce nulla. Semina folisaria, longa pyramidata: ba-

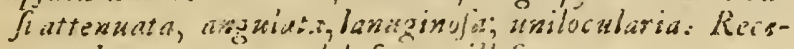
piaculum commane globufum, itlofum.

\section{GLOBULARIA.}

GLCBUIARIA caule fruticofo, folis lancelatis aim Alypm. dentatis ntegrisune. Roj. higdb. 190. 
Alypum monfpelienfium, C. Frutex terribilis. Banb. bif. i. p. 598 . Niff: att. $1712 . p \cdot 336 . t$. 18. Thymelea tolis acutis, capitulo luccila. Barb. pin

47absiat Monfpelii Es in regnoValentino. b

"lfragarice. 2. GLOBULARIA caule fruticofo, foliis radicalibus cunciformibus retufis, canlinis lanceolatis.

Scabiofa bifnagarica 1. Globularia trutefcens, rigidis foliis at radicem ropundioribus cordatis. Pluk. alın. 336. t. $5^{3}$ f. 5. Mlorif. higl. 3. p. ri.

Habitut in Biliagaria fylvis. *

grm. 3. GLOBULARIA caule herbaceo, toliis radicalibus tridentatis; caulinis lanceolatis. F!. Juc6. 109. it. at. 65. * Dalib. parif. 43 .

Globularia caule foliolo, follis ovatis integerrimis. Hort. cliff: 490. Roy. lugdb. 190. Hall. belv. 667.

Aphyllanthes anguillare. Cam. bort. IS. t. 7.

Bellis carulea, cavie foliofo. Bawh. pin. 262.

B. Bellis cxrulea apula. Tabern. bift. 2. p. 709 .

y. Bellis corule monfpeliaca. Tabern. bift. 2. p. 709. Habitat in Europe apricis duris. 2

foinalo. \& GLOBUT.ARIA folis radicalibus crenatu aculeatis, caulinis integerrimis mucronatis.

Globularia spinofa. Tournes. inft. 476

Bellis cacrulea fpinofi. Bish. pin. 262.

Bellis fpinofa, flore globoto. Baub. prodr $12 t$

Habitat in Granadx montibus. Z

matolat r. GLOBULARIA caule lubnudo, foliis cuneiformibus tricufpidatis: intermedio minimo.

Globularia foliis radicalibus cuneiformibus retufis dentatis: denticulo intermedio minimo. Hort. cliff. 491 . Roy. $\operatorname{lng} d 6$. Iyo.

Scabiofa, bellidis folio, humilis; caulenudo, radice repente, folio cordato. Morif. bift. 3. p. jo. $\int$. $6 . t$. I5. $f$. ult.

Bellis crmlea montana frutercens. Bash. pin. 262.

3. Globularia alpina minima, origani folio. Tournef. infl. 467.

Scabiofa, bellidis folio, pyrenaica minima. Morif. bifl. 3 . Hoibitat in Pannonia, Auftria, Helvetia, Pyrenxis. *

6. GLO. 
6. GLOBULARIA caule nudo, foliis integerrimis lan- nulicaslis. ccolatis.

Globularia pyrenaica, folio oblonge, caule nudo. Tournef. inst. $40 \%$.

Scabiofa, bellidis tolio, humilis, canle nudo, radice non repente. Morts. bift. 3. p. 50. f. G. t. I5. f. 4 .

Bellis caerulea, caule nudo. Batub. pin. 262. Kajo. ijaj. $3^{S S 1}$.

Halitiat in Pvicnais \& Auftrix rnontibus. 2

snterduin unicuin foliolum in fiupo.

7. GLOBULARIA caule fubnudo, capitulis alternis fes- orientalis, filibus, folis ianceolato-ovatis integris.

Globularia orientalis, floribus per caulem fparfis. Tosirm nef. cor. 35 .

Habitat in Natolia. Bibrling. *

Radix perennis. Folia obserye orata, in petiolos definentia, acuta, integra, nude, plurima. Caulis pedalis, berbaceus, fimplicifimus, Folitis minimis, lanceohatis, alternis, remotis. Capitula in Jummitate caulis, 7 ad 10 , alterian, jigfilia.

\section{DIPSACUS.}

I. DIPSACUS foliis fellilibus ferratis.

Dipfacus foliis connato-períoliatis, Hork. upf. 25. ariitis fructus reais. Saxv. monsp. x 56 .

Diplacus capitulis Horum conicis. Hort. cliff. 29. Gron. virg. 15. Rov, lugdt. 188. Dalib. parif. 44.

Dipfacus fylveitris aut Virga Paltoris major. $B_{\text {azuh. }}$ isn. 385.

Diplacus fvlveftris. Dod. pempt. $735^{\circ}$.

B. Dipfacus f́ativus. Baub. pin. 385 . ariftis fruetus hanatis. Saur. monjp. 156.

INabitat in Gallia, Anglia, Italia. of

2. DIPSACUS foliis commatis tinuatis

Dipfacus tolio laciniato. Bauh. pin. 385 . Morif. bijt.

fullonism. 3. p. $158 . \int .7, t .3^{6} . f \cdot 4$,

Habitat in Aliatia, A7.0w. $\delta$

3. DIPSACUS foliis petiolatis appendiculatis, Hort. apf. pilasus. 25. Ro\%. luydly. 388 . Dalib. parif. 44.

Dipfacus capitulis florm fuoglobotis. Hort. cliff. 30. Ray. lugúb. 188 .

Dipfactis lylveftris, capitulo minore f. Virga Paftoris minor. Bash. tin. $35 ;$

G Dip- 
Dipfacus tertius. Dod. pempt. 735 . Habitat irs Anglia, Gallia. o

\author{
SCABIOSA. \\ * Corollulis quadrifidis.
}

elpina. I. SCABIOSA corollulis quadrifidis xqualibus, floribus ccrnuis, foliis pinnatis: foliolis lanccolatis ferratis. Hort cliff. 30. Fort. apj. 26. Ro\%. lagdb. I88.

Scabiora alpina, foliis centaurii inajors. Bats. pin. 270. Scabiofa alpina centauroides. Befl. cyjt. cft. I22.

Hatitat in alpibus Helveticis, Iralicis. 2

transfylverica.

fourla.

Suctija.

Syriast.
2. SCABIOSA corollulis quadrifidis xqualibus calyce brevioribus, foliis radicalibus iyratis, caulinis pinnatifidis. Roy. lugdb. 189. Horz. upf. 26. *

Scabiofa altifima ammu, foliis agrimonix nonnihil fimilibus. Herm. Ingib. 539. Marif. bif. 3. p. 46. .6. t. $13 . f .13$

Hibitat in Tranfylvania. $\odot$

ieusnthe. 3. SCABIOSA corollulis quadrifidis æqualibus, fouamis calycinis ovatis obtulis, foliis pirnatifidis. Hurt. cliff. 30. Roy. lugdb. I88. Suz. meth. 241 .

Scabiofa flore ylobolo niveo Bauh. pirz. 207.

Scabiofa fruticans anguftitolia alsa. Bawb. pir. 270.

B.Scabiofa coroilulis quadrifidis æoqualibus, fquamis calycinis oratis, folios larceolatis ferratis.

Scabiofa africana fruteicens, folits rigidis fplendentibus \& ferratis, Hore albicante. Comm. burt. 2. p. 185. t. 93 .

Habitat in colliuss Narbonx, B.in Afric:e. 2 Differ 1 . ab antecedente tantum folits indivifis.

4. SCABIOSA corollulis quadrifidis æqualibus, caule fimplici, ramis approximatis, foliis lanceolato-ovatis. Hort. cliff. 30. Fl. Suec. I I2. Mat. ined. 4I. Roy. lugab, 188. Dalib parif. $4 \%$

Succifa glabra. Bazb. pin. 269.

Succila if. Morfus diaboli. Carre epit. 397.

B. Succila hirfuta. Baub. pirz. 269.

Habitat in Europxpafcuis bumidiufculis. \#

5. SCABIOSA corollulis quadrifidis aqualibus, calycibus ariftatis, caule dichotomo, foliis lanceolatis. Hort. cliff. 30. Roy. lugdb. 188.

Sca- 
Scabiofa fruticans latifolia alba. Baub. pin. 269. Morifo bilt. 3. p. 46. J. 6. to 14. fo 14 ,

B. Scabiolia perticx tolio, flure amethyltino.Vaill. ait.5722. Habitat in Syria, ()

6. SCABIOSA corollis quadrifidis, folitis ommibuts lanced integrifolita, olatis ferrat's. Saduv. mon $\int p$. I 5 6:

Scabiofa annua integrifolia f. foliis bellidis, Magnn. monsps 23 I.

Habitat nonfpelit. $\odot$.

Caulis non bifpidus; Rami putuli; Calycis Syuana lanceolistre, corollis breviores; Corolle rubre: Sauv:

7. SCABIOSA corollulis quadrifidis radtantibus, caule tatatica; hifpido, foliis lanceolatis pinnatifidis: lobis imbricatis. Scabiofa forculis quadrifidis, foliis pinatifidis: lacinils lateralibus erectiuiculis. ast. $m p$, I $7+4 . p$. II. $t$. I. * Scabioli altifima fegetum. Triumt. Raj. Suppl. 236? Hobitat in Tataria. 5

8. SCABIOSA corollulis quadrifidis radiantibus, caule atyen/fis hilpidu. Hort cliff. 3I. Fl. Sisec. I ro. MIat.med. fo. Roj. Iugdb. I 88. Dalib. parif: 44.

Scabiora major hirluta. Baub. pin. 269.

Scabiola arventis. Tabern bit. 442 ,

Scabiora major communior hirfuta, folio non laciniato. Bauh. bifl. 3. p. 2 .

Habitat in Europa folo glareoso, juxta fegetes inque praitis. 2

9. SCABIOSA corollulis trifidis, foliis caulinis tripinna- triandia, tis filiformibus. Sauv. monlp. 268. †

Scabiofá capitulo globofo, foliis in tenuifimas lacinias divifis: Baub. pin. 27I. Magn. monjp. 23 E.

Habitat Monfpelii.

\section{* Corollulis quinquefidis.}

10. SCABIOS A corollulis quinquefidis, foliis radicalious columbaria. ovatis crenatis, caulinis pinnatis fetaceis. Hort.cliff. $3^{\mathrm{I}}$.

Fl. Suer. III. It. gotl: 216. 22S. * Roy: lugdb. I39.

Dalib. parif. 45. Sauv. munfp. 242.

Scabiofa, capitulo globolo, major. Bath. pin. 270.

Scabiofa minor. Cam. epit: $71 \mathrm{r}$.

B. Scabiofa, capitulo globofo, minor. Banb. pin. 270. Habitat in Europe montofis, ficcioribus.

$$
G 2 \text { II. SCA- }
$$


pellatc. II. SCAEIOSA corollulis quinquefidis, foliis difreetis, receptaculis florum fuerotundis. Hort. ciiff. 31 . * Hort. ipe 5. 26. Roy. lugdb. 189.

Scabiola tellata, folio laciniato, major. Bauh.pin. 27. . Scabiofa major hilpanica. Cluf. bift. 2. p. I.

B. Scabiofa ftellata, folio laciniato, minor. Baub.pin.271. Habitat in Hifpania, prafertim in agro Granatenfi ad ver uras. ค

stropurparea I2. SCABIOSA corollulis quinquefidis, foliis diffedis, receptaculis florum lubulatis. Hort. cliff. 31 . Hort. 1:p. 26.

Scabiofa peregrina rubra, capite oblongo. Bauh.pin. 270. Scabiofa VI. Indica. Cluf, hift. 2. p. 3.

Habutat in India? $\odot$

argentea, I3. SCABIOSA corollulis quinquefidis, foliis pinnatis : laciniis lanceolatis, pedunculis nudis lavibus longistimis. Roy. lugdb. 190.

Scabiofa orientalis argentea, foliis inferioribus incifis. Tournef. cor. 34.

Afterocephalus perennis argenteus laciniatus, caule tenui eburneo. Vaill. act. 1722. p. 181 .

Habitst in Oriente. 2

ofritsnta. 14. SCABIOSA corollulis quinquefidis, foliis incifis, caule fruticofo. Hort. cliff. 3I. Roy. lugdb. 189.

Scabiofa africana frutefcens. Herm. tarad. $219 . t .219$. B. Scabiofa africana frutefcens maxima, foliis rugofis \& crenatis, minor. Herm. parad. 220.

- Scabiola africana frutefcens maxima, foliis tenuiffime incifis. Boërb. lugdb. I. p. 128.

\$. Scabiofa minor athiopica frutefcens, foliis lanuginofis Breyn. is 33. t. 26.

itabitist in Atrica.

sretica, I5. SCABIOSA corollulis quinquefidis, foliis lanccolatis fub-integerrimis. Hort. clitf. 3I. Roy. lugdb. 169. Scabiofa fteliata, folio non diffecto. Baub. pin. 271. Morif. bijt. 3. . .6. t. 15.f. 31.

3. Scabiofa cretica frutefcens, auricula urfi folio. Tournef. cor. 34.

Alterocephalus frutefcens, leucoji folio longiore angufto. Vail. act. 1 722. p. 2i; \%

Habitat in Creta \& adjacentibus. 万

Pteroceghala IC. SCABIOSA corollulis quinquefidis, caule procum- 
bente fruticolo, foliis laciniatis hirfutis, papfo plumoro.

Pterocephalus perennis humilis laciniatus \& incanus. Vaill. act. 1722 . p. 184.

Halitat in Grxcia?

Caulis vix e terra promineis Scapisbreviffmis, unifloris.

I 7. SCABIOSA corollulis quinquefidis radiantibus, foliis ochrolente. bipinnatis linearibus.

Scabiofa corollulis quadriñdis, foliis pinnatis: foliolis lanceolatis ruperne incifis. Sary. monfp. 241 .

Scabiofa multifido folio, flore fiavefcente. Baub. pin. 270. Morif. bift. 3. p. 43. f. 0. t. 13. f. 23.

Scabiofa VII. Clus, bift. 2. p. 3 .

Habitat in Germanix pratis fictis. 2

18. SCABIOSA corollulis quinquetidis, caule herbacco, papposno calycibus foliofis florem fuperantibus, calyce plumofo. Roy. lug dib. r 89 .

Scabióá cretica, capitulo pappos mentiente. Tournef. inft. 34. Boerh. lugdb. 1. p. 1 jo.

Habitat in Creta.

\section{KNAUTIA.}

I. KNAUTIA. Hort. cliff. 32. Hart. upf. 2\%. Roy. orimtalisu ingd6. 190.

Lychisi Scabiofa, flore rubro, annua. Boerh. lugdb. I.p. $33:$.

Scabioia orientalis, caryophylli fore. $V a$ inll. at* 1722. p. $2 .+1$.

Hobitat in Oriente. 0

Conferotur Scabiola cxrulea virginiana, Hofcuiis tetrapetalis caryophyllorim more patulis \& lacintatis. platk. alm. 335.

\section{HEDYOTIS.}

r. HEDYOTIS foliis !:unceolatis petiolatis, corymbis ter-fimicesa. minalibus involucratis. Fl. $\approx 2 \% . \sigma_{3} . *$ Amprn. acad. 1. p. 392.

Vaicrianella foliis nerrofis acutis. flofculis iu canlium fummo quafi involucratis. Burm, z.kyl. 2:7. t. 207 . Jabital in Zevlona. "

2. HEDYOTIS foliis lanceolato-Dvatis, floribus verticil- Asyicslarlo. latis. Fl zeyi. 64. "Mat. med. 47 . Amrn. acad. I.p.
391. 
Valerianella paluftris, foliis net vofis oblongis, flofculis ad caulium nodos inter foliorum finus colleetis. Burm. zeyl. $227 . t .108$. f. 1 .

Muriguti. Rheea. mal. 10. p. 63, t. 32, Habitat in Zeylona. 2

herbacea, 3. HEDYOTIS foliis lineari-ianccolatis, caule herbaces dichotomo, pedunculis geminis. $F$. zeyl. of Habitat in Zeylona.

\section{SPERMACOCE.}

tenuior. 1. SPERMACOCE glabra, ftaminibus inclufis. Spermacoce verticillis tenuioribus. Dill. eltb. $370, t_{\text {. }}$ 227. $f .359$

Spermacoce. Roy. lugdb. 258.

Anonymos americana, follis parictaria fcabris, floribus albis ad foliorum ortum vix confpicuis. Pluk. alm. 33. t. $136 . f .4$.

Habitat in Carolina. $\odot$

verticillata, 2. SPERMACOCE glabra, ftaminibus exftantibus.

Spermacoce verticillis globofis. Dill. elth. $369 . t .276$. f. $35^{8}$. Hort cliff. 33 .

Scabioia iamaicenfis huffopifolia. Pluk, alm. 336. $t$. 58. f. 0 ?

pulegium fruticofum erectum, verticillis denfiflimis. Sloan. jam. 64. bift. 1. p. I70?

Ilabitat in Jamaica. Africa.

hifina. 3. SPERMACOCE hifpida, foliis oppofitis obovatis. Fl. zeyl. 62.*

Galcopfis zeylanica, folio oblongo, flore albo. Burm. zeyl. 163 . t. 20 . f. 3 :

Habitat in Zeylona, $z^{3}$

\section{SHERARDIA.}

arrenfis, I. SHERARDIA foliis omnibus verticillatis, floribus ter minalibus.

Shcrardia. Dill. gen 96. Hort. cliff. 33. Fl. Suec. II3: Roy. Ingdu. 25\%. Hall. belv. 456. Dalib. parif. 40. Rubeola arvenfis repens cacrulea. Bamh.pin. 334 . prod. 145 :

Rubia parva. fore caeruleo fe fourgens. Baub. hift. 2. t. 799 :

Ilubist in arvis Scania, Germanix, Anglia. $\odot$

2. SHF.- 
2. SHERARDIA foliis floralibus binis oppontis binis fio-muralis. ribus.

Afperula verticiliata iuteola. Bezls. pir. 334.

Afpcrula verticillata muralis minima. Ciolurriso. ecplor. 302. t. 300.

Habitat in Italia. $\odot$

3. SHERARDIA foliis quaternis xqualibus, caule frut:-frulicof? coro.

Habitat in inguls Adrcenfionis. Osbeck. t

Frutex torofus, mequalis, fcaber, Rarits obtufe tetragoo nis. Folia quaterna, anguflo-lastceolata, integerrina, glabra, marginibus revoluta, articulis ramorum paulo Fongiora, interflinda Stipulis brevifimis, fubulatis. Fio. res oppofiti, fefiles, axillares. Calyx tetrajbyllus, germini imatus, perfiftens foliolis lanceolatis. Corolla infundibuiiformis, quadrifian, alba, longitudine germinis. Antherae quaiuor, oblongì. Pericarpium dicoscum. Clinopodium africanum procumbens plylii foliis. Pluk. mant. 51. t. $344 . f .3$. demto birfunie E' dentibus foliorsm, noftram refert.

\section{A SPERULA.}

I. ASPERULA foliis octonis lanceplatis, torum fafci-oilorata. culis pedunculatis. Fl. juse. II 4 . Mat. mea. 45. Dalib. parif. 46 .

Arperula foliis pluribus, for ibus pedunculo elevatis. Lort. clitf, 33. Roy, lugdh. 255.

Afperula 1. Rubeola montana odorata, Baub. pin. 334. Habitat is Svecia, Germanix umbrofis. 26

2. ASPERULA foliis fenis, foribus feflilibus aggregatis ayvenfis. terminalibus. Hort. upf. 27.

Afperula foliis pluribus, tloribus fefilibus. Hort. cliff.

33. Roy. lagab. 255. Dalib. parif. 47.

Afperula carulca arvenits Laus. yis. 334.

Afperula cærulea. Dod. peinpi. 355.

Habitat in Gallia, Flandria, Germania, Anglia. $\odot$

3. ASPERULA foliis quaternis ovato-lanccolatis, flo- tawrina. ribus falciculatis rerminalibus.

Afperula foilis quaternis orato-lanceolatis, ramis alternis. Hort. cliff. 33. Irid. cliff. 2. Roy. lngdb. 255. Hall. belv. 45 . 5axy. monfp. I 64 .

Rubia quadrifolia \& Iatifolia lxvis. Bawh. pin. 334. Mo. rif. bijt. 3. $\int \cdot$. 3. 3. 2 r. $\int .1$.

Habitat in alpows Hel etia, Italix, as 
ancioris.

4. ASPERULA foliis linearibus: inferioribus fenis, intermediis quaternis, caule fiaccido, floribus plerisque trifidis.

A ipcrula foliis quaternis linearibus, floribus tapius tri. fidis. Fl. Juec. I15. Sauv. morzip. 163 .

Rubeola guadrifolia, caule ramoio flaccido, foribus trifidis. Hall. rupp. 8.

Gallium album tripctalum. Morif.prolua'. 267. Dalib. parif. 49.

Gallium album 3. Tabern. bift. 433. t. 733. f. r. bona. liabitat in Suecia, Tyringia, Gallia, Sibirix collibss aridis faxasfis. ?

syrenaica. S. ASPERULA foliis quaternis lanceolato-linearibus ciltle ereEto, floribus fepius tritidis.

Rubia cynanchica Raatlis. Bath. pin. 333 . prour. 145. Jixer. Xid. 9 .

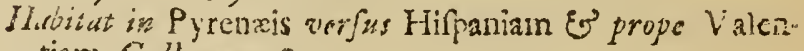
tian Gallorum. $z$

Caules eredi, fpithamai, quadrangulares. Folia omniain caule quaterwa, linecria, carinatch, couta, larion; inferiora etiain quaterna, $\int e d$ brevioralanceolat a obtufiora. folia jumma E faralia oppofita, luitura, acrita, lay. ceoiata. Flores iubulofs, rution, fapius trifidi. 2

ananchica, 6. ASPERULA foliis inferioribus fenis, intermediis quaternis fubulatis uriguetris, floribus quadrifidis. Afperula foliis linearibus quarernis, frimmis oppofitis. Ray lagdb. 255. Saus. monfo. 163.

Iubeola foliis quaternis, feminibus glabris, floribus unbellatis. Hall. belv. 453 .

Rubia cynanchica. Bawh. pis. $333.3 a u h \cdot b i f \cdot 3 \cdot k \cdot 723$.

Gallium montanum latifolium cruciatum. Col. ecpbr. $\bar{x}$. P. 296. $4.297 . f . \mathbf{1}$.

Gallium album minus. Tabern. bift. 433.t. 433.f, 2 . Habitat in Europa pratis aridis. I

\section{YOD I. 1.}

vtrz̨nitra. 2. DOODIA, Hort. cliff. 493. "Gron. virg. 71. Inabitat in Virginic aquo/is.

\section{KNOXIA.}

zeylamira, 1. KNOXTA. Fl. zeyl. 400.

Deitellaria zeylanica, flote minimo, antirhini folio. Raj. Jisppl, 246.

Habiat in Zeviona Jupra truncos aborum putridarsm. 


\section{HOUSTUNIA.}

1. HOUSTONIA foliis radicalibus ovaris, caule com-ea wles. pofito, floribus loliariis.Gren. virg. Is.

Hounonia. Hort. cliff. 35 .

Rubia parva virginiana, foliis ad genicula binis, flore cxrulco nítulolo. Plak. alm. 324. mant. 164 .

Paronychiæ tacie planta tetrapetaloides virginiana, fore cervico. Murif, heft. 3. p. 514.f. 15.t. 4. f. 1 .

B. Chancjarme inodora, allines facie, difpermos tetrapetaloides, quadrato caule, virginiana. Pluk. alm. 97. mant. 45.t. 97. f. 9. Raj. Juppl. jo2.

llavitat in Virginia.

2. HOUSTONI ? foliis ovato Ianceolatis, corymisis purpureh. terminalibus. Gron. virg. Is

Rubia mariana, alfines majoris folio ad caulem binato, florc purpuro-rubente. Pluk, rawh. I64. Raj. 'anppl' 262 .

Hasistat in Virginia.

\section{GALIUM. \\ * Fructi glabro.}

1. GALITIM foliis quaternis lanceolato-ovatis aqualibus rubioide, lubtus fcabris, caulc eresto fructibus glabris.

Habilut in Europa auftral: D. Back.

Facies Galis borealis, Sed Solva duplo hariora, nervis jubsus foabra, Canlis formus eredtus. Panicula brevis, congiomerata. Semina levia.

2. GALIUM follis quaternis obovatis inxqualibus, cali- ,ninfre, libus diffulis. 17. ruec. 119.

Gallum caulibus diffufis, foliis quaternis verticillatis. $F$. lapo. 52.

Galium paluftre album. Bawh. pin. 335.

Habitat :" Europa ruulisimolis. 2

3. GALIUM foliis quaternis linearibus obtufis, ramis berimadenfe. mmolifinuis.

Aparine foliis quaternis obtulis lavibus, Gran nirg. 16.

Rubia tefraphil!a olabra, latiore folio, bermudenfis, feminibus binis atropurpureis $M l a k$. silm. 324.6 .248 . Raj.Suppl. $20 x$.

llabilat is Virginia.

4. GALIUM foliis quaternis linearibus, caule procum- tronum. bente !cabro, corollis trifidis.

$$
\text { is }
$$

Inabi- 
Habitut in Canada. Kalin.

Caulis procumbens, ravafifimus, Ramis ternis quatergisqe, divaricatis. Folia linearia, obtufe, latiufcula, glabra, fubtus parum fcabra. Pedunculi frepius terni, texuifini, foliorum longitudine, uniflori; Flojes minimi, albi, tripartiti. Stamina tria; Fructus didymus, globogrus, lixvis.

sircoring. 5. GALILTM foliis linearibus: caulinis renis; amorum quaternis, caule fiaccido, pedunculis fubbifloris, fructibus glabris.

Ilabitat in America Septentrionali. Kalm.

uizinofum. 6, GALIUM foliis fenis lanceolatis setrorfum ferratoacultatis mucronatis rigidis, corollis fructu majoribus. Aparine folis lineari-lanceolatis acuminatis rigidis, $\mathrm{Co}$ rollis fructu majoribus, Roy. lugdb.255. Fl. jvec. r21. Aparine minor palultris paritienfis, flore albo. Tournef. 3nft. r I 4. Vaill.parif. I4. Fl. lapp. 58.

Habitat in Luropa pafcuis aquofis ferilibus. 24

fourfum. 7. GALIUM foliis fenis lanceolatis carinatis fcabris retrorfum aculeatis, geniculis limplicibus, frudibus glabris. Hort. upf. 28 . *

Aparine femine leviore. Raj. bift. 484.

Aparine foliis crebrioribus \& femine laviore. Morif. bift. $3 \cdot p \cdot 3.32$.

Habitat in Luropa cultis, $\odot$

Sixatie. 8. GALIUM foliis fenis obovatis obtufis, caule ramofilfino procumbentc.

Gailum caule ramotifimo, foliis quinis obverfe ovatis. Hort.cliff. 34. Rav.lugdb. 257.

Callium faxatiic lupinum, molliore folio. I $u$ /. act. I 7 4 . p. 492. t. I5.

llabicat in Hifpania maritimis lapidofis.

minvism, 9. GALIUM foliis octonis lanceolatis mucronatis ferrato-aculeat: glabris incurvis.

Galium folits fenis cunciformi-lanceolatis mucronatis giabris, Hort. ups. 28. *

Gallium faxatile minimum fupinum \& pumilum, flore lutioo. Tournef. in/t. II 52 .

Habisat in imperio Rutheuico, $z$

pyillum, so GALIUM foliis octonis hifpidis linearibus acuminatis fibimbricatis, pedunculis dichotomis.

Rubcola 
Rubeola faxatilis. Bauh. pin. 334: prodr. 145.

Habitat in montibus Galloprovincix.

Caules numerofi, dizitales, angulati; Folia verticillata foliolis 8. .6 , lanceolato-finearibus vel linearibus, acutis, uti caulis undique pilis patentibus bifpida. Rami rariores, alterni; Foliorum verticill: fepe ita conferti, ut folia imlrication digefta conjpiciantur. Panicula rarior, fere terminalis ex pedusuculis bis dicbotomis.

11. GALIUM foliis oetonis !inearibus fulcatis, ramis vernm. floricris brevibus. Hort. cliff: 34. Fl. frec. 116 , Mit. med. 46. Roy. lugdb. 256.

Galium caule erecto, folis plurimis verticillatis lincaribus, Fl, lapp. or.

Gallium luteum. Baub. pis. 335 .

Habitat in Europa frequens. 2

12. GALIUM foliis octonis ovatis linearibus fubferran mollyga. tis patentiffimis mucronatis, caule flaccido, ramis patentibus.

Galium foliis pluribus acutis, caule faccido, ramis patentiffimis. Hort, claff. 34, Roy, lngdb. 25\%. Fl, fiec. II 7 .

Mollugo montana latifolia ramofa. Bauh. pin. 334.

Rubialylveftris lævis. Baub. pin. 333.

Miollugo belgarum, Loh, ic. 802.

Habitat in Europa mediterranea. $z$

13. GALIUM foliis verticillatis linearibus, peduncu-รlпияиm. lis dichotomis fummo caule foriteris. Koy. lugdb. 256. Hort. ups. 27. Saur. mon]p. I61.

Gallium faxarile, glauco folio, Bocc. muf. 2. p, 172. *. II6.

Rubia montana anguftifolia. Bauh. pin. 333 prodr. 145 , Ilabitat in Tataria, Helvetia, Auttria, Monspelii. 2

14. GALIUM foliis verticillatis lineari-fetaceis, pe-paparenи? dunculis folio longioribus. Hort clitf. 34. Roy. lugdb. 256.

Gallium nigropurpurcum montanum tenuitoliun. Col. ecobr. 1. p. 298. Bask. pin. 335 .

Habitat in Italia.

г. GALIUM foliis verticillatis linearibus, peduncuJis breviffimis. Hort. cliff. 34 . Roy. lagdis. 256.

Gallium rubrum. Banh. pin. 33 r. Morij.hif. $3 \cdot p \cdot 332$, 
Gallium rubro fore. Clus. bijt. 2.p.175.

Habirat in Italia.

\section{* Fruetu hifpido.}

incsle. I6. GALIUM foliis quaternis lanceolatis trinerviis glabris, caule trecto, ferninibus hifpidis. Fl. lapp 60. Fl. fier. 178. Hort cliff. 64. Roy. lugds. 257 Hall bslu. 450.

Rubia pratenfis lxvis, acuto folio. Baub. pin. 333. proir. $1+5$.

IAabiat in Europa borealis pratis. 4

venbiam. 1\%. GALIUM foliis yuaternis ovatis aculcato-cilintis, teminibus hilpidis.

Kubjx iemine duplici hifpicio, latis \& hirfutis foliis. Bocconi. Morif. bift. 3. p. 329. f. y. t. 21.5 .5 .

Hiabilat in Europa ainftrali. $₹$

potandifo. 13. CALIUM Doliis quaternis ovatis lavibus obturis, panicula dichotoma, feninibus hifpidis.

Rubia quadrifolia fi. rotundifolia levis. Baub. pin. 334. prodr. 145.

Rubia quadrifolit, femiue duplici hifpido. Baub. bijt. 3.p. 718. Morif. bif. 3. S.9.t.21.f.4.

Hobitat in alpibus Helvetix, Styrie. 2

Aparino 19. CiALIUM foliis octonis lanceolatis carinatis fiabris retrorfum aculatis, geniculis villofis, fructu hilpido.

Aparine foliis lanceolatis acuminatis faberrimis, corollis frude minorious. Ray.lugib.455. Fi.juec. 120.

Aparine foliis lanceolatis. Inort. wiff. 34 .

Aparine vilgaris. Baub. jin. 334 .

Habitat in Europx exlsis E ruderatis. $\odot$

garifinfe. 20. GALITM follis rerticillatis linearibus, pedunculis bifidis, fructibus hifpidis.

Aparine foliis lincari-lanccolaris acuminatis flaccidis, coroilis frucu minoribus. Roy. lasdi. 255.

Aparine minima. Raj. angl. 3. p. 2.25. t. . f. x.

Galium parifienfe tenuifoliun, tore atropurpurco. Tour. ref. $i n / t .664$.

Habiint is Anglia, Gallia. is

\section{CPUCYANELLA.}

manifolia. 1. CRUCIANELLA erecti, fnliis fenis linearibus. Hort. upf, 27. * Sazu, inonip. I6f. 
Cincianella foliis linearibus. Hort. cliff. 32 .

Rubia anguftifolia ficata. Bas:b. pin. 334 prodr, 145 .

Habitat Monfpelii. $\odot$

2. CRUCIANELLA procumbens, foliis quaternis lan- latifolia.

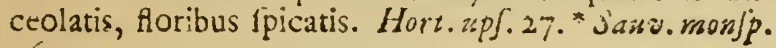
164

Crucianella foliis lanceolatis. Hort. cliff. 33 .

Rubia latifolia fpicata. Banh. pin. 334 .

Habitat, in Creta E Mon'pelii. ()

3. CR UCIANELLA procumbens, foliis quaternis, flo-mayitimsa, ribus fubverticillatis.

Crucianella erecta, foliis quaternis, corollaad folem connivente. Sauv. mun $\bar{p}, 164$.

Rubia maritima. Baub. pin. $33 \%$ Dod. pespt. $35 \%$

Rubia f. Aparine pipata cretenlis Cluf: bif?. 2. p. i>6

Habitat in Creta $\hat{\sigma}^{\circ}$ Monfpelii. D. Sianvages.

4. CRUCIANELLA repens, foliis fenis, fpicis longis. manfpeliasa, Sauv. monfp. 225.

Rubia ipicata tepens. Magn. monsp. 225.

Habitat Monfpelii.

\section{RUBIA.}

1. RUBIA foliis Senis. IJort. cliff. 35. Hort. apS. 28. titräoruw: Niat. med. 44. Roy. lugdb. 254 .

Rubia perennis, fuliis txpius quinis. Sast. monfp. I6r.

Rubia fylventis alpera. Baub. pin. 33 .

B. Rubia tinctorum 1ativa. Bauh.pin. 33 .

Habitat Monfpelii E ad Danubium. Z

2. RUBIA foliis quaternis. Roy. lugdb. 254 .

Rubia quadrifolia afperrima lucida peregrina. Herm. lugdb peregrina. 523.

Habitat - - - 2

\section{SIPHONANTHUS.}

r. SIPHONANTHUS falicis folio, flore fiavefeente, indico. Amm. rutb. 1736. p. 2:4. t. 15.

Habitat in India. b

Folia alterna, lanceolata; Pedunculi fepe e regione oppofiti folii, umbellati.

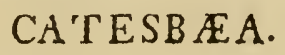

1. CATESBIEA

Sinofa. 
Frutex tpinofus, buxi foliis plurimis fimul nafcentibus, flore tetrapetaloide pendulo fordide flavo rubolongis: fimo, fructu ovali croceo femina parva contiuente. Catesb. carol. 2. p. IOO. $t$. ICO.

dabitat in Providentia.. b

\section{IXORA.}

coccivea. 1. IXORA foliis ovalibus femiamplexicaulibus. Fl.: zty 22.

Jafmimum flore tetrapetalo, Ixora linnxi, Schetti horti ralab. Burm. zeyl. 125. t. 57 .

fasminum indicum, lauri folio, inodorum umbellatum, floribus coccineis. Plak, alm. 196. t. 59. f. 9.

Schetti. Rbeed. nal. 2. p. I7. t. I3. llabitat in India. b

siba. 2. IXORA foliis ovato-lanceolatis:

Jasminum indicum, lauri folio, inodorum umbellatum, floribus albicantibus \& Schetri album. Plak. alm.196. t. IOg. f. 2 .

Bemfchetti. Rbeed. mal. 2. p. 19, t. 14. Habitat in India. 't

\section{SCURRULA.}

parsitica. I. SCURRULA.

Vifcum vitici imnarcens. Camell, luz. $3, n, 3^{6}$, Pet. gaz. t. $63 ., f .8$.

Habitat in China. 5

Arbor. Folia oppofita, petiolata, ovata, integerrima, al-

tcro latere paulo latiora, glabra. Flores axillares, 3 ad 6, propriis pedicellis. Germina inferne attenuata.

\section{PAVETTA.}

indics. 1. PAVETTA. Fl. zeyl. 56. Amoen. acad. 1.p.388. Arbor malabarienfium, fructu lentíci. $B$ aиh.pin 399. Pavate. Rai. bif. I53r.

Pavetta f: Malleomorhe, Rheed. mal. 5.p. I9. t. 10. Habitot in India. b

Corymbi trichotomi, faftigiati, pedunculo filiformi longo infidertes. Stigma oblongum, bifidum.

\section{A VICENNIA.}

officinalis, 1. AVICENNIA. Fl. zeyl 57. Mat. med. 4\$. Anacardium, Dauk. pin. SII. 


\section{Ocpata. Rheed. mal. 4. p. 95.t. 45 . Habitat in India. 5}

\section{MIT CHELLA.}

1. MITCHELLA. Gen. nov. 1083 .

Chamxdaphne, irich. gen. 27.

Lonicera foliis fubovatis, germine bifforo, corollis interne hirfutis, fylo bifido, Grow. zirg. 22.

Syringa baccifera, myrti fubrotundis foliis, floribus albis gemellis. Pluk. amalth. 198. t. 444. f. 2. Catesb. corol. I. P. 20. t. 20.

Baccifcra mariana, clematis daphnoides minori foliu. Pet.gaz. 1. t. I. f. I3.

Harbitat in Carolina, I"erra Mariana, Virginia. b

\section{CALLICARPA.}

1. CALILICARPA. ARt. ups. $174 \pi, p .80$.

Sphondylococcos. Mitch. E. N. C. 8. p. 218.

Anonymos baccifera verticillata, folio molli \& incano, ex a.nerica. Pluk. alm. 33. t. 136. f. 3.

Frutex baccifer verticillans, foliis fcabtis latis dentatis \& conjugatis. Catisb. carol. 2. p. 47. $t .47$.

Frutcx foliis amplis fubrotundis acuminatis ex adverfo binis, viminibus lentis infirmis quafi leni canitie teatis. Gron. virg. 138.

Habitat in Virginia, Carolina. b

\section{POLYPREMUM.}

r. POLYPREMUM. ACE. $u p \rho \cdot x 7+1 \cdot p \cdot 78$.

prackmbens.

Limm carolinianum. Pet.gaz. 9.t. 5 . f. 6 .

antricans,

Halitat in Carolina, Virginia. $\odot$

\section{PENAA.}

I. PEN, $A$ folis ovatis planis.

Tithymali myrtinitis fpecic arbufcula xthiopica, fubro- Sarcosolla. tundis foliis e ftochadis arabic a fuamato capirulo duro lacryma!n funderis. Pluk. mant. 18j. t. 44 . Habitat in Ethiopia. b

Folia obtufuscula; Corollx obtufe, Calyt intermedio flori nullus; Styius magis fubulatus quam in reliqgus.

2. PEN作A toliis cordatis acuminatis, Mat. med. 48. Mucronata. Penæa foliis ovatis acuininatis، Roy. lugdb. 399.

Penxa. Hort. diff. 37. 
Erica africana, unedonis flore amplc, foliis cordiformibus in acumen definentibus. Raj. dendr. 97.

Tithymali myrfnitis fpecie arbuicula xthiopica, fore parvo e lata bafi in acutiflimun mucronem lubito definente, capitulis origani. Pluk. mant. 183.

Hibitat in Ethiopia. $\$$

fryamoja. 3. PEN王A foliis rhombro-cunciformibus carnofis.

Habstat in Æthiopia

Hac reliquis minur; Corolla (ni in proccécnie) asuta. Folia parte dimidia mperinge putuia.

\section{BLARIA.}

cricoides. I. BLARRIA Hort. cliff. 49.

Erica caruca, promontoribona fpei, foliis \& thoribus vil. lolis. Pet. gaz. t. 2. f. Io.

liabitat ad Cap. b. Spei. b

$$
\text { BUDDLFJA. }
$$

emericana. 1. BUDDLEJA. Amm berb. 577. Hort. cliff. 35.

Ophioxylon americanum, foliis oblongis mucronatisleviter ferratis bardana inltar fubtus lanuginofis. Platk. alm. $270 . t .210 . f$. I.

Verbaci tolio minore arbor, floribus fpicatis luteis, feminibus fingulis oblongis in fingulis vafeulis ficcis. Sloan. jam. 139. lift. 2. p. 29. f. I. Raj. Lesdr.97. Habitat in Caribxis ad ripas Ej torrentes.

\section{EXA CUM.}

frmile. 1. EXACUM floribus feffilibus. Fl. zeyl. 25. * Exacum. Amare. acad. I. P. 39!. *

Planta annua, facie centaurii æthiopici. Pluk. pbyt. 275. $f: 3$.

Habitat in Afia \& Africa.

pediunculat. 2. EXACUM floribus pedunculatis.

Centaurium minus hypericoides, flore luteo, lini capitulis. Pluk. mant. $43 \cdot i \cdot 343 \cdot f \cdot 3$

Habitat in Iniia. ( )

\section{PLANTAGO.}

\section{* Scapo rudo}

major. 1. PIANTAGO foliis ovatis glabris, nudo fcapo tereti, fpica flofculis imbricatis.

Plantago foliis ovatis glabris. Hort. cliff. 43. Fl. Jüec. 
122. Mat. med. 49. Roy. lugdb. 40r. Hall. belv. 470. Dalib. parif. 50.

Plantago fcapo fpicato, foliis ovatis. Fl. lapp. $\sigma_{2}$.

Plantago latifolia finuata, Bauh. pin. I89.

Plantago major. Cam. epit. 26r.

B. Plantago latifolia glabra minor. Bauh. pin I $\$$ ).

$\gamma$. Plantago latifolia rofea, floribus quafi in fpica difpofitis. Baub. pin. 189. Hort. upf. 29.

d. Plantago latifolia rofea, flore expanfo. Baub. pin. I89.

¿. Plantago latifolia, foica inultiplici fparfa. Bauh.pin.189.

Habitat in Europa ad vias. 2

2. PLANTAGO foliis ovatis glabris, fcapo angulato; afiatica fpica flofculis dittinctis.

Habitat in China, Sibiria.

Planta ita refert P. majorem, ut quivis facile eandem diceret. At aiffert Spica longiore, floribus remot is छ

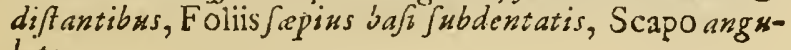
lato.

3. PLANTAGO foliis ovato-lanceolatis pubeicentibus, medis, fpica cylindrica, fcapo tereti. Hort. cliff. 36. Fl. Suec. 123, Roy. lugdb. 401 . Hall, helv. 472 . Dalib. puris. 50.

Plantago latifolia incana. Baub. pir. 189.

Plantago major incana. Cluf. bift. 2. p. Iog.

B. Plantago latifolia hirfuta minor. $B$ aub. pix. 189.

Plantago latifolia incana, $\mathrm{Cp}$ icis variis, $B$ aub. pin, $x 8$ g. Moris. bift. 3. . 8. t. I5. f. 9.

Ilabitat in Europx pafcuis fterilibus apricis argillufis.

4. PLANTAGO foliis lanceolato-ovatis pubefcentibus viryinica, fubdenticulatis, fpicis iaxis pubefcentibus, fcapo angulato. Gron. virg. I6.

Plantago media incana virginiana, ferratis foliis, annua. Morif. bift. 3.p.259. S.8.t. 15. f. 8.

Plantago virginiana, pilofellæ foliis anguftis, radice turbinata. Pluk. alm. 298.

Plantago myofotis f.trinervia hirtuta carolina. Raj.bift. 2. p. 1889 .

Habitat in Virginia.

5. PLANTAGO foliis lanceolatís, fpica fubovata nuda, ianceoina. fcapo augulato, $V$ ir. cliff. 9. Hort. cliff. 36 , Koy. lugdb. 401. Hall. belv. 471. Dalib: parif. 50.

Plantago angutifolia major. Baub. jin. 189.

Plantago minor. Dod. pempt. $\mathrm{JO}_{2}$

H $B$ Plan- 
B. Plantago trinervia, folio anguftifimo. Barb. pin. 189. prodi. 98.

¿. Plantago anguntifolia major, caulium fummitate foliofa. Baнb. pir. 189.

Habitat in Europx compis fierilibus. 2

Noguns. 6. PLANTAGO foliis lanceolatis, fpica ovata hirfuta, fcapo angulato.

Plantago anguftirolia, paniculis lagopi. Baub. pia I8g. prodr. os. Morij. hill. 3.f. 8.t. 16. f. Is.

Habitat in G. Narbonenfi, Hifpania, Lufitania.

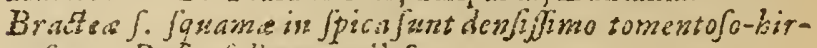
fuis; Bafis folioram piofo.

abicave. 7. PLANTAGO foliis linear-ianceolatis hirfutis, ficica cylindrica crecta, rapo tereti foliis longiore.

Plantago folits inceolato-linearibus, icapo longioudine foliorum, fpica oblonga.. Hort. cliff. 37. Roy. lugdb. 40 .

Plantago folits lanccolato-linearibus, fcapo foliis duplo longiore, fpica oblonga. Sasw. morfp. 26 .

Holottcum hirfuturi albicans majus. Baub. pin. I90. Holofteum falmanticenfe majus. Claf. bift. 2. p. Iro. B. Holoftean hirfunm albicans minus. Bamb. pin. 190. Ifabilat in Hipanire ENarbona aridis.

alpina: 8. PLANTAGO foliis lincaribus planis hirfutis, fpica oblonga erecta.

Plantigo foliis linearibus, fpica oblonga. Hall. belw. 471.

Hoivitcum hisfuram nigricans. Bauh, tir. Iyo.

Habiat in Helvetie alpibus.

wrtica. S. PLANAGO folis lincaribus, fcapobrevifimo lanawo mutante, spica fibrotunda, fapo tereti. Horticliff: 36. Roy, ing $d b .401$.

Hoiventerss r. Lcontopodium creticum. Bazh.tim. 190. 1.entopodiun croticum. Cluff. hilt. 2. p. II. Habitat in Crcta.

matime a. PLANTAGO folis remicrindraceis integerimis: bali linatis, fapo tereti. fl. jaec. iz\%.

Ilantaro íapo fpicato. folis inearibus iubrus conve-

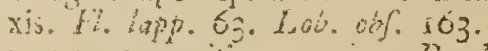

Coronopus nuritims major. Banb. pin. 590.

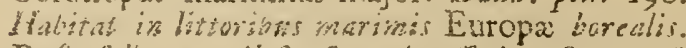

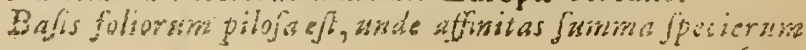


6. 7.8.9. II. Sed qü. vis ratura efficeret t.m varia? an locus; ancopula.

11. PL 1 N'T AGO foliis fubulatis triquetris rigidis, fcapo fubulata, tereti. Roy. lugdb. 402

Plantago foiils triangulari-prifmaticis. Guett. famp. 2. p. $4=8$.

Holoftcum, ftictifimo folio, minuș. Baub. pin. 191.

Serpentina omnium minima. Lob. ic. 439 .

B. Holofteum maffilienfe. Baub. pin. I9o.

Habitat in maritinis Mediterranei aienofis.

32. PLANTAGO foliis linearibus dentatis, feapo tereti. Coronop:, Plantago foilis linearibus pinnato-dentatis. Mort. cliff. 37. Fl. Juec. I26. Ruy. lygab. 401. Dalib.parif. 50. Coronopus fylveftis hirfutior. Banb. pin. 190. : Herba thella. f. Cornu Cervinum. Doh. pempt. Iog.

B. Coronopus hortenfis. Bazh. pis. Igo.

Ilabiiat in Europa glareojis.

13. PLANTAGO foliis lincaribus fubdentatis, fcape te- IJfingii. reti, fpica ovata: braeteis carinatis membranaceis. Lafl. Habitut in Hifpanie collibus agronuing os nzarginibus. $\bigcirc$ Differt a P. Coronopo a qua fit minor of pracocior; jpica ovata, ejus reiolinga. Floribus rarius inturicatis: braefeis glauris navicularibus; cjus vero Jubulatis

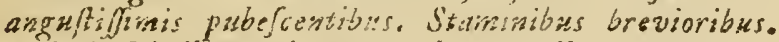
Calicis foliulis aculiorivus; colore corolle inagis fufco. Foliis linearibus, nec lanceolatis. parce desstatis. Srapus pilosus ett. Lafi.

44. PLANT AGO fravo uisioro. Fl. lapp. 64. Fl. Suec. smi qurs, I28. Dalih. purif. 50.

Plantago Horibus femincis fesfilibus ad exortum feapi uniflori maris. Julf. aR. 1742.p. 131. t.7. Gutt. ftamp. 2. p. 26.

Gramen junceum, capitulis quatuor longifimis filamentis donatis. Pluk. alm. 180.t. 35. f. 2. Moris. bift. 3. f. 8.t. $9 \cdot f \cdot 30$.

Habitat ad Eulope littora lacwitr.

\section{B Caule ramorn.}

15. PLANTAGO caule ramofo, foliis integerrimis, fpi- pfyllmm. cis foliofis. Hort. up f. 29. *

Plantago canle ramolo. Vir. cliff. 9. Koy. lugdb.401.

Plantago annua, foliis integerrimis, caule ramofo ero¿to. Hort.clitf. 37. Dalib. parij. 5 I.

$$
\mathrm{H} 2
$$


Pfyllium majus erectum. Baub. pin. Igr.

Habitat in Europx aufralis Jepious. $\odot$

Cynoty. I6. PLANTAGO caule ramofo, foliis dentatis, rpicis aphyllis. Hort. ups. 28. Mat. med. 50.

Pfyllium diofcoridis vel indicum, foliis crenatis. Baub.

pirs. 191.

Habitat in India. 0

SCOPARIA.

dulcis. I. SCOPARIA. Gen. nov. 1098.

Capraria foliis ternis, corollis quadripartitis. Hort. cliff 320. Koy. lugdb. 301 .

Sanioloides. Boerb. lugdb. 2. p. 265. *

Veronjca americana erecta frutefcens \& ramofa. Herm parad. 241. t. 241.

Veronica fruticofa erecta dulcis, hcxangulari caule. Sloan. bift. 1. p. 195. t. 109. f. 2.

Phyteuoides amcricanum, flore albo tetrapetalo. Pluk. alm. 296. t. $215 . f$. 1 .

Habitat in Jamaica, Curaflao. $\odot$

\section{CENTUNCULUS.}

minimxs. I. CENTUNCULUS. Dill. gif. г6г.gen. II . E.N. C. 5. app. 92 .t. 10. f. $3^{\mathrm{I}}$.

Centunculus foliis alternis ovatis. Fl. Juec. I29. Dalib. parif. 52.

Anarallidiaftrum exiguum, foliis lanceolatis alternis. Mitch. gen. 14. t. I8.

Anagallis paludofa minima. Vaill. parif. I 2.t. 4.f. 2. Alfine paluftris minima, flofculis albis. Mentz. pug. $t$. 4. $f .5$.

Habitat in Italix, Gallix, Germanix, Scanix arenofis. $\odot$

\section{SANGUISORBA.}

sficinalis. I. SANGUISORBA fpicis ovatis. Hort. cliff. 39. F7. fuec. I jo. Mat. med. 51. Roy. Iugdb. 240. Dalib.parif. $5 \mathrm{I}$.

Pimpinclla fangviforba major. Baub. pin. 160. Pirnpinella fylveftris f. fangviforba.major. Dod. pempr. Ior.

B.PIMPINELLA major rigida præalta auriculata fubnuda. Boce. mus. 2.p. 19. t. 7 .

Habitat in Europx pristis ficcioribus. $*$ 
2. SANGUISORBA rpicis longiffimis. Hort. cliff. 39. canatenfis. Roy. lugdb. 240.

Pimpinella fanguiforba canadenfis major, fpica longioTe alba. Morif. bift. 3. p. 264. f. 18. t. 8. f. 12.

Pimpirella maxima canadenfis longius fpicata. Cork. canad. $175 . t$. 1.74. Barr. rar. 18. f. 739.

Habitut in Callada. $*$

\section{CISSUS.}

1. CISSUS. F7. zeyl. 60. * Amon. acad. I. p. 390. * vitiginea. $\Lambda$ rbufcula baccitcra circumplicatilis, vitigineo folio fubtus lanato, fructu racemofo tervidiore odoro. Pluk. mant. 27.t. $337 . f .2$.

Schunambu-valli. Rbeed. mal.7.p. . t. II.

Ulabilat in India. 5

\section{EPIMEDIUM.}

1. EPIMEDIUM. Hort. cliff. 37. Hort. upf. 29. Ray. alpinum, . lugdb. 402. Dod.pempt. 599. Lob. bift. 176.

Habitat in Alpium Euganeorum, Ligurinorum, Pontebarum umbrofis. $\#$

\section{CORNUS.}

1. CORNUS arborea, involucro maximo: foliolis ob- forida. verfe cordatis. Hort. cliff. $3^{8}$. Hort. ups. 2.9. Roy. lugdh. 249. Gron: virg. 17.

Cornus mas virginiana, flofculis in corymbo digeftis a perianthio tetrapetalo albo radiatim cinctis. Pluk.alm. I20. Catesb. car. $27 . t .27$.

Habitat in Virginia. 5

2. CORNUS arborea, umbellis involucrum æq uantibus. mas. Hort. cliff. 38. Hort. upf. 29. Roy. lugth. 249. Dalib. parif. 52 .

Cornus fylveftris mas. Baub. pin. 447.

Cornus mas pumilio. Clas. bift. I. $p$. I3.

B. Cornus hortenfis mas. Baub. pin. 447.

Habitat in Sepibus Auftrix. 5

3. CORNUS arborea, cymis nudis. it. $W$-goth. 32 . Sanguinea.

Cornus umbellis involucro multoties longioribus. Hort. cliff. $3^{8}$. Roy. lugdb. 249. Hall. helv, 463. Dalib. parif. 52.

Cornus fernina, Baxb. fin. 447 . 
Virga fanguinet. Dod. pempt. 782 .

Habitat in Europa, Afix, Amcicic borealis dumetis. 5

foreits. 4. CORNUS herbacea, ramis bisis. Fl. lapp. 65.t.5.f. 3. Fl. Jaer. 132. Roy. lugdb. 249.

Cornus pumila herbacea, Chamxpericlymenum dicta. Dill. elth. ro8: t. $9 \mathrm{r}$.

Periclymenum humile. Bauh. fin. 302. norvegicum. Barb. pin. 302. Buxb. ract. 3. p. 268,

Habstat in Suecia, Norvegia, Ruifia. 2

Entalenfis. 5. CORNUS herbaces, ramis nullis. Amon. acad. 1. p. 157.

Pyrola, alfines flore, brafiliana. Bauh. prods. x00.pin. 101. Eurf. X. 106.

Habitat is Canada. 26

torientora. I. TOMEX.

\section{TOMEX.}

Tomex tomentofa. Fl. zey!. 59. * Amon. acad. 1. p $3^{8} 9$.

Arbor ma'abarica llla dicta. Burm. zcy. 26.

Habitat in India. $\hbar$.

PTELEA.

srifolinto. I. PTELEA foliis ternatis.

Ptelea. Hort. cliff. $3^{6}$.

Frutex virginianus trifolius, ulmi famaris. Plak. alm. 59. Dill. elth $147 . f$. $122 . f$. 148 .

Habitat in Virginia. 5

vifrofa. 2. PTELEA foliis fimplicibus.

Dodonxa. Hert. cliff. I44. Fl. zeyl. I 41. Roy. lingdb. 206.

Carpinus vifcora, falicis folio imegro oblongo. Burm. zeyl. $55 \cdot t \cdot 23$.

Arbufcula vifcola, xleagni foliis læte virentibus, amcricalla tricoccos. Pluk. phyt. 14l. f. I.

Habitat in India. $\vdots$.

Hanc arborem idem genus, cum Ptelea agnofeere abfersavit III. B. '尹ublikus.

\section{LIJDVIG IA}

altesrifolia. : LUDVIGIA foijis alternis lanceolatis.

Ludvigia capfulis cubicis apice perforatis. IJurt. wp. 30 . Ludvigia captulis fubiotundis. Hort cliff. 491 . Roy. Iugdb. 252. 
Ludvigia. Gron. virg. I7.

Lyfimachia non rappora, flore luteo majore, filiqua caryophylloide miliorc, ex virginia. Plsk. alm. 235.t. 203. f. 2.

Habitat in Virginia. $\odot$

2. LUDVIGIA foliis oppofitis lanccolatis, eapfulis pe-persmis. duncuiatis.

Ludvigia caule difturo, foliis lanccolatis, capfulis pedunculatis folio dimidio brevioribus $F$. zeyl. 06 . *

Carambu. Kkeed. mal. 2. p. t. 49.

Habitat in India. 2

\section{OLDENI ANDIA.}

๘. OLDENLANDIA pedunculis fimplicisfimis, frueti- urifora. bus hifpidis.

Oldenlaudia calycibus fruetuun maximis coloratis. Gron. 2irg. 1.39 .

Alfine aquatica major repens, foliis acuminatis, virginialia. Pluk alm. 20. t. 74. f. 5. maia.

Habitat is Virrinir.

Caules ramofo-fubdivifi, repentes. Folia oppofita, lance. olato-ovata, jebpetiolatch, integerrima. Flores axiliares, pauci, pedunculis proprisis. Germina bispida.

2. OLDENIANDIA pedunculis bifioris petiolo longi- bifors. oribus, foliis lanceolatis. F'. zcyl. 68.

Habitat in India. (C)

3. OLDENLANDIA umbellis nudis lateralibus alter- umb:llata. nis, toliis linearibus. El. zeyl. 67.*

Lylimachix adinis, faturcj tolio, maderafpatenfis, capfulis in fummitate fere umbcliatis. Pluk. alm. 236.

t. II 9. $f_{0} 4$.

Havilat in India. 2

4. OLDENLANDIA pedunculis multitloris, foliis line- corymbofa. ari-lanccolatis. $t$

Oldenlandia humilis hy Ropifolia. Plum. gen.42. Erbet. pili. t. 4. $f$. I.

Hobitat in America meridionali. $\odot$

\section{AMMANNIA.}

AMMANNIA foliis femiampiexicaulibus, canle tetra- latifolra. gono, Hort. cliff. 344. Hort. "upf. 30.

Ammannia paluftris, caule quadranguiari, foliis angultis.

Amrn. berb. 344 . 
Aparines folio anomala, vafculo reminali rotundo, fcmine minutiflimo. Sloan. bift. I, p. 44. t. 7. f. 4 . Habitat in Caribæis, locis bumidis. $\odot$

yamofior, 2. AMMANNIA foliis fubpetiolatis, caule ramofo.

Ludvigia aquatica erecta, caule rubente, foliis ad genicula binis longis anguftis hyfopi inftar, flore tetrapetalo albo. Cilavt. 774 .

Habitat in Virginia. D. Gronovius. $\odot$

Planta pedalis, inferne Rarnis oppofitis, teretibus, fim. plicibus. Calyces ex alis foliorum folitarii (nec ut in precedenti terni), ad apices ramorum magis cinferti E ferme fpicati.

baccifern, 3. AMANNIA foliis fubpetiolatis, caprulis calyce ma. joribus coloratis.

Ancnymos, linarize folio, orientalis, gallii lutei flore, herba capfularis verticilata, Pluk. alm. $33 . t .136 . f .2 .^{2}$ at non ramofa.

Yabitat in China. Osbeck. (2)

Planta tenera, digiti longitudine, erecta, absaue ramis, caule rufefcente, tereti. Folia opoofit a, lanceolat a, $\int u b-$ petiolata, integerrima. Flores verticillati, ad axillas foliorum plurimi, propriis pedunculis infidentes, minimi. Capfula globofa, rubra, calyce major.

\section{ISNARDIA.}

paluftris. I. ISNARDIA. Dalib.parif. 53.

Dantia paluftria. Petit. gen. 49. t. 49.

Dantia foliis fubovatis pediculatis, floribus in foliorum alis feffilibus. Guett. ftamp. 2. p. II 5 .

Ocymophyllum. Buxb. act, 4. p. 277. t. 27.

Glaux major paluftris, fore herbaceo. Morif. pral. 268. Raj. bift. I102. Supp!. 035. Bocc. mus. 105. t. 84. f. 2 .

Alfine paluftris rotundifolia repens, foliis portulacx pingvibus. Lind. alfat. I $14 . t .2$.

Habitat in Gallix, Alfatix, Ruffix, Virginix fuviis, ?

\section{TRAPA.}

ratans.

I. TRAPA

Trapa petiolis foliorum natantium ventricofis, Hort. cliff. 483. Fl. Suec. I34. Mat. med. 52. Dalib. pdrif. 52 .

Tribulus aquaticus. Baub. pix. 194, 
Panover-T fieraua. Rbeed. mal. i I. p. 65.t. 33.

Habitat in Europæ auftralis, Afiæque ftagnis limofis. $\odot$

\section{DORS'TENIA.}

DORSTENIA fcapis radicatis. Hort. cliff.32. Mat. Contrajerva. med. 53 .

Dorfenia dentarix radice, fphondylii folio, placenta ovali. Houft. act.n. $42 \mathrm{I}$. f. I.

Doritenia Sphondylii folio, dentarie radice.P lum.gen.29.

Drakena radix. Cluf. exot. 83 .

Cyperus longus udoratus peruanus. Baub. pin. I4.

Tuzpatlis. Hern. mex. I47.

ß. Dorflenia dentarix radice, folio minus laciniato, placen- houftoni. til quadrangulari \& undulata. Houft. aEt. n. 42 I. f. 2. IIabitat in nova Hifpania, Mexico, Peru, Vera Cruce, infula Vicentii. 2

2. DORSTENIA pedunculis caulinis. Hort. cliff. 32 . sanlefcens. Parietaria racemola, foliis ad oras villofis. Plkm.jpec. Io.

Habitat in America meridionali. 2

\section{EL $\mathbb{E A G N U S . ~}$}

ז. ELÆAGNUS foliis lanceolatis. Roy. lugdb. 250. axgufifolia. Hort. ups. $3 \mathrm{I}$.

Elæagnus. Cam. epit. 106. Hort. cliff. 38.

Olea fylveftris, folio molli incano. Baxh. pin. 473.

Habitat in Bohemia, Hifpania, Syria, Cappadocia. 5

2. ELÆAGNUS foliis ovatis. Roy.lugdb. 250. Fl.zeyl. Intifolio. 5 .

Eleachnus foliis rotundis maculatis. Burm. zeyl. 92.

t. 39. $f .2$.

Habitat in Zeylona. 古

\section{BRABEJUM.}

1. BRABEJUM. Hort. cliff. 36. Roy. lugdl. 400 . ftellatifoAmygdalus æthiopica, fructu holofericeo. Breyn. cent, limm.

I. $t$. I.

Arbor xthiopica hexaphylla, foliis circa caulem ad intcrvalla fenis. Pluk. alm $47 . t .265, f .3$. Habitat in Ethiopia. 5

\section{RIVINA.}

s. RIVINA. Hort. cliff. 35. Roy. lugdb. 207. H 5

a. $\mathrm{Ri}$ - bumilis. 
sanefcens. a. Rivina humilis racemola, baccis puniceis. Plum.gen. 43 . Solanoides americana, circæa foliis canefcentibus. Tournef. act. I 706 .

Solanum barbadenfe racemofum minus tincorium. Piuk. alm. 353.t. I12. f. 2 .

Amazaitus baccifer, circax foliis. Comm. bort. $x . p$ i27. t. 66 .

fcandens, B.Rivina tcancens racemofa, amplis folani foliis, baccis violaceis. Plum. gen. 48 .

glabra. S. Solanoides americana, circxa foliis glabris. Iankef. a.t. $x ; 00$.

Habit it in Caribxis, Jamaica, Barbados.

\section{SALVADORA.}

pefiran. I. SALVADORA. Garc. act. angl. 1\%49. n. 49x. Gex. nou. 1097.

Habitat ad Sinum Perficum. 5

Frutex foliis oppofitis, Racemo terminali.

\section{A MPHOROSMA.}

monfpelinc.. I. CAMPHOROSMA foliis hirfutis linearibus. Amoen. acad. 1. P. 392. Mat. med. 43 .

Camphorolma. Sauv monfp. 45 .

Sclago caule procumbente, foliis fparfis. Hort. cliff. 32 r. Roy. log $d b .300$.

Camphorata hirfuta. Bauh. pin. 486. Tournef. alz.1 70.5 . p. 313. Buxb. cent. I. p. 18. t. 28. f. I.

Camphorata monfpelienfium. Baxh.bift. 3.p. 379. Lob. adv. 174 .

Habitut in Hifpaniac, Narbonae, Tatariae arenofis.

centa. 2. CAMPHOROSMA foliis fubulatis rigidis glabris. $A$ moen. acad. x. p. 393.

Camplorara altera. Tabern. hift. 57.

Camphorata congener. Bazh. pin. 486. (varia)

Anthylis altera italorum. Lob. ic. 404. Dalech. bift. II 50.

Habitat in Italia, Tataria. *

glabra. 3. CAMPHOROSMA foliis femitriquetris glabris inermibus. Amoen. acad. x. p. 393.

Camphorata foliis confertifimis inermibus lavibus. Hall. belt. 193.

Camphorata glabra. Baub. pin. 286. Dalech. bift. I 79. Habitat in Helvetia. 2 


\section{ALCHEMILLA.}

1. ALCHEMILLA foliis lobatis. Fl. fusc. 135. Mat. zulgart. med. 54.

Alchemilla folits palmatis. Hort. liff. 38.Roy.lugdb. $23 \mathrm{I}$. Alchemilla foliis innplicibus. $\mathrm{Fl}$. I $\mathrm{p} p \mathrm{p} .66$.

B. Alchemilla vulgaris. Bauh. pis. 3iq.

Alchemilla minor. Tuarref. iajt 502.

I1wlilat in Eurova pafcuis. 2

2. ALCHEMILLA follis digitatis ferratis. Fl. lapp. 6r, nipina.

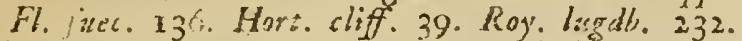

Alchenilla percunis incana argentea, $R$. fericea latinum provocans. Morif. bifi. 2. p. 195. $\int .2$. t. 20. f.3.

Tormentilla alpiria, folits fericeo. Baut pin. 326.

B. Alchemilla alpina pubefcens minor. Tournef. inft. 508. hybrida. Pluk. phyt. 240. f. I.

Habitat in Alpious Europa. \&

3. ALCHEMILLA foliis quinatis multifidis glabris. pentaplylles Alchemilla alpina quinquefolia. Basb. pin. 320 . procir. 138 .

Alchemilla alpina pentaphyllea minima, lobis rimbriatis. Boc mus. i. p. 18. t. 1.

Habitat in monte Canifio, Furca, Gothardo. $*$

\section{$D I G T N I A$}

\section{APHANES.}

1. APHANES Hort. cliff. 39. Fl fuer. 13\%. Roy. lugdi. arvenfs, 231. Gron. virg. 17. Dalib. parif. 53

Chxrophyllo nonuihil fimilis. Bauh. pin, 182

Alchemilla minima montana. Col. ecpbr. $145 \cdot t$. 146.

Llabitat in Europa artis. $\odot$

\section{BUFONIA.}

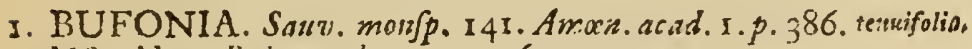
Alfinoides. Raj. angl. 3. p. 346.

Herniaria anguftiffimo gramineo folio, erecta. Magn. bort. 97. t. 97.

Alfine polygonoides tenuifolia, flofculos ad !ongitudinem caulis velut in fpicam difpofitis. P/sk. alm. 22. r. $75 . f 3$. Jiabitat in Anglia, Gallia, Hifpania. $*$ Stamina 4 nimeravit in flore Laefh. 


\section{H AM AMELIS.}

virginianu. I. HAMAMEJLIS, Gron. virg. I 39. Cold. noveb. I3. Catejo. car. 3. p. 2. t. 2.

Trilopus. Mitch. gen. 22.

Piftacia virginiana nigra, coryli foliis. Pluk. alm. 298. Habitat in Virginia.

\section{CUSCUTA.}

mroper. I. CUSCUTA floribus feffilibus.

Cufcuta nuda repens filiformis. Fl. Suec. $13^{8}$. Mat med. 55. Dalib. parif. 53.

Cufcuta nuda repens fumiformis. Sauv. monsp. II.

Cufcuta major. Baub. pin. 219.

Cufcuta. Cam. epit. y84.

epithymum $\beta$. Cufcuta nuda repens filiformis. Sauv. monff. Ir.

Epithymum f. Cufcuta minor. Baub. pin. 219.

Habitat in Plantis Europæ parafitica.

americana. 2. CUSCUTA floribus pedunculatis.

Curcuta caule aphyllo volubili repente. Gron. virg. 18.

Cufcuta inter majorem \& minorem media, filamentis longis \& floribus late fuper arbores \& campos fc extendens, Sloan. jam. 85. bift. I. p. 201 . t. 128.f.4. Habitat in Virginia.

\section{HYPECOUM.}

procumbens, I. HYPECOUM filiquis arcuatis compreffis articulatis. Hort.ups. $3 \mathrm{r}$.

Hypecoum. Bauh. pin. I 72. Dod. pempt. 449. Hort. cliff. 38. Roy. lugdb. 402.

Habitat inter Archipelagi, Narbonæ \& Salmanticenjes Segetes. ()

pendulum. 2. HYPECOUM filiquis cernuis teretibus cylindricis. Hort. ups. $3 \mathrm{I}$. Sauv. monsp. 263.

Hypecoum filiquis pendentibus non articulatis bivalvibus incurvis. Morif. bift. 2. p. 280.

Cumiuum fylveftre filiquatum ponx. Dalech. bift. 698. Habitat in Galloprovincia (5)

erestum. 3. HYYECOUM filiquis erectis teretibus torulofis. Hort. ups. 32 .

Hypecoum tenuifolium, filiquis erectis teretibus. $A \mathrm{~mm}$. ruth. 58. t. 9.

Habitat in Dauria, 


\title{
TETR AGTNIA.
}

\author{
ILE X. \\ * Flores quadrifidi.
}

r. ILEX foliis ovatis acutis fpinufis. Hort. cliff 40 . Hort. Aquifolinm upf. 32. Roy. lugab. 400. Gron. virg. Iz. Dalib.parif. 54 .

Ilex aculeata baccifera. Bauh. pin. 425 .

Habitat in Europa auftraliori, Japonia, virginia. I

2. ILEX foliis ovato-lanceolatis lerratis. Mor.. cliff. 10. Cuffine. Mat. med. 56. Roy. lugdb: 400.

Aquifolium carolinenfe, foliis dentatis, baccis rubris Catesb. car. I. p. 3I. t. 3 I.

$\beta$. Caffine vera floridanorum arbufcula baccifera, aiterni ferme facie, foliis alteinatim fitis, tetrapyrene. $P$ ltuk. mant. 40. Catesb. car. 2. P. 57. t. 57.

Habitat in Carolina. 5

3. ILEX foliis lato-lanceolatis obtufis integerrinis. Habitat in India A fix. 5

\section{B Flores trifidi.}

4. ILEX foliis cuneiformibus tricufpidatis.

afiaticn.

\section{Ilex aculeata, folio tricufpidi. Plum. bift. ml: \\ Habitat in America meridionali. $b$}

5. ILEX foliis pinnatis.

Dodonew.

Dodonæa aquifolii folio tricufpidato. Plum. gen, 20.

ß. Dodonira aquifolii folio angulofo \& aculcato. Plum. suneifolia.

gen. 20.

$\gamma$. Dodonxa aquifolii folio angulofo non aculeato. Plum. gen. 20,

Habilat in America meridionali. 5 .

Folia pinnata: foliolis $2 \mathrm{I}$, Selfilibus, rigidis, orvatis, ackminatis, in medio utrinque denticulo angulatis. Fores racemoft ut in Rhoe.

\section{COLDENIA.}

I. COLDENIA. Fl. zeyl. 69.

Tcucri facie bifnagarica tetracoccos rottrata. Pluk. alm. prosumbens.

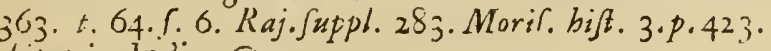
Habitat in India. $\odot$

Frudificationem ulderius examinent alii in vizenti planta, cyo ficcam tantum vidi. 


\section{POTAMOGETON.}

muzur. 1. POTAMOGETON foliis oblongo-ovatis petiolatis natantibus. Hort. cliff. 40. Fl. Suec. 139. Roy.lugdb. 212. Hall. belv. 199. Dalib. parif. 54.

Potamogeton folis ovato-oblongis natanuibus. Fl. Iapp. 68.

Potamogeton rotundifolium. Bazh. pis. 193.

Q. Potamogeton foliis lanceo'ato-oblongis, petiolis longis. Grow. virg. I 39.

Habitat in lurope laczbus of fiurizis. 2

perfoliatum. 2.POTAMOGETON foliis cordatis amplexicaulibus. Fl. lapp. 19. Fl. Suec. 140 . Roy. Iugdb. 2 2 2. Hall.belv. 199. Dalib. paris. 54 .

Futamogeton rotundifolium altermurn. $L \propto \rho$. pruff. 205. t. 6 s.

Hnbitat in Europx lacubus fuwizqune argillofis. z

1ensw\%. 3. POTAMOGE'TON follis ovatis acuminatis oppofitis confertis, caulibus dichotomis, Guett. ftump. I.p. IU2. $f$

Potamogeton minus, foliis deniis mucronatis non ferraris. Magn. 3nonfp. jo3.

Habitat in Gallia.

meens. 4. POTAMOCETON foliis lanceolatis planis in petiolos defincutibus. Hort citf: 40. Fl. fuec. 141. Roy. lugdb. 252 . Dalib. parif. 54.

Potamogeton foliis angultis folondentibus. $B a u b$. pir. 193.

Fontinalis Iucens major. Baub. bift. 3. p. 769 .

Llabitat in Europa lacibus, /tugnis, fluvis argillofis $*$

eifpun. 5. POT AMOGETON foilis lanceolatis alternis undulatis ferratis. Rny. itsub. 2I2. Fl. Jaec. 142. Dalib. parif. 45 .

potanogeton foliis crifois $f$. Laduca ranarum farmentis planis. Bardy. fin 193 .

Habitat in Europa folis fo rivulis.

forratum. 6. POTAMOGETON follis lanccolatis oppofitis fubundulatis.

Potamogeton foliis lanceolatis obfcure undulatis, caulibus longe ramolis. Gratit. Jlamp. I. p. IO2. Dalik. parif. is

Potamegeton longo ferrato folio. Bath. pin. 193 . Hábiat in Europa rioulis. 
7. POTAMOGETON foliis linearibus obtulis, caule conturfom. comprello. Hort. cliff. 40. Fl. facc. 143. Ras. lag d's. 2I3. Dalib. parif. 55 .

Potamogeton caule plano, folis gramineis. undulatis, fpica exigua. Hall. belw. zol.

Potrmogeton caule comprefio, tolio graminis canini.Raj. bijt. 18 ;

Habitat in Europe fojpis poiludofis.

8. POTAMOGETON folits ictaceis parallelis approxi- fortin.36m. miatis difticinis. Fl. Suer. 145. Dalib. parif. 55 .

Poumogeton foliis lincaribus acutis longiffmls alternis contertis. Roy. Ingdi. 213 .

Poturnogeton gramineum ramolum. Baxb. pin. 193. teruir. IOI.

Hobsat in Europa fofjs so paladibus.

9. POTAMOGETON foliis lanceolatis oppofitis acu-fetacinm. minatis. Roy. lagab. 2I3. Dalib. parif. 55 .

Potamogeton ramofum angultitoilum. Basis. in 193 .

Habitat in Europa fojjis palidolofis.

10. POTAMOGETON folis lineari-ianceolntis alter- grmbinezm. uis ienlibibus ftipula istioribus. F.. fuer. 144.

Potamogeton gramineum latiufculum foliis \& ramificationibus dente nipatis. Raj. angl. 3. p. I49. t. 4. f. 3. Fl. 6 apo. 70 .

Havitat in Europe fojfs of paluaibus.

\section{$\odot$}

I. POTAMOGETON foliis linearibus alternis diftin- marmw. Et is interne vaginantibus. Fl. Suec. 146.

Potamogeton putillum fuitans. Boc6. fic. 42 . t. 20.f. 5 . ii. gotl. 221 .

Habitat in Eurupa ad maris litiora. $\odot$

i2. POTAMOGETON folits linearibus oppolitis al- mplllwm. armisquic dittinctis: bali patentibus, caule tereti. $1 \%$ fuec. 147 . D d al:b. parij. 56 .

Potamogeton tolits inearibus alternis remotis. Roy. Iugdt. $21 ;.$

Putainoguto pufillum, gramineo folio breviore. Vaill. paral. t. 32. f. 4 .

Inbiat in Europæ paludibus.

$$
\text { RUYPIA. }
$$

1. RUPPIA. Hort. cliff. 430 . H. wgoth. I\$6. Gust. maitima. Jain. 2. p. 416 . 
Buccaferrea maritima, foliis acutiffimis. Micb.gen.72. t. 35 .

Potamogeton maritimum, gramineis longioribus foliis, fructu fere umbellato. Raj. angl. 3.p. 134.t. G. f. 1 Fucus folliculaceus, fœniculi folio longiore. Baub.pin 365.

Habitat in Europa maritimis. $\odot$

\section{SA GINA.}

grodumbens. I. SAGINA ramis procumbentibus. Fl. lapp. 157. Fl. Juec. 148 . Roy. lugdb. 452 .

Sagina fcapis \& ramis unitloris. Guett. Jtarpp. 2.p.2.77 Aline putilla graminea, thore tetrapetalo. Segn. veron $42 \mathrm{I} . t .5 \cdot f \cdot 3$.

B. Alfine faxifraga graminifolia, flofculis tetrapetalis herbidis \& mulcolis. Pluk. alm. 23. t. 74. f. 2.

y. Saxifraga graminea pufilla foliis brevioribus craffioribus \& fucculentis. Raj. angl. 3.P. 345.

Habitat in Europx pascuis fterilibus uliginofis aridis.

erecta. 2. SAGINA caule erecto, unifloro.

Sagina fcapis unifloris. Guett. ftamp. 2.p. 276. Daiib. parif. 56.

Alfine foliis caryophyllxis. Raj. angl. 3.p. 344.t. I5. $f .4$.

Aline verna glabra. Vaill. parif. 6.t.3. f. 2. Habitat in Gallix, Anglix, Germanix fterilibus gla. reofis.

virginica, 3. SAGINA caule erecto, floribus oppofitis.

Sagine affinis planta minima, floribus albis Clayt. mg 649 .

Habitat in Virginia inter mufcos ad margines fontium. D. Gronovius.

Caulis digitalis, filiformis, erectus; Folia oppofita, Jubu. lata, remota, minima. Flos terminalis \&ु oppofitinurs nulli propriis pedunculis. Perianthium 4partitivn, erectum. Petala 4, oblonga. Stamina 4, longituaine calycis. Germen conicum, longitudine calycis. Stylus nullus. Stigma obtufum. Capiula pyramidalis, roftra. ta, unilocularis. Semina numerofa. An proprii gene ris?

\section{TILLEA.}

aguatica. I. TILLÆEA ereeta dichotoma, foliis acutis. 
Craftula caule dichotomo, floribus lincaribus, floribus quadrifidis. Fl. Saec. 259. Dalib. parif. $9 \$$.

Crafiu!a floribus quadrif dis. Hort. cliff. 497.

Sedum minimum annumm, flore rotco tetraperalo. Vaill, parif. $18 r . t .10 . f .2$.

Ilabitat in Europa inundatis. (

2. TILLIEA creta, floribus lateralibus, foliis obtufis. ruiru.

Tilla crekta. fiort. up. 24. * Sauv mon/p. I 25.

Sedum annum minimum itellatum rubrum. IItagn. m20nfy. 238 . t. 237.

Lialeitat Monlpelii inter mufcos. $\odot$

3. TILLAA procumbens. Hort. upS. 24. Sauv. monjp. snysefa. 129.

Tilla?a. Dalib. parif. 43.

Tillira mufcofa annua perfoliata. Mich. ges, 22, t.20.

Crafula toliis fefilibus connatis, Horibus aggregatis in foliorum alis. Guitt. Jtamp. \&. p. 97.

Polygonum mufcofum minimum. Bocc. fic. 56. t. 29. Sempervivum omnium minimum repens mulcolum, polygoni facie. Bacc. mitj. 2. p. 36. t. 22. Habitat in Irailae, Siciliae, Galliae mafcofss.

Fiores buits licpius trifidi, antecelentam quabifidi; Pbil. Bot. i 78 . 
Clajis $V$.

\section{PENTANDRIA MONOG TNIA. \\ HELIOTROPIUM.}

indionm. 1. HELIOTRPIUM foliis cordato-ovatis acutis reabriufculis, fpicis folitariis, fruatibus bifidis. $7 \%$ z. $\% l .70$. Heliotropium foliis ovatis acutis, ipicis folitariis. Hort. cliff. 45. Roy. lugd6. 405 .

Hcliotropium americanum cxrulcum. Dod. mem. 83. Hluk. phyt. 245.f. 4 .

B. Heliotopum ancricanum carvieum, foliis hormini anguttioribus. Herm. lugalb. 307. Sloan. jam. 98.

Habitat in India utraluc. $\odot$

c:sręarm?. 2. HELIOTROPIUM foliis ovatis integerrimis tomentolis ragolis, fpicis conjugatis. Hort. up. 33. Sauv. monip. 305.

Heliotropium folits ovatis integerrimis, fpicis conjunctis. Hort. cliff. 45 . Roy. lugdb. 404.

Heliotropium majus diofcoridis. Baxb. pin. 253.

Habitat in Europa auftrali. $\odot$

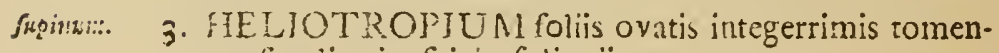
tolis plicatis, fpicis folitariis,

Heliotropium ininus fupinum. Baub. pin. 253.

Heliotrupiun fupinum. Clas. bijt. 2. p. 47 .

Habitat Salmanticix juxta agros, Monfpelii in listo re. $\odot$

cureforteum 4. HELIOTROPIUM foliis lanceolato-linearibus gla. bris aveniis, fpicis conjugatis, Hort. cliff. 45 . Hort, upp. 33: Roy. lugalb. 405. Dalib. parif. $5 \%$

Heliosropium indicum procumbens glauccplyllon, floribus abis. Pluk. alin. 182. t. $36 . f .3$.

Heliotropium martimum minus, folio crlauco, flore albo. Stran. bifl. I. p. $213 . t$. I $32 . f .3$.

Heliotropium curaffavicum, foliis lini umbilicati. Mor if kift. 3. p. 452. S. II. t. 3I. f. I 2 .

Heliotropium americannn procumbens, facie lini umbilicati. Herin. par. $18_{3}$. t. 183.

Habitat is Anerica anlidioris maritimis. () 
5. HELIOTROPIUM foliis linearibus glabris aveniis, orientale. floribus fparfis lateralibus.

Haúitat in Atia. $\odot$

Planta parva, procumbens, repens. Folia linearia, alterna. Flores fubselfiles, niberwi, jolitari, inter folia sparfi.

\section{MYOSOTIS.}

I. MYOSOTIS fenninibus nudis: foliorum apicibus cal-fionioides, lofis, Vir. cliff. 149. Fl. Juec. 149. Roy. lastll. 40i. Hurt cliff: 45 .

a. Myolotis toliis hirrutis. Hort. clitip. 46 . arvenfis: Myolotis hirfuta arvenfis major. Dill. gifl 55. Fl. lapp: 74.

Echium fcorpioides arvenfe. Baub. pix. 254:

B. Mvolotis foliis glabris. Nort. cliff. 46. Walib. parif. paitutris. $5^{8} 8$.

Myorotis glabia pratenfis. Dill. giff. 67. Fl. lapp. 75.

Echium fcorpioides paluttre. Baub. pin: 254.

Habitu: in Europe a campis aridis E. B aquofis forturiginofis. $\odot$

2. MYOSOTIS reminibus aculeatis glochidibus, foliis zirginian. cvato-oblongis, ramis divaricatis.

Myofotis feminibus hilpidis, fuliis lanceolato-ovatis: Gran. virg. 19.

Cyilogloflum virginianum, flore \& fructu minimo Pluk: alm. 120 .

Habitat in Virginia. (?

Semina interion: latere muda, anzulata, erecta, bafi agixa, ut in equenti, frucius nutans.

3. MYOSOTIS feminibus aculeis glochidibus, foliis lan- Lappula, ceolatis pilofis. Fl. foec. I 50. Dalib. parif. 57.

Litholpernum leminibus echinatis. Hort: cliff. 46. Roy. lugdb. 405.

Cynogloflum folis lanceolatis, foribus in foliorum alis fubleffilibus. Guett. Itanip. I. p. 92.

Cynoglofium ninus. Bauh. pin. 257 .

liabitat in Europ $x$ argillofis, nudis, ruderatis. $\odot$

4. MYOSOTIS feminibus nudis, foliis hilpidis, racemis npula foliofis.

Lithofpermum feninibus lavibus, corollis vix calycem fuperantibus, foliis lanceolatis. Roy.lugdb. 405. Sauv. ruonjp. 62.

Echium Juteum minimum. Barb. pin. 255. 
Echioides lutea minima apula campeltris. Col. ecphr '. v. 184 . t. 18 r.

Habitat in Italia, Hifpania, Narbona. $\odot$

\section{LITHOSPERMUM.}

afficinale, 1. LITHOSPERMUM feminibus levibus, corollis calycem vix fuperantibus, foliis lanccolatis. Hort. cliff. 46. Fl. juec. is 1. Mat. med. 57. Roy. lagab. 405. Dalib. parif. 58.

Lithofpermum majus eredum. Baub. pin. Is3. Habitat in Europa ruderatis. 2

aroeuse. 2. LITHOSPERMUM feminibus rugofis, corollis vìx calycem fuperantibus. Hort. cliff 46 . Fl. Jiec. I 52. Roy. lugdb. 405. Hail. belv.518. Dalib. parif. 59

Lithofpermum arvenfe, radice rubra. B.uth. pin. 258 Fl. lapp. 73.

Habitat in Europa agris $E^{3}$ arvis. $\odot$

virginiansiz 3. LITHOSPERMUM foliis fubovalibus nervofis, corollis acuminatis.

Lithofpermum corollarum laciniis acuminatis hirfutis. Gron. virg. I 40.

Lithofpermum latifolium virginianum, fore albidolongiore. Morif. bift. 3 P. $447 . \int$. II. t. 28.f. 3 .

Habitat in Virginia.

Puncta adjperfa folios Sunt excavata, borum latiora feta egredientic nutata.

phrpurocaruleum.

4. LITHOSPERMUM feminibus lxvibus, corollis caJycen multoties fuperantibus. Hort. cliff. 46. Roy. ingdb. 405 .

Lithofpermuin fore magno, caule ex apice radices agente. Hall. belv. 517 .

Lithofpermum minus repens latifolium. Bauh. pin. $25^{8}$. Lithofermum repens majus. Cluf. bij?. 2. p. i $\sigma_{3}$.

Habitat in Ungaria, Anglix, Gallix nemoribus. $z$ '

Tintorinm. 5. LITHOSPERMUM villofum, caulibus procumbentibus fimplicilimis. Mat. med. I $^{8}$.

Lithofpermum procumbeins, feminibus rugofis, foliis hifpidis, radice rubra. Sasv. mon $\int p \cdot 63$. Anchufa puniceis floribus. Baub. pin. 255 . Anchufa monfpeliana. Laub. bifk. 3.p. 584 .

Habitat in Oriente, Monfpelii. 2 
6. LITHOSPERMUM fruticofum, Raminibus corol- fiuticofum. lain xquantibus.

Lithofpermum fruticofum, corollis caiyce majoribus, foliis linearibus hifpidis. Sunv. monsp. 50. 63 .

Anchula angultifolia. Bazb. jin. 25 .

B. Anchuia arborea. Alp. exot. 67. t. 68.

Bugloflum famium fruteficens, foliis rofmsrini obfcure virentibus lucidis \& hirfutis. Touraef. cor. 6.

Habitat in Gallia, Samo Eo Europa aufirali. b

\section{ANCHUSA.}

1. ANCHUSA folis lanceolatis, fpicis inbricatis fecun-offitulis. dis. Hort. cliff. 46. Fl. fuec. 152. Mat. med. 5o. Roy. iugdb. 406. Dalib. parij: 59.

Bugloffum anguitifolium majus. Bash. pin. 256 .

Habitat ad Eulopx ruderata, vias, agros. $*$

2. ANCHUSA racemis fubnudis conjugatis. Roy. lugdb. anguffifolio.

408 .
Borago fylvefris perennis, fore rufo kermefino. Zan. bi 5.49. t. 20.

Buglofum angutifolium minus. Bast. pan. 256. Mov rif. bif. 3. p. $4 \hat{\mathrm{S}}$. f. is. t. $26 . \hat{f} \cdot 4$.

Echii facie Btigloffum minimum, tlore rubente. Lob.ic. $5 \%$ to.

Hatitat in Italia, Germania. 26

3. ANCHUSA ftrigofa, foliis linearibus dentatis, pedi- urdudutu cellis bractea minoribus, calycibus fruetiferis infiatis. Lotf.

Bugloflum lufitanicum, cchii folio undulato. Tosincf. in

Habitat is Hifpaniae, Lufitaniae pratis.

4. ANCHUSA ramis floribusque alternis axillaribus, orientalis. bracteis ovatis.

Auchufa foliis aveniis, floribus folitaris ex alis ramorum, uti rami c caule. Hort. cliff. 47. Roy. lngdb. 404.

Bugloflum orientale, forc luten. Tournef. cor. 6. Buxb. cent. 3. p. 17. t. 29. Dill. elth. 60. t. $52 . f .60$.

Habitat in Oriente. 2

?. ANCHUSA floribus fparfis, caule glabro.

Auchura lutea minor, quam aili Paccoon vocant. Gron.

virginiana, visg. 19. 
Anchura minor lutea virginiana, Puccoon indigcnis disa, qua ic pingunt americani. Pluk, alm. 30 .

Lithofpermum virglnianum, flore luteo duplici ampliori. . Morif. bift. 3. p. 447. . I1. t. 28, f. 4 : liabitat in Virginia. 2

6. ANCHUSA pedunculis diphyllis capitatis. fenpervirens Anchufa fcapis diphyllis. Hort. cliff. 47. Roy. lugidi. 407.

Buglofum latifolum fempervirens. Bauh. pin. 250 . Morif. bit. 3.p 437. S. 11. t. 26. f. 2. Hobitat in Anglia, Hípania. 2

\section{CYNOGLOSSUM.}

offrinale. T. CYNOGLOSSUM ftaminibus corolla brevioribus, foliis lato-lancenlatis tomentoris ferfilibus.

Cynoglofum folitis lanceolato-ovatis, corollis calycom æiquantibus. Roy. ingdb. 406. Fl. Suec. I54. Mat. med. 154 .

Cynogloffum folis ovato-lanccolatis. Hort. sliff. $4 \%$ Cynoglofium majus vulgare. Baub. pin. 257.

Habitat in Europa rudercitis. $\odot$

vir juiwum 2. CYNOGLOSSUM foliis amplexicaulibus ovatis. Cyroglofum foliis amplexicaulibus. Gron. virz. 19. Habitut in Virginia. $\odot$

cheirifolinal 3. CYNOGLOSSUM corollis calyce dupio longioribus, foliis lanccolatis. Roy. lugdb. 406. Sauv. monsp. 64. Cynogloflum creticum, argenteo angufo folio. Baub. pin. 257 . Hort rliff. $4 \%$

Cynoglonium creticuin 1. Cluf. bift. 2. p. 162.

Hubitut in Creta. Hifpania. $\odot$

Coralle albe veris janguneis.

apeininam.4 CYNOGLOSSUM faminibus corollam xquantibus. liort. upf. 33. Sauv. mansp. 64.

Cynogiona montana maxima frigidarum regionum. Col. ccpbr. 1: p. 168, t. 170.

Hotritut in alpibus Apenninis, Campoclarenfibus, umbrof?s. $\odot$

limifnitum, r. CYNOGLOSSUM- foliis lineari-lanceolatis glabris. Hort. cliff. 47. Hort. ups. 33. Roy. lugdb. 406.

Cyuoglolium minus album, liui foliis glaucis, femine umbilicato. Morif. bift. 3. p. 449.5. II. t. 30. f. I I. 


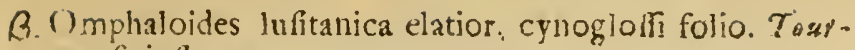
nef. in/t. I 40.

Ilabitat in Lufitania. ()

1 CYNOGLOSSUM repens, foliis radicalibus corda-Omphiloide. tis. Hort. cliff. 47. Ray. lugdt. fo6.

Borago minor verma repens, tolia levi. Moris. bif 3 . p. 437.f. II. t. 26. f. 3 :

Symphrtuin minus, boraginis facie. Bash. pin. 260.

Habitat in Lulitaniz nemorofis. 2

\section{PUI.MUNARIA.}

* Priantbiun longitudine tubi corolle.

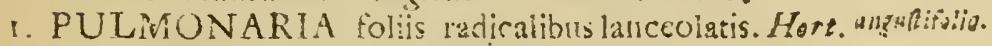
cliff. 44. Kay. lugdb. 404. Dalib. pa if. 60.

Pulmonaria folis radicalibus ovato-lanceolatis inferius decurrentibus. Boebm. lipf. 14.

Pulmonaria 5 gammonica. Cinf. bift. 2. p. 170.

Habitat in Pannonia, Helvetia, Suecia.

Sequenti nimis affinis, frimm folits anguftis diffirm gienda.

2. PULMONARIA folits radicalibus ovato-cordatis off cimlis, feabris. Hort. cliff. 44. Fl. Suec. 156. Mat. med.62, Roy. lugdb. 403. Hall. helv. 510. Duslib parif 60. Symphytum maculofum f. Pulmonoria latifolia. Basí pin. 259.

B. Pulmonaria valgaris latifolia, fore albo. Tournef. inft. 136.

$\gamma$. Pulmonaria non maculofo folio. Clif. hifl. 2.p. 163. Baub. pin. 259.

Habitat in Europa nemoribus. 4.

* Calycer tubo corolla aimidio breoviore.

3. PULMONARIA calycibus abbreviatis, foliis Janceo-virginien latis obtufiufculis.

Pulmonaria calyce rubo curolle breviore, perianthiis quinquepartitis. Gron. zirg. 20.

Symphytum r. Pulmonaria non maculata, folis glabris acuminatis, fiore patulo carulco. Pluk. alm. 359.t. 2.27. f. 6. Morif bif. 3. p. 444.

Habitat in Virginia. $\%$

4. PUYMONARIA calycibus abbreviatis, foliis radica-sisirialibus fubcordaris

Habitat an Sibiria. 4 
Rauix perinnis. Folia glabra, glauca: radicalia corda. ta; cavlisa ovata. Corymbi ramof, wutantes Media inter antecedintem ô fegueniem.

moritima. ร. PULMONARIA calycibus aborevistis, foliis ovatis. caule ramofo procumbente.

Cerinthe fuliis ovatis petiolatis. Hort. cliff. 48. Roy.lugdb. 408.

Eerinthe maritima procumbens. Dill. eith. $75 \cdot 2.65 . f$. $75:$

C)nogloflum procuncens glaucophyllim maritimun. i.m. alm. 126. t. 172. f. 3 .

Cynoglofium percnie maitimum procumbens. Morit. bilit. 3. p. 450. J. 11. t. $28 . f .12$.

Habitat in Angia littoribus filiceis. 20

\section{SYMIHYTUM.}

offisin! . SYMPHYTUM foliis ovato-lanceolatis decnrrentibus. Hort. ciiff. 47. Fl. Juer. 155. Mat. wed. 6r. Roy. busdb. $40 \%$.

Symphyrum Confolida major. Baub: pin. 259.

Havitat in Europe umbrofis fubbumidis. 2

thterofum. 2. SYMPHYTUM foliis fummis oppofit:s. Syrnphytum maius, tuberofa radice. Bauh. pin. 259. Symphytum rndice tuberofa. Cars. etit. jos. Habitat in Germania anfrals. 2:.

quiestale

3. SYMPHYTUM folits ovatis fibpetiolatis.

Symphyrum crientale, folio fubrotundo afpero, flore caruleo. Tozratef. cor. 7.

Symphytum conftantinopolitanum, boraginis folio \&

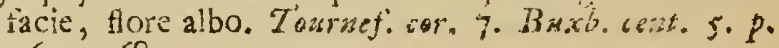
36. t. 68 .

Habitat juxia Conltantinopoli rivulos primo vere. $\mathbf{z}$

\section{CERINTHE.}

raior. 3. CERINTHE foliis ampicxicaulibus, fivetibus geminis, corollis obtuinúculis patuis.

Cerinthe folis cordaris feflilibus. Hort. chiff. 48. Hort. uff. 35. Roy. ingili. 408.

Cerinthe foliis caulem amplexantibus, dentibus Horis revolutis brevifinis. Hull. hein. 515 .

Cerinthe flore muro purpuraicente. Bash. pim. 258.

B.Cerinthe, fiavo fiore, afperior. Bash. pin. $2,5$.

Habirat ir Europa auftraij. () 
2. CERINTHE foliis amplexicaulibus emarginatis, frj- maculata. et:bus geminis, corollis acutis claufis.

Ccrinthe i: Cynogloffum montalum majus. Banb. pin. 25 . ?

Habitat in montenis Europa awftralis. D. Monti.

Differt a C. minore, cuiflore convenit, quod major \& tolia muculata cmarginata.

3. CERINT'HE foli:s amplexicaulibus inregris, fructibus minor. geminis, corollis acutis claulis.

Cerinthe foliis caulem amplexantibus, foribus profunde quinquefidis. Hall. heiv. 5ró.

Cerinthe minor. Bawb. pirs. 259 .

Cerinthe minor f. qiarta. Claf. bifi. 2. p. I68.

Habitat in Aufrix, Styrix agris. (O)

Pr.ecedesiti maxime affinis, at Corolla ₹ quinquefida. procedentis vero tanturu margine quinquiloba.

7. CERINTHE foliis ianccolato-linearibus hifpidis, fc- echioides, minibus quateruis diftinctis. Hort. cliff. $4^{8}$. Roy.

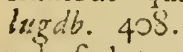

Anchura lutea minor. Baub. pis. 2,55.

Anchufa echioides lutea, cerinthx thore, montana. Col. eiphr. I. P. I 1 . 2.6 .183 .

6. Anchufa lutea major. Bissh. pirs. 255 .

Anchura tertia. Camo epit. 736 .

Anchufa lutea. Dalech. bift. IIOz.

Habitat in Aufriæ, Pannonix, Helvetia, Galliæ, It2lia rufibus. 2;

\section{BORAǴO.}

1. BORAGO foliis omnibus alteruis, calycibus patenti- offeinalis. bus. Hurt. upl. 34. Wat. med. 63 .

Borago calycibus patentibus. Hort. cliff. 44. Roy. Iugáb. 40 3 . Dalio. parif. $6 \mathrm{I}$.

Bugloffum latifolium, Borago. Bauh. piss. 256.

H.2b: iat budie in Normannia ad Colbeck Eg alibi in Europut; venit ulin ex Aleppo.

2. BOR AGO foliis ramificationum oppofitis, calycinis fo-mdicn. liolis fagitiaris.

Borago calyciais toliis fagittatis ereetis Hort. cliff. 45 . Hl. zev!. 11. Roy. lugib. 403 .

Cynoglófioices folio caulem amplexante. Ifrard. atc. IT. p. $325 \cdot f$. 10.

Anchufx degencris tacic, incia oricitalis heros, quadricapfularis. pluk. alm. 30. t. 70́. $f .3$.

Iabitat in India Orientali. 0 3. BO- 
ajrital. 3. BORACO calycinis follolis ovatis acutis ereatis. Hort. cify. 45 . Roy. lingalt. 403

Cynogiofioides atricana verrucora \& hifpida. Ifsard.

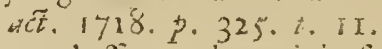

Cynoglofum, boragnis foliio \& facie, $x$ thiopicum. Pizk. alin. 34 .

Ilaisitat is Ethicpia. $O$

Alfinis eft odimodum antecedenti.

wientais, 4. BORAGO calycibus tubo corollæ brevioribus, foliis curdatis. Hor cliff. 45. Roy. lugdb. 403.

Borago conitantinopolitana, flore te velicario. Tournel. cor. 6. itin. 523. t. 523. Burb. cent. 5. pag. IG. t. 30 .

Litubitat circuin Couftantinopolin. is

\section{ASP范RUGO.}

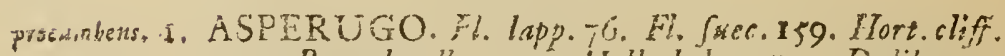
44. Roy. Ingat. 404. Hadl. beiw. 522. Dalib. piniff. $6 \mathrm{I}$.

Buglofun fylvefre, caulibus procumbentibus. Bawh.

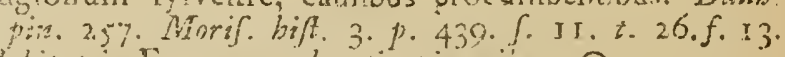
fiabitat in Europx raderatis pinguiuns. $\odot$

\section{LYCORSIS.}

veftarin. I. LYCOPSIS foilis integerrimis, calycibus fruetefentibus infiatis perdulis. Hort. cliff. $4 \hat{i}$. Hort.ups. 35 . Rov. lugdb. 403 .

Echioides flore pullo. Riv. mon. Ir.

Birtoifum procumbens annuum, pullo minimo flore. Morif. hif. 3. p. 439. S. 11. t. 26. f. 1 I.

Habitat in Europa auftrali ()

variegata. 2. LYCOPSIS foliis repandis dentatis callofis, caule de. cumberite, corollis cernuis. Hort. upS. 24 .

1.ycopfis folis repando-dentatis. Hort. cliff. 44. Roy. lingab. 404 .

Bugloffum cretican verrucofum. Stiff. bot. $\{\tau . t .57$. Bigloffun anmun tumile, bullatis foliis, flore carnleo eleganter variegato. Morif. hilt. 3. p. 43\%. f. nu.t. 26. f. 10 .

Hetitat in Creta. 0

regytiace. 3. 1.YCOPSIS foliis callo io-verrucofis, canle diffuro, corollis regularibus.

litibitat in figypto. $\odot$ 
4 LYCOPSIS foliis lanceolatis hifpidis, calycibus fore-arsmfis. licentibus erectis, $\mathrm{Fl}$ lospp. 77. Fl. Snec. 157. Hort. cliff. 4.1. Roy. ingchb.404. Gron.cirg.20. Dalib.pars.61. Buglollum minus filveltre. Bash. pin. 257.

llavizat in Europa agris. $\odot$

5. LYCOPSIS foliis ovatis integerrimis fabris, calyci-oritulsi. bus reetis.

Buglofum orientale angútifolium, fiore pavo cartileo.

Fournet. cor. 6.

Habi: it in Oriente. $\odot$

6. LYCOPSiS ioliis lineari-lanceo'atis confertis tomen-sirgitica. tolis mollibus, caule ereeto. Grun. virg. 140.

Habitat in Virginia ad vias. 2"

\section{F. CHI UM.}

1. ECHIUM caule fruticofo. Hort. cliff. 43. Rov. Itgg to. fraricosutt. 407.

Echium africanum fruticans, foliis pilofis. Comm. bort.

2. pag. 10\%. t. 54 .

Habitai in Athiopia. 5

2. ECHIUM corollis vix ralycem excedentibus mar-italicum. gine villofis. Htart. upf. 3r.

F.chium majus \&alperius, Hore a!bo. Cam. epit. 739 .

B. Lycopis. Bauh. pin. 255 .

Habitat in Anglia, Italia.

3. ECHIUM caule fimplici erecto, foliis culinis laisce- :kigare. olatis hilpidis, Ho: ibus ipicatis lateralibus. Hort. cliff. 43. Fl. Suec. I5S. Ruy. Iugdt. 407. Lialib. parif. G1. F.chium vuigare. Barb. pin. 254. Cluf. hift.2.f.143. Habitat in Europa ad vias ev' agros. $\delta$

4. ECHIUM calycibus fructefcentibus diftantibus, caule cretienn. procumbente. Hort. upf. 35 .

Echium caule fimplici, foliis caulinis linearibus, floribus picatis ex alis. Hort. cleff. 43 .

Echium creticum anguftifolium rubrum. Bash. pin. 254.

Echium crezicum latitolium tubrum. Bumin. pins. 254.

Echium creticim 1. 2. Clasf. bijl. 2. p. i Gy.

Habitat in Creta.

Sturitina ror langiora labiobreviore coralla.

r ECHIUM calle ramoro, foliis caulinis ovatis, foribus orientale. colitariis lateralinus. Hort. cliff. 43. Kuv. Ingcíb .to\% 
Echium orientale, verbafci folio, flore maximo campaunlato Tournef. cor. 6. itin. 3. pag. 94. Habitat in Orientc.

lufitanickn. 6. ECHIUM corollis ftamine longioribus.

Echiom caule fimplici, foliis caulinis lanceolatis friceis, floribus fpicatis latcralibus. Roy. lugdb. 407.

Echinm, amplifino folio, lufitanicum. "Tournif. inft. $135 . ?$

Habitat in Europa amftrali. 2

\section{TOURNEFORTIA.}

Sersata. T. TOURNEFORTIA foliis ovatis ferratis, petiolis ipinefcentibus, fpicis terminatis recurvis.

Pittonia arborcfecsis chanæcirifolia major. Plum.gen.5.

B. T'ittonia arborefcens chamxdrifolia minor Plum.gen.5 Hatitat in America calidiore. 5

kivfutifinn. 2. TOURNEFORTIA foliis ovatis petiolatis, caule hirfito, fpicis ramofifimis terminalibus.

Pitonia hirfutifina \& ramolifima, baccis albis. Plam. ger. 5 :

Habitas in America caliuinre. t

violubilis. 3. TOURNEFORTIA foliis ovatis azminatis, peticlis retiexis, caule volubili.

Tuunctortia foliis crvatis acuminatis. Hort. cliff. 48.

Pittonia fcandens, baccis niveis: nigris maculis notatis. Plum. gen. 5 .

Bryonia nigra fruticola, racemi ramulis varie implicatis Sloan. bift. 1. p. 234. t. 143. f. 2.

Virea aurea ameicana fruteícens glabra, foliis fubtus cæfiis. Pluk. alrn. 389. t. 235 . f. 6. Raj. juppl. 348. Habitat in Jamaica, Mexico, arbores fcandens. $b$

jetidifgrm. 4. TOURNEFORTIA foliis ovato-lanceolatis, fpicis ramofiftimis pendulis.

Tournefortia foliis ovato-lanceolatis. Hort. cliff. 48. Roy. lugdb. 408.

Pittonia racemofa, nicotiana foliis fœetiditìmis. Plum. gen. 5 .

Heliotropium maximum jamaicenfe, limonii mali folio lipra fcabro libtus lanugine ferruginea molli.Pluk.alm. 132. Morif. hift. 3. p. 452 .

tháb:tal in Maxico, Jamaica. b 
5 TOURNEFORTIA foliis lanceolatis feffilibus, lpi- bmilis. cis fimplicibus recurvis lateralibus.

Pittonia humilis, anchulix folio. Plum, gen. 5.

Habitat in America calida. b

- TOURNEFORTIA foliis ovatis integerrimis nudis, glubra. rpicis cymolis.

Heliotropii fore frutex, folio maximo oblongo acuminatu glabro. Sloun. jair. 17j. bifl. 2. p.100.t. 212 f. 2. Raj. dendr. 76.

Hobitat in Jamaica. 5

7. TOURNEFORTIA foliis lanceolatis, floribus co-sibirice. rymbofis, cauie herbaceo.

Mefferfchnidia. I Hort. $p$ : $3^{6}$.

Arguzia montana, Amm. rkth. $3^{8 .}$

Habitat in Daurix apricis glarecifs aridis. 4

Planta dubii etjaminus generis, interim buc relata

\section{DIAPENS!A.}

I. DIAPENSIA toribus pedunculatis. Diapenlia. Fl. lapp. 88. t. I. f. I. * fl. Juec. 172 Hulitat in aloibus Lapponicis. $z$

2. DIAPENSTA floribus fubfeflilibus. Androface caulefens, foliis altemis, pedunculis unithoris. Amon acad. 1.p. 164.

Aretia caulibus teretibus foliis imbricatis, toribus ferti libus. Hall. belv. 486 . t. 8. f. 4.

Habitat in alpibus Hciveticis Gernmi छ Pyndtnerberg. 2 Habitus antecedentis; fructum non vidi.

lapponice,

\section{ARE'TIA.}

s. ARETIA villofa, fcapis unifloris. Hall. belv. 486.f.4. alpina, Habitat in Vallefia monte Losh diato. 2 Fructus anatome nobis deeft in hac plant..

\section{ANDROSACE.}

ANDROS ACE perianthiis maximis. Hort. upS. 36. maxima, Androface cnivcibus fruetuum maximis. Hort. cliff. 50.

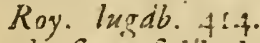

Androlace foliis lanceoiato-ovatis dentatis, calycibus corolla iongior:bus. Wachend. z:ltr. 28.

Androface altera. Cam. epit. 639. Cluf. b:ft. 2.p. 134. Alfine sfinis Androface aicta inajo: Baxb. pin. 251. Habiuatinter Auftriajegctes. () 
icpientriz- 2. ANDROSACE folis lanceolatis dentatis glabris, penalis. rianthiis angulatis corolla brevioribus. $F$. Juec. 160. Androface calyce fruetus parvo. Fl. lapp. 78 .

Androface montana, fiore minore. Buxb. act. 2. p. $369 . t .23 . f .2$.

Aline verna, androfaces capitulis. 3 auh.pin.251.prod.1 I8. Altine minor, androfaces aiterius facic. Baub. pin. 251 . trodr. i1 8 .

Aline adtinis Androface dicta minor. Bunh. fin. 251.

- Malitat in alpibus La!ponia, Rufia apricis glareofis. $\odot$

:illorn. 3. ANDROSACE folits pilofis, perianthiis hirfutis. Arctia villofa, furibus umbellatis. Fiall. beli. 496 . Sedum alfinm hirfutum, lakleo flore, Baub. pin. 284 . Sedum minus $X$, alpinum IV. Cluf. bift. 2. p. 62. Habitat in alpibus Rheticis, Pyrenæis.

halleri. 4. ANDROSACE folitis ciliatis.

Aletia foliis ciliatis linearibus, Horibus umbcllatis. Hall. hel?. 48 3. t. 7 .

Hubitat in alpibies Helvetia.

feten. 5. ANTSROSACE foliis linearibus glabris, umbella involucris multoties longiore.

Androface alpina perennis angutifolia glabra, fore fingulati. Tournef. inft. 123 .

Scdum alpinum, gramineo folio, lakteo fiore. Bawb. pin. 284 . Ray. bit. $10+2$.

Sedum minus XI. Cluf. bij. 2. $p .6$ I.

Habitat in Aufrix alpibus. 2:

camen, 6. ANDROSACE foliis fubulatis glabris, umbella invoIncris breviore.

Androface alpina perennis angufifolia glabra \& multiflora. Tourref. in/t. I 23 .

Sedum alpinum, angultitimo folio, flore carneo. Baub. pix. 284:

Sedum alpinum ejusden. Colunm. ecphr. 2. p. 64. $t$. $65 . f .2$.

Sanicula alpina, anguftifimo folio. Pluk. alm. 333. $\therefore$ 108. f. $r$.

Habitat in alpibus Pyrenæis, Helveticis. 2

\section{PRI MUI.A.}

veris, 1. PRIMULA foliis dentatis rugolis: Hort. cliff. 5r.Fl

oficinalis. corollarum concavo. mat. med. 64. Parif. 62. limbo 
Primula veris odurata, flore lutco fimplici. Bamb. bifl. 3. p. 495 .

Verbafculum pratenfe odoratum. Bask. pin. 241.

B.Primuia. - - - linbo corollarum plano.

Verbalculum pratenfe vel fylvaticum inodorum. $B$ aub. elatior. pin. 241 .

Primula vcris, pallido flore, elatior. Cluf. bif. 1. $p$. $3 \supset 1$.

y. Primula - - - - frapo nulls.

Plimula veris, pallido flore, humilis. Cluf. bift. I, p.302. scaulis.

Veibafculum tylveftre majus, fingulari flote. Busis. pin. 24 I.

Habitat in Europe pratis. 2

2. PRIMULA foli:s crenatis glabris, florum limbo plan:o. farinosa. Hort. cliff. jo. Fl. juec. 162 .

Primula foliis crenatis glabiis. lir. cliff. I2. Roj.lugdb. 415.

Primula foliis ereetis fantigiatis. Fl. lapp. 79.

Primula veris rubro flore. Cluj. psin. 340.

Vertafculum umbellatum alpinum minus. Burb. pin. 242.

Habitat in Alpinis frigidisque Europa pratis uliginofis. 2

3. PRIMULA foliis fcratis glabris. Vir, cliff. I2. Hort. Anricula. upl. 36. Roy. lugdb. 415.

Primula foliis ferratis camolis glabris. Hort. cliff. 50.

Salicula alpina lutea. Basts. pin. $2+2$.

B. Sanicnla aipina purpurea Bazh. p. 242.

$\gamma$. Sanicula alpina, folis rotundis. Bazth. pin.242.

¿. Sallicula alpina, tiore variegaio. Baub. pin. 242.

c. Sancuia alpina angufífolia. Bazn. pir. 243.

ל. Sanicula alpina, foliis yuafi fariua adiperfis. Bumb. pin. $2+3$.

Habitat in alpibres Helveticis, Styriacis. 2

4. PRIMUL.A folii cureiformious dentatis minimis co-minima. rolla longe minoribus.

Sanicula alpina minima carnea. Baub. pis. 243.

Anricula uri VIIL minina. C/uf. hifi. I. p. 30 .

llabuat in Sneberg, Tauro, Judeuberg inque aliflimo monte prope faliswas Autria juperioris, qua ionstitur in Siyriam. 2

5. PRIMULA foliis lincaribus integerrimis; foribus vitalista. leflilibus. 
Primula fiore fubleflili, foliis linearibus. Amxn. acad. I p. 160 .

Vitaliania. Sefl. epift. 69. t. 10. f. I. *

Sedum alpinum exiguis foliis. Bazb. pin. 28.4 .

Sedum alpinum \& gregorii ragienfis 1. Colums. ecphr. 2. p. 63. t. 65. f. I. Raj. hilt. i044.

Habitat in alpibu: Pyrenais Ev Italicis. 2

Calyces longitudise tubi corolla, ultra rsedim quinguefidi, corolle limbus quinquefidus, lovis oz uso oblongis

fategrifolia. 6. PRIMULA folits integerrimis glabris oblongis, caly cibus tubulotis obtulis.

Primula foliis glabris carnofis integerrimis. Hall. belw 495.

Sanicula aipina rubeicens, folio non ferrato. Baub.pon. 243.

Auricula urfi IV. Claf bift. I. p. 303. t. 304.

Habitat in alpious Helveticis, Styriacis, Pyrenaicis. 2

ostufciles. 7. PRIMUIA foliis periolatis cordatis fublobatis crenatis. Habitat in Sibiria. D. Gmeliu.

Herba foliis Jequentis, floribus antecedentis.

\section{CORTUSA.}

nutiboli. 1. CORTUSA calycibus corolla brevioribus.

Cortura foliis cordatis petiolatis. Mort.cliff. 50 . Roy.lugdb. $4 \mathrm{I} 4$.

Cortufa matrhioli. Claf. bift. r. p. 307.

Sanicula montana latifolia laciniata. Bazb. pin. 243.

Hahitat in alpious Autrix, Sibirix.

Gmelini. 2. CORTUSA calycibus corollan cxcedentibus. Amcrn acad. 2 . p. 340 .*

Habitat in Stiria. D. Gmein. 2

\section{SOLDANELLA.}

alpiza. 1. SOLDANELLA. Hort. cliff. 49. Roy. lugdb. 414. Hall. belv. 483 .

Soldanella alpina rotundifolia. Baut. pin. 295. Morif. bilt. 2 . p. $285 . \int \cdot 3 \cdot t .15 \cdot f .8$.

Soldanella alpina. Cam. epit. 254 .

Habitat in sipius Holvetix, Aultix, Pyrmxorum. 2

\section{DODECATHEON.}

Meadia, I. DODECATHEON.

Meadia. Catesó. car. 3. p. 1. t. I. 
Auricula urfi virginiana Horibus bonaginis inftar roftratis, cyclaminum more reflexis. Pluk. alm, 02.t.79. f. 6 .

Habitat in Virginia. *

\section{CY CLAMEN.}

I. CYCLAMEN corolla retrofiexa.

earopiesm,

Cyclamen foliis cordatis, corolla reflexa. Hort. $4 f, 47$. Mat. meit. 6i.

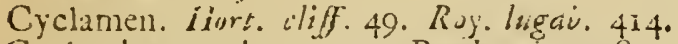

Cyclamina omnia I -.-13. Baub. pin, 308.

Cyclaminus. Cam. epit. 357 .

fiabitat in Auftix, Tataria, Europæ anjtralis nerrorow Sis. 2

Varie:utes fic conikngunt plantas folio angs:lojo so rotundo, uivix ac he vix irrites cientur.

2. CYCLAMEN corolla limbo nutante. Fl. zej\% 401 . indicum. Hobitat ia Zeyiolla. 2

\section{MENYANTHES.}

¿. MENYANTHES foliis cordatis integerrimis, corol- Nymphoilles lis ciliatis.

Menyanthes foliis orb:culatis, corollis margine laceris. Hort. cliff. 53. Koy. lugdb. 430. Dalib. parif. 62.

Nymphra lutea minor, tore fimbriato. Baub. pin. 94. licibitat in Belgii, Dantilci foljis majuribas. 2

Cribella firmplex, Jeljilis e litere petioli, ut in jequenti.

3. MENYANTHES foliis cordatis fubcrenatis, corol-indiso. lis interne pilolis. Fl. zeji. 72 .

Nedel-ämbel. Rbeed. raal. II. t. 55. t. $2 \widehat{8}$.

Habitat in Malabariæ, Zcylonæ foljis.

3. MENIANTHES foliis ternatis. Fl.lapp80. Fl. Fuec. trifoliato. 103. ilurt. wliff. 52. Mat. med.66. Koy.lugaio. 430. Hall. belv. 457. Dalib.parif. 62.

Tifolium piluitre. Baus. pin. jaz.

Habitat in Eurvix paladions. $z$

\section{HOTTONIA.}

.I HOTTON1A Bocrb.lagdu.1.207.LIort.cliff.51.Fl. fuec. palughis, 16.4. Koy. lugd6. 41. Hall. belv. 497. Dalib.parij: $6_{3}$. Milielolium aquaticum $\mathrm{f}$. Viola aquatica, caule nudo. Luzh. pix. Iti. 
Millefolium aqualcum equiferifolium:caule nudo. Bass. Habitat in jojis es paitadibar Europa borealioris. is

$$
\text { HYDROPHYLI UM. }
$$

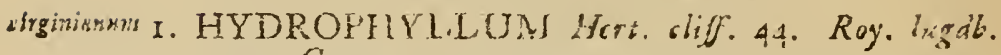
t'3. Gron: virg. 2I.

Deutarix facie pinnta monoptaios, fiuctu rorundo mo-

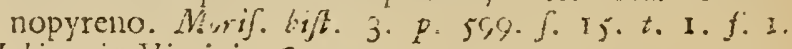
Ilabitat in Virginia. $z$

Hydrobbyilitn. verum sanoldenform in auzis saturn di. nerfigimallanta folits binis periolatis palvastis, bafa ex-

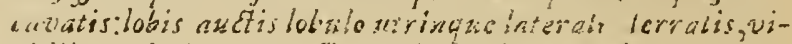

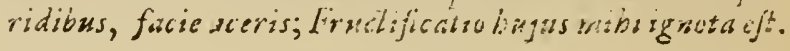

\section{LYSIMACHIA.}

* Peduncuir multijloris,

vrigutir. I. IYSIMACIIA paniculan rucemis teminalibus.

Lyfimachia folis lanceolatis, accmo compolito terminaii. lirid. dibl. 4is. Fl. fues. 166. Roy. lugdh. 416. J yfimachia foliis lanceolatis, corymboterminali.Fl.lapp. 81. Hort. cliff. 50.

1.vîmachia lwiea niajor. Busb. pis. 245 . Thabitat in Eurov: ad ripas E paludes. \#

Ephemerm.? LYSIMACHIA racemis fimplicibus terminatibus, petalis obtutis, naminibus corolla brevintibus.

Lyfimachia accmo limpliciterminuli, fulis lanceolatolinearibus. I ir. cliff. I 3. Kiart. clif. 3. Roy:Izgdb. +15.

Lyfimachio foicata purpurca ninor. Buxl, sent. I. $p$. 2.2. t. 33 .

Lyfimachit orientalis minor, foliis glaucis: Till. pif. ic6. $\therefore$ 40. f. 2.

Hobitat in Media. $\odot$

Canf. Ephemerum mathioli. $B$ ash. pin. 24.4. Brsib. bifl. 2. 1 . 905. Dod persp: 203.

Cunvenit curs: L. atropterpurest babith, ftreltwi a, glassco rolore. Differt Petalis abtsafis, jwizlis, fiumisibus cavolla brevioriurs. fioribus podicillo injidentabus, cunz

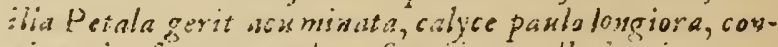

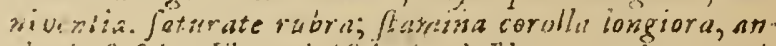
theris fufris: Flores in flicoin lebliles: anterim maxiwat affines jisut. 
3. LYSIMACHIA fpicis terminalibus patulis lanceola-atropurgrirea tis, ftaminibus corolla longioribus.

Lyiimachia toliis !anceolato-linearibus caulem \& ramos fpica ovala terminaute. Hyrt. clifi, st.

Lytimachia foliis lanceolato-linearibus, fipicis terminal:bus. Roy. liegdle. 415 . Mort. upf. 37.

Lyfimachía orientalis angutifolia. Comm. $\operatorname{rar} .93 . t .33$. Habitat in Uriente. $\odot$

4. LYSIMACHIA racemis later:libus pedunculatis.

Lylimachia racemis implicibus lateralibus. Virid. cliff. thyriffora, 13. Fl. Suec. I67. Koy. lagdo. 416.

Ljfimachia ex alis folioram thyrfifura. Fl. lapp. 82. Hiort. clist. 52

Lytimachia bifolia, flore globofo luteo. Baub. pin. 242. Lylimachia lutca. Cilsf. bift. 2. p. 53. $f$. I2.

Habitat in Europa, in palvdibus. 2

\section{* Peciunculis unifloris.}

5. LYSIMACHIA foliis quaternis fubfelfilibus, peduncu- quidrifolin. lis quaternis uniflotis.

Lyfimachia foliis ovato-acutis quaternis. Gron. virg. 20. Anagalis marina lutea, foliis latis ttellatis. Pet. gaz. 5 .

t. 2. f. 5 .

Anagallis lutea foliis \& floribus ex eodem exortu quatuor ex xqualibus furculorum intervallis cruciatim politis. Pluk. irant. I2.

Habitat in Virginia.

6. LYSIMACHIA foliis fubquaternis, pedunculis verti- punstats. cillatis unifloris.

Lytimachia foliis lanceolatis, floribus folitariis. Hort. cliff. 52. Roy. Iugdb. 416. Gron. virg. 20.

Ly limachia lutea minor, foliis nigris punctis notatis.Bauh. pin. $2+5$.

Lyfimachia !ute 2 II. Cluf. bift. 2. p. 52. f. 2.

Blattarix affinis planta rninor, flore luteo, foliis nigris punctis notatis. Morif. hist. 2. p. 491. S.5.t. I0. f. I5. Habitat in Hollandia inter arundizes.

7 LYSIMACHI petiolis ciliatis, floribus cernuis.

Lyimachia foliis orato-lanceclatis luocordatis, petiolis margine utrinque lallatis, floce lolitario.lf acb. ultr. 390.

Lyfimachia canadenfis, jalappx folïis. Sarac. canad. Wulsh. hort. j2. t. I 2 . 
Habitat in Virginia, Calladit.

Caulis eredus. Folia oppolita, oblongo-ovata, integerrima, acuta, glabra: nervis lateralious; petioli canaliculati, ciliati. Pedunculi folitaria, mifiori, nudi.

Linum fel- 8. LYSIMACHIA calycibus corollam fuperantibus, litum. caulc creeto ramofifinmo. Roy. lugáb. 4I6. Hort upf. 37. Sarv. monsp. I 30.

Linum minjmuin ftellaium. Bauh. pin. 214.prodr. 107. Magn. monfp. 163. 4. 162.

Habitat in Gallia. $\odot$

nemornin. 9. LUSIMACHIA foliis ovatis acutis, floribus folitariis, caule procumberite. Hart. cliff. 52. Roy. lugdb. 4 I6. Anagallis lutea nemorum. Baub.pin. 252. Morif.bift. 2. p. $569 . \int \cdot 5 \cdot t .20 . f .5$. Anagallis. Clus. bift. 2. p. 132 .

Habitat in Germaniæ, Gallix, Anglix nernoribus glareofis.

Nummla - 10. LYSIMACHIA foliis fubcordatis, floribus folitariis, ria. caule repente. Vir. cliff. 13. Hort. cliff. 52 . F\%. Suec. 168. Nat. med. 67. Koy.lugdb. 416. Hall.bolv. 481. Nummularia major lute2. Bauh. pin. 309.

Anasallis mas. Cam. epit. 394.

Habitat in Europa juxta agros É fcrobes. \&

renclla. II. LYSIMACHIA foliis ovatis acutiufculis, pedunculis folio longioribus, caule refente.

Lyfimachia foliis fubrotundis, floribus folitaris longe pedunculatis. Guett. ftamp.2. p. I19.

Lyfimachia foliis orbiculatis planis, floribus folitariis rubellis, caule repente. Sauv. mon $j p$. I j).

Nammularia minor, purpuratcente Hore. Baub. pin. 3 Io. prodr. 139. Morif, hift 2. p.567. S. 5.t. 26.f. 2 . Habitat in Gallia, Anglia bamidis.

\section{A NAGALLIS.}

arvenfis. 1. ANAGALLIS foliis indivifis, caule procumbente. Anagallis roliis indivilis. Roy. lugdt. 416 . Fl. Juec. 169 . Anagallis foliis ovatis. Hort. cliff. 52 .

Anagallis phoniceo tore. Baub. pirz. 252.

Habitat in Europa arvis. $\odot$

monelli. 2. ANAGALLIS foliis indivifis, caule creeto. Anayallis foliis lanc colatis. Hort. cliff. 52 . Hort. ups. 33 . 
Anagallis cærulea, foliis binis ternisve ex adrerfo nafcentibus. Baub. pin. 252.

Anagallis tenuifolia monelli. Clus. app. alt.

Habitat - - - 0

3. ANAGALLIS foliis cordatis amplexicaulibus, cauli-latifolid. bus compreflis.

Anagallis hifpanica latifolia, maximo flore. Tournef. injli. I 43 .

Cruciata montana minor, flore caruleo. Barr. ic. 584 Habitat in Hilpania. Larfl. $\odot$

Caulis erecto-patess, brachiatur, ranofus, quadrangularis: angulis oppolitis triplo latioribus, angufioribus vero margine acuto utrinque feptis. Folia Jubcordata,

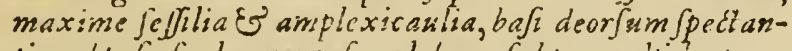
tia, obtufiufcula, neriofa, glabra, fubtus palliae punEtata. Peduncuil axillares, folitarii, uniflori, sudi, teretes, corolla cakulea, fusdopurpurafcente. Filamenta purfarea; Antheris oblongis flavis. Notabilis foliis magnis Ev latis, caule comprelfo, $A$, arvenfi attamen valde affirais.

4. ANAGALLIS foliis finuatis. Roy. lugdb. 4 I6. $\dagger_{\text {t }}$ capenfis. Anagallis purpurea, burfæ paltor is toliis minoribus. $P$ et. muf. 245 .

Habitat ai Caput b. fpei.

THEOPHRASTA.

1. THEOPHRASTA. Roy. lugdb. 528.

ansericans.

Erefia foliis aquifolii longiflimis. Pluk. gen. 8.

Habitat in America aquinotiali. b

Caudex nudus, fimpliciflimus, apice frondofus st in $P$ almis. Folia lanceolata, longiflma, dentata nervis undulatis; ornia ex apice caudicis undique diffufa. Fructificationes ramofae, diffuja, inter fulia ad apicsin caulis.

\section{PATAGONULA.}

I PATAGONULA †

Patagonica foliis partim ferratis partim integris. Dill. elth. 306. t. 226 . f. 293 .

Habitat in Patagonia Americes auftralis. 5

\section{SPIGELIA.}

1. SPIGELIA.

Anthelnio.

Arapabaca quadrifolia, fruein tefticulato. Plam. gen. I I. Barr. equin. I5. 
Arapabaca brafilienfibus diata planta. Niaregr. oraf. 46. Habitat is Cajentia, Brafilia.

Caulis fimplex berbaceus. Folia terminalia quaskor, lanceolate. Foila caulina alia ciuo oppofita. Puanus ex cila fingula folii causisu folitarius, caulifimilimas, termi-

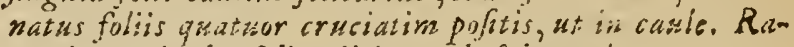
cern: terminales folitarit in coulc Ev ramis.

\section{OPHIORRHITA.}

Mangys. I. OPHIORRHIZA foliis ianceolato-ovatis.

Ophiorrhiza. Fl. reyl.402. Mat. med. 79.t. 1. Amoen. acad. 2. p. IIS.

Habitat in India orientali. 2

Conf. Litnonium mauritanicum, flore minimo, canle foliofo. i'ct. gar. 60. t. $41, f .12$.

Mitreola. 2. OPHIORRHIZA foliis ovatis.

Mitrecla. Hort cliff. 492. Gron. virg. 28.

Mitar. Houll infs.t. brin.l.

Habitat in America meridionali.

\section{A\%ALEA.}

inicis. x. AZALEA floribus fubfolitariis, calycibus pilofis.

Chamarhododendron exoticum, ampliffimis floribus liliaceis. Bregn. prodr. I. p. 23 .

Ciftus indicus, iedi alpini foliis, foribus amplis. ilerm. lugdb. I52.t. I53. Raj. hift. I89s.

Tfutiuf. Komph. amoers. 845.1 .946$.

Habitat in India. $b$

pantica.

2. AZALEA arborea. $\dagger$

Chamærhododendros pontica maxima, mépili folio, flore luteo. Tournef. cor..42. B3zxb. cent. $5 \cdot p \cdot z^{3} 6 . t$. 60.

Habitat in Ponto, T'rapezunte. $\tilde{b}$

luten.

ว. AZALEA roliis ovatis, corcllis pilofis, ftaminibus longilfimis.

Azalca ramis infra flores nudis. Gron. zirg. 21.

Azalca fcapo nudo, Horibus confertis terminalibus, ftaminibus declinatis. Hor:. cliff. 69.

Azalea erecta, foliis ovatis integris alternis, fore luteo piloto pracoci. Cold. ebor. 25 .

Ciftus virginiana, periclyneni forc ampliori minus odarato. Pluk. mant. 4?.

Habitat in Virginia. 5 
4. A7ALEA foliis margine fcabris, crroflis piloto-glu-,$j \mathrm{jc} / \mathrm{s}$ tnolis.

Azalea ramis infra Hores foliofis. Gron virg. 2r. Coll. ebor. 24.

Ciltus virginiana, Hore \& odore periclyneni. Pluk.alin. 106 t. 152. f. 4. Catesb. car. 1. p. 5\%, t. 57.

H.bitut is Virinia. 5

5. AZALEA foliis adfperfis punetis excavatis. Azalea ranis compolitis fuberectis. Fl. SHec. I TT.

Azalea maculis ferrugincis lubtus adipcrfa. Fl. lapp. 89 .

t.6. F. . .

Habstat in Alpibus Lapponix. 5

6. AZALEA ramis diffufo procumbentibus. Fl. Gapp. 90. proeum $3 \mathrm{sm}$. t. 6. f. 2. Fl. faec. x 70. Holl. bislv. 4ib.

Chamxrhododendros fupine feiruyinea, thymi folio, alpina. Bucc. muf. 2. p. 64. $t$;3.

ChamæCittus rerpyllifolia, Horibus carneis. Bsub. gin. 466.

Habitat in Alpibass Europa.

\section{PIUMBAGO.}

1. PLUMBAGO foliis amplexicanlibus. Hort. cliff. 3 3. enrosen. Mat. med. 75 . Koy. lingdb. $41 \%$ Sativ. montp. 63 .

Lepidium Dentillaria dictum. Bash. pin. 97.

Tripolium diofcoridis, Col. ecphr. x. p. r60.t. 16 t.

Habitat in Europa auftrali. 2

2. PLUMBAGO foliis petiolatis. Hort. cliff. 53. Yhort. seylarien. upf. 43. Fl. zeyl. 73. Roy. lugd6. 497.

Denciliara lychnoides fylvatica Teandens, fiore albo. Slonn. bift. 1. p. 211 . t. 133. f. 1.

Lychnis indica fpicata, ocymaltri roilis, fructibus lappaceis oblongis, radice urente. Comm. Wart. 2. p. (C). t. 5 .

Mabitat in India utraque. 2

\section{PHLOX.}

1. PHLOX foliis lanceolatis margine fcabris, corymbis ponicntar. compofitis,

Lyfimachia virginiana umbellata maxima, lyfinachix lutex Horibus amplioribus, Pluk. mant. 12r.?

Habitat in Aunerica feptestricsali. Colienfon. Z

Planta magna, alta. Caulis levis, obrufus. Folia latolanceolatn: margine Aculeis minuriffimis fparfis cxa-

$$
\mathrm{K}+\mathrm{fpe-}
$$


sperate. Corymbi conferti in umbellan Floribus $n u-$ merofipimis.

vaculata. 2. PHLOX foliis cordato-janceolatis lavibus.

Lychnoides marilandica, follis binis oppofitis bafi \& auriculis caulen utrinque ampjexantibus. Raj. Juppl. 489.?

Habitat in Virginia. Kalm. 2

Plantx caulis terctiufculus, fubfcaber, rubrn tiridique undiqsse texisifime mackslatus, erekns. Folia lavia, e bafi amplexicasli cordata, elongata in lasscenlatum sentim acutius. Flores in Raccinum campofitum digetiti.

pilosa. 3. PHLOX follis lanceolatis villofis, caule ereeto, corymbo terminali.

Lychnoides marilantica, calycibus lanuginofis, foliis augutis acutis. Raj.Juppl. 4 yo.

Lychnidea urnbellifera, blattariz accedens virginiana, major repeins preudomelanthii foliis pilofis, flore pentapetaloide fiftulofo. Pluk. alm. I33. t.98. f. 1 .

Habitat in Virginia. *

glaberimsa. 4. PHLOX foliis lineari-lanceolatis glabris, caule erecto, corymbo terminali. Hort. clift. 63. Rov. lugdb. 433. Gron. virg. 21.

Lychnidea tolio melampyri. Dill. slth, 203. t. 166. $f$. 202.

Habitat in Virginia. 2

divaricata. 5. PHLOX foliis lato-lanceolatis: inferioribus altcrnis, caule ramoio.

Lychnidea virginiana, alfines aquatica foliis, floribus in ramulis divaricatis, $P$ luk. mant. I2I?

Habitat is Virginia.

Plantre Caules erectiufculi. Folia lanceolata f. ovatolanceolata, oleracea Es molliufcula, glabra ant parum pilofa: Superiora oppofita, inferiara alterna. Rami alterni, bafl divaricati. Corolla carulea.

vvatu. 6. PHLOX foliis ovatis, floribus iolitariis.

- Lychnidea fiftulofa marilandica, clinopodii vulgaris fojo, flore amplo lingulari. Disk. mant. I 22.t. 34 . f. 4 .

Habitat in Virginia. 2

fubulatn. 7. PHLOX foliis fubulatis hirfutis, floribus oppofitis. 
Lychnidea, blattariæ accedens virginian:a, minor repens, his fitis camphoratæ foliis. Pluk. alm. 233. t. 98. f. 2 .

Habitat in Virginia.

Corcllx lobi emarginati Es tubsus calyce duplo longior eft.

8. PHLOX foliis lincaribus villofis, pedunculis ternis, fibirica.

Amven. acad. 2. p. 342.

Habitat in Afia boreali. 4

Labi Corolla rotundatu integre $E^{2}$ calyces longituaine

tub: corollie.

9. PHLOX foliis retaceis glabris, fiorıbus folitariis.

Lychnidea, blattarix accedens virginialia, camphoratx congeneris, glabris foliis. Pluk.alm. 233.t. 9" f. 3 . Habitat in Tirginia.

\section{CONVOL VULUS.}

\section{* Caste volulisli.}

x. CONVOLVULUS foliis fagittatis utrinque acutis, arverfis. pedunculis unifloris. Fl. Suec. 173. Dalib. parif. 65 . Convolvulus foliis fagitatis utrinque acutis. Hort. rliff. 66. Roy, luirdb. 427 .

Convolvulus minor arvenfis, Bash, pin. 294.

Habitat in Europa agris. 3

3. CONVOLV ULUS foliis fagittatis poftice truncatis, sepium. pedunculis uniforis. Roy. lugdb. 427. Fl. Suec. 174 . Dalib. parif. 6 i.

Convolvulus foliis agittatis poftice truncatis. Hort. cliff. 66.

Convolvulus major albus. B aub. pir, 294.

H.abitat in Europa Sepibus. 2

3. CONVOLVULUS foliis fagittatis poftice truncatis, scommonis. pedunculis bifloris. Roy. Ingdb. 427. Mat. med. 82 .

Cunvolvulus fyriacus r. Scammoniaca fyriaca. Morif.

bitit. 2. p. 12. S. I. t. 3. f: 5.

Scammonia fyriaca. Basn. pin. 29.4.

Habitat in Syria, Mylia, Cappadocia. 2

4. CONVOLVULUS foliis cordatis integris pandurifor- pantaratus. mibusque, calycibus lavibus.

Convolvulus foliis interioribus cordatis, fuperioribus trilobis, calycibus pedunculis petiolisque glabris, caule rubefcente. Gron. wirg. 141.

Habitat in Virginix arenofis.

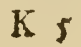

5. $\mathrm{CON}-$ 
moint. 5. CONYOLVULUS foliis cordatis integris trilobisque villofis, calycibus lavibus, captulis hirtutis, pedunculis fubbitioris.

Convolvulus, folio hederaceo, arvenfis, flore dilute purpureo. Dill. elth. 100. t. 84. f. 98.

Halitat in Carolina. 2

Pedunculi uriflori aut bifiuri.

hadivens. 6. CONVOLVULUS calycibus tuberculatis pilonis. Viria. cliff. 18. Hort. upf. 38. Gron. virg. 141. Roy. lugdb. 428.

Convolvulus annum, foliis cordatis rarius trilobis, calyce tuberculato pilofo. Hort. witt.67.

Convolvulus purpurcus, folio fubrotundo. Baish.pin.29\%.

B. Convolvulus cæruleus minor, folio fubrotundo. Dill. elth. 97.9 .82 . f. 94 .

y. Convolvulus fiore purpure, calyce punctato. Dill. elth. 99. i. $83 . f .96$.

8. Convolvulus flore minore lacteo fundo arrorubente. Dill. elth. 98. t. 83 . f. 95.

e. Convolvulus folio cordato glabro, flore vilulaceo. $D$ ill. elth. I00. t. 34 . f. 97.

$\zeta$. Convolvulus carulous, hedera $\mathrm{cco}$ angulofo folio. $B a k b$. pin. 295. Dill. elth. g6. t. 80. f. 01.

\%. Convolvulus cærulcus, hederaceo folio magis angulofo. Dill. elth. 96. t. 80. f. 92.

Convolvulus caru!cus major, folio hederaceo. Dill. elth. 97. t. 81. f.93.

Habitat in Afia, Africa, America. $\odot$

Pedunculi in aliis xniflori, in aliis triflori $\int$. multifio$r$, limites autem inter fingulas a-.-n wix occurrunt.

getatss. 7. CONVOLVULUS foliis cordatis allgulato-ncrvolis, caule repente tuberrifero.

Convolvulus foliis cordatis angulatis, radice tuberora. Hort. cliff. 67. Roy. lugab. 427.

Convolvulus radice mberofa elculenta \&c. Catesb. Gar. p. 60. t. 60.

Convolvulus indicus oricntais Intame f. Batatas. Morif. bift. 2. p. II. . . 1. t. 3. $f .4$.

Convolvulus indicus vulgo Patates dictus. Raj.hja.728

Batatas. Baub. pin. 91 .

Kappa kelengu. Rbeed. mal. 7. p. 95. t. $1 \%$

ilabitat in India utraque. 2

Conf. Convolvalus indicus vulgo Patates dietum. Feru per. 3.p. I6. t. II. toliis palmatis. 
8. CONVOLVULUS foliis cordatis, pednnculis uni- misidlatis bellaris.

Convulvulus americanus, vulgat is foijo: capfulis k1:quetris numerofis. Pluk. alm. 114. $t$. 107. $f$. 1.

Convolvulus lurcus polyanthos. Pizm. amer. 88.t.102.

Conrolvulus polyanthos, folio fubrotundo, Hore luteo. Sloan. jam. 5 r.

Halitit in Martinica, Domingo, Jamiaica. ";

9. CONVOLVULUS fuliis cordatis glabris, caule pe-malnbricur. renni villofo.

Conrolvulus foliis cordatis acuminatis, canle arboreo fcandente. Roy. lugab. 42.9 .

Jastu-kulengu. Rheed. mal. II. p. I05. t. 5. Raj., Jppl. 376.

llabitat in Nialandrix arenolis. I)

10. CONVOLVULUS foliis cordatis pubefcontibus, enraricmis. caule perenni villofo. nedunculis inultitoris.

Convolrulus foliis corditis, caule fruticolo villobo. Vir. Wiff. I 8 . Hor. oliff. 67. Roy. lugdb. +28.

Convolvulus cainarientis iempervirens, foliis mollibus \& incanis. Comm. bort. 2. p. 101. t. 51.

Convolvulus canarienfi, toliis longioribus mollibus incanis. Plok. alm. 114 . t. 325 . f. 1.

Habitat in Canarlenfibus inglis. b

11. CONVOLVULUS foliis cordalis, caule aculeato. aculeatus. Hort. cliff. 496 .

Convolvulus americanus, fubrotundis foliis, viticulis fo:nolis. Pluk. alm. I15. t. 276 . † 3 .

Convolvulus maximus, caule fpinulis obtufis oblito. Sloun. jum. 55.bigh. T.p. Ist. t. g6.j. I? Raj. Juppl. 371 ?

Smilax afpera indix occidentalis. Bauh. pia. 296.

Inabitat in America calidiore. \$

r2. CONVOLVULUS foliis cordatis angulatis, caule Turpethrn. membranaceo quadranyulari, pedunculis multifloris. Fl. 2. cyl. 74. Mat. med. S4.

Convolvulus zevlanicus alatus narimus, folis ibifci nonnihil fimilibus angulofis. Herm. lngds. $177 . t .17 \mathrm{~S}$. 179.

Turpethum repcins, folis althxx vel indicum. Baxb.

pin. I 49.

Habitat in Zeylona. * 
tomentofis. 13. CONV OLVULUS follis trilobis tomentoris, caule lanuginofo.

Convolvulus folio lanato in tres lacinias divifo, flore oblongo purpureo. Slaan. jam. 55. hift. I.p. $154 . t .98$. f. 2. Raj. Suppl. 3 Sr.

Convolvulus jamaicenfis trilobas, foliis tomentofa 12nugine denfiori ac veluti inftar utrinque obductis. Pluk. alm. II 5. t. $167 . f .4$.

Habitat in Jamaica.

altibeoides. I4. CONVOLVULUS foliis palmatis cordatis fericeis: lobis repandis, pedunculis bifiorss.

Convolvalus foriis cordato-digitatis fericeis: foliolis linearibus: intermcdiis duplo longioribus. Vir. cliff. 18. Roy. Ingäb. 42\%. Sauv. monjp. 202.

Convolvulus toliis ovaris divitis bafi truncatis: laciniis intermediis duplo longioribus. Hort. cliff. 67.

Convolvulus argentcus, folio althæx. $B$ auh. pin. 295.

Convolvulus, betonicæ althæaque foliis, repens argenteus. Barr. rar. 5. t. 3I 2.

Q. Convolvulus argenteus elegantiffimus, foliis tenuiter incilis. Tournef. injt. 85 .

Habitat in Europa meridionali.

paniculatus. 15. CONVOLVULUS foliis palmatis: lobis feptemovatis acutis integerrimis, pedunculis paniculatis.

Pal-modecca. Rbeed.mal. II. p. IOI.t. 49. Raj. Juppl.

Habitat in Malabarix arenofis.

Medism. 6 . CONVOLVULUS folits haftato-acuminatis: auriculis deutatis, pedunculis fubunitoris, calycibus fagittatis.

Tala-neli. Rbeed. mal, II. p. II3. t. 55 .

Habitat in India.

Folia lanceolata, apice integra, glabra, acuta, bafidilatata in 2. auriculas recurvas extrorfum $\int u b c^{2}$ natatas. Pedunculi unifiari, rarius biflori; Stipulis lanceolatis, oppofitis, duabus, acuminaitis. Caly cis foliola fagittata, hinc Campanula Medii infar poftice appendiculataretrofpectantia.

* * Cauceproftrato.

fislus. 17. CONVOLVULUS foljis cordatomovatis, pedunculis unifloris: bracteis lanceolatis, Hore fefrili.

Convolvulus foliis ovatis acuris, floribus duplicibractea tuccindis. Kay. lugdb. 428 .

Con- 
Convolvulus folis ovatis acutis. Fiort. cliff. 67.

Convolvulus ticulus ininor, Hore parvo auriculato. Bocc. fic. 89. t. 48. Miorij. bijt. 2. $\int .1$. t. 7. f. 5.

Habitat in Sicilia. (-)

Caulis vix wel admuidumporum, fopiusminime volubilis.

18. CONVOLVULUS foliis fubrotundis, caule repente. nи mжula-

Convolvuiris mincir repens, nummularix folio, fiore c $x-$ ruleo. Sloan. jart. j8. bift. 1. p. 157. t. 99. f. 2. Raj. Juppl. 382 .

Habitat in Inmaica \& Barbados pratis.

19. CONVOLVULUS foliis fubovatis obtufis petiola- al/3noider. tis pilolis, caule difiufo, pedunculis trithoris. Fl. $\approx$ ey $l .76$.

Convolvulus foliis ovatis obnilis, caule filiformi. Hort. cliff. $\delta 8$.

Convolyuli mir.imi fpecies bifnagarica hirfuta, alfnes folio. Fluk. alm. 1 I6. t. 9. f. I.

Anagallis hirfuta minor, foliis alternis, floribus folitariis. Burm. zeyl. II. 九. 6. $f$. I.

Viltnu-ciandi. Rbeed. mal. 11. p. 131.t. 64.

Hebitat in Maiaoaria, Zeylona, Biinagaria, Bahama.

Vurietas babitu lini: caulibus, pasicula, folis lanceolatis Sericeis, bujus jorte fola varietuss.

20. CONVOLVULUS ioliis lincari-cunciformibus tri-tridentatus, cufpidatis: bail diarat: dematis, pedunculis unitloris.

Convolvulus minor procumbens, acetcfellæ foliis tricufpidatis ad inum quaternis: fummo apice tricufpidatis. Pluk. mant. I17. t. $167 . f \circ 5$.

Sendera-Clandi. Rheed. mal. I1. p. 133 . t. 65 .

B.Convolvulus midicus barbatus minor: foliorum apicibus lunulatis. P!uk. alm. 117 . t. $276 . f$. 6.

Havitat in Indis.

21. CONVOL YUUS foliis !anceolatis obtufis fericeis, cheorum. pedunculis multilloris. fíort. cliff. 68. Roy. lugdb. 429. Saи̃. manip. 50 .

Convoliulus major reetus creticus argenteus. Morif. bift. 2. p. i1. f. I. t. 3. f. 1 .

Cncorum album, folio oic argeiteo molli. Baub.fin. 463.

$\beta$. Convolvulus ierpens maritimus ipicatolius. Iriumef. obf. 91. t. 91. \%. 2.

Convolvulus raxatiilis credtus villofus perennis. Burr.rar. 4. t. 470 . Bo66. Mm. 2. p. 7y. 2. 70 
litariis. Hort. cliff. 60. Hort. upf. 39. Fl. z.ejl. 77. Roy.lugdb. 430 .

Quainoclit f. Jasminum americanum. Clus. poflh. 9.

Convolvulus pennatus exoticus rarior. Col. aquat. $73 . t$. 72.

Jasminum millefolii folio, Baub. pin. 398.

Habitat in India. $\odot$

Nycisiea. 2. IPOMOEA foliis pinnatif dis finuatis acutis.

Ialabitat in Virginia. D. Grunovius.

carolina. 3. IPOMOEA foliis digitatis: foliolis petiolatis, peciun culis unitloris.

Convolvulus ininor pentaphyllos, tore purpureo mi nore. Catesb. car. 2. p.9.t. 91.

Habitat in Carolina.

reccines. 4. IPOMOEA foliis cordatis acuminatis: bafi angularis, pedunculis multitloris. Hort. 2 t. 39 .

Ipomce foliis cordaris acuminatis vix dentatis. Hort. liff. 66. Roy. lugdb. 429.

Ipomce foliis cordat's integerrimis, limbo floris quinque fido. Sauv. meth. II 4 .

Quamoclit americana, follio hederæ, fore coccineo. Cornin. rar. 2I, t. $2 \mathrm{I}$.

Convolvulus coccineus, folio angulofo. Himm. amer 89. t. 103 . Kaj. Juppl. 380.

Halitat in Domingo. $\odot$

tuberofa. 5. IPOMOEA foliis painutis: lobis feptenis lanccolatis integerrimis. Hort. isps. 39.

Convolvulus major heptaphyllus, flore fulphureo odo. rato. Sloan. jam. 55. bift. 1. p. 152. t. 96. f. 2.

Convolvulus americanus, mandjucca muititido folio, heptaphyllos, flore albo fundo purpurco, radice tuberof , cortice albo. Pluk. alin. I I . t. $276 . f .5$.

Habitat in Jamaica. 5

rampanulata 6. IPOMOEA foliis cordatis, pedunculis multifloris, perianthio exteriore orbiculari, corollis campanuiatis lobatis.

Adamboe Rbeed. mal. II. p. I15. t. 56.

Habitat in India.

Corolla crafjur; quam in reliquis; sub Periantbio quinquepartito, aliul periantbium minus orouculatuin iniegerrimum. 
7. IPOMOEA folits cordatis acuris integerrimis villolis, alba.

Horibus ternis, corollis indivifis. I

Munda-valli. Rheed. mal. II. p. 103 . t. 50.

Habitat in Mal:abarix arenofis, arbores foundens.

8. IPOMOEA foliis cordatis inteyerrimis, foribus confer- violacee.

tis, corollis indivitis. Sant. inor/p. 114. $\dagger$

Quamoclit foliis ampliffimis cordiformibus.Plum. Spec.3.

Habitut in America meridionali.

9. IPOMOEA foliis cordatis acutis integerrimis, flori-folanifolia. bus folitariis. Roy. $\operatorname{lng} d b .430$.

Quaminalit Solani folio, Hore rofeo. Plum. Spec. 3.

Habitat is America.

10. IPOMOEA foliis cordatis integerrimis glabris lacu-lucnuora. nolis, pedunculis bifloris.

Convolvulus ftellatus, periplocx rotundioris folio. Dill. eltb. $103 .+87$. . .103 .

Habilat in Carolina.

II. IPOMOEA foliis fagittatis poftice truncatis, pedun-glincifolia, culis bitoris.

Convolvulus foliis cordato-ianceolatis. Hort. cliff. 67.

Convolvulus ftellatus arvenfis, folio glauco. Dill. sitk. 103. t. 8\%. S. 101.

Habitat in Mexicre arvis.

12. JPOMOE A foliis trilobis cordatis, pedunculis trifioris. trilcba.

Convolrulus pentaphyllos minor, flore purpureo? S!oan. jam. 55. bifl. I. p. 153. t. 97. f. I. Kaj. Suppl. $38 \mathrm{I}$.

Habitat in America. $\odot$

Caulis volubilis, angulatus. Folia cordata, profundetr:lyba: intermediv ovato; lateralibus fernicurdalis, in tegerrima, glabra. Pedunculi trifori. Corollix cylináricu, violucex. Stiginata duo, globofa. Capfula pilof.e.

\section{* * Fioribus aggregatis.}

13. IPOMOEA foliis trilobis, floribus aggregatis. Fl. be aticafolic zeyl. 79.

Convolvulus indicus villofus, hederie folio tripartito, Hore cæruleo. IJerm. Ingdb. 18:.

Convolvulus zeylanicus hirfutus, foiiis hepaticx. Herm. prodr. 327.

Habitat in Zeylona. 
monifolia. 14. IPOMOEA foliis cordatis acuminatis pilofis, flori* bus aggregatis.

Volubilis carolinicnfis, tamni folio fubhirfuto. Dill. elth. 428. $t$. 318 . f. 414 .

Habitat is Carolina.

Pes tigridis. 15. IPOMOEA foliis palmatis, floribus aggregatis. $\mathrm{Fl}^{*}$. zeyl. 79 .

Convolvulus zeylanicus villofus pentaphyllos \& heptaphyllos minor, Pes tigrinus. Herm. lugab.184.t.187. ACE. bonor. II. p. 2. p. 362. t. 23. f. 2 .

Volubilis zeylanica, 1 es tigrinus. dieta. Dill. eltb. $42 \mathrm{y}$. t. 318. f. 411 .

Pulli-fchovadi. Rheed. mal. II. p. I2r. t. 5o.

Habitat in India.

agytin. 16. IPOMOEA foliis digitatis lupra glabris, caule pilofo, pedunculis multifloris. Hort. upf: 39 .

Convolvulus foliis digitatis pilofis, caule pilofo. Roy. lugd6. 429.

Convolvulus americanus pentaphyllus \& heptaphyllus major. Herm. lugdb. 183 . t. 185 . Raj. bijt. 1881.

Convolvulus ægypticus. $V$ e $\Omega$. alp. 73.

Herba non nominata. Marcgr. braf. 54 .

Habitut in America calidiore. ()

4rimaruefolic 17. IPOMOEA foliis digitatis glabris: foliolis feffilitas, caule læri.

Convolvulus foliis digitatis glabris, caule lavi. Roy. $\operatorname{lng} d 6.429$.

Convolvulus quinquefolius glaber americanus. Pluk. alm. $116 . t .167 . f .6$.

Habitat in America.

\section{POLEMONIUM.}

amlsum. 1. POLEMONIUM calycibus corolle tubo longioribus.

Polemonium, Fl. lapp. 86. Fl. juec. 175. Hort. cliff. I63. Roy. lugdb. 432 . Hall. belv. 490.

Valeriana cærulea. Baub. pin. 164.

a. Polemonium calycibus lanatis. Hort. ups. 40.

y. Polemonium foliis pinnatis, radicibus reptatricibus. Gron.

virg. 22.

Habitat in Europa, A tia, Americx eptentrionalibus. 4

2. PO. 
¿. POLEMDNIUM calycibus tabo corollæ brevioribus: vabrum. Quamoclit pinnnatuin credum, floribus in thyifum di: geftis. Dill. elth. 32x, t. 241 . f. 312 .

Iiabitat in Carolina citcriuris arenofis. B. Fufick.

3. POLEMONIUM foliis inferioribus haltatis, fuperio- dubim: ribus lanceolatis Gron. virg. 142.

Habitat in Virginia.

Facies aliena a Polcrasuis, genus mibi dubium.

\section{CAMPA.VULA.}

\section{a. Folits levioribus angufintoribus}

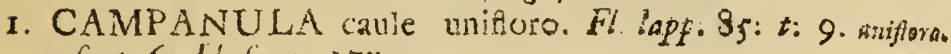
f. 5.6. H. faes: $17 \%$ :

Itabisut in alpitras Lopponicis. $\odot$

2. CAMPANULA canliculis unidoris, foilis cauinis palla ovatis erenatis, caly cibus cernuis.

Campanula alpina latifolia, Hore pullo. Banb: pin. 93. proar. 33. Burf. IV". 21.

B. Campanula folis fubrotundis. Bamb. pin. 84 prodr. 34 . t. $35^{\circ}$

Hivitat is Autria.

Radix filiformis, repess. Caules spitbarnai, eredi fien atuofi, filifiomes, roro raino wni diferove, coque florifero, Folia radicalic é caulina otata, obtufa, fubcrenata crenis dillarlibus, nuda, petiolate. Pedunculus terminalis. Flos cernuss; magnitsdine C. rotundifolia, calyce lievi. 3: floribss plaribus is fummitate caulis variat.

3. CAMPANULA faliis radicalibns renitormibus, cau-rotindifolis. linis linearibus. Fl. lapp. 83. Fl. Suec. 176. Hort.uph. G5. Rry: lugdt. 247. Dalit: parif: ó6

Campanúla minor rotundifolia vulgaris. Baub. pin. 93 . B Campanula minor rotundifolia alpina. Bumb. pin. 93. prodr. 34. $\therefore$. 34 .

भ. Campanula alpina linifolia cærulea. Baub. pin. 93. Fl. lapp: 84 . it. gotl. 229.

Habitat in Eurupe pafcris. 20

4. CAMPANULA foliis trietis radicalibus ianceolato-patula: ovalibus; panicula patula.

Campanula elculentz facie, ramis \& floribus patalis: Dill. clth. 68. t. 58.5 .65 .

Halitat in Angliz, Suecix arvis. of

$$
\text { L. } 2
$$


Rapunculus. 5. CAMPANULA foliis undulatis : radicalibus lanceolato-ovalibus, panicula coarcata. Hort. up.. 40.

Campanula folits radicalibus lanceolato-ovalibus, caule ramofifimo patulo. Hort. cliff. 65. Dalib. parij. 68.

Rapunculus efculentus. Baub. pin. 92.

Rapunculum. Dod. pempt. 165 .

Habicat in Helvetia, Anglia, Gallia. o

Folia lancelate. Raccnus terminalis: rami frmiles, brem viores, eredi. Pedunculi terni $\int a p i z s$, intermedio longiore. Caulis anguiatus, fialier.

decurrens. 6. CAMPANULA foliis caulinis lanceolatis ferratis de currertibus. Fl. fuec. 178.

Campanula minor rotundifolia, flore in fummis caulibus. Baub. pice.93.

Habitat in Finlandia.

perjucifolin 7. CAMPANULA foliis radicalibus oboratis, caulinis lanceolato-linearibus fubferratis fefilious remotis. $F$. Juec. 179. Dalib parif. 67 .

Campanula foliis lineari-ianceolatis crenatis, caule longiffimo fimplicifimo, foribus raris. Vir. cliff. 17 . Hort. cliff. 65. Roy. Imgáb. 246.

Rapunculus perficifolius, magno Bore. Bazh. pin. 93. B.Rapunculus nemorofus anguftifolius, magno Hore, major. Baub. pin. $9 j$.

Ilabitat in Europx feptentrionalis afperis. $z$

pyramidalis. 8. CAMPANULA foliis ovatis glabris fubferratis, caule erecto paniculato: camulis brevibus.

Campanula foliis ovatis glabris obfolete Cerratis, ramis brevifimis cauli approximatis. Vir. cliff. 17. Roy. lugdb. 246.

Campanula foliis ovatis margine cartilagineo crenatis, caule ramofifimo anguftato. Hort. cliff: cof.

Rapunculus hortenfis latiore folio: $f^{\circ}$ Pyramidalis. Baab. pin. 93.

Habitat - - - 5

americana. 9. CAMPANULA canle ramofo, foliis lingviformibus crenulatis margine cartilagineo. Roy.lugdb. 246.

Campanula minor americana, foliis rigidis, tlore cæruleo patulo. Herm. lugdb. 107.

Trachelium americanum minas, flore cæruleo patulo. Dodart. mern. 4. p. 111. t. III.

Habitat in Americs.

10. CAM- 
10. CAMPANUIA foliis lanceolatis: caulinis acute fer-lilifoiin. ratis, floribus paniculatis nutantibus. Hort. upf. 41 .

Campanula uricic foliis glabia, tloribus minoribus pendulis. Amm. rutb. 11. n. $1 \%$.

Hubitat in Tataria, Sibiria. $\delta$

11. CAMPANULA foliis rhomboidibus ferratis, fpica rbomboidalis iecunda.

Campanula foliis rhomboidibus ferratis, fpica unilaterali lubnuda. Hall. bolv. 491.

Campanula drabæ minoris bolis. Bazb. pin. 94. pro. dr. 36.

Rapunculus teucrii folio. Barr. ic. 79. 567.

Rapunculus alpinus, (teucrii folio) thomboidalis. Boce. muf. $75 . t .61$.

Habitat in alpibus Helvetix, Italix.

2. CAMPANULA foliis longis laciniatis fublyratis. lacinina.

Campanula graca faratilis, jacobæa loliis. Tournef. ibir.

1. p. 260.t. 260 .

Ilabitat in Gracia rupibus.

B. Foliis fabris latioribus.

3. CAMPANULA foliis ovato-lanceolatis, caule fim-latifulio. pliciflimo tereti, foribus folitariis pedunculatis, tructibus cernuis. vir. cliff. 17. Hort. clitf. 65. F\%. Juec. 180. Roy. lagió. 245 .

Campanula maxima, folies latiflimis. Bauh. pin. 94. Habitat in Anglia, Suecix montofis, Sepilius $z$

Caulis fimplicilinus, teres. Folia lariceolato-ovate, ferrata. Flores ex alis jwperioribus, folitarii, pedunculati. Calyces glabri. Fructus cernui.

14. CAMPANULA foliis coldato-lanceolatis, caule ra-rapunculoimofo, foribus fecundis pranfis. Fir. cliff. 17. Roy. des. lugdb. 246 . Daliz. parif. 66.

Campanula foliis ovatis cienatis, floribus per caulem uno verlu iparfis. Hort. cliff. $6+$.

Campanula hortenfis, rapunculi radice. Baub. pin. 94,

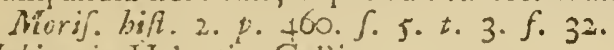

Llabirat in Helveria, Gallia.

15. CAMPANULA foliis ovato-ianceolatis fubcus (ca-bononienfis. bris feffitibus, caule paniculato. $t$

Campanula f. Cervicaria bononinentis, flore parvo. Bauh. bift. 2. p. So4. Marij. bift. 2. p. 46r. S. 5. t. 4. f. $3^{3}$.

Cam. 
Campanula folis lanceolatis leviter ferratis altcrnis, fioris thyrfo fpicato \& ad bain ramoro. Segz. ver. I.p. 176.

Habitat in Baldi Lejingenfum jugis, Bononix.

graminifolia I6. CAMPANTTLA foliis linearj-fubulatis, capitulo terminali. $\dagger$

Campanula alpina, tragopogi folio. Barb. pin. 94.

Irachelium, tragopogi folio, montanum. Col. phyt. 2. p. 25. Bauh. hift. 2. p. 802 .

Thachêlium minus gramineum cæruleo violaceum. Barr. ic. 332 .

Habitat in Italix montibus. Aprutil Solmone vicinis.

fpicat:. 37. CANPANULA hifpida, fpica laya: florịbusalternis, toliis linearibus.

Campanula foliis anchure, fioribus oblongis. Barh. pin. 94.

Campanula hirfuto folio angufo leviter ferrato, fincibus parvis fpicatis. Pluk. alre. 76. t. $153 \cdot f \cdot 3$.

Habitat in Valleila.

Radix crafitic digit:. Eoliaradicalia lineari-lanceolata, caulina finilia Jed breviara. Caulis pedalis, ranis atternis, terminatis fpica longifiria ex Florimusjellilbus, alternis, remotis, plurimis. Corolla fubcylindrsca. Planta caule, folsas, calycibus pilis albis bifpida.

Trachelinm 18. CAMPANULA caule angulato, folits petiolatis, calycibus ciliatis, pedunculis trifidis. $l n$. cliff. 16. F!. Suec. 181. Roy. lugdb. 245. Datib. parif. 65.

Campanula foliis radicalibus cordatis, calycibus ciliatis. Hort. cliff. 64 .

Campanula vulgatior, folis urticx, vel, major \& afperior. Baub. pin. o4.

Halitat in Europa. Sepibus. 2

Folia ovata, fuhcordata, petrolata, dentatr. Pedunculi trifidi, trifior

slonerak. I9. CAMPANULA caule angutato fimplici, florihus feffilibus, capitulo terminali. Vir. cliff. 16. 7 . Suec. 188. it. gotl. I96. it. Jaan. 306. Koy. bugd6. 245. Dalib. parif. $6 \%$.

Campanula folits lanceolato-ovatis crenatis, ramis cap:tnlo florali terminatis. Hort. cliff. $C_{4}$.

Campanula pratenfis, fiore conglomerato. Baub.pin. 94. 'Trachelium alpinum, toribus conglomeratis, foliis afarinæ rigidis \& hifutis. Herm: par. 235 . \%. 235. 
Hebitat in Anglix, Gallix, Sueciæ pratis aridis. $*$

Folia ovato-oblonga, fefilia, abtufinfcula. Flores 3 , fesfiles in alis faliorum; captiulum termixale.

20. CAMPANULA hifpida, floribus feffrlibus, capițulo Cer vierpras. terminali, foliis laiccolato-linearibus undulatis. it. reland. II . Fl. fssec. 183.

Trachelium altiffimum, foliis afperis anguftis, foribus parvis. Bauh. bift. 2. p. 801 . $t, 80 \mathrm{r}$. f. SOI.

Habitat in Helvetix, Svecix, Germaniz asperis fylvaticis.

28. CAMPANULA hifpida, racemo ovato-oblongo ter- thyrfoidss. minali, caule fimplicillimo, foliis lanceolato-linearibus.

Campanula foliis echii. Baub. pir 94.

Alopecurus alpinus quibusdam. Echium montanum dalechampii. Baut. hift. 2. p. 809.

Cervicaria major tenuifolia. Thal. hart. 32. t. 3. *

Habitat in alpibus Harcynix aliisque. 2

22. CAMPANULA capiulis quinquelocularithus teet is Mishinn. caiycis tinubus reflexis. Vir. cliff. I6. Roy. lugdb. 245.

Campanula calycibus a tergo lamellis quinque notatis. Hort. cliff. 64 :

Campanula hortenfis, folio \& flore ablongo. Bazh. pin. 94 .

Viola mariana. Dod. pempte. 163.

B. Campanula foliis anchufa, floribus oblongis. Baub. pin. 94. Hall. belw: 493 .

g. Campanula foliis echii, floribus villofis. Baub. pin.94. prodr. $3^{6 .} \cdot 3^{\text {6. }}$

Hubilat in Germanix, Italiæ nemeribus, హै

23. CAMPANULA capfulis trilocularibus teteis caly-fibirisu. cis finubus reflexis.

Campanula hirfuta ocymi folio caulem ambiente, fore pendulo. Bocc. Sic. 83, t. 45. Morif. bift. 2.p. 459.

f. 5. t. 3. f. 26 .

Habutat in Sibiria. D. Gmelin: Eo Mefianx.

Plant Caulis pedalis, angulatus, parum hispidus. $\mathrm{Pa}$ nicula rarior, laxa. Folia linearia, Semiaimplexicaitlia: caulina fiabre. Flores oblongi, parvi. Calyces bifividi. Varietas ladit coule fubdivifo, foinzs latioribus.

34. CAMPANUIA foliis obovatis crenatis, foribus al-jnxatitis, ternis mutantibus, capfulis quinquecarinatis. $\frac{1}{t}$

$$
\text { L } 4 \text { Cam. }
$$


Campanula cretica faxatilis, bellidis folio, magno fore. Tournef. inft. I I I. Barr. rar. 79. t. 8I 3 .

Trachelium faxatile, bellidis foiio, caruleum creticum. Boic. ins. 2. p. 76 . t. 64 .

Habitat in Cretæ jiopulis faxofis.

* Caule fubdivifo.

cantrients. 25. CAMPANULA foliis haftatis dentatis oppolitis petiolatis, capfulis quinquelocularibus.

Campanula foliis haltatis dentatis, caule determinate foliolo. Hort. cliff. 65. t. 8. Roy. lagdb. 247.

Campanula canarienfis regia $f$. Medium radice tuberofa, foliis finuatis cælis atriplicis amulis ternis circum caulem ambientibus, flore amplo pendulo: colore flammeo rutilante. Pluk. alm.76.t. 276.f. I.

Habitat in infulis Canariis. 2

fruticosa. 26. CAMPANULA caule fruticofo, foliis lineari-fubulatis, pedunculis longiffimis, capfulis columnaribus quinquelocularibus.

Campanula africana, ericæ folio, flore cerulco patulo. Herm. afr. 5 .

Habitat ad Caput b. Spei. 万

Speculum. \& 27. CAMPANULA caule ramofiffimo diffufo, foliis oblongis fubcrenatis, calycibus folitariis corolla longioribus, capfulis prifmaticis. Hort. upf. $4 \mathrm{I}$.

Campanula caule ramofo, foliis ovato-oblongis crenatis. Hort. cliff. 65 .

Campanula calycibus corollam fuperantibus, capfulis columnaribus. Vir. cliff. 17. Roy. lugd6. 247. Dalib. parif. 68.

Onobrychis arvenfis f. Campanula arvenfis ereeta. Baub. pin. 215 .

Habitat inter fegetes Europæ auftralis. $\odot$

7ybrids. 28. CAMPANULA caule bafi fubraniofo fricto, foliis oblongis crenatis, calycibus aggregatis corolla longioribus, caplulis prifmaticis.

Campanula arvenfis minima erecta. Norif. bift. 2. p. $45 \%$. 5 . $5 . t .2 . f .22$.

Speculum veneris minus. Raj. bift. 743 .

Habitat in Anglia, Gallia, inter Jegctes.

Differt a Speculo of $\int$ matre: Caule bafi tartum ramojo, erecto, fuperse vix ramofo, flricto; Floribus fe filibus $3 \int .4$ fimul, Corollis Sirpius in rudimento latentibus nec explicatis. Quin brec ex C. Spec. I nlim orta fit, dubius vix videtur. 
29. CAMPANULA canle fubdivifo ramofifimo, fo- Pentagonia. liis linearibus acuminatis. Hort. cliff. 66. Roy. lugds. 247.

Campanula pentagonia, ilore ampliffimo, thracica. Tournef. inft. I I 2.

Speculum veneris, flore amplisfimo, thracicum. Raj. hift. 742 ,

Liabitat in Thracia. (

30. CAMPANULA caule dichotomo, foliis feffilibus u- Eriuus. trinque dentatis. Hort. clifi. 65. Roy. lugdb. 247. Guett. ftamp. 2. p. 429.

Rapunculus minor, foliis incifis. Baub. pin. 92.

Erins 1. Rapunculi minimum genus. Columa pbytob. 122. $t .28$.

Alfue oblongo folio ferrato, flore cæruleo. Baub. bift. 3. p. 367.

Habitat in Italia, Galloprovincia, Monfpelii. ค

3I CAMPANULA caule fimplici, foliis cordatis den-perfolinte. tatis amplexicaulibus, floribus lestilibus aggregatis. Hort. ups. 40.

Campanula caule fimplicisimo, foliis amplexicaulious. Hort. cliff. 65. Roy. lugdb. 247. Gron. virg. 22.

Campanula pentagonia perfoliata. Morif. bift. 2. p. 457 . f. 5. t. 2. f. 23. Barr. rar. 83. t. II 33 .

Habitat in Virginia. $\odot$

32. CAMPANULA foliis lanceokatis dentatis hifpidis, caperfis. pedunculis longiffimis, capfulis Arigofis.

Campanula africana annuahirfuta, latis rerratisque foliis, flore magno violaceo. Comm. bort. 69. t. 35 .

Habitat ad Caput b. Spei. $\odot$

33. CAMPANULA foliis cordatis quinquelobis petio-bederncen, latis glabris, caule laxo. Dalib. parif. 68 .

Campanula cymbalarie vel hedere folio. Bauh. pin.9i. prodr. 34. Morif. bift. 2.p. 450.5.5.t. 4. f. I8. Pluk. pbyt. $23 . f . \mathbf{I}$.

Habitat in Anglia, Gallia, Hifpania locis umbrofis bumidinfculis.

34. CAMPANULA caulibus diffufis, folits fubovatis integerrimis.

Campanula faxatilis, foliis inferioribus bellidis, cxteris nummulariæ. Tournef. cor. 3. itin. 1. \$. 243. t.243. Habitat in Oriente. 2 


\section{ROELLA.}

ciliats. 1. ROELLA follis ciliatis: mucrone recto.

Roellia. Iort. cliff. 492.t. 35 :

Campanu!a atricana frutefcens aculeofa, flore violaceo.

Carnm. hart. 2. p. 7?. t. 30 .

Campanula africana humilis vilofa, fore exalbido languide purpureo. Seb. tbes. I p. 25. t. r6. f. 5 .

Aculcora mauritanica, eric foliis hirfutis rigidis infefto mucronc pungentibus. Pluk. alm. 8. t. 252 . f. 4 . Habitat in Mauritania, Athiopia. 2

retivilntn. 2. ROELLA foliis ciliatis: mucrone refexa.

Roella foliis imbricatis. Roy. lugdo. 248.

Campanula capitis bonæ 1pei, foliis reticulatis fpinofis. Pet.mis. 2r. f. Ir7.

Habitat an Caput o. Spei. 2

\section{PHYTEUMA.}

1) sticifora. ฯ. PHYTEUMA capitulo fubfoliofo, folitis omnibus lanciolatis.

Rapunculus foliis obtufis, fpica paucifiora. Hall. helv. 497. Rapunculus alpinus parvus comofus. Bauh. bift. 2. pa
\&11.

Habitat in alpibus Helveticis Styriacis.

hexrifoheri. 2. PHYTEUMA capitulo fubrotundo, foliis linearibus

ia. integerrimis.

Phyteuma foliis linearibus, floribus capitatis. Roy. lugdb. 248 ,

Rapunculus umbellatus, folio gramineo. Bauk. pin. 92. Rapunculu. fylveftris cæruleus umbcllatus. Thal. barc. 94. $t .8$.

Rapuntium alterum anguftifolium alpinum. Column, ocplor. 2. p 23. t. 26 .

Habita in alpibus Helvetix, Italia, Pyrenxis. \#

orbicularis. 3. PHYTEUMA capițule fubrotundo, folis ferratis: radicalibus cordatis.

Phyteuma foliis oblongis, (pica orbiculari. Guett. ftamp. I. p. 34. Dalib. farif. 69.

Rapunculus folio oblongo, fpica orbiculari. Baub. pin. 92. Morif. bift. 2.p. $463 \cdot \int .5 . t .5 \cdot f \cdot 47$.

Rapuntium montanum rarius corniculatum. Column. cepbr. I. t. 222. t. 224 . 
Habitat in alpibss Italix. Helvetix, Veronæ, Suffexix.

4. PHYTEUMA foica oblonga, capitilis bilocularibus, fpicnen. folliis radicalibus cordatis.

Phyteuma fnica oblonga nida, foliis caulinis lanceolatis lerratis. Amon. Acad. I. p. I 49 :

Phyteuma follis cordato-Ianceolatis, fpica oblonga. Guet. famp. I. P. 34. Dalib. parif. 69.

Rapunculus fpicatus. Boub. pin. 92. cæruleas. prodr. 32. t. 32 .

Rapunculus corniculatus fpicatus r.Alopecuroides, flore albo \& caruleo. Morif. bift. 2. t. 463. . . 5. t. 5. f. 46 .

Habitnt in Alpefribus Helvetix, Baldi, Angliz, Gallia.

$\therefore$ PHYTEUMA fafcicuio terminali feffili, foliis denta- comeso, tis: radicalibus cordatis.

Rapunculus alpinus corniculatus. Basb. pin. II 3 . pro: ár. 33. $t$ : 33 .

Trachelium petræum minus, Hon. bald. 326. t. 326.

Campanula fohrocochalus pervelvuna, foliorum ad oras infigniter denticulata. Pluk. alra. $77 . t$. I52. $f .6$.

Habitat is Baldi EF Tyrolenfibus montibus. o

6. PHYTEUMA floribus fpal fis, foliis pinnatis. Roy. pinuata. luggdi. 248.

Rapunculus creticus $\mathrm{r}$. Pyramidalis alte:a. Bash.pin. 93.

Rapunculus creticus, Petromarula. Bash.bift. 2., 8II:

t. 812.

Habitat in Creta.

\section{TRACHELIUM.}

ช. TRACHELIUUM. Hort. spf- $4 \mathrm{~T}$.

Trachelium tolus ovatis ferratis. corymbis compofitis, Vir. cliff. 17. Roy. lugdb. $24 \%$.

Trachelium folits ovatis ferratis, caule umbell terminato. Hort. cliff. 06.

Cervaria valerianoides carulea. B.ank. pin. 95.

Habitat in Italiz smbrofis. 8

\section{SAMOLUS.}

1. SAMOLUS Hort cliff. 51. Hort. uss: 42. Fl. Juec. valerandi. 165. Riny. lugd6. 249. Gron. airg. 23. Dalib. parif. 69. Angarits aquatica, rotundo folio non crenato. Bash. pin. 252. 
Aifine aquatica, foliis rotundis beccabungæ. Morif. bift.

2. p. $323 . \int \cdot 3 \cdot t .24 \cdot$ f. 28.

africarus. $\beta$. Samolus africanus, folio rotundiore. Walth. bort. 162. t. 23.

Habitat in maritimis Europa; Afi E Americæ borealis. $\delta$

Differt africana planta, Caule magis ramofo Eु firmiore; jed vi.x fufficiunt nota pro diftineta $\int p e c i e$.

\section{RONDELETIA.}

americann. 1. RONDELETIA foliis reflilibus.

Rondcletia arborefcens, tinifacic. Plum. gin. Is. Habitat in America. b

Arbufcule Folia oppofita, fefilia, lanceolota. Pedunculi communes folitarii, longiflimi, nudi, apice formantes corymbum dicbotomum; in caijus fingula dicbotom: Flos feffilis, cum involucro dipbyllo.

sfinticu. 2. RONDELETIA foliis petiolatis. Fl. zeyl. 80. Cupi. Rheed. mal. 2. p. 37. t. 23. Raj. bift. 1494. Habitat in Malabaria, Zejlona. 5

\section{BELLONIA.}

efparc. I. BELIONIA

Bellonia frutefcens, folio meliffxafpero. Plum. gen. 19. Habitat in America. 古

Arónfculre Folia oppofita, ovata, ferrata, Jubtus afpera: petiolisbrevilfimis. Flores in corymbum.

\section{CINCHONA}

afficinalis. I. CINCHONA. Mat. med. 7 r.

Quinquina. Cond. ait. parif. 1738 . Godofr.mat.2.p.180. Habitat in Loxa Peruvic. 5

\section{COFFEA.}

arabica. 3. COFFEA Hort. cliff. 59. Hort. ups. 4x. Mat. med. 70. Roy lugdb. 239.

Jafminum arabicum, lauri folio, cujus femen apud nos coffe dicitur. Fu 0 . act. $1713 \cdot$ p. 398. t. 7.

Evonymo fimilis xgyptiaca, fructu baccis lauri fimili. Bauh. pin. 498.

Bon. Alp. rgypt. 36. t. $3^{6 .}$

Habitat ix Arabia felici. 5 


\section{LONICERA.}

* Periciymena caule volubili.

ร. LONICER A floribus verticillatis terminalibus feffilibus, Capriff:iinm. foliis furmmis connato perioliatis. Hort cliff. 45. Hort. upf. 42. Virid. cliff. 14. Roy. lugdb. 237. Sautv. monsp. 139.

Periclymentim perfoliatum. Bauh. pin. 302.

Capitolium Italicuin. Dod. pempt. 4II. Hlortul.angl. t. 5. f. I. 2. 3 .

Habitat in Europa aufirali. 5

3. LONICERA fpicis nudis verticillatis terminalibus, fo-Semperviliis fummis connato-perfoliatis. reais.

Lonicera floribus capitatis terminalibus, folis fummis connatis, inferioribus perfoliatis, Hort. cliff. 58. Roy. lugdis. 237.

Pericly menum perfoliatum virginianum fempervirens $\&$ Horens. Herm. lugdb. 484. t. 483 .

Pericljmenum virginianum. Riv. mon. II6.

Mabitat in Virginia, Mexico. b

3. LONICERA capirulis ovatis imbricatis terminalibus, Periclymefoliis ommibus diftinctis. Hort.cliff. $5^{8} 8$. Hort. upp. num. 42. * Fl. Jucc. Ig1. Roy. Iugdb. 237. Dalib. parif. 69. Sauv. monfp. Ij9. it. Scann. 305 .

Periclymenum non perfoliatum germanicum. Baub. pin. 302.

B. Capifoliu:n non perfoliatum. Hort. angl. t. 6. E 8. f. I. 2.

Caprifolium germanicum, florc rubello, ferotinum. Tournef. inft 226.

Habitat in Europa media. 5

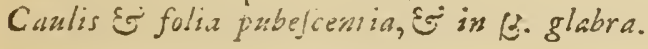

* Chamæcerofapedunculis bifloris,

4. LONICERA pedunculis bitoris, baccis dittinetis, fo-nigra. liis ferraris. Koy. lagdb. 238 . Sauv. monlp. 140.

Chamaceralus alpina, tiuctu nigro gemino. Baub. pin. 451.

Periclymenum rectum, folio ferrato. Bauh. bift. 2. p.10\%. Periclymenum reequm 2. Cluf. hit. 1. p. 58 . Habitat in Delphinatu, Gallia, Hciretia.

5. LONICERA pecunculis bithoris, baccis difinetis, fo-tatarics. lis cordatis ubruis. 2lort. $1 \mathrm{pl}$ l: 42 .

Chame- 
Chamaccrafus fruetu gemino rubro, foliis glabris cordatis. Amm. ruth. is 4 .

Habitat in Tataria. B

Xyloften 6. LONICERA pedunculis biforis, baccis diftintis, foliis integerrimis pubefcentibus. Roy. $\operatorname{lug} d b .238 . \mathrm{F} \%$ juec. Ig2. Daliv. parif. 69. Sauv. monfp. I 40 :

Lonicera pedunculis biftoris foliis ovatis obtulis integris. Hort. cliff. 58 .

Chamæcerafus dumetorum, frudu gemino rubro. Baub: pin. 451 .

Xylofteum. Dod. pempt. $4 \mathrm{I} 2$.

Habitat in Europ frigidioris fepibus. I

2yrenaitn. 7. LONICERA pedunculis bitloris, baccis diftinctis, fo: liis oblongis glabris.

Lonicera pedunculis bifforis, baccis ditinetis, floribus infundibuliformibus, ramis divaricatis. Roy. lugsib. 238.

Xylofteum pyrenaicum. Tournef. inft: 609. Magn, bort. 209. t. 209 . Raj. dessdr. 29 :

Habitat in Pyrenzis.

Differt a precediute Corollis regularibus, Ramis divaricatis, Folits glabris:

strigena; 8. LONICERA pedunculis bifioris, baccis coadunatis didymis:

Lonicerà pedunculis bifloris, foliis ovatis acutis integris. Hort. cliff. 5. Sa Sur. mon?p. 140.

Lonicera baccis bifloris concretis, floribus bilabiatis. $R_{0 y}$. lugdb. 238 .

Chanxcerafus alpina, fruetu rubro genino. duobus punctis notato. Baub. pin. $45 \mathrm{I}$.

Periclyinenum rectum quartum. Claf. bift. 1. p. 59 .

Hatitat in Alpibus Helveticis, Pyrenaicis, Allobrogicis. $b$

csinlea, 9: LONICERA pedunculis bifloris; baccis coadunatoglobofis, llylis indivifis:

Lonicera pedunculis bifloris bilabiatis, bacca fingulari globofa integerrima. Roy. lugdb. 239

Chamæcerdfus montana, fructu fingulari cæruleo, $B a u b$. pin. $45 \mathrm{I}$.

Periclymenum rectum, fruetu cxruleo. Cluf. pon. 85 . Baub. hift. 2. p. I08. Raj, bijt. I 492.

Habital in Helvetia: 
* Caule erecto pedunculis multifloris.

-o. LONICERA foicis terminalibus, foliis ovato-oblon-marilau.ics gis acuminatis diftinctis feffilibus. Gron. virg. $\dot{y}_{4}^{2}$.

Periciymenl virginiani flore coccinea planta marilandi-

ca, fpica erecta follis conjugatis. Raj. deralr. 32. Ciatesb. carol. 2. p. 98.t. 78.

Haúltat in Virginia, Marilandia, Carolina. 5

II. LONICERA capitulis iateralibus pedunculatis, foliis symphori. petiolatis.

Lonicera pedunculis axillaribus capitatis, foliis pctioiatis. Hort. cliff. 58. Ruy. lig gdv. 237. Gron. virg. 23.

Symphoricarpos follis alatis. Dill. elth. $371: \% .278 . f$. 360.

Viris isza caroliniana, foliis fubrotundis hirfutis. Hor tut. aingl. 85.t. 20 .

Hatitat in Virginia, Carolina. b

12. LONICERA perunculis multifloris, involucris pen-parsitita. taphyllis, foliis ovato-lanceolatis petiolatis. Fl.zeyl. 83 .

Periclymenum furrectum, perfica foliis, made:alpata: num. Pluk. alm. 287 . t. 212. f. 5 .

Itticanni, Rbeed. mal. $7 . p_{0}-$ ti 27.

Habitat in India orientali. 5

13. LONICERA racemis !ateralibus fimplicibus, floribus albav pendulis, foliis integerrimis.

Lonicera racemis lateralibus fimplicibus laxis, floribus op: potitis pendulis, geniculis compreffis. Hort. cliff. 496 .

Periclymenum racemofum, fore flavefcente, fructu niveo. Dill. elth. 306. t. 228. f: 295 .

Jafminum folio myrtino acuminato, aliorum adminiculo fe fuftentans, flore albicante racemofo. Sloan. jam: 169. bift. 2. p. 97. t. I88. f. 3. Raj. dendr: 64.

Habitat in Jamaicx, Barbados locis confragofis. B

14. LONICERA racemis terminalibus, foliis ferratis. Diervillor

Diervilla. Hort. cliff. $63 . t .7$.

Diervilla acadienfis fruticofa, tore luten. Tosirnef.act. 1706. t. $7 . f .1$.

Habitat in Acadia, Noveboracu. 5

65. LUNICERA corjmbis terninalibus, foliis ovatis a-cyrymbefo. cutis.

Periciymanum foliis acutis, foribus profunde diffectis. Fewill. pernv. 2. p. t. 45 :

Habitat in Peru. क 


\section{TRIOSTEUM.}

perfolintum. I. TRIOSTEUM floribus verticillatis feffilibus.

Triofteolpermum, latiore folio, Hore rutilo. Dill. elth. 39.4. $t: 293 \cdot f: 378$. Hibitat in America Septentrionali. 2

angufifol. 2. TRIOSTEUM fioribus oppofitis pedunculatis. Lonicera humilis hirfuta, caule obfolete rubente quadrato, foliis lanceolatis adverlis, hore luteo ad alas unico. Gron. virg. 143.

Periclymenum herbaceum rectum virginianum. Pluk. alm. 287 . t. 104. f. 2.

Habitat in Virginia. 4

\section{MORINDA.}

smbellate. 1. MORINDA ereeta, foliis lanceolato-ovatis, pedunculis confertis. Fl. zejl. 81.*

Habitat in India. 5

citrifolia. 2. MORINDA arborea, pedunculis folitariis. Fl. zeyl. 82.

Coda-pilava. Rbeed. mal. I. p. 97. t. 52. Raj. bift. I 442 .

Habitat in India. 5

Royoc. 3. MORINDA procumbens. Hort.cliff. 73. Roy. lugdb. I8\%.

Morinda americana hurnifufa laurifolia. Vaill. af. 722. P. 275 ;

Royoc humifufum, fructu cupreflino. Plum. Spec. II. Periclymenum americanum e cujus radice fit atrameistum. Pluk. alm. 287, t. 212. f. 4 .

Habisat in America calidiore. $b$

\section{CONOCARPUS.}

ereits. I. CONOCARPOS ereeta, foliis oblongis.

Conocarpus. Hort. cliff. 485 .

Alnus maritima myrtifolia coriariorum. Pluk. alm. I8. t. $240 . f .3$.

Alni fruetu laurifolia arbor maritima. Sloan. jam. I 35 .

bit. 2. p. 18. t. 161. f. 2. Raj. dendr. II.

Rudbeckia laurifolia maritima. Amm berb. $58 \mathrm{I}$.

Habitat in Jamaicx, Bermudienfum, Brafilix maritimis. b 
2. CONOCARPUS procumhens foliis fubmotndis. procumbens. Rudbechia lupina. follis tubrotundis. Amm. berb. SS $^{\mathrm{S}}$. Uabiat is Cuba.

\section{MLSS ANDA.}

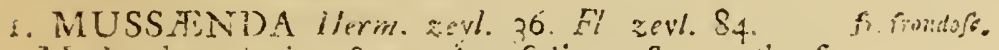
Mullerda zeylanica, nore rubro, folio ex florum thyrfo piodeunie albo. Burm. zeyl. 16r. 1.76.

Belilla. Rheed. mal. 2. p. 27, t. 18. Raj. bijl. 1493. dendr. 126.

fiabilat in India. b

\section{MIRABIIIS.}

r: MIRABILIS. !'ort. diff. 53. Hort.upj.43. Fl. 2ul. Fatiap 35. Matméd. 76.

Nietage. Kav lagdb. 4i7. Culn. noted. 29.

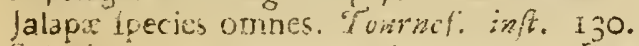

Solanim nexiocanum, tlore parro. Baub. pin. 168. jrodr. Gi.

Q. Solanum mexiocanum, flore magno. Bauh. pin. 168.

Admirabilis peruviana. Claf. bat. 2. p. 8\%.

Labitut in India zetrapue. $\%$

\section{CORIS.}

1. CORIS. Hort. cliff. 68. Hort. nof.46. Mat. med. 80. monpelienfis Roy. lugdb. 304. Sauv. munjp. 46.

Coris carulea inaritina. Bash. pin. 280.

Symphytum petreum. Cuni. epit. 699.

Habitat in Europa auftrais arenofis maritimis.

\section{VERBASCUM.}

VERBASCUNi toliis decurrentibus utrinque tomen. Thitufus.

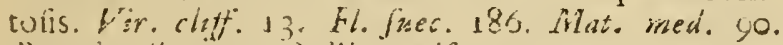
Roj. lugitb. 421 . Dalib parif. 75 .

Verbalcum caule timplici fuperne foribus fefjlibus clasato, foliis utrinque lanigeris. Fiort. cit, is

Verbaicum mas latifolium luteum. Lazh. jom. 239.

l'erbaicun latius. Dud. peinpt. 143.

Ulabitat in Europa glaicolis flerilitis. o

IERBASCUM foliis cuneiformi-oblongis. Hort. Lyobnitis. "ipl. 45 .

Verbafcum foliis oratomacutis futtus villofis crenatis, jor.

cis laxis lanerabus \& terminaibus. Hort. cliff. it. Rov. Ingdb. 421. Dalib. parif. $7 \mathrm{I}$. 
volicum puivernientum, Horc luteo parvo. Baub. bift. 3. p. 312 . Kat. hifi. 1094.

Terbafin mas, angutioribus follis, forious palidis. Baun.pir. 239 .

B. Verbatcuin lychnitis, fiore albo parvo. Fuab.pin. 240. Verbatcum candidum temina. Fucb. bift. 847.

v. Phlomis mas aites. Lob. ic. $5 \sigma_{2}$

Habitat in Europa ruderatis cnltis. $\pi$

nigrim. 3. VERBSCUM folis cordato-oblongis petiolatis. $M \pi t$. med. $9 \mathrm{I}$.

Veruafcum foliis ovatis crenatis fubtus tomentofis, cau-

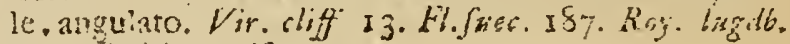
421. Baike parif. 91.

Verbafcrin tolijs ovatis fubtus incanis crenatis, fpica iasa rarius ranola. Hort. cliff. 54.

V'erbalcum nigrum, fore ex luteo purpurafecnte. Bakb pin. 2 p.

Habitat in Europa ad pagos, was. \&

Blattaria, 4. VERBASCUM foliis amplexicaulibus oblongis glabris, pedusculis folitariis. Hort. $u p f .46$.

Vcrbafcum annmum, foliis oblongis finuatis obtufis. Hort. cliff. 15. Guet. ftamp. 2. p. 309 .

Verbafcum foliis giabris ferrato-dentatis, radicalibus finuatis. Roy. lugdb. 421. Dalib. parif. 72. Saur. mors $/ p$. 270 .

Blattaria lutea, folio longo laciniato. Baub. pin. 240.

Habitat in Europic enftralioris locis argillaceis. $\odot$

Arsurus. r. VERBASCUM foliis lyrato-pinnatis.

Vejbafcum humile creticum laciniatum. Baub. pin. 240.

Verbafcum brafica folio. Column. ecpbr.2.p.81. t. 82. Habitut in Creta.

fmintmu, 6. VERBASCUM foliis radicalibus oblongis finuatis undatis tomentolis, caulinis cordatis amplexicaulibus nudiufculis.

$V$ crbarcum foliis pinnato-finuatis hirfutis: fubtus tomentofis. Roy. lugdb. 421. Saur. moñp. 276.

Verbaicum nigrum, foliis papaveris corniculati. Baub, pin. 240. Camer. bift. 403. t. 403.

Q. Terbafoum gracum fruticolum, folio finuato candidis. fimo. Futrn. cor. 8. itin. I. p. 335 . t. 335 .

Habitat Monfpelii, Florentix.

pbaniceum. 7. YERBASCUM foliis ovatis nudis crenatis radicalibus, caule fubnudo racemolo.

Ver- 
Verbafcun foliis ovatis crenatis nudis ícabris, caule ramofo. Hort cliff. 55 .

Blattaria purpurea. Bauh. pix. 241?

Italitat in Europs auftrali, Bohcmia, Lufitania inferiod re. 4

8. VERBASCUM foliis Incifis nudis, caule foliofo, ca- Osbeckli. lycibus lanatis, pedunculis biforis.

Habitat in Hifpania. Osoeck.

9. VERBASCUM foliis lanatis radicalibus, fcapo nudo. wymni,

Cortura foliis ovatis feffilibus. Hort. iliff. 50. Roy. lugall. 417 .

Sanicula alpina, foliis boraginis, villofa. Baub. pin. 242. Auricula uifi myconi. Dalech. bift. 837. Batb. hifi. 3.p. 869 .

Habitat in Pyrenzorum neinorofis.

\section{DATURA.}

1. DATURA pericarpiis fpinofis ereetis ovatis. Hont. Strumontma cliff. 55. Hort "tf. 43. Fl. Juec. $1 \overline{8}_{5}$. Gron. virg.2j. Rov. lagdb. 422. Dalib. parif. 70.

Solanum tetidum, pomo fpinoio oblongo, flore abo. Bauk. pin. I68.

Solanum fativum, pomo fpinolo oblongo, flore albo. Baub. pin. 168.

Tatula. Cam. epit. 176.

Habita: in America, nunc vulgaris fer Europain. ()

2. DATURA pericarpiis fpinofis nutantibus globofis, Metel. Hort. cliff. 55. Hort. apf. 44. Fl. zeyl. 86. Mat: med. 85. Roy. lxgdb. 422.

Solanum pomo fpinoforotundo, longo flore، $B a w h, p i n$. 168.

Hummatu. Kheed. val. 2. p. 47, t. 28.

Habitat in Alia, Africa. $\odot$

3. DATURA pericarpiis inermious nutantibus, caule ar- miorea boreo.

Stramonioides arboreun, oblongo \& integro folio, truetu lavi. Fewil. peruz. 2. p. t. fo. $^{6}$

Habitat in Pcris, b

HYOSCY AMUS.

1. HYOSCIYAMUS foliis amplexicaulibus. Hort. clitf. nizer, 16. Fi. Suec. 18 f. Mat. med. 86. Roy. lagd6, 422. Dalib. parif. 7o. Hall. belv. 512. 
Hyofcyamus vulgaris \& niger. Bastb. pin. r6g. Habitat in Europa ruderatis pisgguibss. $\delta$

albus. 2. HYOSCYYAMUS foliis petiolatis, floribus feffilibus.

Hort. cliff. ; 6. Roy. lugrab. 422. iauv. nosifp. 275. Hyofcyamus albus major. Batib. pin. IGg. B. Hyoficyamus albus minor. Baxh. pin. I69. Hyufcyanus albus vulgaris. Cluf. bilt. 2. p. II 8 Slabitat in Luropa anftrali. $\odot$

wren. 3. HYOSCYAMUS foliis -ctiolatis, foribus peduncrlaris. Hort. cliff. 56. Roy. lugdb. 422 . Hyolcyamus creticus luteus major Baub. pan. IGiy

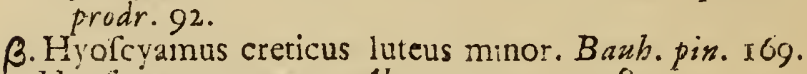

Hyolcyamus aureus. Alp. exat. $99 \cdot t .98$.

Habitat-in Creta. $\odot$

pusillus. 4. HYOSCYAMUS foliis lanceolatis fubdentatis, calycibus fpinolis. Hort. up $^{\mathrm{s}}$. 44 .

Hyofcyanus foliis lanceolatis. Hort. cliff. 56. Roy.lugdb. 422 .

Hyolcyamus pufillus aureus americanus, antirrinin foliis glabris. Pluk. alm. I88. t. $37 . f .5$.

Habitut in Perfia. ()

abyfalodes. 5. HYOSCY AMUS foliis ovatis integerrimis, calycibus intlatis fubglobofis. Hort. ups. $44^{*}$ *

Habitat in Sibiria. 2

\section{NICOTIANA.}

Tabackm. I. NICOTIANA foliis lanceolatis. Hort. cliff. 56. Hort. JipS. 45. Mat. med. 87. Roy. lugdb. $42 \%$.

Nicotiana major latifolia. Bauh. pin. 169.

Blennochoes. Reneal. Jpec. 37. t. $3^{8}$.

Habitat in America, nota Europieis ab $1560 . \odot$

sufica. 2. NICO'TIANA foliis ovatis. Hort. cliff: ;6. Hort.upf. 45 . Roy. lugdb. 423 .

Nicotiana minor. Baub. pin. I 70 .

Pachyphylla. Reneal. Spec. 40.

Habitat in America, nunc in Europa. $\odot$

paniculata. 3. NICOTIANA foliis cordatis, floribus paniculatis: tilbis clavatis.

Nicotiana minor, folio cordiforum tubo floris pralongo. Fewill. peruv. I. p. 717.t. 10. 
Habitat in Peru. $\odot$

Diffitet a fecunda Caule teneriore, altiore, paniculato. Corollis angulfiuribus: limbo brevifimo, obtufiffimo, tubo longo clavuto; calycibus capfulisque acutis.

4. NICOTIANA foliis cordatis, corollis racemofis giutinofa fubringentibus, calycibus inæqualibus.

Halitat in Peru. D. B. '7u/jeu. $\odot$

Folia magis cordata, glatixufa. Flores in racemos paitcor, lingar. Corclite ferme speciei prima, fed magis izarquales Ë ferc ringentesfauce biantes. Stanina ad laius faperius inficiar. Calycis una iacinia reliquis duplo major.

\section{MANDRAGORA.}

1. MANDRAGORA Hort. cliff. gr. Ros. lugdb.423. officinartin?, Mat. ned. 83 .

Mandragora fructu romido. Bauh. pin. 169.

Mandragoras. Dod. pempt. 457 .

Habitu in Hifpanie, Italix, Creta. Cyclacum apricis.

\section{ATROPA.}

I. ATKOPA cale herbaceo, foliis ovatis integris. Bella สоนнน, Atroba. Hort. cliff. 77. Hort. ups. 45. Koy. lugdb.423. Soianum intamoceratis. Bauh, pin. 166. Solanum lethale. Cluf. bift. 2. p. S6. Habiat an Auttrix. Anglia montibus fylvofis. \&

2. ATROPA foliis inuato-angulatis, calycibus claufis 2-phyfalodes. cutungulis.

Alkekengi ampin tlore violaceo. Few.perur. 724,t. I6. IIabitat in Pcru. D. B. Fufjere. $\odot$

Radix fibroja, aisma. Caulis bipedalis, patulus, erectus, ramis anguiatis. Folia alterina, glabra, oblonga, per petiolam decurrentia, obtufe finuesa (Daturx). Pedunculi and latus petioloram folitarii, nadi, unittori. CaIrx ceatus, baffe excifus, angulis quinque comprefis, profunde 5partitus: fotiolis fagittato-uitains. Corollacampanulaín, parum quingue hisu, obtufa. Limbo eredo, fubplicuto, ciarulefciete. Stamina s, fätulata, bufi dilatuta, Subiallofia, crolla longe breviora, fuperne divergentia. Anthere ereita. Germen intra bafin ftamisum. Stylus friformir, longitudine flaminum. Stigma iv 3 
eafitatum. Fruetus cernuss, tectus calyce majors, quinquarrulari augulis comprelpis ar be clnstis, bejt mucronatis. Bacca exfucca, 3. 4. $\int$. 5- Tocularis; fe. mina $\int u b r n t u s c i a$, comprefia. Media inter sitropim हु" Pbyfalidem; a Pbyfalide differt figura corolle, fami-

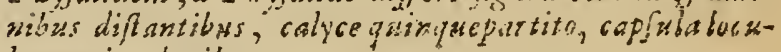
lamentis pluribus.

gimefens. 3. ATROPA caule fruticofo.

Bella-donna frutefens rotundifolia hifpanica, Tournef. isft. $7 \%$. Barr. ic. 1173 .

Habitet in Hipania $b$

Habitzs go omina Phyläidis fomnifera, ut limites generwm in jolo saby ce conflifast.

\section{PHYSALIS.}

ieminitis. 1. PHYSALIS caule truticoro, ramis redis, floribus confertis.

Phylalis caule iruticelo terti, folis ovatis integerrimis, foribus confertis. Horta cliff. 62. Roy. lugdb. 426.

Solsmum fomniferum verticillatum. Basth. pin. 106.

Solanum fomniferum. Clus bit. $2, p .85$.

Habitat in Mexico, Creta, Hifpritia. b

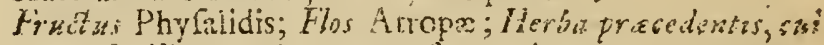
ita firsilis, ut vix genere coparat quent.

Fismom. 2. PYYSALIS canle truticofo, ranis fiexuofiz, floribus conieris.

Enccifers indica, foribus ad foliorum exortus, frustu julcato decapyreno. $R$ aj bih. $\sigma_{j 2}$.

Pevetil. Reced, mal. 4. p. II 3.555.

Habitar in India.

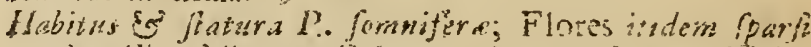

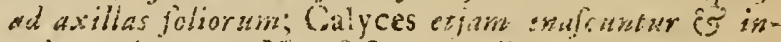

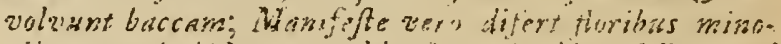

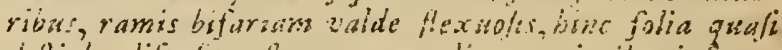

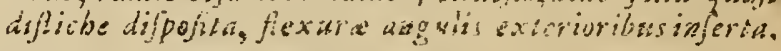

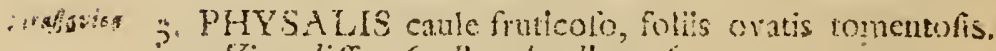
lir cliff. 16 . Roy. iugdb. 436 .

Phyralis cante percuni, follis ovatis lollariis, ramis an-

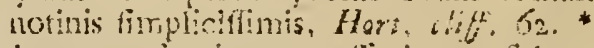

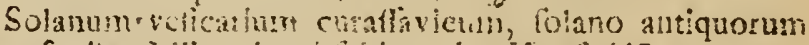

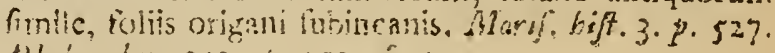

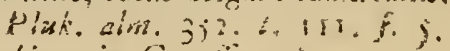

llationt in Coldilias to 
4, PHYSALIS foliis cordatis integerrimis obtufis fcabris, vifcosa. corollis glabris.

Phy falis radice perenni, foliis cordatis obtufis. Itort.cliff. 496. Roy. lugdb. 426 Grow. virg. 24.

Alkekengi bonarienfe repens, bacca turbinata vifcofa. Dill. clib. II. t. Io. f. Io.

Ilabitat in Virginia, Bonaria. \#

5. PHYSALIS foliis geminis.

Alkekergi.

Phyfalis caule timplici aunuo, foliis integerrimis geminatis, floribus folitariis. Hort. cliff. 62. Hort. up 4.49 . Mat. med. 93. Dalib. parif. 73 .

Phylalis radice perenni, foliis lanceolato-cordatis. Vir. cliff. 16. Roy. lugdb. 426.

Solanum vclicarium. Baub. pin. 166.Dod. pempt.454. Hobitat in Italia. $*$

\section{* Annua.}

6. PHYSALIS ramofifina, ramis angulatis glabris.

Phyfalis annua ramolifima, ramis angulolis glabris, foangulata liis dentato-ferratis. Hort. cliff. 62. Hort. ups. 50. Fl. zeyl. 97. Roy. lugdb. $42 \%$

Halicacabun f. Solanum indicum. Comm. bort. I. $p$. 70. t. I\%.

Solanum reficarium indicum. Baub. pin. $x 66$.

Alkekengi indicum glabrum, chenopodii folio. Dill. elth. 13. t. I2. f. I2.

B. Alkekengi indicum glabrum, capficii folio. Dill. elth. I2. t. XI. f. IX.

Habitat in India utraque. (

7. PHYSALIS ramofifima, foliis villofo-vifcofis, pe- pubefsens, dunculis nutantibns.

Phyfalis annua ramofifima, ramis teretibus pubefcentibus: geniculis nodofis. Hort. cliff. 62 .

Alkekengi virginianum, fructu luteo. Fewill. peruv. 3 . p. 5. t. 1 .

Solanuin veficarium virginianum procumbens annuum, folio lanuginofo. Morif. bift. 3. p. 527. S. 13.t. 3. f. 24 .

Habitat in India utraque. $\odot$

Fruetus villofo-vifcofus, nec glaber; maculac corollix fufer, nec pallidac. Pedunculi nutrntes, ncc cerrui.

8. PHYSALIS ramofiffima, pedunculis fruetifcris folio minima. longioribus. Hort. cliff. 62. Roy. lugd6. 427. 
Solanum veficarium indicum minimum. Herm. lugdb. 569. t. $57 \mathrm{r}$.

Pee-inota-inodien. Kbeed. mal. 10. t. 140. f. 71 . Habitat in Indix aridis fordidis.

truinça. 9. PHYSALIS ranolifima, divaricationibus farinaccogerminantibus.

Habitat in America. $\odot$

Facies untecedentium 5.6.7. 8, sed antherx flave, nec cerulex; rami tereves: Jupra plani villofi; Folia villofovifcofa; Alie ramificationum viridi quafi pruina germinant.

\section{SOL A NUM. \\ * inermia.}

verbafcifoli- 1. SOLANUM caule inermi fruticofo, foliis ovatis toMis. mentofis integerrimis, umbellis compofitis.

Solanum arborefcens, verbafci folio. Plum. Spec. 4 . Solanum maxime tomentofum, fpinis carens, virginianum. Pluk. alm. 3; I.t.316. f. I.

Habitat in America. 5

gnineenfe. 2. SOLANUM caule inermi fruticofo, foliis ovatis integerrimis, pedunculis lateralibus filiformibus.

Solanum caule inermi perenni, foliis ovatis integris, floribus ad batin ramulorum confertis. Ray. Ingab. 424.

Solanum africanum lignofum, folio atroviridi angufto oblongo obtufo. Boerh. lugdb. 2. p. 69 .

Habitat in Guine:a, b

PsendoCap- 3. SOLANUM caule inermi fruticofo, foliis lanceolajicum. tis repandis, umbellis leffilibus.

Solanum caule inermi fruticofo, foliis ovato- lanceolatis integris, floribus folitariis. Hort.cliff. 61. Hort. ups. 48. Roy.lugdb. 424 .

Solanum fruticofum bacciferum. Baub. pin. 6r.

Preudocaplicum. Dod. pernpt. 718.

Habitat in Madera. 5

dipbyllsm. 4. SOLANUM caule inermi fruticofo, foliis geminis . altero minore, floribus cymofis.

Solanum caule inermi perenni, foliis ovato-lanceolatis geminis: altero minimo. Vir. cliff. I5. Hort. cliff. 61. Roy. $\operatorname{lug} d b .424$.

Solanum americanum ftrychnodendro accedens, fru. ctu- 
Su medio quafi fiffo. Pluk. alm. 349. t. I11. f.4. mala.

Habitat in America? b

5. SOLANUM caule inermi frutefcente flexuofo, foliis Duliamara. fiperioribus haltatis, raccmis cymofis. Hort. cliff: 60 . Fl. Sutec. 189: Mat. med. 95. Koy. lugitb.424. Dalib. paris. 73 .

Solanum f́candens f. Dulcamara. Baxh. pin. 167.

B. Solanum dulcamarum africanum, foliis cralfis hirfutis. Dill. clth. 365 . t. $273 . f .352$.

Habitat in Europx fepibus bumentibus. b

6. SOLANUM caule inemi frutefente Hexuofo, foliis quercifolium o.longis latcribus finuatis, racemis cyınofis.

Solanum foliis quernis. Few. peruv. $722 . t .15$.

Habitat in Peru. D. "7ulfieu. b

Habitus S. Dulcamarc; Rami angulati. Folia ovatooblonga, in petiolum decurrentia, zenofa, glabra, lateribus pinnato-finuata. Pedunculi rainofi. Corollæviolace a , obtufsores quam Dulcamara: maculis duabus pallidis ad bafin. finguli lobi. Antheix flav.e, ftylo breviorcs.

7. SOLANUM caule frutefcente fubincrmi, foliis cu-bonarienfe. nciformibus finuato-repandis.

Solanum bonarienfe arborefcens, papas Horibus. Dill. elth. 364. t. 272 . $f 351$.

Hnóitat in agro Bonarienti. क

Folia Ef Flores maximi; Aculei aliquot in tenclla planta, non vero in adulta.

8. SOLANUM caule inermi herbaceo, foliis pinnatis in- tuberofun. tegerrimis. Vir. cliff. I 5. Hort. cliff. 60. Hort. ups 43. Roy. lugdb. 423. Dalib. parif. 73.

Solanum tuberofium efculentum. Baub. pin. 167.prodr. So. t. 99 .

Hubitat in $\mathrm{Pclu}$. $\odot-z$

9. SOLANUM caule inermi herbaceo, foliis pinnatis in- Iycoperficum cifis, racemis limplicibus. Vir. cliff. 15. Hort. cliff. 6o. Ruy. Iugd'b. 423 .

Solanum pomiferum, fruetu rotundo ftriato molli Baub. pin. 107.

Poma amoris. Came epit. Szr.

$\beta$. Solanum raccmofum ceraforum forma. Bakb.pin. 67. prodr. 90.

Mabitat in America calidiore. $\odot . \beta z$ 


\section{PENTANDRIA MONOGYNIA.}

peruviarur. ro. SOLANUM caule incrmi herbaceo, foliis pinnatis incifis, racemis bipartitis reflexis, baccis fubpilofis.

Lycopcricun pimpinella folio. Few. peruv. 3.p. 37. t. 25.

Habitat in Peru. D. FuObiex. 2

montanum. II. SOLANUM caule incrmi herbaceo, foliis fubcordatis repandis.

Solanum tuberofum minus, atriplicis folio, vulgo $\mathrm{Pa}$ pa montana. Few. peruv. 3.p. t. 46.

Habitat in Peru. 4

nigrus. 12. SOLANUM caule incrmi herbaceo, foliis ovatis dentato-angulatis, umbellis nutantibus.

vulgare. Solanum caule inermi herbaceo, foliis ovatis angulatis. Vir. cliff. 15. Hort. cliff. 60. Hort. upf.48. Fl. Juec 188. Mat. med. 94. Gron.virg. 24. Roy. lugdb. 433. Dalib. parif. 72.

Solanum officinarum. Baub. pin. 166.

patulum. $\quad B$ - rainis teretibus glabris, foliis integerrimis glabris.

Solanum procerius patulum vulgaris truetu. Dill. eltb $367 . t .275 \cdot f_{0} 355$.

villofum, $\gamma$. - ramis teretibus villofis, foliis angulatis fubrillofis Solanmm annum hirfutius, baccis luteis. Dill. elth. 366 t. 274. f. 353 ,

guineenfe. $\delta$ - ramis angulatis dentatis, foliis integerrimis glabris Solanum guineenfe, fruetu magno inftar cerafi. Dill elth. $366 . t .274$. f. 354 .

virginicum \& - rainis angulatis dentatis, foliis repandis glabris.

Solanum nigrum vulgari fimile, caulibus exafperatis. Dill. elth. $368, t, 275$. f. 256.

pudaicum. 2. - ramis aculeis incurvis, folizs repandis nudis.

Habitat in Orbis totius cultis. $\odot$

Tot varietates $\beta, \gamma, \delta, \varepsilon . \zeta$. videntur : $\int \mathcal{c}$ bybrida pro. les.

\section{S. Spinola.}

Melongend. I3. SOLANUM caule inerml herbaceo, foliis ovatis tomentofis integris, calycibus pipinolis.

Solanum calycibus aculeatis, foliis ovatis integerrimis to* mentolis. Hort. cliff. 6r. Hort. upf. 49. Fl. zeyl. 93. Roy. lugdb. 426.

Solanum pomiferum, fiructu oblongo. Baub, pin. $16 \%$ Mala infana. Dod. pempt. $45^{8}$.

Hahitat in Afia, Africa, America. 


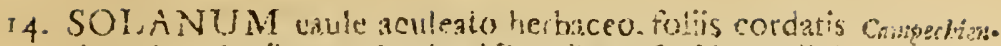

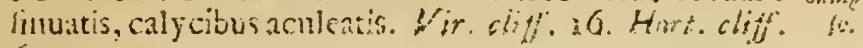
Cis.

Solanum campechlents, calycibus elhinatis. Dill. skh. $36 \mathrm{r} \cdot \mathrm{t}: 2.6 \mathrm{~S} \cdot \mathrm{f}: 377$

Habitat in America ad from Campechiente.

5. SOLANUM caule acnluato herbaceo, foliis cordatis momofut. quiriquelobis: utrinque vliotis aculcatis. Wir. clife. 5 . Hort. cliff. 61. Hort. upf. 49. Koy. lugdt. 425 .

Solanum barbadenfe fpinotim animum, frtedu aureo rov tumdiore pyri parvi inverfi forna \& magnizudine. P!sk. alin. 350.50225 .6$.

Fabiat in Yirginia, Barbagos. O

16. SOLANUM canic aculcato hernace, folis pinnati. virgminum fidis: lacinits finuatis obtulis, calycibus aculetis. Rey. iugdb. 425 .

Solanum amcricanum laciniatun finofifimam. Dith. elib. $360 \cdot t \cdot 368 \cdot f_{0} 267$.

Solanum anuwum virginiaum nigricans fpinoffimum, Hore cervileo. Wluk. alm. 351. $x_{0} 62, j .3$.

Habirat in America. (?)

17. SOLANUM cavie aculento frutcofn, folits angula-indian. tis tomentufs integerrimis: aculeis merinque rectis, calycibus incrmitus. Fl. zeyl. 94 .

Solum cale aculeato fruticofo, folits evatis fumatis intey, erimis, fpinis urrinque erestis. Hort, 6liff. 61. Roy. lasdb. 424 .

Solanum indicuminonom, flore boraginis. Robert. ic.

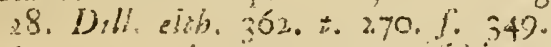

Solanum anericanom perenne tabincanum, frustu py riformi lonyore, fpins plarimis armamm. Pluts als. 350. t. 225. f. 6 .

Hobitat in India usaque 5

18. SOL. ANUM cavie aculcuto fruticoro, follis hattato croline of 2.19ulatis: aculcis utringue tedis, pacennis laxis.

Solarum caulc aribeatu truticon, folits civatis latribus laciniatis aculcis utring̨ue reats. Hort. sliff. 67. *

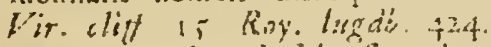

Solanum carolinente pincifun, boraginis foribus fuicatis. Dill. clib. $362.2 .20 \% f^{\prime} 3$ है.

Jesitnz in Caroina. to

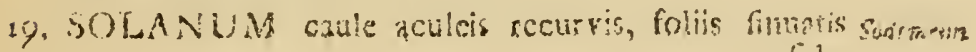
linis- 
fubtus tomentofis utrinque aculeatis, pedunculis acule. ais. $I \%$ z. $\%$ l. $95 . *$ Hort. upl. $4 \%$.

Solanum caule acueato fruticofo, folis oblongis pinuato--laciniatis. ipinis fupinis erectis, pronis recurvis. Hort. cliff. ó I. Vir. cliff. 15. Roy. lagils. \$24.

Solaium pomiforum frutefcens atricanum ipinolun. nigricalis, boraninis Hore, follis profunde laciniatis. Hern. ligdú. 573. t. 575. Morif. bilt. 3. p.521. S. 13. t. T. j.15. Pluk. alm. 25i. t. 226. f. 5 .

Habitat in Arica. 5

incansm. 20. SOLANUM cauce aculeato fruticofo, folis repandis, calycibus acuicatis. Ro $\cdot$ lagdb. 425 .

Solanum finoium incanum, fuitis finuatis, flore bora. ginis, fluetu luteo ovuli gallinacti magnitudine \& torma. Boerb. 2. p. 68.

Habitat - . -

tomertosin. 21. SOLANUM canic aculcato fruticofo, foliis cordatis villotis marene repandis, calycibus incruibus. Hort. cilff. Gi. kay. lugdb tir.

Solanum pomiterum fruteicens, flore boraginis, folio tomentofo incano, iolo caule finofo. Bierb.lugdb. 2. p. 69 .

Habitat in America Septentrionali.

babmer:a. 22. SOLANUM caule acnleato fruticofo, follis lancolnatis angulofo-dentatis. Hort. cliff". ót. Kioy. liestb. 424.

Solanum bahanente fpinofum, penlis angutis reflexis. Dill. elth. 263 . t. $271 . f .250$.

Solanum ipinifcrum frutefcens, fpinis igneis, americ num. Plus. alm. $350 . t .225 . f .5$.

Ilabitat in 3 meric infula Providentia. b

triobatım. 23. SOLANUM caule acuicate fruticofo, foliis fubtrilobis giabris obtufis inernibus.

Habitat in India.

Canlis fubfratefcess. Folia parta, gbibra, obtufa, fubtr:ligha, raro etiam ad balin lobatil. Aculei retiexi in caule petiolis, pedunculis. Pedunculi uniffori; Calyces minimi, incrines. Stylus adjexdens. Figura proxime accedit ad. Pluk. a.j. 3 J6. $f$. 5.

\section{CAPSICUM.}

nmzum. I. CAPSICUM caule herbaceo. Koy. Imgdb. 426. 
Capficum ann:um. itort. cliff. 59. Hort. $35 p 5.47 . F l$ zeyl. 92. Mat. ned. 96.

Piper indicum vulgatifimum. Baub. pin. 132 .

Vallia-capo-molago. Rhced. mal. 2. p. it 35 .

Habitat in America meridionali. $\odot$

2. CAPSICUM caule fruticofo. Roy, lingdb. 426 .

Capticum fintetcens. Hort. cliff. 59.

frktęcens.

Capo-molago. Kbeed. mal. 2. p. iog. t. $5^{6 .}$

Habitat in India. $b$

\section{STRYCHNOS.}

1. STRYCHNOS foliis cratis, caule inermi. Fl. zey\%. Nux vomic 91. Mat. med. 77.

Strychnos foliis quincusnerviis. Wach. ultr. 32 .

Nux Vomica officinarmm. Baub. pin. sil. Raj. hift. 1814 .

Colubrini ligni tertium genus in malabar. Banb.pin. 301 . Caniram. Rheed. mal. 1. p. 67.t. 37. Raj. bifi. I661. Habitat in India. 5

2. STR XCHNOS foliis ovatis acutis, cirrhis fimplicibus. colubrinito Mat. meá. $7 \delta$, Amurn. acad. 2. p. IIg.

Strychnos foliis triner viis ovatis binatis. Wach.ultr. 32 .

Clematis indica fpinofa, foliis luteis. Busth. pin. $30 \mathrm{O}$.

Fructus orbicularis major fufcus triatis. Bauk. pin. 405 .

Modira-cuniram. Kbeed. mal. 7.p. I0.t. 5. Raj. bift. I 66 I.

Iluvitat in India. 5

\section{CHIRONIA.}

1. CHIRONIA herbacea, calycinis foliolis membrana- trinervil. ceo-carinatis. Fl. zeyl. yo.

Chironia foliis lanceolatis trincrviis. Hort. cliff. 54 .

Lyfimachia folio fimuato acuminate trinervio, thore cxruleo amplo, calyce carinato alato. Burm.zey/. 145 . t. 67 .

Habitat in Zeylona. $\odot$

i. CHIRONIA herbacea, foliis linearibus. Hort. cliff. Iino:ies. 54. Roy. lugd6. 433 .

Rapuntio affinis, lini facie, capitis b. fpei. Breyn. cent.

I 75 . t. 90.
Habitat in Capitis b. Spei berbidis. 


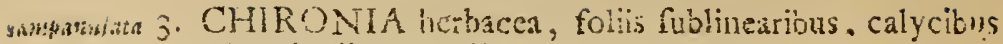
longitudine coislla.

Kabilut in Canauda. Kalm.

Catilis pedalis, veres: Ramis longis. Folia lanceolato-linearia, levia. Flones terminules, fotilarit rotati,

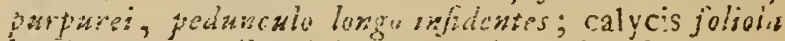
longitudine corollu, fubulata. Anthera fpirales.

maluris. 4. CHIRONIA herbacea, caule acutangulo, foliis ovatis amplexicanlibus.

Hibitat in Viruniniz. Kalms.

Facies Centun rismors. Caulis ie

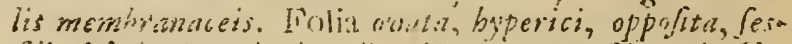

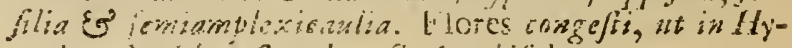

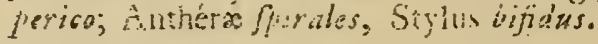

dokmatr. 5. CFIRONIA Horibus duodecemfis.

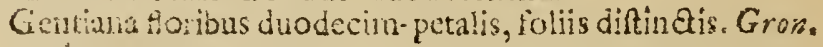
ving. 27.

Balisitat in Virginia

lactifera. 6. CHIRONIA frutefcens baccifcta.

Centauriam minus arborefcens pulpiterum. Comin. rar. 9. $t .9$

Centaurian: mints africanum arborefcens anguftifolitu. Old. aff. 26.

Mroitat in Kithiopia. o

frutefors. 7. CHIRONIA frutefesss caplulifera.

Centaurium minus atricanum aboiefecns latifolium, flore ruberrimo. Comm, rar. 8. t. 8. Old. afr. 26 . Hatitat in Rthiopia. 5

\section{CORDIA.}

Myxa. 1. CORDIA folits fubovatis ferratis-dentatis. Hort. cliff. 33. Wat mid. $17 x$.

Scbettena livlveltris Co domeftica. Bash. pin. 446. Alp. rgypt. 30 .

Sebeliena domelticaf: Myxa. Coram. bort. x. p. I39. t. 70 .

Vidi-marani, Rbeed. mal. 4.p. 77. t. 37.

Habitat in Ligypto, Malabaria. 5

Srisfent. 2. CORDI I foliis oblongo ovatis repandis fcabris. Scheftena fcabra, thore miniato crifpo. Dill. elth. $34 t$. t. $255 . f$. $33 \mathrm{I}$. 
Caryophyllus fpurius inodorus, folio fubrotura s icabro, fore racemolo hexapetaloide coccinco. Slow jam. I36. hif.. 2. p. 20. t. I64. Raj. Suppl. 36. Cutesh. car. 2. p. g1. t. 91.

llobitat in America calidiore. 5

3. CORJ) 1. folis ovatis integerrimis.

Cordia nucis inglandis folio. Plkm. gen. I3?

Habitat in America ineridionali. 占

Folia exarte ovata, learia, in neutra parina frabra. Co. rolla thibus longitudinctantun calycis.

\section{BRUNSEEISIA.}

т. BRUNSFEISTA.

Brunstclia fore albo, frufu crocco molli. Plam. gen. 12. Malitat in Americameridionala.

Folia whlonga, nbtula, integerrima, petiolata; Flores is upicio ramurum flutes.

\section{CESTRUM.}

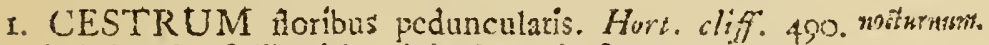
lalmincides foliis pishaminis, Hore virefente nociu odoratillimo. Dill. elch. $183 . \%$ I $33 . f .185$.

Jafinimum laurinis foliis, flore pallido iuteo, fructu atrocæuleo po!ypyreno venenato. Sloan, jam, 160. bift. 2. p. 96. t. 204 . f. 2. Kay. dendr. 63.

Syringa laurifolia jamaiccntis, floribus $\mathrm{cx}$ flavo pallefcentibus. Piuk. alri. 35. t. 64. f. 3 .

Parqui. Fewill. persw. 2. p. 32. t. 32. f. x. Hubitat in Jamaica, Chilli. 5

2. CESTRUM foribus feffilibus. Hort. cilf. 49 .

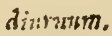

Jaliminoides laurculx folio, flore candide interdiu odorato. Dill. eleb. IS6. t. 154. f. 186.

Iauren!a fempervirens americana, latioribus foliis, floriblis albis odoratis. Fluk. alm, 209. t. 95. f. 1. Raj. dendr. 53 .

Hediunda jalininifore. Fewill.perut. 2. p. 25. t. 20. f. 3 .

Habitut in Chilli, Havana. 5

\section{LYCIUM.}

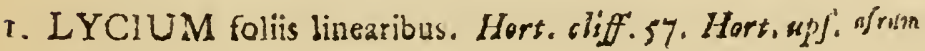
47. 
Jafminoicies africanum, jasmini aculeati foliis \& facic. Nifl: act. I71 I. p. 420. t. I 2.

Rhamnus alter, foliis falfis, flore purpureo. Basb. pin. 4.7.

B. jasminoides aculeatum humile, halimi minoris folio, flore minore, per maturitatem Havefente. Mich, gen. 2.2.4. t. 105.22.

Iabitat in Africa Es in Regno Vaientino. th

arusruti. 2. LYCIUM foliis lanceoiatis irafiufculis, calycibus bificis.

Rhamnus peregrinus, cofmarini folio, candidior. Pink aim. 317 . mant. 60. t. 322. f. 2. malis.

Jasminoides aculeatum, polygoni folio, foribus parvis albidis. Schow: afric. 349. f. 349 ?

Habitat in Afa, Africa? b

Calycis ure bilabo, aut interdurn trilobo, a reliquis peciebs. diverium.

curopenm. 3. LYCIUM foliis cuneiformibus. Vir. cliff. 14. Roy laga'b. 436 .

Jasminoides aculearum, falicis folio, flore parvocx albo purpuralcente. Micb. gen. 224. t. IO5. $f$. I

Rhamnus 1pinis ablongis, flore candicante. Batib. pin 477.

Habitat in Narlıona, Hifpania, Lufitania, Italia. क

\section{CHIS YSOPHYLLUM.}

crinito. I. CHRYSOPHYLLUM.

Chryfophyllum folis ovatis fupcrne glabris, parallele triatis, fubtus tomentofo-mitidis. Ilort. cliff. 491.

Anona foliis fubtus ferrugincis, fructu rotundo majore lævi purpureo, femine nigro partinn rugoío partim glabro. Sloun. jam. 206. bift. 2. p. 170. t. 229. Rui. dendr. 78 .

Cainito. Laet. amer. 390.

Cainito folio fubtus aureo, futetu maliformi. Plum. gen. 10.

B. Cainito folio fubtus aureo, fruetu oiviformi. Plum. है? IO.

Habitat in America calidine. t)

Folia alteria, peiculata, ovata, integerrima. Peduncu.

li laterales, uniflori, nuverofi, brevifini.

$$
\text { SIDFROX YLON. }
$$

iname. I. SIDEROXYLON inerme. Hort. cliff. 69. 
Sideroxylon primum $r$. dein Corix indorum nomine duta abor. Dill. elth. $357 . t .265 . f .34 t$.

Padus foliis oblongis, fructu folitario. Burm. afric. 238.

i. 84. f. 2 .

Mabitat in Ethiopia.

¿. SIDEROXYLON fpinofum. Hort. cliff. 69.

Ebenus jamaicenfis arbufcula, buxi folis, finoia. Pluk

Spino,fum. alm. $132, t .89 . f .1$.

Carou-inœili. Rbeed. inal. 5.p. 77. t. 39. Raj. bif 1634.

Habizat in Malabaria. 5

\section{RHAMNITS.}

\section{* Spinofi.}

1. RHAMNUS rpicis terminaibus, floribus quadrifidis catbarlicus. dievicis. Hort. cliff. 70. Fl.Juec. 193. Mat. med. 72 . Ro1. lugdb. 224 .

Rhainnus catharticus. Baub. pin. 478 .

Cavifpina. Cord. hilt. 175 .

Habitet in Europe axjlralioris Sepibus. b

$$
\text { * * inermes. }
$$

2. RHAMNUS inermis, floribus dioicis, foliis duplica-alpinns. to-crenatis.

Franguia ora tolii ferrata. Hall. belv. 164.

Frangula rugofiore \& ampliore folio. Tournef. inft. 6 I 2.

Frangula altera polycarpos. Baub. prodr. i6o.

Alnus nigra baccifera, rugofiore folio. $\Upsilon$. major. Bauk. bift. 1. p. s62.

Alnus nigra polycarpos. Baub. pin. 428 .

Halitat in alpibus Helveticis. 5

3. RHAMNUS inermis, foribus monogynis hermaphro- Frangu!d, ditis, foliis integerrimis. Hort. cliff. 70. Fl. Szec. 224.

Mat. med. 73. Ruy, lugáb. 224.

Rhamnus inermis, foliis annuis. Fl. Lapp. 60.

Alnus nigra baccifera. Banb. pin. 428 .

Frangula. Dod. pempt. 794.

B. Alnus inermis, foliis ovatis integerrimis glabris. Roy. lavifolius. lusdb. 224 .

Habitat in Europæborealis remorofos bumidiufoulis. of

4. RHAMNUS inermis, floribus dioicis, Riginate tripli-Alasernus. ci. Vir. cliff. 19. Hort. ups. 47. Sawv. monsp. 25. 
Rhamnus inermis, floribus polygamis, ftigmate triplici, foliis ferratis. Hort. cliff. 70. Roy. bugdb. 225.

Phylica clatior. Baub. jin. 477.

Phylica humilior. Baub. pir. 477.

Alaternus. 1. 2. Cluf. hift. 1. p. 50.

Habitat in Europa anftrali.

\section{* * * Aculeati.}

Paliurus. 5. RHAMNUS aculeis geminatis: infetiore reflexo, floribus trigynis. Hort. cliff. 69. Hort. ups. 47. Roy. lugdb. 224. Sustv. monjp. 305.

Rhamnus folio fubrotundo, fruetu compreffo. Baxh. pin. 477.

Paliurus. Dod. pempt. 576.

Habitat in Europa aufrali. 5

Loths. 6. RHAMNUS aculeis geminatis: altero recurvo, foliis ovato-oblongis.

Zizyphus fylveftris. Tussmef. inft. 62\%. Shaw. afr, 63 I. $f: 631$.

Habitat in Regno Tunetano. b

Frutex ramulis teretibus. A culci duo ad exortum folio. rurn: altero horizontali, altero recurvo ut in Palizro, fed Folia omria zizyphi, figura, nervis, glabritie, magnitudine, at margo obfolite E rarius crenatus.

Napeci. 7. RHAMNUS aculeis fubgeminatis recurvis, pedunculis corymbofis, floribus femidigynis, foliis ferratis $u$ trinque lavibus. Fl. z.eyl. 87.*

Habitat in Zeylona. 5

7ujuba. 8. RHAMNUS aculeis folitariis recurvis, pedunculis aggregatis, floribus femidigynis, foliis retulis fubtus tomentolis. Fl. zeyl. 89.

Jujuba indica fpinofa, folio \& fructu rotundo. Plsk: alm. 199. Raj. dendr. 44.

Habitat in India, 5

OEnopolia. 9. RHAMNUS aculcis folitariis recurvis, pedunculis aggregatis fubrefilibus, foliis femicordaris fubtus tomentolis. $\mathrm{Fl}$. zeyl. 88 .

Jujuba aculeata, nervolis foliis infra fericeis favis. Burm. zeyl. 13 I. t. 6I.

Habitat in Zeylona t5

Zizypiys. 10. RHAMNUS aculeis geminatis rectis, floribus digynis, foliis ovato-oblongis. Hort. cliff. 69. Mat.med.74. Roy.lugdb.224. Sawr. monjp. 59 . 
Jujuba fylveftris. Bazb. pin. $44^{6}$.

Zizyphus. Dod. permpt. 807.

B. Jujubx inajores oblongx. Bash. pin. 446.

Habitat in Europa aufirali. 5

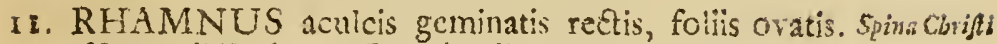
Hort. cliff. 63. * Roy. lugd6. 22. .

Jujube 1: Zizyphus africaia, mucronatis foliis, tpina gemella. Misk. alm. 199. t. 197. f. 3 .

Habitat is Biniopia, Palaftina. 5

Arbufould e Jemissibus mijlis jub nomine Spinx Chrift. Hierofolyma \& $D$. Hallelquift.

\section{PHYLICA.}

1. PHYLICA folï lincaribus verticiliatis.

Phylica toliis orato-linearibus. Ifart. cliff. yo. $R_{\theta y}$. iuguio. 109.

Alaternoides african, erica foliis, floribus albicantibus \& murcofis. Corm bort. 2. \%. 1. 8. I.

Habitat in Ethiopia. b

2. PHYLICA folis lineari-fubulatis: fummis hirfutis. Røy. pums lisgdb. 199.

Ricinus arborefeens sfricanus, tomentofis cavitulis. Seb. ibe. . 1. p. 38. t. $23, f .4 .5$.

Chamalea africana tricoccos \& tetracoccos $12 x$ ifolia, villofá cafarie curonata. Pluk. mant. 45. 2. 342. f. 3. Chamelea foliis anguftis fubtus incanis, Aoribus capitais murcolis. Buirm. afr. II 7 . t. $43 . f .2$

Habitat in 住thiopia. b

3. PHILICA foliis oratis fpatlis.

Chamelea folio fubrotundo fubtus incano, floribus in capitulum collectis. Burin. afr. $719 . t .44 . f$.. Chamxlea africans, foliis rabrotundis. Herman. afr. 6. Hnüitat in Ethiopia. b

\section{CEANOTHUS.}

- CEANOTHUS foliis trinerviis.

Ceanothus corymbis folio longiuribus. Hort. Mtf. 51.

Ccanothus. ACt. apf 1741 . p. $7 \%$

Celaftrus inermis, foliis ovatis ferratis trinervis, racemis ex fumrnis alis longillimis. Hort. cliff. 73 . Circis. virg. 25. Roy. lng 36.435 .

Evorymus novi telgii, cornitemina folis. Comm. bort. I. p. 567.t.86. Kaj. deitar. 69. 
Evonymus, jujubinis foliis, carolinenfis . fructu parvo fere umbellato. Pluk. alm. 139. t. 28.f. 6.

Habitat in Virginia, Carolina. 4 . b

siatichs.

2. CEANOTHUS foliis ovatis enerviis.

Ceanothus racemis folio brevioribus, Fl. zeyl. 98.

Habitat in Zeylona. th

aficakus

3. CANOTHUS foliis lanccolatis enerviis, fipulis fubrotundis.

Celaftrus inermis, foliis lanceolatis obtufe ferratis petiolatis appendicularis. Hort. ciff. 73 . Roy. lngdb.435. Alaternoides africana, lauri ferrata tolio. Comm prel. 6I.t. I I.

Ricinoides africana arborefcens, folio phillyrex longifolix ferrata. Seb. thes. 1.p.35.t.22. f. 6 .

Habitat in Aithiop:a: to

\section{AYPSINE.}

afrisma. I. MYRSINE, Hort.clify. 72.*

Vitis idæa æthiopica, inyrti tarentinæ folio, flore atro.. purpureo. Comm. bort. 1. p.123.t. 64 .

Buxus africana rotundifolia Cerrata Pluk. aim. 74.t.80. $f .5$.

Frutex æthiopicus baccifera, foliis myrtilli. Breyn.cent. 9. $t .5$.

Habitat in 王thiopia. †

\section{CELASTRUS.}

bulla:us. I. CELASTRUS inermis, foliis ovatis integerrimis.

Evonymoides virginiana, foliis non ferratis, fructu coccinco eleganter buliato. Ifnard. ac7. 1 716. p. 369.

Evonymus virginianus rotundifolius, capiulis coccineis elesanter bullatis. Pluk. alm. I 39. t. 28. f.5. Habitat in Virginia. b

frankn. 2. CELASTRUS inermis, caule volubili.

Evonymoides canadentis icandens, foliis ferratis. If $n$. a.t. $1716 \cdot p \cdot 369$.

Frutex viminibus lentis infirmis, foliis profunde ferratis, Gron. virg. 5s.

Habitat ins Canada. b

myrtifoliws. 3. CELASTRUS inermis, follis ovatis ferrulatis floribus racemofis, caule erecto. Mort. cliff. 72 . 
Myrtifolia arbor, foliis latis fubrotundis, fore albo racemolo. Sloan. jam. I6z. bift. 2.p.79. t. 193. f. I. Raj. dendr. 36.

Howitat in Virginia, Jamaica. 5

4. CELASTRUS fpinis foliofis, ramis angulatis, follis 'uxifolius. obtulis. Hort. cliff. 73. Rey. lugdb. 43t.

Lycilim porioricenle, buxi folis angultiorious. Pluk.alin. 237. $t .202 \cdot f \cdot 3$.

INabitat in Althopia. b

Rami E ramuit anguiati. Folia obovate, obtufa, acuto ferrata. Cyma pedunculatic, ex alis.

5. CELASTRUS fpinis nudis, ramis teretibus, folies a-pyitantists cutis. Hort. cliff. 72 .

Lycium xthiopicum, nyracanthx folio. Comm. bort. 1. p. $16_{3} . t .84 . R_{a j}$. derdr. 72 .

Evonymo affinis xthiopica, lycii foilis \& aculeis, fruEu cronymi. Pluk. alirs. 139. i. 280. f. 5.

Habitat in Aithiopia. b

Kami ơ ramuli teretiufculi. Folia ovali-lanceolata, $x-$ trinque acuta, in fetiolos delinentia, fuperne ferruturis acuminatis ut fieve jpinofis, perfiftentia; Cymape dunculatc, iaterales.

\section{EVOAYMUS.}

1. EVON K MUS floribus plerisque quadrifidis.

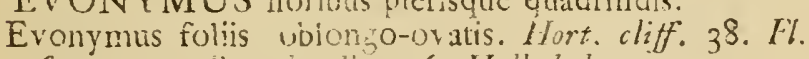

exropsus. fuec. I33. Koy. lugav. 436. Mall. bela. 123 .

Evonymus vulgaris, Granis rubontibus. Baub. jin. +23 . tenuifolins. Evonymus 2. Clat. hilt. r.p.57.

B. Evonymus latifolius. Baub, pin. 428 .

Evonymus 1.i. latifolia. Ciuf. bift. 2. p. 56.

Habia in Europa sepibus 3 . in Pannonia. 5

I. $x$ floie primario conzenit cum congeneribus. Pbil. But. $:-9$.

2. FVONYMUS floribus omnibus quinquefidis. latlfolitus.

Evonynus foliis lato-lanceolatis terratis. Hort. ups. $\mathrm{j}$. Evonyrnus boliis lanceolatis. Gron. virg. I7.

Evonvmus virginianus, pyracanthæ toliis, caplula verrucarum inltal exafperara. Pluk. alm. I $39 . t$. I $15 . f .5$.

Celaftrus foliis oppofitis ovatis integerrimis, foribus fubfoltariis. Hort. cliff. 32 .

Rhus virginianum, folio myrti. Cornm bort. 1. p. I57. 1. 81. Raj. dendr. 57.

Habitat in Virginia. 5 
DIOSMA.

oferfitifolia. . DIOSMA foliis tubulatis acutis oppofitss. Hort. cliff. 7r. Roy. lag 16 . 434.

Spirza africana, folis cruciatim pofitis. Cemm. rar. $\mathrm{I}$.

t. I.

Hypericum africanm vulrare. Seb. thes. 2. p. 4I. $t$. 40. $f .5$.

Habitat ad Caput b. Spei. क

birfute. 2. DIOSMA foliis hinearibus hirfutis. Hort. cliff. 71. Roy. $\operatorname{lug} d b .43+$.

Spiræa âricana odorata, foliis pilofis. Comm. rar. $3 . t .3$. Habitat ad Caput b. Spei. 5

swbra. $\hat{2}$. DIOSMA folits linearibus acutis glabris fubtus bifarian punctatis.

Diofrat folits fetaceis acutis. Hort. cliff. 72 .

Spiras aricana odorata, floribus fvaverubentibus. Comm. rar. 2. t. 2.

Erica whiopica, rofmarini fylveftris folio eleganter punEato, flore tetrapetalo purpureo. Pluk. mant. 68. $t$. 347. $f: 4$.

Habitat in 2 Ethiopia. 5

ericuiles. 4. DIOSMA foliis lineari-lanceolatis fubtus convexis bifarian imbricatis.

Spirxa africana, erica baccifer $x$ foliis. Rat. dicndr. 9 I. Ericæformis, coridis folio, rthiopica, fioribus pentapetalis in apicious. Pluk. amalth. 236.t.279. f.5.

Hitbitat in Ethiopia. I

czicatce 5. DIOSMA foliis lanceolatis ciilatis.

Spiræx forte genus africunam, ferpilli hirfutis foilis, fraticofum, fioribus albis imbeliatis. Plak. amalth 197 . t. 4 II. f. 3 .

Habitat in Aithiopia. b

tautcelata. 6. DIOSMA foilis laniceolatis glabris.

Spitan africana, iatureja toliis bretioribus. Raj. denat. gr.

Habitat in Athiopia. 方

unigora. T. DIOSMA folis ovate-oblongis, floribus folitariis terminalibus.

Cillus humilic ærhicpicus, interioribas foliss rosmarini fylvefris punftatis, cateris autem ferpilli fubrotundis, fiore carneo. Plak. mant. $99 . t .3+2.7 .5$. 
Habis at in Ethiopia, B

Folia rigidiora, E lange majora, quam in pracedentibus. Flos etjam fextuplo major: margine $x t \hat{E}$ fustus punctacus.

\section{BRUNIA.}

3. BRUNIA foliis quadrifariam imbricatis. Hort. cliff. nodiflora. To.

Cupreffo-Pinulus ezpitis b. fpei. Breyn. cent. 22. t. 10. Erica capitata f. noditlora cupreffiformis africana. Plrek. ment. 69. t. $346 . f .4$.

Scabiolæa affinis Arbufcula africana ericoides fphrerocephalos. Rai. hift. 1444.

Habitat in Ethiopia. 5

2. BRUNIA foliis linearibus patulis. Hort. cliff. 7 r. langginosa.

Tamarifcus monomapatenfis, ericae tenuifimo tolio, piIulitera, ramulis lanugine aranearum inftar implexis. Pluk. alm. 36 r. t. 3 r8. f. 4 .

Habitai in Aithiopia.

3. BRUNIA foliis ovatis acuminatis ciliatis.

Habitat in Athiopia.

rilíatis.

4. BRUNIA foliis lineari-lanceolatis confertis.

abrotanojder

Brunia foliis creberrimis lanceolatis, foribus conglobatis. Burm. afric. 266. t. 100. f. x.

Levilanus africanus, erica tolio, capitulo majore. Raj. dessir. 130.

Habitat in Athiopia. 5

5. BRUNIA foliis obovatis tomentolis.

Brunia foliis oblongis incanis, florum capitulo ramu-

Levifartas.

lum termilante. Burm. afy $: 6.267 .6 .100 . f, 2$.

L.cvifanus capenlis, ferpylli folio. Pet.gaz. $9.5 .5 \cdot f .7$. Erica capitatit $f$ nodidora, corios foicolis redis, athiopica. Plrk. maint. 69. t. 346 6. f. 7.

Inlitat in 'Ethiopia. है

6. BRUNIA Aoribus folitaris. Hurt. ciiff. 71.

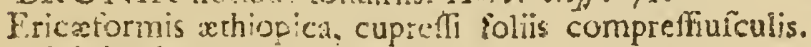
Plak. alm. 136. t. 279. f. 2.

Habitat in Athiopia. b

1. IEA. Gron. virg. i43.

$$
1 \mathrm{THA}
$$

Diconangia. Mitcb. gen. 5 .

Habitat in Virginia. क 


\section{GALAX.}

ephylla. J. GiLAX.

Viticclla. Mitch. ges. 24.

Allonymos r. Belvederc. Gron. virg. 25.

Habitat in Virginia. 2

MANGIFERA.

indica. I. MANGIFERA.

Mangifera arbor. Bois.jaz'. 95. Fl. zeyl. $47 x$.

Mianga indica, fructu magno reniformi. Raj. by/t. 550 .

perrica fimilis, putamine villofo. Busb. pin. 4 jo.

Mao 1. Mau 1: Manghos. Rheed. ma! 4. p. I.t.i. 2. Habitat in India. S

Racemus compofitus, brachiatus; an flores omies bermapbroditi?

americant. I. CUPANIA.

\section{CUPANIA.}

Cupania catanculolio, fruetu feric:o \& ramofo. Plam. ren. 45 .

Hiritat in America calidiori. 5

Folia alterna, obovata, oblonga, obtula, dentutn-ferrata. nervis transwerfaliaus craflics. Flores racemof:

\section{RIB TS. \\ * Ribefia ineryia.}

mbruar. r. RIBES inerme, racemis glabris pendulis, floribus plan. niufculis.

Rires inerme, fotiouj planufcuiis, racemis pendulis. Hort. cliff. 82. Fl. Juec. 197. Hort.upf. 59. Mrt.med. 99. Nir. cliff. 21 . Koy. lugah. 270. Daliv. parle 75. Ribes vulgare acidum. Bauh. bif. 2. p.97. Fl.i.pp.68. Grofluiaria, multiplici acino, it non fpinofa hortentis rubra. Bauh. pin. 455 .

3. Groflularia hortenfis, fructu margaritis fimili. Basb.pin. 455 .

Habitat in Suecia borealibus. if

npirnis. 2. RIBES inerme, racemis erectis: brteteis floit longioribus.

Ribes inerme, floribus planiuiculis, racemis erectis. Hort. cliff. 82. Fl. Suec. T9?.

Ribes alpinum dulce. $\bar{B} x$ sh. bif. 2., . 98. Fl inpp. 97. Grolluhia vulgaris fructu duci, Banb. pin. 455 .

6. $\mathrm{Ri}$. 
B. Ribes montana, oxyacantha fapore. Barb. prodr. 160. Aincen. acui. 1. P. I 70.

Habitat in Suecix, Helvetia, Angliæ Sepibus ficcis. 5

3. RIBES inerme, racemis pilofis, florious oblongis. nigm,

Ribes incrme, Horibus oblongi. Hort. cliff. 26r). Hort. upj. 51. F\%. The'c. 196. Mat. ined. 100. Roy. lugdb. 260. Dalih. para. 74 .

Rites yulgait inctu nigro. Ralb. wall. 32. Fi lapp.99. Circillularia non ipinoia, truftu niero. Buk pir. 455 . B. Rithelinn nigrum penlyiancum, Horibus vblongis. Dill. clth. $32+$ t. $246 . f .315$.

Habitat in Siecia, Helvetia, Penrylvania. t)

\section{* Griffularice acuicista.}

4. RBBES rimis fubaculcatis reclinatis, pedunculi bracea reclinatum, triphylla.

Ribes ramis lubaculeatis reclinatis. Hort. cliff. 82. Hort. up. rI. Rov. kugu. 270.

Groflularia fimofa fativa altera, foliis latioribus. Banb. pin. 4);.

Habitat ia Germania, Heivetia.

5. RIBES ramis aculeatis, petiolorum cilits pilofis, baccis Gnfflaria. hirfutis.

Ribes ramis aculentis, racemis erectis, baccis hirfutis. Hort cliff. 82.

Ribes ramis aculeatis erectis, fructu hifpido. $\mathrm{Y}$ ir. clifi. 21. Roy. lugdt. 20y.

Grorlularia fructu maximo hifpido margarita:um fere colore. Raj. hift. 1494 .

Malitat in Europa. 5

6. RIBES ramic undique aculentis. How. upr. ri.

Grotularia udy:unthe tolis anpliovibus, e finu hudiunuscantbo. nis. Plin. aralth. 212. Dill. elth. x66́, t. I39. f. I 16. Habitut 2i. Lanada. h

7. RIBES racemis aculeatis, baccis glabris, petioli bractea $U_{z a} \mathrm{cr} / \mathrm{pa}$ monophylia.

Ribes ramis aculcatis erectis, fruetu glabro. Hort. cliff. 82. Fl. Juec. 195. Roy. iugdb. 273. Hall. belv. 346. Balib. parif. 74 :

Grofiularia fimplici acino vel fpinofa fylveftris. Bawh. pir. 455.

Hiabitat in Europa boreali. 5 
cynosbati. 8. RIBES aculeis. fubaxillaribus, baccis aculeatis raccmofis. Habitat in Canada. Kalm. 5

Facies precedentium. Folia parum fiffa. Aculcus inftar fpince fub alis. Baccæ magnitudine nucis coryli, zsedique armatie aculeis robuftis.

\section{GRONOVIA.}

susider. I. GRONOVIA. Hort. cliff. 74. Gronovia fcandens lappacca, pampinea fronde. Houft. Miart. cent. 1. p. 40. t. 40. Amirt. berb. 346. Habitat in Vera Cruce.

\section{HE.DER A.}

Helix. I. HEDERA foliis ovatis lobatisque. $F l$. lapp. 9r. $F l$. fuec. 190. Hort. cliff. 74. Mat. med. 98. Roy. lugdb. 2.23. Hiall. belv. 164. Hedera arbores. Baub. pin. 305.

B.Hedera poetica. Baub. pin. 305.

\%. Hedera major therilis. Baub. pin. 305.

Hobitat in Eurova arboribus putrefcentibus, inque jepibus. 5

guanquefolia 2. HEDERA foliis quinatis ovatis ferratis. Hort. cliff: 74. Koy. lugdb. 223. Gran. virg. 24.

Vitis hederacea indica. Stapel. thistr. 364.

Edera quinquefolia canadenfis. Corm. canad. 99.1. 100. Helix. Mitch. gen. 30.

Habitat in Canada. t5

Capfula utringue turbinata, bilocularis, pelyperna. Flores mafeuli a femineis diftindti $D$. Mitcholl.

\section{VITIS.}

sinifere $x$. VITIS foliis lobatis finuatis nudis.

$V$ itis foliis palmato-angnlatis. Hort. cliff. 74 . Hort. ups. 5o. Mat. med. 97. Giow. virg. 144. Roy.lkgdb. 222.

Vitis vinifera. Baxis. pin. 229.

npyrem. Q. Vitis corinthiaca r. apyrena. Baub. hiff. 2. $\% .72$. Ilubitut in Orois quatuor portibus temperatis. b

indica. 2. VITIS foliis cordatis dentatis fubtus villofis, cirthis racemiferis. Fl. zeyl. 99 . *

Vitis iylveltris indica, acinis cotundis. Raj. derar. 67. Hautat in India. 5 
3. VITIS toliis cordatis fubtrilobis dentatis fubtus toncu- Labrufcs. terlis.

Viris fylveftris virginiana. Baxh. pin. 290.

Vitis vinifera fylveftris americana, tol is averia parte denia lanuine tectis. Pluk. phjt. 249. $f_{0} 1$.

$V$ its fructu minore rubroaccrbo, folio fubrotundo minus laciniato, fubtus alba lanugine tecto. sloan. bijt. 2. p. 104. t. $210 . f .4$.

Habitat in America Septentrionali. b

4. VITIS toliis cordatis dentato-ferntis utringue nudis. impina.

Vitis vilpina dicta virginiana nigra. Pluk. alm. 392.

Vitis aceris folio. Raj. deizdr. 68.

Lubitat in Virginia. to

5. VITIS tolits ternatis: foliolis fubrotundis terratis. trifolia,

Vitis pearne doorica, foliis ternis fubrotundis ferratis. Rij. dewir. 68.

Habitut in ladia. b

6. VITIS foliis quinatis: foliolis multifidis. Hort. cliff. lacinigas. 74. Roy. lzzib. 223.

Vitis laciniatis foliis. Carn. canad. 182. t. 183.

Vitis apii tolio. Bazh. bift. 2. p. 73.

Habitai

7. VITIS foliis fuyadecompofitis: foliolis lateralibus pin- when. natis.

$\checkmark$ itis caroliniana foliis apii, ura corymbofa purpurafcen-

te. AEz. buans. 2. part. 2. p. 365.t. 24.

frritex fomdens, petrofelini toliis, viginianus claviculis donatus. Plak, mart. 85.1. it 2

Habitat in Carolina, Virginica. 方

\section{LAGOECIA.}

x. IASOECIA. Hart cliff. 73. Hort. apr. 52.

Cuminum fylventre, capitulis globofis. Вай. pix. 186.

Cuminum jylvefte. Cam. epit. 5z8.

Habitat in Creta, I.cmno, Lyfia, Galatia.

\section{SAUVAGESIA.}

2. SAUVAGESIA.

Cininsiles.

llabitat in Domingo.

Habitus Hyperic: ant Corchori. Caulis eredus. Folia alterna, ovato-lanciolato, obtufe ferrata. Stipula acate, ciliatu.

ereace. 


\section{CLAYTONIA.}

virginica. I. CLAYTONIA foliis lineaibus.

Claytonia. Gron. virg. 25 .

Ornithogalo affinis virginiana, flore purpureo peitapetaloide. Pluk. alm. 272. t. 102. f. 3. Rudb. clyj. 2. p. I 39. f. 6 .

Habitat in Virginia. $*$

fibirica. 2. CLAYTONIA foliis ovatis. Hort. ups. 52 . * Limnia. At. ftockb. 1746. p. 130.t. 5.* Liabitat in Sibiria 2

\section{ACHYRA NTHES.}

apira. I. ACHYRANTHES caule erecto, calycibus reflexis fp:Cæ adpreftis. Fl. z.e:l. 105.

Achyranthes cania erecto. Hort. cliff. 42. Roy. lugab. 418.

ficula. đ. Amaranthus ficulus fpicatus. Bocc. fic. 16. t. 9. Pluk. phyt. 260. f. 2.

j!1ica.

B. Amarantus fpicatus zeylanicus, foliis obtufis amarantho ficulo bocconi fimilis. Burm. zegl. 16.t. $5 . f .3$. Amaranthus fpicarus, dietamni cretici folio, maderafpatentis. Pluk. alm. 26. t. 60. f. 4 .

Halitat in Sicilia, Zcylona, Jamaica. 5 Planta indica $\beta$ foliis obtufioribus differt a ficula.

lappacea. 2. ACHYRANTHES caule erecto, lpica interrupta,flo. ribus extcrne lanatis.

Achyranthes floribus externe lanatis interrupte fpicatis. Fl. zeyl. 103 .

Blitum fcandens, fruetu lappacco. Burm. zeyl. 47. t. I8. $f$. I.

Centaurium ciliarcminus, circxa foliis firmioribus, fpicatis floribus. Pluk. alin. 93. t. 82. f. 2.

Wclia-Cudircli. Rbeed. mal. ID.p. t. 59. Habitat in India.

lanota. 3. ACH IRANTHES caule erecto, fpicis ovatis lateralibus, calycibus lanatis.

Chenopodium incanum racemofum, folio majore minori oppofito. Burm. zeyl. 60.t. 26. f. I.

Amaranthus indicus verticillatus albus, foliis lanugine in. canus. Pluk. alm. $27 . t$. $75 \cdot$ f. 8.

Scherubala. Rbeed. mal. 10.p.57.t. 29.

Habitat in India. 
4. ACHYRANTHES caule repente, capitulis lateralibus repens. feffilibus.

Achyrantha repens, foliis bliti pallidi. D:il. stth. 8.t.7. f. 7 .

Tabitat in Turcomannia. $\odot$

5. ACHYRANTHES foliis oppofitis linearibus, panicula corymoso dichotoma. Fl. $\approx$ eyl. I 100 .

Paronychia foliis ad genicula confertis acuris, floribus umbellatis. Burm. zey. i84. t. 65. f. 2.

Amaranthus folio tenuifimo incano mollugini xmulante. Borc. muf. 4t. t. 39 .

Elichryfo affinis haba indica polygonoides ramofior, toliis caulium nodos ambicntibus. Pluk. alm. 134. $t .8$. f. 6.

\section{Habiat an Zeylona.}

\section{CELOSIA.}

^. CELOSIA foliis lanceolatis, pedunculis angulatis, mgentea. fpica ovato-oblonga.

Celolia foliis lineari-lanceolatis. Hort cliff. 43. * Roy. lugdb. 419 .

Amaranthus (jica albefcente hibitiorc. Mart. rent. $7 . t .7$.

Habitat in America. $\odot$

2. CELOSIA follis oblongo-ovatis, pedunculis teretibus crijata, fubftriatis, ipica oblonga.

Celofia foliis lanceolato-ovatis. Hort cliff. 43. Hort. upf. 52. Roy. lugdb. 419.

Amaranthus panicula incurva. Baub. pin, 121.

B. Ammanthus criftatus. Cam. epit. 792.

Habitet in India? $\odot$

3. CFLOSIA foliis lanceolatis tomentoris obtufis, fpicis lanata. confertis, ftaminibus lanatis. Fl. zcyl. IO2.

Haluitat in Zeylona.

4. CELOSIA foliis cuneiformibus acutiufcnlis, fpicis glo- nodiforn. bofis iateralibus. $F l$, zeyl. IOI.

Amaranthoides indicum nodiforum, capitulis ex albo virefcencibus. Burm. zeyl. I6. t. 5. $f: 2$.

Amaranthoides indicum globofum, ad caulium nodos floridum, foliis folitariis lummo apice barbatis. Pluk. alin. $27 . t$. $133 \cdot f .2$.

Mlabitat in Zeyluna. 
patziculata. 5. CELOSIA foliis lanceolato-ovatis, panicula diffufa filiformi. Gron. virg. I44.

Amaranthus panicula fiavicante gracili holofericea. Sloan. jam. 49. hift. 1. p. 1 +2. t. 90.

Amaranthus nodofus, pallefcentibus foliis bliti parvis, americanus, multiplic: fpeciola fpica laxa, $f$ panicula fparfa candicante, Plsk. alm. 26. \%. 26i.f. I.

Habitat in America Septentrionali

\section{ILLECEBRUM.}

verticilln- I. ILLECEBRUM floribus verticillatis nadis, caulibus 1 1 procumbentibus.

Illscebrum caulibus procumbentibus. Roy. lagdb. 2I4. Dalib. parif. 76. 126.

Iileccorum. Hort. cliff. 492 .

Paronychia ferpillifolia paluftris. Vuill. parif. $15 \% \cdot t$. I5. $f .1$.

Polygala repens nivea. Bauh. pirt. 215 . Habitat in Europæ pafouis udis.

fuffutico- 2. ILLECEBRUM Anribus latcralibus folititiis, cauliinm. bus fuffruticolis.

Illecebrum caule ereeto. Roy. lingdb. 25.4.

Polygonum herniaria foliis. Lob. adv. 404 ? Dalecb fajt. 1124 ?

Paronychiahifpanica fruticola, myrti folio. Tournefo inft. 508.

Habitat in Hifpania.

cymaftm. 3. ILLECEBRUM f picis cymofis fecundis, caule diffufo. Polygoni hifpanici genus Clufii. Daleck. bift. I 125 ?

Habitat Monfpelii. D. Samrages. ()

Planta fucie Sedi aut Polygoni; caulis filiformis, brachiatus. Folia oppofita, linearia, crailinfoula. Flores dige$\rho i$ in fpicas fecmndas, Spica in cymas ram latcrales quan terminales. Calyces marzine membrsnaceo ut in Statice, terminati fetis quinque.

Panonyshiz. 4. ILLECEBRUM floribus bracteis nitidis obvallatis. caulibus procumbentihus.

Herniaria Lquamis nitidis flores fuperantibus. Hort cliff. 41. Liort. utf. 54. Roy. lugdb. 215. Sawu. monsp. 129 ,

Paronychia hilpanica. Ciuf. bilt, 2. p. 183.

Polygonum minus candicans, Eaub. pin. 23 .

Habitat in Hilpannia Ẽ Narbona. $z$ 
5. ILI,ECEBRUM floribus bracteis nitidis occultatis, cnpitus $n \pi$. capitulis terminalibus, camle erceto.

Herniaria ereeta, fquamis nitidis fores occultantibus. Sawv. munsp. I 29 .

Paronychia narbonenfis crecta. Tournef. inft. 508.

Polygonum minus candicans, capitulis furrectis. Magn. monsp. 209.

Polysonum montanum niveum minimum. Lob.ic. 420. Habatat in $G$. Narbonentis, Hifpania.

\section{GLAUX.}

1. GLA UX. Hort. cliff. 43. Fl.suec. I99. Roy. ingdb. manitimn, 41.7 .

Glaux foliis elliptico-oblongis. Fl. lapp. 72.

Glaux maritima. Banb. pin. 215.

Aline bifolia, fiuctu coriandri, radice geniculata. Lafel prafl: 13. t. 3 .

Habitat in Europa maritimis, falfis. 2

\section{THISIUM.}

ז. THESIUM panicula foliata, foliis linearibins.

Theffur. Hort. cliff. 41. Hall. helv. 18 3 . Dalib. parif. 75 .

Thefium floribus fparfis. Snur. monsp. 48.

Linaria montana, fiofculis albicantibus. Bash. pin. 213.

Sefamoides procumbens montanum, linarix folio, Ho-

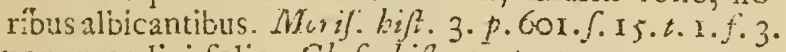

Anonymos lini folio. Cluf. hift. 1. p. 324 .

B. Onobrychis IV Jutea. Eauh. jin. 2I 5. Dale'ch. bijt. 49 I. Habitat in Europa ficcis montofis.

2. THESIUM floribus feflilibus latcralibus, foliis lineari-alpinnm. bus.

Alchimilla alpina, linarix foliis, calyce forum albo in foliorum alis. Till. pif. 6 .

Alchimilla linarix folio, floribus \& vafculis in foliorum alis fellilibus. Shaty. Spec. I4.

Habitat in Italix alpibus.

3. THESIUM Horitus capitatis, foliis triquctris.

Thefium Horibus capitatis. Roy. iugdb. 214.

Thymelza folis linearibus alcernis, Horibus cx uno petiolo copiofis. Burm. afric. 133. t. $48 . f .3$.

Thymelaa africana, lini angufto folio, Horibus albis villofis. Raj. dendr. 55 .

Iabilat in Ethiopia. 5

copitutum. 
mabeliatum. 4. THESIUM foribus umbeliatis, folis oblong:s.

Centaurium luteum atcyrordes virginianum. Plak. mant. 43. t. 342. $f: 1$.

Habitat in Virginix. Penfylvanix palcuis ficcis.Kalm. 2

Radix perennis. Folia alterna, ovali-loncelata, integerrima. Rami alterni, in Jummitute cantis: Urmbelinla terminales: incolucro tetrapbyllo, parvo: Flofali 5

\section{RAUVOLEIA.}

tetraphylls. I. RAUVOLFIA. Hort.cliff: 75. t. 9.

Rauvolfia tetraphylla angultifolia. Plim. gen. Ig.

B. Rauvolea tctraphylla latifolia. Plum.gen. I9.

Hiabitat in America calidiore. t)

\section{CERBERA.}

Aboinj. I. CERBERA foliis oratis.

Thevetia. Hort. cliff. 75. Roy. iugdb. $41 \hat{\jmath}$.

Ahouaj. Thev. intaret. 66. Tuurnef. injt. 658. Raj. bift. I 676 .

Ahouaj major. Pir. braf. 19.

Arbor anicricana, foliis pomi, fructu triangulo. Banb

pin. 43 4.

Habitat in Brafilia. 5

Manghas. 2. CERBERA foliis ianceolatis: nervis transverfalibus Fl. zevl. $106 .{ }^{*}$

Manghas lactefcens, foliis nerii craflis venofis, jafmini tlore, fructu perfici fimili venenato. Burm. zeyl r. 50. t. 70. f. $x$.

Manghas fructu venenato. $B a u b$. pin.440. Raj.hift. 1552 Odollam. Rbeed. mal. 1.'p. 71. t. 39.

Habitat in Indiis ad aquas. क

Arbor ladtefcens. Folia alterna, fpar $\int a$ ad apices ramo. rum, lato-lanceolata, petiolata, glabra, integerrina, pedalia. Racemi terminales, ramofh, inaquales. Perianthium pentapbyllum foliolis lanceolatis, patentibus, coloratis, deciduis. Corolla alba, infundibuliformis: Tubo calyce longiore, interwe angulato. Limbo quinquepartito, lobis ovatis, tubo brezioribus. Stam. Fila. menta 5, brevijlima, tubi fuperiori parti inferta. Anthere ovate, tetragone, tecte lanugine tubi. Pift Germen bifidum. Stylus filifornis, tubo fere brevior. Germen ovatunt, fiflum. Pericarpium Drupa ovata, magnitudine ovianferis, viride punctis albis minutisfistis, wno latere comprefium futuraque obsoleta; Se- 
mina 2, veluti duas raltaneas neagnas includens, vesinatus, vornitorius. Osleck.

3. CERBERA toliis linearibus longiffimis confertis.

Ahouaj nerii folio, Hore luteo. Plum. Spec. 20.

Nerio affinis angutifolia lactelcens, flore luteo. Pluk. alin. 253 . t. 207. f. 2.

Halitat is America calidiore. $\$$

\section{VINCA.}

1. VINCA caulibus procumbentibus, foliis lanceolato- manor. ovatis.

Vinca foliis ovatis. Hort. cliff. 77. Hort. ups. 53. Mat. med. Ior. Roy.lagdio. 412. Dalib. parif. 75 .

Clematis Daphnoides minor. Buśn. piru. 301.

Clematis Daphnoides. Doa. pempt. 405.

Habitat in Germania, Anglia, Gallia. b

2. VINCA caulibus ereetis, foliis ovatis.

Clematis Daphnoides major. Bazb́. pin. 302. Doa. major, peinpt. 406.

Habitat ia Gallia Narbonenfi, Hifpania. 5

Hxc species vix fuficienter a priori diflineta, licet major eredior, quod a loco vel parentious ortum $\int u \int p i c a$. mur; qui itague conjungere velit wix errat

\section{NERIUM.}

1. NERIUM foliis lincari-innceolatis ternis. Hort. cliff. Olender, 76. Hort. upf. 53. Fl. zeyl. ro8. Roy. lugdí. 412

Nerium tioribus rubercentibus. Baub. pin 464.

Rhododendrum. Dod. pempt. 85i.

Habitat in Creta, Palxltina, Syria, India. 5

2. NERIUM foliis lanceolato-ovatis, ramis divaricatis. divaricatum Fl. zeyl. 109."

Apocynum zeylanicum indicum fruteicens, nerii flort candidifímo. Herm, par. $4 c$.

Habitat in India. o

3. Nerium foliis ovaris acuminatis petiolatis. Fl. zcyl. 107. antidy/enteMat. med. 102. Tictsm.

Codaga pala. Rbeed. ma!. r. p. 85. $t$ 47.

Habitar in fridia. $b$

PLUMERIA.

PLUMERIA foliis ovato-cblongis. Hort. cliff. 76. rabraricy. ingdb. 412. 
Phumeria flote rofeo odoratifimo. Tournef. infl. 659. Catesb. car. 2. p. 92. t. 92.

Nerium arboreum, folio maximo obtufiore, fiore incarnato. Sloan. jarm. 154, bifs. 2. p. 6r. t. 185 . f. 1. E' t. I $86 . f$. I.

Jafminum indicum. Mer. Juriz. 8. t. 8 .

Clematis arborea americana, laurinis amplifimis foliis, flore lacca colore odoratifimo. Pluk. mant. 50 . alm. 109. t. 207. f. 2.

Habicat in Jamaica, Surinamo. b

alla. 2. PLUMERIA folis lanceolatis revolutis, pedunculis fuperne tuberofis.

Flumerii flore niveo, foliis longis anguttis \& acuminatis. Tournoi. infl. 659 .

Apocynum ancricanum frutefcens, longifimo folio, Hore albo odoratifino. Cornm. hort, 2. p. 47. t. 2.4. Nerium arboreun altifinum, folio angufto, Hore albo Sloan. jum. 154. bijt. 2. p. 62. Kaj. dendr. il 4 . Herm. paral. 49.

Habitat in Jamaica.

- btufa, 3. PLUMERTA foliis lanceolatis petiolatis ohturis.

Plumicria fore uiveo, folis brevioribus obtutis. 'T. CG. tesl. car. 2. p. Y3. t. 93 .

Habitat in America calidiore. $\$$

\section{CAMERARIA.}

latifolie. 1. CAMERARIA foliis fubrotuncis ntrinque acutis. Hart clitf. 76. Roy. leg:th. 412 .

Canicraria lato myri folio. Plum gen. 18. Hubitat ia America calidiore.

ongusifoliu. 2. CANiERARIA foliis linearibus. $\dagger$ Caneraria anguito linaria folio. Plam. gen. 18. Habitat in Alncrica calidiore.

\section{TABERN AMONTANA.}

eitrifolin. i. TABERN $2 M M O N T A N A$ foliis oppofitis ianceolatis. Tabermemontalia foliis la necolatis. Hort. cliff. 76 . Roy. $\operatorname{lng} d h .413$.

Tabernaniontana citri fonis undulatis. Plant gen. 18. Pala. Rhced. mal. I. p. SI. t. 46.

Halitat in utraque lridia. $\hbar$

lamifolia. 2. TABERNAMONTANA folits oppcfiris owatis. $\frac{1}{4}$ Tabenemontana laurifolia, fo:e albo, fructu roimidi.

ore. Aims. herb. 212.

Ne- 
Nerium arborsum, folio latiore obtufo, flore iuteo minore. Sloan. jam. 154. bift. 2. p. 62. 1. 185. f. 2. Habit at in Jamaica ad ripos flivviurum. o.

3. TABERNAEONTANA foliis alternis. Curutu-paia. Kheed. zaal. 4. P. A. 43.

Habitat in Malabaria. f,

\section{CEROPEGIA.}

1. CEROPEGIA umbetlis pendulis, foribus ereftis. Niota-niodem-valli. Rbeed.mal. 9. P. 27. t. 16. Habitat in Malabaria 24

Miternifolio

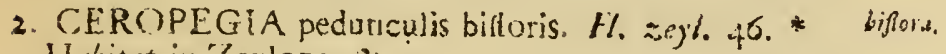
Habitat in Zeylona. 2

\section{DIGNNIA. \\ PERIPI.OCA.}

1. PERIPLOCA floribus interne hirfutis. Peripluca follis lanceolato-ovatis. Hort. eliff. 78. Roy. lagit. $4 \mathrm{10}$. J'riploca folio oblongo. Bayts. pisy. 303. Apocynum 2 angultifolium. Ciaf. bist. 1. p. $12 \%$. Hiaticiti in Syriat. 2

2. PERIPLOCA Ipicis inbricatis.

Periploca follis ovatis acutis glabris, fpicis inbricatis. Fl. 2eegl. 113 : *

Apocynum caule volubili percnni, folits rovato-lanccolatis. Roy. ling ib. 412 .

Periploca foliis angutis acutis glabris. Burm. :eyl. 18\%. t. 8 ; $f .1$.

Apocyni genus tendens cr india orientali. Pluk.mant. 17. t. 3ig. $f .2$.

Habitat in Lcylona. t

3. PERIPLOCA caule hirfuto.

Cynatichun canle volubili ramoro, foliis fubovatis cun!

Cundelo.

brum. 
B. Cynanchum foliis planis finuatis, flore pallide viridi, fructu craffo glabro viridi. Burm. afric. 34 . t. 1 1 . $f .2$. Habitat in Africa. 2

resuifolik. 4. PERIPLOCA foliis ineari-lanceolatis.

Cynanchum radice grandulofa, foliis angutis finuatis, floribus urceoiatis miniatis. Burm. afric. $26 . t$. 15 B. Cynanchum linearibus foliis acutis, floribus urceolatis rubris. Burm. afric. 37. t. I6. f. 1 .

Habitat in Cap. b. Spei dunis.

\section{CYNANCHUM.}

notum. I. CYNANCHUM caule volubili herbaceo, foliis cordato-oblongis glabris. Hort. cliff. 79. Hort. aps. 54. Roy. $\operatorname{lug} d b .409$.

Scammoilia monfpeliac a afinis, foliis acutionibus. Bawh. pir. 294.

Apocynum 3 latifolium. Clat. bijt. 1. p. I25.

Habitat in Sicitia, Hifpania, Aftracan. 2

frberofux. 2. CYNANCHUM caule volubili inferne fuberofo fisfo, foliis cordatis acuminatis. Hort. cliff. 79. Roy. lugah. 409. Gron. virg. 2\%.

Periploca carolinienfis, fore minore ftellato. Dill. elth. 300. t. 229. f: 296.

Habitat in America caliaiore.

yirtsm. 3. CYNANCHUM caule volubili fruticofo inferne fuberolo fiffo, foliis ovato-cordacis. Hort. clisy. $79 . *$ Roy. lugdb. 410.

Periploca fcandens, folio citrei, fructu maximo. Plum. Spec. 2.

Apocynum fcandens virginianum rugofum, pullis amplis fioribus, capfulis alatis. Morif. bift. $3 . p$. GII f is.t. 3. f. 61 .

Apocynum icandens fruticofum, fungofo cortice, furinamenie. Herm. par. 53 .

Habitat in America, $ち$

menfpeliss cum.

4. CYNANCHUM caule volubili herbaceo, foliis $=2 n i-$ formi-cordatis acutis. Hort. cliff. 79. Roy. lugdb. 409 . Suz?. monjp. I33.

Scammonea monfpeliaca, foliis rotundioribus. Baub. pin. 294.

Apocynum IV latifolium: Scammonea valentina. Clnif. bift. 1. p. I 26.

Habitat in Hifpania Es Narbone marstimis. $z$ 
5. CYNANCHUM caule creeto divaricato, foliis cor- cręnnm.

datis glabris. Hort. cliff. 79. Roy. lugdb. 409. Saziv. morrfp. I $3 \hat{j}$.

Apocyntim folio fubrotundo. Baub. pin. 302.

Apocynum I, latiolium. Clms, bift. I. p. I24.

Habitat in Syria. 2

\section{APOCYNUM.}

x. APOCYNUM canle rećtiufculo herbaceo, foliis on fol. antivofavatis utrinque giabris, cymis terminalibus.

mi.

A pocymum caule erecto annuo, foliis ovatis. Roj. lugdb. 411 .

Apocynum foliis ovatis. Hort. cliff. 80 .

A pocynum canadenfe, foliis androl $x$ mi majoris. Bocc. fic. 35. t. 16. f. 3. Morif: bift. 3. p. 609. S. 15. t. 3. f. I 6 .

Hibitat in Virginia, Canada, 2

2. APOCYNUM caule reetiulculo herbaceo, foliis ob- cannabinum. longis, cymis lateralibus.

Apocynum tolis ovatis acutis fubtus tomentofis. Gron. virg. 28.

A pocynum canadenfe ramofum, flore viridi albicante, filiqua tenuiflima. Morif. bift. 3.p. 609. S. I5. t.3. f. I4.

Apocynum virginianum, flore herbaceo, filiqua longisfima. Morif. pracl. 232 .

Apacynum canadenfe maximum, fore minimo herbaceo. Pluk. alm. 35 . t. I. 3 . $f$. I.

Apocynum crectum virginianum ramofum, caule fubrubente, efulæ raræ foliis, filiquis tenuifilmis. Pluk. alm. 35. t. 260. $f$. 7 .

Habitat in Cunada, Virginia. 2

Corolle virides, nec piete sunt.

3. APOCYNUM caule rectiufculo herbaceo, foliis ova- atentim. to-ianccolatis. Roy. ligdb. 4IY. Sauv. monjp. 133. A pocynum foliis ovato-lanceolatis. Hort. cliff. So.

'T'thymalus maritimus, purpurafcentibus floribus. Barb. pin. 29r.

Efula rara e lio venetorum infula. Lob. bift. 201.

Habitat in Adriatici maris infulis. 2

4. APOCYNUM caule erceto frutefeente, foliis lanceo- frutescens, lato-ovalibus, corollis acutis: fauce villolis. $F \%$ zeyl. 114
03
Apo. 
Apocyllum caulc erecto arboreo, follis ovatis acutis. Roylugdb. 412 .

Apocynum ficibus fafciculatis. Fl. zeyl. 23.t, 12.f.x. Ifabitat in Zeylona. 5

retichatmm. 5. APOCYNUM caule volubilipcrenni, foliis ovatis venolis. Koy. lugdb, fro.

Habitat in India.

\section{ASCLEPIAS. \\ * folitis oprofitis planis.}

*n.7ntata, x. ASCLEPIAS foliis feftilibus oblongis lanceolatis un. dulatis, petalis ciliatis.

Ajocynum africanum, lapathi folio, Comm, rar, 16.t. 16.

Habitat in Africa, 2

signater. 2. ASCLEPIAS folïs amplexicaulibus oblongo-ovalia bus. H\%.zey!. 112 .

Apocynum erectum majus latifolium indicun, $P / u k$. atm. 35. t. 175. f. 3 .

Beid el oflar. Aly. (rgypi. 85.t. 86.

Ericu. Rbeed. mal, $2 \cdot p \cdot 53 \cdot t \cdot 3 \mathrm{I}$, S.b. thes, I. p. $4^{\mathrm{I}}$ t. 25. $f . r$.

Halita: in India, Egypto. 24

Nectaria promunt non cornicula Jubulata, Sed lamisas folidas conniventes.

fyriace: 3. ASCLEPIAS foliis ovalibiss fubtus tomentofis, caule fimplicifimo, umbellis nutantibus.

Afclepias caule eregto fimplici herbacco, folis ovalibus fubtus tomentofis, umbellis nutantibus. Vir.cliff. 20. Hort. upf. 53, Gron. virg. 27. Roy. lugdb. 410 .

Afclepias caule erefto fimplici annuo, foliis ovato-oblongis tubtus incanis, umbella nutante. Hort. cliff. 78. A pocynum majus fyriacum rektum. Corm. canad.90. Apocynum fyriacum. Clus. bift. 2. p.87.

liabitat in Virginia. 4

17\%ен,

4. ASCLEPIAS foliis ovatis fubtus pilofiufculis, caule fimiplici, umbellis nectatiisque ereetis,

Apocynum floribus amane purpureis, comiculis furre* Etis. Dill. eltb. $31-t .27$ S. 30.

tubitat in America feptentrionali. 2

purpuralicens 5. ASCLEPIAS foliis ovatis fubtus villofis, caule fimplici, umbellis ereetis, neetariis refupinatis. 
Afclepias foribus obfolete purpureis, curniculis refupinatis. Dill. eith. 32. ¿. 28. $f .3$ t.

Apocynum erectuin noveooracerifi, foliis minus incanis., Horc ex obioleto dilute purpuraicente. Herm.

par. 33 .

Itabitat in Carolina. $*$

6. ASCLEPIAS foilis ovatis rugofis nudis, caule fim- variegats. plici, umbellis fubleffilibus: pedicellis tomentolis.

A pocynum americannm erecrum, tuberofa radice, non incanum, foliis rigidioribus latis fubrotundis, Horibus albis intus purpureis, fummo caule corymbum magnum efformantibus. Plak. alin. 34. t. 77. $f$. I.

A pocynum vetus americanum, wifank. Dill. elth. 32 .

Habitat in America boreali. 2

7. ASCLEPIAS foliis lanceolatis glabris, caule fimplici, ninca. umbellis creetis lateralibus folitariis.

Afclepias caulc crcho fimplici annuo, foliis lanceolatoovatis glabris, pedunculis alternis, umbellis eteetis. Gron. virg. 27.

Apocynum perficatix mitis folio, corniculis lakteis. Dill. eltb. $33 \cdot t .29 \cdot f \cdot 32$.

Apocynum americanum, toliis anygdali longioribus. Plaim. Spec. 2

Hallitat in Virginia \& America calidiore. $\delta$

8. ASCLEPIAS foliis lanceolat's, caule fiperne đ̣ivifo, inearnatio unbellis terminalibus congeltis.

A fclepias caule erceto ramoro annuo, foliis lanceolatis, umbellis terminalibus crcetis pluribus. Vir. cliff. 20. Hort. diff. 98. Roy. lizgdb. 411. Gron. virg. 27.

Apocynum minus rectun caindenfe. Corn. canad. $9 t$.

93. Barr. rar. 8. t. 72 . Raj. hijl. 1089.

Habital in Canada, Virginia. 2

Caulis uti dividitur folia e regione tris producit.

9. ASCLEPIAS foliis lanceolatis periolatis glabris, can- curaffivica. le fimplici, umbellis creetis folituriis.

Apocynum caule erecto fimplici annuo, foliis lanccoiatis, umbellis alternis crectis. Mort. cliff: $7^{8}$. Roy lugdb. $4 \mathrm{I1}$.

Apocynnm radice fibrofa, petalis coccineis, corniculis croceis. Dill. eith. 34 . t. $30 . f \cdot 33$.

Apocyrum curaffavicum. f. americanum, fibrofa radice, floribus aurantiis, chamanerii foliis latioribus. Herra. par. 36. t. 36 .

Habilat in Curaffao. 4.6

บo. A- 
necumbent. 10. ASCLEPIAS foliis viilofis, caule decumbente.

Afclepias caule decumbente hirfuto, foliis o vatis ob:utis villofis fubfeffilibus. Gron. virg. 27.

Apocynum carolinianum aurantiacum pilofum, $P$ et. ficc. 90.

Habitat in Virginia. $z$

artiferm II. ASCLEPIAS folis ovatis, caule ereeto, umbellis proliferis breviffimis.

Afclepias caule erecto fimplici herbaceo, foliis ovatis acuminatis, corymbis compolitis longitudine petioloram. Fil. zeyl. 111 .*

Habitat in Zeyiona. 2

Vincero:i- 12. ASCLEPIAS foliis ovatis bafi barbatis, caule ereeto, cum. umbellis proliferis.

Afciepias caule ereeto fimpliciflimo herbacco, foliis cordato-lanceolatis, racemis conglomeratis aiternis. F!. juec. 200. IMat. med. 103. Dalib. parif. 76.

Aiclepias ciulc erecto annuo, foliis ovato-ianccolatis. foribus confertis. Hort. cliff. 78 .

Afclepias albo flore. Bash. pin. 303 .

Vincetoxicum. Dod. pempt. 407.

Habitat in Europa glareofis. 2

rigra. I2. ASCLEPIAú foliis ovatis bafi barbatis, caule fuperne fubvolubili.

Afclepias caule fubvolubili herbaceo, foliis ovato- lanceolatis, floribus confertis patentifimis. Roy. lagdb. 410. Hort. ups. 53. Sauv. monjp. 133.

Afcleplas nigro tore. Baub. pin. 303.

Vincetoxicum flore nigro. Cam. epit. 560.

Habitat Monfpelii in collibas. 2

\section{* * folios latere revoluti;.}

fruticofn, 24. ASCLEPIAS foliis revolutis lanceolatis, caule fruticofo.

Afclepias caule erecto fruticofo, foliis lanceolatis, umbellis nutantibus, conceptaculis inflatis pilofis. Hort. cliff. 78. Hort. upf. r4. Vir. cliff. 20. Roy. lugdb. 410.

Apocynum ereetum africanum, villofo fruetu, falicis folio. Herm. parad. 23. t. 24 .

Avocylum erectum clatius, falicis angutto folio, folliculis pilofis. Pluk. alm. 36. t. $13^{9}$. f. 2.

Habitat in Ethiopia. $\vec{\alpha}$ 
If ASCLEPIAS foliis revolutis lineari-lanceolatis op-fibirica, pofitis ternatisque, caluie decumbente.

Afclepias montanit numilis, radice longius proferpente, lini foliis. Arum. rutb. Io.

Habitat in Sibiria. 2

16. ASCLEPIAS foliis revolutis linearibus verticillatis, vevitcillata. caule erecto.

Afclepias foliis verticillatis lineari-fetaceis. Gron. virg, 26.

Apocynum marianum ereetum, iincarix anguftifimis folis, umbcilatum. Pluk. mant. I\%.

Apocynum narianum, foliis angufifimis ftellatis. Pet. misf. 609.

Habilat in Virginia.

$$
\text { * * * foliis a'ternis. }
$$

17. ASCLEPIAS foliis alternis ovatis, umbellis ex eo-rubra. dem pedunculo comnuni pluribus.

Apocynum caule erefo fimplici annuo, foliis ovatis acuminatis alternis, pluribas in pedunculo umbellis. Gron. virg. 27.

Fiabitat in Virginia.

18. ASCLEPIAS foliis alternis lanceolatis, caule divari-tuberofa, cato piloro.

Afclepias caule erecto divaricato villoro, foliis lanceolatis, umbellis fimplicibus fubterminalioiss, Hort. cliff. 78. Roy. litgdb. $41 \mathrm{r}$.

Apocynum novæ angliæ hirfutum, tuberofa radice, floribus aurantiis. Herm. lugdb. 646. t. 647. Dill.elth. 35. t. 30. f. 34 .

Habitat in America boreali. 2

\section{ST APELIA.}

1. ST APELIA denticulis ramorum patentibus. Vir. cliff. variegata. 20. Roy. lugdi. 400.

Stapelia denticulis ramorum extrorfum prominulis. Hor: cliff. 77. Hort. upf. 53 .

Apocynum humile aizoides, filiquis erectis, africanum, ilerm. lugab. 52. t. 53. Stifl. bot. 32.

Habitat ad Cap. b. Spei. E

2. STAPELIA denticulis ramorum ercetis. Hort. cliff. bifuta, 77. Roy. lugdb. 409 .
05
Afcle- 
Afclcpias africana aizoidcs, tore pulchre fimbriato.

Cornz. rar. 30. t. 19.

lisubitut ad Cap. b. Spei. o

\section{HERNIARIA.}

Ylabra. 1. HERNIARIA glabra. Baub. bift. $3 \cdot \vec{p} \cdot 378$.

Herniaria calycibus braetea nudis. Hort cliff. $4 \mathrm{I}$. Fl. fisec. 207. Mat. med. 104. Rog. bugdk 2 I r. Hall. helv. I82. Dalit. parif. 76 .

Polygonum minis f. Nillagrana major. Dauk pin.28r. Habitat in Kuropa apricis,glareofis, ficcis. $\odot$

birma 2. HERNIARIA hirfuta. Lumb. bift. 3. p. 379. llabitat in Ar

tenticniata. 3. HERNIARIA? qux Polygonum lenticulatum. Polygonan minus tenuifolium. Bazb. pin. $2 \hat{8}$ r. Polygonam minus lentifolium. Bauh. prodr. Is $\mathrm{I}$. Habitat in Hifpania montilons Ejcurial, Monspelit.

Flores nou vidi; ut excilen Botanicos ad bujus reneris forle diftinetifini exainen, hic plantan adjeci; Habitus proximus berniaria, Jed mollifimus.

\section{CHENOPODIUM.}

* foliis cinzulo/is.

Bonus Hen - 1. CHENOPODIUM foliis triangulari-fagittatis integer. vicks rimis, Hort. cliff. 84. Fl. Juec. 208. Mat. ined. Iots. Roy, luzdb. 279. Hall. belo. 174. Dalib. paril: 79. Lapathum unetuofum. Baub pin. II Bonas Heuricus. Bash. bift. 2. p. 965 . Habitat in Europa ruderatis. 2

urbicwm 2. CHENOPODIUM foliis triangularibus fubdentatis, racemis confertis ftrigtımimis cauli approximatis longifimis. $F$. fuec, 20 \%

Chenopodium latifolium minus ramofum, periolis longiifimis ex foliorum alis confertin nafcentibus. $B u x b ́$. ball. 60. t. I.

Habitat in Europa burcalis plateis. $\odot$

vibrum. 3. CHENOPODIUM foliis cordato-triangularibus obtufrulculis dentatis, racentis erectis compofitis fubmudis caule brevioribus. Fl. juec. 210. Nîit. med. 107. Dalib. parif. 78.

Chenopodium erectum, foliis fubtriangularibus antice finuato-dentatis, racemis erectin foliolis lateralibus Hort, cliff. 85. Roy. Lusdb. 20\%. 
Atriplex fylveltris latifolia. Banh. pin. IIg

Pes ancrinus. Dalecis. bijt. 542. $\quad 5 t^{2}$

Habilat in Europar altis, ruáeratis. $P$

4. CHENOPODIUM foliis ovatis acutis dentatis, lace- murats

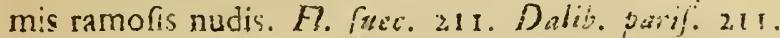

Chstropodium cleetum ramoliffimum, folits triangularibus dentatis, racemis ramolis caulem fuperantibus. Hort

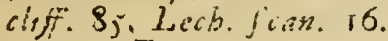

Hatriat in Europiemuris aggeriousque. $\odot$

5. CHENOPODIUM filiis thomboideo - triangulari-alkm, bus erofis pofticc interris: fnmmis oblongis, racemis erektis. H. Juec. 212 . Dalib. parif. 80.

Chenopodiun foliis inferior:ions ovaris acutis antrorfum dencatis: fuminis lanceolatis. Vir. cliff. 22. llort cliff. 85. Gron. virg. 145 Roy. lugdb. 219. Hall bie? 2.575

Habitat iss agris Furopa. (?)

6. CHENOPODIUM foliis rhomboideis dentato finun- viride. tis, raceinis ramofis fubmlidis. Fl. freer. 213 . Latil. parif. 78 .

Chenopodium fylveftre, opuli folio, Vaill. par:f. $3^{6 .}$ 7. f. $\mathrm{r}$.

Chenopodium folio oblongo integro. Dill, app. $\sigma_{2}$

Habitat in Europec cultis oleraceis.

7. CHENOPODIUM foliis cordatis angulato-acumina hybrinth. tis, racemis ranotis nudis, Fl, Juec. 214. Daib. parif. 79.

Chenopodium foliis triangulari-fagittatis: infra medium finuato-dentatis, racemis longiflinis. Hort. rliff. $8_{4}$ Roy. lagä. 219.

Chenopodium tramonii folio. Vaili.parif. 36. $6.7 . f .2$ Atriplex fylvettris latifolia, acatione tolio. Banb. pin is

Habilat in Europa culis. Q

CHENOPODIUM foliis oblongis fintratis, acemis Botry. nudis multifidis. Hort. cliff 8.4. Hont up 55 . Mot ined. 109. Roy. lugdb. 219. Saxz. montp. 273.

Botrys ambrofioides vulgaris Baub. pin. 139

Botrys: Dod. pempt. 34.

Habitat in Europx aufralis aremofis. $\odot$

9 CHENOPODIUM foliis lanceolatis dentatis, race- ambiajierites. nis 
mis foliatis fimplicibus. Hort. eliff. 84. Hort. ${ }_{1}$ s 5 . 56. Roy. lugk'b. 219.

Botrys ambrohoides mexicana. Bauh. pin. I38. 516.

Botrys odorata fuaveolens americana mexicanave. Morif. bift. 2. p. 605. S. 5. t. 35. f. 8 .

Habitat in Mexico, Lufitania. ()

multifidim. 10. CHENOPODIUM foliis multifidis: fegmentis linearibus, Horibus axillaribus feffilibus.

Chenopodium fempervirens, foliis tenuiter laciniatis. Dil!. elth. 78 . t. 66. f. 77.

Habizat in Bonaria. 5

antbelminti- II. CHENOPODIUM foliis ovato-oblongis dentatis, cunn. racemis aphyllis.

Chenopodium, lycopi folio, perenne. Dill. elth. 7 . $t$. 66. $f: 76$.

Habitat in Penfylvania, Bonaria. 2

g!aucum, 12. CHENOPODIUM foliis ovato-oblongis repandis, racemis nudis fimplicibus glomeratis $\mathrm{F}$. Juec. 215. Dalí. parif. 77 .

Chenopodium foliis ovato oblongis repande finuatis, fiorum racemis glomeratis ex ala folitariis. Vir. cliff. 22. Hort. cliff. 85. Roy. lagdb. 2 I9.

Chenopodium anguftifolium laciniatum minus. Tourref. inft. 506 .

Habitat ad Europæ fimeta. $\odot$

$$
\text { * * foliis integris. }
$$

Vulatia. 13. CHENOPODIUM foliis integerrimis rhombeo-ovatis, Horibus conglomeratis. Fl. Suec. 216. Mat. med. 108. Dalib. parif. 77.

Chenopodium foliis triangulari-ovatis. Hort. cliff. 84. Roy. lugdib. 218.

Atriplex fotida. Baub. pin. Irg.

Vulvaria. Dalecb. bift. 543 .

Habitut in Europre cultis olcraceis, $\odot$

polyperman s 4. CHENOPODIUM foliis integerrimis ovatis, caule decumbente, cymis dichotomis.

Chenopodium foliis ov atis integerrimis, caule decumbente. Vir. cliff. 21. Fl. Suec. 217 . Roy. lugdb. 218. Dalib. parif. 77 .

Blitum foliis ovatis. Hort. cliff. 28.

Blitum polyfpermum, Bauh. 1in. 118.

Polyfporon caffiani, batlil, anguillare. Lob. bift. 128

Hahitat in Europx cultis. ()

15. GHE 
๘. CHENOPODIUM foliis lineari-lanceolatis planis Scoparia. integerrimis. Hort. cliff. 86. Hort. ups. 55. Kuy lagd6. 220.

Linitia fcoparia. Bamb. jin. 212.

Ofyris. Dod. pempt. I5I.

Habitat in Gracia, Japonia. $\odot$

16. CHENOPODIUM foliis fubulatis femicylindricis, maritimxm.

Chenopodium foliis fubulatis; fuperne planis, fubtus convexis. Hart. cliff. 86. Fl. ruec. 2r \$. Koy. lugäb. 220.

Kali minus album, remine fplendente. Bauls. pir. 289. Morif. bift. 2. p. 6ro. . . 5. t. 33. f. 3.

Habitat in Europx maritimis.

17. CHENOPODIUM foliis linearibus teretibus carno- fruticof $f_{1 n}$ fis, caule fruticofo. Hort. cliff. 86. Roy. lugdb. 220. Gxett. farmp. 2. p. 425. Sauv. monfp, 7.

Chenopodium, fedi folio minimo, frutelcens perenne. Boerb. lught. 2. P. 91 .

Sedum minus ar̉oorefcens. Munt. bift. t. 469.

Habitat in Galliæ, Hifpaniæ maritimis. b

18. CHENOPODIUM foliis filiformibus acutiufculis, aliafinum. caule erecto. Hort. upf. 55 .

Chenopodium altiffimum, foliis fucculentis. Buxb. cent. I. p. $21 . t .31 . f .2$.

Kali gramineo folio. Bush. pin.289. prodr. 133. Burf, $X I T: 20$.

B. Chenopodium foliis n̂liformibus inermibus mucronatis, caule ramofiflimo. Hort. "ps. 56 .

Habitat ad Aftracanurn, ad Jalinas faxonicas inque Italia.

19. CHENOPODIUM foliis linearibus obtufis: fubtus falfum. convexis, caule ramofo: ramis deflexis. Hort. up .55 .

Chenopodium maritimum, foliis fedi teretibus. Buxb. cent. r. p. 21 . t. 31 . f. I.

Habitat ad Aftracanum. $\odot$

20. CHENOPODIUM foliis teretibus obtufis tomento- bivjk:km. fis alternis, caule herbaceo. Sauv. monsp. 7.

Kali minus villofum. Baub. pin. 289. prodr. 133 . Kali parvum hirfuten. Bauh. bift. 702.

Halitat Monfrelii in maritimis.

2. CHENOPODIUM foliis lanceolat's carnofis, co- grifatum. rymbis dichotomis fpinotis.

Habital in Sibiria. (

Cau. 
Cauiis Spithomens, inequalis, ranufo-patalus. Folia car nofa, lancculata, obtzifa. Cocymbi exillares, dichotom mi, folio longiores, terminati $\int p$ inis inerinibus. Flones filfiles in divaricationibus.

sirginicum. 22: CIENOPODIUM Soliis linearibus obtufs lubcanaiculatis, peciuncalis axiliaribus: dichotorais muticis. Hobitat in Virginia? $(0$

\section{BETA.}

an'guris. 'I BETA. Hort. clite. S3́. Hort. wit. 56. Mat. med. II 3 . Rny. Ing 30.20 .

perasnic. Beta fylvuitris martima. Buuh. pira. I 18.

rubri.

B. Beti ruera vulgaris. Bash. pin. its.

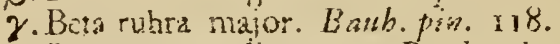

¿. Reta rabra, ladice apa. Bush. pin. IIs.

8. Beta lutez majot. Bauh. pia. ri8.

そ. Beta pailide virens major. Baub. pin. ins.

cicia. $\quad \eta$. Beta alba vel pallejcens, qua Cicla officinatum. Baub. pin. I 18.

S. Bera communis viridis. Bamb. pin. II8.

Habistat in Angliae E' Belgii litoribus maris. $0^{*}$

\section{SALSOLA.}

knli. i, SALSOLA herbacen, folis libulat's mucronatis, $c a$. Ivcibus ovatis ayillaribus.

Sallola folis pungentibus. Hort. cliff. 36. Fl. Suec. 20t. Roy. lugáb. 220. Gron. virr. 28,

Frali fpinoium cochleatum. Bash. pin. 289.

Gail frinofo afinis. Baub. pia. 289. Murif. bift. 2.f. 5. t. 33 . F. II.

Habilat in Europa litoribses maris. 6

retera. 2. SAISG) A herbacca, foliis fubulatis mucronatis, ca* lycibu', explanatis.

Saliola foliis conico-jubulatis mucronatis, calycibus co. zolliformibus obufis coloratis crenatis. Hort. upf. $5^{\hbar}$. Kali hurnite, alis purpure is torem rofaceum mentientibus, $B * x$. cont. I. p. o. t. J4. f. 2.

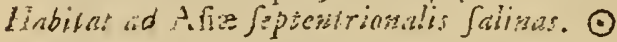

praje:uta. 3. SALSOLA frutefcens, foliis lincaritus pilolis inermi. bus. Amorn. acad. 2. p. 346. *

Habitut in Nia borcali, Yirginia. 
lute purpureo. Sloan. jam. 8i: bift. I. p. 205. Raj. juppl. so6.

Kali curaffavicum procumbens, foliis fubrotundis. $P l u k$. alin. 202. t. 95.5 .4 .

Habitat in Jamaica, Curaffao.

\section{GOMPHRENA.}

* floribus terminalibus, caule crecito.

giovoj. T. GOMPHRENA caule erecto, foliis ovato-lancedatis, capitulis folitatiis, pedunculis diphyllis. Hort. cliff. 85. Hort. upf. 57 . Fl. $\approx .2 \%$. I15. Vir. cliff. 22. Roy. lugdb: 418 .

Amarantho affinis indiæ orientalis, floribus conglomeratis, ocymaltri folio. Brej\%. cent. 109. t.51. Comm: bort. r. p. $85 . t .45$.

Habizat in India. $\odot$

perennis. 2. GOMPHRENA foliis lanceolatis, capitulis diphyllis, flofculis perianthio proprio diltinctis.

Amaranthoides perenne, fioribus ftramineis radiatis. $D$ ill: elth. 24.t. 20. f. 22 .

Habitat in Bonaria: 2

Serrata

3. GOMPHRENA caule ereeto brachiato, capitulis folitariis terminalibus fefilibus, calycibus fertatis.

Habitat in America.

iatermpta. 4. GOMPHRENA caule erefto, fpica interrupta, Roy: lugdh. $4 \mathrm{I} 9$.

Habitat "America.

* * foribus lateralibus, caule diffulo.

flavd. 5. GOMPHRENA pedunculis oppofitis bifidis tricapitatis, capitulo intermedio ieffili.

Gomphrena pedunculis ad alas geminatis tricapitatis. Hort. cliff. 87.

Habitat in Vera Cruce.

vermicularis 6. GOMPHRENA foliis carnofis obtufis, capitulis oolongis terminalisus:

Caraxeron numile, cepea foliis, capitulis albis. I'aill. adt.

$5722 . p .264$.

Amaranthoides humile curaffavicum, ecpex foliis lu. cidis, capitulis albis. Herm. parad. I5.t. 15. f. 4.5 Pluk. alm. 27.t. $75 \cdot$. f. 9 .

Amarantho a frinis aizoides if. Amaranthoides minor a. 
mericana procumbens, ledi ier etifolii folis $\alpha$ facie, flore oblongo niveo. Breyn. prod. 2.

Trifolii lpica Crithmum máritimum non fpinofumbra. lilienfe. Raj. hift. $1 \hat{3} 3 \mathrm{I}$ 。

Habitat in Brafilia, Curantao.

7. GOMPHRENA caule repente, foliis lanceolatis fub- Jefilis. fefilibus, capitulis oblongis leffilibus axillaribus. Fl. $z e y \%$ I 16 .

Amaranthus humilis, foliis oppofitis, flofculis ex alis glomeracis, Burm. zeyl. 17. t. 4.f. 2.

Coluppa. Rliced. mal. Io. p. 2t. t. 9.

Habitat in India.

8. GOMPHRENA cauie repente, capitulis rotundis fes- Ficoidea filibus, foliis lanceolato-ovatis.

Gomphrena caule difufo repente, capitulis feflilibus. Roy. lygdk. 418 .

Amaranthoides marina repens, polygoni folio, capitulis argenteis. Plum. Spec. 20.

Habitas in America meridiusali.

9. GOMPHRENA foliis lanceolato-fubulatis, caule di-polygonoides. chotomo viliofo, capitulis axillaribus pedunculatis.

Amaranthoides humile curaffaricum, foliis polygoni. Herin. prodr. I 7 . t. I 7. f. I. Sloan. jam. 49. bift. I. p. 141. t. 86. f. 2. Raj. Juppl. I26.

Habitat in America meridionali.

\section{BOSEA.}

I. BOSEA. Hort. cliff. 84: Roy. lugab. i23.

Tilia forta arbor racemofi, folio longiore fubtus albicante nervis purpureis infignito, fore pentapetalo purpurco. Sloax. jam. 135. bijt. 2. p. 19. t. I s 9. f. 3 . Raj. dencir. 85 .

Frutex peresrinus horto boliano yervamora dictus. listith. bort. 24. ta 10.

Habitat is Canariis infulis. 5

\section{ULMUS.}

1. ULMUS folitis duplicato-ferratis, bafi inzquailbus. canpentrit.

Uimus fruetumemiaranacco. Hori. cliff. 83. Fi. Jaec: 219. Mat.med. 105. Roy. irgdb. 223. Dalib. parif.82.

Ulmus campetris \& tieophrati Basts.pin. 246.

Ulnus. Dod. pempt. 83\%.

Habitat in Europa ad pagos. b

jersantort. 
maevican, 2. ULMUS folits æqualiter ferratis: bafi inæqualibus. Uimus fruetu membranacco, foliis fimpliciffine ferratis. Gron zirg. 145 . Habitat in Virginia. $b$

pumila. 3. ULMUS foliis requaliter ferratis: bafi aqualibüs.

Ulmus humilis. Armo rath. 260.

Ulmas pumila, foliis parvis glabra, cortice fungofo. Pluk. alm 293.

Habitat in Sibiria. E

NAMA.

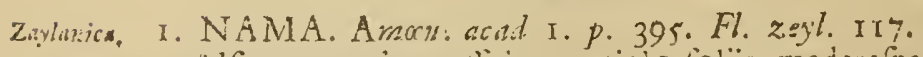
Aline veronica attinis, gratiola foliis, maderaipatana. Pluk. alm. 22. t. I $30 . f .2$. llabitat in India. $\odot$

\section{HEUCHERA.}

mmericans. 1. HfiUCHERA. Hort. cliff. 82. Gron. virg. 29. Ray. iugdb. 437 .

Cortufa alnericana, toce fqualide purpureo. Hicrm. parai. i 3 I. t. I3 1 .

Samicula f. Cortufa americana fpicara, floribus fqualide purpurcis. Pluk. aim. $332 . t .58, f .3$.

llabilat in Virginia. 26

\section{SWERTIA.}

pramis, y. SWERTYA corollis quinquefijis, foliis radicalibus uvalibus.

Swertia. Hort cliff. 53. Roy. Ingdl. 433 .

Gentiana palutris larifolia. Busb. Fin. 185 .

Gentiana XII, punctato fore. Ciuf. bift. I. p. 316.

Habitat in Helvetia, Bavaria. 2

difformis. 2. SWERTIA corollis quinquefidis: terminali fexfida, pedunculis lorgiffmis, foliis linearibus.

Gentiana foliis linearibus acuminatis, peduncuils longislimis nudis unifloris oppofitis. Gron. virg. 30.

Habitat in Virginia.

rotutis 3. SWEKTIA corollis quinquefidis, foliis Janceolatolincaribus.

I'nbitst w Sibiria. D. Gmelin. ○

Plenta jpithama'a. Folia lanceoloto-linearia; Rami alterni, pedunculis unifluris; Corolla planue. 
4. SWERTIA corollis quadrifidis quadricornibus. $A$ - corniculato muen. aced. 2. p. 344 .

Hubitat in Sibiria, Cimelin; Canada, Kalm. $\odot$

5. SWERTIA corollis quadrifidis ecornibus. Aman. dicbotona, acced. $2, p .345$.

Habitat in Sibiria D. Gnelin. ()

\section{GENTIANA.}

* Corollis aninguefidis fubcampaniformitus.

1. GENT'IAN A coroliis quinquefidis rotatis verticilla= lutes. tis, calycibus fpathaceis. Hall. belv.,+ 9 .

$\mathrm{Gcitiana}$ floribus lateralibus confertis pedunculatis, $\mathrm{co}$. rellis rotatis. Hort. cliff: Eo. Fl. juec. 201. Mat. med. I10. Roy. lugdb. 432. Sant. monsp. Ij6.

Gentiana major lutes. Baub. pir. IB F. Fi. lapp. g6.

Gertiana. Cain. epit. 415.

Afterias. Reneal. Spec. 64. t. 63 .

¿Fabitut is alsithis Norvegicis, Helveticis, Apeminis, Pyrenie, Tricientinis. 2.

2. GENTIANA corollis quinquefidis campaniformibus parpureto ver ticillatis, calycibus tublpathaceis.

Gentian. corollis campaniformibus verticillatis, folits imis petiolatis ellipticis. Hall. bciv. 479 .

Gentiana major purpurea. Bnub. pin. $18 \%$

Gentiant major alia. Camo epst. 416.

Cuilantha. Keneit. Peec. G5.

Halitut in alpibss Helveticis. 2

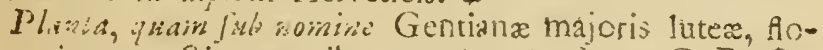
ribus punctis carentibus campanule forma C. B. I 87 meminit, bujks jpecies erat, lecta a Burfero.

3. GEN'TJANA corollis quinquefidis campanulatis pun- punctuta etatis, calycibus quinquedentatis.

Gentiana major, flore punctato. Bazis. pir. 137.

Habitat in Hclvetia, Sibiria. 26

Hujas rarietatem legit Cl. Gmelinus in Sibiria folits lineuri-lancealatis, Floribus terminulibus ternis, pedunculis proprïis, corollis fowis prateis sparfis purpurafcentibus.

4. GENTIANA corollis quinquefidis campanulatis $c p^{-4}$ afelppiarled. pofitis ferfilibus . toliis amplexicaulibus.

Gentiana foliis ovato-lauceolatis, fioribus campanulatis in alis feffilibus. Hall. helu +78 . 
Gentiana floribus lateralibus folitariis feffilibus, corollis creetis. Hort. cliff. So. Roy. lugdb. 432.

Gentiana afclepiadis folio. Baub.pin. I87.

Dalyftephana. Reneal. Spec. 67. t. 68.

Hulitut in alpibus Helvetia, Pannonix, Mauritanix. \#

Enemsans?- 5. GENTIANA corollis quinquefidis campanulatis opibs: pofitis pedunculatis, foliis iinearibus.

Gentiana floribus terminalibus ratis, corollis ereetis plicatis, foliis linearibus. Hurt. cliff: So. Fl. fuec. 202. Roy. lugdb. 432 . Dalit parif. 81 .

Genciana anguftifolia autumnalis major. Bazh. pin. I88. Gentiana paluftris anguftionia. $B_{\text {aus }}$ pin. 188.

Cyana. Reneal. Spec. 6q. t. 68.

Habitat in Europ $x$ pafcuis bumidiufculis. 2

inponrrn. 6. GENTIANA corollis quinquefidis campanulatis ventricofis verticillatis, foliis trinervis.

Gentiana tloibus ventricofis campanuiatis crectis quinquefidis, foliis ovaro-lanccolatis. Graz. virg. 29.

Gentiana virginiana, fiponarix folio, Horc carculeo longiore. Morij. bift. 3.p. 484 . S. I2. t. 5. f.4. Catest. car. 5. p. 70.t. 0 .

Habitat in Virginia. 2

villog. 7. GENTIANA corollis quinquefidis campanulatis rentricolis, foliis villofis.

Gentiana floribus ventricofis campanulatis ereetis quinquefidis, foliis oblongis actininatis levitcr villofis. Gron. virg. 145.

Itabitat in Virgina. 27

warlis. 8. GENTIANA corolla quinquefida campanulata caulem excedente.

Gcutiana corolla campanulata caulem longitudine excedente. Hort. cliff. 8r. Roy. lugitl. 432. Hall. belv. 477 . Sam inonjp. I 36.

Gcntiana alpina latifolia, magno flore. Baub. pin. 187 . prodir. 97.

Q. Gentiana aipina anguftifolia, magno flore. Bubh.pin. 187.

Thylacitis. Reneal. fpec. 70. t. 68.

liabiat in alpibus Helveticis, Autriagis, Pyrcnaicis. 2

* * Corollis quingrefidis infundibaliformibus.

2.m. CENTIANA corolia quinquefida infundibuliformi cailun exceuente, foliis zadicalibus confertis majoribus.

Gen- 
Gentiana fore unico tabulofo, folis ad terram congeflis acutis. Hall. belv. 476 .

Gentiana alpina verna major. Bash. pin. 188.

Gentianella verna minor. Claj. bift. 315 .

Ericoila. Renzal. Spec. 75. t. 68.

Habitat an alpibus Heivctia. 2

10. GENTIANA corolla quinquefida infundibuliformi, bnearics. foliis obtufis.

Gentiana foliis ovatis, caule uniforo. Hall. kelv. $4 \varsigma^{6}$,

Gentiana caule unifloro, flore hypocrateriformi quinque fido: laciniis fubrotundis crenatis. Hort. cliff. $8 \pi$.

Gentianclla elegantifima bavarica. Cam. bort. 65. t. Is. $f .2$.

Ilabitat in alpibus Helvetix, Pavaria.

11. GENTIANA corollis quinquetidis infundibuliformi- -ivalis, bus, ramis unifforis alternis.

Gentiana corollis infundibuliformibus quinquedentatis, ramis alternis uniftoris. Fl. SHec. 204.

Gentiana corolla infundibuliformi: denticulo laciniis interpolito. Fl. lupp. $95 .^{*}$

Gentiana humillima, caule ramofo, tubo floris longis fimo. Hall. belv. 475 . $t$. 7 . f. 5 .

Gentiana alpina xftiva, centaurca minoris folio. Baub tin. 188 .

Habitat in Lapponix, Helvetia fummis alpibus. ()

12. GENTIANA corollis quinqucfidis infundibuliformi- “ầnatica. bus terminalibus feffilibus, foliis inargine membranaceis.

Gentiana foliis margine membranaceis bafi coadunatis. Amoen. acad. 2. p. 3.43 .

Gcntiana humilis aquatica verna. Amm. rath. $4 . t$. I. Habitat in Sibiria. D. Amman. $\odot$

13. GENTIANA corollis- quinquefidis hypocraterifor $u$ utriculosa, mibus, calycibus inflatis plicatis.

Gentrana utriculis ventricolis. Bath. fin. 188.

Gicutianclla carulea cordata. Column ecphr. $220 . t .221$.

Gentianella annua, azureo fore. Barr. rar. I8. $t$. 48.

Habitat in Alpibus Helvetix, Italix. $\odot$

14. GENTIANA corollis quinquefidis infundibuliformi- Centasrism. bus, caule dichotomo.

Gentiana fotiis lineari-janceolatis, caule dichotomo, co$\mathrm{P}_{3}$ sol- 
rollis infundibulirormibus quinquefidis. Hort. eliff. 81. Fl. Suec. 205. Mat. med. I 12. Itylis timplicibus. Vir. cliff. 21. Koy. lugdb. 7. Dalib. parif. 81.

Centaurium ininus. Baub. pix. 278.

Erithraa. Renealim. Spec. 77. $\therefore$. 76 .

B. Centaurium minus pumilum ramolifimum. It. al.157. Rofen. fcait. IO.

Centaurium minus paluftre ramofifimum, flore purpureo. Vaill. parif. 32. t. 6. f. I.

g. Centaurium paluftre minimum, flore inaperto. Vaill.paparif. 32. t. 6. f. 2.

Habitut in Europa apricis, presertim maritimis. ()

fricats. I5. GENTIANA corollis quinquefidis infundibuliformibus, floribus alternis feflilibus.

Gentiana corollis infundibuliformibus quinquefidis laxe ipicatis, foliis lanceolatis. Saur. monpp. I32.

Centaurium ninus fpicatum album. Baub. pi». 278. prodr. I30. t. I 30. Baub. bitt. 3.p. 353 .

Centaurium minus album. Tabern. ic. 750 .

Habitat in montibus Euganeis \& Monfrelii. $\odot$

quirquefoli." só. GENTIANA corollis quinquefidis infundibuliformibus, caule acutangulo, foliis ovatis amplexicaulibus.

Habitat in Penfylvania. Kalm.

Planta ragnitidine Ef ftatura Sequentis. Caulis indirifus, teiragonus angulis menbranacess. Folia ovata, Sefilia, antplexicaulia, trinervia, acuta. Pedunculi oppofiti, apice ferenies Flores quingue, Jubpedisellatos. Calyces breviffimi, anguft, Corollx infundibuliformes, jubcerulec: limbo parve, fauce pervia.

Amarelia. 17. GENTIANA corollis quinquefidis hypocrateriformibus fauce barbatis.

Gentiana corollis hypocrateriformibus fauce barbatis. Hort. cliff. Sr. Fl. juec. 20j. a. Ro\%. l::gdb. 432. Dalit. parif. Si. Wiat med. IIx.

Grmiana fioribus confertis faucibus membranula laciniata clauis, foliis ovato-acuminatis. Guett. Jtump. 303.

Gentiana pratenfis, flore lantginofo. Baxis. pin. Is8. Gentiana antumualis ramola. Baub. pin. is5.

Ontantha. Reneal. Spec. 71 .

Habitut in Europx pratis. (?) 
* * Corollis non quinqli fidis.

18. GENTIANA corollis quadritidis fance barbatis. cartpefiris.

Gentiana corolla hypocrateriformi tubo villis claato, calycis foliis airernis majoribus. H\% hpp. $9 \mathrm{f}$. Fl.Juec. 203. B.

Gentiana purpurea minima. Column. ectbr. x. p. 223. t. 221 . Borr. ic. 97, $f: 2$.

Gentianella alpina verua minor. Bauk. pin. 183.

Eyrythalia. Renealm. Spec. 72.

Habitat in Europa pratis ficcis. ()

Pracedenti nimis affiris Ef fere varietas aut hibriak.

I9. GENTIANA corollis quadrifidis margine ciliatis, ciizuta. Gentiana corollis hypocrateritormibus laciniis margine barbatis. Hort sliff. 8I.

Gentiana anguftifolia autumnalis minor, floribus as latera pilofis. Bash. pin. i 88.

Gentianella carulea oiis pilotis. Bash. pin. 108.

Gentianella cærulea fimbriata anguftifolia autumnalis. Colums. ecphr. I. p. 222. t. 221. f. I.

llabitat in Helverix, Italix, Canadx murtibus.

20. GENTIANA corollis quadrifidis imberbibus ierti-rmcint. cillatis feffilibus.

Gentiana floribus confertis terminalibus, corollis auddrifidis imberbibus interjecto denticulı. Hors. iliff. 8i. Roy. lugdib 432. Dalib.parif. So.

Gentiana cruciata. Bumb. pin. 188 .

Gentiana minor. Cum epit. 417.

Tretorrhiza. Renealim. Spec. $74 .+73$.

Habitat in Pannonia, Apenninorum, Helvetia moninfis apricis. 26

25. GENTIANA corollis quadrifidis, floribus acauli- regjilis, bus, foliis ovitis.

Gentianoides flore luteo. Fewill. permw. 3.p. 20.t.14. Habitat $1 "$ Chilli.

22. GINTIANA corollis quadrifidis imberbibus, caule filiformis. dichotomo fliformi.

Genuana corollis infundibuliformibus quadiafis, pedunculis rernis, folis linearibus. Saur. monfp. 132. Gentiana caule dichotomo, foliis linearilanceolatis. Horibus infundibuliformibus quadrifidis longritime pedunculatis. Guett. famp. 1.p. 305. Dalib. porij. 82 .

$$
P+
$$

(jô. 
Centaurium paluits luteum minimum, Raj. bij. 1 og2. Vaill. parif. 32. t. 6. f. 3 .

Hobitat in Galin. 0

perfoliutis

23. GENTIANA corollis octofidis, foliis perfoliatis.

Geintiana caule dichotomo foliis conmetis, corollis

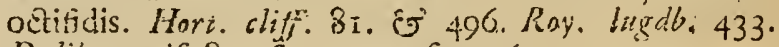

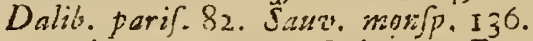

Centaurium lateum perfoliatirn. Baub. fin. 278 . Morif. hilt. 2. p. $565 \cdot f .5 . t .26 . f .1 .2$.

Centaurium parvum, Bore latco. Clar thift. 2.p. I80. Chlora. Reneai. Spet: 80. t. 75 .

Habita in Gallia, Anglia, Hifpania, $\odot$

\section{PHYLLIS.}

nobln. 7. PHYLLIS fipulis dentatis. Roy. lugdb. 92.

Phylijs. Hort. cliff. 87. Hort. mpj: 57 .

Valitanelia canarienfis frutefcens Simpla nobla di\&a. Dill. elth. 405. t. 299. f. 386.

Buplcuroides qux Arbor umbellifera. Walth bort. 11 . t. 6.

Habitat in Cinariis. 5

2. PHYLLIS ftipulis integerrimis. Roy. lugdb. 92. t Habitat in India. $b$

Flores buins mibi ignoti junt.

\section{ERYNGIUM.}

feritum. ๑. ERYNGIUM folits gladiatis ferrato-fpinofis: floralibus muittifidis.

Eryngium folis giadiatis utrinque laxe ferratis: denticulis fubulatis. Hort. cliff. 88. Grom. virg. 30. Roy. $\operatorname{lng} a b .529$.

Eryngium, folis anguttis ferratis, foxtidum. Slonn. jam. 12\%. bifi. 1. p. 26.4. 2. 156.f. 3.4.

Erylgium americanum, yucca fulia, fpinis ad oras mollinfoulis. Pluk. alon. 13. t. 175. j. 4. Kaj. Juppl. 339. Moris hif. 3. p. 167.

Scorpil fpina. Hern. mex. 222.

Hubitat in Virginia, lamaica, Mexico, Canada. *

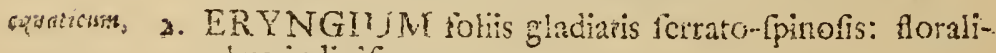
bus indivifis.

Erynginm folit gladiatis urrinque laxe ferratis: fummis tanturn dentatis fubulatis. Gras. virg. 146 . 
B. Eryngium lacuftre virginianum, foribus ex albido caruleis, caule \& foliis ranunculi Hammei minoris. Pluke. aliz. I 37 .

Habitat is Virginia 2

3. ERYNGIUM foliis radicalibus ovalikus planis cre-phan:ıms natis, eapitulis pedunculatis. Hort. rliff. 87. Hort. ups:

37. Roy. lugdb. 92. Dalib. parif. 83.

Eryngium latifolium planum. Buuh. pin. 87.

Eryngium pannonicum latifoliun. Cluf. bifk.2.p.158.

Habitut in Ruflia, Polonia, An!tria, Helvetia. \#

4. ERYNGIUM foliis radicalibus oblongis incifis, cau-pujiltmitia le dichotomo. capitulis felfilibus. Hort. cliff. 87. Roy. lught'b. 93 .

Eryngium planum minus. Baub. pin. 386.

Eryngium pufillum planum moutoni. Chuf.bifl.2.p.1 $\% 8$. Habilat in Hifpania.

3. ERYNGIUM foliis radicalibus fubrotundis plicatis \{pi- maritimum. nofis, capitulis pedunculatis. Hort. cliff. 87. Fl. Juec. 220. Roy. lugdb. 93 .

Eryngium maritinum. Bazh pin 386.

Eryngium mariuum. Clns, bift. 2. p. 169. Cam. epit. 448 .

Habilat ad Europx littora arenofa naritima

6. ERYNGIUM foliis radicalibus cordatis oblongis, ca- aiginum. ulinis pinnatifidis, capitulo fubcylindrica.

Eryngium alpinuni cærulcum, capitulis dipfaci. Baub.

pine. 386.

Eryngium carnleum gencyeirc. Lob. ic, 2. p. 23.

Habitat in alpibus Helvetix, Italiz. $z$

7. ERYNGIUM foiits radicalibus pinatis tripartitis Ifort canteffre cliff: 87. Mat. med. I I4. Roy. landl. 93.

Eryngium vulgare. Bash. pin. 386.

Eryngium campeltre vulgarc, Cluj. bijt. 2. p. Iry

Hicbitat in Germanix, Gallix, Hifpanix, Italia uzcal-

is, 2

S. ERYNGIUM foliis radicalibus digitato-muitifidis. amethy Eryagium montanum amethyfisum. Beub. pin. 396 . 1й. Mrif. bift. 3. p. I65. S. 7. t. 35. f. 2

Eryugium totum caruleum. Befl. eyjt. o. II. t. 8.f.4.

Hatitat in Styria montious. ₹

Habot rialta affinia inm procedesat: 


\section{HYDROCOTYLE.}

trigaris. 1. HYDROCOTYLE foliis peltatis, umbellis quinquepioris.

Ij. Arocotyle foliis peltatis orbiculatis undique emargiLatis. Hort. cliff. 88. Fl. Shec. 221. Roy. Lugdh. 93. Hall. belv. 425 . Dalib. parif. 83.

Ranunculus aquaticus, cotyledonis folio. Baub.pin. 18c. Cotyledon aquatica. Lob. ic. $38 \%$.

llatitat in Europx inundatis.

vribellatc.

2. HYDROCOTYLE foliis peltatis, umbellis multif.uris. Hydrocotyle repens, tlarcalba, cotyledonis folio. Gron. virg. 30 .

Hydrocotyle maxima, folio unbilicato, foribus in um. bellam nafcentibus. Plum. Jitec. 7 . ?

Erva de capitron. Marcgr. braf. 27.

Acaricoóa. Mif. braf. go.

Hacitat in America.

Plant a fimillima precedenti, hinc cum en mixta; differt foapo folits auplo longiore, flofoulis non 5 , fedpluribus quam vigint? in umbellam fimplicem digeftis.

aucricana. 3. HYDROCO'T YLE foliis reniformibus fublobatis cre* matis.

Habatat in America feptentrionali. Kalm.

Plntutx fucies prima co magnitedo. Folia antice finn vis hisnte ad contrum usque cillecta, margine in 9 lobos obfoletrs divifa quarkm finguli tribus crenis minoribas notata. Umbella quinquefiora.

ofinties. 4. HYDROCOT YLE foliis reniformibus aqualiter crenatis. Hort. clifj. 88. Fl. zeyl. 1 18. Roy. lugdb. 94.

Valerianella zeylanica paluftris rcpens, heder terreItris folio. Herm. par. 238 . t. 23 S.

으uculo aftunis umbellifcris accedens, chelidonii minoris folio, zeylanica minor. Pluk. alim. 3i4.t. 106. f. 2 .

Codagan. Rheed. mal. Io. p. 91. t. $4^{6 .}$

Habitat in India.

Differt a precedente marginis denticulis, f. crenis equalibus, confiftentia fuliurum duplo crafiore co fere incana; petiolis pluribus a gericula cauis, cum in procedente folia folitaria.

ebinen/ss. 5. MYDROCOTYLE foliis linesribus, umbellis mulw cifloris. 
Habitat in China.

Magnitudo priscedentium; Caulis repcns. Folia linearia, levia, obtufa, plani, fiepius bina ad articulos. Scapi longitudine folii. Uintella multiflaia:

\section{SANICULA.}

3. SANICULA foliis radicalibus fimplicibus, flofeulis o-ewropen. milibus feffilibus. Hl. Suec. 222. Mat. med. II 5 .

Sanicula flofculis omnibus fefiilibus. Gron. virg. 147.

Sanicula. Hort. cliff. 88. Ruy. lugdb. 93.

Sanicula officinarum. Baub. pin. 319.

Diapenfia. Cam. epit. $\% 53$.

Habitat in Europx Jylzis montolis. 4

2. SANICULA foliis radicalibus compofitis, foliolis on canaden,ise vatis, Gron. virg. I 46.

Sanicula canadenfis, amplifimo laciniato folio. Torr nef. inft. 326 .

llabitat in Virginia. *

Structura ita precedentis, ut vix differenia, fed planta decuplo fape omnibus partious ruajor.

3. SANICULA finfculis mafculis pedunculatis, herma-newilandica. phroditis reffilibus. Gron. virg. 3 r.

Sanicula foliis feptlobatis inæqualibus, flofculis maficulis pedunculatis. Hort. upf. 57.

Sanicula marilandica, caule \& ramulis dichotomis, en chinis minimis in codein communi pediculo ternis. Raj. Suppl. 260.

Habitat in Marilandia, Virginia. 2

\section{ASTRANTIA.'}

1. ASTRANTIA foliis quinquelobis: lobis trifidis. Hall, major. belv. 439 .

Afrantia. Hort. cliff. 98.

Hellcborus niger, finicula folio. Baub. pin. 186.

Veratrum nigrum. Dod. pempt. $3 S_{7}$.

Habitat in alpibus Helvetix, Hetrurix, Pyrenæis. 2

2. ASTRANTIA foliis digitatis rerratis.

Altrantia foliis digitatis feptenis integris dentatis. Hall. belr: 440.

Helleborus, fanicula folio, minor. Bauh. pis. 186. prodr. 47. Ris. hifl. 47 ).

Habitat in alpibus rielvelia. 4 


\section{BUPLELRUM. \\ * Herúucea.}

roturdifoli. I. BUPLEURUM involucris univerfalibus nullis, fowas. liis perfoliatis. Hort. upf. 64 .

Bupleurum foilis ovatis perfoliatis. Hort.cliff. 104. Roy. lugdb. 109. Hall. beiv. 437.

Perfoliaia vulgatiffima arventis. Baub. pin, 277.

Perfoliata. Dod. pompt. 104.

B. Perfoliata minor, tamis inHexis.Baub.pin.277.prodr. 30.

Perfoliata flore multiplici. Baub. pin. 277.

Perfoliata crifpa f. mufcofa. Ca:n: bort. t. 37 .

Habitat inter Europæ auftralis fegetes. $\odot$

fellatust. 2. BUPLEURUM involucellis coadunatis, univerfali triphyllo.

Bupleurum alpinum, anguftis nervofis foliis, calyce univerfali leviter incilo. Hall. bels. 438 . $t$. ro.

Perfoliata alpina anguftifolia media. Baub. pin. 277. prodr. I 29. Burf. VI: 5 .

Habitat in alpibus Helveticis.

Folia radicalia linearia; Jumma ovata, lanceolata, feffilia; involucri univerfalis foliola ovata, aqualia: partialis 5 , coalita ultra medium.

petram, 3. BUPLEURUM involucellis coadunatis, univerfali pentaphyllo

Bupleurum foliis auguntis \& nervofis, umbella univerfali quinquefolia, peculiari fex fida flellata. Hall. belv. 438 .

Pertoliata alpina, gramineo folio. Bash. pin. 277.

Sedum petroum, bupleuri folio. Porz.bald. 247.

Habitat in alpibas Helvetia, Baldi. $*$

Folia linearia, Seffilia. Involucri univerfalis foliola $5, a-$ qualia, latiora; partialium 5 , coalita ad medium.

anguiofum. 4. BUPLEURUM involucellis pentaphyllis orbiculacis, univercali triphyllo cvato, foliis smplexicaulibus coroto-lanceolatis.

Perfoliata alpina angultifolia major, folio angulofo. Bazh. fin. 277 . prodr. I29. Burf. VI: 4.

C. Perfoliata alpina angultifolia minor. Bauh. pin. 277. prodr. I 29. Lurf. VI: 6.

Whebitat in Pyrenais. $\beta$.in Vallefix alpibus. $\%$

Planta affinis maxime 2 , uti patuit ex Burferi colleetioac, licet involucri partialis foliolu in bac diftincta. Iit varietate 3 . folia anguftiffima f triata, is a. vero lan. ceoteta nec nervolo-firiata. 
5. BUPLEURUM involucellis pentaphyllis ovatis: uni- longifolizum. verfali fubpentaphyllo, foliis amplexicaulibus.

Bupleurum foliis inis petiolatis, fuperioribus ovatis perfoliatis. Hall. belv. 437.

Perfoliata montana latifolia. Baub. pin. 277.

Pelfoliata montana. Cam. bort. 120. t. 33 .

Hatitat Góttingx, inque monte Fura Helvetia.

Fulia ovata, frofunde amplexicaulial: radicalia petiolata; Involucr. univers. 3. vel quinquepbyllam; partiale

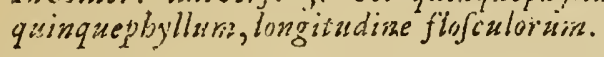

6. BUPLEURUM involucellis pentaphyllis acutis, falcatum. univerfali diphyllo, foliis lanceolatis optulis petiolatis.

Bupletrum foliis radicalibus pedunculatis: fummo fubrotundo, caulinis linearibus feffilibus. Grett. flamp. 59.

Bupleurum foliis petiolatis falcato-cllipticis acutis. Hallin belv. 439 .

Bupleurum folio fubrotundo $f$. valgatifimum. $B a z h$. pin. 278.

Bupleurum. Riv'. pent. 44.

Iiophyllum. Cord. bi/t. 69.

Habitat in Mifnix, Vallcfix Sepibus. $z$

Folia ovali-ablonga petivlis foliaceis; Involucrum usivierfalo diphyllum, insquale; partiale quinquephyllum, mecronatum.

7. BUPLEURUM involucellis pentaphyliis acutis: u-odortitss. niverfali triphyllo, Hofculo centrali altiore, ramis divaricatis.

Bupleurum foliis gramincis, 'calycc peculiari quinquefido arittaro rigido. Hall. belo. 439 .

Perfoliata minor angultifolia, bupleuri folio. Bexh. pin. 277.

Perfuliata minima, bupicuri folio. Column. ecphro r.p. 84. t. 247.

Ilabitat in alpibus Vallefiz. $\odot$

Folia lineari-lanceolata. Caulis ranzofifirnus, divaricatus; involucr. zunivers. Subpertaphbyllum foliolis latioribus rigidis acutiss partiale pentaphyllasin fimi$i_{e}$; fiofculi 9 , int crimedii petiolus auplo altior.

\$. BUPLEURUM involucellis pentaphyllis lanceoiatis rannienio:Iongioribus: univertali triphyllo, folits caulinis lanceo. des. iatis.

Bupleurum foliis anplexicaulibus: inferioribus lincaribus, 
fummo cordato-oblongo. Hort cliff. $104 . \mathrm{Hall}$. belv. 437. Roy. lugdb. IIO.

Perfoliata alpina anguitifolia minima. .Baub. pin. 277. prodr. I 30. Burf. XVI: 8.

Perfoliatum gramineum helveticun alpinum pumilum facie ranunculi. Lob. illufir. 137. Park. theatr. 335. t. 338.

Habitat in Helvetia, E Pyrenæis.

vigidum. 9, BUPLELTUM caule dichotomo fubnudo, involvcris minimis acutis.

Eupleurum foliis lanceolatis rigidis: radicalibus obtulis, caulinis acutis. Roy. luydb. rro. Sauri. mansp. $7 \sigma_{0}$

Bupleurum folio rigido. Baub. pin. 278 .

Bupleurum alterum latifolium. Did. psisip. 633.

Hubitat Monfpelii. 2

terriffimum. 1ว. BUPLEURUM umbellis fimplicibus alternis pentaphyllis fubtrifioris.

Bupleurum foliis linearibus acutis cofilibus. Mort. cliff. 104. Roy. lugdb. 110.

Bupleuruni tectium minimum. Colurn. expbr. Io $p$. 85. ะ. 247. Morif. bift. 3. p 3co. .: 9. t. 14. f.4. Bupleurum anguftifimo folio. Baub. pin. $27 \delta$.

drabitat in Germania, Anglia, Gallia, Jtalia. $\odot$

$$
\text { * * Frutefcentia. }
$$

viltofan. II. BUPLEURUM frutefcens, foliis amplexicaulibus dentatis fubtus viliofis.

Perfoliata foliis oblongis finuofis fubtus incanis. Burm. afr. 196. t. 7 I. f. 2 .

Habitat in Aithiopia. 5

fraticofum. 12. BUPLEURUM frutefcens, foliis obovatis integerririnis.

Bupleurum, foliis obverfe ovatis in petiolum attenuatis: Hort. cliff. 104. Rou. Ixodb. 109. Sauv. monfp. 60. Scfeli xthiopicum, falicis folio. Baub. pis. I6t.

Scfeli xthiopicum frutex. Dod. pempt. 312.

Habitat in Gallia auftralis $\int a x 0 \sqrt{2}$ maritimis. 5

differme. I3. BUPLEURUM frutefcens, foliis vernalibus dccompolitis planis incifis, eltivalibus filiformibus angulatis trifidis.

Bupleurum foliis radicalibus pinnato incifis, caulinis fafciculatis tetragonis, $R_{\theta y}$. Iugdb. 110. 
Bupleurum frutefcens, foliis ex uno punc? plurimis junceis tetragonis. Burm. afr. 195. t. 7\%. f. I?

Habitat in Fithiopia (mea aliunde) b

Flores nnuduin apud nos protulit. De genere :taque befsto. Foila bjersalia Petrofelini, aftivalia Spartii.

\section{ECHINOPHORA}

1. ECHINOPHORA foliolis fubulato-spinofis integer - rpinusu. rimis.

Echinophora foliis decompofitis. Hach. ultr. 200.

Caucalis caule lignofo, foliolis fubulato-fpinofis integerrimis. Roy. luyd6. 96. Sauv. monsp. $25^{8}$.

Crithmum nraritimum fpinnfum. Busb. pin. 288.

Crithmum jpinofum. Dod. pempt. 705 .

Habitat ad litora maris prefertim nediteranei. $*$

2. ECHINOHHORA foliolis incitis inermbets.

Echinophora toliis lupradecompofitis. W'ach.ultr. 200.

tenui,olin

Caucalis caule lignolo, foliis incilis. Roy. lugdv. go.

Paltinacha fylveftris anguftifolia, rucue ceninato. $B$ ash. pin. I 5 I.

Paftinaca echinophora apula. Column. ecphn. I. p. 98. t. 101.

Habitat in Apulia maritimis apricis, falfis. 26

\section{TORDYLIUM.}

x. TORDYLIUM involucris umbelia longioribus. Hort. yyriacum. cliff. 90. Hort. upf.58. Roy. lugd6. 95. Sazv. meth. 230.

Tordylium fyriacum humilius, femine granulato majore. Morif. hift. 3.p. 317. f. 9. t. 16. $j \%$

Gingidium foliis paltinace larifolix. Baub. pin. Ist. Habitat in Syriz. (0)

2. TORDYLIUM involucris partialibus longitudine pe- officinule. talorum, foliolis ovatis laciniatis. Hort.cliff. 90 . Hort. «p.58. Roy. ligd6. 95. Mat. med. 145. Sawo.nonjp. 2.30.

Sefeli creticuin minus. Baub. pin. I6r.

Sefeli creticunn. Dod. pempt. 3 I 4.

Habitat in Narbona, Italia, Sicilia. (-)

3. TORDYLIUM umbellulis remot:s, foliis pinnatis: ap::1sm. pinnis fubrotundis laciniatis. Kort. cliff. 9o. Roy. jugdla. 94 . 
Tordylium apulum minimum. Colsmn. eephr. 1.p I22. $t$. 124.

Sefeli creticum minimum. Bants. pin. 161.

Habitat in Italix, Apulix incultis.

Umbellula' fingula fofouli marginales tres majores fora* diati.

)aximutim. 4. TORDYLIUM umbella conferta radiata, foliolis lanceolatis incifo-fcrratis. Hort. cliff. go. Roy. lugdb. 94. Sauv. morjp. 230. 259.

Tordylium. Riv. pent. I.

Caucalis maxima, fphondylii aculeato femine. Baub. pin. 152 .

Sefcli creticum majus. Bauh. pin. IGI.

Habitat in Italice ruderatis fepibus.

intigolium. 5. TORDYLIUM umbella conferta mudiufcula, foliis pinnatis: foliolis lanceolatis incifo-ferratis.

Caucalis umbella univerfali trifida: partialibus pentafpermis, toliis pinnatis ferratis. Kort chat. 9 i. Koy, lugdb. 95. Dalib. parif. 84. Sazt. momp. 2,6 .

Caucalis arventis echinata latifolia. i3azh. pirs. 152 . Lappula canaria latifolia. Bauk. pin. 3.p. 8x.

Habitat in Gallia, Italia. 0

fintbrifcus. 6. "TORDYLIUM umbella, conferta, foliolis orato-linn. ccolatis pinnatifidis. Hort. cliff. 90. Fl. fuec. 224 . Roy. lugalib. 94 .

Cancalis umbella conterta, foljolis ovato-lanccolatis pinnatifidis. Guett. ftemp. I. $\%$. 8I.

Caucalis femine afpero, lofculis rubentibus. Bawh. pin. I52. prodr. 80.

Caucalis minor, flore rubente. Morif bift. 3.p. 308. f. 9. t. 14. f. \&.

Habitat in Europæ fepterstronalis arvis raderatis. $\delta$

s.odojm. 7. TORDYLIUM umbellis rimplicibus fefilibus, feminibus exterioribus hifpidis.

Cancalis umbellis feffilibus fimplicibus. Hort. apf. 58. Hort cliff. 91. Roy. lugdb. 95. Dalib. parif. 85.

Caucalis nodola, echinato femine. Bash. pin. I53. prodr. 80. Iaub. bift. 3. p. 83.

Habitat in Gallia, Italia cid viizs. $\odot$

\section{CAUCALIS.}

grandifgra. I. CAUCALIS involuct is fingulis penłaphyllis: folio- 


\section{FENT'ANDRLA DIGYNIA.}

10 unico ciuplo majore. Hort. cliff. gr. Roy. ingdio.

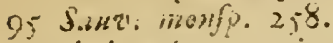

Caucalis inyolucro minerfali pimacifido, purtialibus indivilis, umbelis mulinida. Fl: fatco: 225 . Dalib. purif: 84 .

Calicalis arvenfis echinata, magan Hore. Bash.pir.is2. Echinophora fore magno. $R i$. pint. 25 .

Echinophora pycnocarpos. Colssws. ecphr: $1 \cdot p \cdot q 1 . \ell$. $9: 1$.

Habitat in Europa anforaliori irter fegetes.

2. CAICACAS myolucro univeriali longitudine umbel- duscorkes. loj lanceolato.

Caucalis dutici fylveltris folio, echinato magno fructu. M.Ign monlp. 292.

Hsibitat ivonipelii D. Savages:

Folia jupradecompofis Dusca valgaras. Involucrum univerfale pentaphylium: folichis lanceolatis, longitudi-

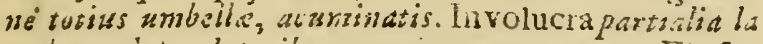
to-lanceoiata, lateribus wemoranacean acuta: FiofcuIi copiofi albi: bermaphroditi 3 in radio; fiofobulis ti-

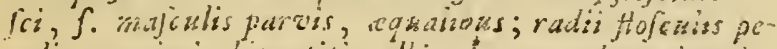
talis naximis bipartitis albis. In precedente inzo/acruin unbella dimidio brevizs or radiz pera!a rotundiora.

j. CAUCALIS involucro univerfali monophyllo, par-maritanid: tialibus triphyllis. Marbr. E. N.C. I T t2. vol. $\%$. tor.

Caucalis mauritamca rulgari fomilis, led fenine majorc. IJ'alth: hort. $12 \%$.

Habilat in Minuritania.

a. CAUCATIS umbelia trifida. umbellulis triffermis, pintycarpos: involucris triphyllis. Hort. clitt. 91. Hor: ups: 58 . Roy. Ingab. 95. Iasu. monfp. 253.

Caucalis inontpelica ecininata, magno fructu: Bauh. pin: $15 j$.

Echinophora aitera afperior platycarpos. Col. ecplor. I: p. 95. t. 94.

Hobitat in Italia, Munipelii: $\odot$

5. CAUCALIS umbollis parentibus, folioiis parrialibus cientaiis. fupradecompotitis laciniatis: lacinulis linearibus: Kay. lingalb. 95 .

Caucalis orientalis altifluna, folio ferulæ. Tournef cor.23. Habitat in Oriente. 8
Q
o. CAU- 
ieptophyile. 6. CAUCALIS feminum aculeis triglochidibus uncinatis: pilis r erticillatis hifpidis. Guett. famp. 8o. $D_{a-}$ lib. parif. 85 .

Caucalis arvenfis echinata, parvo flore \& fructu. Baub. pirs. I52.

E.chinophora tertia leotophyllon purpurea.Columnecplor. I. p. 96. $t, 97$.

Habitat in Gallia, Italia.

\section{ARTEDIA.}

rgtawiata. 1. ARTEDIA feminibus qquamatis. Hort. cliff. 8g. Hort. uf 5. 59. Roy. lug db. go.

Thapfia orientails, anethi. folio, femine cleganter cre. nato. Tournef. cor. 32. itin. 3. p. 298.

Gingidium foniculi folio. Baub. pin. I $5 \mathrm{I}$.

Gingidium rauwolini. Cam. bort. 67. t. 16.

Habitat in Libano. $\odot$

maricate. 2. ARTEDIA feminibus aculeatis. Hort. cliff. 89 . Roy. lugd6. 96. Herg. viadr. 8i.

Cauculis major daucoides tingitana. Morif. bift. $3 \cdot p$ 308. $\int .9 . t .14 . f .4$.

Echinophora tingitana. Riv. pent. $2 \%$.

Habitat in Mauritania.

\section{D) A UUS.}

fartat DAUCUS feminibus silpidis. Hort. cliff. 89. Hort. "pS. 59. Fl. Swet. 223. Mat. med. I 42. Roy. lugdb. 07. Gron. virg. iI Dalib. parif. 85 .

Dáucus vuigaris. Cims. bs/t. 2 p. 198.

Paftinaca tenuifolia fylveltris diofcoridis. Baub. pins, I 5 I.

B. Paftinaca tenuifolia Sativa radicelutea, Baub. pin. I 5 , \%. Dancus rativus radice atrorubente. Tournef. inft. 307. Habitat in Europe iampis exaridis. $\delta$

vinnaga 2. DAUCUS feminibus nudis. Hort. cliff. 89. Roy.lugdb. 97. Sauv. monjp. 257 .

Gingidium timbella oblonga. Bauh. pin. 151 .

Gingidium altermin. Dod. pempt. 792.

Habitat in Europa anftrali.

Cingidinm. 3. DAUCUS radiis involucri planis: laciniis fecurvis. Roy. lugdb. 97.

Gingidium folio chxrophylli. Bauh. pin. Isı.

Gingidium Matth. coikn. $372 . t .373$. 
Paftinaca tenuifolia marina, foliis ovicure virentibus \& quafi lucidis. NIagn. monjp. 199.

Paftinaca tolio cenantlics. Bock. fic. 74.

Habital Monfpelii.

\section{AMMI.}

1. AMMI foliis inferioribus pinnatis lanceolatis ferratis, "sojus: fuperioribus multifidis linearibus. Hort. $1 p \int .59$.

Ammi laciniis foliorum caulis lanceolatis. Hort. cliff.

89. Roy. lugdb. 96. Sauv: nonjp. 232:

Anmi niajus. Baub. pin. I59.

Ammi vulgaic. Dod. pempt. 415:

Habitat in Europa asfrali. $\odot$

2. AMMI foliotum omnium lacinuils lanceolatis. Guett: glomifolinn $\operatorname{tamp}$. 2. p. $433 . * t$

Ammi petrxum glancifolium perenne. Morif. hijt. 3.p: 295.

Daucus petræus glaucifolius: Barb. hift: $3 \cdot p \cdot 5 \delta$.

Habitat is Gallia. 2

\section{BUNIUM.}

1. BUNIUM. Hort. cliff. 91, Roy. lugab. 107:

Bunium bulbo globofo. Sauv. morsp. 250.

Buibucaftas unm.

Bulbocaftanum majus, folio apii. Bnub. pin: x6z.

Nucula terreftris. Lob. bift. 429.

Habitat in Germania, Anglia Gallia.

\section{CONIUM.}

1. CONIUM feminibus ftriatis. Hort. ups. 92. Fl: Suec. macelatim. 226. Roy. ingdb. $10 \%$

Cicuta major. Bauk. pin. Ito.

Cicutaria major vulgaris. Cluf, bift. 2. p. 200.

Habitat in Europx cuitis, agris; ruderatis. $\delta$

2. CONIUM feminibus aculeatis. Hort. cliff. y2. * Rog. africnitum: lagatb. 10\%.

Ciucalis atricana, folio minore rutx. Boerb. lugab. $x$.

p. $0_{3} \cdot t \cdot 63$ :

Habitat in Africa.

3. CONIUM feminibus radiato fpinofis. Roy. Iagdb roT. Royenif Habitat - ....

Q. 2 I. SE- 


\section{SELINUM.}

Sylvefite. I.SELINUM radice fuffiformi multiplici. Hort. cliff.93.

Hort. upf. 59. Roy. lugdh. Ioú.

Apium fylveftre, lacteolucco turgens. Baub. pin. 153 Tyffelinum plinii. Lob. hift. 4.09. Morif. hift. 3. p. 319. S: 9. t. 1\%. f. 2.

Habitat in Harcynia, Galliz. 2

eqalubre. 2. SELINUM fublactefcens, radice unica. Hall. belr' 443. Selinum foliolis \& lacinulis oblongo-linearibus. Guett. ftamp. 2. p. 70 .

Tyffelinum paluftre lactefcens. Fl. lapp. r 10. Fl Suec. 227. Hort. cliff. 92. Rov. lugdb. 116.

Sefeli paluftre lactefcens. B̈auh. pin. 162 . prodr. 85. Habitat in Europx Septentrionalis paludibus. $z$

\section{A THAM ANTA.}

Libanastis, 1. ATHAMANTA foliis bipinnatis planis, umbella hemifpharica, feminibus hirfutis. Fl. Juec. 226. Libanotis pinnulis circa coftam decuffatis. Hall. belv? $45 \mathrm{I}$.

Libanotis minor, apii folio. Baub. pin. 157.

Daucus montanus, apii folio. Baub pin. I 50 . prodr. 77 . Daucus montanus, pimpinella faxifrag $x$ hircinz folio. Pluk. alm. I 29. t. 173. f. I.

Habitat in Sueciæ, Germaniæ pratisficcis apricis. $z$

fibriss. 2. ATHAMANTA foliis pinnatis incifo-angulatis. Selinum foliis fimpliciter pinnatis incifo-angulatis. Hort, $\operatorname{ups}$. 60. *

Habitat in Sibiria. 2

Oreoselinxm 3. ATHAMANTA foliolis divaricatis.

Selinum foliolis ovato-acutis acute ferratis \& incilis. Hort. cliff. 92. Roy. lugdb. 106.

Selinum foliolis lacinulisque oblongo-linearibus. Guett. ftamf. I. p. 70.

Selinum pinnis ad angulos obtufos pinnatis: pinnulis incifis non ferratis. Hall. belv. 444 .

Apium montanum, folio ampliore. Baub. pin. 153. Oreofelinum. Cluf. bift. 2. p. 195. Riv. pent. 8. Habitat in Germanix, Galliæ, Anglixe collibus apricis $z$

fictic. 4. ATHAMANTA foliis inferioribus nitidis, umbellis primordialibus fubfefilibus, feminibus pilofis. Hort $x p \int .60$. 
Athamanta foliolis multifidis planis, feminibus villofis. Hort. cliff. 93. Roy. Ingdb. 97.

Daucus ficundus liculus, fophix folio. Zan. bift. 80.

Habitat in Sibiria. 2

5. ATHAMANT A foliolis linearibus planis hirfutis, pe-cretenfis. talis bipartitis, feminious oblongis hirfutis. Mat.med.

143.

A thamanta foliis capillaribus, feminibus hirfutis. Hort. 93. Roy. Ingdo. 97.

Daucus foliis foniculi tenuilfmis. Bauh. piss. 1 50.

Daucus creticus. Cam. epit. 536 .

Habitat in Helvetia.

6. ATHAMANTA foliis multipartitis: laciniis lincari- anmu. bus teretiufculis acuminatis. Roy. lagdb. 98.

Myrrhis annua, femine friato villolo, incana. Morif. uimb. 67.

Myrrhis tenuifolia annua cretica, femine lanugine alba pubelcente Morif. bift. 3. p. 302.

Habitat in Creta. $\odot$

7. ATHAMANTA feminibus membranaceo-ftriatis, fo- chinen?t. liis fupradecompofitis lavibus multifidis.

Havitat - - Chinensem dixit Bartbram, quifeminn milit ex Virginia.

Caulis angulatus, levis, credus, parsim flexwofus. Folia Cberopbylli, levio. Umbella manus expanfa, aiba. Sernina fingulas alis longitndinalibus parvis; involss. crsum displex.

8. ATHAMANTHA Soliolis capillaribns, feminibus gla- Aicum. bris thriatis. Hort. cliff. 93. Hort. wp. 60. Mat. med. I 44. Roy. lugdb. 97. Sazr. man $[p .256$.

Mcum foliis ancthi. Baub. pin. 148 .

Mieum. Dod. perapt. 305.

Habitat in Alpibus ltalix, Hifpanix. Helvetix. 2

\section{PEUCEDANUM.}

1. PEUCEDANUM toliis quinquies tripartitis filifor- ojficinole, mibus lincaribus.

Peucedanum foliis quinquics tripartitis lineari-fubulatis integerrimis. Hort. cliff. 93. Hort. 12pj. 60. Mat. med. 126. Roy. lugdb. 98. Sauv. monfp. 182. 257.

Peucedanum. Baub. hift. 3. p. 36. Kaj. bifl. 416.

c. Pcuccianum germanicum. Bash. pin. 149.
Q.3
6. Peuce. 
B. Peucedannm majus italicum. Both pin. It9.

Habitat in Furoda asfiralioris pratss ping vibus; 4

areine. 2. PEUCEI)ANUM foliolis linearinas ramolis. Hert. cliff. 94. Kov. liggth. 98.

Ferila, colits libanulidis brevioribus, alpeftris, umbellis amplifimis. Hierts. lagils. I. p. as. liabitat -

Silaus.

3. PEUCEDANUM follolis pimatifidis: laciniis oppofitis. Hori. clift: 94. Roy. lugdb. 98. Jauv. monfp, 257.

Sefeli pratenfe. Baub. pin. I62.

Siler alievin pratenfe. Dod. pernpt. 3ı0.

liabitat in ticlvetia, Narbona.

modon. 4. PEUCEDANUM foliolis alternatim multifidis. Hort. cliff. 94. Rov. insab. 98.

Silaum (qnoi Ligruficum creticum, folio foniculi, çaule nodolo. Tournef. cor. 23.) Bocrb. lugdb. I. p. 51. Habitat in Creta.

\section{CIITHMUM.}

martinum. 1. CRITHMUM toliolis lanceoiates carnofis. Hort. cliff. Hort. "ups. OL. Ray. Irgáb. 98. Jazr' monsp. 258. Crithmum f. Fenciculum maritinum mirus. Bazb. pin. $28 \%$.

Foniculum marinum f. Empetrum 1. Calcifraga. Lob. 1c. $3 y^{2}$.

Mabitut ad oceani Europxi Sitora 2

racturn 2. CRITHMUM foliolis latcralibus bis trifidis. Horf clity. 08. Roy. iugló. 58 .

Apinin prenaicum, thaplix facie. Tousnef. inft. 305. Habitat in pyrenais.

\section{CACHRYS.}

Ethnotis. 1. CACHRYS folitis pinnats: foliolis acutis multifidis. Hort cliff. 91. Koy. lugdb. 99. Souv. monjp. ros. Cachrys femine fungoro fulcato plano minore. folis peucedani anguftis. Morij. hift. 3. p. 267. j. 9. t. r. f. i. 6 .

Libanotis rerulze folo, femine anguloro. Baub. pas. 158 . thabitat in Sicilia, Monfpelii. 2\%

$$
\text { FERULA. }
$$

rommanis. I. FER ULL foliolis linearibus longifinis fimplicibus 
Hort. cliff. 95. Itort. zups.6r. Roy.lugdb.99. Sauv. monsp. 257.

Ferula femina plinii. Baub. pin. I48.

Fcrula. Doi. pempt. $32 \mathrm{I}$.

Habitat in Europa auftrali. 2

2. FER ULA foiliolis multipartitis: laciniis lincaribus pla- glancr. nis. Hort. cliff. 95 . Roy. lagadb. 99.

Ferula folio glauco, femine lato oblongo. Baub. bift. 3.p. 45 ,

Habitat in Sicilia, Italia. 2

3. FERULA foliolis laciniatis: lacinulis tridentatis inx- tingitazu. qualibus, Hort. cliff. 95. Hor: upp.61. Roy. lugdtb. 99.

Ferula tingitana, folio latifimo lucido. Herm. par. 165. t. 105 .

Habitat in Hifpania, Barbaria. z

4. FERULA foliis pinnatifidis: pinnis linearibus planis Fernlage tritidis. Hort. cliff. 95. Ro\% ling dl. 99.

Ferula latiore folio. Morif. bijl. $3 \cdot p \cdot 309 \cdot f \cdot 9 . t .15 . f .1$.

Ferulago latiore folio. Baаb. piat. I 4 s.

Habitar in Sicilia.

5. FERULA foliorum pinnis bafi mais, foilolis fetaceis. oricntalis. Hort. cliff. 95. Ko\%. lugab. 100.

Ferula orientalis, folio \& facie cachryos. Tournef. cor. 22. $\operatorname{stin} .3 \cdot$. . 239. 2. 239 .

Habitat in Oriente.

6. FERULA foliorum pinnis utringue bafi anctis: folio- mooides. lis fetaceis. Hort. chiff. 95. Roy. lugdb. 100.

Laferpitium orientale, folio mei, Hore luteo. Tournef. cor. 23.

Irabitat in Oriente.

7. FER ULA fnliolis appendiculatis, umbellis fubfesfilibus. nodiffira.

Ferula foliorum alis urringue auct s. foliolis linearibus integerrimis, umbellis terminatricibus libfeffilibus. Roy. tugdb. ICO. Hort. upf. 6I.

Libanotis ferula folio \& femine. Bazk. pin. is 8.

Yanax afclepium, ferniæ facie. Lob. ic. 783.

Habitat in Eurcopa auftrali, Iltria. 2

8. FERULA lucida sanadenfis Gron, virg. $14 \%$. Hort. enualenfin, upr. 6I.

Habitat in V'irginia. 4

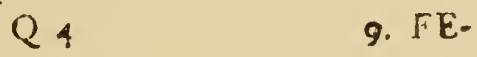


Afafetida. 9. FERULA foliolis aiternatim finuatis obtufis, Mat. med. II 8 .

Atra foetida difgunenfis umbellifera liguftico affinis. Krempt. amon. 535. t. $53^{6}$.

Hubitat in Peria. 2

\section{LASERPITIUM.}

latifolism. T. LASERPITIUM foliolis cordatis incifo-ferratis. Lart. cliff. 90. Fl. juec. 220. Mat. mid. 22\%. Roy. trgdio. Tor. Hall. helv. 440 .

Litanotis latifolia altera $t$, vulgatior. Bcub. pin. Irt. Libanotis lotivoin ma!or. Bantion. is\%.

Sereli xthiopicum horba. Dod. nempt. 312.

Habitat in Europas nemaribus facris 2

tricbm. 2. TASERPITIUM folinlis trilobis incifs.

Lioailotis Jatifolia, aquiegla tolio. Basb. pin. 157. proair. 83.

Angelica foliolis tripartitis: lobis fuverne incifis obtufis. Roy. lugdi. 104:

Habitat in Corgano monte. \#

galicum. 3. LASERPITIUM fololis cuneiformibus furcatis.

Laterpitiun foliolis ramulofis fellitbus. Roy.lmgab.ror Lacerpitium foliolis quinquelobis. fiort. clift. 96.

Laropitium galiicum. Banh pin. 1 5o.

laferpitim e regionc nafilix sllatum. Bauh. bijt. 3 . p. 137.

Hatitat in Europa arfofrali.

ตุusafifoii- 4. LASERPITIUM foliolis lanceolatis integerrimis feswit?, filibats. Furt. cliff. o6. Kay. lugdb. 102.

Laferpitiun angufifolium majer, fegmentis longioribus \& indivitis. Morif. kilt. $3.7 .321 .6 .9 . t .19 .6 .9$.

Laferpitum tolis longioribus dilute virentibus coijugation pofitis. Pluk. alm. 207.t. Iox. f. 4. Hnbitat in Europa auprali. 4

twenisum. 5. LASFRPITIUM foliolis lancelatis integerrimis: extimis coalitis. Hort. clitt. yo. Brenim. lapl. 205.

Lalcrpitiun foliis radicalibus parcuifin mis. $R y y$. lugdb. 103 .

Laferpitium dnucoides prutenicum, rifcofo femine. Breyz: (ent. 167. 2.84.

Hobrtat in Bornfla, Liplia. 2

6. LA- 
6. I,ASFR PITIUM foliolis lanceolatis integerrimis pe- $s_{i t u r}$

tiolatis. Lort. cliff. 96. Mat med. 124.

Liguticum quod Seleli officinarum. Baub. pin. 162.

Siler montanum. Morif. kilt. 3.p. 276. . .9.t.3. f. I.

Hovites in Alutria, Helvetia, Gallia. 2

7. LASERPITIUM foliolis oblique cordatis, petiolis chironizw. hirfulis.

Panax Heracleum. Morif bift. 3. 3 I5. f. g.t. I7. f. I.

Panat patinace folio Baub. piz. 156.

Panaces peregrinum. Dod pimpt. 309.

Siabitat Monfioclii. 3

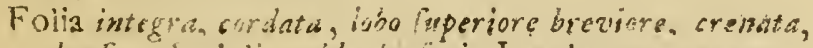
obtufu. Fetioli valde borjuti. Involucrim par wam, tam univerfale, quam partiale; binc dizerla a Paftinaca Coftina.

\section{HER A CLEUM}

7. HERACLEUM foliolis prmatifidis. Hort. eliff. ro3. Sphondylium Fl. Suer. $221 . R y$. lugdb. $2 \times 3$.

Sphondylium vulgare hid fitun. Banb. per. 157.

B. Sphondvlium hirlutum, folis angultioribus. Bryb. pin. 157. predn. 83.

Habitat in Europe nemorofss. I

2. HERACLEUM foliis pinnatis: foliolis quinis: in-fimismm. termedis lethlibns, corollulis uniformibus. Hort. wff. 65.

Habirat in Sibiria. ह

Flures buins viridi.lutei. at prioris slib.

3. HERACLFUJM foilis pinnatis ; folic lis quinis: in-Panaces. termedis feflilibus, Horibus ratiatis. hort. up $6_{5} 6_{5}{ }^{*}$

Heracleum foliolis palmatis erratis. Hort. cliff. ro3. Rov. Ingdó. I I 2 .

Panax Chondylii folin f: Heracleum. Baxb. win. 157. Habrtat in Apenninis, Sibina. d

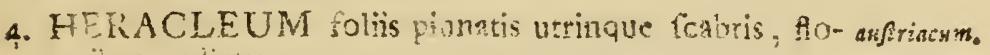
rions radiats.

Sphondylium alvinum paryum. Bash. pizs. Ir7.

Habilat in Alozous atiltix.

Planta pedalss. Volia pinsata: foliolis s. ounto-oblongis.

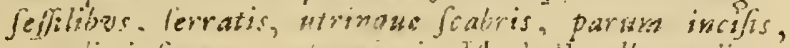

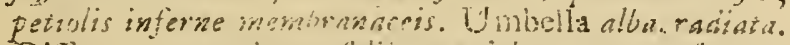

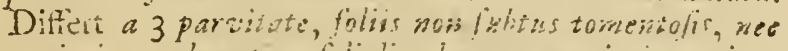
extimis coadunatis; foliolis deram nongis integris. 
alianm. 5. HERACLEUM foliis fimplicibus, floribus radintis. Sphondylium aipinum glabrum. Bazb. pin. 157 . prodr. 83. t. 83 .

Spholidylium montanum glabram, albo fore. Burs ie. 55 :

Habitat in Helvetix Alpibus.

\section{L.IGUST'ICUM.}

revificum. r. IAGUSTICUM foliis multiplicibus: follolis fupcine inciris. llort cliff 97 Hort. ups. G2. Mat.med. 1.19. Roy. lngell. 104. Sauv. monlp. 26r

Ligulticun rugare. Baub. pra. $15 \%$

Levilticum vulgare. Miorif bifl. 2. p. 275. S. 9. t. 3 . f: $\mathrm{r}$.

Habitat in Apenninis Liguriæ. 4

scothicum. 2. LIGUSTICUM folits biternatis.

Ligulticum foliis duplicato-ternatis. Hort. cliff: 97 . Fl Juec. 232. Rov. lugdb. 104. Gron. virg. 31.

Ligufticum humilius fcothicuni. Pluk. alm. $217 . t .96$. $f: 2$.

Apium maritimum. Fl. lapp. 107.

Sefeli maritimum foothicum. Herm. par. 227. t. 227. Habitat ad litora Muris in Anglia, Suecia.

pelepornefit- 3. LIGUSTICUM foliis multiplicato-pinnatis: foliolis cum. pinnatim incifis. Hort. cliff. 97. Koy. lugdb. 104. Sauv. monsp. 259 .

Cicutaria latifolia toetida. Baub, pin, 16r.

Sefeli peleponnefunce. Cian. epit. It4.

Habitat in Peleponefiacis \& Rheticis montibus nemorofis. $\overrightarrow{0}$

aufrincum. 4. LIGUSTICUM foliis bipinnatis: foliolis contuentibus incifis integerrimis.

Sefeli montanun, cicutæ folio, glabrum, Baub. pir. I 61 .

Scfeli i. montanum pannonicum. Clul. bift. 2 p. I93. Habitat in Aultria alpinis.

\section{ANGELICA.}

Archangeli- I ANGELICA foliorum impari lobato. Fl. lapp. ror. cr. H. luec. 233. Mat. ined. 120. Hort. cliff. 97. Roy lugdb. 103 .

Angelica Fativa. Bauh. pin. I55.

Angelica major. Dod: pempt. 318, 
R. Archangelica Clas. hift.2.p. 205.

Habitut in Alpibus Lapponix, ad rimulos. J

2. ANGELICA foliis aquaibus ovato-lanccolatis fer-lylofris. ratis. Hort. cliff. y7. Fl. Juec. 234. Mint. med 121.

Gion. ving. 3i. Hall. belve 444. Koj. lingdir. 103.

Angelica fylueltris major. Bash. pin. 155.

Angelica fylveltris iod.pempt. 318. Fo lapp. 102.

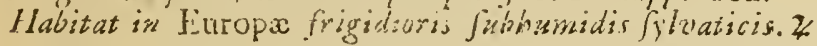

3. ANGELICA extino foltorum pari coadurato: tolio atropyrowterminali petiolato. Roy. la'gib. 103.

rea.

Angelica canacunis atropurpurea. Ciurn. canadig8.t. I99.

Hubicas in Canada.

4. ANGELICA foliolis xqualibus ovatis incifo-ferratis. Imcian. llurt. wiff. 97. Hort. aps. 62. Koy. tugdh. 103.

Angelica lucida canadentis. Corn casat. 196. t. 197. inoril hilt. 3. D. 231. l. 9. 4. 3. f. 8.

Habitat in Canada. of

\section{SIUM.}

1. SIUM folits pinuatis, umbella terminali. Hort. cliff. latifolium, 98. Fl. fuer. 235 . Roy. lurdb. 104, 11ull. helv. 435. Sium latifolium. Brash. pins. 1 is.

Sim. Riv pent. 7\%.

Habitat in Europx rivulis $\mathrm{g}^{2}$ ad ripas faludofas. 2

2. SIU M foliis pinnatis, umbellis axillaribus feffilibus. Hort. nodifforun, ciiff. 98. Roy. lugab. 105. Sauv. monyp. 23 I.

Sium ayuaticum procumbers, ad alas Horidum. Moris. bift. $3 . p_{0} 283 \cdot 5 \cdot 9 \cdot t \cdot 5 \cdot f \cdot 3$.

Havitat in Europa ad ripas fluviorum.

3. SIUM foliis pinnatis, floralibus ternatis. Hort. cliff. 98. Stfarum. Havt. upf. 62. Roy. lugdb. 104.

Sifarum geimanorum. Biush. pan. 155 .

Sifarum. Dod. pempi. 681 .

Habitat in China? ?

4. SIUM foliis ferratis pinnatis rameis ternatis. vide $M_{a t}$. Ninfs. med. $117 .+$

Sifrum montanum coræenie, radice non tubcrora. K.erntf. amuen. SiT. t. Sis.

Habitat :n China. 2

5. SIUM folis pinnatis, foliolis lanccolatis fubintegerrimis. rigidins. 
Pimpinella foliolis lanceolatis glabris acuminatis fapius integerrimis, rarius ferratura notatis. Gron. virg $\cdot 32$. Ocnanthe maxima virginiana, pronix temine foliis. Moiij. bifi. 3. p. 288. . I I. t. $7 . f .1$.

Habitat in Virginia. $\%$

Falearin. 6. SIUM follolis lincaribus decurrentibus connat s, Hort. cliff: 99. Roy. lugdb. 105. Sazv, monsp: $23^{2}$.

Eryngium arvenfe, foliis ferratis. Bauh. pin. 386. Ammi percmic repens, Marif. hift. $3 . p .294$ f. $9 . t$.

8. t. 1.
Habitat in Fandra, Helvetia, Bonemia, Alfatia, Gailia. 2

gracsm 7. SIUM foliis bipinnatis, Hort, chiff. 98, * Roy.lugdi.

Ligulticum grxcum, folio apii, Tournef, cor, 23.

Habitat in Græcia,

ficulum. \&. STUM follis radicalibus ternatis, caulinis bipinnatis. Roy. ingdb. 105.

Myrrhis folits pattinaca late virentibus. Tournef. cor.22. Daucus, partinaca folio. ficulus, Zax, bift. 78 . t. 30. Habitat in Sicilia.

\section{SISON,}

Amowiнm. I. SISON foliis pinnatis, umbellis creetis. Roy. ho áo. roy. Saur, manfp. 2,j2.

Sifon foliis pinnatis. Hart, cliff. $9^{8}$.

Sifon guod A momum orticinis nottis. Bauh. pin, 154. Petrofelinum macedonicum ficlivii. Dod. pempt. 69\%. Habitat in Anglia bumettis lutuls.

segetsm, 2. SISON foliis pinnatis, umbellis corntis, $R$ oy, $l$ mgth. 105. Hori. upj: 63.

Sium terrettre, unbellis rarioribus, Morif. bift. $3 \cdot p$. 283. $\int .6 . t .5 . f .6$.

Habitat in Anglix agris inter fegetes. o

Enatenrc. 3. SISON foliis ternatis. Hort. cliff. 9\%. Gron, wirg. I4\%. Roy. lingdb. 106.

Myrnis canadenifis trilobata. Morif. hift. 3. p. $301 . f$. 9. t. Ir. f. 4 .

Ilabitat in Ameriaca feptentrionals. 2

4. SISOM Toliolis caut
Mat. aned. 140. 
Anmi lacinulis foliorum caulis capillaribus. Hort. clitj. S9. Roy. lugdb. 96.

Ammi parvum, folis foeniculi. Bash. pin. I59.

Amini. Cum. epit. 522 .

Habitat in Apuia, AEgypto. ()

5. SISON repens, umbellis bifidis. It. fran. 39\%. *

imuทภลเนm.

Siun folis lubmerlis capillaribus, emerfis pinnatis. Roy.

lugdb. I05. Suuv meth. 232

Siun minimum, foliis inis ferulaceis. Morif. bif. $3 . p$. 223. f. 9. t. 9. f. 5 .

Sium minimum umbcllatum, folio varians. Pluk. pbyt. 6I. f. 3 .

Habitat in Europx inundatis.

6. SISON foliolis verticillatis capillaribus.

Carum foliolis fetaceis verticillatis, radice napiformi: tam. Sazv. monfp. 168.

Bunum bulbis oblongis, Sauv. monsp. 256.

Oenanthe foliis pinnatis: foliolis lincariter laciniatis. $D_{a-}$ lib. parif. 90.

Daucus pratenfis, millefolii paluftris folio: $B a k b$, pin. 150.

Daucus pratenfis. Dalech. bift. 718 .

Carvi foliis tenuifimis, afphodeli radice. Tournef: inft. 90.

Hábitat in Gallia, Pyrenxis. 4

Involucrum buic miviverfale \&o partiale.

\section{BUBON.}

I. BUBON foliolis rhombeo-ovatis crenatis, umbellis uscedonis numerofifimis. Hort. cliff. 95. Hort. upj. 62. Mat: curm. med. I 33. Roy. lugdb. 100.

Apium macedonicum. Bauh. pin. 154.

Petrof clinum macedonicum. Lob.ic. 708.

Habitat in Macedonia, 8

2. BUBON foliolis rhombeis ferratis glabris, umbellis Ga'banm. paucis. Hort. cliff. 96. Mat. rned. 132. Roy. lugdb. IOO.

Anifum africanum fruticefcens, folio anili, galbaniferum. Pluk. alin. 3I. t. I2. f. 2.

Ferula africana galbanifera, folio \& facie liguftici. Herm. par. 163.1 .163 ,

Habitat in Athiopia. 5 
gummife. เพพ,

Mgidins.

currirnm. 1. CUMINUM. Mat. med. I 39.

Cuminum femine iongiore. Barab. pin. I46:

Cuminum fativum. Carn. epit. 518.

thabitat in Egypto, Eihiopia. O

\section{OENANTHE.}

ffinlofo.

2. OENANTHE foliis omnibus multifidis obtufis fubxqualibus. Hort. cliff. 99. Fl. juec. 237. Roy.lugdb. 107.

Oenanthe chriophylli foliis. Bauh. pin. I62:

Uenanthe cicurx facie, fucco viroio crocante. Lob: adv. 326. Aat. angl. 1747: n. 490.p. 235. t. 3 .

Habitat in Europæ paludibus. 2

proliferd. 3. OENANTHE umbellularum pedunculis marginalibus Iongioribus ranofis mafculis: Hort. upf. 63.

Oenanthe flofculis difei fellilibus radii pedunculo ramofo elcvatis. Vir. cliff. 24. Roy. lugdb. ros.

Oemnthe flofculis ribdiantibus umbcllarum proliferis. Hort. cliff. 99.

Oenanthe prolitera apula. Baub. pin. I63. Morif. bift: 3. p. 289. f. 9. t. T. . .5.

Habitat in Sicilia, Apulia. is 


\section{PENTANDRIA DIGYNIA.}

* OENANTHE fructibus globofis. Hort. cliff. 99. glowiora. Roy. lugdb. IOS.

Cenanthe lufitanica, femine craffiore globofo. Touraef. inglt. 313 .

Hatilat in Lufitania.

5. OENANTHE foliolis radicalibus ovatis incifis, cau-pimpinellow linis integris linearibus longilimis fimplicioribus. de: Hort. cliff: 99. Roy. Iugdb. 108. Sauv. monsp. 259.

Oenanthe apii fulio. Baub. pin. 162.

Oenanthe paltinace fylveftris folio, remine atriplicis. Bassh. pin. I6z.

Oenanthe aquatica pimpinclla faxifragx divilura. Pluk. alm. 268: t. 49. $f: 4$.

Habitat Monfpclii $\mathcal{F}^{\circ}$ in Europa auftrali.

\section{PHELLANDRIUM.}

r. PHELLANDRIUM foliorum ramificationibus di- aquatictrn. varicatis.

Phellandrium. IIrt. cliff. roo. Fl. Suec. 238. Roy. lügdb. 108. Lod. pempt. s9I

Cicutaria paluitris tenuifolia: Baub. pin, r6r.

Hulbitat in Europe foljis. ơ

2. PHELLANDRIUM caule fubnudo, foliis pinnatis. Antelivin. Meun alpinum, umbeila purpurafcente. Baub. jin. 48 . Mutellina. Paub. bi/t. 3.p. 60. Cam. epit. 8. Habitat in Helvetia. " 4

\section{CICUTA.}

I. CICUTTA umbcllis folio oppofitis, petiolis marginaris pero/s. otitufis.

Cicura. Hort. cliff. 100. Mat. med. 129. Fl. Suec. 2 jy Ruy. lugdb. IOQ.

Cicuta aquatica. Fl. lopp. I03.

Sium crucx folio. Baub. pin. I 54 .

Habitat in paludibus Europx fterilibus. 2

?. CICUTA ramis bulbiferis.

Ainm foliorum lacinulis iapillaribus, caule angulatu. bu!liferi. Gron. virg. 3 I.

Urmbellifera aquatica, foliis in minutifima \& plane capil. laria legmenta divifis. Raj Suppl.26n.

Habitat in Virginia, Canada. 
256 PENTANDRIA FIGYNIA.

9amestata. 3. CICUTA folionmu ferfuturis mucronatis, petiolis inembranaceis apice bilobis.

Aigopodium foliolis ianceolatis acuninatis ferratio. G.nn. virg. 32:

Angelica caribæarum ciacior, olufatri folio, flore albo, ferninibus luteis ftriatis, cumini odore ćlapore. Pleḱ. alm. 31. $t .76 . f .1$.

Angelica virginiand; ioilis acutioribus, femine friato minore, cumini fapore \& odore. Ailorif: bifk. $3 \cdot \hat{p} \cdot 28 \mathrm{i}$. Habiont in Virginize aqko/is:

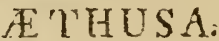

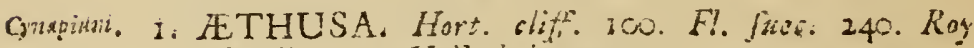
lugdb. 109. Hail. beiv. 433 .

Cicuta minor petrofelino fimilis: Bawh. pin, 160.

Cicutaria fatua. Lob. ic. 280 .

Habitat inter Eurods olers. 9

\section{COKIANDRUM.}

fartsum, i. CORIANDRUM tructibus globofis. Hort. tliff. 1co.

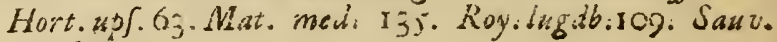
monsp: 200:

Coriandrum inajus. Baub: pin, 158 .

Coriandruns. Cam: epit. 523 .

Habitat in Iralia agris: $\odot$

tefticulatum: 2. CORIANDRUM fructious didynis. Hort. cliff. 100 . Roy. lugdb. 1 ug. Sauv. monep. 260 .

Coriandrum minus tefticulatum. Baub: pin. 1s $\delta$. Pla: ulm: I 20: t: IOG. f. 2:

Coriandrum ininus odorun. Baun: hift. j p:91, Habitai in Europæa dujtralis agris: $\odot$

\section{SCANDIX.}

odorate. I. SCANDIX ieminibus fulratis angulatis. Hort: cliff 101: Hort. wo? 64: Roy: lugdb: III: unbellarum difen malculo.

Myrrhis major, Cicutaria odorata. Baub: p:n, 160; Myrrhis. Dod: pempt: 701:

Habitat in alpibus Alvarnia: $*$

Puter. \& 2. SCANDIA feminibus lavibus roltro longitimo. Hort. cliff. Ior: Hort: upf: 6a. Roy. lugab. III. Scandix, femine roftrato, vulgaris. Basb: pin: 152 . 
Peeten veneris. Cam. epir. 302.

Aubial inter Germania Guropt anjtralioris fegeres. (5)

3 SCANDIX feminibus nitidis orato-fubulatis. Mort. Cerefolium. cilff r10. Fl. Juet. 242. Mlat. sneid. 13T. Gron. Wirg. 31. Koy. Kazth. I11.

Charophillum Cominibus lavibus, umbellis ad nodus fefrilibus. Bxlom. lipf. 402.

Charophyllum faticum. Basts, pin, isz

Charefolium. Dod. pemit. 700.

fiabifat in apris EF arvis Europa aullialiaris $\odot$

SCANDIX reminibus ovatis hifpidis, corolls uni-minifom formibus, caule lavi.

Scandix leminibus hipiäis. Hort. chiff. tor. Fl. jues. 241. Roy. layd6. is 1 .

Mvrrhis fylvellis, feminibus alperis. Baub. pin. 160.

Myrthis fylveftris equicolorum. Coltmn. epphr. I. $p$. 110. t. 112.

Hnbitut in Europx aggeyibus terrexis.

5. SCANDIX ferninibus fubulatis hifpidis, Horibus ra- aufialir, diatis, caulitus levibus

Scandis ieminibus roftraris patulis pedunculo breviori-

bus. Saru monfp. 260.

Sicandix cretica minor. Bauh. pin. is 3.

Scandix. Semine roftrato, italica. Baub. pradr 78.

Anifomarathrum. Col. ecplor. 1. p. 39. 1. go.

Habital in G. Narbonenfi; Italia. Creta. $\odot$

6. SCANDIX feminibus fubcylindricis hifpidis, caule nodofa hifoido, genlculis tamidis.

Charophyllum anticulis tumidis, umbella univerfalitrinidil Horl. clitt. 102. Roy. lugdí. 112.

Cerefolium annuam nodofum, temine afpero majore. inorij. hijt. 3. p. 303. S. 9. t. 10. f. 4 .

Myrnhis nodotia annua, femine afpero. Morif. Mlof. 288.

Mabitut in Sicilia. O

7. SCANDIX feminibus pedunculo villofo brevioribus. grandifura. Roy. lugdb. 111.

Scandix oricutalis, Hore maximo. Taurnef. cor, 23

Habitat is Oricnte.

8. SCANDIX feminibus nitidis ovato-fubulatis, foliis procumbens decompolitis. Gron. virg. I47. 
Cerefoliun virginianum procumbens, fumarix foliis. Morif. bif. 3. p. 303. f. II. t. II. f. ult. Hisbitat in virginia.

\section{CHAROPHYLLUN.}

\section{* Foribus amibus brmapradicis.}

fyliefire. I. CI]AROPHILLUM nofculis orritibus fertilibus, caule aquali.

Charophyllum feminibus Javibus nitidis, petiolis raneis scqualibus. Hort. rliff. 101. Fl. Juec. 243. Ruy lugdb. 112. Alat. mal. IA?.

Charophyllum Sylvetre perenin, cicuta folio. Tounnt. inft. Ir t. Fl. latp. ro.4.

Myrrhis fylveftris, fominibus lavibus. Bamb pin. 160 Cicuraria rulgaris. Dod. pempt. 701.

Ilabitat in Europa pomaris of caltis. 20

hulborn, 2. CHEROPHYLLUM caule lavi: geniculis tumidis.

Chxrophyllum folits fupradecompofitis: caulinis articulis lavibus fuperne incrattatis. Hart. upf. 64.

Chropinyllum radice turbinata carnofa. Hort. cliff. 102. Roy. lugdb. I 12 :

Cicutaria bubola. Baub. pin. 16r.

Myrrhis faters. Riz. pent. 49,

llabiut in Aliatia, Hungaria, Helvetia. $\delta$

* Floribus difci malcuitis.

Nenulum. 3. CHAROPHYLLUM caule fcabro: geniculis tumidis.

Chrerophylum caule maculato: geniculis tumidis. Hort. cliff. 102.Fl. Jucc. 24 t. Roy. lugdb. I I2. Gort. gelr. 59 .

Chierophyllum rylvetre. Baub. fin. 152 .

Myrrhis annua vuigaris, caule fuicu. Morif. bift. 3.p 302. f. S. t. I0. f. 7.

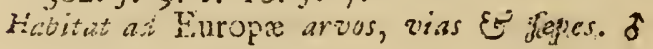

kirfitum. 4. CHEROPHYLLUM caule æquali, foliolis incilis acutis.

Charophyllum foliolis diffectis, petiolis ramifers um rerialibus ueringue membrana auctis. Ilort. clije. 10.1 Roy. lusgdi. I11. Sazv. monjp. 262.

Cerefolium lorifolim hirfutum album \& rubrum. Morif. big. 3. p. 304 . . 9. 5. 10. f. 6. 
Cicutaria paluftris latifolia alba. Bashs pin. Ión.

Cicutaita paluftros latiolia rubrat. Barb. pin. 161.

Myrrhis peremnis alba minor, toliis hirlutis, femine aureo. .11. Haill. jen. 282. t. 5 .

Myrrhis broccenbergenfis. Bawh. pin. 160.

Seleli montanum, cicutr folio, fubhirfutum: Bauh.pis: I6I: prodr. 85 .

Habitat in dipibus Helvetia. z

5. CHEROPHYLLUM caule xquali, Foliolis ferratis aromaticnm. integris.

Chxrophyllum foilolis lanceclato-ovatis terratis inte-. gris. Hort. cliff. 102. Roy. J"stb. 112.

Cerefolium, rugoto angelicx folio, aromaticum. Busc.: maf. 2. p. 20.t. 19.

Angelica fyiveitris hiriuta inodora. Disus. pin, $1 ; 6$. prodr. 82 .

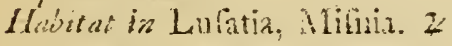

6. CHEROPHYLLUM fruticofum.

Cicula arbor virginiana. Pluk. arait. $4 y$.

Cicutaria arbor viginiana. Kal, fapt. 257.

llabitat. in Virginia is

Cialis fratelcens. Folia charopblli, aropla, hapadecompunrborefesss.

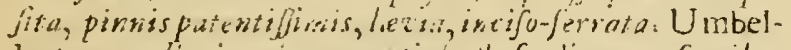

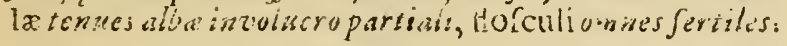

\section{SESELI.}

1. SESELI caule declinato, umbeluis ante flotefcontiam pimpivelloi. nutantibus.

Hebitat in Furopa aufruliore. 2

Radix perensis, Folia tinnata pinnis inuttifidis, jegmentis alternis: hae ctiom altepration jert t, fegmentis li-

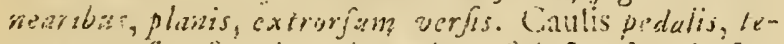
res, ante fiovefentian decumbins, jub florefonsta ferine cactas foliob uno alteruve: petiolo mimbranaceo, ipalaformi, obisazo; equo yedrencalius fimplex. Um. bella ante flavelcentisin rutantes ut in Dimpinella

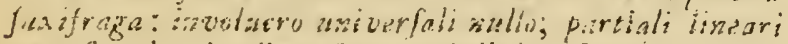

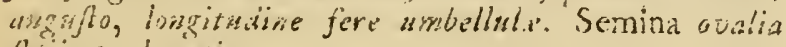
forits 3. elevatis:

2 SESELI petiolis ramiferis membransceis oblong is inte montmkm.

yris, folits caulinis anguftiffimis. Horl cliff. 102. Ruy.

liggub. IIs. Dalib. parif. 92. Saru. monfp. 256.

Meun latitolium adulterinum. Basio pin. 148. 
Saxifraga montana minor italica, foliis in breviores partes divifis. Maril. bift. $3 . p .2 .72 . f .9 .+2.2 . f .1$. Hubitat in Gallia, Italix cullibus. 2

Iแนенm. 3. SESELI petiolis ramiferis membranaceis oblongis inregris: foliolis fingularibus binatisque. Guett. jlamp. 64. Foniculum fylveltre, glauco folio. Tournef. inft. 3,1 r. Daucus, glauco folio, fimilis friculo torruoto. Baub. bijt. 3.p. I 6 .

Saxitiaga nontana minor glauca \& rigidior. Morif. bstt. 3. p. 273 .

Halitat in Gallia. 2

involucellorkm foliola fopius coariunata funt.

elotu. 4. SESELI petiolis rameis membranaceis oblongis ntegris, foliolis binatis ternatisque. Gutt. Jiamp. I. p. 64. Dalib.parif. 92 .

Fanculum fylvelinc clatius, ferule folio longiore. Tusynet. inft. $31 \mathrm{I}$. fill. parif. 54. Sauv. munlp. 250. Apiun montaium, tolio tenuiore. Banb. yin. I 53.

Habiat in Gallia. 2

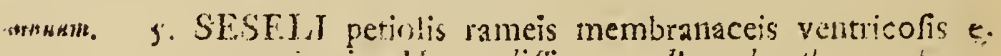
marpinatis. Hort. diff. 103. Koy. Ingdb. 112.19au. reosip. $2 ; 6$.

foniculum iyjveltre annum, tragof clini odore, umbeila aiba. Fiall. parif. 54.t. 9.f. 4 .

Libanotis tenvifolia germanica. Baub. thn is. Burf. Mabitat in l'armmia, Gallia. $\odot$

Ancisuter 6 . SESLLI periolis mernbrana deftitutis. Roy. bgdb. I I 2 Foriculum lubianicum minimum acre. Toursef. sist.

$3 \mathrm{i} 2$.

Ammoides. Bulh. pin. 159.

Haidita in Lulitania. (o)

cortumasna. 7. SESE L i caule allo rigioio, foliolis linearibus falciculatis. Ocuathe itriata rigida. Hort. diff $9 \%$. Samv. munfp. $25 \%$

Sefeli maftilienfe, faniculi folio. Bath pin. 101. lieniculum toruofurn. Bath bift. 3. k. 16. Aabitai in Europa auftrali. 2

Caulis rigia:s, quaft lignofus, foliis mulroties altior. Fo-

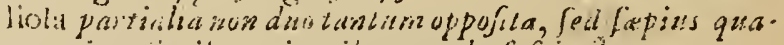
tuor interiorious minuribus, wnde faf cicatibu.

rorifolit, 8. SESELI foliis bipinnatis fublinearibus, petiolis bafi membranaceis, feininibus ovalitus.

Carvi. 
Carvifolia. Baub. pin. 158. Baub. hift. 3. p. 1 y.. Vaill. parif: t. . . f. 2 .

Airgelica tenuitolia. Riv. pent. 18 .

Lhalitat in Helvetia, Germamia, Auglia. *

\%. SESELI foliis duplicatompnatis; foliolis incifis acu-prencenm. tis, involucris reracen umbchila longioribus.

Carvi alpinum. Baub. pis. 158 , prodr. 84. Burf. VIII: 36.

Hibitar in Pyreinatis.

Canlis pedalis, teres, frriatus. Folia radicalia duplicato-jisinata, laxa, parnm dicaricaia: Colialis pinnatis, iongitudisaliter incifis, acuminatis, cunciformibus; Foliwn in carsie fepe uwicuin, ex cuius alu exit ra. onus; petisli radicules fimplices; caulinus lato-membraiacesus. Umistla unive:falis izudc, bionga, pedunculis circiter odto: partialis conforta, brcvifinan, unifiris: involucro polyphyllo fenaceo. longiore umbellisiss.

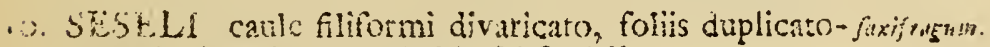
ternaris linearibus, unbchis lubrexfidis.

Pimpinclla jaxifraga tonuifolia, Bazh. pin. 160. proir. S4. Burf. Vlll: 5 .

Heblitat ad Lacosin Gencvenfom.

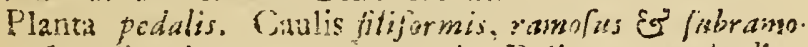
fus, divaricatas, teris, tenatis. Folia parys, duplica. isterwata, linearia, raro lobuta. Umhella nude,

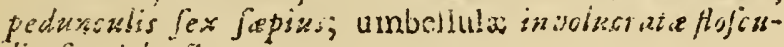
lis fex ad od:.

\section{'THAPSIA.}

1. THAPSIA foliolis dentatis bafi cuadunaris. Hurt.cliff. velusa Ios. Kov. lugdt. 113.

Thapfia lacifolia villof. Bash. piar. 1.48.

Thapfis. . Clut. bi/t. 2 p 193.

Hablitue in Hifpania, Lufitania. *

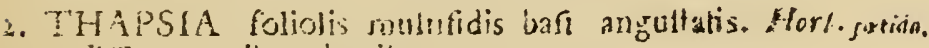
ritit. IC5. Koj. lugdh. is

Thaplia carcta elligie Bastis. but 3. P. IS7. Mord sifl. $\therefore$. 319. f. 9. 5. 19. i 7 .

Hohitat in Hitpania. 2

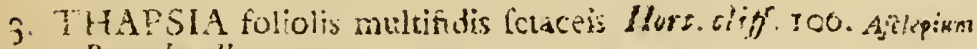
$R 0)$. lngdb I13. 
Thapfia renuifolia, petiolis radiatis. Livorif bift. $\hat{\jmath} \cdot \nu$. it9 $\int .9 . t .18$. f. 9.

Janax Arclepinm, femine folioro. Bash pin. Iss.

Ponax Afclepium apusum. Cónmn.erphr. r. p. 8\%, 2.86 . IJabitat in Apulia.

axigaliaton 4. THAPSIA foliis ternatis ovatis.

Simm folio infumo cordate, canlinis ternatis; omnitus creutatis. Gran. virg. $3 \mathrm{I}$.

Ilabiat in Virginia.

Semina fingula gaudent alis r, longitudinuliuus, membranaceir, Gindulucra nulia fun uit is precedenti, cuin yza gonere compungo, quamris facic diverfa.

\section{P.ASTINACA.}

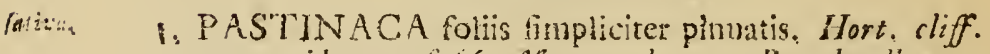
105. Hurt. spf. or, Anar, med. 130. Rov, lugdt. 114 Gort. gstr. 60 .

Pafinaca fylveftris latifolis. Bauh. pin. I5\%.

B. Paftinaca lariva latiolia. Bauh. pin. is

Habitat in Eurnox aultralioris ralerat is EO pajouis.

Onanures: 3. PASTINACA folits decompofitis pinnatis. Hort cliff. I0. Mlat. med. F 3 I, Roy. lugdb. I I 4 .

Paliax Coltium. Bahb pin. y gć.

Panax Heracleum. Norif, hift. 3. p. 315. S. 9. t. I7. f. 2.

Ilnbitat is itulia, Sicilia.

\section{SMYRN IUM,}

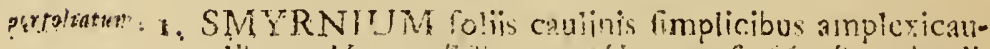
libus. Hort. clitt. 104. Hort. up. 66. Koy. lugdb. 114.

Smyrnium peregrimum f. rotundo f. oblongo folio. Bauh. pin. IsS. prodr. 82 .

Sinyrnium amani montis. Dod. penat. 698.

Lúbitat is Italia, Creta. d

Olufotrure. 2, SM YRNIUM foliis calinis ternatis petiolat is fermatis.

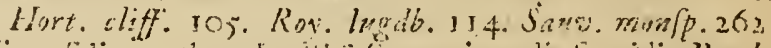
Hippolelinum thcophraiti i. Smyrnium diolcoridis. Baxb fin. 154 .

Hippofelinum. Doo'. pempt. Gos.

llabital in Scotia, Wallia, Crallia. o

anem, 3. SMYRNIUN foliis pinnatis, pofticis ternatis, flor... lis omnibus fertilibus. 
Agnpodium foliis caulinis fummis wovenis. Hort.cliff. 107. Ray. laggdb. II5.

Angelica acadienfis, flore luteo. Dod. aft. 55. Raj. bi/t. $136 S$.

Angelica humilior \& minor, flore luteo. Morif. hift. 3 .

B. Sinyruium foliis caulinis decompolitis acuminatis. Gron. 2irg. 148.

Smvrnium aureum, luvis ternis quinisve, marianum.

?'luk. mant. $17 \hat{\text { in. }}$.

Jistitat in America boreali.

4. SMYRNIUM folis caulinis duplicato ternatis inte- integerrigerrinis,

Snyrnitum folits caulinis ternatis petiolatis: foliolis oblon-

g(n-6) vatis integerrimis. Gron. virg. 148.

Habitat in Virgilitia.

\section{ANE'THU.}

1. ANETHUM fruetibus compreftis. 1Tort. aliff. :06. grayeoriar.

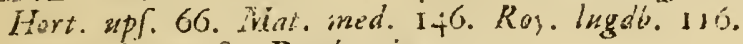

Ancthum hortenfe. Bauh́. pin. 147.

Hiabitat inter Latitania 80 Hifpanize ferretes. $\odot$

2. ANETHUM fructibus oratis, Zlori clifi ro6. Ilort. "revicumm. upf. 66. Niat. meat. ith. Roy. lagáb. ino.

Foeniculum dulce. Bazh. pin. 147 .

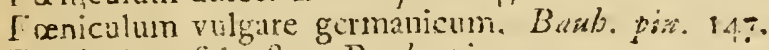

Foniculum fylvellrc. Baub. pin. 147 .

Hubital in Narbonx, Aremoria, Madera rupibusers-

katcis. के

\section{CARUM.}

1. CARUM. Dod. pempt. 299. Fl. bapp. 105. Fl. fuet. carm

245. Nat med. 138. Hort. cliff. 106. Koy lugdh.

iro. Hall. helic. $4=8$.

Casum pratenfe, Carvi officinarum. Ban's pin. i 5 3.

Habitat in Curope burealis pralis. $\delta$

\section{PIMPINEI.LA.}

1. PIMPINELLA folijs piunatis: foliolis radicalibus forifraga. ubrotundis; fummis linearibus.

Pimpinella foliolis fubrotundis. Fl juec. 245. Mat. meá. i25.

Pimpinclla. Short. cliff. 106. Ray. lugdb. 15 .

$$
\mathrm{R}_{4}
$$


Pimpinclia faxifraga minor. Baub.tin. 100.

G. Pinpinella farifraga major alter. Baub. pin. Is9.

maior. $\gamma$. Pimpinella faxiraga major, umbella candida. Barh. pin. 159.

d. Pimpinella farifraga major, umbella rubente. Baub.pin. $1,59$.

Mubin in Europx pofouis ficcis. 2

Has inster os - Dlimiles mon reperi; $\beta$ ensim fat in pa. lo latzer? proustuit $\gamma$.

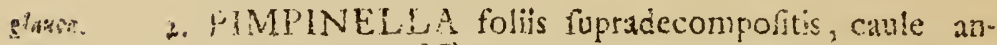
guato ramolifino

Tragolelnum folis tentitrine divifis: pinnulis ultimis trinartitis. Hall. hole. 430 .

Sefe ipeton: ramiferis membranaceis oblongis integris folinlis binatis ter!atisulue. Guett. ftamp. $3 . p$ i4.

llabsat in Helvetia, Gillia.

D):fert "Dauco montano multifido brevique folio $C$. B. involucro partiali wullo, ceteruin fat fimilis.

mrentmi. 3 JMPINELLA foliis radicalibus pinnatis crenatis. funmis sunciformibus incitis.

Anifnm foliis radicalibus pinmaris. Hort. ct:f?. [0]

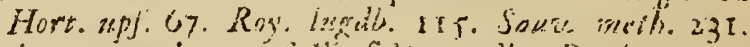
Apium peregrinm, olins fubrotundis Baub. pan. 153 Daucus terrius dioforidis. Colamn. ecphr. A.p. Io\& t. 105 ;

Habilat in Itaiix pafcuis ferilibas. Z

Atoitits

4. PIMPINELI.A fillis radicalibus trifidis incifs. Anifum: Soliis radicalious fimplicibus. Ihort. cliff: 107.

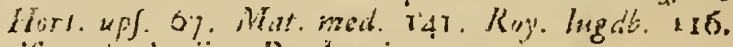
Anifum hesbariis. Bawh. pin. Is9.

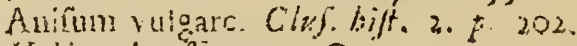
Hubitut in Aigypto. $\odot$

\section{A.PIIS}

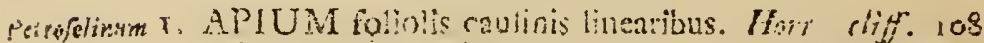
Hort. zpf. 6\%. Mint. med. 127. Roy. lagds. ?10. Apium hortente Perrofelinum vulzo. Bustio pir. 153. Apium hortenfe. Dod. pesifit. Oat.

C fium vel Petrofelimm cilfum? Bauh. pin 153. Habitat in Sardinia inwio featurigines of

grughes. 2. APIUM fuliolis caninis cuneiformibus. Horl cliff.

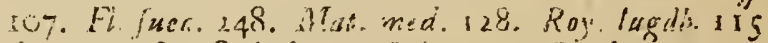
Apium palufre S. Apium afficinarum. Basb. pin. 154 
G. Apium dulce, Celleri iraicum. Tournef. inft. 305.

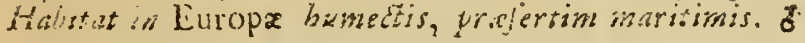

\section{AGOPODIUM.}

1. A:GOPODIUM fuliis cauinis fummis ternatis. Hort. Podaziaria. clitf. 107. Fl. Juec 277. Koy. lestdb. I15. Anguticn ylveftris minor. f. erratica. Baub. pin. 155. Herda gurardi. Doú. pempt. 320.

Habitat in Eurcpa ad fopes ingute pornarios. 2.

\section{IRIGTNIA.}

\section{RHUS.}

I RH? IS fontis pinnatis obtuánfcule ferratis ovalibus fub-coriaria. tus villofis. Niat. med. I50. Rinis follis pinnatis lerratis. Hort. cliff. 210. Hart uph. if. Knj. lusdb. 243. Sazz. moxfp. 22\%.

Rhas folio ulmi. Baub. pin. $4^{1} 4$. Rrus coriaria Dod. pimpt. $77 \%$. llabitat in Europa auftrali. b

2 RHIJS folis pinnatis ovatis acuminatis ferratis, fut- Mansa.

rus comentolis. Whitat in Java. Osbeck.

3. RHUS folis pinmatis ferratis ianceolatis utrinque su-glabra. dis.

Rhus foliis pinnatis ferratis. Grom. virg rot. Coid. maveb. 63:

Rhus virgincum, panicula fparia, rumis patulis glabris Dill. elts. $323 . t .243 . f .3 r 4$.

Rhus anguftifolium. Bauh. pin. 4 T4.

Sumach anguftifoiium. Bauh. prodr. 15 . Barf. XXIT, $7 \%$

Habsiat in Aneriea feptentriorali.

t. IRHUS folis pinnatis integerrimis, petiolo integra. $M T_{\text {a }}$. Wh med. Is I.

Rhus folits pinnatis integerrimis. Hort. wîff. 11:. Hort.

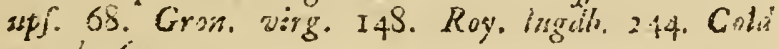
noveb. 64 .

Toxicodendron foliis alatis, fruetn rtombnide Liil elth. 390 . B. 292 . f. 377 .

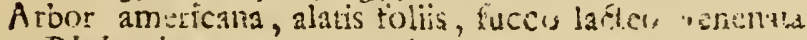
Pluk alirs. 45. t. 145.1 .1$. 
Arbor Poyfon-wood-Tree. SAt. angl. $n 367 \cdot p 145$

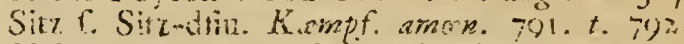

Iabitat in imerica fepte trionai, Iaponia. 5

Copalinm. 5. RHUS folits piubatis integerrimis, pctiolo membranaceo articulato. Roy. lagdb. 24. Mat. mes. Is2.

Rhus elatior, foliis impari pinuatis, petiolis membranaceis articulatis. Gron. virg. I $4 \%$.

Rhus obfonionm finilis ancericana, gummi candidum fuidens non ferrata, foliorum rachi medio alata. Plak. alv. $318 .+5.56 . f . T$.

Habitat in America jeptentrionali. b

radicans 6. RHUS foliis tematis: foliolis petiolatis ovatis nudis in tegerrimis, caule radicante. Hort. witf. 110. Gror virg. 33. Koy. lugdb. 244.

Hecela trifulia canadenfis. Corn, canad. 96. t. 97. Barr. ic. 228.

B. Toxicodendron amplexicaule, foilis minoribus glabis. Dill. elih. 390 .

z. Toxicodendron reetum, foilis minoribus glabris. Dill eith. 390. t. 201 . f. 375 .

Habitat in Virginia, Canada. 5

Iaxicodendr 7. RHUS foliis ternatis: foliolis pctiolatis angulatis pubefcertibus.

Rhus foliis ternatis: foliolis petiolatis ovatis acutis pabefcentibus: vunc integris, nunc linuatis. Gron.vig. 49. Toxicodenciron tripinyllum, folio finuato pubetccite. Tounnef. init. ort.

Arbor trifolia venenata virginiana, follo hirluto. Kaj. bift. 1799.

Habitat in Virginia, Canada. †

umon:ofun. 8. RHUS follis ternatis: toliolis fubfetiolatis rlombeis angulatis fubtus to:tucnlolis.

Rhus foliis ternatis: : coliolis ovatis utringue acutis dentats: lateralibus petiolatis. Inort. clijf. i ir.

Rhus foliis ternatis: toliolis petiolatis ovatis acutis dentatis. Jir. cliff. 25 . Koy. higd's, 24 .

Rhus africanum trifoliatum majus, folitis sboufis \& in. cilis hirfuris pubelcentibus. Plak. alm. 319.t. 214 f. $\rightarrow$.

Vitix trifotia minor indica ferrata. Comm, bort. I. $f$ I79. $t .92$.

Habirat ad Cap. b. Spei. 5

9. $\mathrm{RH} !$ 
9 RHUS foliis rematis: foliolis ovatis acuminatis ferra-Cobbe. is, pedunculis iometiofis.

Rhois trifoliata trutex ialwaecentis, floribus juliformibus. Pet. muf. 679. Raj. cendr. 58.

Kobbs. Fl. zevl. 44 .

Habiat in Zeylona.

10. RHUS foliis ternatis: foliolis petiolatis lincari-lancen-angufifoll latis inregerrimis fubtus tome:1tolis. Liart. cliti. I II, um. Roy. lagdio. 2 dit.

Rhus aricanum trifoliatum majns, foliis frotes argenteis acutis \& margine incilis. Plak.alm. 3i9.\%.219. f. 6 .

Rhus fruticofum, iolis irifidis linearibus acuiribatis. Burm. afric. 251. t. gI. f. 1 .

Habitat in A thiopia. b

31. RHUS folitis ternatis : follolis feffilibus cunelformin Incidum. bus levibus. Fir. cliff. 25. Hort. cliff. 111 . Hort. wf. 69. Roy. Ingalh. 2.43.

Rhus africanum trifoliatun minus glabrum, fpleadente folio tubrotundo integro. Plsk. alm. 319.t. 219.7 .9$.

Rhus arboreum trifoliatum latiolium, burm. afr. $25^{2}$. t. or. f. 2,

Virex trifolia minor indica rotundifolia. Comm hort.2. p. 151. . 93 .

Habitat ad Cap. b. Suei. is

:2. RHUS folits fimplicibus obovatis.

Cotinus foliis soverfe uvatis. Frort liff. Ix I. Roy

Cotimus. $\operatorname{lig} 2 \% .43$.

Cotimis coriaria. Dod. penpt. 780 .

Cocconilea f. Coccygria. Eauh pin. +15.

Habitat in Lombardia Mralia iv wa races Apcuninorum. is

\section{VIBURNUM.}

1. VIBURNUM foliis integerrimis ovaris: maticatio- Tiums. nibus lubrus villofo-glmidulotis.

Viburnum foliis ovatis integerrinis. Laut upf. Gi. Sauv. monsp. 1 jo.

Tinus. Hort. cliff. 100.

Yinue 2. 2. 3. Clus, hin. 1. p. 40.

Laurus inus f. fylvetris: trium gencrum! Jash. hifl. $3 \cdot \mu \cdot 418$.

Laurus fylveltris. comi femina foliis fubhisfiris. Bauh. pir.abi.

B. Lau- 


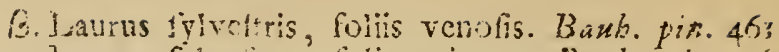

* taurus fylvefins, follo minore. Baub. pin. 45 .

Habiat in Lafiabia, Hifpania, Italia. b

n:Adum, 2. YIBURNUM foliis integerrimis lanceolato-oratis. Tinus rolis ovatis in petiolos terminatis integertimis Gran. qirg. 33 :

Habitat in Virginia. 5

Cyirs in bac nuda, in precedenti involucraie.

mutifolintr. 3. VIBURNUM folits tubrotundis crenaro ferratis g: bris. Gron. virg. 33 .

Vibumum canadenfe glabrum. Faill ad. r $722 . p \cdot 2 \mathrm{a}$. Mefpins, puritia virgitiana non fpinofa, tuctu ni

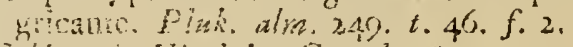
indoitat in linginia, Canda. b

dentam. 4. IBIIPNUM foliis ovatis dentato-1erratis ovaris. llabitut in Virginta.

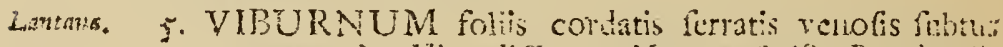
tomeitotis. Vir. eliff. 2.5. Hort. ups. 68. Roy. latgib. 242. Sax? mosho. 136.

Viburnum. Hurt. cliff. $0 \%$

Viburnum vulgo. Bauk. $24 n .249$.

Lantana. Doc. pemp

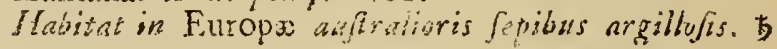

acerifulinat. 6. VIBURNYM folits iobat:s, patiolis lavibus.

Qpulus. Grow. verg. 149.

lisbitat in Vining. b

Opulus 7. VBULRTUM folis inbats pctiolis glandutofis.

(Ypulus, Hort. cliff. iog. Fl. Juec. 24\%. Roy. luglb. 243.

Sambucus aquatica, fore impici. Banh. pin. 456. Sambucus patultis. Dow. anipt. 846 .

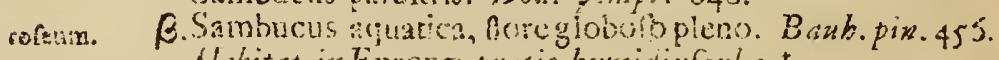

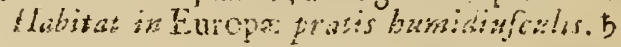

Lentrgo. 8. VIEUR NUM follis fertuatis ovatis acuminatis glabris, petiolis glantuloris.

Yicibitat in Conadia.

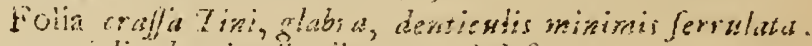

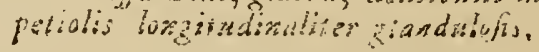

\section{CASSINE.}

Peratra. I. CASSINE foliis ohlongis ferratis. 
Cafine. Hort. cliff. 72. Mat. med. 153. Koy, lagd's 242.

Phillyrea capenfis, folio celantri. Dill. elth. $315 \cdot t .236$ f. 305 .

Ceratus Sebefenx domentic $x$ foliis aliquarenus accedens pizk. alm. 94. t. 97. i. 3.

Fruter xthiopicus, alaterni foliis. Seb. thef. I. p. 40. t. 29. $f .5$.

Misbitat in Ethicopia, Carolina. b

2. CASSINE foliis fubovatis integerrimis.

Mamrocenia. Hort cliff. 108.

Frangula fempervirens, folio rigido fubrotundo. Dill. elth. I 46. $t$. I $21 . f .147$.

Ceralus capennis, fruclu rubro, folio fere obturo. Pet gar. $t .5 \%, f: 4$ :

Cerafus africana, folits plewumque in fummo finatis. fructu rubro. $P / z, k$. alm. 49. ¿. 158. f. 2.

Habitut in fithiopia. H

\section{SAMBUCUS.}

1. SAMBUCUS aymis tripartitis, itipulis foliceis. Sambucus caule herbaceo fimplici. Lir. cliff. 25 . Fl. fsec. 2.51. Mut. med. 149. Hort. cliff. 110. Koy. lugdb. 2.45 .

Sambucus humilis 5. Euatu;. Buhb. par. 456.

Ebulus. Fuchs: bifl. O5.

B. Sambucis humilis l: Ebulus folio iaciniato. Banh. pin.

+50 .

Habitat. in Europat. z

2. SAMBUCUS cymis quinquepartitis, foliis fub-bipin- camalenfis. natis.

Habitat in Canada D. Líalm. 2

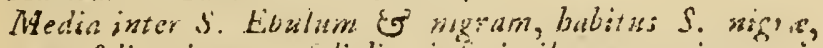
at folia pinasta; fuliolis inferiuribus ternatis, nirnibus magis ovatis; fruticat, fact piemmene perit jupra terrarn hyeanc. Cyina froucteria xti in aigra. Sripula filiformes, truncutat, ut in $S$. wigra; net in foliola enpanfa, ut in Ebula.

j. SAMBUCUS symis quinquepartitis, cauli al horeo kigr, Sambucus caule ivboreo ramolo, Horibus inubellatis.

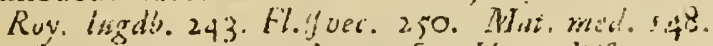

Sambicus caulc perenni ramofo. Horl. cliff 100 .

Sambucus fructu in unbella nigro. Bash.pin. 456 . 
Sambucus, Dod. fempt. 8.45.

B. Samblicus frasiu in umbella viridi. Baub. pin. $45^{6}$.

iacinire, q. Sambucus laciniato folio. Baub. pin. 456. Dod.pempt. $8+5$

liabitat in Germania. b;

vucho/c. 4. SAMBUCUS acemis compofits ovatis, caule arboreo

Sarmbuctis caulcarboreo ramofo, Aoribus race!nofis Poy

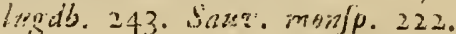

Sambucus racenola rubra. Bazeh. pin. 456 .

Sanbucus racemola, acinis rubis. Banb. bin.1:p.54\%.

Halitiat in Europx anfrelis moniofis. :

\section{'T. ANTHOXYLUM.}

Clay berct 1 . ZANTHOXYLUM folis pinnatis.

lis,

Zanthoxylum. Hort, cliff. 487 .

Zanthoxylun fpinofum, jentifcilorgioribus foliis evo-

nvmi frugtu capfulari. Ciatefb. car. 1. p. 26. 1.26.

Hazitat in Jamaica, Carcolina, Virginia $b$

rifoliatsut 2. Z ANTHOXYLUM foliis ternatis.

Habitai on Chira. Osbeck.

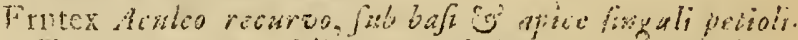

lolia rernate, folitaria, ad flores terna: foliolis o.

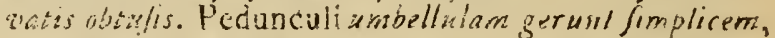
be nifpherirem. Styius irigizis eft, at nequeat firaliis jociari.

\section{STAPHYLEA.}

phamati 1. STAPHYLEA foliis pinnatis. Hort. cliff. is 2 Hort. "upl. 69. Koy. lugde". +36 .

Staphylodendron. Ojelerh. bift. IOz.

Piftacia Cylveltris. Bairb. pin. 40 r.

Habitat in Europe auf? ralioris jucsulentss.

mifolio, 2. STAPHYLEA foliis ternatis: Hort. rliff: 1:2. Roy. ixcdb. tiz. Cold noveb. 62.

Siphylodendron triphyllum, valcuio tripartito. Gron. vitg. 34:

Staphylodendron virginianum trifoliatum. Herm. lug ab. 230.

Piflachia virginica fyiveltris trifolia. Morif: blaes. 295. Sittivat in Virginia. b

\section{TAMARIX}

gallici I. IAMARIX Horibus pentandris. Sort. cigf: III. Roy. lusdh. 436. Sanv. monjp, 45 . 
Tamarix pedunculis nudis, floribus pentandris. Hort. sper. 09 . Am. mea' ist.

Tamarix altera, folio ienuiore, f.gallica. Jaub.pin. 485 .

Iamarifcus narbonensis. L.66. 6. 21 S.

Hubnat in Callia, Hiparia, Italia. b

2. TAMARIX foribus decondris. Mor:. cliff. III. Roy. germazica. ligirdb. 436.

Tamarix futicofa, folo craflore, f. germanica. Baub. tis3. 4 i.5.

Tamarifeus germanica. Lob. ic. 2 i 8 .

Habitat in Gomanix locis inusuatis. b

\section{TULNERA}

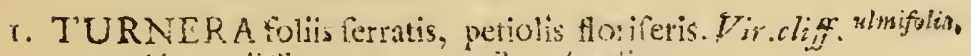

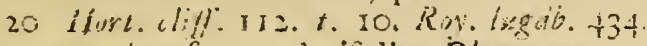

Tumera tiutefens Mmifolia. Plum.zen. 15. Mart. cent. 49. t. 4\%.

Ciftus urtica folio, flore luteo, vafculis trigonis: Sivan. jum. 86. hifh. i. 5. 202. t. I27. f. 4. 5. Kaj. dendr. 492.

Helianthemoides. Hazk. ingäb. 2.p. 260.

6. Turnera frutefcens, iolio longioie \& mucionato. Mart. rent. 49. 1. 49.

Ilatial in Jamaica, $\sigma$ in America calidiore. $\delta$

\section{TELEPHIUM.}

1. TELEPHIUM. IIort. nps. 70.

Imperati.

7 elephiurn foliis oblongo-ovatis, racemis fecundis terminaibus. Fir. rilf. 20. Hort. cligt. 73. Koy. Ingth. $43+^{\circ}$

Telubium repens, folio non deciduo. Bath.pir. 287. 7 leprium legitimum. Cizf. hifl. 2. p. 67.

Cifus folio majorana. Brish. pin. 465.

Wabitat in Gallo-provincia. 26

\section{CORRIGIOLA.}

1. CORRIGIOLA. liort. upr. ;o.

litoralis.

Corrigiola canle ratciculis thoruni terminato. Hort sliff.

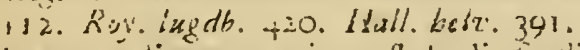

Polygonun litoreun minus, folculis ipadiceo albicanttibus. Eauh. pin. 2.91. prodr. 13t. Marij. bijt. 2. p. 593 . .5. 5. 1. 20. . . 1 .

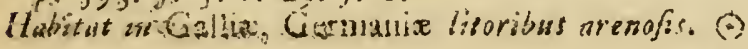


PHARNACEUM.

Cerian, 1. PHARNACEUTM glabrum, pedicellis folia xquanti bus. Pbil, hot. 258. *

Cerviana. Minuart. monotr. 1

Alfine pumila, gallii tacie, foliis glaucis. Amm rutb.84.

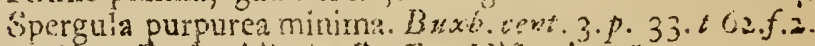
Habitat Roftockit, in Ruflia. Hilpania $\odot$

inson'm, 2. PHARNACEUM pedunculis communibus longifimis. Hort. cliff. 492. * Roy. lugdb. 221.

Habitat in Africa.

Figura forte baketur in Plak. plyyz. 304. f. 4

\section{ALSINE.}

netio. ALSINE peralss bipurtitis, foliis ovato-cordatis, $F$ lapp. 135. Fi fuec.. 36\%. Hort. cliff. 173. Grosz. virg

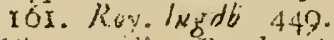

Altine media. Buth. jin. 250.

Alfine minot Dod. pempt. 20.

Habitat in Europie raitis. $\odot$

regetais. 2. ALSINE petalis integris, foliis fubulatis.

Spergula follis filiformibus unum latus pectantibus ftipulis membranaccis vaginantibus, pedunculis um bellatis. Guett. ftomp. 290. Dalit. parif. 133. Alfire fegetalis, gramincis foliis unum latus fpectantibus Vaill. parif. 8. t. 3. f. 3 .

Habitat Parifis. (O)

\section{BASELLA.}

rubra. I. BASELLA foliis p!anis.

Bafells. Rheed. mal. 7. p. 45. t. 24. Fl. zeyl. I Iy Cufcuta foliis ubcordatis. Hort. cliff. 39.

Habitat in India. o

alba,

2. BASELLA folis undatis.

Baicila florealbo \& caulibus viridibus Thran. carol. It. Halizat in Syria? $\odot$

SAROTHRA.

Gentinnoz- I. SAROTHRA. Gien. nov, 5075.

des. Gentiana caule ranisque ranolifimit, foliis jubulatis $m$. ninus. Gruin. airg. 29.

Cencaurium minus fpicatum, angultillimo rolio, $6.8 \mathrm{co}$ parium marilandicum novum. $P / u k$. mant. 43 . t. 342. $f: 4$.

Habitat in Yirginia, Penfylvania apricis giareojis. 


\section{TETR AGTNIA.}

\section{PARNASSIA.}

1. PARNASSIA. Fl. lapp. 109. Fl. Suec. 252. Hort. palngaris. clitf. I 3. Roy. laggdt. 420. Hall. Lelv. 316. Dalii. feiri. go.

Gramen parnafli albo fimplici fore. Baub. pia. 309.

Hepatica alba. Cord. bift. 53 .

Pyrola rotundifolia paluttris, flore unico ampliore. $M I_{n}$. rif. bif. $3 . p .505 .5 .12 . t .10, f .3$.

Habitat in Europx uliginofis. 3

\section{$P E N T A G \Upsilon N I A$}

\section{ARALIA.}

1. ARALIA arborcecens, caule foliolisque aculeata. Jir. Jpinosa, cliff. 26. Gron. virg. 34 .

Aralia caule aculcato. Hort. cliff. I I3. Roy. lugdb.92. Angelica arborefcens fpinofir. Arbor indica fraxini tolio, cortice fpinofo, Comin. hort. 1. p. 89. $\ell .47$.

Chriftophoriana arbor aculeata virginicntis. Plrk. alin; 98. t. 20.

Habitat in Virginia, b

2. ARALIA caule petiolisque aculcatis, foliolis inermi-chinenis. bus villolis.

Habitat in China. Osbeck.

Caulis fimplex, aculeis fpinofifimus, nudus, in fumrnitate tantum foliofus. Petioli compofiti, tripartiti, acuteait, villof. Folia partialia pinnato $\mathcal{E}^{2}$ infuper foliola 2 ad rarnificationes petioli. Foliola $\int$. pinste ovatio, Serrata, Jublus prafertim villofe, duplo rasjores, aucm in pracedente. Panicula ramofa umbellalis numerofis. Differt itaque a pracedent: quod nulli aculei in foliolis per difcum secundum verias ailfperfi; quod folia mon glabra fed duplo majora. Habitus etjan diverfus.

-3. ARALIA cauie foliofo herbaceo lrvi. Hort. upf. ;o. memoja. Cold. noveb. $6 \%$

Aralia racemis umbelliferis lateralibus. Vir. cliff. 26. Aralia ex alis forifera. Hort. cliff. IIj. Roy. lugdb. yz. 


\section{PENTANDRIA PENTAGYNIA.}

Panaces carpimon C. racemofa caliadenfis. Corn. casad. 74. t. 75 . Barr. ic. 705.

Chritophoriana camadenfis racemofa \& ramofa. Morif. liff. I. p. 9. . . 1. t. 2. .. 9 .

Habitat in Canada: 2

muilisainis. 4. ARALIA caule nudo. Hort. cliff. 113. Gron. virg. 34. Ruy. lugsib. 94.

Aralia caule nido, radice repente. Cold. noveb. 66.

Chriftophoriana virginiaila, zarzæ radicibus furculotis \& fungofis. Plak. alm. 98. t. 238. f.5.

Habitat in Virginia, fimillima (forte eadem) in Iava. 2

\section{BARRERIA.}

capenfis.

1. BARRERIA.

Erica capitata $\int$. nodiflora, corios foliis rectis, wthiop.ca. Pluk. mant. Go. t. $346, f .7$.

Habitat in Athicpia. 5

Frutex; Rami por Spatia determinata conferti, erect: rusefcentes, asdperfic pilis albis. Folia alterwa, aptroximata, ovato-banceolata, integerrina, pilis albis velut ciliata; Capitula florum terminalia; Simillima eft habitu Divfria ciliate.

\section{STA TICF.}

Armuria. 1. STATICE caule nudo fimplici capitato. Hort. cliff. I 5 . Fl fuec. 253. Gron. virg. 1 50. Roy. lugdb. 194. Limonium aphyllocaulon granineum globofum. Morif. hift. 3. p. Cor. S. 15.t.1.f. 29.

Caryophyilus montanus major, flore globolo. Bazh. jin. 2.I 1.

B. Caryophyllus montanus musor. Baub. pin. 211 .

Habitat in Europa Eे America leptontrionalis cam. pis. 2

I.imoniнin. 2. STATICE canle nudo paniculato tereti, foliis lavibus.

Statice caule nudo ramofo. Hurt. cliff. 115. Fl. Suec. 254. Gron. virg. 150. Roy. lugdb. 192.

Limonium naritimum mains. Baub. pin. 192.

B. Limonium maritimu!n ninus, olex folio. Bart. pist. 192.

$\gamma$. Statice foliis obverfe-ovatis glabris, caule nudo ramofo. Sauv. monfp. Is.

Limohium parvum, bellidis minoris folio. Bazh. pin. x92.

d. Limo- 
\& Limonium maritimum rninimum. Baub. pin. 192. prodr. 99. Bace. jic. 25 . t. I9.

Habitu in Europx \& V Virginie maritimis. 2

3. STATICE caule nudo paniculato foliis Spathulatis re- corasta tulis. Sauv. monfp. ry.

Limonium maritinum ininus, folis cordatis. Bauk.pin. 192. prodr. 99.

Limonium ninimun cordatuin $\mathrm{f}$ folio zetufo. Barr. ic. 805 .

Habitat ad maris Mediterranei litora. $¥$

4. STATICE caule nudo paniculato tereti, foliis tuber-echioises. culatis.

Statice foliis obverfexoyatis verrucofis, caule ramoro rudo. Sauv. monfp. Ir,

Limonium minus annum bullatis folis: Magzamonsp. $157 . t, 156$.

Irabitat Monfelii. $\odot$

\& ST ATICF caule fubnudo paniculato proftrato, tamis reticulata, fterilibus retrotlexis nudis, foils cuneiformibus.

Statice foliis obverfe-ovatis, ramis nudis humifulis, intricatis Sarev. monfp. 15.

Limonium minus, virgulis retiformiter fe invicen implicatis Plok. alm. 221. t. 42, f. 4 .

Limonium reticulatum. Raj. bift. 396. Borc. Jic. 82. t. 44 .

Habitat in Melita.

6. STATICE caule fubnudo dichotomo incipiti, foliis fpectost ininceolatis nucronatis, foribus aggregatis.

Limonium foliis lanceolatis muctonatis radicalibus, caule ancipiti dichotomo, ftipulis fimplicibus. Hort. utp: 71. Gmel. Jioir. 2. p. 221. 1. 9) f. f. r.

Limonium foribus clegantifimis. Raj, bifl 397.

Limonium elatius, plantiginis foliis procumbentibus in aculeum terminaris, floribus albis in copitula congugeft:s. Amin, ruth. I2g.

Habitat in Tataria. o

7. STATICE caule lubnucio dichotomo, foliis lanceo- tataristo Iatis nuctonatis. floribus alternis difancibus. Gmel. fibir. 2. p. 223. t. 92 .

Limonimm orientale, plantaginis folio, floribus umbellatis. Tournef. cur. 25 . Boerb. lugdb. 1. p. 76. t. 76 .

Limonium clatius, plantaginis foliis procunbentibus in 


\section{PENTANDRIA PENTAGYNIA.}

aculieum tcrminatis, noribus albis fpicatis. Amm. ruth. 130.

llabitat in Tataria. $\delta$

Eckinus. 8. STATICE caulc nudo paniculato, foliis fubulatis mu. cronatis.

Limonium folis caulinis fubulatis pungentibus. Roy. lugd6. 192.

Limonium oricntale frutefcens, caryophylli folio in aculeum rigidillimum abcunte. Tournef. cor. 25 .

Limonium cefpitolum, foliis 2culcatis. $B w x b$. cent. 2. p. 18. t. 10.

B. Limonium gracum, juniperi folio. Tournef. cor. 25.

Echinus f. Tragacantha altera. Alp. exot. $57 . t .56$.

Habitat in Gracix Ej Media deferis.

ficxnofr. 9. STA TICE caule nudo ramofo ficxuofo, corymbis terminalitus, foliis nervofis. Gmel.

Statice foliis ovalibus muticis nervofis, canle nudo alternatim ramofo fiexuofo, corymbis terninantibus. Gimel. fibir. 2.p. 217. t. 89. f.I.

Habitat in Sibiria.

frfiuticofr. 10. STATICE caule fruticofo: fuperne nudo ramofo, capitulis feffilibus, foliis lanceolatis vaginantibus.

Statice foliis e lanceolato-linearibus caulinis bafi vaginantibus, capitulis alternis fetilibus. Gmel. Jibir.s.p. 216. t. 88 . f. 2 . 3 .

Habitat in Sibiria. D. Gmelin. 5

r.6mopetala. I I. STATICE caule fruticofo foliofo, floribus folitariis, foliis lanceolatis vaginantibus.

Statice foliis caulinis lanceolato-linearibus. Hort. cliff. I 16. Roy. $\log 16.192$.

Limonium lignofum. Bocc. Jic. 34.35 . t. 16.17. Habitat in Sicilia.

anies, 12 . STATICE caule fruticofo foliofo ramofo, foliis fubulatis.

Statice caulibus fruticolis teretiuf́culis, foliis fubulatis caulinis, foribus ex corymboro tafciculatis. Gmel. fibir. 2. p. 2 I8.

Limonium maritimum humile, ephedræ facie, calycibus florum aureis. Arim. rutb. 1 32. t. 18. f. 2.

Habitat in Dauria campis montofis.

fin:ate. I3. STATICE foliis radicalibus alternatim pinnato-finuatis: 
atis: caulinis ternis triquetris fubulatis decurrentibus. Hort. upf. 71 .

Statice folits caulinis decurrentibis. Hort. cliff. i 6 6.

Limon:um percginum, foliis afplenii. Bash. pin. 193.

I jimonii fpecies. Rauw. itir. $313 . t .314$.

Limonium ranvolfanum. Cluf. cur. $33 . t .33$.

8. Limonium atricanum, caulc elato, folifs integris hirfurs, petalo pallide tiavo, calycc amicene purpureo. Mart. ceni. 43. t. 43.

H.lbitat in Sicilia, Palaltina, Africa. o

\section{LINUM.}

\section{* Folits alternis.}

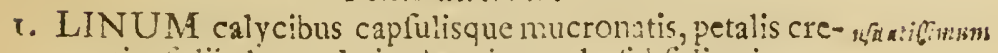
natis, foliis lanceolatis alternis, caule lublolitario.

Linum ramis folisque alternis lisear-lanceolatis, radice aunua. Hort. clift. II 4. Roy. lugdb. +33 .

Linum toliis aiternis lanccolatis integerrimis, calycibus acuminatis angulatis, capfulis mucrouatis. Hort. upf. 71. Mat. med. 156 .

Linum arvenfe. Bauh. pin. 2I4. Raj. bift. 1073.

B.Linum fativum. Barb. pin. 21 t.

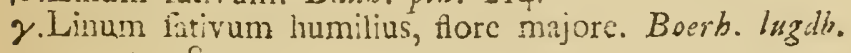
I. p. 284 .

2. Linum fativim latiolium africanum, fiusu majorc. Tournef. inft. 339 .

Habilat hodio inter fegetes Europæ auftralis. ()

2. LINUM calycibus capfulisque obtufis, foliis alternis perenne. lanceoiatis integerrimis.

Linum foliis alternis lanceolatis integerrimis, calycibus apice obtufis, capfulis muticis. Hor:. npl: $7 \%$.

Linum perenne, ramis foliisque alternis ?ineari-lancentis. Hort. cliff. I1 4. Koy. lugdb. 434. Sauv. monfp. 53 .

Limum perenne majus cærulcum, capitulo majorc. Morif. bift. 2. p. 573 .

Linum fylvettre cæru!cum perenne ercetius, fore \& capitulo majorc. Kaj. angl. 3.0 .352 .

Habitat in Sibiria et Cantabrigix 2 .

3. LINUM calycibus hirlutis acuminatis fefflibus alternis, birfotum. caule corymbofo.

Linum fylveftre latifolium hirfutum cærulcum. Baah. pin. 339. Morif. bift. 2. p. 573. 5. 5. t. 26. f. 5. Raj. bift. 1073 . 


\section{$27^{8}$ PENTANDRIA PENTAGYNIA.}

Linum fylveftre latifolium. Cluf. bift. I. $p .3^{17}$. Habitat in Auftrix, Tataria editis graminofis.

naverenense. 4. LINIJM calycibus acuminatis, foliis lanceolatis fpariis ftrifris fcabris acuminatis, caule tereti hafi ramofo. Linum fylveftre cæruleum, folia acuto. Baub. pin. 2 14. prour. 107. Raj. bi/t. 1073.

Linum fylveftre anguftifolium, cartuleo ampla fiore. Magn. moisp. I6r. Sauv. ming. 54 .

Habitat in Galloprovincia, Monfpelii, unde Burferus attulit C. Bauhino. 2

:maifolium. 5. LINUM calycibus acuminatis, foliis fparfis lincari-fetaceis retrorfum fcabris.

Linum perenne, foliis anguftioribus, calyce ariltato. Hall. helv. 371 .

Linum fylveftre angultifolium, flore magno. Bauk, pirs. 214.

Linum fylvefte $V$. anguftirolinm. Cluf. hift. I. p. 3 I8. B. Linum iylveftre anguftifolium, flore marrio intenfecxruleo. Tournef. ingt. 340.

$\gamma$. Linum fylveftre anguftifolitim, flore magno violaceo. Tournef. inft. $34^{\circ}$.

d. Linum fylveftre anguntifolium, fiore magno lineis purpureis diftin cto. Tournet. inft. 340 .

E. Lirum filveftre angultifolium, tore magno cærvieo \& velut cinereo. Tournef. inft. 340 .

Lini folveftris $\mathrm{V}$. anguftifolii aliud genus. Cluf. bift. I. p. 318.

$\zeta$. Linum fylvefue anguftifoliun, flotibus dilute purpurafcentibus vel carneis. Baub pin. 2IA.

Linum fylveftre VI. anguntifolium. Cluf. bijl. I. $p$. 319.

Linum oxyphyllum multicaule Bocc. mus. 2. p. 169. t. 125.

". Linaria capillaceu folio, altera. Bauh. pin. 213.

9. Linum anguttifolium albim, ramufculis per terram sparlis. Tokirnef. inft. 340.

Habitat in Gillix, Helvetix aridis berbofis. $\#$

aufriacum. 6. LINUM calycibus rotundatis obtufis, foliis lineaibus acutis.

Linum fyiveltre angufifolium, foliis ratioribus. $B a u b$. nis. 214 .

Lintin fiveftre It. Tavers, 26.822 ,

Lisbitat in Auttria inferiore. 
7. LINUM calycibus acutis alternis, capfulis muticis, pa-virgininnwm nicula filiformi, foliis alternis lanceolatis. radicalibus ovatis.

Linun ramis foliisque alternis lanceolatis feffilibus nerro longitudinali inftruetis. Gron. virg. 35 .

Habitat in Virginia. Penfylvania.

Caulis filiformis, pedalis, paniculatus. Folia radicalia ovalia, integer rima, levia; caulina alterna, lanceolata. Flores alterni: peaunculis brevifimis. Calyces acuti. Capfulx globofe, muticre; Corollæ luter.

8. LINUM calycibus acutis, foliis lineari-ianceolatis al- trigynnm. ternis, paniculæ pedunculis bifloris.

Linum foliis lineari-lanceolatis, pedunculis bifidis, noribus luteis. Sauz' monisp. $; 3$.

Linum fylveftse minus, flore luteo. Baub. pin. 214.

Habitat in Monfipelii. D. Satrages.

Planta Spithamea. Liaules ad bafin foxpe ramos duos oppofitos exferunt. Corolla flava, rotata, tubo Supra bafin cobarente longit dine calycis. Pittilla in boc Sapius 3 obfervavit Ill: Sauvages.

9. LINUM calycibus fubferrato-feabris lanceolatis fub- flazum. feffilibus, panicula ramis dichotomis.

Linum fylvettre latifolium luteum. Bauh. pin. 214 .

Linum latifolium luteum. Baub. bift. 3. p. 454.

Linnm fylveftre it r. latifolium. Cluf. bifl. 1. p. 317.

Habitat in Aultria.

10. LINUM calycibus foliisque lanceolatis ftrictis mu- fritzum. cronatis: margine fcabris.

Linum toliis afperis umbellatum luteum. Magu. mon/p. 164. Raj. bifl. 1076. Sauv. mones. 53.

Lithofpermum, linaria folio, monfpelienfium. Bauh. pin. 259.

Pafferina lobelii. Bash. bilt. 3. P. 454.

Habivat in Monfpelii, Hilpanix, Sicili: Sgualidis. $\odot$

I. LINUM foliis linearibus acutis frabris, caulibus fuf- fulfiruticofruticofis. film.

Linum angufifolium fruticofum valentimum, foliis rigidis \& aculeatis. Tournef. inft. 340 .

Habitai in Regna Valentino.

12. LINUM foliis cuneiformibus, caulibus arborefcenti- arboremm. bus.

$$
S_{4} \quad \mathrm{Li}-
$$


Linum arborenm. Alp, exoi: 59, t. 13. Habitat in Creta. b

campatsu?aixin.

2. LINUM foliorum baifi utrinqque puncto glanduloro.

Linum foliis indis fpathulatis, foribus luteis. Saur. monfp. $-T^{6}$.

Linum fylveftre lutcum, foliis fubrotundis. I3auk. pix. 212. Tournef. inft. 340. Magi. cher. $26 \mathrm{r}$.

Campanula lutca linitolia montis lupi, fore volubilis. Lob. ic. 414.

Campanula linifolia lutea. Baub. hift. 2. p. 917.

llabitat in Galloprovincix montibus, Monfpelii in mon tc lupi. 2

Focies a Lino diverfe, famina unita bafireddunt plartan dubiam, quam accuratius examinent, qui vivat adive queunt.

nnitionam, 14. LJNUM calycibus ovatis acutis muticis, folits lance+ olatis: in eriorious oppofitis.

Linum caule fimplici, ramis folisque inferioribus oppo-

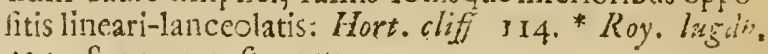
434. Sauv. monsp. 147 .

Linum foliis oratis, foribus racemolic. Guett. famp. 2. p. 499 .

Linum maritimum luteum. Baub. pin. 2 ז4.

Linum luteum narbonenfe. Baub. bift. h. p. 454. Raj. hif. 1074.

Linum fylveftre. Dod. pempt. 534 .

Habitat in Autria ad Thermas badenes, Monfpelii.

$$
\text { * * Foiiis oppojitis. }
$$

gficanm, 15. LINUM foliis oppolitis lineari-lanceolatis, foribus terminalibus pedunculatis. Roy. lupdí. 434 .

Linum atricanum luteum, foliis conjugatis. Bocrh. lugib. I. p. 284 .

Habitat in Africa.

yodiglorum.

I6. LINUM foliis oppofitis lanccolatis, floribus alternis fefilibus, caule fimplici. Hort. cliff. I 4 .

Linum lureun ad fingula genicula Horidum. Bavib. pin. 214. Merif. bij. 3. p. 574. f. J. t. 26. f. 11. Raj. lifit. 1026.

Linum luteum fylvelte jatifoium. Colzimn. ecpbr. 2. p. 79. t. 80 .

Hobitat in Italia pratis argillofis. 
17. LINUM fnliis oppofitis ovato-lanccolatis. caule di-cabbaticins. choromo, corollis acutis. Hort, cliff. 372. Fl. Suec. 255. Mat. med. 157. Roy. lugdb. 434.

Linum praterie, forculis exiguis. Bauh. pin. 214.

Spergula bifolia, lini capitulis. Loef. praff. $261 . t .86$. Habitat in Europx Septentrionalis pafcuis $\int u c c u l e n t i s .(-)$

18. LINUM foliis oppofitis, caule dichotomo, floribus Radiclat tetrandris tetrangyis. Hort. cliff. I 4 . Fl. Suet. 256. Roy. Jug d6. 434 .

Chamel inum vulgate. Vaill. parif. $33 . t .4 . f .6$.

Linocarpum, ferpilli folio, multicaule \& multiforum. Mich. Ge2. 23.t. 21 .

Radiola vulgaris forpillifolia. Raj. angi. j. p. 16I.t. I5. f. 3 .

Polygonum minimum 1. Millegrana minima. Baub.pin. 282 .

Habitat in Eurnpr fabulo inundato. $\odot$

19. LINUM foliis quaternis.

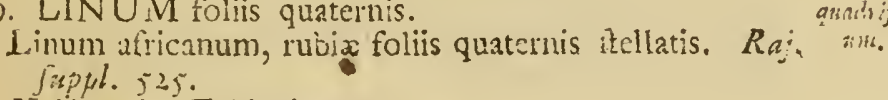

Habitat in Æthiopia.

2). LINUM folis verticillatis. :ertirilia.

Linum fylveltie, flore cæfio, foliis verticillatis. Bocc. iun: muf. 2. p. 49. t. 42. Raj. Juppl. 524. Barr.rar.685. t. 1226.

Habitat in Italia. $\odot$

Calyces $\mathcal{E}^{\circ}$ folia Superiora villofa.

\section{ALDROVANDA.}

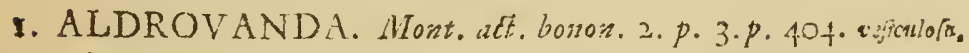
t. 12 .

Lenticula paluftris indica, foliis fubrotundis binis capillamciatis ad imum barbatis. Pluk. alm. $211 . t .41 . f \cdot 6$, Habitat in Italix 0 Indix paindofis. D. Mlonti.

\section{DLOOSER:A.}

1. DROSERA fcapis radicatis, foliis orbiculatis. F. lapp. rotmendiforis. 109. Fl. Suec. 277. Mat. med. 158. F\%. zeg\% 120. Gron. virg. 3r. Roy. lugdb. 120.

Ros folis folio rotundo. Bawh. pin. $35 \%$.

Sallirora 1 . Ros lolis. Thal. herc. t. 9. $f$. I. Habitat in Europx, Alia, Americx palidibus.
$S 5$
2. DRO- 
iongifolin. 2. DROSFRA fcapis radicatis. follis oblongis. Fl. lapp. I IO. Fi. Suec. 258. Roy, lugdb. 417.

Ros folis folio oblongo. Baub. pin 357.

Salfirora $\mathrm{f}$. Sponfa folis $\mathrm{f}$. Ros Solis $\mathrm{f}$. Rorella. Tahl. berc. I I6. t. g. f. 2.

Habitat ins Europa ubique cum precedente; an itaque fatis diverfa species?

Infitanicin 3. DROSERA fcapis radicatis, foliis fubulatis fubtus convexis.

Kos folis lufitanicus, foliis afphodeli minoris. Morif. bift. 3. P. 620. f. 15. t. 4. f. 4. Pluk. alm. 323.t.117. f. 2. Raj. Suppl $55^{\mathrm{I}}$.

Habitat in Lulitania.

capenfis. 4. DROSERA feapis radicatis, foliis lanceolatis.

Drofera folins ad radicem longiffimis, Horibus fpicatis. Burm. afr. 209.7. 75, f. $\mathrm{r}$.

Ros folis africanus, foliis prælongis, caule nudo altiffmo. Raj. Suppl. YI5.

Ros folis africanus, folio lata \& longo. Herm. afric 19. Habitat in Æthiopia.

indiso. 5. DROSERA caulc ramofo foliofo, foliis linearibus. Fl. z.eyl. I2I.

Ros tolis ramo ias, caule foliofo. Burm. zeyt $207 . t$. 94. $f . r$,

Araca-puda. Rheed. mal. xo. p. - - t. 20.

Habitat in India,

\section{CRASSULA.}

coccinea. I. CRASSULA foliis planis cartilagineo-ciliatis bafi connato-vaginantibus. Vir. cliff. 26. Hort.cliff. 16 . Roy. lugdio. 454 .

Cotyledon africana frutefcens, fiore umbellato coccineo. Comm. rar. 24. t, 24.

Habitat in IEthiopia. 5

serfolista. 2. CRASSULA foliis lancenlato-fubuiatis feffilibus connatis canaliculatis: fubtus convexis. Hort cliff, u r6. Roy. lugdb. 45),

Craffula altifinina perfoliata. Dill. elth. r r.4. t. 96.f. 13 . Aloë africana caulcicens perfoliata glauca \& non fopinolia Comm prel. 74. t. 23 .

Habitat in 王 thiopia. 


\section{PENTANDRIA PENTAGYNIA. $\quad 283$}

3. CRASSULA foliis fubulatis obfolete tetragonis, Itort. tetragana. cliff. I I6. * Roy. lugdb. 45 5.

Habitat in Ethiopia. b

4. CRASSULA foliis oppofitis obture ovatis integersi- cultrata. mis : hinc anguftioribus. Hort. chiff. 496. Roy. lugdi. 455 .

Crafiula anacampferotis Solio. Dill. elib. I5. t. 97. $f$. I1.4.

Habitat is \#thiopia. 5

5. CRASSULA foliis oppofitis oblongis planiufculis di-ciliat a. llinetis ciliatis. Hort. cliff. 496 . Roy. lugd6. 455 .

Crailula cauicfcens, foliis fempervivi ciluciatis. Dill. elt th. II6. t. 9 \%. f. II 6 .

Habitat in Aithiopia. $z$

6. C.RASSULA foliis oppofitis patentibus fcabris.

jabra.

Craffula mefembryanthemi facie, foliis longioribus aSperis. Dill. eltb. $117 . t .99 . f$. 117.

Cotyledon africana frutefcens, foliis arperis anguftis acuminatis, flore vireicente. Mart. cent. 24. t. 24.

Habitat in Africa?

7. CRASSULA foliis ferrato-dentatis planis altermis, altenifolia. caule fimplicifimo, Horibus pendulis. Hort, cliff: 497. * Roy'. lugdb. 455.

Cotyledon, flore luteo, media. Herin, lugdb. x91.

Habitat -

8. CRASSULA fo!iis fubularis radicatis, caule nudo, nudicauis. Hort. cliff. I r6. Roy. ingab. 455 .

Crafiula cefpoía longifolia. Dill. eish. x Í́. t. $9 \$ . f$.

115 .

Habitat in Fthiopia. 4

9. CRASSULA caule Alaccido prolifero determinate-fo- orbicalaris. liolo foliis patentifrimis imbricatis. Hort cliff. 496. Roy. lugdb. 455 .

Craffula orbicularis repens, folis fempervivi. Dillelth.

I $19 . t$. $100 . f .118$.

Habiat in Athiopia. *

10. CRASSUI_A caule fiaccido repente, foliis oppofitis. pelittirs.

Craffula, portulaca facie, repens. Dill. 6tt. 119. $t$. 100. $f$. 11 io.

Habitat in Athiopia. 


\section{SURIANA.}

waritimis. I. SURIANA. Hort. cliff. 492.

Suriana foliis portulaca anguftis. Plum. gen. 37 .

Thymelax facio frutex maritimus tetrafpermos, flore tetraptalo. Sloan.jam. I38. hif, 2. p. 29.t. 162.f. 4 . Raj. dendr. 96.

Arbor americana, falicis folio, frondofa bermudienfis. Plak. alim. 44. t. 24r. f. 5 .

Hubitat ad littora maris is Be:mudis, Jamaica.

\section{SIBBAIDIA.}

procimbens. I. SIBBALDIA foliolis tridentatis. Fl. lapp. III. Fl. futer. 260. Hall. Welv. 342. Roy. lugd. 276.

Fragaria aftinis fericea incana. Bawk. $F$ : $32 \%$. prodr. 139.

Fragaria fylvetri affinis planta, fore luteo. Sibs feot. 2. p. 25. t. 6. f. I.

Pentaphyloides fruticofum minimum procunbens, fiore lute o. Pluk. alm. 284. t. 2r2. $f$. j.

Holitat in Alpibus Lapponix, Helvetix, Scothix. 2

ereitis.

2. SIBBALDIA foliolis linearibus multifidis.

Ientaphylloides foliis tenuifíme laciniatis, flofculis carneis. Amm. ruth. II 2 . t. I5.

Habitat in Sibira D. Gmelin.

\section{POLTGTNIA. MYOSURUS}

minimus. 1. MYOSURUS.

Aiyofums folits integerrimis. Hort. cliff. IiY. Fl. Sues. 26r. Roy. ingdb. 492 .

Holoneo affinis Cauda muris. Baub. pin. 190.

Cauda muris. Dod. pempt II 2 .

Hobitat in Europa collibus apricis aridisa 0 
HEXANDRIA MONOGYNIA. 28;

\section{Clallis VI. \\ HEX A N D R I A \\ NI UNOGTNIA.}

BROMELIA.

t. BROMELIA foliis ciilato-fpinofis mucronatis, fpica Anumus coirofa.

Bronelia foliis fpinofis, fructibus connatis caulem cingentibus. Hort cliff. I 27. Hort. upf. 73. Roy. lugal'. 24 .

Carjuus braílianus, foliis aloës. Bawh. pin. 384 .

Ananas acofta. Cornm. bort. I. p. Ieg.t. 57.

Tappa-T liakla. Rbeed. mal. II.p. I. t. I.

B. Ananas aculeatus, fructu pyramidato: carne aurca. Tosin nef. inft. 6,53 .

$\gamma$. Ananas aculeatus, fructu conico carne aurea. Plaḱ. Spec. 20.

D.Ananas lucide virens, folio vix ferrato. Dill. elib. 25. t. 2 I. f. 22 .

Ananas non aculentus Pitta dietus. Plum. Spec. 20.

Habitat in nova Hifpania, Surinamo. 2

2. BROMELIA foliis ciliato-1pinofis mucronatis, race-pingrt: mo terminali.

Bromelia folïs açuleatis, raseino laxo turminali. Hort. cliff. 129 . Roy. Iugab. 25.

Ananas americana fylveftris altera minor. Pluk. mant. 29. t. 258 . f. 4 .

Pinguin. Dill. elth. 320 . t. 240, f. 3 II.

Habitat in Jamaica, Barbados. $\$$

3. BROMELIA foliis ciliato-fpinofis mucronatis, pani-Karátas cula difinara.

Bromelia foliis fpinofis oblique recurvis, fructibus difpermis racemofis. Hort. $u p s .73$.

Karatas foliis altifimis anguntifimis \& aruleatis. Plun. gen. IO?

Habitat in America meridionali. 2

4. BROMELIA foliis ferrato-fpinofis ob ats, fpicis al-lingulald. ternis. 
Bromelia ramofa \& racemofa, folijs arundinaceis ferratis. Plum. gen. 26.

Habitat in A merica meridionali. $z$

nหdicaniis, 5. BROMELI. follis radicalibus dentato-fpinofis, caulinis integermismis.

Bromelia pyramidata, aculeis nigris. Plum. ger. 46. Habitat in America meridionilit. 2 .

\section{T:LLANDSIA.}

xtriculata. đ. TILLANDSIA culmo paniculato.

Tillandir foliis bafi conniventions in utriculum. Hort. rlitit. I 2.9 .

Vifcum caryophylloides maximum, fore tripetalo pa!lide inteo, fomine filamentofo. Sloan. jart. 76 . bift. I. p. I8S. Raaj Juppl. 405 .

$V$ ifci modo arboribus indicis adnafcens. Bauh. pin. 423. Caraguata multiplici fpica, flore albo. Ylam. gen. IO, Habitat in Americe oneridinsalis arboribus.

firdta. 2. TILLANDSIA foliis fuperne dentato-fpinofis. Cariguara clavata \& fpicata, foliis ferratis. Hizm.gen. 10. Habitat in America meridionali.

lingulata. 3. TILLANDSIA foliis lineari-lingulatis integcrimis: bafi rentrlcoís.

Caraguata latifolia \& clavata. Plum. gem. 10.

$\checkmark$ ifcum caryophylioides maximum, capitulis in furnmitate conglomeratis. Slocin. jam. 77. hift. I. p. 189. t. 120. Raj. Jappl. 405 .

Llabizat in Aneric meridionalis arboribus vetwlits.

tonufolia, as. TILLANDSIA foliis lineari-fubulatis integerrimis imbricatis, fpica finplici laxa. Roy. lzegdb. 25.

Caraguata tenuifolia, pancioribus fpicis. Plum. gen. IO. Habitat in America meridionalis arboribus.

\section{RENEALNIL.}

fanicu!nts. I. RENENLMIA foliis radicalibus brevifimis, caule fubnudo, ranis fi:bdivifis adlcendentibus.

Renealma ramofilima, foliis variegatis \& ci-cinatus. Plum. ge\%. 27.

Ilabitat in America meridionali.

polyfacbia. 2. RENEALMIA rcapo fpicis imbricatis lateralibus. Vifcum caryophylloides anguftifolium, Horibus caruseis. Catefb. car. 2. p.89. t.89.?

Rene. 
Renealmia f́pica multiplici, flore albo. Plum. gest. 37. $\beta$. Renealmia, ipica multipici, alia anguftifolia. $P / \mathrm{mm} . g \mathrm{en}$. Habitat in Amcrica calidiore.

2. RENEALMIA foilis linearibus reclinatis, rcapo fim- monolincbia. plici imbricato, fpica fimplici.

Renealmia non ramofia lquamata, \& foribus niveis. Plum. gen. 37.

Habitat in A merica meridionali.

4. RENEALMIA foliis fubulatis icabris, pedunculis u- recuriata. nitoris. Koy. lugdb. 25 .

Vifcum caryophylloides minus, foliis pruinæ inftar call= dicantibus, flore tripetalo purpareo, femine filainentolo. Sloan. jan. 77. bift. I. p. I90. t. I20, f. I. Raj.JupF!. 406.

$\beta$. Vifcun caryophylloides minus, foliorum imis viridibus apicibus fubrubicundis, flore tripetalo purpurco, femine. tilamentofo. Sloum. jam. 77. bift. x. p. 190.t. 122.

Habitat in jamaicæ arboribus.

5. RENEALMIA filiformis intorta. Hort. cliff. I2g. ufteoides. Grox. virg. 36. Barr. aquin. 99. Roy. lugd6. 25.

Vifcum caryophylloides tenuiffinum e mmis arborum mufci in modum dependens, foliis pruine inftar candicantibus, thore triperalo, femine filamentulo. Sloan. jam. 77. bift. 1. p. 191. t. I22. f. 2. 3. Raj. Suppl. 406.

Cufcuta, ramis arborum innafeens, caroliniana, filamentis lanugine tectis. Pluk. alm, 126. t. 26. $f .5$.

Camanbaya. Marcgr. brof. 46. Pet. gaz. t. 62. f. Iz. Habitat in Virginix, Jamaica, Brafilix arboribus.

\section{BURMANNIA.}

I. BURMANNIA [pica gemina, Burm, zeyl, 50, t. 20, diffichu. f. I. Fl. z.eyl i 28 .

Burmannia fpica duplici. Hort. cliff. 128. Roy. lugib.

I 25.

Habitat in Zeylonx paladofis

2. BURMANNIA flore geinmino.

Gurmannia fore dup!icı. Hort. sliff. 28.

bifiora.

Jurmannia fapo bitloro. Gron. virg. 36. Habitat in Virginiss paludolis. 


\section{TRADESCANTIA}

viriminna, 1. TRADESCANTIA. Hort. cliff. 127. Hort. npS.73. Gron. virg. 36. Roy. lugdb. 37.

Ephomerum phalangoides tripetalum rien repens virgi nianum gramincum. Morif. bifl. 3. p. 606. S. 15. t. 2. $f .4$.

Allium r. Moly virginianum. Baub. pin. 5o6. Habitat in Virginia. 2

\section{PONTEDERIA}

ovatd. 1. PONTEDERIA foliis ovatis, Horibus capitatis. Narukila. Rbeed. mal. 11.p. 67.t.34. Raj. Sxppl. 573. Habitat in Malabarix aguofis. 2 .

corlate. 2. PONTEDERIA foliis cordatis, foribus fpicatis. Pontederia floribus foicatis. Hort. cliff. 133. Gron. virg. 37. Koy. lugd6. 37. Cold. noveb. 69.

Gladiolus lacuftris virginianus cæruleus, fagitta folio. Pet. gaz. I. t. x. $f$. I2.

Sagittæ limilis planta paluftris virginiana, fpica florum cærulea, Morif. bift. 3.p. 618. S. $1_{5}$. t. 4. f. -

Plantagini aquatic $\approx$ quodammodo accedens, floribus caruleis hyacinthi fpicatis. Pluk. mant. 152. t. 349. fo zult.

Hebitat in Virginix aqrofis. \#

bnftat. 3. PONTEDERIA foliis haftatis, foribus umbellatis. Pontederia foribus umbellaris. Fl. zeyl. I 29 .

Sagitt $x$ quodammodo fimilis planta maderafpatana, fioiibus medio caule quafi ex utriculo prodeuntibus. Pluk. alm. 326. t. 220. f. 8. Morif. bift. 3. p. 618.S. 15. t. 4. $f .7$.

Carimgola. Rbeed. mal. I p. 91. t. 44. Habitat in India. 4

\section{GALANTHUS.}

nivalis ז. GALANTHUS. Hort. cliff. 134. Hort. upf. 73. Roy: ligaib. 35 .

Leucojum bulbofum trifolium minus. Baub. pin. 56 . Erangelia. Reneal. Jfec. 97. t. 26.

Ifibitat ad radices Alpium Verona, Tridenti, Viennæ. 2 


\section{LEUCO) UM.}

LEUCOJUM fpatha unillora livlo claratu.

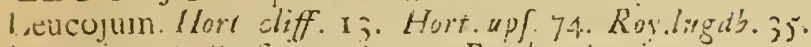

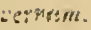

Leucojum bulbolum vulgare. Batib. pin. jo.

Oliganthenum. Reneal. $\int p e c .9 \%$. t. 100.

Hulbitat in (ieemanix, Helvetize, Italiz rombrofis pra. lis, ad rivitios.

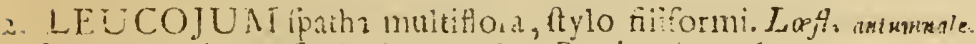

leucolum bubolun autummale. Bauh. pir. if.

Leucojum bulbolum aurumrale tenvifoliam. Cinf. bift.

1. p. 170 .

Leucojum bulbolum majus f. multinorum. Baak. pan iิ.

Habutat in Luitania. "

\section{NARCISSUS.}

I. NARCISSUS fiatha unifora neEari limbo rotito poc̈ticns. brevillimo. liort. ut. 74 .

Narrilius foliis enlifurmibus, Horis nectario fotato beevitimo. Hort. diff. I34. Roy. lugdb. 35 Sauz. miniti i\%

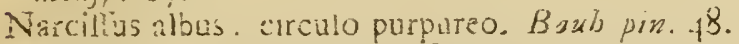

Narcillus incdio plirpureus. Dod. permpl. 223.

B. Narciffus medio purpureus multiplex. Bauts. pir. y. $^{4}$ llavitut in Gallia Narbonenfi, ltaiia: 2

2. NARCISSLIS fparha unifiora, nectarn limbo campa= Preudo Nur nulato eresto pitalo æuuale. cifjus.

Narestus foliis enf:formibus, forum nectario lonsitu-

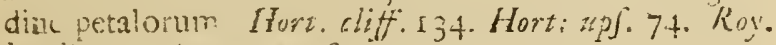
lugdij. 35. Sanz. munfp. I7.

Nacillus fylretris pallius, calyce luteo. Baub. pin 52.

Narcillis lutets jylveltris. Doi. pempt. 227 f. I 2. Habutat in Anglix, Hirranix, llalia nemoribus. $\mathbb{Z}$

3. NARCISSLIS foitha unitiora, nedario turbinato ma- Buibuolinm ximo, genitalibus declmati.

ivarcifu. foliis fubulatis, nedario maximo patulo, genitalious declinatis. Forl. cliff. 134 Rov lugib. 3r. ivarciffus montanus alter, fore fimbriato Bus. pin 53.

Narciflus montanus junciolius, ca!yco aureo. Bauh. bin. 53 . 
Pfeudo-Narciffus juncifolius 2, flavo flore. Clus. bijt. I. p. 166.

Habstut inter Ulyfliponem Eं Hifpalim. 2

rerotinus. 4. NARCISSUS fpatha uniflora, neetario breviffimo fexpartito. Lackl.

Narciffus albus autumnalis minimus. Baub. pin. 51 . Rudb. elys. 2. p. $64 . f .8$.

Narciflus fcrotinus. Clut. hift. I. p. r62.

Narciffus autumnalis minor. Clus. bifp. $25 \mathrm{I}$. t. 252.

Habitat in Hifpania. $*$

Fonquilla. 5. NARCISSUS fpatha multiflora, neetario campanulato brcvi, foliis fubulatis. Hort. $z p .75$.

Narciffus foliis lubulatis, florum nectario brevifimo Hort. cliff. 134. Roy. lugdb. 35. Sauv. monsp. I9.

Narciffus juncifolius luteus minor, Bauh. pin. $5 \mathrm{I}$.

Narciffus juncifolius, oblongo calyce, luteus major. Baub. pin. SI.

Narciffus juncifolius minor \& 2. Cluf. bift. 1. p. 6o.

Habitat inter Hifpaiim \& Gades inter Guadalopam $\mathcal{E}^{2}$ Toletum in uliginofis. *

Tasetta, 6. NARCISSUS fpatha multiflora, neetario campanulato, foliis planis. Hort. ups. 74 .

Narciflus foliis enfiformibus, florum nedtario campanulato erecto petalis longe breviore. Hort. cliff. 134 . Roy. lugdb. 35,

Narciffus medio-luteus, copiofo flore: odore gravi. Baub. pin. 50.

Narciflus luteus polyanthos lufitanicus. Baub. pin. 50.

Narciffus flore pleno, I. 2. Clas. hift. I. p. 50.

Habitat in Galliz Narbonenfis, Lulitanix, Hifpaniz ma . ritimis. 2

\section{PANCRATIUM.}

zeylanzuњ. I. PANCRATIUM ipatha uniflora, petalis reflexis. Fl. $\approx c \% l .126$.

Narciffus zeylanicus, fiore albo hexagono odorato. llerm. lugdb. 691, t. 093. Comm. bort. 1. p. 75. t. 38.

Catulli-pola. Rbeed. mal. I1.p. - t. 40.

Habitat in India. 2

mexitumin. 2. PANCRATIUM fpatha biflora. Hort. cliff. 133. Roy. Ingab. 34 . 


\section{HEXANDRIA MONOGYNIA.}

Pancratium mexicallum, flore gemello candido. Lill. elib. 299. t. 222. f, 289.

Habitat in Mexico. 2

3. PANCRATIUM fpatha multiflora, foliis lanceolatis. caribewn Hort. cliff. I3i.

Narciffus americanus, flore multiplici albo hexagrono odorato. Comm. bort. 2. p. 173 t. 87.

Narciffus totus albus latitolius polyanthos major odoratus. Sloan. jam. 115. bifl. 1. p.244. Mart, ceitb. 27. t. 27.

Irabitat is Jamaica, Caribxis. 2

4. PANCRA.IIUM fpatha multitora, potalis planis, fo-maritimum liis lingulatis.

Narciflus maritimus, Bauh. pin. 34 .

Lilio-Narcifrus albus maritimus minor. Morif. bift. 2. p. 365 . . . 4. t. io. f. 28 . *

Hemerocallis valcntina. Cluf. hift. I.p. 16\%

Habitat in HiSpanix maritimis circa Valentiam $\omega$ in fra Monfpelium. 2

5. PANCRATIUM ipatha inultifora, foliis linearibus, Caroitutu ftaminibus neetarii lonsitudine.

Liliolvarcillus poiyanthos, flore aibo: Caiesb: cor: 3 .

p. 5. t. 5 .

Habitat in Jamaica, Carolina $*$

6. PANCRA TIUM 1patha multiflora, foliis enfiformi-illyrzcum, bus, ftaminibus nectario longioribus. Rog. lugdb. 34.

Narcillus illyricus Jilitceus. Baub. pin. 55. Seb. thef: I. $p$ т. $t .8$. f. $\mathbf{~}$. Lilionarciflus hemeroeallidis facie. Befi. eyf. vern. 3 ,
t. I6. $f$. I.

Habitat in Illyria? ze

7. PANCRATIUM ipatha multiflora, foliis ovatis nur- amboinenfes volis:

Narciflus amboinenfis, folio latiflimo fubrotundo.

Conm. bort. I. p. $7 ;$ t. 39 .

Habitat in Ambonid. 2

\section{CRINUM.}

I. CRINUM foliis ovato-lanceolatis acuminatis felinlibus latifolinm.

Sjovanna-pola-tali. Rebed. mal. 11. p. 77. ․ 39.

Habitat in Alia arenojis. 2 . 
Folia. 3. S. 4. digitos transwerfos lara, a bafi fenfim attenuata Antherx filiformes, lineares, incumbentes, longitudine diniáii filamextif. corolla.

afintism. 2. CRINUM folits carinatis. Fl. zeyl. I2\%. Lilium zeylanicum bulbiferum \& umbelliferum. Herm lugdl. 682. t. 683.

Tangheholli. Rbeed. mal. II. p. 75. t. $3^{8}$.

Hibitat in Malabaria, Zeyloua. $z$

anericnmsil 3. CRINU M corollarum apicibus introrfum ungviculatis Crinum. Hort. cliff. 127. Hort. up. . 76. Koy. Iugdb: 37 . LilioAfphodelus americanus fempervirens maximus polyantnus albis. Cornm. rar: '14. $t$. 14. Dill. elth. I94. t. 160. f. 195:

B. Lilio Alphodelus americanus fempervirens minor albus.

Cumm. rar. 15. t. 15 .

Habitat in America. 4

afionnm. 4. CRINUM foliis fublanceolatis pianis, corollis obtufis. Polianthes foribus umbellatis. Vir. cliff. 29. Hort. cliff. 126. Roy. lugdb. 27.

Hyacinthis africanus tuberofus, Hore cx ruleo umbellato. Rreyis. prodr. I. p. 39. icon. 2j. t. 10. Eorm. bort. I. p. 13j. t. 67. Set. thef. I. p. 29. t. 19. f. 4 .

Hyacintho affinis, tuberofa radice, africana, umbella cærulez inodora. Pluk. alm. 187. t. 195. f. I. Habitat in Ethopia.

\section{A MARYLLIS.}

inter. I. ANIARYLLIS fpatha uniflora, corolla xonuli, famiribus declinatis. Itort. cliff. I 35. Roy. lugdb. 36 . Narciffus autumnalis inajor. Cluf. bift. I. p. I64. Colchicum luteum t. majus. Baub. pin. 69. Habitat in Hifpania, Italia, Thracin. $z$

1:amajca. 2. AMAR ILLIS tpatha uniflora, corolla aquali, piftillo declinato. Hort. cliff. I35. Gron. virg. 30. Roy. lugdb. $3^{6}$.

Liliona cilîus virginicnfis. Catesb. car. $3 \cdot p .12 .412$. Lilic Narcifus lilisorus carolinianus, flore aibo fingulari cuin rubedine diluto. Pluk, alm. 220.t. $43 \cdot t \cdot 3$ LilioNarcillos indicus pumilus monanthos albus. Mor rif. bijl. $2: p .266 . j$. t. t. 24. f. 4 . Habitat in Virginia. * 
3. AMARYLLIS ipatha uniflora, corolla insequali, ge-fornofisfams. nitalibus declinatis. Hort. cliff. 135 . Ilort. ofr. 75 . Aat. Jtockb. 1742. p. 93. t. 6. Roy. Ingdb. 35.

LilioNarciffus jacobaus, flore fangvinco nutante. Dill. elth. 195. t. $162 . f$. 196.

Narcilfus jacobæus major. Rulb. ely. 2. p. 89. f. Io. Habsiat in Amcrica meridiunali. $z$

4. AMARYLLIS fpatha multiflora, corollis campanuia-Belle domn. tis æqualibus, genitalibus declinatis. Hort. cliff. I 35 . Roy. lugdb. 36.

Lilio Narciffus polyanthos, flore incarnato: fundo ex lutco albefcente. Slaan. jam. II 5 . bift. 1.p. 244. Seb. thef. I. p. 25 . t. I 7. f. I.

Lilium rubrum. Merinn. Surin. 22. t. 22.

Habitat in Caribxis, Barbados, Surinama. 2 ;

5. AMARYLLIS ipatha nultiflora, corollis revolutis, Farnienfis. genitalibus trictis. Hort. up $\int .75$.

Amaryllis fpatha mutilora, corollis xqualibus patentisfimis revolutis, genitalibus longiffimis. Hort. cliff. I 31 . Roy. lugdb. 36.

Narciflus japonicus, rutilo flore. Carn. canad. I57. to I 8 . Rudb. ely. 2. p. $23 . f .14$.

Lilium farnienfe. Dugl. monugr. t. I. 2.

Habitat in Japonia, nunc in Sainiæ infula Anglia. 4

6. AMARYLLIS fpatha multiflora, corollis campanu-zeylanica. lat $x$ qualibus, fcapo tereti ancipiti. Roy. lugdb. 36. Lilio Narciflus zecylanicus latîolius, flore niveo externie linea purpurea friato. Comm. bort. 1. p. 73. t. 73 .

3. LilioNarciffus africanus, filla foliis, Hore niveo linea purpurea friato. Ebret. pi it. 5. f, 2.?

Habitat in Zcylona. 2

7. AMARYLLIS ppatha multiflora, corollis campanu- longifolia. latis æqualibus, fapo compreffo longitudine umbellæ. Roy. lugdb. 36.

Litium africanm humile, longiftimis foliis, polyanthos farurato colore purpuralcens. Herm. parad. 195. $t$. 195.

Habitat in Æthiopia. $*$

8. AMARYLLIS fpatha multiflora, corolis inæqualibus, orientalis. foliis lingriformibus. Büttr. cunon. 215 .

Anaryllis Ipatha multitora, foliis ovato-oblcngis obtufis. Roy. Imgdb. 37.

$$
\mathrm{T}_{3} \text { Li- }
$$


LilioNarciifus indicus maximus fphæricus, floribus plu. rimis rubris liliaceis. Morif. bijt. 2. p. 568. f. 4. $t$. 10. $f$. 35 .

Narciflus indicus orientalis. Swert. flor. $3 \mathbf{I} . f$. I. Habizat in India. $z$

gutsts. 9. AMARYLLIS fpatha multiflora, foliis ciliatis.

LilioNarciflus fphæricus æthiopicus, foliis gurtatis \& $\mathrm{cl}$ lii inftar pilofis. Pluk. alm. 220.

Lilium aflicanum fphæricum, floribus obfolete puniceis minoribus, foliis guttatis ad margines cilii inftar pilotis, bulbo longo. Herm. lugdb. 375 .

Habitat in Athiopia.

\section{BULBOCODIUM.}

vernum, 3. BULBOCODIUM foliis lanceolatis. Roy. lugdb.41. Bulbocodium. Hort. cliff. I 33 .

Colchicum vernum hifpanicum. Baub.pin. 69. Rudb. ely. 2. p. $128 . f .2$.

Colchicum vernum. Ciluf. bift. 2. app. 203.

Habitat in Hifpania. 7

ferotinum. 2. BULBOCODIUM foliis fubulato-linearbus. Roy. lugdt. 41 .

Bulbocodinm alpinum juncifolium, fore unico: intus albo extus fqualide rubente. Raj angl. $3 \cdot p \cdot 374$. $t$. 17. $f$. I.

Pfeudo-Narciffus gramineo folio. Baub. pin. 5 I. prodr.

27. Rudb. elys. 2. p. 64. f. 9 .

Labitat in Alpibus Helvetia, Anglia.2

A I HYLLANTHES,

mon/pelienfis 1 . APHYLLANTHES. Hort. cliff. 493. Sauz.monsp.8. Aphyllanthes monfpelicnfiun. Lob. adv. 190. Baub. bift. $3 \cdot p \cdot 336$.

Caryophyllus cæruleus monfpelienfium. Baub.pin. 209. Morif. bift. 2. p. 562. S. 5. t. 25. f. 12.

Habitat Monlpelii prope Cafrelneuf locis montofis fa. $x$ ofis ferilibus.

$$
\begin{aligned}
& \text { * FLIUUM. } \\
& \text { Folizs caulinis planis. }
\end{aligned}
$$

Ampelopra- I. ALLIUM caule planifolio umbellifero, umbella gloJinit. bofa, faminibus triculpidatis, radice laterali.

Allium ftaminibus alternc trifidis, foliis gramineis, foribus fphæricc congeftis, radice laterali folida. Hall. all.5. 
Porrum radice laterali folida, foliis linearibus, caule e* recto, unbella fubglobofa. Roy. lugdb. 40.

Allium lpharico capite, folio iatiore 1 . Scorodoprafum altcrum. Baub. pin. 74. Rudib. elyf. 2. p. 151. *

Habitat in Oriente, inque infula Holms Anglice.

2. ALLIUM caule planifolio umbellifero, ftaminibus Porrum. tricufpidatis, radice tunicata. Hort. upS. 77. Mat. med. 165 .

Allium Itaminibus alterne trifidis, foliis gramineis, floribus fphrrice congeftis, radice tunicata cauli circumnata. Hall. all. 5 .

Porrum radice ambiente tunicata oblonga folitaria. Hort. cliff. 136. Kay. lugdb. 40.

Porrum commune capitatum. Baub. pin. 72.

Porrum fativum latirolium. Bauh.pin. 72 .

Habitat - . -

3. ALLIUM caule planifolio umbellifero, umbella glo- lineare, bofa, itaminibus tricufpidatis corolla longioribus.

Porrum caule tereti foliofo, foliis linearibus planis, umbella globofa, ftaminibus corolla longioribus. Gmel. Sibir. I. p. 56, t. 13. E I4. f. x.

Habitat in Sibiria.

4. ALLIUM caule plan ifolio umbellifero, umbella gio-Victorialis. bofa, ftaminibus lanceolatis corolla longioribus. Nivict. med. 163.

Allium foliis caulinis lanceolatis, floribus umbellatis. Roy. lugdb. 39.

Allium radice oblonga reticulo obdueta. Hall. all. 17.

Allium montanum latifolium maculatum. Bauh. pin. 74.

Allinm anguinum. Canz. epit. 329. Habitat in Alpibus Helvetix, Italix.

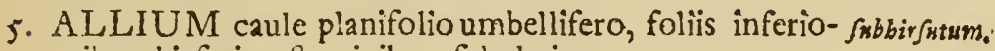
ribus hirfutis, Raminibus fubulatis.

Allium foliis radicalibus fubhirfutis, cauinis glabris, floribus umbellatis. Hall. all. 15 .

Allium foliis lanceolato-linearibus, florum umbella $\mathrm{fa}$ ftigiata. Roy. lugdb. 39.

Moly anguftifolium umbellstum. Baub. pin. 75.

Moly diofcoridis. Cluf. bift. I. p. 192.

Habitat in Africa, Italia, Hifpania.

$$
\Gamma_{4} \text { c. AL. }
$$


6. ALLIUM catie planitiolio umbeilifero, ramulo bul bifero, faminbus timpliciblis.

Allium caulc tereti, propgine ex a! A Hort.cliff: 137 . Rav. tugd6. 30. Sañ. inowp. 18.

Allium foliis caulinis lanceolatis, Horibus umbellatis, cx ala bulbifermn. Hall. ali. I9.

Noly latifolium liliforum. Bauh. pin. 75 .

Moly indicun, fore purpurco. Swert. Fl. 6it. Halitiat - - - -

obliquna. 7. A [LLIC]M caule planifolio umbelifero, faminibus filiformitus flore triplo longioribus, foliis obliquis.

Allim radice tunicata, foliis planis linearibus caulinis, capitulo unbellato. Grnel. Jibir. I. t. 49. t.?

Habitat in Sibiria.

Caulis bisedulis, teres. Folia alterne, fluna-canaliculata, bliqua. Vaginis teretibus. Umbella globora; Spatha globofe, acurninata. Petaia oviata, erecti, concisz'a, flaria carina viridi. Filamenta alíida, cosolla diuplin longtnra. Anthere lutea. Gerinen juhglobofurn.

vanufism. \& ALLILM caule fubplanifotio umbellifero, ftaninibus fubulatis longioribus; umbella globoli, foilis lincaribus fubconvexis.

Alliun fcapo nudo tereti fareto, foliis femicylindricis, ftaminibur corolla longioribus. Gmel. fib. 1. p. $52 . t$. 9. f. I.

Habizat in Sibiria. G. Demidoff

Caulis ferme bipedalis, icres. Folia alterne, planiufcula, canaliculata, fubtus convexa, margine obtufa. Umbella globofa. Petala ovata, puipurafcentia carina faturatiore. Filamenta purpurea, corolla farum longinra. Anthere violacea. Germen fubrotunáum: riviulis 3, viridibus E' medin caule ex ala folio oppolita. Ramus nudus, lnngitudine caulis.

rofium. 9. ALLIUM caule planifolio umbellifero, umbella faftigiata. Ataminibus corollam xquantibus, foliis lavibus. !

Allium foliis Enfiformibus, radice bulbillis Ripata, Hn. ribus amplis umbellatis. Sauv. monfp. 42 .

Allium fylyefte 1 . Moly minus, rofeo amplo flore. dî́agn. munjp: II. t. 10.

Hrbitat Monpelii in vincis

futivu, In. ALLIUM caule planifolio bulbifero, radice compofita, ftaminibus tricufpidatis. Hort. uph. 76. Mal. med. 104. 
Allium radiois buibo multipartito, capitulo bubifero, foliis lincaribus. Ilort. cliff. 137. Roy. laggét. 39.

Alium ftaminibus alterne trifidis, foliis gramineis, $\mathrm{Ca}-$ pitc bulbifero, radicibus in unum bulbunl congruentibus. Hall. all. J.

Allum fativun. Bauh. pin. 73.

Alliums. Cium epit. 328 .

iavitution Sicilia.

1. ALIJUM caule planifolio bubiforn, folijs crenulan t15: raginis ancipitibus, faminibus tricufpidatis. Hort.

Srovidoupf. T7.

Allium capitulo bulbofo erecto, foliis planis fubcrenatis, vaginis ancipitibus. Fl. fuec. 266. It. ol. 60 .

Allium flaminious alterne trifidis, cafite bulbifero, foliis gramine:s laviter ierratis. Hall. all. 3.

Allium niontanum bicorne latifolium, Ho:e dilute purpuraicents. Bauh. pin. 74. Kusio. elyf. 2. p. I55.*

B. Allium Itaninibus altcrne trindis, capite bu!bifero, fcapo aric maturitatem contorto, Hall. all. 2.

Allium fatium alterum 1. Alliopantim andis fummo circumroluto. Hauh. pin. $\overline{3}$.

Allii genus Opholcorodion dictum quibusdam. Baub. hift. 2. p. 559 .

Porrum radice laterali cordata folida, pecunculo revoluto, capite bulbifere). Hort. chiff. I 36.

Habital is Uelandia, Dania, Pamonia.

2. ALLILM caule planitolio bulbifero, vaginis tereti-arentam. bus, Ipatha mutica, ftaminibus tricuppidati . /1./6an.227.

Porrum blanifolium, faminibus alteric trifidi, unbella buibifera. Rupp. bali. I5t. t. 2. t. 2.

Habitut in '1 huringia; in Falltria Scanix.

13. Al,LIUM caule planirolio bulbifero, flaminibus fu-carimatur. bulatis

Allium umbella bubifera, vagina bicormi, foliis carinatis. Hall. all. 24. t. 1. f. 2 .

A.mpeloprarum prolifcrum. Lob. ic. is6.

P. Allium inontanum bicorne anguttifolium, flore dilute purpuraicentc. Bazb. fin. 74 .

Allium 1: Moly montanum 2. Cluf. bift. 1. p. 195.

Habitar in Germania.

\section{* Folis caulinis teretibus.}

4. AI I.IUM caule tcretifolio umbellifero, folis ficmi-fpharesepte teretibus, Itaminibus tricufpidatis corolla longioribus. lor.

$$
T i
$$


Allium ftamiuibus alterne trifidis, foliis gramineis, radicc multiplici, floribus fphærice congeftis. Hall. all. 7.

Porram caule tereti folioto, toliis linearibus planis, umbella globefa, ttaminibus corolla longioribus. Gmel. fib. I. p. 56. t. I3. Eु 14. f. I

Aliium montanum, capite rotundo $B$ auh. pin. $75 . R u d b$. elys. $1 . p \cdot 157 . f .7$.

Allium r. Moly montanum, purpureo flore. Cluf. bift. I. P. 195 .

Allii genus forte Scorodoprafum alterum. Baub. bift. 2. p. 564 .

Scorodoprafum montanum juncifolium, capite--rotundo dilute janthino, floribus paucis. Mich. gen. $25 \cdot t$. 24. $f .2$.

Habitat in Italia, Sibiria, Helvetia.

defiendens, 15. ALLIUM caule fubteretifolio umbellifero, pedunculis extericribus brevioribus, ltaminibus tricufpidatis. Hort. ups. 78 .

Allium ftaminibus alterne trifidis, foliis fiftulofis, capite ivave rubente fphærico non bulbifero, radice laterali. Hall. all. 8.

Allium ftaminibus alterne trifidis, foliis fiftulofis, capite fphærico non bulbifero atropurpureo, Hall, all. 9. t. I. $f$. $\mathrm{r}$.

Allium 1. Moly latifolium, capite fphærico, flore purpureo. Rudb. clyf. 2. p. I60. f. 20.

Moly atropurpureum. Rudb. elyf. 2. p. I65. f. 13.

Habitat in Helvetia.

mofchetum. 16. ALLIUM caule teretifolio fubnudo umbellifero, umbella fattigiata. petalis truncatis, faminibus tricufpidatis. Loefl.

Allium foliis teretibus caulinis, floribus umbellatis. Hall. all. I4.

Moly mofchatum, capillaceo folio. Baub. pin. 76. prodr. 28. t. 28. Rudb. elys.2.p. I66.f. I4. * Sauv. monsp. ro.

Habitat in GalloProvincix, Narbonæ, Hifpanix apricis clevatis.

ftnvin. 17. ALLIUM caule teretifolio umbellifero, umbella glabofa, ftaminibus fubulatis.

Allium umbella non bulbifera lutea, vagina bicorni, foliis teretibus. Hall. all. $2 \mathrm{I}$.

Alium montanum bicorne, flore pallido odore. Baub. pin. 75 . 
Allium f. Moly montanum 4. Clas. bija. 1. p. 216. Habitat in Pannoilia.

8. ALLIUM caule teretifolio bulbifero, ftaminibus tri- vinicale cuipidatis.

Alliuin ftaminibus alterne trifidis, foliis fiftulofis, capite bulbifero, radice multiplici. Hall. all. 4 .

Allium fylveftre campeftre purpurafcens. Baub. pin. 74.

Allium campettre juncifolium capitatum purpurafcens majus. Baub. pin. 74.

Porrum fylveftre vinearum. Baub. pin. 72.

Porrum fylvefte, gemino capite. Bash. pin. 72.

Habitat in Germania.

9. ALLIUM caule teretifolio bulbifero, foliis fcabris oleracum. femiteretibus iubtus fulcatis.

Allium umbella bulbitcra, vagina bicorni, foliis teretibus. Hall. all. 23. f. 4 .

Cepa capitulo bulbofo prolifero, foliis femiteretibus novemangularibus fcabris filtuiolis. Fl. Juec. 265. *

Porrum radice folida, caile eresto, capitulo bulbifcro. Roy. lugab. 40. Gort. gelr. 69.

Allium montarum bicornc, Hore cxalbido. Baub. pine 75.

Habitat in Suecia, Germania.

* Foliis radicalibus, frapo mudo.

20. ALLIUM fcapo nudo ancipiti, folits linearibus pla- nutms. nis, ftaminibus triculpidatis. Hort. up . 80.

Porrum feapo nudo ancipiti, antcquam Horucrit nutante, foliis enfiformibus: hinc paullo convexioribus. Ginel. fibir. 1. p. 55. t. I8.

Habitat in Sibiria,

21. ALLIUM fcapo nudo ancipiti, foliis linearibus fub-renescens. tus convexis lævibus, umbella fubrotunda, ftaminibus fubulatis. Hort. ups. 79 .

Allium caule ancipiti teretiufculo, foliis enfiformibus: hinc paullo convexioribus. Grnel. Jibir. 1. p. 53.t.I I. f. 2 .

Allium foliis linearibus, florum umbella fubglobora. Roy. lugäu. 39.

Allium radice bulbofa, foliis gramineis, umbella erecta non bulbitera, vaginis brevifimis. Hall. belv. 297 . all. 16. n. 2 .

Allium montanum, foliis narciff, majus. Bazk. pin. 75 . 


\section{HEXANDRIA MONOGYNIA.}

Iinbitat in Sibiria, Sicilia.

Pctala erecta, a fe inzicem debifcentia. diftantic, casaliculata, inflexa.

angulifuss, 22. ALLIUM fcapo nudo ancipiti, foliis linearibus canaliculatis fubtus fubangulatis, umbella faftigiata. llirt. upf. 79 .

Cepa fcapo nudo fubangulato farcto, foliis linearibus fubtus angulufis, ltaminibus corolla brevioribus. Gimel. fibir. 1. p. 58. t. 14. f. 2.

Allium radice fenefcente liguofa tranfverfa, umbella erecta. Hall. all. I6.

Alium petræun umbelliferum. Bauh. hift. 2. p. 564 . t. 14 .

Allium montanum, foliis narciff, minus. Baub.pin. 75 :

Havitat in Sibiriæ bumidiufalis.

Folia interdum fubtus vixix angulata, at Scapụs $\int u p e r n e$ parum angulato-ftriatus; Pctala interiora apice patentia, omnia lateribus conniventia.

Coiafer Allium fylveltre 1 . Moly minus, violaceo amplo flore. Magn. nonsp.

uтfinum, 22. ALLIUM feapo nudo femioylindrico, foliis lan= ceolatis petiolatis, $11 \mathrm{mbella}$ faltigiata.

Allium foliis lanceolatis, fcapo nudo fomicylindraceo, bulbo fetis obvallato. Fl. Suec. 263. It. gotl. 169.

Allium foliis radicalibus petiolatis, Horibus umbellatis. Roy. lugdb. 39. Hall. all. I 8. Gmel. fib. I. p. 49.

Allium foliis lanceolatis, umbella lax2. Hort. cliff. 27. Allium fylveftre latifolium. Baub. jin. 74 .

Allium uifinum. Fuchf. hift. 739. Cam. epit. 330.

Habitat in Europx Septentrionalioris nerrurafis.

triguetrum. 2.4. ALLIUM rrapo nudo triquetro.

Allium caule triangulo. 'Fournef. inft. $3^{85}$. Roy. lugdb. 39.

Moly parvum. caule triangulo Baub. pin. 75.

Moly canlc \& foliis triangularibus. Park. par. 1.42. $t$. I $43 . f$. 4 .

Habitat in Hifpania.

Cepa. 25. ALLIUM fcapo nudo inferme ventricofo longiore foliis teretibus. Hort. upf 7\%: Mat. med. 166.

Alium ftaminibus alterne trifidis, caule ad terram ventricofo. Hall. wll. Io.

Cepa rcapo nudo ventricofo foliis longione, radice depresk. Hort. cliff. 137. Roy. lingdb. 40. 
Cepa vulgaris. Bauh. pin. 71 .

Cepa. Cam.epit. $\hat{\jmath}^{2} 4$.

Hobitat - ..-

26. ALLIUM fcapo nudo fubcylindrico, foliis lanceo- $\pi / \%$. fitis temilibus, umbelia fanigiata. Mort. upf. 76 .

Alliun foliis radicalibus fenflibus lanceolatis, floribus umbellatis. Roy. lagdb. 35. Hall. all. 20.

Allium foliis lanciolatis; umbella laxa. Hort. cliff. 27.

Moly latifolium luteum, odorc allii。Bath. pin. 75 .

Moly flavo tlore. Swert. flor. 1. t. 60. $f$. 2 .

Moly inontanum latifolium, Gavo flore. Ciluf. app. alt.

Habitat in Hungaria, Baldo, Monipelii.

Inctala patcntia, tria exterioramagis patestia, interiora e:ecta.

27. ALLIUM fapo nudo folia adæuuante, foliis tercti-fiftulos $\mathrm{km}$. bas ventricolis. Hort. upf. 78 .

Allium ftaninibus fimplicibus, caule medio ventricofo. H.ill. all. II

Cepa fcapo longutudinc foliorum, folis rentricofis, radice oblonga. Hort cliff. 136 . Roy. lugdb. 40.

Cepa oblonga. Bauh. pin. 71. Dod. permpt. 657.

Habitat in - - -

28. ALLIUM fcapo mudo 2üyuante folia :eretia fubu- Schenopralato-filiformia. Hort. upf. 48 .

Allium ftaminibus fimplicibus, foliis radicalibus teretibus fcapi longitudine. Hall. all. T2.

Cepa fcapis folissque fubulatis terctibus fittulofis æqualibus, fpathis globofis. Fl. Suec. 264. It. *l. 54. 64 .

Cepa feapo longitudine figuraque foliorum, foliis fubulatis filiformibus, fpath:s globolis. Hort. Witf. ${ }_{13} \mathrm{G}$.

Porrum fectirum juctolium. Baub. pin. 72.

Schonoprafum. Dod. pempt. C8g.

B. Cepa fcapis foliisque teretibus, capitulis pyramidatıs. Gmel. fivir. 1. p. 59. t. 15. f. I.

Cepa palultris altifima. Buxb. cent. 4. p. 27. t. 4t. -Aabicat in alpeftribus Sibirive, Oelandia locis rupeftribus.

29. ALLIUM fapo nudo tereti inani. follis fubulatis fi= rontit? liformibus, capitulis laxis paucilloris. Grnel. Jibir. 1. p. 61. t. I5. f. 2.3 .

Habitat in Sibiria.

30. ALLIUM feapo nudo fubnullo, folis linearibus. Chismamoly Moly humile, folio gramineo. Baks. pin. 75.

Chas- 
ChamæMoly, an Moiy diof́coridis. Column. ecphr. 325 t. 326 .

Habitat in Italia,

\section{LILIUM.}

candidum. I. LILIUIM foliis fparfis, corollis campanulatis: intus glabris. Hort. rliff. I 20. Hort. upf: SO. Mat.med. I73. Roy. Jugadb. 30:

Lilium album, flore erecto, vulgarc. Bamb. pir. 76.

Lilium eandidum. Dod. pempt. 197.

E. Lilium album, floribus dependentibus, $\mathfrak{f}$ peregrinun. Bauk. pin. $7^{6}$.

Habitat in Palæltina, Syria. $z$

büifcrum. 2. LILIUM foliis fparfis, corollis campanulatis ereetis intus fcabris. Hort. cliff. 120. Hiort. upf. So. Koy. lugdb. 31. Grwel. Jibir. I. p. 4I.

Lilium purpureo-croceum majus. Baub. pin. 76 .

B. Lilium purpureo-croceum, flore pleno.

y. Lilium purpureo-croceum minus. Baub. fin. $7 \%$.

d. Lilium phœniceum. Eauh. pin. 77.

E. Lilium bulbiferum Intifolium majus. Bauh. pin. $7^{\circ}$

ฯ. Lilium bulbiferum anguftifolium: Baub. pin. i;

ท. Lilium bulbiferum minus: Bauh. pin. 77.

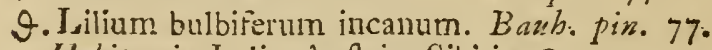

Habitat in Italia, Auftria, Sibiria. 2

pomqouи 3. LILIUM folits sparfis fubulatis, thoribuis reflexis, corollis revolutis. Hort. eliff: 120 . Hort. upf. 81. Roy. litgdb. $3 \mathrm{I}$.

Lilium 1 adice tunicata, foliis fparfis, floribus reflexis, corollis revolutis. Ginel. fibir. I. p. 42 .

Lilium, foribus reflexis, anguftifoilum. Baub. pin. 78.

Lilium rubrum precox. Clus. hift. I. $p$. I 133 .

p.Lilium miniatum anguftifolium. Baxh. pin. 79.

r. Liliuin brevi \& gramineo folio. Baub. piri. 79 :

Habitat in Fyrenæis, Sibiria. 2

Folia linearia, acuta, triqueira, canaliculata, Sparfa. Neetarii rima valde dentata.

ebalceriont- 4. LILIUM foliis Iparfis lanceolatis, floribus reflexis, co-

sun. 'rollis revolutis. Hort. sliff. 120 . Hort. upS. S1. Roy. lugdb. $3 \mathrm{I}$.

Lilium byzantinum miniatum. Bash. pin. 78 .

Lilium rubrum $\mathrm{f}$. miniatum byzantinum. Cluf. bift.1 p. $\mathbf{3}^{\mathrm{I}}$. 
B. Llium by zattinum miniatum polyanthos. Baub. fin. 79 . $\gamma$. Lilium purpuro-fangvincum, Hore reflexo. Baub. pin. 78.

Hemerocallis calcedonica. Lob. ic. 169.

Habitat in Perfia. 2

Racemus ante florefcentiam vix incuratus st in 3.5 . et Caulis usque ad apicem Foliis veffitus confertis.

5. LILIUM foliis verticillatis, floribus reflexis, coroliis Marlagen. revolutis. Hort. cliff. 120 . Hort. upf. SI. G'mel.fibir. I. p. 44. Roy. lugdb. 31 .

Lilium, Horibus reflexis, latifolium. Baub. pin. 77 .

Lilium fylveftre. Dod. penipt. 201.

B. Lilium, floribus reflesis, alterum hirfutum. Baub.pin ; 9 .

Habitat in Hungaria, Helvetia, Sibiria, Lipfiæ.

6. LILIUM foliis verticiliatis, flonibus reflexis, corollis sana?enfs. campanulatis.

Lilium anguftifolium, flore flave maculis nigris diftincto. Tournef. intt. 371. Barr. rar. 778, t. 125.

Lilium Martagon canadenfe maculatum. Morif.bift.2. p. 408. S. 4.t t20. $f: 9$.

Lilium f. Martagon canadenfe, floribus magnis flavis non reflexis. Catesb. car. 3. p. II. t.. II.

Habitat in Callada. 2

7. LILIUM foliis verticillatis, flore erecto, corolla cam- eantchat. panulata. Ameen. acad. 2 p. 348 . *

Habitat in Canada, Camfchatca.

- Camschatca planta petalis ovatis Sefolibus, figmatibus tribus absque ftylo; e Canada petalis lanscolatis unguiculatis cuin Jtylo; varietates tamen fuere.

\section{FRITILLARIA.}

t. FRITILLARIA racemo comoro inferne nudo, fo- imperialis, liis integerrimis. Hort. upf. 82 .

Petilium foliis caulinis. Hort.cliff. Irg. Roy. lugde. zo. Lilium f. Corona imperialis: genus. Bauh. pin. 79 .

Tufai. Clus. bift. I. p. 127.128.

Habitat in Perfia? e Conftantixopoli verat in Europam circa 5570.2

2. FRITILLARIA racemo comofo inferne nudo, fo- regin, liis crenatis.

Corona regalis, lilii folio crenato. Dill. eltb. I 10.t.93. f: 109 .

Hubitat ad Cap. b. Spei.

FRI- 
3. riea. FRITILLARIA racemo mudiufcuio, toliis obliquis. Hort. upr. 82.

Fitillaria raceno nudo terminail. lort. cliff; 119.

Fritillaria radice rotudida. Roy. lugdb. jo.

Lilium perficum. Bauh. pin. 79.

liliun fufianum. Claif. bift. 1.j. 130.

Habitat in l'erfia? e Sufis verat in Europam 1513. 4

prreneict. t. FRITILLARIA foliis infimis oppotitis. hort. cliff. 8 r.

Frivllaria floic minore. Baub pin. 04.

Fritillaria pyrenaa. Cluf. hift. 2. p 256. poplls. io. liditat ib Pyrenxis. 2

Melingris. 5. IRITILLARIA foliis omnibus alternis. Hort. "j. St.

Fritillaria e foliorum alis forens. Hort. cliff. In

Fritillaria radice deprefla. Roy. lus $d b .30$.

Fritillaria præcox purpurea varicgaia. Basis. 1is. Ca4.

Mcleagris. Reneai. Ipec. I47. t. 146.

Q. Fritillaria alba variegala. Baxts. pin. 64.

$\gamma$. Fritillaria alba oracol. Banis. pin. G.4.

d. Fritilaria ferotina atropurpurea. Bauh. pin. 64.

Hubitatio Gallia, Italia

\section{UVULA.hIA.}

ample.sfoitu „, UVULARIA folis amplexicunlibus.

Uvularia foliis cordato-oblong:. Rey. ingdb. 29.

Smilax perfoilata ramofa, flore albo. Barr rar. $y^{8} ;$. 720.

Polygonatum latifoliun ramolum. Bath.pin. 30 z. Is aub. hili. 3.p. 531. Morif.hift. 3.p.537.f. 13.t.4.j.11. Raj. hilt. 655 .

Poiygonatum lanfollum 4 ramolum. Gluf, hift. I. p. 276.

Limurus alexandma, Cam. apti. 930

Int,alat in Boheniai, Silelix, Saxonix, Delphinatus mantibes.

perfoliata. 2. UVULARYA folits perfoliats. Amaen. acnd.2. p.337

Urularia caule perrotiato. Gron. virg. 37. Cold. noveb. 74.

Uvularia folio integerrimc, Rny. lugdb. 27.

Uvularia. llort. clatt. I $2 \mathrm{I}$.

Polygonum ramofum, tlore luteo, majus. Corn. canad. 35. Nurif. bifl. 3. F. $538.5 .13 .4 .4 \cdot f \cdot 12$. 
Polygonatum latifolium perfoliatum brafilianum. Baub. pin. 303. prodr. 139. Burf. XVII. 6I.

Hubitut in Virginia, Canada. planta Burferi ex Tospinambualt Brafilice apharinacopeco allat 0 O C.B. coin.

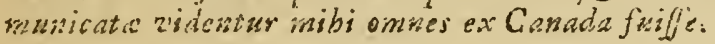

$\therefore$ UVULARIA foliis refibibus.

Uvularia foliis fefilibus, Here unico. Cold.noves. 73 .

feffitifolis,

Habitat in Cunada. Kalin.

Habitus precedentis: Caulis bifiaus, usigorus. Folia laaceolato-ovata, alteria, at ubi Flos ex altero r.mo exit, folia bina adjut. Pedwnoulus nudus.

\section{GLOORIOSA.}

1. GLORIOSA. Hort: slifi, I21. Fl, zey?. I22. Roy. Süterbs ligito. 29.

Methonica malabarorum. Herm. lugdb. 699. . 699. Pisk. ulm: 249. t. 116. f. 3 .

Lilium zeyianicum fiperbum. Gonm. bort. ז. p 69. th $3 x$.

Merdoni. Rbead. inal. 7. t. 107. f. 57.

Habivat is Malabaria. 2*

\section{FRYTHRONIUM.}

1. ERYTHRONIUM. Hart. cliff. IIg. Gmel. fis. I. Dens suris

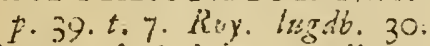

Dens canis latiore rotundioreque folio. Bab. pir. S7i.

Dens caninus: Dod:perpt. 203:

Q. Dens calls angultiore longioreque folio. Bauh. pin. 5 .

y. Erythronium folis ovato-oblongis glabris nigro macilatis. Gron virg. I TI. fare fiavo.

Habitat in Liguria. Allobrogibus, Angufta Taurinorum,

Sibiria, Viruginia. 2

\section{TULIPA.}

1. TULIH'A flore fubintants, foli:s innceolatis:

Tulipa miner iutes italica. Baub. tiss. 63:

Siluestris.

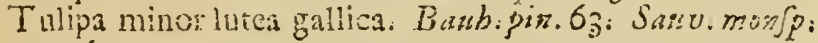
306.

Halitat Monfpelii, isgtre Apenninis, Limäini. 2

Dittinguitur a fequente: Caule altiore, Foliis angufrer:bus, Floris colorc lutio jubtus osrefernte, petalis acu-

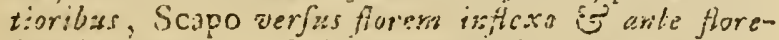

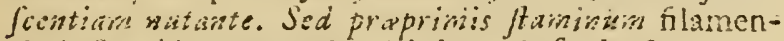

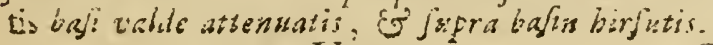

$$
\text { บ. } 7 \mathrm{U} \text {. }
$$


gejnirima. 2. TULIPA flore ereeto, foliis ovato-lanceolatis. Tulipa fcapo triphyllo, foliis ovato-lanceolatis. Hort. up 5.82 .

Tulipa. Hort. cliff. I18. Roy. lugdb. 31:Fl.Juec. 262. Tulipa (genus fere totum) Baub. pin. 57.

Tulipa turcarum. Cord. bift: 213 :

Habitat in Cappadocia, unde in Europarn 1559 . 26

breyzisna. 3. TULIPA caule polyphyllo, foliis lincaribus.

Sifyrinchium, ex phoniceo fuaverubente Hore, xthiopicum. Breyn. cent. t. 36. Rudb. elyf. 2. p. 13. f: II. Habitat in Athiopia. 4

\section{ORNITHOGALUM.}

lutesm. I. ORNITHOGALUM rcapo angulofo diphyllo, pe-dunculis umbellatis fimplicibús. $1 \%$. Juec. 270.

Ornithogalum ficapo diphyllo, pedunculis fimplicibus terminalibus, filamentis omnibus lubulatis. Mort. cliff. 124. Roy. lugdb. 3 I.

Onithogalum luteum. Bauh. pin. 71.

Pyrrochiton. Reneal. Spec. 91. t. 90.

Ifibitat in Europx cultis macellis. \#

7iminum. 2. ORNITHOGALUM feapo angulato diphyllo, pedanculis umbellatis ramofis. $\mathrm{Fl}$. Juec. $27 \mathrm{I}$.

Ornithogalum luteum minus. Bauh.pin. 71 .

Hypoxis. Reneal. Spec. 92.

Habitat in Europa cultis oleraceis.

birfatm. 3. ORNITHOGALUM 1capo angulato, podunculis umbcllatis villofis.

Ornithogalum feapo billoro. Roy. lugdb. 3I.

Ornithogalum virginianum luteum. Pet. gaz. I t. I. $f \cdot 3$.

Ornithogalum luteum parvum virginianum, folits gramineis hirlutis. Pluk. alm. 272.t. $350 . f .12$.

Ornithogalun vernum luteum, foliis angultis hirtatis. Gron. virg. 37.

Habitat in Virginia, Canada.

Spec 1. 2. 3. maxime allines Junt.

biza've. 4. ORNITHOGALUM Horibus umDcllatis, fpatha bl. valvi. Gron. virg. 37. †

Habita* in Virginia.

pyretsicim. 5. ORNITHOGALUM racemo longifimo, filamen- 
tis lanceolatis, pedunculis foriferis patentibus xqualibus: fruetiferis fcapo approximatis.

Onithogalum raceno longilime, filantentis dilatatolincaribus, caplulis ereetis. It. iran. 220.

Onithogalum fpica longifima, filancentis triangularibus. Hall, belr, 294.

Ornithogalum anguftitolium majus, Horibus ex albo virefcentitiss, 33 anb. pin. 70. Rudb. cly. 2 . p. I34.f.j.

Ornithogalum majus. C/uf. bijt. 1. p. iS7.

Ornithogalum pyienaicum. Clas. cur. 21.

Stachyoides. Keneal. Jper. 93. t. 90.

Habitat in Aipious Helveticio, Generentibus, Pyrenaicis. 2

6. ORNITHCGRLUM racemo longifimo, folits lan-latifolinm. ccolato-culif armibus.

Ornithogalum latifolium \& maximum. Baub. pin. 7o.

Ornithogalum vel Lilium alexandrinum, floribus albis innummerabiibus. Swert. florit. 58 .

Habitat in Arabia, Egypto.

Folia pedalia flus yuam duos pollices lake. 2

7. ORNITHOGAT,UM racemo conico, Horibrs nu- tyramidale. merolis adfcendentibus. Roy. lugdb. 32 .

Ornithogalum anguftiolium fpicaturı maximum. Bawh. pin. 70. Rudo. elyf. 2. P. 134. f. 4 .

Ornithogalum lactcum maximun. Bell. eyjt. zers. s.t. I 4. $f .2$.

Habitui: in collibus Lulitanix. 24

\section{* Staminibus alternis emarginatis.}

8. ORNITHOGALUM floribus corymbofis, pedun-arabisnt. culis icapo hunilioribus, flamentis emarginatis. Roy. lz:gdir. 32 .

Onithogatim umbcllatum maximum. Bawh. pin. 69. Ornithogalum arabicum. Cluf, bift. I t.p. i 86. Befl.egjt. zern. 5. . 12. i. 1.

Melanomphale. Reneal. Sper. 8g. t. 90.

Habitat juxta Alerandrum Aigypti. z

3. ORNITHOGALUM floribus corymbofis, pedun-umbellatum. culis feapu atioribus, filamentis emarginatis. Hort. clitf. I2.4. Hort. upf. 84. Roy. Iugáb. 32.

Ornithogalum umbellatum niedium angutifolium. Buzb. pin 70.

Eliocarmos. Reneal. Spec. 88. t. 87 .

Habitat is Germannia, Gallia.z 
six:uns. 10. ORNITHOGALUM Roribus fecundis pendulis, neetario ftamineo carnpaniformi.

Ornithogalum foribus fecundis pendulis, filamentis latis emarginatis. Hort. Gliff. $2_{24}^{4}$. Hort. off. 84 . Roy. $l z: g d b .32$.

Ornithogalum exoticum, magno fore minori innato. Bumb. pin. 70. Rudb. ely. . p. 137.f. I2.

Ornithogalum neapolitamm, Eluef, app. 2. p. 9. t. 9. Habitat in Italia Neopoli. 2;

enpense II. ORNITHOGALUM foliis cotdato-oratis. Koy. lighdb. $3 \mathrm{I}$.

Ornithogalun africanum, plantaginis rorcæ folio, radice tuberofa. Comm. bort. 2. p. I75. t. 88.

Oruithogalo affinis radice tuberola, cyclaminis folio, fore pallide cærvleo. Breyn. rent. t. 41 . Rudb.elys. I. p. $138 . f$. I4.

Habitat ad Cap. b. Spci. :

caruderfe. I2. ORNITHOGALUM petalis alternis patentibus: interioribus ereotis.

Ornithogalum luteo-virens indicum. Corn. canad. Í́o. Rudb. elyf. 2. p. I 40. f. \%. Raj. bift. II 54 .

$\beta$. Orniriogalum africanum, thore viridi:altero alteri innato. Herm. par. 209. t. 209.

Habitat is Africa. ?

\section{SCILLA.}

maritiwn,

I. SCILLA radice tunicata. Hort. cliff. 123. Hort. $n p \int$. 89. Arat. med. 362. Roy. lugalb. 32. Scilla vulgaris, radice rubra. Bauh. pin. 73. Scilla hifpanica. Clas. hift. I. p. I 7 r.

B. Scilla radice alba. Baub. pin. 73 . Habitat ad Hifpaniæ, Siciliw, Syrix iittoria arenofa. Ib Lilia Hya- 2n SCILLA radice fquamata. Hort. cliff. Roy. lagdb.32. Hyacintinus Itellaris, folio \& radice liii. Bauh. pis $4 \sigma_{2}$ Hyacinthus Rellatus, liii folio. Bazb. pin. 46. Habitat in Bifcria, Aquitania, Hipania, Pyrenæis. \#

itslicas.

3. SCILLA radice folida, corymbo conferto hemitpharico.

Scilla radice folida, fioribus corymbolis confertiffimis. Hort hliff: 123. Roy. lingdh. 32 .

Hyacinthus fellaris \{picatus cincreus. Bamb. pin. $46 \mathrm{x}$. Hyacinthus freilaris itaicus. Beft. eyt. zqum. 42 . f. $T$. 
Hyacinthus fellatus cinerei coloris. Cluf. biff. I. p. I84. Habizat. . . - 2

4. SCHLLA radice folida, corymbo conferto conico, peruviumar Hyacinthus indicus bulbofus fteliatus. Baub. pin. 47. Rudb. clyf. I. $f$. $37, f$. I.

Hyacinthus ltellatus peruallus, Cluf. bijf. I. $p$. I82. $H_{2}$ bitut in Lufitania. 2

5. SCILL A radice folida, flcribus lateralibus alternis fub- "menas mutantibus. Hort. cliff. 123. Roy. lugdb. 33 .

Hyacinthus itellaris cerulcus amoenus. Basb. pin. 46. Rudb. ely. 2. p. 34. t. 7 .

Hyacinthus itcllaris bizantinus. Befl. egft. zern. $43 \cdot f .3$. Hinlitat forte Bizantii, unde venit in Europam I 590 . 2

6. SCILLA radice foilda, floribes erediuŕculis pauciori- bifolta,

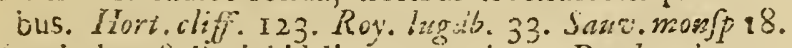
Hyacinthus fteliaris bifolius germanicus. Bamb. pir. 45 . Hyacinthus cierulcus mas minor. Fusbl: bift. 837 . Hakitat in Galia, Germania. \&

7. SCILI A radice folida, foliis filiformibus linearibus, authrmelis. floribus corymboîs, pedunculis nudis adfcendentibus longitudine floris.

Scilla radice foilda, foilis fetaccis, foribar faftigiatis, pedenculis arcuatis cx ala tuberculi mammi!'aris. Guett. ftamp. 131. Dalib. parif. 102.

Scilia radice folida, capo multifloro, floribus capitatis, Saur. mon $\int \bar{p}$. 19.

Hyacinthus ftellaris autumnalis minor. Bash. pin. 47. Hyacinthus auturnnalis minor. Cluf. hift. r. p. I85.

Habitat in Hifpania, Gailia, Verona folo glareofo. 2

8. SCILLA folio tcretiufculo, laterc fubrpicato.

Bulbus moliophyllus, fiore albo. Baub. hift. 2.p. 622 .

mifolia,

Mlabitrit in Lulitania.

\section{ASPHODELUS}

I. ASPHODELUS caule foliofo, foliis triquetris fiftulo- Imtens.

fis. Hort cliff. 127. Hort. ups. 83. Roy. lugdb.33.

Afolodelus luteus Herc \& radice. Baub. jin. 28.

Afrhodelus femins. Cam. epit. 372 .

Ilabitat in Sicilia. $\sigma$

2. ASPHODELUS caule mudo, foliis ftriotis fubulatis fifulosus, ftriatis fubrifulolis. Hort. cliff. 83 .

$$
\mathrm{U}_{3} \text { Arpho. }
$$




\section{HEXANDRIA MONOGINIA.}

A tphodelus caule nudo, foliis ftrictis. Roy. lugdbr 34 . Aphodelus foliis fiftulofis. Banh. pin. 29. Alphodelus minor. Cilaf. hit. i. p. 197.

Hobitat in Gallo-Provincia, Hilpania, Creta. 2

yomofis: 3. $\triangle$ SPHODELUS caule nudo, foliis enfiformibus carinatis lavibus. Mat. med. I 72 .

Afphodelus caule nudo, follis laxis. Hort. cliff. 127.

Ruy. ins db. 24. Sauv. monfp. 20.

Afphodelus albus ramofus mas. Baub. tin. 28.

Afphodelus albus non ramofus. Banth. pin. 28.

Afphodelus. I. 2. Cluf. bift. 1. p. I.97.

Habitat in Narbona, Lufitania, Hifpania, Italia. 3

\section{ANTHERICUM.}

\section{* Pbalargium foliis canaliculatis.}

Foroluzum. I. ANTHERICUM foliis planis, fcapo ramofo, corollis revolutis.

A fphodelus foliis compreflis afperis, caule patulo. $T_{\theta-}$ urnef. inlt. 343 .

Habiat _... 4

samofinm. 2. ANTHERICUM foliis planis, fcapo ramofo, corollis planis.

Anthericum foliis. planis, corollis planis deciduis. It. gotl. 178 . * Fl. fuec. 267 .

Anthericum caulibus ramolis ${ }_{2}$ foliis planis. Guett. farmp. P. I 29 .

Phalangium, parva flore, ramofum. Bauh, pin. 29.

Phalangium najus. Cam. epit. 580 .

Habitat in Europa auftralioris rupibus calcareis. 4

zilinga. 3. ANTHERICUM foliis planis, fcapo fimpliciflimo. Hort. up. 83. It. Scan.

Authericun caulibus non ramofis, folijs planis. Guct. famt: I. p. 128 .

Phalangium, parro flore, non ramofum. Baub. pin. 29. Morif bifz. 2. p. 333. f. 4. t. I. f. 10.

Phalangium non ramolum. Lob. ic. 48 .

Habitat in Helvetia, Germania, Gallia.

$$
\text { * Bulbine folizs carncfis. }
$$

fortefens. 4. ANTHERICUM foliis camofis terctibus, caule fruticofo.

Anthericum caulefcens, foliis puipofis terctibus fubulatis fupine convexo-planis. Wuch, utr. 305 . 
Fiulbinc caulefcens. Hort. cliff. I22. Roy. lagdb. 122. thalangium capenfe caulefcens, foliis cepiriis fuccofis. Dill. elth. 310. t. 231. f. 298.

Haít at ad Cap. b. Spei. b

5. ANTHERICUM foliis carnofis fubulatis planiurcu- alosids. lis. Hort. apf. 83 .

Anthericum foliis pulpofis lanccolato-fubulatis fupine excavatis. Wach. wltr. 3 u.

Bulbine acaulis. Hort. cliff. I23. Roy. luzdb. 33.

Phalangium capenle feffile, foliis aloefornibus pulpofis. Dill. elth. 3 12. to $2 \hat{j}^{2}$. f. 300 .

Hatilat ad Cap. b. Spei. $z$

6. ANTHERICUM follis carnofis fubulatis femitereti-Afplocielcibus ftrictis. Hort. ups. 83 .

Anthericum acaule, foliis pulpofis teretibus fubulatis fupine convexo planis. Wrach. ultr. 305.

Habitat in Ethiopia. 2

Folia wix friati, sed frick a, margine afpera, dorfo verfus alterum latus gibbojiora.

7. ANT'HERICUM foliis carnofis fubulatis teretibus. ^nижит. llort. ups. $3_{3}$. *

Anthcicum acaule, foliis fetaceis caule angutioribus. U'ach. ultr. 305 .

Hitbrat in Ethiopia. ()

\section{* Nartbecium foliis enfiformibus.}

8. ANTHERICUM foliis enfiformibus, filamentis la- afferagim. natis. Fl. Juer. 268. Gmel. fibir. 1. p. 73. t. i8.f.2. Anthericum icapo foliolo laxe fpicato, filamentis villotis. Fl. lapp. 136 Roy. lugdb. 45 .

Narthecium. Mocbr. E. N. G. I742.p. 389 . t. s. f.

1. Wach. ultr. 303. Gort. gelr. 69.

Pleudo-Afhodelus paluftris anglicus. Baub. pir. 29. Afphodelus luteus paluftris. Dod. vempt. 208.

Habilat in Europie borealis uliginofis. "z

9. AN THERICUM Eoliis enfiformibus, perianthiis tri-calyculatam. lobis, filamentis glabris. Fl fzec. 269. It. gotl. 194. 221.

Anthericum filamcutis lavibus, perianthio trifido. Hort. cliff. 140. Gron. virg. 3y.

Anthericum (capo nudo capitato, filanentis glabris. Fl. lapp. 13 : : I0. $\int .3$. 
Phalangium alpinum paluftre, iridis folio. T. Segu. ver. 2. p. 6i. t. 14

Pfeudodfphodclus alpinus. Baub. pin. 29.

Halitat in alpibus Helvetia, Lapponia, Sibirix. Is

Gchus nullum in tota claff: Liliacea difficilius deter minatur: 8 oflifragum 99 calyculatum habitre toto ita uriuntur, ut demta fructificatione vix diftinguantur, at Species 9 gerit Stamina glabra, Pericarpium Subglobofum, stigmata tria fine ftylis fó Perianthium triva!vi. Species 8 anrestitur jpeciebus 4.5.6.7. Staminihus birfutis, at differt Gcrinine pyramidato, Semizibus paleaceis, Corolla perfiftente. Species i. 2. 3.differüt a speciebus 4. 5. 6. 7, Sinninibus glabris, babits Afpbodeli, adeoqus vel fub uzo eoderique senere

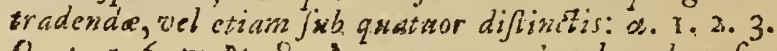
B. 4. 5. 6. 7 ; \%. 8; 8. 9. proponende; boc dure fieret dificilline charactex fpecieruin a obtineretur.

\title{
LEONTICF.
}

Chryfogt- T. LEONTICE foliis pinratis: petiolo communifinpli

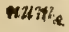

\author{
ci. Hort. Gliff. 122 .
}

Leontoperalon folis cofte fimplici innafcentibus. Tour nef. cor. 49.

Leontopetalo affinis, follis quernis. Baub. pin. 324 Morif. bift. 2. p. $285.5 .3 . t .5 .5 .3$.

Chryfogonum diofcoridis. Rauv, itin. Iio, Raj nifta 1326.

Habitat inter Gracix Jegetes. z Lastapeta
zum.
inm. LEONTICE foliis decompofitis: petiolo communi trifido. Hort cliff. 122.

Lcontopetalon foliis coftæ ramofæinnafcentibus. Tournef. cor. 49.

Leontopetalon. Bauh. pin. 324. Cam. epit. 565. Morif. bift. 2. p. $285 \cdot f \cdot 3 \cdot$. . x $5 \cdot f \cdot 6$. Raj. bift. 1326.

Habitat in Apulia, Hetruria, Creta. Z

Thatiat roi: 3. LEONTICE folio canlino triteruato (27), florali bi* des. ternato (9).

Leontice folits fupradecompofitis. Gron. wirg. I5I. Cold. noveb. 75 .

Habitat in Virginia. 2

Modus crefcendi Epimedii. Caulis usdus, tcrminatus Foliis tribus, patentibas, petiohizis: Petioins fingulus irifulus, adnatis sovem foliolis, quorum iateralia

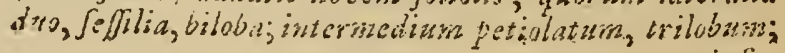
infra 
infra divifur.am jrimam caulis exerit e obere folizin Petiolis tribse: frogulis firsplicibus tripbyllis, infros quos Racenus limplex cum dubus lateralibus.

4. LEONTICE foliis fimplicibus tripartito-multifidis, Leontop:ta corollis monopctalis calyculatis. $\dagger$

Leontopetaloides. Amin. a.t. 8. p. 2ri. t. I13.

Habitas in India.

Habitus brejus gexeris, at flos videtur fatis diverfus, an jufficiesier fro diflinblo genere determinent autoptis.

\section{ASPARAGUS.}

7: ASPARAGUS caule herbacco eredto, foliis fetaceis, officinalis, tipulis paribus. Fl. juec. 272. Mat. med. I69. Hort. ciiff. $121 . R 6 y, \operatorname{lig} d b .28$.

a. Afparagus maritimus, crafliore folio. Baub. piz. 49. marimus. B. 1 fparagus rylveltris, tenuiflimo folio. Baub. pia. 490.

7. Atparagus fativa. Bazh. piat. 489 .

Afparagus. Cam. epit. 259.

Habitat in Europæ arenojis. 2:

2. ASPARAGUS caulc inermi, ramis declinatis, foliis keclinatss. fetarcis, Roy. lugdb. 22.

Habitat in Africa.

3. ASPARAGUS aculeis folitarïs, foliis enfiformibus falcats:, falcatis. Fl. zeyl. $\times 23$. *

Afparagus foliis falcatis ex uno pundo numerolis. Burm. zeyl. 36. t. 13. f. 2 .

Habitat in Zeylona. 5

4. ASPARAGUS aculeis folitariis, ramis refcxis retro- retrofratis. fraetisque, foliis fafciculatij.

A paragus frutercens, foliis fafciculatis fetaceis terminalibus, ramis reflexis retroliexis. Hurt cliff. r21. * Roy. lugdá. 28.

A praragns africanus tenuifclius, viminalibns virgis, fofiis laricis ad inftre ex uno puncto munerolis feliatim poistis. Pluk. ainalth. 4Q. 4. $375 . f .3$.

Habitet in Africa. 5

5. ASPARAGUS aculeis folitariis, caule creeto, follis nfinticus. falciculatis, ramis filiformibus.

A fparages aculcis alternis, ramis tolitaris fliformibus, foliis fetaceis talciculatis lateralibus. Hort. chith. 122 . * Roy. incdi. 28.

Habitat in Alia.

U 5 6. A- 
wim. 6. ASI'ARAGUS aculeis folitariis, ramis flcxuofis, fo.. liis fafciculatis angulatis muticis deciduis.

A fparagus aculeis folitariis, ramulis flexuofis binis oppolitis pinolis foliofis, foliis fafcictilatis. Roy. lugdo. 29.

Afparagus aculeatus, fpinis horridus. Baub. pin. 490. Corduba tertia. Cluf. bift. 2. p. I 78 .

Habitat in Lufitania, Hitpania. b

ditifolitis. 7. ASPARAFUS caule inemi frucicofo, foliis aciformibus percnnautibus mucronatis ternis aqualibus. Atparagus foliis aciformibus pungertibus, caule fruticoto inermi. Sauv. monfp. 45 .

Afparagus foliis acutis. Bauk. pin. 490.

Alparagus fylveftris. Cam. epit. 260.

Habitat in Lufitania, Hifpania. b

aryllus, 8. ASPAKAGUS aphyllus, pinis fafciculatis inæqualibus divergentibus. Hort, cliff. 122. Roy. lugab. 2y. Afparagus aculeatus aiter, tribus aut quatuó fpinis ad cundem exortum. Bauh. pen. 490.

Corduba altera. Cluf. bift. 2. p. 178 .

B. Apparagus creticus fruticofus, cratlioribus \& brevioribus aculeis, magno fructu. Tosernef. itin.91. t. 15. Habitat in Sicilia, Hifpania, Lulitania. b

mpenfis. 9. ASPARAGUS fpinis lateralibus torminalibusque, ra mis aggregatis, foliis falciculatis.

Afparagers foliis quinis fetaceis, fpinis terminalibus lateralibusque, ramulis ternis quateruisque. Hort. cliff. 121 .

Afparagus aculcatus, triplici fpina, furrectus. Pluk. alm. 5. i. $15 . f .4$.

Habitat ad Caput b. Spei. b

samenofur. IO. ASPARAGUS toliis folitariis lineari lanceolatis, caule flexuofo, aculeis recurvis. Fl. zeyl. I 24:

Aiparagus aculeatus zeylanicus maximus farmcntofus. llerm. luzdb. 62. t. 650.03.

ILabitat in Lcylona. b

\section{CONVALLARIA.}

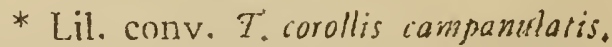

minis, a. CONVALLARIA capo nudo. Fl. lapp. Ii 3. Fl. jitc. 273. Mat. ined. 167. Hurt ckiff. 124. Ray. lugdb. 26. Gimel. Jibir. 1. 1" 34. 
Lilium convallium album. Bash pin.jof

Lilium Convallium alpinum. Baub, pin. 304.

Lilium convallium latifolium. Baub. pin. $; 0 \%$.

Habitat in Europa feptentrionali. 3

* * Polvgonata $T$. corollis infundibuliromibiss.

2. CONVALLARIA foliis verticillatis. I. liDp. ITA verticitatr. Fl. Siec. 215 . Hort. cliff. 125. Roy. ingaí. 26.

Polygonatum anguftiolium non ramofum. Baub. jin. 303

Polygonatum alterum. Dod. pempt. 345 .

B. Polygonatum anguftioliuin ramofum. $D u s b$. pin. 304 .

Habitat in Europx feptentrionalis faltibus, pracipititi. 2

3. CONVALLARIA foliis alternis amplexicaulibus, Paigonncaule ancipiti, pedunculis axillatibus miHoris. Mat. twit. med. I68. Gmel. fibir. 1.p. 34. Pbil. but. 218.

Convallaria foliis alternis, floribus axillatibus. F\%, fases.

274. Hort.cliff. 124. Grom. virg. 37. Koy.lugdb. 20.

Comvallarid foliis alternis, pedunculis pendulis unifluris. Sazv. rnonjp. 42 .

Polygonatum latifolium vulgare. Bauh. pin. 305.

B. Polygonatum floribus ex lingularibus peduizculis. Bauk. bift. 3.p. 5 io.

Polygonatum latifolium, fore majore odoro. Bauh.pin. 303.

Habitat in Europa Septentrionalis procipitios rupibusque. 2

4. CONVALLARIA foliis amplexicaulibus, caule tere-qultifors. ti, pedunculis axillaribus multifloris. Phil. bot. is 8.

Convaliaria foliis alternis, pedunculis pendulis multitoris. Sazv. monjp. 42.

Polygonatum latifolium maximum. Bazh. pin. 303 .

Po!ygonatum latifolium I. Cluf. hift. I. p. 275 .

Habutat in Europx jeptentrionalis precipitios, supibus.z

* * Smilaces $\mathcal{T}$. corollis rotatis.

5. CONVALI.ARIA fullis feffilibus, racemo terminali momofn. compofito.

Convallaria racemo comporito. Roy. Ixģai. zó.

Convallaria foliis alternis, racemoterminali. liort. cliff. 125. Gron. virg. 38.

Polygonatum racenofum. Corn. canat. $3^{6}$. t. 37. Polygonatum ramofum \& racemofum ficatum. Mosif. bijl. 3. p. $537 \cdot 5 \cdot 13 \cdot$ t. 4. f. 9. 
Polygonatum racemofum americanum, ellebori albi foliis ampliffimis. Pluk. alm. jcr. t. 3II. f. 2 .

Ilabitat in Virginia, Canada. 2

Sellate. 6. CONVALLARIA foliis amplcxicaulibus plurimis, racerno terminali timplici.

Polygonatum virginianum erefum fpicatum, fore ftellato. Morif. bift. 3.p. r36. S. 13. t. 4. f. 7 .

Polygonatum canadenfe fpicatum fertile. Corn. canad. 33.5 .33$.

Habitat in Canada. 2

trifolie. 7. CONVALLARIA foliis amplexicaulibus ternis, raccmo terminali fimplici.

Convallaria floribus racemofis, foliis ovatis oblongis caulinis. Gmel. Jibir. I. p. 36. t. 4 .

Phalangium verarri foliis. Amrr. ruth. I 37.

Habitat in Sibiriæ Sylvis. \#

bifolin. 8. CONVALLARIA foliis cordatis. Fl. lapp. I I3. Fl. suec. 276. Hort. cliff. 125. Koy. lugdb. 26. Gmel. fibir. $x, p .35$.

Lilium convallium minus. Banh. pir. 304.

Gramen parnafi. Cam. epit. 744 :

Habitat in Europa borealis pratis deprefis asperis. *

\section{POLIANTHES.}

tuberofn. I. POLIANTHES.

Poilanthes floribus alternis. Hort.cliff. 127. Hort.upf. 76. Fl. zeyl. 225 .

Hyacinthus indicus tuberofus, flore narcifi. Baub. tin. 47. Rudb. clyf. 2. p. 39.f. 4 .

B. Hyacinthus indicus tuberofus, flore hyacinthi orientalis. Bazb. pin: 47. Ruab. cly.: 2. p. $3^{8}$. f. 2 .

Hyacinthus indicus, tuberoia racice. $C l u f . b i \beta .1 . p$. $1>6$.

Helsitat in India. 2

\section{HY A CINTHUS.}

nouf friths. I. IIYACINTHUS corollis campanulatis fexpartitis apice revolutis. Hort. cliff. I25. Ray. lugd. 27 . Sauv. monit. 17.

Hyacinthus, oblongo flore cervileus major. Bauk. pin. 43 .

Habitat in Anglia, Gailia, Hifpania, Italia. $₹$ 
Brątex funt jepius foribus longiores, Ev bine. Pctala apice revoluta. Stigma guttula madidum.

2. HYACINTHUS corollis campanulatis lexpartitis, cernus. racemo cernuc.

Hyacinthus hiparictis. Clis. bifs. I. p. I77.

Hyacinthus, oblongo flore fuavter rubenic, minor. Bash, tin. 44.?

Irabitat in Hifpania. 2

Cionzenit cuin H. non feripto babitu so faxie, quam* vis minor; difert vero folitis magris lineuriuns, minus lanceolatis, crectioribus, Kacevo magis nutante; Chow rollis incarnatis nec corruleis, tereticribus, cum petalorsm lateribus ad bafin vitnus plons petentibus ne' dorfo linec elevata notatis, minusiyze revolutis (quarswis reglexa) quarm in illo, Piftillam demum faminibus breviaus eft. Bractea bine, faturatius incarnats.

3. HYACINTHUS corollarum caterioribus petalis di-serotinus finetis, interioribus coadunatis.

Hyacinthus obfoleto Hore. Baub. pin. 44 .

Hyacinthus, obfolet coloris, hilpanicus ferotinus. Ches. bift. $1 . p \cdot 177$.

Havitat in Hipania, Mauritania. 4

4. HYACINTHU'́ corollis campantiatis femifexfidis muethysthws bafi cylinàricis. Hort. ep p. 85.

Hyacinthus, oblongo caruleo fore, ninor. Baub.pin. 44. Rudb. ely. 2. p. 27. f. 8 .

Hyacinthus minor hilpanicus anguftifolius. Baub. hift. 2 p. 587.

Habitat in Hifpania? $z$

5. HYACINTHUS corollis infundibuliformibus femi- orientalito lexfidis bali ventticofis. Hort. upf. 5j. Hort. clifj: 125. Roy. lug 26.27.

Hyacinthus oricntalis, (pec. $1-15)$ \& plenus $(1-j)$ Bazib. jin. 44 .

Hyacinthus orientalis major \& minor. Dod. pempt. 216. Hubitat in Alia, Africa. 2:

6. HYACINTHUS corollis ovatis, Hont. cliff. 126 . Wuscart Hort. $z p$. 95. Ro\%. lagdb. 2.8.

Hyacinthus racemofils noichasus. Babh. pin. 43 .

Mufcari obfolvtione thore. Clasf. bi/2. I. p. I 78 .

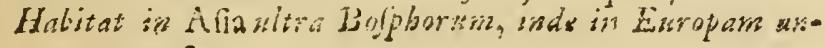
to 1554 . 2: 
monfrofits. 7. HYAINTHUS corollis fubovatis. $V i r$, cliff. 28. Roy. litg:!'. 2\}.

E. 13 aciuthis froribus panicnlatis monftrolis. Hort.cliff. 126.

Hyacinthus panicula carmlea. Bash. pin. 42.

Hyacinthus famefius, panicula comofa. Col. ecpbr. 2. p. ID. t. I 2 ,

Habitat .. - primuin inverita in agro Papienfi, E iuxta Buran Gallix. Ais fequenis fola varietas?

comofus. 3. HYACINTHUS corollis angulato-cylindricis: fummis ftcriibus longius pediccltatis.

Hyacinthus corollis globofs : fiunmis pedunculatis, foliis enfiformious. Sauv. mon $p$. 17.

Hyacinthus comofus major furpureus, Baub. pro. 42.

Hyacinthus. Cam. epit. 798.

Habitct is Gallix E Europa anfralis agris. 24

hotryoules. 9. HYACINTHUS corollis globofis uniformibus, foliis canaliculato-cylindricis.

Hyacinthus corotlis glubois. Hort, cliff. I26. Hort. upf. 85 . Roy. lugab. 28.

Hyacinthus corollis globolis, foliis in cylindrum convolutis. Sarv. monfp. IO.

Hyacinthus racemofus cæruleus minor juncifolius. $B$ aub. gin. 43 .

Hyacinthus botryoides valgaris. Lob. it. 107.

Habisat in Italia.

racemofus. 10. HYACINTHUS corollis ovatis: fummis feffilibus, folis enfiformibus. Saur. monz $p$. 17 .

Fyacinthus raccmotus cærulcus minor latifolius, Baub. pis. 43,

Hyacenthus botryoides r. Cluf. hift. I. p. I8I. Habitat in Europa auftrali. 2

Orebioides. I1. IY A CINTHUS corollis irregularibus fexpartitis.

Hyacinthus orchioides africanus major bifolius maculatus, flore fulphureo obloleto majore. Breyn. prodr. 3. p. 24. . . II. f. 2.

Hirbitat in Athiopia. 4

lanatus. 12. HY ACINTHUS co:ollis lanatis, caule ramolo. Koy. lagitb. 27. Habitat .... 


\section{ALETRIS.}

I. ALETRIS. Gen. noz. 1076 A LETRIS. Gen. noz. IO 6 forinosn.
Hyacinthus caule nudo, foliis ling viformibus acuminatis
dentatis. Gron. vinm. 88 .

Hyacinthus Horidanus fpicatus. Pluk. amalth. I I $t$. $4 i 7 \cdot f \cdot 3$.

livitat in America fepientrionali. 2

\section{LCCA.}

I. YUCCA foliis integerrimis. Vir. cliff. 29.

Yucca foliis margine integerrimis. Hort. cliff. 130.

Hort. up. 88. Koy. Iugdb. 29.

Yucca foliis aloës. Buth. pin. ox.

Yucca indica, foliis alö̈s. Barr. rar. 7o. t. J I 94.

Cordyline foliis pungentibus integcrimis. Roy. lugab. 22 .

Habitat in Canada, Pcru. b

2. YUCCA foliis crenulatis ftrietis.

nloifolin.

Yucca toliis crenulatis. Lir, cliff. 29.

Yucca foliorum margine crenuiato. Hurt. cliff. I $30 . x$.

Iucca arborefcens, tolits rigidioribus rectis ferratis. Dill. elth. $435 \cdot i \cdot 323 \cdot f \cdot 416$.

Alö, yuccæ folis, caulelcens. Pluk. alm. I 9. t.256.f.4. Aloë americara, yuccæ folic), arborefcens. Comm. pral. 64. t. 14 .

Mabitat in Jamaica, Vira Cruce. b

3. YUCCA toliis crenatis nutantibus.

draconis.

Yucca foliorum margine crcnulato. Hort. cliff. i $30 . \beta$. Hort. 1 it. 88 .

Yucca draconis folio Cerrato. Dill. elth. 437. t. 324 . f. 417. Comm pral. 42. 67. t. 16.

Draconi arbori athnis americana. Baub. pan. 5o6.

Cordylire foliis pungentibus crenatis. Roy. lugdi. 22. Habitat in America. I

4. YUCCA foliis ferrato-filamentolis.

flamentoja.

Yucca foliis lanceolatis acuminatis integerrimis margine filamontofis. Gron. virg. 152.

Yucca foliis filamentolis. Morif. bift. 2. p 419.

Yucca virginiana, foliis permarginem apprine filatis. Pluk. alm. 396.

Habitat ui Virginia. b

I. ALOE fioribus pedunculatis crenuis corymbolis fub-perfolints. cylindricis. 
Aloê foliis caulinis dentatis amplexicaulibus vaginantibus. Hort. cliff. 1 32 . Hort. uts. 86. Ray.lugdb.23. a. Aloë africana caulefcens, foliis magis glaucis caulem amplectentibus \& in mucronern obtufiorem definenti bus. Coinm. prel. 68. to 17. rar, 44. $t$ t 44.

B. Aloë africana caulefcens, foliis minus glaucis; dorfi parte fuprema fpinofi. Cornm preh. 69. t. 18.

y. Aloë cfricana caulefcens, foliis glaucis latioribus \& undique foinofis. Comm. prel. 70. t. I9.

d. Aloë africana caulefoens, folitis glaucis breviaimis, foliorum fummitate interna \& externa nonihii fpinofa. Comin. jrat. $73, t .22$. rar. $45 . t .45$.

E. Aloë africana caulefcens, folis giancis: corfo integro fpinoto. Comm. pre?. 71. t. 20.

$\zeta$. Aloe africana caulefcens, foliis glaucis brevioribus: foliorum parte interna \& externa nonnibil ipinofa: Corim. prel. 7x. 2. 21 .

7. Aloë africana caulefcens̀, foliis glaucis caulicm ampiccentibus. Comm. bort. 2. p. 2\%. t. 14.

7. Aloë africana caulefcens, foliis fpinofis maculis ab utraque parte albicantibus notatis. Coinm. bort. 2. F.9. $t: 5:$

- Aloë africana caulefcens perfoliata gialaca \& non fpinofa. Coing pral. $74 ., 2.2 .3$.

*. Alö aficana, foliis glaucis: margine \& dorfi parte fitperiare fpinofis, Hore rubro. Comm. pral. $75 \cdot t .24$. bort. 3. p. 23, t. 123

ᄀ. Aloë arricana maculata fpinofa major. Dill. eltb. xy.t. I 4. $f .15$.

$\mu$. Aloë atricana maculata fpinofa minor. Dill. eltb. 18 . t. I. . f. I6.

- Aloë aricana initriformis finofa. Dill, etch, $2 x, t . i \%$. f. 19 .

ל. Aloë fuccorrina anguftifolia fpinof , Dore purpureo. Comm. borit. r. $\vec{p}$. 91. $t .48$.

Aloë amcricana, ananse floribus fuave rubentibus. $P$ lusk: alm. 19. t. 2:40. $f_{i}: 4$.

humilis, o. Alö foliis ereatis fubulatis radicatis undique inerme pinolis. Hort. cliff: 31 . Ray. Iugdt. 24.

A io $\ddot{e}$ africana hunilis, fpinis inermious \& rerrucofis obfita. Comm. prel. 77. t. 26. rar. $46 . t: 46$

Habitat in Athiopia. 5

Plawatat o ad hane speciem pertinere docnere flores, quantris babitu aridcatur alieria.

$\operatorname{res}$.

* Alö tolits f́pinolis confertis dentatis vaginantibus pla 
planis maculatis. Hort. cliff. 1 30 . Hort. $a p 5.86$. Mat. med. 160. Koy. lugdb. 22.

Aloe vulgaris. Bash. pis. 386.0

Kadanaki 1.' Catevala. Rbeed. mal. ix.p. 7.t. 3.

Habitat in Indiis. $\frac{1}{4}$

Flores nobis non vifr, ideoque non determino; facies tamen ita procedentis eft, 4 t easders elle vix dubiturein.

2. ALOE floribus pedunculatis cernuis racemofis prifma- zariegnta, ticis : ore patulo xquali.

Aloc foliis canaliculatis trifariam imbricatis radicatis erectis: angulis cartilagineis ternis. Hort. cliff. 132 . Hort. ups. 87. Roy. lugdb. 24.

Aloe africana humilis, foliis ex albo viridi variegatis. Comin.presl. 79. t.28.rar. 27.t. 27. Till. pif. 7.t.7. Habitat is Ethiopia argillofis. 2

3. ALOE Roribus pedunculatis, pedunculis ovato-cylin-aifticho. dricis carvis.

Aloe foliis linguiformibus patulis difticis. Hort. rliff. 132. Hort. aff. S6. Roy. lugdh. 23.

Aloe aricana, tlore rubro, folio maculis albicantibus ab utrique parte sotato. Comm. bost. 2. p. 15. t. 8.

B. Aloe africana flore rubro, folio trangulari \& verrucis albicantibus ab utraque parte notato. Comm. bort. 2. p. IT.t. 9 .

Aloe africana fenilis, foliis carinatis verrucofis. $D i l l$. eltis. 22. t. I8. f. 20.

o. Aloe africana, foliis planis conjugatis carinatis verrucofis, caule \& fore corallii colore. Mirt. cent. It. t. it.

ع. Aloe africana arborefcens montana non finofa, folio plicatilis. longifimo plicatili, fore rub.0. Comm. bort. 2. p.5. t. 3 .

Habivit in Africe rupibus.

4. ALOE forius felifibus horizontalibus infundibuli- byacintboin formibas requalibus limbo revolutis. des.

Aloe foliis lanceolatis planis rectis raticatis. Hort.cliff. 32. Hift. «p). 5. Fl. zeyl. I 30. Koy. lagdb. 24,

a. Aloe zeylarica pumila, tolijs variegatis. Comm bort. zaylanias. 2. p. 4r. t. 2i. Pluk. alm. I9. t. 256. f. 5 .

B. Aloe guincenfis, radice reniculata, foliis c viridi \& a-guinenas. tro undulatim variegatis. Comm. hort. 2.p. $39 . \therefore 26$ : proel. 94.6 .23 . 
Habitat $\alpha$ in Zeylona, $\beta$. in Guinea. $*$

Plantx $Q$ flores non vidi, dubian emendent rel confirment autopta.

foiralis, 5. ALOE floribus feffilibus ovatis crenatis: fegmentis interioribus conniventibus.

Aloë foliis ovatis acuminatis caulinis quinquefariam imbricatis. Hort. cliff. 132. Hort. upj. 87. Roy. lug 36.23 .

Aloe africana crecta rotunda, folio parvo \& in acumen acutifinum exeunte. Dill. elth. I6.t. 13.f.14. Comm. prel. 83. t. 22 .

Habitat in Africa rampeftribus. 5

retufin. 6. ALOE fioribus feffilibus triquetris bilabiatis: labio inferiore revoluto.

Alö̈ foliis rhomboidalibus ventricolis quinquefariam pofitis radicatis triquetris plano exfantibus. Hort. cliff. 132. Hort. ups. 87. Roy. lugdb. 24.

Aloê africana, breviffimo craffifimoque folio, flore viridi. Comm. bort. 2. p. 2. p. I1. t. 6. Till. pis. 6. t. s. llabitat in Africa argillofis. 2

viscosa. 7. Aloë floribus feffilibus infundibuliformibus bilabiatis: laciniis quinque revolutis: fumma erecta.

Aloë foliis canaliculatis trifariam imbricatis: caulinis $\mathrm{g}-$ pice reflexo-patulis. Hort. cliff. 132. Hort. apf. 8\%. Roy. Lugdi. 23.

Aloé africana ereeta triangularis \& triangulari folio vifcofo. Comm. pral. 82. t. 3I. Till. pif. 6. t. 5. Dill. elth. 15. t. 13. f. 13 .

Habitat in Fthiopia campeftribus. 2

pusila. 8. ALOE floribus feffilibus bilabiatis: labio fuperiore ereहto; inferiore patente.

margntiti- a. Aloë foliis ovato-fubulatis acuminatis tubcrculis crati-

fera. rilagineis undique adfperfis. Hort. cliff. 131 . Roy. lagdb. 24.

Aloë africana, folio in fummitate triangulari, margaritifera, fiore fubviridi. Comm. bort. 2. p. 19. 2. 10. B. Alö africana margaritifera minor. Cumin. bort. 2. $p$. 21. t. 11. Dill. eltb. 19. t. 16. $f$. 17 .

y.Aloë afcicanta margarititera minima. Comm. prat. $4 \hat{\jmath}$. Dill. clib. 20. t. I6. f. I8.

practinoi- d. Aloë atricana humilis arachnoidea. Comm. prel. it dos $t .27$. 
E. Aloë foliị ovato-lanceolatis eamolis apice triquetris: angulis inerme dentatis. Hort, cliff. 131. Hort. upf: 86. Roy. lug aib. 24:

Aloë africana minima atroviridis, fpinis herbaceis nua merofis ornata. Bocrb. Jagdb. 2. p. 131. t. 131.

Habitat in Ethiopia campelfritus: z:

Flores in boc genere fpecierum certiffimi inäices conjusgunt Margaritifiram $\mathscr{F}^{\circ}$ Arachiogiceam.

9. ALOE foribus feffilibus refiexis imbricatis prifmaticis. Uvaria, Aloë foliis linearibus radicalibus membranaceis. Hort. cliff. 133. Roy. Iugüo. 23.

Aloè africana folio triangulari longifimo \& anguftifimo, floribus luteis fætidis. Conmm. bort: $2, p \cdot 29 . t$ i:. Seb. thes. 1. p: 29. $t$ : 19. $f: 3$ :

Habitat ad Cap. b. Spci. 4

$$
\text { A G A V... }
$$

1. AGAVE foliis dentato fpinolis, fapo ramofo. Gex, antmicams rov. I 102.

Agave folis fpinofo-dentatis mucronatisque. Hort. upf. SI.

Aloci foliis lanceolatis dentatis fpina terminatis radicalibus. Hort. rliff. 130 . Roy. iugdb. 22 .

Alö̈ folio in oblonguin mucronen abeunte: Bauh. pin. 286.

Tabitat in America calidiore. 5

2. AGAVE foliis dentatis, ftaminibus corollam æquanti- vivipara: bus.

Aloë annericana polygona. Comm. rar. ós. t. ós.

Habitit in Amterica.

Confer. Alocamericana lobolifera. Herm.lagdb. 16.2. I7. 3. AG AVE foliis dentato-fpinofis, feapo fimpliciffimo virginitw.
Ger. nus: 1102 .

Aloe foliis lanceolatis fpina cartilaginea terminatis, fioribas altcrnis feffilibus. Gron. virg. $15^{2}$ :

Habitat in Virginia. 26

4. A $r$ A VE foliis integermmis. Gez. nov. Iroz.

Aloe foliis integerrinis patentiufeulis aculco-terininatis; radice caulcleente. Hort. clitf. 132:

Aloe amcricana, viridi rigidifino \& icotido folic, Pièt dieta indigenis. Comm hort. 2. p. 3.5. t. 18, 
Aloe americana, radice tuberofa, minor. Pluk. alm. 19. t. 258 . f. 2.

Habitat in Curacao. b

\section{HEMEROCALLIS.}

Li)io Apko. 1. HEMEROCALLIS fcapo ramofo, corollis monopedeins. talis. Hort. up 8.88.

Hemerocallis radice tuberofa, corollis monopetalis. Hort. cliff. 128. Roy. lugdb. 26.

fiavus. $\quad$. Hemerocallis radice tuberofa, corollis monopetalis lutcis. Gimel. Sil. I. p. 37.

LilioAfphodeius luteo fore. Cluf. bift. I. p. I37.

Liliam luteun, afphodeli radice. Baxh. pin. 80.

fulvas, $\quad \beta$. Lilium rubrum, afphodeli radice. Baub. pin. 80.

Lilio-afphodelus puniceus. Cluf, bift. I. p. 137.

Habitat a in Hungaria, Sibiria campis uliginofis, at $Q$. Hybrida $\mathcal{E}$ conflans, $e x$ Lndia Urientali. $\#$

Liliaftrm. 2. HEMEROCALLIS fcapo fimplici, coroliis hexapetalis campanulatis. Hort. cliff. 128. Roy. lugdb. 27. Ilall. belv. 290.

Phalangium magno fiore. Bazh. pin. 29.

Phalangium allobrogicum majus. Claf. app. alt.

Thalangium. Dalech. hilt. 852.

Habitat in Alpibus Helveticis, Allobrogicis. 2;

Hiabitu conveniunt Hisec, Antherica 1. 2. 3, Ajpbodeliz. 3, Sea' quis charaiter comedteret?

\section{ACOR LSs}

calnmus. 1. ACORUS. Roy. iugab. 6. Fl. Juec. 277. Mat.med. I6. vuliraris. a Acorus verus $[$. Calamus aromaticus oficinarum.Banh. pin. 34. Hort cliff: 137.

Typha aromatica, clava rugofa. Morif. hift. 3.p. 246 f. 8. t. $33 . f .4$.

verus. B. Acorus afiaticus, radice tenuiore. Herm. lagdb. 9. F\%. ziegl. 132 .

Waembu. Rheed. mal. II. p. 99. t. 60.

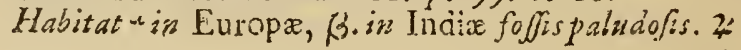

\section{ORONTIUM.}

equaticum. r. ORONTIUM. Gen. nov. 1086. f. 3. * Arum folio enervi ovato. Gron. virg. In $\hat{j}$. Arum fluitans, pene nudo. Banift. virg. I926. Mlubitut in Virginix, Canadx paludibus, fcaturiginibus. 2" 


\section{H 玉 MANTHUS.}

I. HÆMANTHUS foliis lingviformibus planis. Roy. coccineus. lugdb. 42.

Hæmanthus foliis obtufis bafi truncatis. Hort. cliff. $\times 27$.

Hremanthus africanus. Comm. bort. 2. p. $127 . t .64$. Habitat ad Cap. b. Spei. z

2. H良MANTHUS foliis lanceolatis undulatis. Hort. punticeus. cliff. 127. Hort. upf. I 27. Roy. lugdb. 42.

Hæinanthus colchici foliis, perianthio herbaceo. Dill. elth. 107 . p. 140. t. 2.

Hyacintho affinis africana, bulbofa radice, caule elegantifime maculato. Seb. thef. 1. p. 20.t. 12.f.1.23. Orchis 1. Satyrium e Guinea. Swert. fior. x.p. 62. f. 3 . Habitat in Africa. 2i

1. CALAMUS.

\section{CALAMUS.}

Arundo zeylanica fpinofifima major, fructibus rotundis

fcabris acidis. Burm. zeyl. 36. Fl. zeyl. 468.

Arundo nucifera Rotang dicta, fructu Padicei coloris

ftriis purpureis venufte teflulato. Pluk. alm. 53.

Arundo Rotang dicta. Pif. mant. 188.

Fructus cannæ de Benghala. Baub. pin. 405.

Habitat in Indix $\int y$ lvis juxta fluenta. $t$

\section{JUNC'US. \\ * Culmis nudis.}

1. IUNCUS culmo fubnudo tereti mugronato, panicula acutus. terminali, involucro diphyllo fpinofo.

Juncus culmo pungente, panicula ex folii folitarii axilla. Sauv. minjp. 9.

Juncus panicula univerfali culmo breviore infime coarctata, fecundariis paululum laxis, capfulis triquetro-fubovatis nitencibus. Gustt. ftump. 2. p. 412.

Juncus acutus, capitulis forghi. Baub. bift. 2. p. 520 . Morif. bift. 3. p. 232. f. 8. t. 10. f. 15.

$\beta$. Juncus panicula univerfali culmo longiore, fecundariis laxis longe pedunculatis: media præcipue. Guett. famp. 2. p. 4 42 .

Juncus acutus maritimus anglicus. Raj. bift. 1303. Morif. ibid. $f$. 14.

Habitat in Angliæ, Gallix, Italiæ mariimis paludofis. 2

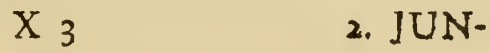


sorglomera. 2. JUNCUS culmo nudo ftriko, capitulo laterali. Roy. tits.

$$
\text { lagdb. 44. Fi. Suec. } 273 \text {. }
$$

Juncus lxvis, panicula non fparfa. Baub. pin. 12. theatr. ${ }_{1} \delta_{3}$.

Juncus lwris, panfcula conglomerata. Schench.gram.3.13. Juncus. Cam. epit. 780 .

Habitat in Europe borealis uliginofis. \#

effufus. 3. JUNCUS culmo nứdo ftrito: panicula laterali. Roy. lugdb. 44. Fl. Saec. 279.

a. Juncus culmo nudo acuminato ad bafin fquamato, floribus fefịilibus. Fl. lapp. 110 . Hall. bclv. 254 .

juncoides alpiinum, flotculis junci glomeratis atrofufcis. ŝbeuch. bift. 323 .

B. Juncus culmo nudo acuminato ad bafin fquamato, Horibus pedunculatis. Fl. Iapp. 117. Gron. virg. 38.

Juncus levis, panicula fparfa, major. Baub. pin. 12. theatr. 182. Scheuch. gram. 341 .

Juncus lxvis. Dod. pempt. 606.

Habitat in Europa uiginofis, a in alpibus. $\%$

inflexus. 4. JUNCUS culmo nudo: apice membraraceoincurvo, panicula laterali.

Juncus culmo nudo, paniculam arcuatim tegente. Sazv. monsp. 9 .

Juncus, acuminc reflexo, major. Baub.pin. r2. prodr. 1 84. Morif. bilt. 3.p. 233. S. 8. t. I0. f. 25. Barr. ic. 204 . Hall. belv. 252.

Juncus, acumine reflexo, alter. Baub. pin. 12. prodr. 22. Scheuch. gram. 345 .

$\gamma$ Incus panicula univerlali laterali culmo longiore, fecundariis fparfis. Guett. Jtarnp. 4t2.

Juncus acutus, panicula lparfa. Baub. pin. $\mathbf{4}^{\mathbf{1} 2 .}$ Habitat in Europa auftrali. $\%$

Wifformis. 5. JUNCUS culno undo filiformi nutante, panicula laterali. Roy.lugdí. 44. Gron. virg. 152. Fl. luec.280. Juiccus parvus, calamo lupra panjculam longius produeto. Raj. angl. 3. p. 432. F\% lapp. r 18.

Juncus lxvis, panicula lparta, minor. Baub. pin. 12. teatr. 183 . Jcheuch gram. 347.t. 7.f. 1 .

Habivat in Europa uliginofo-paludojis turfofis. 4

trin̂lus. 6. JUNCUS culmo nudo, foliis floribusque tribus terminalibus. Fl. lapp. 119. Fl. Suec. 281. Roy. lugdb. 43. Hali. belu. 253 . 
Jurcus, acumine retlexo, minor \& trifidus. Baub.pin 12. prodr. 22. t. 22. thcatr. 186.

Juncoides alpinum trifidum. Scheuch. gram. 325 .

Hicbitat in Alpibus Lapponicis, Helveticis, Pyrenxis. 2

7. JUNCUS culmo nudo, foliis fetaceis, capitulis glo- Iquarrofus. meratis aphyilis. Fl. Suec. $2 \$ 2$.

Juncus foliis fetaceis, culmo nudo, capitulis glomeratis terminalibus. Roy. lugdb. 44.

Juncus montanus paluftris. Kaj. bift. I303. Fl. lapp. I2I.

Gramen junceum, foliis \& ipica junci. Baub. pin. 5.

Gramen junceum, femire acuminato. Loef. pruff. bs. t. 29.

IHabitut in Europx borcalis fefpitofis. 2

$$
\text { * Culmis foliojis. }
$$

8. JUNCUS foliis nodoio-articulatis. Fl. Suec. 28 r. axticulatus. Juncus foliis articulofis, panicula inæquali, capitulis fesfilibus, capfulis fubulatis triquctris. Roy'. lugdh. 43 .

Juncus foliis articulonis, floribus umbellatis. Tournef. inft. 247. Fl. lapp. $\mathrm{J} 20$.

Gramen junceum, folio articulato, aquaticum. Bash. pin. 5. prodr. 12. theatr. 76 . Scheuch. gram. 331.

6. Gramen Junceum, folio articolofo, cum utriculis. Baub. prodr. 12. Scheuch. grarn. 333 .

$\%$ Juncus alpinus, folio atticuloto. Scheuch gram. 333. Gramen junceun, folio articulofo, fy!vaticum. Baub. pin. 5. thestr. 75 . Morif. hift. 3. p. 227. S. 8. t.9. f. I. Scheuch.grin. 334 .

d. Junci foliofi, folis per ficcitatem nodofis. Mich.ger. $3^{8 .}$ n. 1. ....13.

Ifabitat in Europx aquofis. 2

9. JUNCUS foliis linearibus canaliculatis, capfulis ob-bulbofns. tufis. Fl. fuec. 284.

Juncus foliis lincaribus canaliculato-concavis, capfulis triangularibus. Guett. ftamp. 134.

Juncus foliis angulatis, culmo fabnudo, panicula tertinali prolifera, capfulis ovatis. Roy. lizgdb. 43 .

Gramen junceum minimum, capfutis tiangularibus. Raj. bift. I307. angl. 3. p. 434. Morif. bift. 3. p. 227. $\int .8 . t .9 . f .3$.

Juncus bulbifer, foliis terctibus non articulofis. Mich. gen. 39. $\pi .1 .2 .3$.

B Juncoides calycibus palcaceis glomeratis, folio varians. Screuch. grim. 39 .

G:a- 
Gramen junceum aquaticnm, paniculis cum foliis capillaribus limul ortis proliferum. Pluk. alm. 179. $t$. 32. f. 3. Morif. bift. 3. p. 227. f. 8. t.9.f. 4 .

$\gamma$. Juncus foliofus minimus campentis \& nemorenfis. Gron. virg. I5.

Gramen junceum elatius, pericarpiis ovatis, american num. Pluk. alm. 179.t.92. f 9.

Gramen junceum virginianum, calyculis paleaceis, bicorne. Moris. hift. 3. p. 223. . 8. t. 9. f. 15 .

Habitat in Europæ pafcuis Jterilibus fubbumidis, at $\gamma$ in Sibiria, Virginia.

bufonins. 10. JUNCUS culmo dichotomo, foliis angulatis, floribus folitariis feffilibus. Roy. lugdb. 43 . Fl. fuec. $28_{3}$. Hall. helo. 254.

Juncus paluftris humilior, panicula laxiffima. $R u p p$. jen. I 30 . Fl. lapp. I22.

Gramen nemorofum, calyculis paleaceis, erectum. Scbeuch. gram. 327 .

Gramen nemorofum, calyculis paleaceis. Bauk. pin.7. theatr. 100 .

Hololteum. Lob. ic. 18.

B. Gramen nemorofum, calyculis paleaceis, repens. Scheuch. gram. 329.

$\gamma$. Gramen nemorolum, calyculis paleaceis, fpecies altera procerior. Scheucb. gram. 328.

2. Gramen bufonium erectum anguftifolium majus. $B$ arr. ic. 264 .

8. Gramen holofteum alpinum minimum. Baub. pin. 7. prodr. 64. theatr. rOI.

ciramen juncoides minimum anglo-britannicum. $R a j$. angl. 3. p. 434.

Habitat in Europa inundatis. $\odot$

bighmis. 15. JUNCUS folio fubulato, gluma biflora terminali. Amuen acad. 2. p. 266.t. 3. f. 3. *

Habitat in Alpibus Lapponicis. D. Montin. 2

Planta faciem gerit Jcbuni ferruginei.

triglumis. 12. JUNCUS foliis planis, giuma trifora terminali. $F$. Suec, 286.

Juncus gluma triflora culmum terminante. Fl. lapp. I 15. t. I0. $f$ : 5 .

Junchis exiguis montanus mucrone carens. Baub. pin. 12. prodr.22, theatr. I83. Kudb. elpf.x. p. 103. f.8. Habitat frequens in Alpibus Lapponicis Tauro Raltadienfi. 2

I3. JUN- 
13. JUNCUS foliis planis pilofis, corymbo ramofo, $F /$. pilofis. fuic. 28 ?

Juncus folis pianis, panicula diffura, pedunculis proliferis: Aofculis intermediis feffilibus. Roy. lugdb. 43 .

Gramen ncmorolum hirfitum latifolium majus. Buiuh. pir. 7. Morif. bi/t. 3. p. 22r. S. 8. t. g. f. ., *

B. Gramen hirfutum anguftitolium perenne, lini utriculis. Barr. ic. 740.

$\gamma$. Tuncus foliis planis, culmo paniculato, fioribus fparfis. Fl. lapp. 12,

Gramen hirfutum nemorofum anguftifolium slpinum, mniculis obfcure rufefcentibus. Scheuch. gram. 3Iz. t. 6.

d.Gramen nemorofum hi:futum latifolium majus.Scheuch. gram. 317.

Gramen hirfutum latifolium maximum, juncea panicula. Morif. hift. 3. p. 225 . .. 8. t. 9. f. 2.

. Gramen hirfutum anguftifolium majus. $B$ anb. pin. 7 . prodr. 16. theatr. 105. Morif. bif. 3. p. 225. S. 8. t. 9. f. 3. Scheutch. gram. 318.

$\zeta$. Gramen hirfutum latifolium minus. Bauh. theatr. IO2.

ท. Juncoides montanum nemorofum, flore niveo. Scheacb. gram. 32C.

Gramen hirfutum anguftifolium minus, paniculis albis. Bash. pin. 7. theatr. 106 ,

Habitat in Europx fylwis, at varietates. B. $\lambda \cdot \varepsilon \cdot \zeta . \eta$. in Europee aufralioribus, $\gamma$. in Alpibus, $z$

14. JUNCUS foliis planis fubpilofis, fpicis feffili pedun- campeftris. culatikque. Fl. Suec. 288.

Juncus foilis planis, panicula rara, foicis feffilibus pedunculatisque. Hort. cliff. 137. Roy. lugdb. 42. Grois. virg. 38 .

Juncus villofus, capitulis pfyllii. Taurnef. inft. 246. Fl. lapp. 126.

Juncoides villofam, capitulis pfyllii. Scheuch. gram. 3 IO. Gramen hirfutum, capitulis piyllii. Baub. pin. 7.theatr. 103.

$\beta$. Juncus foilis planis, culmo panicu,jto, fpicis ovatis. Ft. lapp. 127. t. IO. f. 2 .

$\gamma$. Juncoides hirfutum, capitulo glomerato. Scheuch.gram.

Gramen hirfutum, capitulo globolo. Bauh. pin. 7. theair. 104 .

d. Juheus montanum nemorolum villofum latifolium elatius 
latius, capitulis fiorum candidis \& fplendentibus. Nich. gen. 42 .

$\varepsilon$. Juncoides latifolium alpinum glabrum, panicula fublurca fplendente. Scheuch. gramen. 3 T.4.

$\zeta$. Gramen hirfutum elatius, panicula juncea compacia. $R$ aj. angl. 3. p. 4 I $6 .$.

भ. Juncoides bohemicum, panicula minore nigricante, fcapo fiper eandem erecto \& longius producto. Mich. sen. 42.

libitat in Europa pencuis ficcioribus. 7

Spicatus. 15. JUNCUS foliis planis, fpica racemora nutante. $F l$. lapp. 125. i. 10. f. f. Fl. Syec. 289.

Tunces aipinus latifolius, panicula racemolia nigricante pcrdula. Till. pif. gI.

Irabitat it Lapponiec Alpibus. 2

\section{RICHARDIA.}

foswa. I. RTCHARDIA. Houf? mil:

Habitoi in Vera Cruce. 2.

Slante ex pellatis XLIY. Caulis altus, brachintus, $\int u b$. arriculatus, objolete tetragonus, bifpidas: Pilis rigidiuftealis, fparfis, refiexis. Folia $\&$ lanseolatu-orata, dilernasim nervaja, integerrima, $\int$ ubpetiolata, $\int c a-$ bra. Flores in capiubla terninali a, palfim exjam in vcrticillas cowgeft; cajorisia terminalia, radiata Folits + vel pluribus, fcilicet altermis ininoribus. Co-

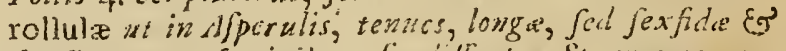
frufius ex 3 feminibus; Jic diffor t a Spermacoce nismero of cateris.

\section{PRINOS.}

vericillaius I. PRINOS foliis longitudinalitur ferratis.

Prinos. Grow. virg. 39.*

Habitat in Vinginia. 5

glaber. 2. PRINOS foilis apice jerratis.

Habital in Canada. Kalm. b

Arbor. Foliis alternis, petiolatis, oblongis, confiftentibus, glabris, verfus apiccm ferraturis utrinque fopizus binis acutis, facie ferme Mrrica. Pcdunculi axilla. res, par ui, fepizes triflori. Flores non widi.

BERBERIS.

vulgari, 4. BERBERIS pedunculis racemolis, Mat, med 2 go. 
Berberis fpinis triplicíbus. Hort. cliff. 122. Fl. Succ. 290. Roy. lugdb. 438 . Hall. belr. 424 .

Ecrberis dumctorun. Bauh. pin. $43^{4}$.

Berberis vulgaris 1. Crépinus. Cam. epit. $\$ 6$.

Habitat in Europix fylvis. b

2. BERBERIS pedunculis unithoris:

sertica

Berberis cretica, buxi folio. Tournef. cor. 42.

Berberis alpina cretica. Baith. pin. 45.

Lycium creticum. Alp. cxot. 21. t. 20.

Lycium e Candia. Pun. ital. 137.

Holsitut in Creta. 5

\section{LORANTHUS.}

I. LORANTHUS.

americanns,

Loranthus racemofus, flore coccineo, baccis nigris. Vaill. at. 1722. p. 274 .

Lonicera flore coccinco, baccis nigris. Plum: gen. I 7 . Habitat in America calidiore. 5

\section{FRANKENIA.}

I. FRANKENIA foliis lincaribus bafi ciliatis.

lavis.

Frankcnia foliis confertis. Roy. lugdb. 452 .

Frankenia foliis aciformibus congeitis Sazz? mon $\int p \cdot 46$. Franca floribus folitariis feffilibus, foliis prifmaticis trianguiaribus. Guett. ftamp. 2. p. 459 .

Franca maritima fupina faxatilis glauca ericoides fempervireus, flore purpureo. Mich. gen. 23. t.22. f. I. Lychnis fupina maritima, eriçæ faciẹ. Raj. argl. 3. p. $3^{8}$.

Anthyllis repens italica, thymi foliis, rubente fiore, por lygoni facie. Till. pis. 46.

Cali f. Vermiculari marinæ non difimilis planta. Baub. hift. 3. p. 703

Polygonum fruticofum fupinum ericoides cinereum, thymi folio, hifpanicum. Barr. ic. 714. Bocc. muf. J. p. 7.t. II. .

Polygonum matitimum minus, foliis ferpylli. Baub. pin. $28 \mathrm{i}$.

Habitat in Europx auftralis maritimis. $z$

2. FRANKENIA caulibus hirfutis, floribus farciculatis hrrfuth terminalibus.

Franca maritima fupina multillora candida, caulibus hir. futis, foliis quali vermiculatis. Mich. gen. $23 . t .22$. f. 2 .

Poly- 
Polygonum creticum, thymi folio. Baub. pin. 281 . prodr. I3I.

Alfine cretica maritima fupina, caule hirfuto, foliis quafi vermiculatis. Tournef. cor. 45 .

Habitat in Apulia, Creta.

2ulverulenta 3. FRANKENIA foliis obovatis retufis fubtus pulveratis.

Frankenia foliis ovalibus. Sauv. mons/p. I68.

Franka maritima quadrifolia fupina, chamæfyces folio \& facie. Mich. gen. 23.

Anthyllis valentina. Cluf. bift 2. p. 186.

Anthyllis marina, chamæryces fimilis. Baub. pin. 282 . Habitat in Sufexix, Narbonx, Italix, Apulix littoribus. $\odot$

In ordins $N$ aturali ad $X L$ referatur.

\section{PEPLIS.}

Portala. I. PEPLIS. Fl. lapp. 128. Fl. Juec. 291. Hall. belv.406. Glaucoides paluftre, portulace folio, Hore puipureo. Mich. gen. 21. t. 18.

Glaux paluftris, flore ftriato clauro, foliis portulace. $T$. Petit. gen. 43 . t. 43 .

Glaux aquatica, folio fubrotundo. Loef. pruf. Io6. $t$. 20.

Glaux altera, fubrotundo folio. Vaill. parif. 80 . t. Is. $f .5$.

Alfine paluttris minor ferpillifolia. Baub. pin. 251.

Habitat in Europx imundatis. $\odot$

\section{$\mathcal{D} I G \Upsilon N I A$. \\ VELEZIA.}

rigida. I. VELEZIA. Lafl.

Silenc foliis fubulatis cauli appreffis calycibus rigidis intermedio longioribus. Sauv. monsp. 145.

Lychnis fylveltris minima, exiguo fore. Baub.pin.206, prodr. IO?.

Lychnis minima rigida cherleri. Baub. bift. $3 \cdot p \cdot 352$. Raj. bif. 997.

Lychnis corniculata minor. Barr. rar. 665. t. IoI8. Ior 7. Basc. mul. 2. p. 50. t. 43.

Habitat in Europa auftrali. $\odot$

Stamina toniflima difficillime numerantur; in fuccis fpe- 
ciminibus 5 vidi; at in viviscirciter o lanfing. Si bujus ordo naturalis fit $x$. XL, numerws naturalis erit faminum $\int e x, \sqrt{f}$ vero $X L I I$, erit quinque.

\section{ORYZA.}

1. ORYZA. Baub.pin. 24. theatr. 479. Cam epit.192. Sativa.

Dod. pempt. 5c9. Catesb. car. 1. P. I4. t. It. Hort. cliff. 137 . Mat.med. 174. Roy.luga'b. ys.

Habitat forte in Ethiopia, colitur in Indiz paludofis. $\odot$

\section{ATRAPHAXIS.}

1. ATRAPHAXIS ramis fpinofis. Hort. cliff. 135. Tpinose. Roy. lizgdb. 409 .

Atrip̧lex oricntalis, frutex aculeatus, fiore puichro. Tournef. cor. 38. Jumxb. cent. I. p. 19. t. 30. Dill. elth. 47. t. 40 f. 47 .

Ifabitat in Media ad arbem Hanien locis glarenfis juxta fluvios. b

2. ATRAPHAXIS inermis.

Atraphaxis inermis, foliis undulatis. ITort. cliff. 137 . Rny. lugdb. 409 .

Arbufcula africana repens, folio an latera crispo, ad polygona relata. Dill. elth. $3^{6} \cdot t \cdot 32 . f^{\prime} \cdot 3^{6}$

Habitat in withiopia?

\section{TRIGTNTA.}

\section{FLAGELLARIA.}

1. FLAGELLARIA. Fi. zcyl. 133. Amosn acad. 1. imdicy.

p. 398 .

Panambu-valli. Rbced. mal. 7. p. 99. t. 53. Raj. jufpl. 573 .

Hiabiat in Java, Malabaria, Zeyiona. 5

Fiutcx buinaram alizudinein fuperans. Rami difsichi.

RUMEX.

* Hormapbroditi: valiulis fioris granuio notatis.

1. RUMEX floribus hermaphiroditis: valvulis integerri- astisntia. mis: unica granirera, folis cordatis. Alat. med. 178. Lapathum hortenic, fulio oblongo. Laun. pin. 114. Lapathun fativum. Dod. peinpt. 648 . 
Clabitat in Italia. 2

Confer. Lapathum hortenie latifolium. Barb. pin. Iт5.

ranguineus. 2. RUMEX floribus hermaphroditis: valvulis integerrimis: unica granifera, foliis cordato-lanceolatis. Hurt: clitf. 138. Hort. upf.89. Nat. med.528. Koy.lugahi 2,29 .

Lapathum folio acuto rubcre. Baub pin. 115.

Lapathum rubens. Dod.pempt. 650. Cam. epit. 229: Habitat in Virginia. 3

Falucla exterior floris greno magno globofo rubro notata, rarius $0^{\circ}$ alteragrano minimo.

alpinir, j. RUMEX forlbus hermaptiroditis: valvulis integerrimis graniferis, foilis inis cilipticis. Sauv.mon/p. 60:t Rumex folio pecali cordato, radice repente. Lemonjer. Sart. monjp. 111.

Lapatbum androgynum obufifolium, fpica confertisfima. Hall. bil?. 170 .

Lapathum horterfe rotundifolium $\mathrm{f}$. montanum. Barba fin. II 5 .

Lapathum rotundifolium. Claf: bift. 2. p: 69 .

Habitat in Helretia, Monfpelii. *

serticillntis: 4. RUMEX floribus hermaphroditis: valvulis integerrimis: oinnibus graniferis, foliis lanceolatis: vaginis cylindricis.

Lapathum aquaticum, folis longis anguftis acutis, fioribus ad genicuia verticillatim congeftis. Cirox. virg: 30.

Hab́tiat i, Virgiaia. 2

Briternica: 5. KUMEX floribus hernaphroditis valvulis integerrimis: omnibus graniferis, foliis lanccolatis: vaginis obfoleus. Mat. med. 17.

Rumex aquatica, calycis foliolis ommibus xqualibus, radice exterius nigra vel flava. Cold. noveb. 83 .

Lapathum foliis longis latis vix acuminatis coltis caulibusque rubenubus, radice intus crocea. Gron. virg. 3\%.

Ilabitat in Virginia. it

In precedenti fipula cylindrica membranacea fere ad dimidium acersans internodizm, is bat vero non item, fid zet in Eziroticis. Pedicelli in priori crafjiores iz hac capillares: frior magis fpicata; bee magis paniculata. Plantarn Gron. in Fl. virginica babui a $\mathrm{Cl}$. Aubare, qua nun rubra erat casile aht cojtes.

6. RU- 
6. RUMEX floribus hermaphroditis: valvulis trifido-fe- agyintacis. taceis: unica granifera. Hort. zy/. \&y.

Rumex floribus hermaphroditis, foliis oblongis, valvulis dentato-retaceis longiflimis. Wach. ulir. 391.

Lapathum xyyticum, capfula feminis alba \& crenata. Dill. elth. r9r. t. 158. f. I9I.

Lapathum xgyptiacum annum, parietarix foliis, capfula feminis longius barbata. Till. fif. $43 . t .37 . f . \tau$.

Habitat in AEgypto. $\odot$

7. RUMEX floribus hermaphroditis: valvulis dentatis : perficarioiomnibus graniferis, foliis lanceolatis.

Habitat in Virginia. ()

Plauta $\int p$ ithamad, ramofiflima. Folia larceslate, petislata, lievia, undata, integra: Floris zalvula dontibus utringue tribus longis, omwes tect.r granis pallidis magnis.

8. RUMLX floribus hermaphroditis: valvulis dentatis " maritimar. graniferis, foliis linearibus. Lecb. fcan. 26. It. Scan. 248 .

Lapathum aquaticum, luteole folio. Tournef. inft. 504.

Lapathum aquaticum, angultifumo acumiriato folio Borr. muf. 2. p, 142. t. 104 .

Habitat in Europa litoribus maritimis.

9. RUMEX floribus hermaphroditis: valvulisintegris gi2- $\mathrm{cr}$ /puss niferis, foliis lanceolatis undulatis acutis,

Rumex floribus hermphrodicis: valvulis integerrimis planis, foliis cordato-oblongis. Fl. Suec. 292. Hort. cliff133. Roy. lugdb. 229.

Rumex foliis cordato-oblongis acuminatis integris. $\mathrm{Fl}$. lapt. 329.

Lapathum folio acuto crifpo. Baub. pin. II5.

Lapathum acutum crifpum. T'abern. ic. 436 .

Habitat in Europæ Juculentis. 2

I0. RUMEX floribus hermaphroditis: valvulis dentat!s acutus, graniteris, foliis cordato-oblongis. Hort. cliff. $13 \delta$. Mat. med, 176. Fl. fuec. 293. Rov. lugdb: 229.

Lapathum acutum 1. Oxylapathum. Raub. hift. 2. $p$. $98_{3} . L 0 \dot{0} . i 6,28 \%$.

Lapathum acutum. Raj. hift. 175 .

Habitat in Europæeacculentis. 2

11. RUMEX floribus hermaphroditis: valvulis dentatis, obtiffolizs. foliis cordato-obiongis obrutiufculis crenulatis. $t$ 
Lapathum involucro feminis dentato, foliis obtufis ora crifpula. Hall. belv. 172.

Lapathum lylvetre, folio fubrotundo, reminis involucris dentatis. Murif. bift. 2. p. 580 .

Lapathum folio minus acuto. Baxb. pin. II I.

Lapathum vulgare, folio obtufo. I. B. Raj. bift. 175 . Lapathum. Cam. epit. 228.

Habitat in Germania, Helvetia, Gallia, Anglia. $z$

* Hermaphroditi: valoulisgranulo deftitutis fondis.

pulciser. I2. RUMEX toribus hermaphroditis, foliis lyratis, Cuett. framp. I. $p \cdot 7$.

Lapathum ramis procumbentibus, feminis involucro cientato, folis inferioribus inftar fidium. Morif. bift. 2. p. 580 .

Lapathum pulcrircm bononienfe finuatum. Baub. bifi. 2. p. 9.98. Kaj. bijt. 1. p. I 74 . Habitut in Gailia, Italia, Veronx.

beephalo I3. RUMEX floribus hermaphroditis; valvulis dentatis phorus. nudis planis reflexis. Hort. upf. 90.

Rumex fructious denratis calyce rethexis, caput bovinum. referentibus. Hort. siiff. I 39 .

Acctora, ocymi folio, neapolitana. Barb. piz. II 4. Acctofa, ocymi folio, bucephalophoros. Col. ecpbr. $x$. p. Isx. t. I, 0 .

Hubitat in Italia. $Q$

*quatics. I4. RUMEX floribus hermaphroditis: vatvulis integerrimis nudis, foliis cordatis.

Lapathum aquaticum, folio cubitali, Bauh. tin. I 6 .

Lapathum palultre. Túuern. ic. $43 \%$.

Hippolapathum. Dalech. bifs. 604. Carn. evit. 232. Herba britannica, Munt brit. t. t.

Liabiat in Europa ad ripasjuviorum है paindam. दे

Lunaria. 15. RUMEX foribus hermaphrodirs: valvulis lavibus, calle arborco, foliis fubcordatis. Fir. riff. 32 . Hort. cliff. 139. Roy. lugdli. 320.

Acetorix arborufcens, fubroindo folio. Pluk. alm. 8. t. $252 . f .3$.

Lunaria nagorum arabum. Bauh. bift. 2.p. 994 ?

Llabitat in Canariis. b

wegrearius. 16. RUMEX foribns hermaphroditis geminatis: valvularumalis maxinis membranaceis rettexis, follis indi-

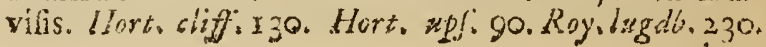


Acetufa americana. foliis longifimis pediculis donatis. Bash. pm. I 44 prodr. 54. Morif. bift 2 F $; 83$. 5 . s. t. 28. f. 7 .

Habitat is Africa. ()

7. RIIMFX floribus hermaphroditis dintingtis. vasuula refeo. rum alis maximis membranaceis, foliis erotis. Roy. liggdí. 230.

Acctora xoyptia, rofeo feminis involacro. Baub. afr. 5. f. i.

Hahisat in Agypto. $\odot$

18. RUMIEX floribus hermaphroditis, foliis cordaro-ha- fintatus ftaris. Vir, cliff. 32. Hort shiff. 138. Hort. Wf. 89. Koy. lusitib. 230 .

Acetofa rotundiolia hortenfis. Bash. pia. 114 Morif. bi/t. $2 . p .583 \cdot \int \cdot 5 \cdot 2.28 . t$. . .

Lapathum androgynum acelolum, foliis lagittatis, ràmis divergentibus. Hall. betv. 170 .

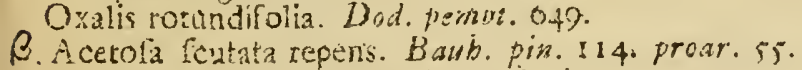

Lisbitat in Helvetia, Galloprovincia, sner acervos la. pidisu. $¥$

Iq. RCMEX floribus hermaphrodicis cigynis. Hort. cliff digynm 135. Fl. fuer. 297 . Roy. Ingdly. 230.

Rumex foliis orbiculatis emarginatis. Fl. lapp. 132. Acetora rotundicolia alpina. Brab. pin. 55. frodr. Ala. A cetola repens vettmoriandica, cocniearia follis nonnihil linuatis. Pluk. alm. s. $t .252, f$. 2 .

Acetora britannica rotundifolia, ructu comprefo. Blair. obf: 6? t. (57.

thabiot in floibus Lapponcis, Heivericis, Wallicis.

\section{* * Floribus dic?inis.}

20. RUMEX foribus androgynis: calycibus semineís jpinornmonophyllis: valvulis exterioribus reflexo-uncinatis:

Hort. ufs. 80.

Rumez foribus androgynis, calycibus fruetus urcinatis.

llort. cliff. 139 Koy. ingalb. 230.

Beta cretica, ienine aculcato. Bash pin. 1 8 . podr. 57 . Beta cretica, femine fpinoto. Basb. bijt. 2. p. 962 .

Habitat in Creta. 0

21. RUMEX floribus dioicis, folis oblongis angiatatis. Acetola,

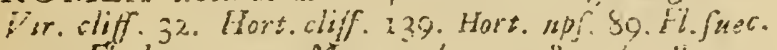
295. El. lapp: 30. Mut med. 529. Ray. lugdb 23! 
Acetofa pratenfis. Bawh. pin. I4.

B. Acetor praterfis, flote albo. Tournef. inft. 502.

\%. Oxalis crifpa. Baub. bift. 2. p. 9yo. Tabarn. ic. 440.

D. Acetor montana maxima. Baub. pin. 114. Scbeuch. alp. 129.

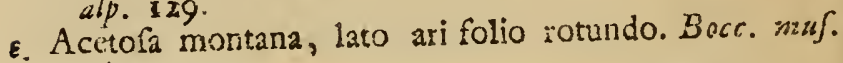
$165 . t .125$.

Habitas in Europa pajcuis. \& in Rlpibus. 2

4cstofella. 22. RUMEX floribus dioicis, foliis lanceolato-haftatis. Vir. cliff. 32. Hort. cliff. $139.5 \%$ lupp. 1 31 . Fl. fuec. 296. Roy. lugdb. 23I. Gron. virg. 153 .

Acetofa arvenfis lanceolata. Baub. pin. Ir 4 .

Oxalis ovina. Taburn. ic. 440.

B. Acetora lanceolata anguttifolia repens. Baxb. pin. It prodr. 55.

y. Acetola arvenfis minima non lanceolata. Baub. pin.

II4.

d. Acetora minor erecta, lobis multifidis. Bocc. muf. I 64 . t. 126 .

Habitat in Europx pafcuis is arvis arenofis. 26

\section{SCHEUCHZFRIA.}

palufiris. 1. SCHEUCHZERIA. Fl. lapp. i33. t. 10. f. 1. F\%. fuec. 297. Roy.lugdb. 45. Hall. belv.258. Gracl.jio. I. 3. 73. Berg. viadr. 67 .

Juncus floridus ininor. Baub. pin. 12. prodr. 43 theatr. 190. Rudb. elys. 1. p. 110.f. 2.

Juncoidi affinis paluftris. Ssheuch. gram. $33^{6}$.

Gramen junceum aquaticum, femile racemofo. $L a c$. priff. 114. t. 29.

Habitat in Lapponix, Helvetix. Boruffia, Suecix paln: dolis. 2

\section{'I' RIGLOCHIN.}

eargire. 1. TRIGLOCHIN capfulis trilocularibus fublinearibus. Fl. Suec. 298. Act. Jtockb. 1742. D. 147. t. 6. f. I.

Triglochin fruệu tenui. Fl. lapp. I34. Roy. lngatib.44. Hall. belv. $25^{8}$.

Gramen junceum ipicatum f. Triglochin. Bauh. piz. 6. theatr. 80.

Calamagroftis IV. Dalech. bift. 1006.

B. Juncago maitima perennis, bulbofa radice. Mich. gex 44. 
Juncago matitima. Balt. vur. 55. 5. 271. Habilat ia Europa iamondalis uliginufis. of

2. TRICIOCHIN caplulis fexlocularibus avatis. Finariomun.

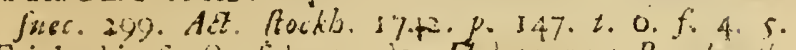

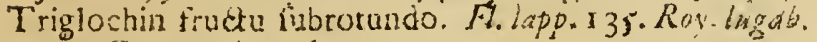

45. Gort. geir. $7^{6 .}$

Juncago paluitris \& maritima pesennis, fruetu brcviore

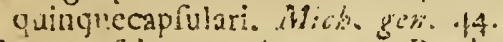

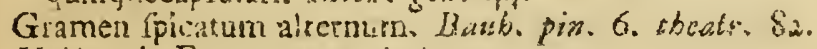
Habitat in Europe martimis.

\section{MELANTHIUM.}

1. MELANTHIUM petalis ung vichatis. Melamhim toliis linearibus integernimis longinimis, fioribus particulatss. Gron, virg. 59. Habitat it: Virginia. 2

2. MELANTHIUM petalis jeflitibus, Amarn. acad,2. fikirichm. D. 349. 8. 1. . $^{*}$

Orinthogalum fipis florum longithmis ramolis. Ginet. fib. I. $p+5 . t .8$.

Habitat in Sibiria. 2

\section{MEDEOLA.}

1. MFDEOLA foliis vernicilatis, ramis acu!cutis. Fruticulus fuliis rufce fiellatis. Dill, eith. 148, t, 123.

f. 140.

Habital an America calidiore. to

2. MEDEOLA foliis verticillats, ramis incrmibus. Miedeola foliis ftellatis lanccolatic, truetu baccalo nothenta. Mits nickm. Gron. wirg. 39. *

Lilimn f. Martagon pufillum, floritus minutifine horbaceis. Flyt, alm. 401. t. $328 . f_{*} 4$.

Habsict in Virginia. o

3. MEDEOLA fOhiis alternis.

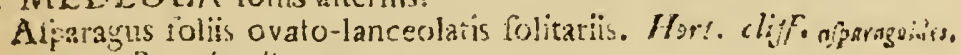
Q2.2. Roy. Ing db: 20 .

Afparagus africanus icandens, murti folio. Till. pis 16. t. 12. $f .1 .2$.

Ulabitas in Fthiogia.

THILLIUM.

- TRILLIUM fore peduriculato cernag. 
Paris foliis ternis, flore pedunculato nutante. Cola. noreb. Sr.

Solanum triphyllum, fore hexapetalo carneo. Catesh. carol. 1 . p. 45 .

Habitost in Carolina. $¥$

eretinm. 2. TRILLIUM flore pedunculato erecto.

Paris foliis ternis, fiore pedunculato erecto. Ammers acad. I. p. 154 : $^{*}$

Solanum triphyllum brafilianum. Barb.pin. 167 . prodr. 91. Burf. IX: Y2.

Solanum triphylluin canadenfe. Corn.casad. 166.t.167

Solano congener triphyllum canadenfe. Morif. baft. 3

p. 532 . S. I 3. t. 3. f. . .

Habitat in Virginia.

sagle. 3. TRILILIUM fore feffili ereहo.

Paris foliis ternatis, Aore fenfli erecto. Gron. virg. 44. Solanum virginianum triphyllum, fore tripetalo atropurpureo in foliorum finu, absque pediculo, feflili. $P$ lsk. alma. 352 . t. III. $f$. $G$.

Solanum triphyllum, Hore hexapctalo: tribus petalis purpureis, ceteris viridibus reflexis. Catesb. car. I. $p$. so. $\pi$. 50.

llabitat in Virginia, Carolina. 2

\section{MENISPERMUM}

canadenfe. 1. MENISPERMUM foliis peltatis fubrotundis angula-

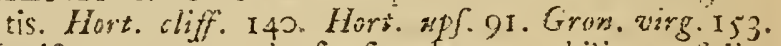
Menifpermum canatenfe fcandens, umbilicato folio, Tournef. act. 1705. $P$ : $3 \mathrm{II}$.

Hedera monophyllos virginiana, couvolvuli folijs. Pluk. alm. 181. t. $36 . f .2$.

Habsiat in Virginia, Canada. $*$

virginicun, 2. MENISPERMUM foliis cordatis peltatis lobatis, Gron. virg. 40.

Menifpermum folio hederaceo. Dill. elth, 223. t. 178. f. 219 .

Habitat in Virginix \& Carolinæ maritimis. \&

cavolinwm. 3. MENISPERMUM foliis cordatis fubtus villofis. Habitat in Carolina.

Cocculus. 4. MENISPERMUM foliis cordatis retufis mucronatis. Mat. med..175. 
Arbor, aritiolochiz foliis, maderafpatana, fructu paryo inedica ad inftar convoiuto. Pluk. alm. 43. t. I3 f. 2 .

Cocculus officinarum. Bazl. pin. 5ir. Plaḱ. mant 52. t. $345 . j .2$.

Natialain. Rbeed. mal. $7 \cdot p$ I. t. I. as?

Habitat in India. b

5. MENISPERMIUM foliis orbiculatis fubtus villofis. crbicalatum.

Cocculi orientalis trutex convolvulaceus, orbiculatis foliis prona parte villolis. Pluk. smalth. or.t. $384 \cdot f .6$. Habitat in infula Crocodilarum Afix.

6. MENISPERMUIM folis lancoolato-ovatis viliofis. birfutsin. Cocculi indici altera fpecies minor fcandens, vinca pervincæ folis villofis. ljuk amalth. 6I. to $384 . f$. 7 . Habitai in India.

7. MENISPERMUM folis lincar-lanceolatis hirfutis. myofociare. Cocculi indici fuecies minima, myojoridis hirfutis tolis \& facie. Pluk. plat. $384 . f_{0} 3$.

Habitat in Judia.

\section{SAURURUS.}

1. SAURURUS foliis cordatis petiolatis, fpicis folitari. cornหs. is recurvis. Hort. "ps. 91 .

Saururus foliis profunde cordatis ovato-lanceolatis, fp:cis folitariis propendentibus folio brcvioribus. Roy. lugall. 8.

Saururus foiiis profunde cordatis ovato-lanceolatis, fpicis folitariis folio longiozibus. Hort. cliff. 139. Gron. virg. 40.

Scrpentaria repens, floribus ftamincis fpicatis, bryonize nigræ folio ampliore pingvi, virginicnfis. Pluk. alm. 343. t. $117: f_{0} 4$.

Havitat in Marilandia, Virginia. 2

\section{COLCHICUM.}

x. COLCHICUM foliis planis lanccolatis eredis. Hort. nutumale ciff: 140. Hort. upf. 90. Roy. lugdb. 41. Sauv. monfp. I8. Leebs. lipf. 29.

Colchicum commune. Bash. pin. 67.

Colchicum. Fuch. bift. 356.357 .

3. Colchicum flore pleno. Baub. pin. 67. Habitat in Europæ nuftralioris Jucculentis. $\mathbb{Z}$

$$
\text { Y } 32 \text { COL. }
$$




\section{4: HEXANDRIA TETRAGYNTA}

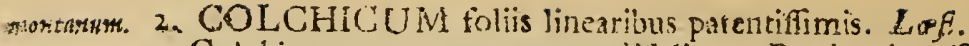
Colchicum montarum anguftifolium. Baxh. pir. 68. Colchicum montanum. Cluf. bilp. 26\%. 8. 267. kift. I. p. 200.

Habitat in Lfifparia, Helvetia. 2

Folia wnis cum flaribus autumino erssmpunt.

Mariegusum. 3. COLCHCUM folis nndulatis patenribus, Hort, cliff 140. Ror. Lkg d6. 42.

Colchicuu chionenfe, foribus fritillarix inflar tcffulatis, foliis undulatis. Woif. bift. 2. p. 34I. S. 4 t. 3. $f .7$.

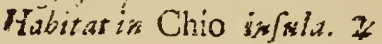

\section{HELONHAS,}

Eullata . HFIONIAS. Gen. anv. 1077. $f$. в.*

Ephonerum phalangoides virginianum, flocoulis arbutcis butiatis in ficam difpolitis. Pluk. alin. 135. 6.174 f. 5. Murif. kifl. 3. p. 606. f. 1j.t. 2. f. s

Habitat in Perifylvaniex paludofis.

\section{TETRAG NIA, \\ PETIVERIA.}

allizeat \& PETIVERIA. Hort. cliff. I4r. Hort. upf. gr Aa. fockb. 5 744. p. $28 \%$. t. 7 .

Periveria folani fólis, loculis fpinolis. Plam. gen. 50.

Verbeñ aut Scorodonix affini: anomala, Hore albido, calyce afpero, alii udore $\$ l_{0}$ an. jam. 64. bijk. I. p. 172. Raz. fippl. $28 \%$

Habitus in Jamaica nemorchiss. of

\section{POLYGRNLA. \\ A LISMA.}

plantopg. $\triangle$. ALiSMA folïs ovaris acutis, fruetibus obture trigonis. Alifuna fruRlu norufo rrigono. Fl. lapp. $138 \mathrm{Fl}$. Jutes.

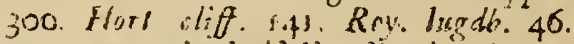
Plantigo aquaticalatiolia. Bazeb. Pin 1900. Plantago aquatica. Cam. epit. 26.4.

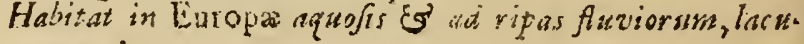
un. 4 
2 ALISMA folijs oratis acutis, fructibus globofis.

Dantafonium maximum, plantaginis folio, flore favefcente, fructu.globofo. Plam. Spec. $T$.

Hivisat in Ancrica meridonali. "

3. ALISMA foliis cordato-obiongis, foribus hexagynis. Damani-

Alima fruetu fexcurni. Hort. cliff. 141. Roy. lugdb.

uin.

46. Sauw. monsp. J4.

Piantagu aquatica ftellara. Bauk. pix. 190.

Plantage aquatica minor altera. Lob. ic. $30 \mathrm{r}$.

Daniafonium ftellatum. Walecb. bifi. 1058.

Hoblitat in Anglix, (iallia aquofis.

4. ALISMA foliis cordatis obrufis.

Damafonium ramofum, folio cordiformi. Vaill. at.

corrifolin. 1710 . p. 28.

Sagirtaria virginiana, obmfiore lato folio, floribus minoribus albis. Morif bift. 3. p. 6I8. f. 15. t. 4. f. 6. Habitat in Virgini.i. 2

5. AIJSMA foliis ovatis obtufis, pedinculis folitariis. natass.

D.mafonium repens, potamogetoris rotundifolii folio. Vasll. ast. 1719.7 .29$. t. 4 . f. 8.

Damafonium radiculas emitens ex geniculis. Faill.parif. 4 io.

Ranunculus paluttris foliis gramineis \& fubrotundis. Pitit. gen. 47.

Habitat in Gallix, Suecix folfs.

6. ALISMA foliis lineari-lanceolatis, fructibus globofo- Ramuctilnifquarrolis.

Alilima fruktu globofo undique echinato. Hort. claff. 141.It. got. 298. Hl.fuer. 301 . Roy. lagdb.46. Gort geir. 77. Sizuz. minulp. I4.

Damaionium angutilinito plantaginis folio. l'aill.aff 1719. p. 35 .

Plantago aquatica humilis anguftifolia. Bawb. bifl. $3 \cdot p$ 738 . Lob. ic 300.

Ranunculus agiaticus, plantaginis tolio anguftiffino. $\boldsymbol{T}$. Pet. gas 41. t. 26. f. I2.

llabitai in Colandia, Belgii, Angiix, Gallix fofis.

1. ALISMA foliis lublatis. Gron. virg. I53 Habitat in Virginis.

fubulut: 
Claplis VII.

\section{HEPTA NDR I A \\ MONOGRNIA.}

'TRIENTALIS.

wropea. I. TRIENTALIS foliis. lanceolatis integerrimis.

Trientalis. Fl. lapp. 139. Fl. Jusec. 302. Koy. luga'th. 438. Alfine alpina. Swenckf. filef. Irt.

Pvrola alfines flore enropæa. Bash.pin. 191.prodr.ror. Pyrola, alfines flore minor brafiliana. Baub. prodr. 101. t. (fub Hermodactyli inmine) 99. Burf. X. 107. Habitat in Europæ borsalis $\int y /$ ws EO juntperetus. 2:

capenfis, 2. TRIFNT ALIS foliis fubrotundis crenatis. Roy.lugdb. $538 . \dagger$

Habitat ad Cap. b. Spei.

Plantam banc non vidi, ex auduritate Clariff. D. Ro-. yeni adpojus.

\section{ASCUL US}

Hipo Cafta- 1. ISCUT,US florious heptandris, Hort. upf. 02. num. 玨culus. Hort. cliff. 142. Koy. lug 16.463 Caftanea folio multifido. Cluf. bilt. 1. p. 7 . Habitat in Alia Septentrionaliore, unde in Europam: Is ro. b,

Pavia.. 2. ESCULUS fioribus oetandris.

Pavia. Boerh. lugdb. 2. p. 260. t. 260. Hort. angl.54. t. 19. Hort. cliff. 143. Roy. lugdb. 463.

Samonna pifonis f. filiauifera bratilienfis arbor, digi-tatis folis cerratis, noribus teucril purpureis. Pluk. alm. 32.6. $t$. 50. f. 4 .

Habitat in Carolina. Brafilia. b, 


\section{Clajgis VIII.}

\section{O CTA NDR I A \\ MONOGRNIA.}

TROPEOL.UM.

I. TROP EOLUM foliis integris, petalis acuminato $\mathrm{fe}$ mains. taceis. Hort. zpf. 93.

Troprolum foliis peltaris orbiculatis. Hort. cliff. 145 .

Cardamindum minus \& vulgare 1 . Fewill. peruv. 3 . p, 14. t. 8.

Nallurtum indicum majus. Bauh. pin. 305.

Nalturtim indicum. Lob. ic. 166. $f$. 2. 1.

Habitat in Peru, Lima. () 2.

2. TROP EOL UM foliis fubauinquelobis, petalis obtufis minus. Hort. up. 93 :

Tropenlum folits peltatis orbiculatis. Hort. cliff. 143 .

Cardamindun ampliori folio \& majori thore. $T$. Few.

peruv. 3. p. 14. t. 8.

Acriviola maxima odorata. Boerh. lagltb. 1. p. 244.

Viola inodora candens, natturii laporc, maxima odora-

ta. Herin. lugdb. 629. t. 629.

Hahitat in Peru, unde in Europam venit 1694 coura Be-werningii. $\odot *$

3. TROP IEOLUM foliis palmatis, peralis multifidis.

Cardamindum quinquetolii folio, vulgo Malla. Few. peruv. 2. p. 756. t. 42.

Habitat in Peri, nondum mibi vifa in Eurapa. $\odot$.

\section{OSBECKIA.}

x. OSBECKIA.

chirenfis.

Echinophora maderaloatana, fideritis non ferratis nervom

fis folis, truetu capfulari caucalidis amulo. Plys. alm. 332. t. $173 \cdot f \cdot 4$.

Kadali maderafpatanum minus, capfulis pilofis. $R_{a j}$. fuppl. apt. 236 .

Habitat in India: in honorem Petr. Osbeck, Szesi, qui 1751. plantas Chine E Jave periculojo atsnere adsit, legit, exaininavit, dejcripjit, conmunicavit.

Habi:us.Mcloftome. Caulis ereans,oracbiatws, ackte tetraY 5

gonus. 
gonins. Folia angufto-lancelata, trincrvia, oppofita,

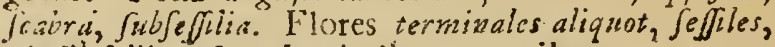
cinct ${ }^{3}$ folios 4 fare longroribus patestibus.

RHEXIA.

virginicn. 3. RHEXIA calycibus glabris. Gran: virg. 4I. Aifautus yegetabilis carolivianus. Pluk. amalt. 8.

Loyfimachia non pappofa virginiana, tuberaria foliis hir* fittis, fore tetrapetalo rubello. Pluk. alm. $235 . t .202$. f. 8 .

Habitat in Virginia.

Caulis ietraforns angulis membranaceis. Folia oppofita, fublinccolata, internodiis langiora, Seffilia, trinervia, pilis vagi, hifpidiafcalla, fuijerrata ferraturis fetaceis. Pedunculus ierminalis, dichotomsts. Fiores folitaria ex dicbotomia, Subjefliles, petalis rubris; Aatherisfalciatis, luteis.

Maniona. 2. RIEXIA foliis ciliatis.

Lyfinachia not pappofa, terræ marianx, 1:ptoneuros, Hore tetrapetalo subello, folio \& caulc hirfitie ferruginea hifidis. Pluk. matst. I2'3. $t, 428 . f$. I.

Hatbitat in M.arilandia.

\section{OENOTHERA.}

Fientis. 3. OENOTHERA folits ovato-lanceolatis planis. $V i r$. cliff. 33. Hort. upj. 94. Gron. virg. 254. Ray.lugdb. 251. Gort. Eelr. 73

Oenothera folitis ovato lanceolatis denticalatis, floribus bateralibus in fummo cautis. Hort. cliff. 144 .

Tyyimachia lutea corniculata. Baub. pin. 245: 516. * Morif. bift. 2 . p.271.f. 3.t.:1. f. 7 .

Habisat in Virginis unde $\mathrm{s} G \mathrm{i} 4$, nunc vulgaris Europe. of

maliginta. 2: OENOTHERA folis lanceolatis undulatis.Vir. cliff: 33. Gruar. virg. 42. Roy. lugdb. 25r.

Ochothera foliis lineari-lanceolatis dentatis, nooribus e medio ciulc. Hort. $\operatorname{xps} .144$.

Onagra bonaricnfis villofa, tore mutabili. Dill. clif $29 \% \cdot t \cdot 219 \cdot f \cdot 286$.

Habitat in ugro Bonarienfi. $\odot$

Jiaticaja gulis.

Oenothera forum calyce monophyllo, hinc tantem aperto. Giron. girg. 42 
Onagra angultiolia, caule rubro, thase minore. Tournef. inft. 302 .

Habitat in Virginia. 2

Calys purpurajcens, tetraphyllus, fed rumpitur altero fepius Es unico latere. Tubus filiformis, anguftiflimus. Captiala songulis 4 acutis comprefis. Folin rarius denticulata.

\section{GAURA.}

๘. GAURA. Gen. nov. xim.

Lylimachia lutea angultiolia virginiana, fore minore. Pluk. alin. 235 . t. 202. fa.7. mula.

Hobuitat in Virginia. Peniflvania. 2

\section{EPILOPIUM. \\ * Staminibus declinatis.}

3. EPIIOBIUM foliis farfis lincari-lanceolatis.

Epilobium fioribus diftormibus, piftillo declinato. $F$. ang uffifolie. frect 304.

Spilobium foilis lanceolatis integerrimis. $F l . \operatorname{lopp}$. 1 45 . Hort. cliff. 154 . Roy. lugdb. 250.

Lyfimachia Chamenerion dida anguftifolia, Bauh.pia. 245 .

B. Lylimachia Chamænerion dicta latifolia. Bsuh. pin. 245 .

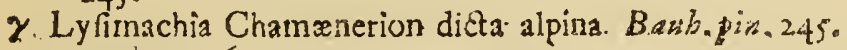
prodr. 126.

Habitat in Europa boreali. 2

2 EPILOBIUM foliis altcrnis lanceolatc-ovatis. Habitat in Sibiria. Z

Differt a fricuedenti fioribus siplo majoribus, folius lanceolallo-ovatis, alternis nec jparfis. utrinque lavibfims somento moliffirnis. $H_{a c}$ er anteceders differunt a jequentibus in non pancis, his enim Flores :mequales petalis integris; fiftllum declinatum; Folia ai-

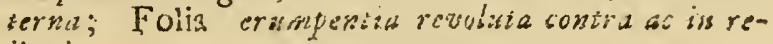
liquis.

* Stcminibus erectis reguluribus, petalis bifidis.

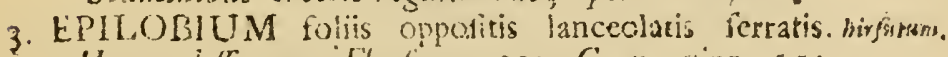
Horl. cliff. 145. F\%. Jisto. 305 Gron. virg. 154. Rog. lugith. 25I.

Lyin machia filiquofa hirfuta magno Aore. Baub.pin.245. Lyfiruachia purpurea. Fusbr. hijt. 491 . 
B. Ly rimachia filiquofa hirfita, parvo flore. Baub. pin. 245. proir. it 6.

Habitat in Enropæ bumidaufculis. 4

m:ontry uri, 4. EPILOBIU M foliis oppofitis ovatis dentatis.Fl.iapp. 147. Fi. fuec. 305. Hort. cliff. 145. Koy. latg db. 25i. Jyfimachia filiquofa glabra major.

Pfeudo-Lyfimachium purpurean primum Dod.pempt. 8.5.

Habitat in Europa mont ofis.

ietragonume. 5. EPILOBIUM foliis lanceriato-linearibus denticulatis: imis oppolitis, caulc tetragono. Sauv. monfp. 75 .

Lyfinachia filiquofa glabra. minor. Bauh. pin. jo3. Raj. bift. 861 .

Lyfinachia minor.. Tabern. i6. 854 .

Heibitat in Europa $z$

palufter 6.. EPILOBIUM foliis oppofitis laneeclatis integerrimis, pelalis bifidis, caule erecto. Fl. Juec. $30 \%$.

Epilobium foliis linearibus. F/. lopp. I 49. Roy. lugdb. $25[$.

Lyfimachia filiquofa glabra angufticulia. Bnub. pin. 245. B. E.pilobium folis lanceolatis, ramofe forens. Fl. lapp. 48 . Habitat in Europa bumidist culis. is un. Alpibus. 4

alpinum. 7. EPILOBICM foliis oppofitis ovato-lanceolatis integerrimis, filiquis feifilibus, caule repente..

Epilobium folis ovalibus: fuperioribus attenuatis. $F /$. juec. 308 .

Epilooiun foliis ovato-oblongis integerrimis. Fl.lapp. 150.

Epilobium, folis ellipticis obtufe lanccolatis, totum lave. Hall. bciv. 400.

Chamænerion alpunum, alfines foliis. Scbeuch. alp. 132 . 332.

Habitat in Alpibus Helvericis, Lapponicis. 2 Repens eft, primo vere florens. germinibus Seflilibus.

GRISLFA.

seentand. I. GRISLEA. Hort. cliff. 146. Habitat in America calidiore. 5

\section{A LLO PH Y LUS.}

aeylmicha. I ALLOPHYLUS. Fl. zejl. 140. Habitat in Zeylona. 5 


\section{MIMUSOPS.}

1. MIMUSOPS foliis alternis remotis. Fl. zey!. 138. Elengi Kauki indorum. Pisk. alm. 203. Freyi. ceset. 20 t. 3. Elengi. Rbeed. mal. I. 1. 34. t. 20.

2. MIMUSOPS folis confertis. Fl. ze\%l. I37. Kankt. Habitat in Zeylona. क

\section{JAMBOLTFERA.}

I. JAMBOLIFFRA. Fl. zeyl. 139. * piduncula:n. Jambolones. Buub. pir. 466.

Habitat in India. $b$

\section{SANTALUM.}

I. SANTALUM. Mat. med. $13_{3}$.

allumin

Santilum vermm. Brayn. is. 94 t. 5. f. s

Sintalum album. Burn. pin. 392.

Habitat in India. b

\section{MYMECYLON.}

1. MEMECYLON foliis ovatis. Fl. zeyl. I 36. Cornus fylveftris, foliis croceum colorem tingentibus, flofculis ad folioram alas globolis. Busm zeyl.70.t. 30 . Habitat in Zeylona.

\section{LAWSONIA.}

I, LAWSONIA ramis inermibus. Fl. $z \varepsilon y$. inerimis.

Liguftum agyptiacum latifolium. Bauls. pin. 476 .

Alhenua f. Henna atabum. W'alth. hort. 3. t. 4 .

Pontaletice. Rbeed. mal. 4. p. I17. t. 57 .

Habitat in India, 留gypto. 5

2 LAWSONIA ramis fpinofis. Fl. ze\%l. 1 34 .

Rhamnus maiabaricus, Mail-anfchi. Plak. alm. 38, t.

copitellunur, 220. $f$. 1 .

Mail-anfchi. Rbced. mal. I. p. 73. t. 40.

Habitat in incia. to

\section{YACCINIUM}

* Foliis annotinis deciduis.

1. VACCINIUM pedunculis uniforic, follis ferratis o-Myrsil\}s, vatis deciduis, caule angulato. Fl. lapp. i43. Ft. fuec. 313. Mat. wed. 184. Hort. cliff. I48. Kigy. lagkb. 239. Hall. belu. 4i9.

$\mathrm{Vitis}$ jdan toliis oblongis crenatis, fructu nigricante. Paun. pis. $47^{\circ}$. 
Myrtillus germanica \& Vitis iciæa. Dalech. bija. tor. I 9 k.

Habitat in Eurupa borealis Jylais umbrojss. to

(Antinemm. 2. VACCINIUM pedunculis folitariis unifloris, antheris corolla longioribus, fwiis oblongis integerrimis.

Vaccuium ftaminibus corolla longioribus. Gron.arg. 43 . Vitis idaa americara, longiori mucionato folio \& crenato, floribus urceolatis racenolis. P/sk. alm. 33I. t. $339:$. 3 .

Ylabivat in Ametica feptentronali, b

Fratex. Folia oblonga, integerrina. Pedunculiaxillates,

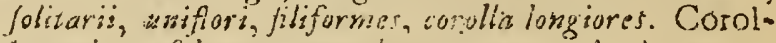
la quinumefiale, camponsulato patcnies. Anthera 10. Stylus fiore langior.

whinasm. 3. VACCINIUTM peduncuils uniforis, folis integerrimis oralibus bait ciliatis.

Vaccinum foliis of alibus integertinis deciaus. $F$. futc. $3 ! 2$.

Vaccinim folits annuis integerrimis. Fl. happ. I 42 . Hall. belo. 414.

Vitisida a tolis lubotundis exalbidis. Bamb. piss 470 .

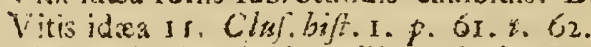

Itehifat in Succia borealitus $5 \mathrm{~J}$ alpinos, uliginatis.

aibum.

-. VACCINIUM pedunculis nuplicibus, foliis integer* rimis ovatis fubtus rornentolis.

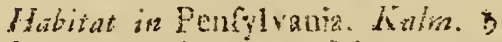

Irwiex. Folia oviaia, jubss tomersofi. Flores duo uel

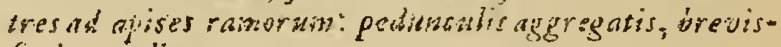
finis, wids.

marranatnm 5. VACCINIUM pedunculis implicifinnis uniforis, foliis ovatis mucronalis glabris integerrimis.

Fabital in America feptentrionali. Kalm.

Futex Romis terestitos, glancss. Folia elliptica vtrizque glatea. integeryims, murronata, petioles cunalicwialis infedentia. Pedunculi kniflori, foliis pastobreziores.

norymofwm. 6. VACCINUM fioribus corymbolis oratis, toliis ob. longis acuminati, integerrimis.

finbitat in America Septentrionali. Kalm. \$

brutex. Tolia oblonga, acriannervis fublus villatis Coyniot ex genmaceo involucro. follhes. Corollxe cylin-

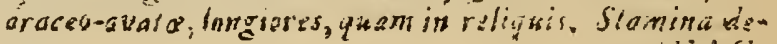
xem. 
7. $Y$ ACCINIUM racemis filiformibus foliotis, folis ab-frondofmm. long is integerrimis.

Vaccinium bliis ovatis integris deciduis, racemis fotiofis. Grow. virg. 155 .

Habitat in America Jeptentriosali. b

Fratex. Folia cúbriga, integerrina. Raccmionfrafulia, iradeis oblongis, parwis. Fedunculi partiales bratteis longives, infirudi bratcolis dualius filiforsibus. Curolia orato-iampiwalat a. Sramina 10.

3. V.ACCINIUM racemis nudis, caule fruticofo; foliis ligutimn?. crenulatis objongis.

Hubital in Penfilvania. Kalin. B

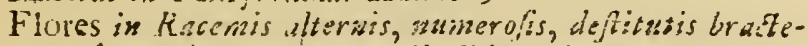
is, $\delta$. foliolis, guta kota facile difing wi ur.

9. VACCINIUMI foribus racen!olis, foliis crenulatis o- Arofoflaphy vatis ac'ltis, caule arborco. iss.

Vitis idxa orientalis maxima, ccraf folio, tore variegato. Tournef. cor. 42. it. 2. p. $223 . t .223$.

B. Vitis idza cappadocica maxima, mefpili folio, florevarieguto. Tourrefi cur. 42.

Hatrias in Cippadocia. 5

Racemi folis langior:s, infra folia liti, foliolis aratis irflirutzi.

\section{* Foliis Jenzpervirentióus.}

ro. VACCINIUM racemis terminalibus nutantibus, vitis ides. foliis obovatis revolutis integer rimis fubtus punctatis.

Vaccinium toliis obverfe ovatis perennantibus. Fl.lapp. 145. Fl. Suec. 314. Mat. med. 185 . Hort. cliff. 145 . Roy. lugalb. 239. Hall. belz. 414. Gort. gelr. 81.

Vitio idxa foliis fubrotundis non cienatis, baccis rubris Baub. pin. 470 .

Habitat in Europa frigidioris fyllis macris. b

11. VACCINIUM foliis integerrimis revolutis ovatis, onrocess. caulibus repentibus filiformibus nudis.

Vaccinium ramis filiformibus repuntibus, foliis uritis pcreinantibus. Fi. lapp. 145.

Vacciaum ramis fliformibus, folits oratis peremant:bus, pedunculis finplicibus nipu!a duplici. fi. fater. 318. Mai. me!. I80.

Vitis idza palutris. Basb. piw. 471.

Vaccinia palutria. Dod. peinot. 770. Lab. ic. Iog. Linbatat in Europa paludibus lphagnogue replabis. : 
Racemus brevifimus, pedunculis longiffrmis: bradteis 2 alzernis; Curolla rezoluta.

hifpiduizm. 12. VACCINIUM foliis integerrimis revolutis ovatis, caulibus repentibus filiformibus hifpidis.

Vitis idaza paluntris americana, oblongis fplendentibus foliis, fruftu grandiore rubro plurimis intus acinis refelto. Pluk. alm. 392 . t. $320 . f$. 6 .

$V$ itis idrea paluntris vifgunana, fruetu majore. Roij. hiff 68 ;.

Ilabitat in Virginize paludofis.

Struclura antecedentis, fed rnajora einniti, E Caulis Squanis feiaceis inbricatus.

\section{ERICA. \\ * Antheris hicornibus.}

onguris. 5. ERICA antheris bicornibus inclutis, corollis inaqualibus camparulatis mediocribus folis oppotitis fagitatis. Erica folits quadrifariam imbricatis triquetris glabris erectis, corollis inæeyualibus calyce breviotibus. Bors. cliff. $145.1 \%$ fact 300 . Koy. ingdb. 442.

Erica vulgaris glabra. Bauh. pir. 485 . Fl inpp. 1.4t. Habiral in Eucopa compeftribses flerilibus frequens. b. Eomparatiza mediocris, longior, brevior corolletelpicit propartiontint ad calyserts.

whbilute. 2. ERICA antheris beconibus exfertis, corollis globorts umbellatis, follis remus acctolis glabris. Lucegl. epifl. 2. 2.8.

Ilabitat in Lufitania. b.

Iruticulus habitu Erica vulgaris. Folia terna, acerofu, brevia, giciora, fubitis iinen alóa nutata. Urmbellulx madia aosque involacro. Calyx compofizss. Curolla p.aliide corriea, angzlata.

berbacea. 3. ERICA antheris bicornibus inclufis, corollis campa. nulatis Inediocribus fecundis, foliis teruis triquctris patulis.

Erica procumbens herbacea. Baxt. pin. 486 .

Erica coris tolio 8. Cinf: bils. I. p. 44 .

Habirat in Europa asflstaliori.

ciners. 4. ERICA antheris bicornibus inclues, corollis oratis tacomofis, toliis ternis glabris linearibus.

Erica foliis linearibus ternis, foribus globofo-oblongis laxe fpicaris. Grett. fiamp. 2. 1/2 110. 
Erica humiiis, cortice cinereo arbuti flore. Baub.pin. $4 \$ 6$.

Erica coris folio ó. Clat: hift. $x$. p. 47 .

Hauitat in Europa media.

5. ERJCA antheris bicornibus inclufis, corollis campanu- ropasis, latis longioribus, foliis ternis patentibus, ramis tomentotis.

Erica cre $\mathcal{A}_{a}$, follis ternis, Horibus ad alas feffilibus verticillatis. Saub. munfp. 170.

Erica major fcoparia, foliis deciduis. Bauh. piss. 48 r. Erica fcoparia, Rofeulis herbaceis. Lob. ic, 2. p. 2is. Saziv. monsp. ó $^{\circ}$

Halizat Monfpelii, in Hitpania, E Europa aufirali. 5

6. ERICA antheris bicornibus inclufis, corollis fubora caf rno tis mediocribus folitariis, roliis ternis. caule arboreo. Erica foliis lineari tubulatis ternis, corollis ovatis, calycibus acuris patulis. Hori. cliff. 148 .

Habit it in Ethiopia. b

7. ERICA antheris bicornibus inclufis, corollis ovatis viridi-pure iongioribus, racemis corymbolis íceundis, foilis térnis. purea.

Erica foliis lariceolatis oppolitis imbricatis, foribus uno verfu racemolis. Hort. cliff. 149. Saur. monsp. 170.

Erica major, foribus ex herbicco-purpureis. Bakb. pin.

Erica corios tolio 3. Clus: bijt. I. p. 42.

Habitat in Lulitania. 5

8. ERICA antheris bicomibus inclufis, corollis fubglo- Tetralix. bofis aggregatis calyce longioribus, foliis quaternis ciintis patentibus.

Erica folits fubulatis ciliatis quatcrnis, corollis globofoovatis terminalibus confertis. Hort. cliff. 148. Fl.juec. 310. Roy lugdb. 44 .

Erica ex rubro nigricans fcoparia. Baub. pin. 485. Habitat in Furopx borealis paladidibus cafpitofiss. 只

9. ERICA antheris bicornibus inclufis, corollis campanu- atoren. latis longioribus, foliis quaternis patentiffimis, caule fubarboreo tomeitofo.

Erica erecta, foliis quaternis, Horibus fpicato-racemofis. Sard. mon $[p$. 170 . 46 .

Erica foliis acerolis iinearibus patentifimis, corollis o: vatis, fiaminibus brevibus . Hurt.eliff. 47 . Roy. Ingdb. +42 .

Erica maxima alba. bazh. pin. $4^{35}$

$$
\text { Z Erics }
$$


pallido-pur- 10. ERICA folis in fummitate quinis, caule procumben ëuren. te. Segu. ver. 280.

Erica procumbens dilute purpurea. Bauh. pin.486. Raj. bift. 1715.

Erica foliis corios, flore purpureo dilatioris coloris. Baub. bift. 1. p. 358 .

Erica coris folio VII. Cluf. bift. I. p. 43 .

Habitat in Europa int/trali. 5

Numerofum gregen Ericarum Æthiopicarum aliorumque infinita diligentia dudism concuiftut, deforibft, delineavit E abjolvit Botanicus vers mugxus 111 . Adrian Royenus, quas ut cdot publicique juris faciat, omnes Botanici mecum Serio efflagitant.

* Anteris fimplicibus obtiifis emarginatis.

ciliaris. 11. ERICA antheris fimplicibus inclufis, coroilis ovatis irregularibus, floribus terno racemolis, foliis ternis ciliatis. Lœfl. epift. 2. n. 9 .

Erica hirfuta anglica. Baub. pin. 602

Erica XII. Cluse. hi/f. I.p. 46.

Habitat in Luritania. 5

Planta Suffruticofa, bipeddis. Folia terna, patentia, Sesfilia, ovato-oblonga, acuta, margine reflexa, ciliata. Racemus terminalis, terro-verticiilatus. Corolla magisa, ovata, ore contracto incquali.

trifiorn. 12. ERICA antheris bifidis inclufis, corollis fubglobofis fubvillofis ternis, pedunculis triphyllis, foliis ternis. Habitat in Ethiopia. b

curvifona. 13. ERICA antheris bifidis exfertis, corollis clavato cylindricis curvis folitariis longis, foliis fubternis.

Erica foliis liuearibus quaternis oppolitis villofis, corollis longiffimis folitariis. Hort. cliff. 148.

Erica africana frutefcens. Seb. thef. 2. p. 20. t. 39.f.5. Erica fpicata, floribus oblongis ex carneo purpureis. Pluk. mant. 67.t 346.f.9.

Habitat in Ithiopia. 5

Graniades. 34. ERICA antheris bifidis exfertis ftylo brevioribus, corollis globolis tectis calyce lanato, foliis ternis.

Eriocephalus bruniades ericæformis monomopatenfis, capitulis globulorum inftar interius cavis \& denfa lanugine tcetis. Piuk. mant. 69. t. 347. f. 9.

Frutex africanus aromaticus, Seb. thes..2.p. 64.t.63. f. 7.

Habitat in Fthiopia. 5 
45. ERICA antheris bifidis exlertis, coroliis globofis caprata. calycibus hiipidis

Erica africana calyce lanuginofo ex viridi luteo capitnlum referente, floribus concoloribus exiguis lanugine oblitis. Seb. thef. r. p. 30. t. 20. r. I.

Habitat in Finiopia. b

16. FRICA antheris bifidis fimplicibus exfertis, corollis carnon. ovaris fublongioribus, foliis quaternis triangularibus patentibus.

Erica procumbens, ternis foliolis, carnea. Baub.pin 486. Erica coris folio IX. Cluf. bift. 1. p. 44 .

Habitat in Pannonia, Helvetia.

17. ERICA antheris bifidis fimplicibus exfertis, corollis multif?s!ns. campanulatis longioribus, foliis quinis linearibus patentibus.

Erica, foliis corios, multiflora. Baub. bift. $1 \cdot p \cdot 356$.

Erica juniperifolia denie fruticans narbonentis. Lob.bift. 620. Saur. $\operatorname{mon}\{\dot{p} \cdot 46$.

Habitat Monfpelii. $b$

18. ERICA antheris bifidis inclufis, cornllis globofis gla-pilulifers. bris quaternis, foliis quaternis fetaceis patulis.

Habitat in AErhiopia. b

19. ERICA antheris bifidis exfertis, corollis clavatis, ca-coccinea. lycibus duplicibus.

Erica africana anguftifolia grabra, floribus oblongis tubulotis dependentibus coccineis, cum longifimis filamentis concoloribus. Seb. thef. I. p. 32. t. $21 . f .4$.

Habitat in Aithiopia. 方

20. ERICA antheris bifidis exfertis, corollis globofis me-corifolio. diocribus, pedunculis triphyllis, foliis quaternis.

Erica atricana glabra tiuticoia, coris folio, arbuti flore dilute purpureo. Seb. thef. I. p. 32.t. 21. f. 3.

Habitat in Aithiopia. 5

2I. ERICA antheris bifidis inclufis, corollis cylindricis abietina. longioribus aggregatis, foliis verticillatis dentato-aculcatis.

Erica foliis rubulatis glabris quinis pluribusve verticillatis, foribus longinnmis terminalibus confertis. Hort. cliff. I 48 .

Erica atricana, abietis folio longiore \& tenuiore, fori$\mathrm{Z}_{2}$ 
bus oblongis fatuizite rubris. Raj. dendr.g6. Seb.tobef. r. $) .3 r \cdot t \cdot 2 \pi \cdot f . \tau$.

Habiat in Athiopia. 5

gnatbaloides 22. ERICA antheris bifidis inclufis, coroilis globofis ternis, calycibus cuplicibus obtufis.

Halitat in IEthiopia. b

Facies piantse Grapbaliz.

pinkeneti. 23. ERICA antheris bifidis exfertis, corollis fubicylindricis indivifis longioribus, calycibus limplicibus, fuliis linearibus verticillatis.

Chamæpithys $x$ thiopica, foliis late virentibus, Hore oblongo phoniceo plus quam eleganti $f$ piusquenetii. Pluk. mant. $45:$ s. $344 \cdot f 3$.

Habitat in Ethiopia.

\section{DAP HNE. \\ * Fieribus lateralibus.}

Mezerexm. I. DAPHNE foribus ferlilibus ternis caulinis, foliis lanceolatis deciduis.

Daphne Horibus f́inlibus infra folia elliptic(o-lanccolata. Fl. lapp. 1 40. Fl. Juec. 3I I. Mat. med. 179. Hort. cliff. 147. Roy. bugh. 201.

Laureola tolio decidio, flore purpureo, offeinis Laureola femina. Bash, pin. 462.

Daphnoides. Cem. epit. 937.

Iabirat in Europa borealis fylvis. 5

Tyymelaa. 2. DAPHNE Horibus fefiilibus axiliaribus, foliis lanceolatis, caulibus fimpliciffinis.

Daphne floribus tetrandris lecundun caules fimplicifimos. sav. monfp. 56 .

Thymelea tolits polygalaz glabris. Baub. pin. $46_{3}$.

Sanamunda viridis vel glabra. Baub. prodr. 160.

Sananmndia glabra. Bazb. bift. I. p. 592 .

Habitat in Hifpania \& Monfolii in Hort Dei. 5

rarton vara 3. DAPHNE floribus feffilibus aggregatis axiliaribus, foliis ovatis utrinque pubefcentibus nervolis.

Fonyela folis candicantibus \& ferici inftar molliuus Batib. pin. $46_{3}$.

Tarton-Raire galloprovincix monipelienfium. Lob. ir. 371.

Habitar in Galloprovincia. 5

alpina. 4. DAPINE Horibus feflilibus aggregatis lareralibus, fo liis lancolatis obtufufculis fubtus tomentofis. 
Thymelxa toribus inter folia, folio utrinque hirfuto. Hall. belv. 187. Sauv. manzip. 57.

Chamelea alpina, folio inferlie incano. Bauh. pin. 1462.

Chamclea alpina incana. Lob. ic. 370.

6. Chamelxa fabaudica, folio utrinque incano, fiore abo. Kaj. bifl. 1589.

Thymelaa, incana, mezerci folio \& facic, furculis adinodum fiagilibus. Plak. alm. 366 . t. $229 . f .3$.

Habitat in Alpibus Helvetix, Genevx, Iraiix.

5. DAPHNE racenis axiliaribus, foliis lanceolatis glabris. Lakrenla.

Daphne racemis lateralibus, foliis lanceolatis integr!s. Hort. cliff. 147. Hort. ups. 94. Mat. med. 180. Sazv. monjp. 57.

Laureola fempervirens, flore viridi, quibusdam Laureoia mas. Basib. tim. 462.

Laureoiz. Dod. perinpt. 365.

Habiat in Anglia, Helvetia, Gallia, Baldo. 5

6. DAPHNE pedunculis lateralibus bifloris, foliis lance-pantica. olato ovatis.

Thymclaa pontica, cirrei foliis. Tournef. ilin. 3.p. iso. t. $x 88$.

Habitat in l'onto. o

\section{* Floribus terminalibus.}

7. DAPHNE capitulo terminali pedunculato, foliis op-indica. politis oblongo-ovatis glabris.

Habitat in China. 5

Frutex parzus. Folia oppofita, oblongo-ovata, integerrima, glabra. Peduncilus terminalis, breviffirazs, afice gerens fiores 6 ad 8 Seffiles.

8. DAPHNE floribus congettis terminalibus fefrilibus, Chennm. foliis lanceolatis nudis.

Daphne humifula, foliis oblongis lores fefliles terminales fubcingentibus. Sauv. monj $p$. 57.

Thymeira afinis facie externa. Bash. pin. 463.

Cnteorum. Maith. bist. 46. Clirf. bift. 89.

Habizat in Helvetia, Hungaria, Pyrenæis, Baldo, L. B. Murschisulon. क

\% DAPINE panicula teminali, foliis lineari lanccolatis Gritinns. acuminatis.

Daphne foliis lanceolatis bali angultioribus, racemo nudo terminali. Saro. inonjp. 56 ;

$$
\text { 'Z? Daph- }
$$


Daphne floribus raccmofis, foliis lineari-lanceoiatis acuminatis integris. Guctt. fiamp. 2.p. 427.

Thymelea follis lini. Bauh. pin. 463 .

Thymelxa. Clue. bift. 1. p. 87. Carr. epit. 974.

Habitat in Hilpania, Italia, G. Naibonenti. $b$

foumrosa. 10. DAPHNE foribus terminalibus pedunculatis, foliis fparfis linearibus patentibus mucronatis.

Thymelwa capitata lanuginofa, foliis creberrimis minimis aculeatis. Burm. afr. 134. t. $49 . f$. 1 .

Habitat in Athiopia. b

painftis. DIRCA.

I. DIRCA. Gen. nov. 10\%8. *

Thymelaa thoribus alois primo vere erumpentibus, roliis oblongis acuminatis, viminibus \& cortice valdetenacibus. Gron. virg. 155.

Habitat in Virginix palsdofis. b

\section{GNIDIA.}

pinifolis. 1. GNIDIA foliis fparfis lineari-fubulatis.

Rapunculus foliis nervofis linearibus, Horibus argenteis non galeatis. Burm. afr. 112, t. 41. f. 3 .

Habitat in Ethiopia. 5

tomentora. 2. GNIDIA foliis alternis ovaro-lancealatis.

llabitat in Athiopia. 5

Fores tomentofi, capitati, terminales.

opofitifolix. 3. GNIDIA folits oppofitis lanceclatis.

llabitat in Eihiopia. 5

Fiutex ramis reetis. Folia oppofita, laxceolata, glabra, integerrima. Flores terminales, conferti, infunaibuliformes, tubo villefo, petalis emarginatis.

fratefens. 1. B/ECKEA.

\section{B $E$ CKEA.}

Habitat in China. D. D. Abrah. BECK. S.R. Mitis. Suecice medicus aidinariss, Amicas nofier cere fincerus, c cujus borto ficco plurimas rariores ftirpos obtinuimus, etiom baiz primus nobifcum communicavit.

Frutex habitu abrotams, ramis virgatis: Kamulis oppofitis, brevibus, fimplicibus. Folia oppofita, linearia, acuta, glabra, imegerrima. Flores axillare's, jolitarii,pediucula nudo longitudise floris, foilis longe breviore. Pcranthium infundibuliforme; randucástatum. Petala 
tala 5 , fubrotusia, patula, calyci inferta. Filimenta 8, quorum 6paria, E 2 solitaria, Lreviffima, inflexa. Anther $\int$ ubovat is, parve. Germenfubrotundum. Stylus filiformis, corolla brevior. Stigma capitatum. Cbinexfibus Tjongina. Osbeck.

\section{$D I G \Upsilon N I A$.}

GALENIA.

I. GALENIA. Hort. cliff. I 50. Roy. lugdb. 209. Sherardia. Font. epift. Is.

Kali lignofum, fore inufcofo, rofmarini folio. Bacc. mus. 150. $t$. I to.

Atriplex africana lignofa frutefeens, rosmarini foliis. Till.

pis. 20. t. 25.

Habitat in Africa. o

\section{MOEHRINGIA.}

I. MOEHRINGIA

Aline montana, capillaceo folio. Baub. pin. 25 . Scbe$m i x \int c o s a$. usbz. alp. 503. t. 6. Pluk. alm. 23. t. 75. f. 1.

Aline Caxifraga anguftifolia minima montana. Cold. ecphr. I. p. 292. t. 290.

B. Alline renuifoliamufcofa. Bawh. pin. 25 I. Morif. blef. 10. hift. 2. p. 551. S. 5.t. 23. f. 12.

Habitat in Alpibus Helvetix, Italix, Autrix.

\section{TRIGTNIA.}

\section{POLYGONUM}

* Atraphaxoides casle frutefcente.

1. POLYGONUM caule fruticolo, calycinis toliolis du- frutefens. obus refiexis. Hort. upf. 95.

Atraphaxis incrmis, toliis planis. Hort. cliff. 138. Roy.

liggdo. 209.

Lapathum orientale, frutex hninilis, fore pulchro. Tournef. cor: $3^{9}$.

Lapathum dauricum montanum fruticals, ramis late rpartis. Amm. ruth. 227.

Habstat in Sibiria, Dauria. 5 


\section{* Biftorta fpica unica.}

Biftorta, 2. POLYGONUM caulc fimplicifimo monoftachyo, foliis ovatis in petiolum decurrentibus. NIat. med. I 98 . Biltort: foliis ovato-oblongis acuminatis. Hort eliff. 150. Hort, upf. I 50. Ro\%. lugah. 2.77.

Biftorta major, radice magis intorta. Baub. fin. 192. Biltorta. Cam. epit. $68_{3}$.

Habitat in montibus Helvetix, Aufrix, Gallix. \&

ziจip:zrım. 3. POLYYGONUM caule fimplicifimo monottachyo, ofliis lanceolatis.

Biftort: folis lanceolatis, Fl. lapp. 152 . Fl. Juec.321. Hor'. clifi. 1 jo.

Biftorta montana minor, radice intorta inodora, fofculis in fpicæ cacumine albis fterilibus, inferna ipic parte tuberculis proliferis turbinatis puniceis ffcunda. Amin. rith. i 69 .

Biftorta alpina media. Bauh. pin. r92.

Biftora alpina minor. Baub. pin. 192.

Habitat in Europa jubaipinis palcuis duris. 2

serrarum, 4. POLYGONUM foliis crenatis.

Polygonum folio oblongo crcnato, Shaw. affr. 489 . Habitat in Mauritania.

* Perficaria piftillo bifilo.

sirginianum 5. POLYGONUM foribus pentandris digynis, corollis quadrifidis, foliis ovatis.

Pericaria fioribus pentandris digynis, corolla quadrifida inæquali. Wach. witr. 258 .

Perficaria florum ftaminibus quinis, ftylo dupici, corolla quadrifida inæquali. Hort. cliff. 42. Groa. virg. 43. Koy. lugdb. 216.

Peificaria tirutefcens maculofa virginiana, fiore albo. Marif. bilt. 2. p. 539. Raj. bift. 183 .

Habitut in Virginia. $*$

Lespathifoli- 6. POLYGONUM foribus pentandris femidigynis, ftaHIM. minibus corolla regulari æqualíbus.

Pericaria Horibus pentandris digynis, corolla rcgulariftaminibus aquali. Hach. ultr. 257.

Perficaria Horum taminibùs quinis femidigynis, ftylo bifido corollæ rerulari æquantibus. Hort. cliff. 42 .

Perficaria major, lapathi folijs, calyce floris purpueo. Tournef. inft. 510. Raj. fuppl. IIg.

Pcrficaria Hydropiper. Lob. ic, 315. Jabitat in Gailia. 
7. POLYGONUM floribus pentandris femidigyais, far amplibinm. minibus corolla longioribus.

Perficaria florum ftaminibus quinis corollam fuperantibus, flylo bitido. Hort. cliff. 41. Roy. lugdí. 216.

Perficaria floribus pentandris digynis, corolia taminibus breviore. Fl, juec. 318 .

Potamngeton falicis folio, Banb. pin. 193.

Habitat in Europa.

8. POLYGONUM foribus pentandris trigynis axillar:- maritin:"., bus, foliis lanceolatis, caule lìpulis obtecto fruticofo.

Polygonum martimum latitolium. Batz. pin. 280.

Polygonum marinum. Cain. cpit. 691.

Habitat Monfpelii, in Italia, Virginia. 5

Staminabuic $\int_{i}$ eciei quina admumerat $D$. Siawvages, a me nos numerata.

9. POLYGONUM foribus pentandris trigynis, folits osreatitm. lanceolatis.

Perficaria fpicis longis numerofis, vaginis integris, florie bus pentandris tigynis. Ginel.

Hobitut in Sibiria. D. Gmelin.

Stipula funt vaginnc integra, ventricofa, leves, ampliores multo quem caulis. Folia lawccolata, revoluta. Flotes racemuje.

10. POLYGONUM Aoribus hexandris femidigynis, fo- Hyirogiper. liis lanceolatis, Atipulis fubmuticis.

Polygonum foliis lanceolatis, floribus hexandris femidigynis. Mat. med. 187.

Perficaria floribus hexandris femidigynis, $\mathrm{Fl}$. fuec. 320 .

Perficaria florum ftaminibus fenis, llylo bifido. Mlor: cliff. 46. Roy lug dib. 216 .

Perficaria urens f. Hydropiper. Baub. pir. Ior.

Hydropiper. Do 3 . pempt. $60 \%$.

Hlabitat in Europe Jubbumidis. $\odot$

21. POLYGONUM flcibus hexandris digynis, fpicis Fefferria. ovatis oblongis, toliis lanceolaris, Mipulis ciliaris.

Perficaria floribus hexandris digynis. F. Satec. 319.

Perficaria florum flaminibus fenis, fyloduplici. Hort. cliff. 42. Gron. virg. 157. Roy. lugdb. 216.

Perficaria mitis. Bazh. bift. 3. p. 779. Fl. lapp. 77.

Perlicaria mitis maculofa \& uon inaculofa, Barb. pim.

IOI.

Habitat in Europa caltis. $\odot$

$$
\text { Z5 }
$$

12. PO. 
Fagotritico fimilis, anguntiori folio, convolvuli modo icandens, caule pinulis deflexis denfius obfito. Pluk. mant. 74. $\pi$. 394. $f .5$.

Planta pofterior e novo belgio. Laët. amer. 73. $t .74$. llabitat in Virginiz, Marilandia madidis.

"rifolizm. 2I. POLTGONUM foliis haftatis, caulc aculeato.

Fagotritico fimilis fpinofa fandens, ari folio latiore, foridana. Plak. amalth. 8\%. t. 398. f. 3 .

Planta prior e novo belgio. Isact. amer. 73 .

Habitat in Virginia, Florida.

Tataricun. 22. POLYGONUMI foliis cordato-fagittatis, caule inermi erecto, feninibus fubcientatis.

Helxine caule erectiufculo inermi, foliis cordato-ragittaris, feminibus lubdentatis. Hort. ups. 96 ,

Hcixine caule ereato inermi, foliis cordato-fagittatis, leminum angulis dentatis. Hort. cliff. $15 \mathrm{I}$,

Fagotricicam flbiricum. Ait. flocḱ. $17+4 . p .117$. t. 4 .

Habitat in Tataria.

Pugnpyma. 23. FOLYGONUM foliis cordato-fagittaris, caule creEiaículo inermi, feminum angulis aqualibus.

Polygontim caule ereetiufculo inermi ramolo, foliis cor dato-fagirtatis, feminibus lavibus, Mat. med. 188.

Helxine caule erectiufculo inermi, foliis cordato-fagittatis, feminibus integerrimis. Hort. up. 96.

Helxine caule erectulculo inermi, folis cordato-fagittaris. liort. cliff. 151. Hl. Succ. 217. Roy. lugab. $21 \%$

Eryfinum cereale, folio hederaceo, Bauh. pis. 27.

Ocymum cereale. Tabern. bijz. 276.

Habizat in Afia. ()

Cansolualus. 24. POLYGONUM foliis cordatis, caule volubili, foribers planiufculis, -

Helxine caule volubili. Fl. lapp. I54. Fl. Juec. 323. Hort. cliff. 150. Gron. rirg. 157. Roy. lugdt. 217.

Convolvulus minor, femine triangulo. Bauis.pir. 294.

Convolvulum nigrum. Dod. perspt. 39 a.

Habitat in Europx agris. $\odot$

fem:den. 25. POTYGONUM foliis cordatis, caule volubili, foribus carinatis.

Fagopyrum fcandens amcricanum maximum. Tournef. inftis. YIJ.

F agopyrum fcandens, saulc rubente, femine nigro. Gron. virg. 44. Ciold. woveb. 93 . 
Fagotriticum voltbile majus virginanum. Pluk. aln. 143. $t .177 . f: 7$.

Fagopyrum leandens $\complement$. Volubilis nigra major, fore \&

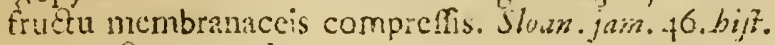
r.p. $139 . t .0,0.1$.

B.Fagopyrum prelongum dumctorum, feninibus alatis duplici more difpofitis. Dill. app. 60.

Fagopyrum lyivaticum fianciens, flore foliaceo. Pont. ainib. $26 ;$.

Habitat in Amcrica. $\odot$

Flores pluate $\beta$. non rivit, at fructura liajus ejt.

* Caule arbarco.

26. POLIGONUM foliis fubrotundis, caule arboreo, vaifs. fruclibus baccatis.

Uvifera foliis fubrorundis amplifimis. Hort. cliff. 487 .

U vifera littorea, foliis anplioribus fere orbiculetis crasfis, americana. Plak alim. $394 . t .236 . \mathrm{J} .7$.

Prusus maritima racemofa, folio rotundo glabro, frudu minore purpureo. Slown. jam. $2 \varepsilon_{3}$. hijt. 2.p. 129. t. 220.f. 3. kaj.dendr. 40. Catesb. cur. 2. p. g,o. t. 96.

Halist in Caribearum listoribus maritimis. b

E.w bubitu huc retuli (Jures ron vial), rel exin bujus generis vel proxim: erit.

\section{PAULLJNIA.}

1. PAULIJNIA ioliis ternatis, caule aculento, cirrhis "satica, nullis. Fl. seyl. i 43 .*

Chamala trifolia aculeata. Burm. zeyl. s. $^{8}$ t. 24.

Frutex baccifer indicus fpinolus trifolius, fioribus fpicatis. Pluk alm, 202. t. 95. f. .5.

Kal.i-toddali. Rheed. mal. $5 \cdot p$. s. $t .4$ r.

Halistis in India. 5

2. PAULLINIA foliis ternatis, petiolis teretiufculis, fo- Serima, linlis ovato-oblongis.

Paulinia foliis ternatis, foliolis crenatis, pedunculis cirrhiteris. Hort clifi. 152 .

Seriana fcandens trichylla \& vacemofa. Plum. gen. 34. Habitatio Americal calidiurc. b

3. PAULLINIA foliis ternatis, fuliolis cunejormibus curnru. obtulis fubdenratis.

Paullinia foliis teraaris, foliolis obtulis vis demiculatis giabris doincutibus in fetiolum propium. Kavi. cliff. ist. 
Alfinaftrum ferpillifoliam, flore albo tct:apetalo. Vaill. purif. s. t. 2. f. 2.

B. Alfuaftrum ferpillifolium, fiore rofeo tripetalo. Vaill. parif. 5.t. 2. $f$. I.

Habitat in Europa inundatis. $\odot$

A/jumaftrim. 2. ELATINE foliis verticillatis. Roy. lugdh.452. Sauv. monfp. 164. Boem. liph. I27.

Elatine foliis emerfis lincaribus, immerfis capillaceis. Sauv. act. monft, 1743. p. Sc.

Equifetum paluttre, inarix fcoparix folio. Bass. pin. 15. Alinaftrum gallii folio. Vaill. parif. 6 . t. 1. $f .6$.

R. Allfinaltrum gratiolæ folio. Tournef. inft. 244. Raj fuppi. 502.

Hubitat Abox, Lipfix, Parifiis, Monfpelii in fogfis. 


\section{Clafjis IX.}

\section{ENNEA NDR I A}

MONOGRNAA.

\section{AURUS.}

1. LAURUS foliis trinervitis otato-oblongis nervos u-Cinnomnientibus. Fl. zey. i 4 . Ińat med. 190.

Laurus boliis oblongo-ovatis nitidis planís. Hort. rliff. 154 .

Cimanomum, folìs latis ovatis, frugiferum. Burm. 26)l 62. t. 27.

Cinnsmolrum f. Canclla Zevlanica. Bwh. pin. 408. Caffia cinnamomea, Herm. lugáb. 129. t. 6,5.

Habitur in Zeylonia. 5

2. LAU UTIS foliis trinerviis lanceolatis nervis fupraba-cadia fin unitis. Fl. zeyl. I th. Met. med. IgI.

Cinnamomum perpetio forens, folio tenuiore acuto. Buriz. zey\%. 63. t. 28.

Cinnamomum f. Canella malabarica fojavanentis. $B$ ab.

pir. 409.

Carua. Ribed. mal. I. p. 107. t. s\%.

idabitur in Malabaria, Sumatra, Java to

3. LAURUS foliis tinerviis innccolnto-ovaris: nervis ctmphorn, fupra batiu unitis. Mat. ined. I92.

Lauras foliis ovatis utrinque acmminatis tunerviis nitidis, petiolis lacis. Hort. cling I 54 .

Laurus Camphonifera. Kumpf. jup.

Camphora officinarum. Bash. pin. joo.

Arbor camphoritirajaponica. Breyn, prodr. 2. to 10.86 16. $t .2$.

Kabitat in Janoria. b

4. LAUKUS foliis ianceolacis venofis percnnantibus, fo- nobiat ribus quadritidis dioicis. Ilwt. clifi: 155. Hism: asps. o5. Mit. aled. I94. Roy. lugulo. os.

Laurus vulgaris, Bash. pir. 400 .

I.aurus. Com. epit. 6.0.

robitat in Italia, Grxcia. क 
indica, 5. LAURUS foliis lanceolatis perenuantibus ventofis planis, ramulis tubcrculatis cicatricibus, floribus racemo. fis. Hort. cliff. 154. Gron. 2 irg. 159.

Laurus indica. Pluk. alm. $210 . t$. $301 . f .1$.

Laurus latitolia indica. Barr. rar. 123. t. 877.

Cinuamomnin fylveftre americanum. Sco. ther. 2. p. 90. t. 84. f. 6 .

Habitat in Virginia. 5

Perfes. 6. LAURUS foliis ovatis coriaceis transverfe venofis perenuantibus, floribus corymbofis.

Perfea. Clatf. bifl. 1. $p .2$.

Pcrfea americana. Brub. pin. 44r.

Pyro fimilis fructus in nova hifpania, nucleo magno. Bauh. pin. 439.

Prunifera arbor fructu maximo pyriformi viridi, pericarpio efculento butyrace nueleum unicum maximuma nullo ofliculo tedum cingente. Slaar. jam. 132. bift. 2. p. 132. t. 222. f. 2. Raj. acndr. 48 .

Arbor americana, ampliffimis pergamenis lolis, fuperticie nitidifima, froetu pyriformi crultacco cortice coriato. Pluk. alm. $39 .$, t. $26 \%$ f. I.

11abitat in Amcrica culida. ᄒ

Beybona. 7. LAURUS foliis lanceolacis transveife venofis, calycibus fruetus baccatis. Hort cliff. 154. Gron. zirg. 46. Ray. ingaib. 226.

Laurus carolinienfis, foliis actiminatis, baccis cærucis, pedicellis longis rubris infidentibus. Catest. car. 1. p. $\sigma_{3}, t . \sigma_{3}$.

Habitat in Carolina, Virginia. 5

xfiatiis. 8. LAURUS foliis venofis oblongis acurninatis annuis; ramis fupra-axiilaribus.

Laurus folis ianceolatis enervibus annuis. Gron. wirg. Is9.

Laurus foliis enervibas ovatis utrinque acutis. Gron. virg. 46 .

Habitat in Virginia ad ripas rivulorum.

Pedusaculi bujus fructiferi colorati junt.

Berzoin. 9. LAURUS foli:s encrviis ovatis utrinque acutis integris annuis. Hort. cisff. 154. Mat. wed. 195. Grois wirg. 45. Roy. lugdk. 226.

Arbor virginialia, citreæ vel limonii folio, Benzoinum fundelis. Comm. bort. I. p. $189 . t .97$. 
$\Lambda$ tbor virginiana, pifhanimis foilo, baccata Benzoinum redolens. Pluk. alise. 42. t. 139. $f .3 .4$.

II.abitat in Virginia. o

xo. I.AURUS foliis integris irilobisque. Hort. cliff. $\times 54$. Sughifrat.

Mat. mod. 193. Gron. virg. 46. Ray. lagdb. $22 \%$

Coid. noveb. 94.

Cornus mas odorata, folio trifido: margine plano, Sasfaphras dicka. Pisk. alm. 130. 1. 222. f. 6. Cuatesb. rar. 1. P. 55.1 .55 .

Sallafras arbor, ex forida, ficulneo folio. Bauh. fin. $4 \hat{i} 1$. 3. Cormus mas t. Salnaras laurinis toliis indivilis. Plate. amalsh. 66.

IItaitat in Virginia, Carolina, Florida. b

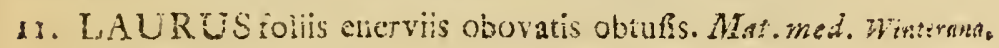
I0).

Winteranus. Hort diff. 488 .

Ciniamomuin $\int$. Canella peruana Bats. pin. 409.

Cafina lignea jamaicentis, hareol $x$ folis fubcinereis, cortice piperis modo acri. Pial. alin. Sy. to I GJ. fo I.

Catfa cinnamomea f. Cinnamomun lylveftre barbadenfi:m. Plak. alm. 8g.t. 160, f: 7 .

Arbor baccifera laurifolia aromatica, fructu viridi ca-

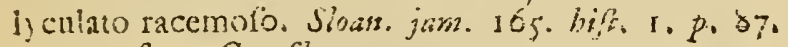
t. 191. f. 2. Caterb. car. 2. p. 50. to 50.

Habitat in Janmica, Barbados, Carolina. क

Flores ipje non cidi.

\section{TRYGYNR*4. SPONDIAS.}

1. SPONDIAS. Hor. chift: 484 .

Mornbin arbor, folio traxini, fruetu luteo racemofo. Plum. gen. 44 .

Prinus brafiicinfs, fructu racemofo, ligno intus pio oficulo: Slank jam 282. hift. 2. p. 125.

Prunus americana. hiver. fut. 3. t. 13.

Acaja \& Ibametara. Marcgr. braf. 129.

Habirat in Bralilia, Jamaica.

\section{RHEUM.}

1. RFEUM foliis glabris, petiolis fubfulcatis:

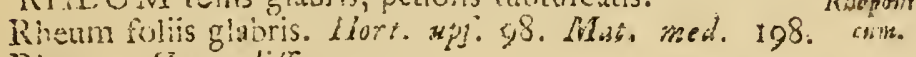
Rheum. Hori. litff. 155: 
Rhaponticum. Alp. repont. I. t. I.

Rkaponcicum folio lapathi rnajoris glabro. Baub. pin. II 6.

Habitat in Thracia, Scythia. $z$

Rbabriba-

2. RHEUM foliis fubrillofis, petiolis rqualibus. Dif. inin. Rbabarb. 1. t. 1. *

Rheum folis fubvillolis, Hort. upf. of. Mat. incd. 197.

Rhabarbarum finenfe, folio crifpo, flagellis rarioribus \& minoribus. Arrim. berb. 206.

Rhabarbarum folio longiori hirfuto crifpo, florum thy rfo longiori \& renuiori. Ams. ruth. 9 .

Acetofa montana, folio cubitali oblongiore cripo, floribus in fuoviridi luteolis. Meforfibmidis. Amin. rath. 226 .

Habitat in China ad murum $\mathcal{E}^{2}$ in Sibiria. 2.

Ribes. 3. RHEUM foliis granulatis, petiolis xqualibus.

Lapathum orientale, alfero \& verrucolo folio, Ribes atabibus dictum: Lill. elth. 191. t. 158. $f$. 19.2.

Lapathum orientale tomentofun rotundifolium, Ribes arabum dicum. Breyn. E. N. C. cent. 7. P. T.

Lapathum oricnalc afperum, folio fubrotundo, fruetu masiono purpures. Pocuck orient. 189. t. 84 .

Ribes arabum. Rauw. It. 266. 282.

Ribes arabum, folits petafitidis. Baub. pin. 455 .

Habit.st in Perfia, Libano, Carmelo. 2

Flores bujus speciei non vidi. Facies Jualet brjus gene* ris elle.

\section{$H E X A G \Gamma N I A$. \\ BUTOMUS}

umbellatus. I. BUTOMUS. Fl. lapp. 159. Fl. Juec. 328. Roy. lugatb. 45. Hall. helv. 209.

Juncus floridus inajor. Bant. pin. 112.

Sedo aftinis Juncoides umbellata painttris. Morif. bift.

3. p. 458. S. I2. t. 5. f. 1 .

Gladiolus aquatilis. Doa. perizt. 600.

Habitat in Europa aquofis. 2 


\section{Claffis $X$.}

\section{E C A NDR I A}

\section{MONOGRNIA.}

\section{SUPHORAl}

1. SOPHORA foliis pinnatis. foliolis numerofis villofis alopecuroioblongis.

Sophora. Hurt. cliff. ijo.

Ervum orientale alopecuroides perenne, fructu longisfimo. Tournes. cor. 27 . Lill. clth. I $3^{\text {h. }}$

Glycyrahiza filiquis nodofis quafi articulatis. Buxb. cent. 3. P. 25. 6. 46

Hobitat in Gricute. 2

2. SOPHORA foliis pinnatis : foliolis numerofis fubro-tomentoja tundis.

Sophora comentofa, foliolis fubrotundis $F \%$ zeyl. 16$\}_{3}$ *

Indigophora loliis tomento is. Hort. cliff. 48,7 .

Colutea zeylanica argentea tota. Herm. lugdb. 169. $t$.

I71. Rai. bif. 1720 .

Hakitat in Zeylona. b

3. SOPFHORA foliis pinnatis, foliolis feptenis glabris. heptaphylla. Sophora glabra, foliolis repienis. Fl. $2 . \mathrm{eg} / .104$.

Fruticulus finenlis, fenna fylveftris tolio angultiore, nodola filiqua roftro longiore donata Pluk. amalth. उ8. t. 45 T. f. I0.?

Habitet in India. to

4. SOPHORA tolns ternatis feffilibus: foliolis lineari- Gerifoites. bus.

Geniitra africana, foliis galii. Old. afr. 3т.

Habitat ad Cap. b. Spei.

i. SOPHORA foliis tematis fubfeffilibus: foliolis fubro- tinctoria. tundis glabris.

Cytifus toliis fere feffilibus, calycibus bractea triplici auctis. Gron. virg. $\delta 2$.

Cytitus procumbens anericanus, fore luteo, ramofinimus, yui Anil luppeditat. Pluk. alm. I29.t. 86. $\mathrm{f}$. 2. Einret. 1. I. f. 3 .

Havirat in Barbados, Virginia.
A 33
6. $\mathrm{SO}$. 
Intanoides. 6. SOPHORA folifs ternatis petiolatis: foliolis ovalibus pilofis.

Snphora foliis ternatis, fpica verticillata. Amoen. acad. 2., i. 350 .

Hasitat in Cantînatca. G. Demidoff.

\section{ANA GYRIS.}

utida. r. ANAG YRIS. Cluf. bift. 1. p. 93. Anaryris foribus lateralibus. Rog. lagäb. 371. Anayyris foutda. Bauh. pin. 397. latutat in Italix, Sicilix, Hifpania montibus. 市

\section{CERCIS.}

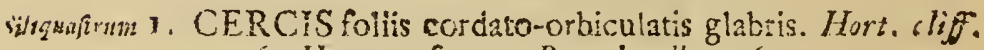
56. Hort. upf. 99. Roy. lugdb. 463.

Siliqua fylvettris retundioilia. Eaath. pin. 402 .

Arbor juda. Dod. pempt. 736 .

Iuleitat in Italia, Hifpania, Narbona, 5

«uratenfia a. CERCIS foliis cordatis pubelcentibus. Hort. cliff. 156. Hort. upf. 9\%: Roy. lsigdb. 463. Gron. visg. 47.2 Ceratia agreftis virginiana, tolio rotundo miliori. Kaja devár. 100.

Habitat in Virginia, $\$$

\section{BAUHINIA.}

fomtens. r. BAUHINIA caule cirrhifero.

Clematis indica, folio bifido, fore fructuque carens ar bores tranfcendens. Rai. Suppl. 328.

Naga-mu-valli. Rheed. mal. S. p. 57. t. 29.

Habitat in Malabaria. 5

arnleate. 3. BAUHINIA caule aculeato. Hort. cliff. 156. c.14. Roy. iugdib. $4 \sigma_{3}$.

Plumeria aculeata, folio rocundo \& emarginato. Plum. gen. 23.

Habitat in America calidiore. - 3

dicuricate. 3. BAUHINIA foliè ovatis: lobis divaricatis.

Bauhinia foliis quinquenerviis: laciniis acuminatis remotiffimis. Hort. cliff. I 56 . t. I5. Roy.lugdh. 464 . Habitat in Ametica. 5 .

wagutato, A. BAUIFINIA foliis ovatis: lobis parallelis.

Bauhiniafoliis ovatis oblongis recta liuea bifidis. Hor clitf. I57,

Hatitat in Aincrica. b

S. BAU. 
r. BAUHINIA foliis cordatis: lobis coadunatis obtulis. varicgata. Aibor 1. Thoma $\mathrm{C}$. Affitra. Zanon. biff. 26. t. I5. Choranna-mandaru. Rheed. mal. 1. p. 57.t.32. Raj. bift. $175^{1}$.

Habitat in Malabarix, Madera arenofis.

Corolle fatentes: Petalis ovatis, acutis, rofeis. luteo purrpureugze variegatis.

6. BAUHINIA foliis fubcordatis bipartitis rotundatis fub- purposecia. tus tomentolis.

Chovanna-mandaru. Rhced, mal. 1. p. 59. t. 33.

Habitat in Indix arenofis. is

Flores patentes, parpurafcentes: Petalis lanceolatis, diJiantibus.

\% BA UHINIA foliis cordatis: lobis femiorbiculatis to- tomentofn. mentofis.

Bauhinia folis cordato-fubrotundis: laciniis rotundatis.

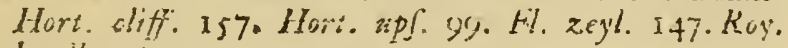
lugáb. 40i4.

Bauhinia folitis fubrotundis, flore flavefcente itriato. Burin. zeyl. 44. t. 18.

Mandara maderafpatenre, foliis frmioibus bifulcis glabritie Splendentibus. Pluk. alm. 240. t. 44. f. 6 .

Chatifchena-pon. Rleed. mal. I. $p .63 \cdot t .35$.

Habitat in India. 5

Corolla camepandata, albo flavefcentes: Petalisuboratis

8. BAU HINIA foliis ovatis: lobis acuminatis femiovatis. acambsata.

Bauninia incrmis, foliis cordatis femibifídis: Iaciniis a." cuminato-ovatis ereetis dehricentious. Hort. cliff. 157. Fl. $\approx 6 \%$. $14 \mathrm{~S}$.

Senne fpuria aur Afphaito affinis arbor filiquora, foliis bifidis. Sloan. jam. 150. bift. I. p. 5 I.

Veintta-manciru. Rheed. mal. I. p. GI. t. 34. Kaik bif. 1751 .

Halitat in Indiis. 5

Corolle campamulat.e, alba: Peitalis obtufi:.

\section{PARKINSONIA.}

1. PARKINSONIA. Hart. diff. 157.t.13. Hort.2pp. actleatn 99. Koy. lugdb. 465 .

Parkinfonia aculeati, foliis minutis uni coftx adnexis. Plis: . 20.7. 25.

Parkinfonia aculeata, foilis mimofe uni colta afuxis. Walth. bort. 6. t. 13 .

Habitat in Ancrica calidiore. b

CAS. 


\section{CASSIA. \\ * Semine.}

dipingila. 1. CASSIA foliis conjugatis, ltipulis cordato-lanceolatis Habitat in Indiia. $\odot$

Fr:stex Caule tereti. Folia conjug aùa $\int$ duso in petsolobre. zi, jemiorbiculata, obtufi, friata. Stipulice cordats. lanceolate, totos ramos obtes rentes.

46/us. 2. CASSIA foliolis bijugatis ovatis. Fl. zey?. I53:

Senna quadrifolia, inliqua plana hirfuta, Hore aureo langw . neo, Burm. zeyl. $212 . t .97$.

Senna exigua maderafpatana tetraphylia filiquifera glabra thorum pediculis ad cxortum foliorum propendentibus. Pluk. olm. $34 \mathrm{~T}$ t. 60. $f \mathrm{~T}$.

Loto afinnis regytiaca. Bunb. pir. $3 j^{2}$

Hatitat in India, Aigypto. $\odot$

Tagera, 3. CASSIA foliolis bijugatis, ftipuis ciliatis.

Cabia $i$, Senna lpuria tetraphylla arborécens, filiquis tenubus longiftinis pendulis. Amm. berb. 6nj. 12.33 ? Tagera. Rbeed mol. 2. p. 103, t. 52? Kai. bift. I743? Habitat in lindia

Fruticulus pracumbens: Ramis filiformibus. Petiolibre. rilfimi; Folia quentenr femiorbiculata, Jenofa, ; rair aw exteriora majora. Stipula cordata $f$ cordato baracolitu, margin piloje.

Tora. A. CESSIA folivlis trijugatis ovatis: exterionibus majoribus; glaticula lobilata inter inferiora. Kuy. latilb. 468. i. zeyl. 152. Hor: upl. ICo.

Caflia humilis. fitiquis ionu greci. Plism. Jpec. is.

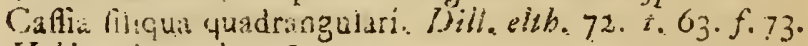
Habitat in unda. $\odot$

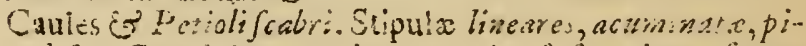
lofer. Glanduix acuminate, apice fufces, inter forgula paria 2 inferiora. nas vern ister catimum par fita.

bicapfularis, 5. C.ASSIA foliolis trijugatis obovatis glabris: interioribus rotundioribus minoribus: glandula interjecta globofr. Hart. cliff. I 59. Hort. upf. 100. Ryj. Iugdb.468. Cofia hexaphylla, filiqua bicapfulari. Plam. fpec. is. Hohitat in lidia.

Arbarefens cft. E'glaberrima. Folida interiorabrcuinra

smayzinata. 6. CA.SSIA foliolis trjjugatis ovatis roundatis emarginatis xqualibus. Hort. cliff. 559 . Roj. ligid6. 407. 
Caffa minor hexaphila fruticofa, Enna fuliss. Sloan. jam, 146. bift. 2. P. 44. t. I80. f. 1. 2. 3. 4. Raj. dinár. IIO.

Habitat in Caribxis. 5

7. CASSIA foliolis trijugatis oyatis obtufiufculis. obtufifolik.

Caftia fotida, foliis lenna italisx. Dill. elth. 71. t.62. f. 72 .

Cafita mine- herocice plerumque hexaphylla, folio obtufo. Joan. jain. I 4s. hijt. 2. D. 47. t. ISo. f. F.? Hebitat in Cubs.

8. CASSIA foliolis trijugatis quadrijugatisque fubovatus. Senra. liort. cliff. $15 \%$. lilut. med. 200. Koy. lugdb. 468.

Semna Alcxandrina 1. foliis acutis. Baub. pin. 397. Morif. heji. 2. p. 201. S. 2. t. 24. f. i.

C. Senna italica f. foltis obtulis. Baub pin. 397. Morifo bilt. 2. p. 200 . f. 2. t. 24. f. 2 .

Serilia. Dod. pempt. 36 I.

Habitat in Egypro. $\odot$

9. CASSI A toliolis quadriyugatis ovi.to-lanceolatis retro- fatcata. facatis: glandula baleos petiolorum. Hort. cliff. 159.*

Habitat in A merica. $\odot$

10. CASSIA Doliolis quinqucjugatis ovato-lanceolatis occidentalis. margine feabris: exterioribus majurious; glandula baleos petiolorum.

Cafia foliolis quatuor parium ovato-lanceclatic, glandula bafeos petioiorum. Hurt. ciaff. 159. Roy. lagkb. 467.

Senna uccidentalis, ouore opii virofo, orobi panuorici fo!: : mucronatis, glabra. Corrm, bort. 1. $p$ 5I. t. 26.

Habitat in Jamica.

Laulis $\int$ : quinecali, functis raris fcaber, exaratus deor fan "ingulo petiolo fulcis duobus. Folia fuperiora Folivlis yuinauet urium, orato lanceolatis, glabris waurgine fcabris, acuminatis, exterioribus fenfin majoribus, foetidis. Raccmus terminalis. Floies lutei absque macz!!a.

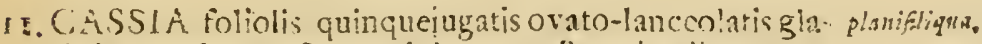
bris, glandula bafeos petiolorum. Roy. lagdb. 40 .

Caflia tilicuis planis. Plum. fper. I8.

Latitat in America calidore.

12. CA's $1 \mathrm{~A}$ foliolis quinquejugatis ovatis acuminaris fintus. glabili, petiolis eglandulofis. Fl. zeyi. 1.19. Alsi. mea. 1 g.

A 25

Caระ 
Cafia foliolis quinoue parium lanceolatis: extinis minoribus. Hort. ifff. is 8 .

Cartia fitula alexandina. Banh. pin. 405 . Comm bort. I. P. $215 . t$. 130 .

Conna. Rhecd. mal. x. p. 37. t. 2I.

Habitat in India, Egypto.

mryta. I3. CASSIA foliolis fexjugatis ovatis acuminatis lanatis. Hort. cilf. 159. Roy. lugdb. 467 .

Caflia americana ferida, folis amplioribus villotis. Toarzzef. is/t. 619.

Senna occidentaiis, odore opii virofo, foliis orobi pannonici mucronatis hirlutis. Hesm. lugdb. 556.

Hubbitat in America.

ligufriva. 24. CASSIA foliolis repremjugatis lanceolatis: extimis minotibus, glandula bafeos petiolorum. Hort. cliff. 120. Hort. ipf. 100. Gron wirg. 47. Roy.lugdi.467.

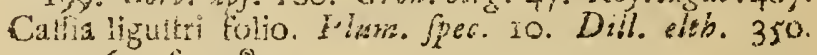
t. $269 . f .33 \%$.

Caffia bahamenfis, pimis foliorum mucronatis anguftis, calyce foris noul reflexo. Mart. cent. 21. t. 21.

Habitat in Virginia, Bahama. Z

4hta. I5. CASSIA foliolis ofojugatis ovali-oblongis: interioribus minoribus, perioiis eglandulotis, ftipulis patulis.

Iurt rliff. I58. Hort, apf. 100. Roy. ligkib. 467.

Cafia fylveftris foetida, filiquis alatis. Pium. spec. 18. Faba dulcis. Mer. furin. 58.t. 58 .

Habitat is America calidiore. $b$

mavilandicu. 16. CASSI A foliolis oftojugatis ovato-oblongis xqualibus, glanduia bafeos petiolorum. Hort. cliff". ${ }_{59}$. flort. apf. 100. Roy. lugadb. $46 \%$.

Caffia mimofx foliis, filiçua hirfuta. Dill elth. 35 r. $t$. 260. $f .339$.

Cafiz mariandica, piunis folionm oblongis, calyce Horis reflexo. Mart cemt. 23. t. 23 .

Hobitat in Virginia, Marilandia. $k$

kifera. $\quad$ 7. CASSIA foliolis ofojugatis ovaiibus emarginatis, glandula mucronata inter intin!a. Hort. cliff. 5 59.

Habitat in Indis. b

ienxifroms, 18. CASSIA foliolis novemjugatis oblongis, glandula fubulata inter infima. Roy. lagdb. 478 . 
Scrma fpuria frutefcons, liliquis tenuifimis. $\operatorname{Han} \hat{f} \mathrm{~m} g$ : Mlabitat in Havana. o

9. CASSIA foliolis decemjugatis lanceolatis, glanduia Sopacra, bafeos oblonga. Fl. zeyl. I ro."

Scnua vigintifolia, filiquis tetetibus. Burm. zeyl. 2 I $_{3}$. 4. 98 .

Ponnam-Tongera. Rbeed. mal. 2. p. Iar. t. 52. Habitat in India.

16. CASSIA foliolis duodecim-jugatis obtufis acumine, wriculati. glandulis fubulatis pluribus, Alipulis renifünibus barbatis. Fl. zeyl. 151. *

Senina fpuria maderafpataria, caule ad foliorum alas geminatis fubrotundis appendiculis auriculato. Pluk.aim 34I.t. 3I4.f. 4. Raj. dends. 110.

Habitat in India.

25. CASSIA follolis duodecim jugatis oblongis obtufis invanisa, giabris, giandula rulla.

Cäfia fiftula javanicil, flore carneo. Commo hart. $1 . \dot{y}$. 2:7. $t$. III.

Habitat in India.

Flores mibi nos protialit.

* Chamreriftx foliolis numerofis.

22. CASSIA foliolis multijugatis, giandula petioii pedi- Cinamecrifta cellata, ftipulis enfiformibus. Hort. upf. IOI.

Cafia fuliolis plurimum parium linearibus, itipulis finbuiatis. Hort. cliff. $15^{-8}$. Gron. virg. 47.

Chamacritta paronis major. Camm. bort. 1. p. 53.t. 37.

CliamarChrifta pavonis ame:icana, filiqua multiplici. Breyn. cent. 64, t. 24.

Habitat in Jamaici, Larbados, Virginia. $\odot$

Fuliolit 20; Pedunceilss fontio Jupra petiolume egrediens.

43. CASSIA fol:olis multijugatis thearibus: glandria ba- minafoter. feos petiolorum obfoleta, ftipulis fetaceis. Fl. zoyl. I54.

Habitat in Zeylona.

Petioli absque glanduia. Caulis non fexrofors. Sipula lanceolatio, feta terminatis.

24. CASSIA foliolis multijugatis, fipulis dimidiato-cor-fexte/s. datis.

Scuna fipuria occidentatis, filigua fingulari, foliis herbx 
mimorx. Herm. lugab. 558. Sloun. jan. 150. Raj juppl. 18.

Chamecrita pavonis brafiliana, filiqua fingulari Breyn. cent. 65. t. 23.

Habitat in Brafilia. $\odot$

mititans. 25. CASSIA foliolis multikgatis, fioribus pentandris.

Callia calycibus acutis, Horibus pentaindris. Wurt. cliff $49 \%$. i. 36. Hori. ups. 101 .

Scnisa fpuria virginiana, mimofa foliis, Horibus parvis nicticantibus. Pluk. alm. $34 \mathrm{I}, t .3 \mathrm{I}+\mathrm{f} . \mathrm{f} \cdot 3$.

Lrivitat in Virginia. $\odot$

procmbens. 26. CASSIA foliis multijugatis, caule procumbente.

Caffa amcricana procumbens heibacce, mimofe foliis, forious parvis, tiliquis anguttis planis. Comm. $\mathrm{fe}^{-}$ trop. $t$. il.

Habitat in Indiis. $\odot$

\section{POINCIANA.}

pulcharima I. POINCIANA aculeis geminis. Hort. "pr. 101. Poinciana foliis duplicato-pinnatis: foliolis oblongo-o vatis, caule incrmi. Hort. cliff. $1,5.3 \%$ zeyl. 159. Koy. insedb. Iro.

Frutex pavoisinus, Crita pavonis. Brenn. cent. 6r.t. Flos pavonis. Ner. Sur. $45 . t .45$.

T'icti-mandaru. Rheed. mal. 6. p. I. t. I.

Mabitat in indiis. $t$,

\section{CAESLPINIA.}

brafilienfis. I. CAESALPINIA foliolis obovatis integerrimis. Iñat. incd. 205.

Catalpina polyphylla aculcis horrida. Plum.gen. 26. PSeupo-Santalum croccum. Sloan. jam. 2r3. bift. 2. p. 184. t. 132. f. 34. Raj. dendr. I32. Catesb. car. 2. p. $51 . t .51$.

Halitat in Jamaic $x$, Carolinx collibus. 5

Crils. 2. CASALPINIA foliis ovatis integerrimis.

Cafalpinia aculeis tecurvis, foliolis ovatis. $F l$. zeyl. [17. * Hort. app. 102 .

Acacia gloriofa, lentici folio, foinofa, flore fpicato luteo, filiqua magna. Pluk. alm. 4. t. 2. f. 2 .

Chrina pavonis, glycyrrhica folio, ninor repens fpi- 
nofistima, fore luteo fpicato minino, filiqua latisfima echinata. Ereyn. ic. 58. t. 28

Hanitat in Zeylona. b

3. CASALPINIA foliolis emanginatis, filamentis lana-Sappan. tis. Fl. zey\%. 258. * Mak. med, 203 .

Lipno bratilano fimile. Bazk. pin. 393.

Tliampangam. Rbed. mal. 6.p. 3. t.2.

Halitat in Indiis. D

4. CFSALPINIA foliolis cmarginatis, leguminibus lul-veficana. catis ovalibus

Ciclalpina. Amm. berb. (104.

Swma fpuria arbore fpinoti, foliis alatis ramolis f. decompolitis, fore lnce, tiliquis bievibus fulcatis nigris, fatinz odore. Slawn. jam. 149. bilt. 2. p. 150. t. 131. f. 12. Rai. desir. III.

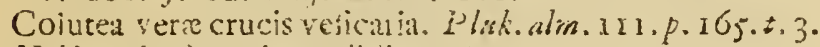
Habitat in America calidiore, b

\section{GUILANDINA.}

1. GUILANDINA aculcata, foliolis ovalibus acumina-Bondkc. tis. Fl. $\approx 0 \%$ 1 5 -6. Hort. upl. IOI

Guilandina caule truetuque aculeatis. Hort. cliff. Ifs.

Bonduc vilgare minus polyphyilum. fium. gen. 25.

Arbor exrtica fpimnia, folis lentilci. Baun. pin. 399.

Carerti. Kheed. mal. 6. p. 35. t. 22.

Habitat in Indias. o

2. GUILANDINA inermis, foliis fuboipinnatis: foliolis Moringa. interioribus ternatis. Fl. zeyl. 15). Wat. insed. 202.

Lignum peregrinum aquan cormlam leddens. Bash. pin. 41 \%.

Moringha zevlanica, foliorum pinnis pinnatis, fore majore, fruetu angulóo. Barm. zey. $162 . t .75$.

Morungu Rheed. inul. 6. p. 19. t. -

Habitat in Zeylona. I

Semina ex Afia tribus membranis longitudinaliter abuta fuere, ex Ajrica wero meinbranis his darachi.

3. GUILANDINA inermis, folits bipinnatis: bufiapice- dioisa. que limpliciter pinuatis. Gen. piant. 2. p. jis.

Hulitat in Callaula. 5

$$
\text { GUAJACUM. }
$$

i. GUAJACUM follolis bijugatis obntis.

Gua- officitale. 
Guajacum foliis pinnatis: foliolis quaternis obtufis. Hort. cilf: 18\%. Mat. med. 20\%.

Guajactm fore carulco, fruetu fubrocundo. Plkm gen. 39.

Guajacum jamaicule, folis velut muria conditis fpiffius virentibus, torc fubceruleo. Plak alm. ISo. t. 35. $f .4 \cdot$

Guajacum magna matrice. Baub. pin. 448.

Pruno vel Evonymo affinis arbor, folio alato bureo fubroturdo. Sloan. jam. 156. bift. 2. p. 133.t. 222. f. 3.4 .5 .6 .

Arbor ligni Sandi vel Guajacum, Seb. thef. $1 . p .86$. t. 53. . . 2.

3. Guajacum iamaicenfe, lentici fubrotundis follis late rirentibus, flore albo. $\hat{k} / 4 \dot{k}$. alim. $180.6 \cdot 35 \cdot \hat{j} \cdot \hat{\jmath}$.

Habitat is Ifipaniolia, jamaica. s

jonrtant.

2. GUAJACUM foliolis multijugatis obtulis.

Guajacum folis pinnatis, follolis obvereoratis integer* inis. Koy. lnged 208.

Gualacum llore carnleo fimbrato, frudu teragono. plum.gzn. 39 .

Guajacum propemodum line matrice, Banis. pin. 44 s. Infminum valgo nmericanum 1. Euouy noafinis occidentalis, alatis rufci foliis, nucifcra, cortice adgenicula fungoio. Plut. alm. 139. t. 94. f. 4.

Habitat in Americes infuia f. Foharnis de Porto Riceo.

afrum, 3. CUAJACUM foliolis multigugatis acntis.

Guilandinoides. Hort. cilff. $489 \%$

Acacia Africans, qux Acacia timiis, folits myrti parvis aculeatis pinnatis, fore coccinco tetapetaloide. If altb. bor: 2. $t .2$.

A fir arbor acacia fimilis, folins myriaculeatis folendcn ribus. Busts. legrdb. 2. p. 57 .

Kabiatat in Ethiopar. b

\section{CYNOMETRA}

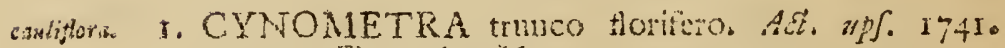
p. $99 . F \%=20 \% .166$.

Cynomorim. Rampf. notit: $1 . p \cdot 16_{3}, \ldots .62$. Habitat in India. 5

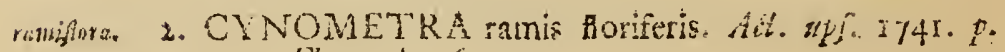
7\%. $47.25 y \% .167$. 
Cynomorium fylvatre. Rasipf. astob. 1. p. $164 \cdot 2.53$. Iripa. Rbeed. mal. 4. p. 65. t. 31 .

Halitat in Intia. o

\section{ANACARDIUM.}

1. ANACARDYUM. Hart. cliff. 16r. Fl. zeyl. I6r.acsidentale. Mat. med. 206. Hort. ups. 102. Roy. lugdb. 463. Anacardii alia f́pecies. Bant. pins. yz.

Pomifera f. porius Prunitua indica, nuce reniformi. Ciatesb. car. 3. p. 9. \pm 9.

Acaiou. Pif bras. 58. mant. 193.

Calchou. Mer. jorin. I6. t. 16.

Kapa-mava. Reced. mal. 3. p. 65. 2.54.

Hoslituti in Indis. $b$

\section{DIC'TAMNUS.}

1. DICTAMNUS. Hort. cliff. IGx. Hort. whf. 102, ahus

Mat. med. 208. Roy. luglb. 463. Sawv. monsp. 232.

Dictanulus albus vuigo Fraxinclla. Bawh. pir. 222.

Traxinclia Reneal. Spec. 122\%, to 22 .

Habitat in Germania, Gailia, Italia, 26

\section{JR UTA.}

1. RUTA foliis deconupoitis. Hors. chiff. 145. Hori.graveolens, spf. 102. Mat. Meti. zog. Roy. lugdb. $46 \%$.

Ruta fylveftris major. Bsstb. pin. $33^{6}$. Murif. bill. 2 . p. $507.5 .5 \cdot t \cdot 1+.5 .3$.

B. Ruta chalepenfis enuitolia, Horum petalis villis featenribus. Morif. bift. 2. $p$. 507.

Ruta hortenlis altcr: Bazb. pin. 336. Raj. hif. S74.

y. Rutit tortentis latiolia. Banh. fin. $33^{6}$.

Ruta gravcolens hortenfis. Dod. pempt. Iig.

d. Ruta hortentis latifolia arbalcula fimilis. Buerb. lugdb. r. $p \cdot 260$.

Ruta arrican: maxima. Scbuer. hort. 24.

Habitat in Europx aiftralis, Alcxandria, Mauritunix llerilibsus. b

Flos primarizes quinquefidus, rcliqui quadrifids. Pbil. Bot. I 78.

Confer: Ruta fylveftris minor. Bauh. pin. 33\%. Cam. montans. epit. 495 . Ruta montasia legitima. Cilsf. bift. $2 . p$. 136. app. alt. fir. ftratura castem, fincie diftiada. 


\section{8t DECANDKIA MONOGYINA.}

pasuvins. 2. RUTA folis ternatis fefilibes.

PlendoRuta paturind tritolia, forbus luteis umbellatis. Mich. geiz. 22. $t$. 19.

Habital prope Patavium.

fmirolit. 3. RUTA foliis fmplicibus iadivilis.

Ruta folits limplicibus tolitaris. Liort. cliff. I46.

Ruta fylveftris linitoliahifpanica. Iovec. mus. 2. p. 82

$\therefore 73$. Earr. ic. 1186.

Q. Ruca inontana, folits inlegris librotundis. Buxb. cent.

2. P. 30. t. $28 . t .2$.

$\gamma$. Rata orientalis, linarix fulio, fore parvo. Tourssef. cor.

19. Buxb. comt. 2. p. 30. t. 25. $f .1$.

Habitat in Hifpania; 2 . in Kodatro; $\gamma$. in Media. 2

\section{TOLUIFERA.}

Balfinuis. I. TOLUIEERA. ingtat. med. $20 \mathrm{r}$.

Ballamum Toluramum, folis ceitıx fimilibus. Baub pin. 401 .

Havitut in America prope Carthagenam. b

\section{HAMA TOXYLUM}

Campechiz- 3. HEMATOXYLUM. Iort. cliff. I fo. koy. ingdb. $\because: \mathrm{m}$.

hignum campechianum; fpecies quadam. Sloan. jam 273 . bif. 2. p. I83. th $10 \mathrm{f}$ 1.2. 3. 4. Cuatest cat?. j. p. 06. t. 66.

dabitut in Compeche Americes. 万

\section{ADENANTHERA.}

poroninis J. ADENANTHERA foliis decompolitis. Roy. lugáb. 402. Fir. cliff 36. Fl. z.e.l. I60. *

Poinciana folis duplicato-pinnatis: foliolis alternis. firt cliff. : 58 .

Muncliadi. Rbeed. mal. 6. p. 25. i. 14. Lidabitat in India. b

$$
\text { MEYIA. }
$$

Azcdurach, I. MEIJIA folijs bipinatis. Fl. $\approx c y /$. I 62 .

Meila foliis deconpulitis. Itort. Sliff. 16r. Rog, ingdh. 462.

Azedarach. Dod. pempt. 848 .

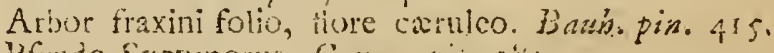

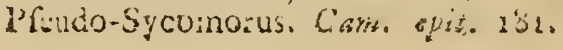


B. Azedarach fempurvirens \& forens. Tournef. inft. 616. ReinperviAzadirachta indica, foliis ramolis minoribus, fiore al- rens. bo lubcxruleo purpurafcente majore. Comm. bort. I. p. $147 . \pm .76$.

Habitat in Syria, G. in Zeylona. b

2. MELIA foliis pinnatis. Hort. cliff. 16 I. Fl zeyl. 161, * Azadiracbta Roy. lugde. 462 .

Olca malabarica, frasini folio. Pluk. alm. 269. t.247. $f: t$.

A.redarach foliis falcato-ferratis. Burn. zeyl. 40 t. I 5 . Azadirachta indica, tolio fraxini. Breyn. ic. 21. $t$. Is. Arbor indica, fraxino fimilis, olce fruetu. Baub. pin. 416.

Aria Bepou. Kheed. mal. 4. p. 107.t. 52.

Ilabstat in India. b

\section{ZYGOPHYLLUM.}

i. ZYGOPHYLLUM capfulis prifmatico-pentäedris. Fub.goo.

Hort. ups: ruz.

Zygophyllum foliis petiolatis. Hort. cliff. 160 . Roy. laxg 36.450.

Capparis portulaca folio. Baub. pir. $4^{80}$.

Capparis Fabago. Dod. fempt. $7+1$.

Habitat in Syria. 2

Folia ovata, fetivlata. Petala s,btufa.

2. 'ZYGOPHYLLUM capiularum angulis comprefro- Morgfanc. membranaceis.

Fabago triphylla \& tetraphylla, flore tetrapetalo, fructu nembranaceo quadrangulari. Burm. aft. 7. t. 3 f. 2 .

Frabago capenlis frutefccus major. Dill. elih. 142,t. II6. $f .141$.

Planta africana frutefcens, portulacx foliis, Murgani fyrorum, ex brevi pediculo binis. Pluk. amalth. 173 . t. $429 . f .4$.

Habitat in Mtthiopia. $b$

Folia ubverfe oucuta, petiolata; Peta! acata.

3. ZYGOPHYLLUM capfulis globoro-depreflis. fefilitulikn:

Zygophyllum foliis tesfilibus. Hort. cliff. 160 . Ray.
lugd 60.460 .

Fabagc, capenfis frutefens minor. Dill. eith. 142. t. 116. f. 342.

B b 
Fabago humilis quadrifolia glabra, flore albido, fructu rolundo. Burm. afr. 4, t. $2 . f$. I.

Fabago africana arborefcens, flore iulphureo, frualu rotundo. Conm. rar, 10. t. 10.

Habitat in 4 thiopia.

Folia juteffilia, oblonga. Petala crenata.

fulwam, 4. ZYGOPHYLLUM captulis ovatis acutis.

Fabago flore lureo, petalorum ungribus rubris, fruetn filcato acuto oblongo. Burm. afr. G.t. 3.f.I.

Habitat in Fiopia.

Folia Seffilia.

cocisesm, 5. ZYGOPHYLLUM caprilis cylindricis.

Fabago arabica teretifolia, flore coccinco. Shau afr. 23I.f. 23 I.

Habitat in Ehiopia.

Folia terctia.

Spi:nfum. 6. ZYGOPHYLLUM caule aculeato.

Fabago tenuifolia fpinofa, fruau rotundo. Burm. afr 5.t. 5 .

Habitat in Ethiopia. b

Folia linearici, acsita.

\section{FAGONTA.}

reves. FAGONIA fpinota, foliolis lanceolatis planis lavibus. Hort. $\operatorname{xp} \int .103$.

Fagonia fpinofa. Hort. cliff. 160.

Trifoliurn fpinofum creticum. Baub. pin. 330. proa'r. 142. Ciluf bift. 2. p. 24̧2.

Habitat in Creta. 0

wifmien. 2. FAGONIA inermis.

Fagonica hifpanica non fplnofia. Tourref. infth. 26.5. Habitut in Hifpania. Z

arabica.

3. FAGONIA fpinolia, toliolis linearibus convexis. Shaw. afr. 229.

Fagonia :Irabica, longifinisis acuicis armata. Sbaw. afr. 229. Hibitat in Arabia.

TRIBULUS.

maximus. "TRIBULUS foliolis quadrijugis: exterioribus majoribus.

Tribulus foliolis trium parium pinnatis. Liort. sliff. I60. 
Tribulus tereftris major, fiore maximo odorato. Sioun jern. 90, bift. 1. p. 209. t. 132.f. 1, Raj. Juppl.65O. hiabitat in Janaic ar arids. $\odot$

.TRIBULLIS foliolis quinquejugatis tubxqualibus. lankgivofin.

Tribulus foliolis quinque parium. F\%. zeyl. i 68 . "

'Tribulus terreftris zeylanicus, cauliculis villodis, fruetu acuminato. Burm. 2eyl. 226. t. 106. f. . .

Havirat in Zeylona.

3. TRIBULUS foliolis fexjugatis fubxqualibus. Horf. setrefti is. sliff: 160 . Hort. wf5. 103. Roy. lagdb. 460. Sawo. moinste. 227.

Tribulus terreftris, ciceris folio, fruetu aculeato. Bamb. pin. $2 ; 0$.

Tribulus terrettris. Lob. ic. 2. p. 84 .

Tribulus terrettris minor incanus hiffanicus. Barr.rar. r4. $\mathrm{A} . \operatorname{sr} 8$.

In ritat in Europa auftrili ad Sewitas.

4. TRIBULUS foliolis of ojugatis fubxqualibus.

Ciffoiric:

Tribulus foliis octo parium pinnatis. Ray. lug. 16.460.

Tribulus tertefris major curairavicus. Herm. putr. 236 . t. 236 .

Tribulus tereftris americamis, argemones Hore fiaro. Pluk. alin. 374. i. S4 Raj.Juppl. 64\%.

Hobitat in America calidiore.

\section{MONOTROPA.}

I. MONOTROPA Horibus lateralibus ociandris; termi- Hongepitisys. inali decandro. Fl. fuet. 320 . Phil. but. \$. 178 .

Orobanche qua Hypopithys dict potelt. Baub. pin.8S. prodr. 31 .

Orobanche Hypopithys lutea. Mentz.pug. 3.f.5.

Orobanche flore breviore duplici, verbarculi odore. HTorif. hifb. 3. p. r04. f. 12. t: IO f. f. 20.

Orobanche verbafculi udore, Plot. oxj 146.t.9. f.6. Plizk. alin. 273.t. 20n: f. 5 .

Habitat in Suecix, Germania, Anglia, Canad foltis. Parafitica radicuin.

2. MONOTROPA caule unifioro decandio.

sniffore

Micnotropa Hore nutante. Gron. virg. 41.

Orobanche monanthus virginiana, forc maiore pentapecalo. Morif. bift. 3. $P$ 502. f. 12. t. 16. fi 5. mal.

B b 2

Oro- 


\section{DECANDRIA MONOGYNIA.}

Orobanche virginiana, fore pentapecalo cernuc. Pluk. alm. 273.t.209. f. 2. Catesb. car. 1. p. 36.t.36.bon. Habitat in 'Marilandia, Virginia, Canada.

\section{JUSSI EA.}

sеренs. 1. JUSSI $E A$ repens, thoribus pentapetalis decandris, pedunculis folio longioribus. $\mathrm{Fl}$. $\approx 2 y \%$. 169.

Nir-Carambu. Kbeed. mal. 2. p.99. t. 51. Raj. bift. Isio.

Habitat in India.

perrtiuna. 2. JUSSIÆA ercen, floribus pentapetalis, pedunculis foliofis.

Onagra laurifolia, Hore amplo pentapetalo. Few. pe. rui. 7 i6. t. II.

Habitat in Lima.

Juffraticosa. 3. JUSSI EA ereeta villola, fincibus tetrapctalis odtandris pedunculatis.

Ludwigia capfulis oblongis uncilialibus. Roy. lugdb. $25^{2}$.

Lyfimachia indica non pappofa, Hore lutco minimo, filiquis caryophyllum aromaticum mulantibas. Herm. lugatb. 396.

Catambu. Rbeed. mal. 2.p. 55.t. 49. Raj. bift. I510. Habitat in India.

crecta, 4. JUSSIEA erecta glabra, floribus tetrapetalis o dris feffilibus. Fl. z.evl. 170. Hort. up/. 103.

Ludwigia capfulis oblongis. Hort. cliff 491 .

Lycimachia vifcofa glabra, parietariæ foliis, virginiana. Pluk. alm. 235. t. 203. f. 4 .

Jafminum catalonicum, flore luteo. Scb. thef. I. p. 42 . t. $24 . f .3$.

Habitat in America $\&$ forte in Virginia. $\odot$

\section{SCHINUS.}

4yricozdes. x. SCHINUS foliis fimplicibus lanceolatis finuatis.

Habitat is Ethiopia. $\hbar$

Frutex panicula diffusa, diffinftifremus a Myrica, снi fimillimus facie.

Malle. 2. SCHINUS foliis pinnatis: foliolis ferratis: imparilongiffimo, netiolo aqua!i.

Schinus folis ferratis impari longithno. Hort. cilff. $4^{8} 3$. Lenticus peruviana. Bakb. pin: 399. 


\section{DECANDRIA MONGGYNIA.}

Lentitcus africana. Seb. thef. 2. p. 7.t. 5. f. 5. Molle. Cluf. monurd. 32z. t. 322.

Habitat in Peru. b

3. SCHINUS foliis pinnatis, petiolo xquali, foliolis in-Areire. tcocrimis xylzalibus.

Nolle foliis nun ferratis. Few. perav. 3. p. 43. t. 30 Aroira. Pif: braf. 132.

Habitat in Brafilia, Peru. क

4. SCHINUS foliis pinuatis: foiiolis oblongis, petiolo mar- Fagaro. ginato articulato ine:rii. Mitt. med. 533 .

Lauro affinis, jnimini folio alato, cofta media nnembranulis ntringne extantibus alata, ligno duritie ferro vix cedens. Jlian. jarn. 137. bift. 2. p. 25. t. 662. f. ז. Raj. dcisdr. 86 .

Ilabitar in Jamaicx campeltribus. of

Confer Sco 1: Santio. Kempf: ariuen. 8g2.

5. SCHINUS folïs pinnatis, petiolo marginato articulato tragodes. futtus aculeato.

Śchinoides petiolis fubrus aculeatis. Hort. cliff. 489. * Rhoi obfoniorum fimilis leptophyllos tragodes americaria Spinota, rachi medio appendicibus avcto. Plak. aim 319. \%. 107. f. 4.?

Habitat in America o

6. SCHINUS follis pinnatis, pecicio marginato articula- Limenia.

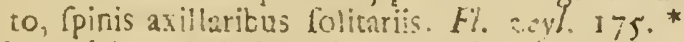

Malus Limonia indica, fructil pufrllo. Kaj bift. 1658. Tterou katou Naregam. Kkece. mna 4. t. - - - t. I2. Habitat in India "rraque. 5

\section{BAKTRAMIA.}

I. BARTRAMLA. Fl. ziyl. I74.

Triumlerta Xill. Amm. bert. 370 .

Lappula benghalendis tetrafpermos, ribefii folio, echinis orbicularibus ad toliorum ortum plurimis fimu! íeslilibus. Plak. alm. 206. i. $41 . f .5$.

Agrimonta madoraspatana, folio rotundo fingulari iubtus incrno. Pet. gatz. 3i. t. 42. f. 10.

Ilabisat in India. 5

\section{MELASTOMA.}

1. MELASTOMA foiliis denticulatis ovatis acutis. scinoden. Melanoma foliis ovato-lanceolatis crena is nervis quin- drom. $\mathrm{Bb} 3 \mathrm{a}$ que 
que longitudinalibus: extimis obfoletioribus. Hori. cliff. 162.

Acinodendrum americunum pentaneuron, foliis ciaffis hirfutis ad ambitum ratioribus ferris. Plak. mant it. $159 . f .1$.

Groffularia americana, piantaginis folio ampliftimo. l'ism. fier. 18.

Groffulariz fructu non fpinola, malabathri foliis longa \&. rufa lanugine hirfutis, frustu maiore cxruleo. S\% an. jam. Ió, hi/t. 2. p. 8\%. t. 197. f. 2.

Habitat in A merrica calidior to

Grofhtarist 2. MELASTOMA foliis denticulatis ovatis acuminatis: der. nervis interioribus ante bafin coaùunatis.

Groffularia alia plantaginis folio, fructu iariore violaceo. Plum. hilt mfs.

Arbor americana, latiori \& acuminato folio trinervio, utrinqueglabro \& margine leviter crenato. Plak. aims. 40. t. $249 . f$. 4. 1

Habizat in Surinamo. D. Bartfch.

berrar - AELASTOMA follis denticulatis lanceolatis quinguenervibus, caule hifpido.

Groffularia plantaginis folio anguftiore hirfuto. Pium. spec. I 8.

Arbufcula jamaicenfis quinquenervis, minutiflme dentatis tolis \& caule pubefcentibus, Pluk. alm. 40. $t$. 264. $f: x$.

Habitat in America meriafionali. 5

as!asercen, 4. MELASTOMA foilis integerrimis nvato-lanccoiatis fubtus fericeis; nervis ante bafin condunatis. Hort, cliff. 102.

Acinodendrum americanum, ampliore folio trinervi, inferius a!ba lanugine incano, maximo urrinque glabro. Pluk. mant. 4. t. 250. f. 2 .

Arbor racemosa brafiliana, folio ma/3hathri Breyr.tent. 3. 2.2 .4$.

Muiva. Marcgr. braf. I1\%.

Habitat in Brafilia, Jamaica, Surmamo. 5

matabatbi: F. MELASTOMA foliis lanceolato-ovatis quinquener$\therefore 0$. vibus fcabris. Fl. zeyl. 1 Y1.*

Mclaftoma quinquenervia hirta najor, capitulis fericeis villofis. Bistr. zeyl. $155 . t .73$

hadali. Rheed. ma! 4. t. 87, $t,\{2$.

Hobitat in India. 5 . 
6. MELASTOMA foliis lanccolatis trinervibus fea-njera. bris. At zcyl: 172.

Katcu-Kadali, Rbeed, inal, 4. p. 9x, 4. 43. Raj. bill r 403 .

Habitat in India. 5

7. MELASTOMA toliis ovatis trincrvibus glabris margi- orlonsen, ne hilpidis, Fl. zeyl, 173.

tiabitat in India. b

\section{KALMLA.}

3. KALMIA foliis oratis, corymbis terminalibus. Gex. tatifolin. nov. 1079. *

Andromeda foliis ovatis obrufis, ccrollis corymbofis inturdibuliformibus, genitalibus declinatis. Gron. ¿irg. róo.

Chamx Daphne foliis tini, floribus bullatis. Catesb. cor 2. \$. 5). .09 .

Ciflus ChamaRhododendros mariana laurifolia, floribus cxpanfis fummo ramulo in umbilan plurimis Plak alm. 49. 6. 319 f: 6 .

Jabiar in Marilandia, Virginia, Penfyivania. 5

2. KALMiA folis inceolatis, corymbis latcralibus sugumfolio Gen. now. 1079. "

Azalea folis lancenlatis integerrimis non nervofis gla. bris, corymbis terminalibus. Gron, virg. 21 .

Chama Daphne rempervirus, folis oblongis anguftis, foliorum falcienlis oppofiris Catesb. car. $3 \cdot p \cdot 17 . t$. 17. f. I.

Cittus fempervirens laurifolia, foribus eleganter bulla. tis. Pluk. alm. 106. t. x61. f. 3 .

Anonyma. Ciadd. noveb. 100.

Habict an Penlylvania, Nova Cxfarea, Noveboraeo.

\section{LEDUM.}

1. LEDUM. Fl. lapp. 160.

Ledum folis linearibus fubtus nirfutis, noribus corym. bofis. 1\%. fues. 341. Mnt. med. 210

Ciltus Ledon foliis solmarini ferrugineis. Bauh. pin. 467.

Rolmatinum fylve:re. Cam. epit. 540.

Habitat in Europæ Septontrionalis paladibas uligino fis. 


\section{RHODODFNDRON.}

ferruginewm I. RHODODF $\triangle$ D RON foliis glabris fubtus leprotis, corollis intundibuliformitus.

Azalea maculis ferruginejs fubtus adfpeefa, floribus derandris. Lemonier. Saut. monff. 57 .

Ledum foliis giabris, finre tubulofo. Hall. belv. 417. Ledum alpinum, foliis ferrea rubigine nigricantibus. Bauh. pir. 468. Raj. hift. 1005.

Evonymus theophrafti. Dalech. biff. 27.

Monrana aliobrogum lentifcifolia. Lob. ic. 366 .

Habitat in Alpibus Helveticis, Allobrogicis, Yyrenæis. 5

datricyms. 2. RIODODENDRON folis glabris atrinque nudis, corollis rotatis.

Chamerhododeildros folio glabro majufculo, amplo fore roleo. Amm. ruth. I81. $t .21$.

Hellitat in Dauria.

hirfutturn 3. RHODODENDRON foliis ciliatis nudis, corollis infundibuliformibus.

Ledum follis glabris ciliatis ovatis, fiore tubulofo. Hall. belv. 418 .

Ledum alpinum hirfutum. Baub. pin. $4 c ́ \delta$. Raj. bift. 1005 .

Ledum aipinum. Cluf. bift. r. p. 82.

Balfamum alpinum. Lob. ic. 468.

Habitat in Alpibas Helveticis, Auftriacis, Styriacis, B

Clsim,ecifus 4. RHODODENDRON foliis ciliatis, corollis rotatis Ledum foliis ferpylli ad margines cilii inftar pilofis, Hore purpureo. Mich. gen. 225 . t. io6.

CharnaCiftus hirfuta. Baub, pin. 466.

ChamaCittus VIII. Cluf. hift. 1. p. 76.

Ciftus pumilus montis baldl. Barb. bifz. 2, p. 19. Raj. bift. 1005 .

Ciltus Chamerhododendros foliis confertis ferrea rubigine nitentibus niargine pilolis. Pink, alma, 106, $t$. 23. $f: 4$.

Habitat in Baldo ev prope Salisburgume t

ल*imun. 5. KHODODENDRON folis nitidis ovalibus margi ne acuto reflexo.

Lcoum laurocerati folio. Amon, arad. 2. p. 200.

Chamærhododendros, lauri polio, Tempervirens, floribus bullatis corymbolis. Catesb. car. 3.P. 17,t.17.f.2

llabitat in Virginia. Collingon b

Rami 
Rami EO Folia maynitudine Ẽ confiftentia Padi Laurocerafi dict, ienis reticulatis inforipta, marginereflexa.

\section{ANDROMEDA.}

1. ANDROMEDA pedunculis folitariis lateralibus, co- terragona rollis campanulatis, foliis oppolitis imbricatis obtutis revolutis.

Andromedi foliis quadrifariam imbricatis obtais. Fl. füre. 33 .

Andromeda, foliis quadrifariam imbricatis obtufis, ta.lis floreus. Fl. lapp. 166. t. 1. f. 4. Hort. cliff. 163 .

Habitat in Alpihus Lapponicis. 2

2. ANDROMEDA pedunculis folitariis terminalibus, hyptcon's corollis caupanulatis, foliis confertis fubulatis.

Andromeda follis aciformibus confertis. $F l$. lapp. $I \sigma_{j}$. t. I. f. 3. Fl. Suec. 337.

Habitat in Alpibus Lapponicis. 2

3. ANDROMEDA pedunculis aggregatis, corollis ova- carled. is, foliis fpartis linearibas obtutis pianis.

Andromeda foliis linearibus obiufis fparlis. Fl. lapp. 165. t. 1. f. 5. Fl. suec. 336. Hork. cliff. 163.

Erica folio abietis, fiore arbliti, Buxb. cesst. 4. $p \cdot 26$. t. 53 .

Havitat in Lapponix Alpibus. th

4. ANDROMEDA peduneulis aggregatis, corollis cy marisu, lindricis, foliis alternus ovatis integerrimis.

Audromeda toliis ovatis, pedunculis fafciculatis, capfulis pentagonis apice dehifcentibus. Gron. virs. 49.

Arbufcula mariana, bevioribus evonymi folits pallicic virentibus, floribus arbuteis ex eodem nodo plurimis, fpicatim uno verfu erumpentibus. Pluk, mant. 25.t. $44^{8}$.

Hahitat in Virginia. 5

5. ANDROMEDA pedurculis aggregatis, corcllis ova- Polifolio. tis, joliis alternis lanceolatis revolutis.

Androineda foliis alternis lancecolatis margine reflexis.

F\%. lapp. 163. t. 1. $\int .3 . \mathrm{Fl} . \int \mathrm{sec}$. 335. Hort. cliff. 16. Roy. lugdb. 440 . Hail. belw. 416.

Polifolia. Buxb. aft. 2. p. 345. cent. 5.p.28.t.49. S. $t$.

Erica humilis, rofmarini foliis, unedonis fore, capfula ciltoidc. Pluk. alm. 136. 2. 1 75 . f. 3.

Ilaveat in Europa frigidiuris paludibus iurfojis. b $\begin{array}{ll}1365 & \text { 6. AN. }\end{array}$ 
panicu'ate. 6. ANDROMEDA racennis recundis nudis paniculatis: corollis fubcvindricis, foilis aiternis oblongis crenulatis.

Andromeda folis ovatis acutiscrenulatis planis alternis, floribus racemolis. Hurt cliff 162. Gran. virg. 45 . Frutex foliis terratis, floribus forgioribus fpicatis fuo. vilidibus, fica pentagona. Catesb. car. 2a, $p, 43 \cdot x \cdot 43$ -

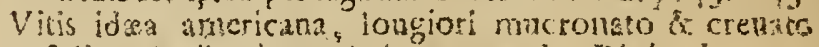
foljo, foribus urceolatis racemoliș. Fluk. alm 39 . Habitat is Virgunia,

caemasa. 7. ANDROMEDA racemis fecrndis bratestis, corol. lis gitbo-cylindricis, foliis altermis oblongis ferstis Jubutat in Penfiglonia. Kalm.

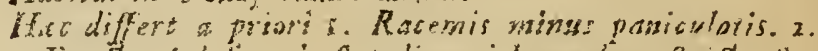

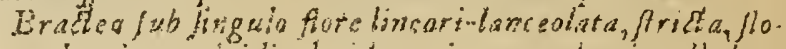
re longione, zigidi, decitas; in yescedents nullabra

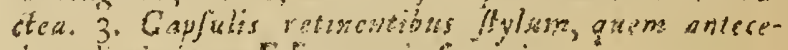
dens dimitite. Fobirs magis ferratis.

atorea, 8 ANDROMEDA racemis fecundis nudis, corollis ro. tundo-ovacis.

Andiomeda arbore, folis oblongo-ovatis integerrimis, Alorbus panicalatis rutantibus : racents limplicillimis. Gron. rirg. 48 .

Frutex foliis oblongis acuminatis, floribus ficatis uno verfu difpofitis. Catesh. car. 1.p.71. 3. 7r.

Habitat in Virginia, Carolina. b

colyculrtin 7. ANDROMTDA racemis lecundis foliaccis, corollis fubcylindricis, floribas alterniz lanceolatis obrufis punetatis.

Ciftus Ledon f. Andromeda, foribus monoperalis par. vis abbis tubulofis fpicatim in Cutrinis ramulis dispoftis "folits \& facie vitis idxa, caplula minima fic. ca quiriguepratita. Cron. vig. 2i. $\overrightarrow{3}$

Chand Daphne. Buxb. act I. P. 24t.t. 8. f. x.

Hatian in Virginia, Canada, Sibiria b

Frutex folic utiali-lanceolatis, coriacois, myrica consiflentia, ublufis, margizse recusurvis, adfperfis bunktis our confoirusis, sallofis, ab utraquc parie. Racemiex ramis propriis, foliolis ovolibus altersis, in quorum ala Fias folitariss, pedicellatus. Calyx a baft tegitur duotus foliolis oriatis. Flores ad unum latus nutant. Stamina 10, antharis ablongis. 


\section{EPIG EA.}

1. EPIG IAA. Gen. nav. I087.

repens.

Memecylum, Mich. gen. 13.

Arbutus foiiis ovatis integris, petiolis laxis longltudino

foliorum. Gron. virg. 49.

Pyrolx affinis repens fruticofa, foliis rigidis feabritic exafperatis, flore pentaperaloide fiftuloro, Plak. alm. 309. t. 107. f. $\mathrm{t}$.

Fabisat in Virginix, Canadie ponetis. 5

\section{GAULTHERIA.}

1. GAULTHERIA. Kaim. Gen. nov. 1080, f.6. trexmben. Anunyma pedunculis arcuatis. Cold. noveb. 98.

Habitas in Camada fterilibus arenojts.

\section{ARBUTUS.}

1. ARBUTUS caule ereeto, folits giadris ferratis, bac-Unedo. cis polyfpermis. Hort. Gliff. 163. Roy. lagdls 40 Sarr. monfp. $5 y$.

Arbutus folio Ferrato. Eash. pin. 460.

Aibutus. Cam. epit. 168.

Mabitat in Europa adftrali. o

Baccæ pohjpernat tuberculis feminuin exapperata.

2. ARBUTUS caulbus procumbentibus. foliis ovatis fub-acadenfin

irratis, foribus fartis, baccis polyfpermis.

Vitis idxa acadienfis, tuliis alaterni. Tournefinft.

Habitat in Acadia. b

3. ARBUTUS caulis procumbentibus, foliis rugrolis fer-atain.

ratis. Fl. lapp. 161. Fl. Swer. 340 Hort. sliff. 163

Roy. Ingub. 440. 11all. hela. 4 is.

Vitis idxa follis oblongis albicamtibus. Banb. pin. $47 \%$.

Vitis idxa. Cinf. bin. 1. Gi.

- Iabitat in Alpibus Lipponix, Helvetix. Sibiria b

4. ARBUT'US caulibus procumbentibus, foliis inceger $v u a$ wyi, rimis. Fl. lapp. 162 t. 6. f. 3. Fl. Juec. $33 \%$. N1 at sined. 211 . Rlart. cliff, 163. Roy. lagdb. Aso. Mall beli. 415 .

Uva urfi. Clusf. Bijt. 1. p. 63.

Radix idara putata \& Uva urf. Bash. hiff. 1.p. 524. Arbutus noveboraceutibus Bearberry. Culd nois. 104. Habitat in Europa frigida, Canada. s 


\section{CLETHRA,}

aluifolin 1. CLETHRA. Gron. virg. 47. Alnifolia americana ferrata, floribus pentapetalis albis in fpicam difpolitis. Pink.alm.18.t.115.f.1. Catesb. car. 1. p. 66. t. 66.

Habizat in Carolina, Virginia, Penfylvania. 5

\section{PYROLA.}

voisndifolit 1. PYROLA ftaminibus adfcendentibus, piftillo declinato. Fl. Juec. 330. Mat. med. 212. Amen. acad. 1. p. 156 .

Pyrola laminibus \& piftillis declinatis. Fl. lapp. I69. Pyrola foliis integerrimis. Vir. cliff. 37. Roy. lugdb. 440.

Pyrola foliis fubrotundis, feapo racemolo. Hort. cliff 162.

Pyrola rotundifolia major. Bauh. pin. 191.

Pyrola noveboracenfis. Cold noveb. 99.

Habitat in Europa Septentrionaliore, Virginia, Brafilia. 4

mnot: 2. PYROLA Horibus racemolis difperfis, ftaminibus piPtillisque reetis. It. gotl. 206 . Fl. $\int$ uec. 331 .

Pyrola foliis fubrotundis, fcapo undique racemofo, genitalibus rectis. ACt. Fockih: $1741, p .192$.

Pyrola foliis ohirer ferratis iubrotundis racemofis, flor:bus tuba reeta. Hall. helv. 420.

Pyrola minor. Riv. pent. 149. Raj. angl. $3 \cdot p \cdot 363$. Habitat is Europa frigidiore. $z$

jecunda 3. PYROLA racemo unilaterali. Fl. $\int$ uec. 332.

Pyrola tloribus uno verfu fparfis. Fl. lapp. I68.

Pyrola folio inucronato terrato. Bash. pin. I81.

Pyrola 2 tenerior. Cluf. pair. sob.

Hatitut in Enropx borealis $\int y$ lvis.

mbilata. 4. PYROLA pedunculis fubumbeliatis. Ft. Swec. 333:

Pyrola frutefcens, arbuti flore. Baub. pin. I91.

Pyrola 3 fruticans. Claf. pan. 507.

Habitat in Euroqx, Afix \& Americx feptentrionalis sylvis. 5

macklats. 5. PYROLA pedanculis bifloris.

Pyrola periolis zpice bifluris vel trifloris Gron. virg. 48 . Pyrola marilandica minor, folio mucrenato arbuti. $P$ et muf. 675. 
Pyrola mariana, arbuti foliis anguftioribus, trifoliata ad medium nervium linea alba utrinque per longitudinem difcurrente. Nluk. want. 157. t. $340 . f_{0} 4$.

Habitat in Americx feptentrionalis fylvis. b

6. PYROLA fcapo unifloro. Fl. lapp. 167. H. Suec. 334. wniflera, Hall. belv. 420.

Pyrola roturdifolia minor. Bauh. pin. 191.

Singulari flore ampliore. Morif. bift. 3. p. 505. f. 12. t. 10. $f: 2$.

Habitat in Europa borealis Jyluis, 2.

\section{DIGTNIA.}

\section{ROYENA.}

2. ROYENA foliis ovatis fcabriulculis. Hort. cliff: 149 . tusida. Kis. lugilb. 411 .

Staphylodendron africanum fempervirens, foliis fplendentibus. I. p. $187 . t .96$.

Staphylodendrum africantm, folio fingulari iucido. llerm. parad 232. t. 232 .

Piftacia africana. Pluk. alm, 298. t. 63.f. 4. t. $317 . f \cdot 5$. Heititat ad Cap. ¿. Spei. 5

2. ROYENA foliis lanceolatis giabris. Roy. prodr. 44I. glabra.

Royena foliis lanceolatis. Ifort. cliff. I 49 .

Vitis idæa æthiopica, buxi minoris folio, Horibus albis. Comm. hort. 1. p. $12,5, t .65$.

$V$ itis idxa $x$ thiopica, inyrti foliis, folculis dependentibus. Pluk. alm. 391. t. 321 . f. 4 .

Habitat ad Cap. b. Spei. $b$

3. ROYENA foliis lanceulatis hirfutis. Roy. lugdb. 44 r. birfuta.

Arbutus foliis lanceolatis integerrimis hirfutis. Hurt. cliff. 163.

Staphylodendrum africanum, folio lanuginofo rofmarini latiore. Boerb. lugdb. 2. p. 235 .

Habitat ad Cap. b. Spei. b

\section{HYDRANGEA.}

1. HYDRANGEA. Gron. virg. 50. $\uparrow$

Habitat in Vireinia. b

Frutcx ex ordise Aroufizarum XIX, folis oppotitis, floribus in unanbaigefis. 
Folia duplici ordine punctorsm callojorum nolata evadunt albida.

hurferiana. э. SAXIFRAGA foliis aggregatis imbricatis fubulatis la:vibus, caule fubnudo unifioro.

Sedum alpinum, faxitragi albx flore. Bash, jin. 284. Burf. XVI: 6.

Habitat in Tauro, Raftadiendi, $z$

Fucies Sedi mimoris. Folia jzmaperina, denfe imbricata, acuta, carinata, glabra. Caulis wis digutialis, rafejcen.

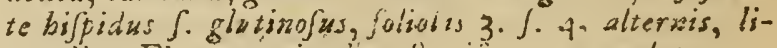
nearibus. Flos magnizudine Saxifrage granulata: venis incarraitis.

bryoides, 6. SAXIFRAGA foliis ciliatis reflexis, caule nudiufcitic unifforo.

Saxiiraga toliis denfffimis, foliolis ciliatis, caule uniforo. Hall. belv. 403 .

Saxifraga pyrenaica minima lutea mufco finilis. Tournef. injt. 253 .

Sedum mufcofum. Baub. bift. 3.p. 6, s. Sebrush. alp. 142. t. 25. f. 2 .

Sedum ejusdern alpinum quartum. Col. ecpbr. 2. p. 66. t. 67. f. 1. 2.

Habi:at: in Alpibus Helveticis, Iysenaicis.

oronchialis. 7. SAXIFR A GA foliis imbribatis subulatis ciliatis fpinofis, caulc mbrudo multittoro.

Habitat in Sibiria.

Siclones oblongi, confertim inbricati; Folits plastis, fitbulatis, mucrosato-fpinofis, jpinefo-ciliatis. Cauils altus nudiufculus, folits aliquot manimis mueronatis snargine i.evibus. Panicula parva.

iteliari. 8. SAXIFRAGA foliis ferratis, caule nudo ramofo peralis acuminatis.

Saxitraga foliis lanceolatis dentato-ferratis, caule nudo fimplici. Fl. fuec. 355 .

Saxifraga caule nudo fimplici, foliis lanceolatis dentatis, petalis acutis. Fl. lapp. 175 .

Sanicula myofotis, floribus albicantibus fere umbellatis. Pluk. alm. 331. t. 58. f. 2. Eं. t. 222. f. 4 .

Sedum montanum hirfutum, mucronato \& dentato folio, flore albo guttato. Morif. bifl. 3. p. 478. f. 12 t. 9. $f .13$.

Habitat ir: Alpibus Spitsbergenfibus, Lapponicis, Hel. veticis, Styriacis. Weitmorlandicis. 
9. SAXIFRAGA foiiis ovalibns retufis oblolete ferratis crafifoin, lotiolatis, caule zudo, paricula conglomerata.

Saxitriga folits ovaiious cremalatis, cuultaus nildis. Girbe!. Hatutat in Alpilus Sibiriz. 20

Radit crabitie fere digisi. Folin fore pelmaria, coricacea,

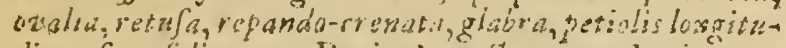

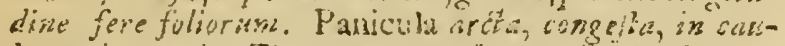

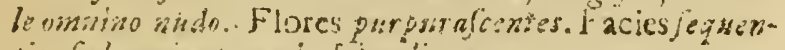

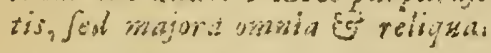

to SAXIFRAGA foliis abovatis crenatis Cubfefilibus, malis: caule nudo, fioribus congeltis.

Saximga foliis uiboratis cienats, caule nudo, roribuscopititis. F\%. fuec. 354 .

Saxitragn caule mudo finplici, foliis alliprico-fubrotundis crenatis, toribus capiatis, $2 \%$ lapp. 176, t. $2 . f$. r. 6.

Saxifaga foliis cordnto- cralibus crenatis; corollalba, caule hirfuto aphyllo. Gros virg. 160.

Saxiragn folis oblongo-totundis dentatis, thoribus conipactis. Ruij. angl. $3 \cdot P \cdot 354 \cdot 1 \cdot 16 . f .1$.

Sempervivatn minus kamatim. Matz. fpitzh: $43 . t . F$ $f$ A.

Hositat in fumaras Alpibus Spizbergenfibus, Lapponicis, Arronicis, Vir orinil, Curacia. 2

1x. SAXIFRAGA foliis cordato-oralibus tesufis cart- Gom, lagineo-crcnatis, caule nudo paniculato. Hort. clift. $167 . *$

Genm foliis petiolatis retutis, ora cartilaginea, rersasa: caule ramofo. Hall. birle. 400 .

Sanicula rontana rotundifolia minor. Bauh. pias. 243. thabitat in Mlpibus Helveticis; Pyrenaicis. 2

E. SAXIFR. IGA foliis renicormibus dentatis, caulenu- rutusirola. do paniculato.

Geum folio circinato acure creliato, piltillo loris rubro. llighn. bori. $87 .+87$.

Huluibat in Aipion's Pyrenais, Sibiricis. 2

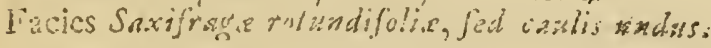

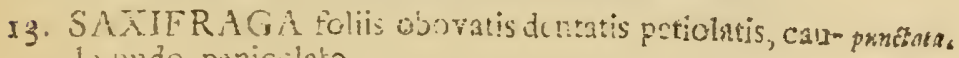
le mado paniculato.

Gennticorne ferratmi, pallidiore folio rom diorc, fo-

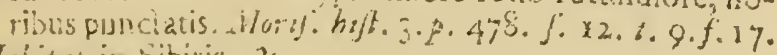

Habitat in sibiria, 2

$$
C=\quad * F_{b-}
$$


* Foliis indivifis, Caule folio/n.

oppoftifolia. 14. SAXIFRAGA foliis caulinis ovatis oppofitis imbricakis: fummis ciliatis. Fl. Suec. 359.

Saxifraga foliis ovatis quadrangulo imbricatis, ramis procumbentibus. Fl. lapp. 179. t. 2. f. 1. Hall.belv. 403.

Sedum alpinum ericoides purpurafcens. Baub, pix 284 . prodr. 132. Mtorif. bift. 3. p. 480 . S. 12. t. 10.f. 36.

llabitat in rupibus Alpium Spitzbergenfium, Lapponicarum, Fyrenaicarum, Heiveticarum. 2

Caules filifurmes, dependintes, repentes. Folia ovata, quadrifariam imóricata, oppojsta, Sefilia, ciliata. Flos terminalis, Solitarius, fefjilis.

Nper. 15. SAXIFRAGA foliis caulinis lanceolatis alternis fpinofo ciliatis, caule inferme procumbente.

Saxitrag foliis fimplicibus ciliatis, caule foliofo ramoro. H.all. belv. 403 .

Sedum alpinum, toliis crenatis afperis. Baub. pin. 284. prodr. 1.32.

Sedum alpinum hifpidum fere fpinofum, flore pallido. Baub. bijt. 3. p. 695. Morif. bift. 3. p. 479. S.12. t. 10. f. 25 .

Sedum minimum alpinum villofum alterum. Park. theatr. 738 .

Habirat in Alpibus Helveticis.

antumualis. 16. SAXIFR A GA foliis caulinis linearibus alternis ciliatis radicalibus aggregatis.

Saritraga ciliorum margine ciliari, floribus luteis maculotis. Hall. belv. 399.

Saxifraga anguttifolia autummalis, flore luteo guttato, foliis florum nagis acuminatis. Breyn.cent. 106. t. 48.

Sedum angultifolium autumnale, flore luteo guttato. Morif. bift. 3. p. 477. S. 12. t. 8. f. 6.

Habitat in bumentihus Boruffix, Anglix. Helvetix.

Calyx corolla longe brevior E'viridis eft.

Hirculus, 17. SAXIFRAXA foliis caulinis lanceolatis alternis nudis inermibus, callie ereeto.

Saxifraga petalis latiflimis luteis lineatis. Hall. belv. 399. $t$. 8.

Geum paluftre luteum bicorne, nardi celticx fimilis. Mor if. bift. 3. p. 477 .

ChamæCiltus frificus, foliis nardi celticx. Baxh. pin. 460. 
Hirculus qui ChamæCint gcnis. Ciuf. cur. 5 .

Habitat in Suecia, Helvetia, Lapponia, Sibiria.

Petaia iad bafn Lacuna nectarifers ex rimabivalvi apicibus acuitis initructa.

18. SAXIFRAGA folits caulinis lineari-fubulatis fparfis aizbiles. mudis inermibus, caulibus decumbentibus.

Saxifraga toliis lincaribus fpartis glabris. F\%. Suec. $35 \%$

Saxifraga foliis fubulatis fartis $7 \%$ lapp. 178.

Sedum alpinum, Hore pallido. Banh. pin. 284, Marif. hist. 3. p. 477. S. I2. t. 6. f. 3 .

Sedum miuus Vl. Cluf. bijt. 2. $p_{\text {. }}$ 6o.

Inbitat in Afribus Lapponicis, Styriacis, Weftmorlandicis, Baldo.

19. SAXIFRAGA foliis csulinis reniformibus dentatis rotmulifolit. petiolatis.

Saxifraga foliis renitormibus acute crenatis, caule râmofo foliolo. Hort. cliff. $16 \%$ Koy. lugdo. $453^{\circ}$ Hall. belv. 400.

Sanicula montana rotundifolia major. Baub. pin. 243 . Sanicula alpina. Cam. epit. 764.

Habitat in Alpibus Heiveticis, Aultriacis. $z$

* Folicis lohatis, Caule creczo.

20. SAXIFRAGA foliis caulinis reniformibus lobatis, granulata. caule ramofo, radice granulata. Hort. cliff. $167 . \mathrm{Fl}$. fuec. 350. Mat. med. 215 . Roy. lagdb. 453. Hall. belv. 401.

Saxifraga rotundifolia alba. Bazh. pis. $3 \circ 9$.

Suxifraga alba. Dod, pempt. 316.

Saxifraya IV. Cam. epi:. 719 .

llabitat in Europa apricis. \&

11. SAXIFRAGA foliị caulinis palmato-lobatis; cauli- bulbifert, nis leliilibus, caulc ramofo bulbifero.

Saxifraga bulbofa altera bulbitera montana. Col. ecphr. 1. p. $318 . t .317$.

Suxifraga ad folia bulbos gerens. Bauh. pin. 309.

Sedum hicorne rotundifolium ereetum, radice granulata, \& ad caulcm tubercula proferens. Moris. hijt. 3.p. 474. S. I 2. t. g. f. 24.

Habitat in Italia, pratis jaxofis umbrofis. 2

22. SAXJFRAGA foliis caulinis paimatis petiolatis, cau-cernua. le fimplicifino unitoro buibifero.

$$
\text { C. } 2 \text { Saxi- }
$$


Sarifraga foliis palmatis, cauic fimplici uniforo. $\boldsymbol{F}$. iapo. 172. t. 2. f. 4. Hort. diff. $167.4 \%$. Snec. $35 x$. Labitat ia Aipibus Lapponicis freqsens. 2-

Flosparum nutat. Folia caulina glabra, mag is palinata (s)

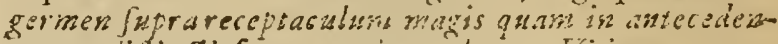
se, at difindisfirna a priore planta. Fitictar tainen athnis Jegrentis, lices $\mathbb{F}^{2}$ ab hai diftincta.

irateris. 23. SAXIFRAGA foliis caulinis palmatis: fummo fora ii ovato, caule fimplici fubbitioro.

Saxifraga foliis radicalibus quinquelobis, florali ovato, Fl. lorp. 174. t. 2. f. 7. Fl. Suec. 352.

Habitat a.d Alpizm Lapponicarum latere EO rivulos.

grendicalic 24. SAXIF RAGA folis caulinis almato multifidis fparlis: laciniis acutis, caule erecto.

Saxifraga tridactylites grcenlaudica, caulibus valde foilotis. Will. elth. 337 t. $353 \cdot f \cdot 329$.

Hobitat in Grenlandia, forte etiamz in Pyrenais Es Helveticis slpilus.

tritajylites. 25. SAXIFRAGA foliis caulinis cunciformibus trifidis alternis, caule erecto 1 imofo. Fl. Juec. 353 .

Saxifraga foliis trifidis bafi anguftis, caule ere fto. Roy. lugdb. 457. Sawv. morre? 208 .

Saxifraga foliis omnibus trilobis bati anguftis, caule ere. cto. Fl. lapp. I73. Hort. cliff. I 68.

reitornas. Sedum tridactylites tectorum. Bauh. pin. 285 .

Paronychia altera. Dod. perapt. II 3.

alpina. B.Saxitraga alba petræa. Pon. bald. 339. f. 337.

Saxifraga aizoides alpina, trifido folio, major alba. Pluk. alm. 33 r. t. 222. $f_{0} .3$.

Scdum tridactylites alpinum majus album. Baub. pir. 284. Morif. bijt. 3. p. 479. S. 12. t. 9. f. 28.

Habitat a in Europæ arenofis, 6 in Alpibis Lapponicis, Pyrenæis. $\odot$

sedoides. 26. SAXIFRAGA folits caulinis aggregatis alternis oppolitisque fublanceolatis, flore pedunculato.

Saxirraga a pina minima, foliis ligulatis in orben circumactis, Hore ochroleuco. Segu. ver. $45^{\circ}$. t. 9. $f .3$.

Ilisbitat in Aloibus Tridentinis, Sibiricis.

refpitosa. 27. SAXIFRAGA foliis radicatis aggregatis linearibus integris tritidisque, caule crecto fubmido fubbifloro.

Saxifraga foliis limplicibus \& trifidis, caule pæne apliyl10 pauritloro. Hall. bely. 405. 
Saxifraga foliis partim integris partim trifidis. Segu. ver: $451 . t$. $9 . f .4$.

Sedum trảaciylites alpinum minus. Bazib. pin. $2 \$_{4}$. prodr. I:T.

Habitat in Aipilus Lapponicis, Helveticis, Tridentinis, Monfpcli. 2

* Folitis lobatis Caulibus procumbentihus

28. SAXIFRAGA foliis canlizis cordatis trilubis intc- tymbstoria. grisque, caulibus procumbentibus.

Saxifraga cxigua, foliis cymbalaria. Baxbo cent. $2 . p$. 40. t. $45 \cdot f .2$.

Habitat in Oriente.

29. SAXIFRAGA foliis caulinis ovatis lobatisc, caule fi-bideraceat liformi flaccido.

Saxifiaga creticaninua minima, hedcraccofolio. Tozrnef. cor. 18.

Habitat in Creta.

30. SAXIFRAGA foliis caulinis linearibus integris trifi- bypreizes, disve, ftolonibus procumbentibus, canlc crecto nudiufcula:

Saxifraga procumbens, foliis lincaribus integris trif disque. Hort. cliff. 168. Ray. hysdb. 453. Scassv. monjp. 208. Gort. getr. 24s.

Saxifrng: folis omnibus anguftis petiolatis apice tridentatis, caule foliofo ramofo vifcido. Hall. heli. 404.

Sedum alpinum, trifido folio. Bass. pin. 284. Morij. hift. 3. p. 479. f. 12. t. 9. f. 26.

6. Saxifaga procumbe!ns, foliis linearibus integris trinidis dx quinquefidis. Roy. lugdl. 454. Sanz. monsp. 20 S.

Halistut in Alpibus Helveticis, Auftriacis, Pyrenaicis, Weftmorlandicis. \#

31. SAXIFR A GA folis caulinis cunciformibus apice aiffethens. dentatis, caule adfecendeite fubvillofo.

Sedum tridactylites alpinum, caule foliofo. Basij. pir. 284 .

Scrium tridaktylites alpinum majus. 3. Bawh.prodr. I3!. Bür. XVI. $8 \%$.

Hebbitat in Pyrenicis, Ialddo, T2uro Raftadienfi. 2

\title{
TIARELLA.
}

1. TIARELLA foliis cordatis. Gen. nev. 188.

Witella fcapo nudo. Mort. cliff. I67. * Roy. lagd's.

$45 \%$ Giren. virg. 160.

cordifolis.

\begin{abstract}
45. chica airg.
\end{abstract}


Cortufa ameicana, floré fpicato, petalis integris. Herm. par. I 29. $t$. I 29.

Habifat in Americat Ẽ Afia feptentrionali. $z$

trifoliat.x. 2. TIARELLA foliis ternatis. Gen. nov. 188.

Mitelia foliis ternatis. Aman. acad. 2. p. 351.

Habitat in A.ria borcali, G. Demidotf. 2

\section{MITELLA.}

diphylla, I. MITELLA rapo diphyllo. Gen. nov. 29. Hurt. cliff. 167. * Roy. lugdb.45\%. Cold. noveb. 96.

Cortufa americana altera, foribus ininutim fimbriatis. Mentz. pug.t. Io.

Cortufa americana, fpicato flore, petalis fimbriatis. IIerm. par. 130.

Habitat in America reptentrionali.

nuda. 2. MITELILA rcapo riudo. Amona acad. 2. p. 352. Habitat in Afia boreali. 2

\section{SCHLERANTHUS.}

เnnuนs,

7. SCLERANTHUS calycibus fruetus patulis. Fl. Suec. 348.

Scleranthus. Hort. cliff. 166. Roy. Iugdb. 215.

Polygonum, gramineo folio, majus erectum. Baub. pin. 281

Polygonum montanum, vermiculatæ foliis, Baub.pın. $28 \mathrm{I}$.

Vermiculata 110vis planta. Cal. ecpbr. I. p. 295.t. 294? Habitat in Furopx arvis, arenofis. (?)

perennis, 2. SCLERANTHUS calycibus fructus claufis. Fl. Srec. 349.

Knavel incanum, ilore majore, perenne. Raj, angl. 3. p. I6o. t. $5 . f$. I.

Alchimilla graminco folio, majori flore. Vaill. parif. 4. t. I. f. 5 .

Habitut in Europa campis apricis arenofis, 4

\section{GYYSOPHILA.}

aggregats. I. GYPSOPHILA folijs mucronatis recurvatis, floribus aggregatis. Gen. nov. IIO3.

Saponaria calycibus pentaphyllis, floribus aggregatis, foliis mucronatis canaliculatis recurvis. Hart. upf. yo7. Caryophy!lus faratilis, erica foliis, umbellatis coryın- 
bis. Baur. pin. 211 . prodr. 105. Raj. bift. 1033. Magn. monsp. 53.t.5.

Habitat in morte Vignon Gallix, Monfpelii, Pyrenæis. $¥$

2. GYPSOPHILA foliis lanceolatis, ftaminibus piftillo repens. brevioribus. Geiz. not. J103.

Saponaria caule fimplici, foliis fubulatis planis, cx alis ramulofa. Hort. cliff. i 66.

Alfine orientalis altifima, gramineo folio, flore albo. Busxb. cent. 3. p. 32. t. 60 .

Alfine anguftifolia caryophylloides multiflora glabra purpurafcens, radice altragaltit. Pluk. alm. 22. t. 75 . f. 2.

Caryophyllus faxatilis, foliis gramineis, minor. Bazh. fin. 211 . Burj. XI. I 26.

Habitat in Sibirix, Aultrix, Hclvetix montibus. Z

Corollx alb.e, extus incarnatee, emarginate; anthere rufescentes polline violaceo.

3. GYPSOPHILA foliis lanccolaris fcabris, corollis re- panicnlcta, volutis. Gen. nov. Iros.

Alfine fiutefcens, caryophylli folio, flore parvo albo. Girb. tanaif. 15.

Habitat in Sibirix, Tatarix defertis Sabulofis, Tawrow, Biclogrod. 2

Folia margine fcabra, acuta. Stamina in fundo foris latent. Petala revpluta, minora quarn in congeneribus. Styli longiores corolla, incurvi.

4. GYPSOPHILA foliis lanceolatis fubtrinerviis rectis. altigina. Gen. nov. I103.

Saponaria calycibus pentaphyllis, corymbis faftigiatis, foliis lanceolatis, caule adfecendente. Hort. upj.10\%.

Habitat in Sibiria. 2

Differt a Sequente magnitudine dupla vel quadrupla o. mnium partium; Strudura eadem, tomen auterfaspecies.

5. GYPSOPHILA foliis lanceolato-lincaribus obrolete fafiginis. triquetris lævibus obtufis fecundis. Gen, nov. I ro3.

Saponaria caulc limplici, foliis lincaribus ex alis fulio. rum confertis teretibus. Hort. cliffi. I G6.

Saponaria calycibus pentaphyllis, curymbis faftigiatis, foliis linearibus, caule adfcendentc. It.gotl. 292 . Fl. fuec. 246. Sau\%. monfp. 145.

Saponaria petalis ovatis, foliis glaucis pulpofis linearibus. Hall. jen. 117. t. 2. f. I.

$$
\mathrm{C} \text { c } 4
$$


Caryophyjlus faxatilis, floribus gramineis, umbellatis corymbis. Bauh. pin. 211.

Polygonum majus ercetum anguftifolium, foribus candidis. Mentz. pug. t.2.f. 2 .

Habitat in Gotlandix, Boruffix, Helvetie rupibus 2

Caulic in bac, non in antecedente, ante fiorefoentsum procumbit, binc folis fectuda.

parfolinis, 6. GYPSOPHIL A foliis ovato-lancedatls femiamprexicaulibus.

Saponaria folis lanceolatis, calycibus campanulatis an. gulatis. Hurt. chiff. 165 .

Spergula multifiota, toliis inferioribus faponatia, fupe. rioribus beher linilibus. Dill. alt 9.365 . 2. $276 . f .357$ Habitat in Hifpana so Oriente.

rigito, \%. GYPSOPHILA foliis lincari-lanccolatis planis, caule dichotomo, pedunculis bitoris, petalis emarrinatis. Gen. \%0\%. 1103.

Saponaria caule dichoromo, folìs fubulatis planis. Hor cliff. 445 . Roy. Iustib. 445 .

Siponaria caule brachiato, capillaceo folio, calyce caralpanulato, Aoribus fparfis. Sauv. monfp. $145^{\circ}$.

Tunica minima. Dabch. bifo 1 ris.

Hubitet Monpelii et forte is Beigio. ?

myro:t 8. GYPSOPHILA folits linearibus planis, caule dicho. tomo, peralis crenatis. Genv nov. 1103 .

Saponaria calycitus pentaphyllis, corollis crenato-emarginatis, foliis fubulatis planis. Fo. Juec. 347 . S6mz. monsp: 144 .

Saponaria foliis lincaribus, Fl. lap\%. I7I.

Caryophyllus minimus muralis. Bawh. pin. $21 \pi$.

Lychnis parva paimeris, foliis acuris baccolats, tofcue lis purpureis. Alenta pug.t. 7. f. 4.

Ilabitat in Suecia, Gormania, Heivetia al zias. (o)

Similis Diastbo faxifrago, at Garet fandris calycinis.

\section{SAPONARIA.}

afinalis. SAPONARIA calycibus cylindricis, tolis ovato-lanceolatis. Hort cliff, 165. Hort. $1 \%$. 106 . Mat. med. 214. Roy. lugdi. 444. Gron. virg. 100. Gort.gelr. 245. Saponara majot !evis. Bath. pis. 200.

Seponaria vuigaris. Cam. epat. irz.

Mybrina, G. Saponaria collcava anglicd. Baub. pin. 206. Morif.bift. 2. $.548 . j \cdot 4.2 .22, f \cdot 52$. 


\section{DECANDRIA DIGYNIA.}

Gentiana folio convoluto. Bush, kiji. $3 \cdot p \cdot \$ 2 I$. Hatoitat in Europa madia. \%

2. SAPONARIA calycibus pyramicatis quinquangulari-Vacaio. bus, foliis bvatis acuminatis teflilibus. Hort. clits. If6. Hort. "ps. 107. Ruy. Jugds. 443. Gret. framp. 237. Snit: miore 15.153.

Lychnis fegetnm rubra, foliis perfoliatis. Barb.pin. 2c4. Vaccatia. Dod. pernpt. 104.

Halitat iiter fegetes Gallia, Gormaniz of

3. SAPONARIA calycibus cylindricis rilloris, canibus Oeyncides. dichotomis procumbentibus.

Saponaria minor quibusdam. Bawh, bift. 3. p. 344.

Lychnis vel Ocynoides repens montamum. Bauh.pik, 206.

Habita in Helvetia es Monfpelii locis petrofis. *

4. SAPONARIA calycibus cylindricis villofis, caule di-orimtatis. chotomo ereeto patulo. Inwt. upf. IC6. n. 2. *

Saponaria caulc dichotomo, foliis lanccolatis petiolatis, Horibus folituris pedunculatis. Ruy. iugdz. 445 .

Lychnis orientalis annua fupina, antirthin folio, fore minimo purpurafcente. Tommef. or. 25. Dill. eltb. 205. t. 167. f. 204

Halitat in Oriente. $\odot$

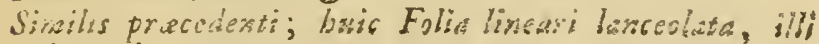
lanceolatomatisa.

\section{ANTHUS. \\ * Tlores ageregnti.}

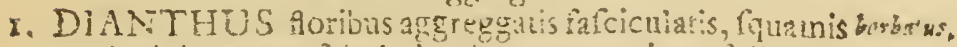
calycinis orato-lubulatis tubum aquantibus, foliis iancecilatis. Hort.clitf.165. Hort. 3tf. 165. Roy.lugat. 44t. Sar 2 . monsp. I 44 .

Caryophyllus hortenfis tarbatus latiolius. Baub. pin, zos.

Thyrlis. Reneal. Sper. 47.

B.Caryopiyllus barbatus hortculis anjuRifolius. Baxh. in. 209.

Armsius flos aiter. Doch pemps. i yó.

Maliat in .... 2

2. DIANTHUS foribus fubagrgregatis, fquamis caiyci- earthrians.

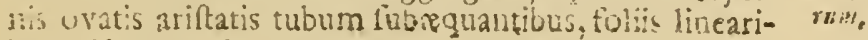
bus. Hars. wf. 105.

$$
\mathrm{C} \subset 5
$$


Dianthus foribus aggregatis, fquamis calycinis lanceoiatis, corollis crenatis. Guett. ftamp. 284.

Caryophyllus fylveftris vulgaris latifolius. Baub. pin. 209.

Caryophyllus arvenfis, calyculo florum numerofo. $L \propto \int$. pruff. 37. $f .7$.

B.Caryophyllus fylveftris, flore rubro plurimo de fummo caulc prodeunte. Segu. zer 434. 2 . 8. f. 2.

Habitat in Germanix, Italix Sicilix ferilibus apricis. 24

Arutria. 3. DIANTHUS foribus aggregatis fafciculatis, fquamis calycinis lanceolatis villofis tubum æquantibus. llort. cliff. 165. Fl. Suec. 345. It. gotl. 301. Roy. lugdb. 443. Saur. monsp. I 44 .

Caryophyllus barbatus fylveftris. Baub. pin. 208. Armeria fylveftrisaltera. Lob. ic. 44 s.

Habitat in ferilibus Gotlandia, Germanix, Gallix, Italiz. $\odot$

prolifer. 4. DIANTHUS floribus aggregatis capitatis, fquamis calycinis ovatis obtufis muticis tubum fuperantibus.

Dianthus floribus aggregatis, capitulo magno, fquamis calycinis ovatis obtufis magnis. Hort. upf. ro6. Sauv. monfp. 144.

Caryophyllus fylveftris prolifer. Baub. pin. 2c9. Segu. veroiz. 2.6. $t$. 7 . f. I.

Caryophyllus fylveftris annuus, multis capfulis fimul junctis donatus. Morif. bift. 2. p. 563 .

Habitat in Germanix $\mathcal{E}$ anftralioris Europæ pafcuis ferilibus. $\odot$

\section{* Flores folitarii, plures in eodem caule.}

Caryopbylius 5. DIANTHUS floribus folitariis, fquamis calycinis fubovatis brevifimis, corollis creliatis. liort. cliff. 164 . Hort. ups. 104. Mat. med. 213. Roy. lugdb. 443. Sauv. monjp. 14.3.

coronarius. a. Caryophyllus hortenfis fimplex, flore majore. Bauh. pin. 208.

B. Caryophyllus altilis major. Bauh. pin. $20 \%$.

$\gamma$. Caryophyllus maximus ruber \& variegatus. Baub. pin. 209.

imbricatus. ¿. Caryophyllus - - - flore pleno ex fquamis Calycinis longiflime imbricatis. Hort. cliff. $l$. $c$.

Carypipyllus fpicam frumenti referens. $E . N$. C. cent. 3. p. 368. t. 9. Hort. cliff. 164. Pbil. bot. 8.

inodorus, \&. Tunica angultifolia procumbens, petalis jerratis. Hall. belv. 382 . 
Carrophyllus fylveftris biflorus, Bath. pin. 209,prodr. 104 .

Caryophyllus fylveftris, flore rubro inodara, calyce oblongo cuin brevibus ung vibus. Segu. ver, $435 . t .7 . f \cdot 3$.

Habitet in Italia. Rrsjus.

Coionarius o cum reliquis $\gamma$. $\beta$. $\delta$. forte cx e inodoro pronnintas eft.

Varielas if maxinse fingularis eft.

6. DIAN'THUS floribus folitariis, fquamis caly cinis lan- deitoidss, ceolatis binis, corollis crenatis. Hort. cliff. ${ }_{164}$. H. jürer. 342. Sauv. monsp. 143.

Caryophyllus minor repens nollras, Raj. hift. 988. Dill. elth. 402.

Cariophyllus fylvettris vulgaris latifolius. Bar:b.pin. 209, Betonica coronaria $\mathrm{r}$. Caryophyllus minor, folio viridi nigricante, repens. Baub. bift. 3. p. 329 .

Habitat in Europæ pratis. 2

7. DIANTHUS floribus fubfolitariis, fquamis calycinis glaucus. lanceolatis quaternis, corollis crcmatis. Hort. cliff. 164. Hart. zpS. 104.

Tunica ramolior, flore cardido cum corolla purpurea. Dill. elth. 400. t. $298 . f .348$.

Habitat in Anglia. 2

8. DIANTHUS floribus folitariis, fquamis calycinis fu- chinenjis. bulatis patulis tubum æquantibus, corollis crciatis. Hort. cliff. 164. Hort. ups. 104. * Roy. lugdib.443.

Caryophyllus fincnfis fupinus, leucoji folio, flore urico. Tournef. act. 1705. p. 34\%. f. 5.

Habitut in China. $\odot$

9. DIANTHUS floribus folitariis, fquamis calycinis plumarius. fubovatis breviffimis, corollis multifid is fauce pubefeentibus.

Dianthus floribus folitariis, petalis multifidis bafi canaliculatis. Hort. upf. $105 .{ }^{*}$ Sauv. monfp. 143.

Dianthus floribus folitariis, corollis lacero-partitis, fquamis calycinis ovatis acutis. Fl. Suec. 344 .

Dianthus petalis multifidis $F$. lapp. I7O. Hort. cliff. 174. Roy. lugdb. 443.

Caryophyllus flore tenuifime diffecto. Bauh. pin. 209. Caryophyllis fylveftris, flore laciniato odoratifino.

Baub. pin. 210.
Habitat in Europæ E Canadx pafcuis nemorofis. 
* Carle nimiferro berhaceo.

arastius. IO. DIANTHUS camlibus uniforis, fquamis ealycinis ovatis corollis mulifidis, foiiis linearibus. It. gro!l. 318. 77 . 1itec. 343 .

Dianthus foliis brevibus, fquarnis muticis, caule unifioro. Sari, riteth. [43.

Caryophyllus tylvettris humilis, flore unico, Bunb.pin. 209.

Caryophyilus fylveftis r. Clas. bifi. x. p. 282. Dill. cith. 402 .

Armerius fios tertius. Dod. pempt. 176 .

Habitat in En:opo frigidionis serena nobili. 2

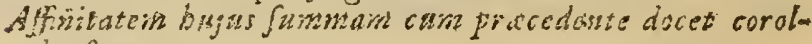
loe faris.

g/aina, II. DIANTHUS calle unifloro, corollis crenatis, fquamis calycinis extcrioribus tuoum æquantibus, folis lincaribus obtufis.

Caryophylius pamilus latifolius. Bauh. fin. 200 prodr 104. Buis. II. 95.

Caryophylius fylveftris, fiore magno inodoro inatuto. Baxh. pirs. 209.

Caryophylus fylveltris 2. Cluf. bift. r. $28_{3} \cdot f \cdot r_{1}$ bon.

Ilabiat in Stiria, duftria. 2

Racix lignofo, exferens caules plures. Caulis bongitudime digivi, articulis tribus confans. Folia caulis lineria, obtufinfcula, piana, obtuja, zel verfiss terram, wbi cefpites confiztumat, lanceolato-linearia. Calycis Squance exteriores langitudine twbi calycis; interiores dimidio brevisures. Corolla magaa. Petala calycis lan gitudine, rotukaian, dentibus brevifimis numerofiscrse nata, fauce parum risllofa.

orracens. 12. DIANTHIJS caule fubunitioro, corolis crenatis, tquamis calycinis brevifimis, folits fubulatis.

Caryophyllas sylveltris zepens multiforas. Bazh. pir. 209. Burj. XI. 99.

B. Tunica mpetris, folio cafio molli, fore carneo. Dill. eith. $401 . t .298$. f. 385 .

Habitat Monfpelii. 2

Radix pernis.s. Folia radicalia copiofa, ereata, in cefpitem isibiricata, aissuinata, facie llatices ferme. Cauies aliquot, fpirbarici, 4 articulis finplicifjimis con-

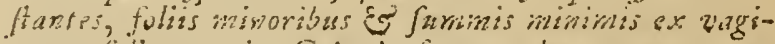
na perfolicia ontis. Calycis fyzaria latee, ovata, acu- 
tow brevisfirre: paribus renotis. Corolia linabus dimidio bresicur tibo calysis, rotuadatus, crewitzs. Fios zuxicus in caule, interdian Es alter ex ala fuliijuprems.

\section{* Firutefientes.}

13. DIANTHUS caule fruticoro, foliis fubulatis. Gilerens.

Caryophyllus creticus arboreus, juniperi fclio. 'Tournef. cor. 2.3 .

Caryophyllus arborefcens creticus. Bamk. Jin. 208, prodr. 104.

Betorica coronarid arborea cretica. Baub. bift. $3 \cdot k \cdot 328$. Habital in Cirta. b

14. DIANTHUS caule fruticofo, foliis lanceolacis, fruticofus, Caryopliyllus grecus arborens, leucoji folio perama* ro. Fournef. cor. 23 . itis. 1.p. 183. t. 9.

lisibitas in Giracin. b

* Calycibis angulatis.

15. DIANTHUS calycibus quinquangularibus, fquamis suxifingu. caiycinis lanceulatis cequalibus, folis tubulatis.

Dianthus radice repente, ramis decumbentibus, foliis fubulatis. Roy'. las de. 444.

Dianthus calyce lato \& brevifimo, Hall. belv. 381.

Caryophyllus taxifragus ftrigofior f. Caryophyllus fylveflris, fiore minimo. Baih pin. 211 .

Lychnis punita caryophyliata, flore rubello, italis $\mathrm{F}$.zo morrhoidalis aldrovandi. Barr. rar. 64. t. 998.

Habitat in Helvetia, ciallia, Ingolftadii. 26

\section{TRIGTNIA.}

\section{DRYPIS.}

r. DRYPIS. Ger. emac. 1312.

Drypis italica aculeata, floribus albis umbellatis compaहis. Mish.gen. 24. t. 23 .

Drypis theophraiti \& angvillaræe. Dalech. biff. $1+8 \overline{5} 0$. Lob. ic. 759. Tabern. ic. 144. Barib.kift. 3.p. 722. Spina umbella, toliis vidua. Bazh. piw. $3^{88 .}$

Carduus foliis tenuifime fpinofis ad inttar juniper. Morif. hift. 3. p. I 6r. $\int \cdot 7 \cdot t \cdot 32, f . \delta$.

Habitat in Italia, Mauritania.

frinojn. 


\section{CUCUBALUS.}

raccifer. 2. CUCUBALUS calycihus campanulatis, petalis diftantibus, truetu colorato, ralnis divaricatis.

Cucubalus canle ramoto, noribus trigynis, fructu colorato globofo. Hoit. clift. 170.. tiort. ups. 107. Roy. Iugdb. 448. Seuv. mois p. 152.

Alfine fcandens baccifera. Brsh. pin. 250.

Alfine repens. Dod. peript. 403.

Habitat in Tataria, Germanix, Galliæ, Italiæ nemoribus. 2

Belew. 2. CUCUBALUS calycibus fubglobofis glabris reticulato-venofis, capfulis trilocularibus, corollis lubnudis. Fl. $\int u e c .300$.

Cucubalus floribus trigynis, calycibus glabris, capfulis trilocularibus. Hort. cliff. 176. Roy. lugdb. 448.

Cucubalus calycibus ovatis hermaphroditis. Fl. iapp. 180.

Lychnis fylveftris, qux Behen aibum vulgo. Baub.pin. 205.

Papaver fpumeum. Lob. ic. 340.

3. Ly chnis maritima repens. Basth pin. 205. It. gotl. 197. Habitat in Europa Jeptentrionalioris pratis ficcis. $Z$

Fabarius. 3. CUCUBALUS foliis obovatis carnofis, Roy. lugdb. 448 .

Lycnnis maritima faxatilis, folio anacampferotis. Tournef. cor. 24. Boerb. Jugdb. I. p. 214.

Betien album r. Polemonium faxatile; fabaria folio, ficulum. Bacc. muf, 133. t. 92.

Habitat in Sicilia.

vifcofus. 4. CUCUBALUS fioribus lateralibus decumbentibus, caule indivifo, foliis bafi reflexis.

Cucubalus foilis amplexicaulibus, floribus verticillatis, pedunculis erectis. Roy. lugdb. 448.?

Lychnis montana vifcola noctitlora hirfuta latifolia alba, floribus absque appendicibus. 7311 . pif. 105 .

Lychnis orientalis maxima, buglofi folio undulato. Tournef. cor. 24. itin. 2. p. 36r. t. 36r.

Lychnis major noetiftora drubenfis. Raj. bift. 995.? Habitat in Svecia, Italia, Anglia. $\delta$

fellatus. 5. CUCUBALUS foliis quaternis. Hort. upf. I IO.

Drypis folitis quaternis. Cold. noveb. Iob.

Silene toliis quarernis. Gron.vvirg. 5o.

Lychnis caryophyllæus virginianus, gentianæ toliis gla- 
bris quatuor ex fingulis geniculis caulen amplexantibus, flore amplo timbriato. Raj. bift. i\$95.

Habrtut in Virginia, Canada.

Yctala, absque corona, quadrifida, lobis bipartitis.

6. CUCUBALUS caule dichotomo, petalis quadrifidis. quadrifins. Lychnis vifcola angurtifolia major. Bauh. pin. 205.

Lychnis fylveftris X. Cluf. bijh. 1.p. 291.

Caryophyllus minimus humilis alter exoticus, flore candido amailo. Lob. ic. 445 .

Habitat in Styrix munte ad oppidum Eifeneriz. 2

7. CUCUBALUS foribus erectis, petalis emarginatis gyptiacus. retrotlexis: utrinque denticulo notatis. Haljelqu.

Habitat in Rgypto.

8. CUCUBALUS petalis bipartitis, floribus fecundis de-tataricus. cunibentibus, pedunculis oppofitis folitariis erectis, caule fimplicilimo. Hort. upf: I I t.

Lychnis feptentrionaiium, foliis hyllopi, floribus uno rerfu politis albis. Hall. gott. 33 .*

Habitat in Tataria. 2

9. CUCUBALUS petalis bipartitis, floribus paniculatis, ratbolicus. flaminibus longis, foliis lanceolato-ovatis. Hort. ups. III. *

Silene foliis ovatis utrinque acutis, caule paniculate, floribus mutantibus tenuiffimis, Roy.. Iugdb. 447.

Lychnis vifcoía altilima, flore muicofo, ocymaltrifacie. Cupan. catb. 110.

P. Lychnis nocturna non vifcola, herbaceo flore. Dill. elib. 425 . t. $316 . f .408$.

Habitat in Italia, Sicilia. 2

10. CUCUBALUS floribus dioicis, petalis fetaceis Otites. indivilis. Hort. cliff. 272 . Roy. lugab. 445 .

IJychnis vircola, Ho:e mufcofo. Baub. pin. 206, Sefamoides magrum talmanticum. Clue. hijt. 1.p.275. Mabisat is Silefia, Aultria, Gallia, Sibiria. 2:

II. CUCUBALUS acaulis. Fl. lapp. 104. Fl. Suec. 368, acaslis. Koy. laigab. 44\%. Hall. belv. 375

Lychinis atpiua punnila, tolio graninco. Baub.pin. $200^{\circ}$

Dill. elth. 206. t. $167 . f .206$.

Mufcus alpinus, lychnidis fore. Baub. bift. $3 \cdot p \cdot 76-7$.

Habitat in Alpious Lapponicis, Heiveticis, Anglicis. 2 
referus. 12. CUCUBALUIS foribus fpicatis alteruis fecundis fubfeflilibus, corollis obfoletis nudis. Hort.uff. I $22^{*}$ *

Lychnis regetum meridionalium annua hirta, floribus albis uno verfu difpotitis. Mforif. bift. 2. p. 544. Raj. bift. 990 .

Lychnis fyivefris alba, fpica reflexa. Mragn, monjp. $17 \%$. t. $1 \% 0$.

Kabitut Monfpelii.

\section{SILENT. \\ * Eloribus lateralibus folitariis.}

anglice 1. SILENE hirfuta, petalis emarginatis, floribus erectis, fruetious reflexis hirfutis alternis. Hort. upf. Ix 3 .

Vifeago ceraftii toliis, vaículis pendulis anglica. Dill. eltb. $41 \%$. t. 309 . f. 398 .

Lychnis fylventis hirruta annud, fore minore albo. Faill. parif. I21. t. I6. f. 12 ..

Habitat in Anglia, Gallia. $\odot$

Petala in bare emarginata non crenath, in sequente of e* carginata $\Theta$ cremata.

lufitnita 2. SILENE hirluta, petalis dentatis coronatis, foribuserectis, frtictibus retlexis fubfeflilibus aiternis. Hort. upj. I 3 . Hort. cliff. $1>2$.

Silene foribus alternis, petalorum limbis integris crenatis. Hort. cliff. I 72 .

Vifcago hirfuta luitanica, fellato fiore. Dill. cltb. 420 , s. $311 . f_{1} 4 \mathrm{Cr}$.

Habitat in Lufitania. 0

quinquerk. 3. SILENE patalis integerrimis fubtotundis, frugtibus enera. rectis alternis. Hort. cliff. I 7 I. Roy. lugdh. 446.

Silene fpica incurva uno verfu: florida, foliisimis ipathulatis. Saur. mosip. 346 .

Lychnis hirfuta minor, flore rariegato. Dod. rsim. $4 . p$. 291.

Habitat in Hilpania, Lufatia, Italia, Gallia. $\odot$

7o6turas. 4. SILENE floribus fpicatis alternis fecundis feffilibus, petalis bifidis.

Silene foliis lanccolatis, caule ramofo \& floribus recundis erectis, calycibus hirfutis. Roy. lxgdb. $1+7$.

Vicago hirta noetitlora, foribus cbloletisficicatis. Dill. elth. 420. t. 310 . f. 4 co.

Lychnis fylveitris noeturna pilofa, Horibus unius ordio nis dilute-purpureis. Cisp. cath. I Ig. Raj.Jupl. 480 . 
Lychnis fegetum meridionalium annua hirta, floribus abis uno retín difpolitis. Morif. hif. 2. p. 346. $\int$. 5. t. 36. f. 7 .

Habitat in Italia, Penfylvania. $\odot$

؟. SILENE floribus fubfricatis alternis fecundis, petalis sallica. indivifis, fruetibus ereetis.

Silene hiriuta, foliis reffilibus oblongo-cuneitormibus obtulis, caly cibus ftriatis, fruetibus erectis alternis. $L_{6-}$ lik. parif. 129 .

Vilcago hirra galiica, Rore parvo carnco, petalis integriša Dill. elth. 4ig. t. $310 . f: 399$.

Hinbitat in Gallia. ()

6. SILENE hirfuta, petalis emarginatis, fruetibiss ereetis cerrfoides. alternis hirfutis fetfilibus.

$\checkmark$ ifcazo ceraftei follis, vafculis ereatis ferinlibus. Dill. cllth. 416. t. 30\%. f. 397.

Hawi:at in Europa auftrali. $\odot$

* Floribus betera!'ibus cainfertis.

7. SILENE petalis bifidis, foribus iateralibus fecundis cer- rutani 1:uis, caule recurtato.

Silcne foliis lanceolatis, caule paniculato, floribus nutantibus, calyce Rriato, corolla involuta. Hort. cliff. $17 \mathrm{I}$. Fl. fisec. 366. Roy. longdb. 446 .

Lychnis niontana vifcofa alba latifolia. Baub. pin. 205. Hiabitat in Europe bureilis pratis ariais. $¥$

8. SIL.ENE peralis bifidis : coronula fubcoacunata, flori- amanto bus fecundis, pedunculis oppofitis triforis, ramis a!ternis.

Silene petalis bifidis coronatis : corolla ccadurata, calycibus erectis raris pilofis. Hort. upf. II 4 .

Holistat is Tataria. 1

9. SILENE petalis bitidis, caule fruticoro, foliis lato-lan- fruticu/2, ceolatis, paticula trichotoma.

Silenc cartle foliufo fruticofo, follis lineari-ianccolatis acutis glabris, captulis ovatis. Vir. rliff. 39. Hort.

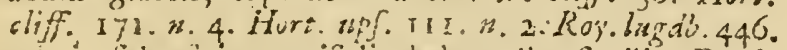

Lychnis fylveliris inyrtifolia beher albo fimilis. Bataib. pin. 205 .

Orymoides fruticofum. Cam. hori. Ion. 2.33 .

Saponaria frutefeens, acutis foliis, ex licilia. Bass fos. 58. i. 30.

Jabio a in Sicilia. 5 
signuea 10. SILENE follis rauicalibus cochleariformibus obtufislimis, canle fubverticillato.

Silene folis lanceolatis, carle paniculato nudo, foribus erectis. Hort. cliff. 1.7x. Rog. ingdit. .746.

Silene folis obverfe cyatis cratis, limbir curollx bitiois a fole revolutis. if ach. wlir. $39 \mathbf{1}$.

Lychnis ocymafiri facie, fiore viridi. Lierm. par. 199. 1. I99.

Habitat in Lunitania. oै

* Floribus ex dicbrtomia castlit.

Conoider II. SILENE calycilus foctros globofis acuminatis ftrits

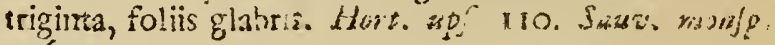
146.

Cucibalus calycibus conicis friatis. liott rliff. $: 7 \%$. Roy. lugalb. $44^{8}$.

L) chris fylvettis latifolia, calycibus angidis firiats. Baub. pin. 205.

Lychnis rylveftris 2. Cinf. bin? : p. 288.

Habitat inter fegetcs Hipania. ()

carica.

12. SILENE calycibus frubus conicis leñs triginta, fo. lis mollibus. Hort. up io 110 .

Lychnis fyiveftris angufifoia, calycibus turgidis itria" tis. Bats. pirn. 205.

fychnis glabra anmua, folis oblongis rucromatis, flore amplo rubello, capiala chlonga promidali. Wast. bift. 2 o. 542.5 .5$. t. 36.5 .6$.

Habitat in Hipina, Galloprovincia. $O$

Bahen. 33 . SILENE calycibus ovatis giabris verofo-rtirulatis, capfuis trilocuiatibus.

Lychnis veficaria cretica, parvo tore purpurafcente. Dill. elth. 427 . 5 . $7 . f .409$.

tychnis cretica,parvo fore, calyce friato purpurafcente Totirnef. cor, 24.

Hubisiat in Creta. O

Differt a Cucubain Beben corona corolle, fetalsmang

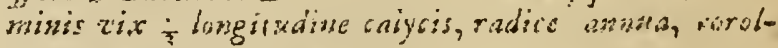

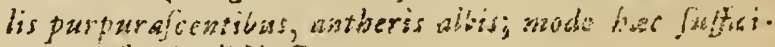
ant pro juecse dististisis.

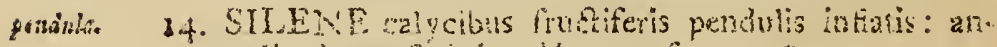
sulis decenfoabris Hort.

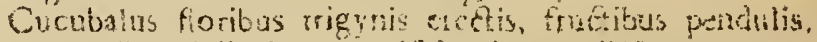
caljeibas thits decen crifpis. Hart shto syo. 
3. Cucubalus Roribus trigynis ereeti, calycibus fruetus penduis angulofis. Hort. rliff. $17 \mathrm{I}$.

Vicago hirista ficula, lychnidis aquaticx facie, fupina. bill. elth. 421. t. $312 . f .404$.

Haśta in Creta s $^{2}$ Sicilia. $\odot$

15. S1l. ENF calycibus decemangniaribus: dentibus tubum nostifora. xquantibus.

Ciscubalus caljcibus rrugus ovatis trectis: angnlis decema: alternis venofis. Hiort. ups. 3. † Fl. Juec. Frafat. Sarto. monsp. 146.

1.jchnis nodkifora. Banb. pin. 205. Raj. bift. 994.

Jeymoides noetitorum. Cim. hort. 109. 6. 34 .

Habina in Suecia, Germania. $\odot$

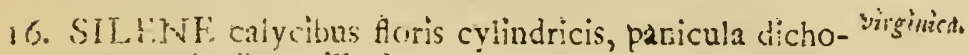
oina, calycibus villoris.

L.ychnis tore fimplici fpeciofo coccineo, folits ohlongis acuminatis adverfis, caule vifcolo. Gror. virg. 161.

Irititat in Virgin!ia. 2:

Planta proiymorpha. Florer fach, Cucubali dioici albi, at falurate runri; Calyces an, aufliores quam in cungener:bus, hirfuti. Stamila run jtylis extraflorempromintntia. Canlis ane fimplex digit: longitudine, terminn-

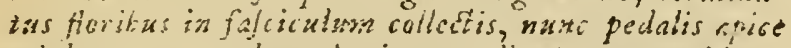
trichoturnss, foduncull intermedio jemper unifioro.

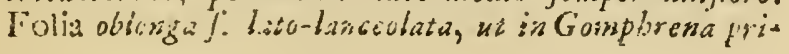
incis

1\%. SIL.ENF folits lanceolatis glabris,pedunculis trifidis, mirrbina. petalie enarginatis, caly cibus uvatis. Roy. lugab. $44 \%$.

Silene co ytrio dichntomo, foribus pedunculatis. ramis alternis cred is, foliis lanceolatis integerrimis. Gron. virg. 50.

Vilcain americana notitlora, antirthinito:io. Dili. clth. $442,2.31,1,403$.

Hobiut in Virginia, Carolina. 2

1\%. SILENE creda lavis, calycibus fubglobolis giabris verolis, corollis inspertis. Ifort. ip/. 112 . *

Vifcago lutitanica, thore rubello vix confpicuo. Bsll. t. 32.4 .35 .3 .406$.

Ilabitat in Luticania. $\odot$

19. SILFNE cauie dicho:ono paniculato, calycibus 12 in inertn. vibus, petalis breviffinis emarginatis, foliis glabris lancenlatis. 
Vifcago Iavis, inaperto Nore. Dill. eith. 424. t. 315. f. 407 .

Habitat in Europa auftraid. $\odot$

eretican 20. SILENJ erecta lavis, calycibus ercetis fulcatis, petalis emarginatis. Hort. ups. I12.*

Vifcago foliis inferioribus bollidis, mperioribus tunica, calyce fricticre \& turgidiore. Dil, ilth. $422 i .314$ f. 404.405 .

Habitat in Creta.

pollenfis. 21. SILENE caule dichoromo panjculato, calycibus firiatis, petalis bifidis, foliis linearions.

Silene caule erceto, pedunculis longinimis erectis uniforis, foliis lineari-lanceolatis, Ruy. lasklb. 447.?

Habitat ins. Lufitania. Luef. O

Habitus S. incpertu, at Folia angufiora, E' Calyecston- gitudinalster firiati. Planta jpitionaxa, brachinta, dicbotoma. Folia lisedria acsita glabra. Peduncul! filiformes, anguftigimi, longi, eresti, e dicbo:omia caulis, wiviflori. Calyces clavati, longi, purturascentes, friss atieritis allis. Simmina longindine fere corolla.

Martipult, 22. SILENE petalis biffis, caule dichotomo, fioribus axillaribus fefilibus, foliis glabris.

Silere floribus triflylis, foliis lanceolatis fefillibus, capfulis triloculatibus, floribus terilis. Saur.monfp. 145 . Lychnis fylvetris vifcoia rubra altera. Bats.pin. 205.

Lychus fylucteris 3. C'luf. bift. I. 289.

Havitat in Hilpania, G. Narbcnenfi.

foltphylla. 23. SILENE folis farciculatis felaceis: ramorum torentium oppofitis. Roy, lagdb. 447 .

Lychnis fylvefris, plurimis foilolis limul junctis. Baub. pin, 205 .

Lychnis lylveftris VITY. Clus. bitt. I. p. 200.

Hubitat ia Pannonia, Auftria, Bohenia. 2

\section{YCHNIS.}

Armeris. 24. SILENE fioribus facciculatis faltigiatis, foliis fupe rioribus cordatis glabris. Hort up f. I 10 .

Silene foliis lanceolato-ovatis glabris, foribus termina. libus fafciculatis foftigiatis. Hort. cliff.'172, Roy, lugdb. 4 fú. Sawe. monjp. 153

Lych- 
Lychnis vifcola pupurea latifolia lavis. 3 aub.pix. 205. Armerius fios cinarrus. Dod. pemt. 176 .

Habitat in Auglia, Gallia. $\odot$

25. SILHNE foribus ereetis, petalis emaiginatis, calyci- rapuris. bus tretious, folis lsnceolatis. F\%. jzsec. 367. It. If: 50 th. I4.

Silene foribus erectis laxe difantibus, ${ }_{j}$ caule dichotomo. 1\%. lapp. 183 .

Aifinz alpiua giabra. Baub. pia. 251. prodr. ir8.

Auricula muris alpina glabra. Bazh. hift. $3 \cdot p \cdot 360$.

B. Caryophyllus holoftens alpinus gramineus. Bash. pin.

210. prodr. 104. Burs. XI. 117.

Habitat in montibus ariais Suecia, Helvet:x. \&

Varietus fo. foliis tinearibus in smóra nata.

26. SILENE caulibus uniforis, pedunculis longitudine saxifraga, caulis.

Caryophyllus laxitragus. Baub. pin. 2 Ir.

Saxitraga antiquorun quibusdam. Bauh.hift. 3.p.338.

Habitat in montilus cretaceis Gallix, lialix. 2

Radix lignola,ramofa. Caules plures, digitiales, fimplicisfimiziabri. Foila oppifita lincaria acuta glabra, per 4 aa 6 oppojitiones. Pedunculus terminalis, filiformis longisudise iaulis; raropedusculus alter lateralis. Flos unicus. Calyx chavatus giabrr. Petalia bifida ibinouca. lyce breviore.

27. SILENE caule foliofo herbaceo, foliis lanceolatis a-bupleuroides cutis glabris, calycibus erectis. Hort. cliff. I71. Roy. $\operatorname{lugdb} .446$.

Lychnis orientalis, buplcurifolio. Tournef. cor. 2. itin.

2. p. 139. t. I54.

Hillitat in Perfia.

\section{STELI.ARIA.}

1. STELLARIA foliis cordatis petiolatis, pedunculis ra- nenursm, molis.

Alline altifima nemorum. Baub. pin. $25 \mathrm{I}$.

Alfine inontana hederacea maxima. Col.ecplir. 1.p. 299.

t. 290.

Hibitat in furopa nemoribuse

2 STELLARIA foliis ovatis feffilibus, canle dichotomo, aicbotoma. fioribus inlitariis, peduncuiis fruetiteris reticxis.

$D d 3$ 
Habitat in Alpibus Hejveticis, Sibiricis. (o) Kami divaricati, dicbotomi. Eedunculi frotaferitotire Hexi.

edins. 3. STELLARIA foliis 1ancecolatis ferrulacis, petalis quin qucpartitis.

Alfine faxatilis, angufto \& oblongo falicis folio, flore albo tenuifime laciniato, Amm, ruth. 83. t. 10. Hatitat in Sibiria.

Helefea, 4, STEI LARIA foliis lanccolatis ferrulatis, petalis bifidis.

Alfine foliis lanceolstis. Hort, cliff. x 72 . Fl. juec. 37 r. Ko\%. lagd's. 449.

Caryophyllus bolofteus arvenfis, flore majore. Baut. pin. 210

Gramen. Fuchis: bift. I36.

Habitat in Europa nemoribus.

fauminea. 5. STELLARIA folis lincaribus integerrimis, florlbus pauiculatis.

Alline foliis linearibus. Fl. lapp. 180 , Fl. fuec, 372 . llort. cliff: 172. Rov. lugdb. 449 .

Cáryophyllus arventis glaber, flore minore. Baab. pin. $2: 0$.

Gramen floridum minus, Tabern. ic. 232.

B. Alfine, folio gramiueo anguftiore, paluftris. Dill. app. (2).

$\chi$ Carioplingllus holoftcus alpinus anguftiolius Bauh.pin. 2I0. prodr. 104. n. 6." Durf. XI: 2.

Habitat in ficcis juriperetis fejibus tactis Europa. 4.

coraides, 6. STELLARIA lolis oblongis, pedunculis fubbifluris. Caryophyllus, holofteus inonaanis angultifolius alter. Baub. piz. 210. prodr. 104. Burf. X1: 1!8.

IIabitat in Alpibus Lapponicis, Horta Dei monlpeliculi.

Gifora, ?. STELLARIA foliis fubulatis, fcapis fubbilloris, petalis emarginatis, germinibus oblongis, calycibus ffriatis.

Sargin ramis ecentis bifloris. Fl. lapp. 158 *

Mothringia frapis hitlois. Fl. Juer. 316.

Arcnuria folis Lubulalis, calycibus thiatis, germinibus oblongis, floribus corymbolis. Aninn. acad. $1, p .15^{8}$. * Habitat in Alpibus Lipponicis. Z

Planta parva, facti Jiggina. Folia radicalia fubulata, in 
acernum congefta. Canles digitales, filiformes. maxima parte nuds: Supersebifids in 2 pedunculos fitifertn to rifoliorsm: altero pedunculo in medio folialis duobus.

\section{A RENARIA.}

r. ARENARIA foliis ovatis acntis carnofis. Fl. Suec peploides. 375. Fl. inpp. 149. Ft. al. I 5 I.

Alline litorilis, foliis portulacx. Baub. pin. $25 x$. Las. prull. i2. t. 2.

Telephium maritimum, portulaca folio. Buxb.aft. 3 . p. 271

Habitat ad listora maris Europxi borealis. $\boldsymbol{K}$

2. ARENARIA foliis ovatis carinatis recurvis quadri-estraguetra. fariam imbricatis. Bash. pin. 211. prair. 125. Burf. Xl. 135.

Habitat in Pyrenxis 20

Herba amnino Gypfonbila aggregata, Sed Pedunculvis nsiffor us , terminali:

3. ARENARIA Eoliis ovatis cbufis, peduncula hterali lateripora, bifloro.

\section{Habitat in Sibiria.}

Canlis digialis filiformis fimplicifrmus. Folia coato. obtsefa josopetsuluta glabra. Pedunculus axillaris uricas longus bifidus. Curolla calvce inggior.

4. ARENARIA foliis ovatis acutis petiolatis nervofis. trinervio. Hort. cliff. 173. Fl. Succ. 374. * Roy.lugdb. 471 . Alfine plantaginis tolio. Bauh. hiff. $3 \cdot p \cdot 364$.

Habitat in Eurcup fylvis. Q

5. ARENARIA foliis fubovatis acutis fesfiltbus, corollis serpyllifolia. calyce brevioribus. Fl. juec. 373. Hort. cliff. 173. Roy. ingdb. 451 .

Nifinc minor multicaulis. Bawh. pin. 251.

Alfine minor. Fucbf. bift. 2.3.

Habitat is kuropa fylvis glareofss. ()

6. ARENARIA foliis tiliformibus, fipulis membrans.. rubra. ceis vaginantibus. F\%. juec. 376 .

a. Alfine, ipergule facie, minor 1. Spergula minor, fub-campeftris. caruleo tore. Baut pin. 251. prodr. 119

Polygonum foliis gramineis, fpergula capitatis. Loe.

prafl: 203.5 .63$.

B. Menaria foliis lineatibus longitudine intermediorum. inarina. Hort. cliff. 173. Gion. virg. I61. Roy. lugdl. 451 .

$$
\text { D d } 4 \text { Siper. }
$$


Spergula matina nottrac. Rai. tifi. 1034 .

Aline pergula facic nedia. Bash pin. $25 \mathrm{l}$.

Habitat $\alpha$ in Europa arenulis collibus, $\beta$. in litoribus marinis. $Q$

Stamina ia campeftri certe 10. Sunt; in maritimaprope Abnar: ftamista tantum 5 obfervavit $D$. Kalm.

faxatilts. 7. ARENARIA foliis fubulatis, caulibus paniculatis, $\mathrm{ca}^{\mathrm{a}}$ lycum foliolis ovatis.

Arenaria folis fubulatis, calycinis laciniis membrana ipfis latiore auctis obtufis. Guett. ffamp. 2. p. $28 \mathrm{r}$.

Spergula folils aciformibus deplis, ramis ramolis fubnudis. Sauv. monsp. 45 .

Alfine glabra, tenuiftmis folis, foribus albis. Herm, par. 12. t. 12.

Aifine faxatilis \& multifora, capillaceo folio. Vaill. parif $7 . t .2 . f .3$.

Alfine faxatilis, laricis folio, minor \& minori flore. $T$. Magn. monfp. I1 t. $1 \mathrm{r}$.

Habitat in Germania, Helveria, Gallia, Sibiria. *

texritolia. 8. ARENARIA foliis fubulatis, caule paniculato, pedunculis fimplicibus, capfulis erętis, petalis calyce brevioribus.

Arenaria foliis fubulatis, calycinis laciniis membrana ipfis angutiore auctis acutifimis. Guett. Jtamp. 2. p. 282.

Alfine tenuifolia. Bash. bift. 3. p. 364. Vaill. parif. 7. t. 3. f. 1. Segu. ver. 418 . t. 6. $f .2$.

Habitat in Helvetia, Gailia, Angiia, Italia. z

Habst in flore famina decern.

laricifolia. 9. ARENARIA foliis fetaceis, caule fupernenudiufculo, calycibus fubhirfutis.

Alfine folis falciculatis, petiolis fimplicibus, calyce hirfuto. Hall. beir. 388 .

Aline alpina, juncto folio, Besh. pin. 25x. prodr. I18. Lychnoides, juniperi folio, perennis. Vaill. parif. I21. Habiant in montojus Helvetix, Geneva, Parifiorum, Monipei.j. 2k

mucranate. 10. ARENARIA folis fetaceis mucronatis, corollisbrevilimis, ealvcibus inferne inucronatis.

Aline foliis fafeiculatis tenuifimis durisque, petalis integris. Hall. belv. 357, t. $7 . f .2$,

Habitat in Helvetia. 
11. ARENARIA foliis ovatis ciliatis acutis.

cilistal,

Alline, ferpillifolio, multicaulis \& multitiora. Segz. ver. $421 . t .5 . f .2$.

6. Arenaria foliis ovatis nervolis fefinlibus inbricatis acutis. Amuer acad. 1. p. 162. \%. 155.

$\%$ Alfinc foliis lanceolatis, petalis integris calyce majoribus. Hall. belv. $390 . t .7 . f .3$.

Habiat in Alpibas Helvcticis, Pyrenxis. 26

12. ARENARIA foliis fubulatis fubtus hifpidis.

Habitat Monfpelii in monte calcaris.

Habitus Jpergula. Caules fimplices, pilis rat is adfperf. hifpida.

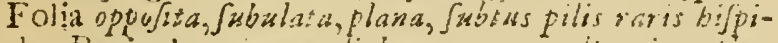
da. Panicula primora dichotorru, rax alternis peduniulis rarnofa.

\section{CHERLERIA.}

1. CHERLERIA. Hall, belo. 391. $t 6$.

Lychnis alpina, muicolis toliis denfius ttipatis, foribus seioides. parvis, calyce duriore. Pluk, alru. $233 . t .42 . f$. 8 . Sedum montanum perpuillum luteum.. Morts. bijt. 3 . P. 47 I. S. 12. t. G. $f .14$.

Sedum montanum perputillum, lureolis flotibus, $P$ ai $k$. theatr. 738 .

Habitat in Nipibus Helvetix, Valefix, Gothardo. is

$$
\text { GARIDELLA. }
$$

GARIDELLA. Hort. clifi. I70. Hort. "ps. I08. Nigella. Roy. lugdio. 481 .

Garidellatolis tenuipime divifis. Garid.prov. 203.t. 39. Nigellathum raris \& foniculaceis tolis. Magn. bort. I. 43. . 143 :

Nigella cretica, folio foniculi. C. B. Murif. bift. 3.p. 516. $\int .12 . t .13 . f .6$.

Habitai in Galloprovincia. $\odot$

\section{MALPIGHIA.}

5. MALPIGHIA foliis ovatis integerrimis glabris, pe-glabra. dunculis umbellatis. Hort. cilf. I6g. Ilow. upf. I0s. Roy. lugdis. 45\%.

Cesafus jamaicenfis, fructu tetraryrono. Comm. bort. I. $t$ 145. t. 75 .

$$
\text { D d } 5
$$

Cera- 
Cerafus americana, myrti conjugatis foliis, frugtu acer bo tetrapreno. Plik alor. 94 t. 157. . 7.

Arbor baccitera, folio fubrotundo, fruelu cerafino fuicato rubro polypyreno: oficulis cantaliculatis. Slo:2\%. jam. I72. biff. 2. p. 105.t. 207.f. 2. Raj. desdi. 74. Mabitat in Jamaica, Branlia. Surinamo, Curarao. $\$$

«rew.

2. MALPIGHIA foliis obiongo-ovatis : fetis decumben. tibus rigidis, peduuculis unithoris aggregacis.

Malpighia anguftiolia \& latifolia, fruetu fubrus fpinord. Plum. gcn. 46.

Mefpilus americana, folio lato fubtus fpinofo, fructu rubro. Tourner. inft. 642 .

Arbo: baccifera, folio oblongo fubtilifimis fpinis fubtus obfito, fructu cerafino fulcato polypyreno. osficulis canaliculatis. Sloan. jam. 172. bift. 2.p 106. $t$. 20\%. f. 3. Raj. dendr 74.

Habitat is America calidiort. b

equfifolis. 3. MALPIGEIA foliis ovatis integerrimis fubtus ton:en. tofis, racemis terminalibus.

Malpighia latifolia, cortice fangvineo. Barr.equin. 72.?

Tilie affinis Ixurifolia, arbuti toribus albis racemolis odoratis, fructu pentagono. Sisan. jam. I 36. bift.2. D. 20. $t .16_{3}, f .1$.?

Habitat in America calidiore. 5

Árbor. Foliis ovatis palmanibus crafis fubpctiolatis in. tegerrimis, jupra pubefaentibus, $\int$ nutus toneintofis. Racemi terminales langi tomentofi.

veibncifo"ia 4. MALPIGHIA foliis lanceolato-ovatis tomentofis integerrimis, racemis terminalibus.

Malpignia humilis, verbaf́ci folio facie, caule ciasfisfimo. Barr. reguin. $7 x$.

Habitat in América calidiore. 5

Folia lanceolatorovata, in petiolos definentic, pedalia, Tillofi, fubtus denfifimo tomento veflita. Racemi.terminales, longi, villoji.

aquifolis. 5. MALPIGHIA foliis lanceoiatis dentato-fpinofis fubtus hifpidis.

Malpighia anguftis \& acuminaris aquifolii foliis. Plsm. ger. $4^{6}$.

Lisbitat in America calidiore. $b$

ercigers.

6. MLPIGHIA ioliis fubovatis dentato-fpinofis. 
Malpighia tunmilis, ilicis cocciglandifera fuliis, Plwm. gen. 46.

Nhabitat in America calidiere. 5

\section{BANISTERIA.}

1. BANIST'ERIA foliis alternis lanceolatis ferntis, lupnloices.

Paullinia foliis fumplicibus lanceolatis ferratis. Hort. upf.

97.

Jupulus fylventis americana claviculis donata. Pluk. alm. 229. t. 201. f. 4. EJ t. 163. f. 3 .

Habitat in Barbados. is

2. BANISTERIA foliis finuato-angrilofis. A cer feandens, folio angulofo. Plem. 1 pic, 18.

angulnfi.

Ciematis anguloro folio, aceris fructu. Plum, amer.77. t. 92. Raj. Jupp?. 323 .

Iaroitat in America calidiore. 5

3. BANISTERIA foliis ovatis, fpicis lateralibus, femi- purureo $^{-}$ nibus erectis.

Acer fandens, preudaacacia follo, fore purpurafcrute. Plam Jpec. 19.

Habirat in America meridionali. 5

4. BANISTERIA toliis ovato-oblongis acuminatis, n-benghalenfis cenits lateralibus, feminibus pareutihus. Fl. zej!. 7 \%.* Acer fcandens, foliis citri, flore cxrulen fpicato. Plum. sper. 18 .

Acer icandens, foliis baurinis Shant, jam. 13\%. bifl.2. j. 26. Raz. dendr. 74 .

A cer benghalentis, laurinis folis, frucku tergemino. I' 'ak. alim. $7 . t$. 3. f. 1.

Havitat in Indiis $b$.

3. BANISTERIA foliis ovatis, ramis dichotomis.

Banilleria tolits ovatis, ramis dichotomis, feminitus ezdichotons. trotfum tenuioribus, introrfum lacinulam emittentibus. Hort cliff. 169 .

Habitat in Anerica caldiore. b

6. IBANISTERIA foliis ovatis, ramis brachatis, Cemini- juger.a bus extrortum tenuioribus.

I3nilteria foliis ovalis, ramis ramolis, feminibus extrorfuri tenuioribus, introrfum lacimlanr emitrenlibus. Lurt rlifi 169.

Acer foudens, convolvuli folio, Rore ex aureo cinctco. blum. Jper. I8. 
Acsr fcandens minus, apocyni facic, folio fubroundo. jloan. jaks. 139. bift. 2. $\% .27 . t .162 . f .2 . R a j$. desdr. 94.

Trioptcris americana fcandens, fructu fulgente majore aureo. Plak. Mant. 185.

Habitat in America. I

4rashinta. 7. BANISTERIA foliis tubovatis, rainis brachiatis, feminibus introrfum angultioribus.

Banifteria folits fubovatis, ramis ramofis, feminibus introrfum tenuioribus nullam lacinulam emittentibus Hort. cliff. 109. *

Habitat in America. 5

\section{TRIOP'TERIS.}

immicenfis. 1. TRIOPTERIS. Hort. clitf. x

Triopteris jamaicenfis, anguito ialicis folio, fructu minore fufco. Pluk. alm. 377.

Aceri vel Paliuro affinis, angufto oblongo ligultrifolio, fiore tetrapetalo herbaceo. Sloan. jam. 133. bift. 2. p. 27. t. 162. f. 3. Raj. dendr. 94.

Habitat in America-calidiare. 5

\section{PENT AGTNIA.}

AVERRHOA.

bilimbi, I. AVERRHOA caudice nudo fruetificante, pomis oblongis obtuiangulis. $F l$. zey. 177 . Blinbingum teres. Rumpf. amb. 1. p. I18. t. 16. Bilimbi. Rheed. mal. 3. p. 55. t. $45 \cdot 46$. Habitat in India. $b$

Carambola. 2. AVERRHOA axillis foliorum fructificantibus, pomis oblongis acutangulis. Fl. zeyl. I $>8$.

Mala goënnia, fructu octangulari pomi vulgaris magnitudine. Bazh. pin. 433 .

Prunum ftellatum. Rampf. amb. I. p. II 5. t. 35 .

Tamara Tonga 1. Carambolas. Rbeed. mal. 3 . p. st. t. 43.44 .

Halitat in India. b

acids. 3. AVERRHOA ramis nudis fructificantibus, pomis fub* rotundis. Fl. zeyl. 179 .

Neli-pouli. Kbeed. mal. 3. p. 57. t. 47. 48. Raj.bift. I 450 .

Habitat in India. 5

CO. 


\section{COT'YLEDON}

1. COTYLEDON foliis fubrotundis planis integerri-orbicklato iris. Hort cliff: 270, Roy. Ingdo. 454 .

Cotyicdon africanum trutefcens incanum, orbicularis fo. lij. Herm. lugdh. 349. to 551. Marif. hifi. 3. p. $47+1.12 .7 .7 \cdot f \cdot 39$.

Cotyledon africana frutefcens, folio longo \& apigutto, fiore tlavelcente. Cumm. rar. $23, t .23$.

Inabitat ad Cai. b. Sper. 5

2. COTYLEDON folis femiglobofis. Hort. sl:f: 1 76. hemifario Roy. lugdb. +5t.

ca..

Cotyledon capenfis, folio femigiobato. Dill. eltb. I 12.

t. $95 . f, \mathrm{II}$ I.

Habisai in Hithiopis. B

3. COTYLEDON folits ovalibus crenatis, caule fpi-ferrats. cito.

Cotylecion foliis radicalibus ?anceolatis crenatis: caulinis fubulatis. Klort diff. 497 . Ruy. lugdb. 454 .

Cotylecicil cretica, folio oblongo imbriatu. Dill. elth. I1 3. t. 95. $f$. I I 2 .

Habitat in Creta, Sibiria.

4. COTYLEDON folis oblongis fpinofo-mucronatis, ?pinos, calile fpicato.

Havilat in Sibiria. D. Grneliz.

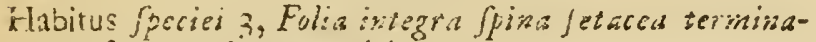
th, fiores quingucpartiti.

5. C.OT YLEDCN foiiis cucullatis ferrato-dentatis al- un:bilicus $\&$ teris is, caule ramoro, lloribus creetis.

Cotyledon toliis peltatis. Vir. cliff. 39. Roy.lugd\%. $45+$.

Conylcion Dore luten, radice rcpente. Dod. Mirri. 265 . repens. 5. 73 .

Cotyledon radice tuberofa longa repente. Morif. pras. 257 . Raj. hift. 1875 .

Cotyledon luteur umbilicatum fpicatum, radice repen . te majus, Morif. hift. 3. p. 471 .

Uinbilicus repens. Cam. etit. ¿̇sS.

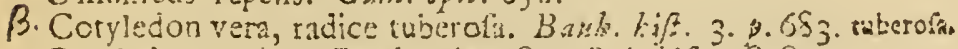

Cotyledon major. Bawh. pim. 295 . R ai. bijt. 1378 .

Cotyledon umbilicus veneris. Clat. hifl. 2. 0.63 .

Sedum lutcurn murale ipicatum, tolio umbilicato rotundo. Morif. bift. 3.p. 470. S. 22.t. 10. $f \cdot 4$.

Ilabitat in Lulitania. $b$ 
dainiato. 6. COTYLEDON folis lacihiatis, floribus quadrifidis. IIort. cliff. 175 . Roy. ligdb. 454 .

Cotyledon afra, folio crallo lato aciniato, Aorculo aureo. Boert. lugdb. I. p. 288. t. 288.

Telephima africanum, anguftiori folio, fore autathiz. co. Pluk. alm. 362. t.228. f.3.

Habitat in IEgypto. b

\section{STDUM. * Planifalia.}

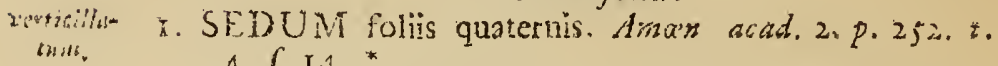
4. . r.t. *

Sedum aparines facie, tauromenitanum. Raj. extr. 233 . Morif. is in. 3. p. 473 .

Il.bitat is Europa maxime aufarali, Eण Sibiria. b

Telentimu. 2. SEDUMI foliis pianiurculis ferntis, corymbo foliofo, canle crecto.

Sedun folits planiureulis patenthas ferratis, corymbo

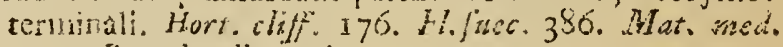
$217 . \operatorname{Roy} \cdot \log d 6.45^{6}$.

Tclephium vulgare. Bauh. pin. 287

albun, Telephum abum. Fuch. hilt. Soo.

furjurcum B. Telephim purpureun majus. Baub. pin. $28 \%$.

$\gamma$. Telchim purpurcum minus. Bawb. pin. 237 prodr. 133.

\&. Telephium latifolim peregrinum. Baub. fin 287

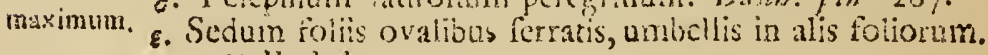
Hall. belv. 35 .

Telephium hilganicum T. Cinf. hifi. 2. p. 66.

Telcphim repens, folio deciduo. Baub pin. $18 \%$ Anacainplecrs maxima. Paxs. bift. 3. p. 682.

Heiblitat in Europx ficcilfrmis. 2k

Ansmari- 3. SEDUM folits cunciformibus integerimis, ciulibus tos. decumbentibus, foribus corymbois.

Scimn foliis fpathulatis indivifis, umbelia terminali. Sazi. monto 77.

Telcphim Th. Cepar plancii. Chnf. big. 2. p. 67. Anacamplores nimor, retundiore rolio, ímpurviens. Bauk, hijt. 3. p. 682 .

Helbifat in - .... - *

Aiscon 4. SFDUM foliis lanceolntis feratis planis, calce cre cio, cyma teffli terminali.

Sedim follis planis ferratis, corymbofoliolo, Mort, upf. :16. 
y. Sedum minus luteum, ramulis refexis. Boub. pin. 283. Habitat ad radices mostium Europz. 2

absm. ro. SEDUM folis oblongis obtutis teretiufculis reffilibus patelitibus, cyma ramora. Hort. cliff. $17 \%$. Fl suec. 38\%. Roy. 3kgdb. 457. Hall. belv. 398 . Sedum minus teretifolium aibum. Baub. pin. 28 . Vermicularis f. lllecebra majot. Lob. bijt. 205 . Habitat in Europa petris.

rubens. Ix. SEDUM foliis fubcylindricis obtufis alternis, cyma fempercicat.

Sedum arvenfe, Gore rubente. Baub.pin. 283 , prodr. 132 . Halitat in Gailia, Italia.

nere. 12. SEDUM foliis fubovatis adnato-feflibus oibbis ereEtiufculis alternis, cyma trifida. Hort. cliff. I 7 . Fl. fecc. 389. Mat. med. 2!8. Roy. imgalb. 456 .

Sempervivum minus vermiculatuin acre. $B a$ an. pin. 28 . Jlicchra 1. Sempervivum tertium. Dod. pempt. I29. Habitat in Europx campis ficcifimis flerilifinis. $z$

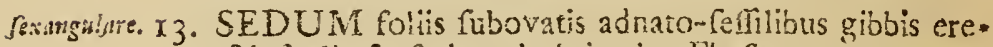
diuiculis fexfariam imbricatis. F\%. Juec. 390.

Sempervivum minus vermicilatum infipitum. Baub. pis. 284 ?

Sempervivim milimum. Cam. epit. 856 .

Habitat ik Europe borealis ranpis apricis ficcis. 2

Differta precedenti, cuifinillinum, Folits fexfariam oblique imbricatis, Rumiz sungaum copiofis, ut cefpitem. confituast, Floribus ing jingulo ramo cymie varo witra tres.

97nnsm. 14. SEDUM caule eredo folitario annuo, follis ovatis feritibus gibbis altetnis, cyms recurva. Fl. fuec. 39 ?. Sedum minimum non acre, flore albo. Raj. angl. $3 \cdot p$. 270. t. I2. f. 2. figura tenss.

Haititat in Europa boreali. $\odot$

willow. 15. SEDUM caule eresto, folis planiufculis, podunculisque fibpilofis.

Sedum paluitre fubhirfutum purpureum. Baxh. pin. $2 \delta_{3}$. Sedum mirus in l. f. paiuftre. Clui. bift. 2. p. 50.

Habitat in praits paludofis Germania, Anglix, Gillia.

PENTHORUM:

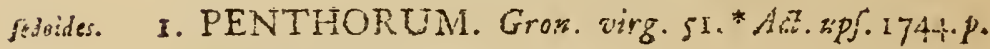
12. t. 2 .

Habitat in Virginis. *. 0

OXA. 


\section{OXALIS.}

\section{* Scapo radicali.}

1. QXALIS fcapo unifloro, foliis ternatis, radice fqua-Acetofella, mofo-articulata. Hort. cliff. $175 . \mathrm{Fl}$. Jner. 385. Roy. iugalk. 458. Mat. med. 216.

Oxalis foliis termatis, fcapo uniforo. Fl. lapp. 194.

Trifolium acetofum vulgare. Bazh. pis. 330.

Frifolium acetofum. Dod. pernpt. 578 .

B. Oxys flore fubcaruleo. Tournof. mizt. 88.

Oxys Hore purpurafcente. Tousnef. inft. 88.

Habitat in lutopx borealis fylois. 2

2. OXALIS fcapo unifloro, foliis ternatis, radice bul. purpured bof́3. Hort. cliff. 175. Roy. lugdb. 4;9.

Oxalidi afinis planta bubofa arricana, flore purpureo miano. Brey's. cent. 102. t. 46.

Oxys bulbofa aricana rotundifolia, caulibus \& tioribus purpureis amplis. Comm. hort: I. p. 4I. t. 2 I.

Oxys bulbofa trifolia hirluta, flore albo. Burm. ifr. $6 \%$ t. $27 . f: 3$.

Habitut in Ethiopia. 2

3. OXALIS feapo uniforo, foliis ternatis femibifidis: lom zifora, lobis lanceolatis.

Habitat in Virginia.

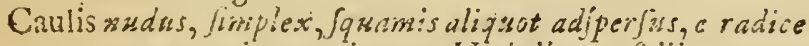
per terram exit termisatus Cimbella ex folios novem Ev flore unico. Folia petiolate, terisatu: foliolis felfilibus plus quam Jerninifidis: lobis lancsolutis. Pedunculus unitiorios: in inedio fispularurn pari rotatus: Flos nisicus, longus,

4. OXALIS fcapo uniforo foliis ternatis bipartitis:

Uxalis bulbota, angunis digitaris foliis, flore folitario lutco. Burm. afr. 08. t. 27.5 .4 .

Oxys africalia bulbofa, foribus amplis luteis, folits minimis hirfutis. Raj. fuppl: 549 .

Oxalis africana bulbura, foliis limpliciter decaphyllis; Hore flavo. Burm. at $r .69 . t, 27 . f$. 5 .

Oxalis bulbofa, finplici caute ad fummun foliofo, flo= re luteo. Burn. atr. 8r. t: 30. f. 1 .

Habitat in Etriopia. $*$

y. OXALIS pedunculis unifloris, caule dichotomo. Oxalis caule bulkifero: Hort. kliff. 175: Roy. lugdb. intsarmintue $45 \%$ 
Oxys bulbofa xthiopica minor, folio cordato, flore ex albido purpurarcente. Cormm. bort. I. p. 43. t. 22.

Hetbitat in Ethiopia. Z

violacea. 6. OXALIS fcapo umbellifero, foliis ternatis obcordatis.

Oxalis caule aphyllo; flore purpureo, radice tuberofa rotunda. Gron. virg. $16 x$.

Oxys purpurea virginiana, radice lilii more nucleata. Pluk. alm. 274. t. 102. f. 4.

Habitat in Virginia, Canada. 2

Pes capra. 7. OXALIS fcapo umbellifero, foliis ternatis bipartitis. Oxalis bulbofa pentaphylla \& hexaphylla, floribus $\mathrm{m}: \cdot$ ghis luteis \& copiolis. Burm. afr. 80. t. 29.

Habitat in Ethiopia. 2

fenfitiva. 8. OXALIS fcapo umbellifero, foliis pinnatis. Fl. zeyl 180.

Oxyoides malabarica fenfitiva, caule viridi glabro, flore luteo majore. Gari. act. angl. 730 . p. 379. t. 2. Herba Mimofa malabarienliam. Zan. bijt. 199. t. 61 .

Herba viva. Clue. exot. 2 jo.

Herba viva foliis polypodii. Baxb. pin. 259.

Todda vaddi. Rbeed. mal. 9. p. 33. t. 19.

Habitat in India.

* Foliis caulinis alternis.

verficoler. 9. OXALIS caule fimplici, pedunculo unifloro abbreviato, foliis filiformibus fubramolis

Oxalis bulbora trifolia, foliis linearibus obtufis, flore externe rubro, intus albo. Burm. afr. 65. t. $2 \% \cdot f .1$

Oxys africana, foliis tenuifimis in fummitate caulis. Rrj. Suppl. 598 .

3 . Oxys bulbofa africana angutifolia, flore rubro obfow leto amplo. Raj. Suppl. 548 .

Oxys africana, foliis temuiftimis, flore amplo verficolo. re. Pluk. amalth. 169. t. 434. f. 6.

Oxalis bulbora anguftifolia, caule foliofo, flore rubro. Burm. afr. 66. t. 27. f. 2 .

Habitat in Ethiopia. 2

bivtat

10. OXALIS caule ramofo, pedunculis unifloris, foliis feflilibus lanceolatis.

Oxalis caulc ramofo, foliis lineari-lanceolatis feffilibus, floribus lateralibus folituris. Roy. lugdb. 532 .

Oxalis radice longa fibrofa, caulibus rainolis, foliis ternis anguftis, forum petiolis longifinmis. Burm. afr. 7. t. $28 . f$. 2 . 


\section{DECANDRIA PENTAGYNIA}

Oxys africana, hirfutis latioribus foliis, fore magno purpureo. Pluk. amalth. I64.

B. Oxalis bulbola, foliis angultis ternis hirtis, flore purpureo. Burm. afr. 70. t. 28. f r.

Oxys africana bulbofa, thore purpurco, caule foliofo. $R$ aj. Suppl. 599 .

Oxys africana bulbofa, dory chnii monfpelienfium parvis foliis, floribus purpureis amplis. Fluk. amaltb. I64. t. 434 . f. 7 .

Habitiot in Aithopia.

11. OXALIS caule ramoro diffufo, pedunculis umbelli- corriculats. feris. Hort. cliff. 175. Hurt. upf. I 6 6. Roy. lugdb. 458. Saur. manp. Th3. Gort. gelr. 91.

Oxys havo Hore. Claf. bift. 2. p. 249.

Trifolium aectofum corniculatm. Bazh. fin. 330. luteum minus repens. ejam procumbens. Morif. li.?. 2. p. 183 . . . 2. t. 17. f. 2.

Halitast in Italia, Sicilia. $\odot$

Conjer. Oxalis lutea annua, floribus dentatis. Few. per. 3. p. 49. t. 24.

12. OXALIS caule ramofo erecto, pedunculis umbelli-firza, feris. Gron. wirg. 161.

Oxys ancricana credtior. Tukrnef. infi. 80.

Trifolium acetofun corniculatum luteum majus reetum. indicum t. virgineun. Morif. bift. 2. p. 18. . S. 2. t. i7. f. 3 .

Ilabitat in Virginia.

13. OXALIS caule fruticofo, foliis ternatis: intermedio frrtafcens. petiolato.

Oxys lutea frutefcens, trifolii bituminoli facie. Plam. fiec. 2.

Habitat in America meridionali. 5

\section{A GROSTEMMA.}

J. ACrROSTEMMA hirfuta, calycibus corollam æiquan-Gribgo. ribus, petalis integris nudis.

Agroftemmà. Mort. cliff. 175. Fl. Juec. $3^{83}$. Roy.

lugd6. 449.

Lychnis regetum najor. Buts pirs. 26t.

Lolium Fucbs. bilt. I27.

Habitat inter Europa Segetes. (9) 
Caliz zosa. 2. A GROSTEMMA glabra, toliis lineari-lanceolatis, peralis emarginatis coronatis. Hort. upj. I I 5 .

Lychnis fegetum, Nigellattrum minus glabrum dicła, Hore eieganter rubello. Morif. bift. 2. p. $543.5 \cdot 5$. t. $22 . f .32$.

Lychnis folits glabris, calyce duriore. Boce. fic. 27.

PlendoMelarthium glabrum liculum. Raij. bijt. 999. Habitat in Sicilia. ()

coraxaria. 3. AGROSTEMMA tomentola, foliis ovato-laciniatis, petalis integris coronatis. Horl. zep. II5.

Coronaria. Hort. cliff. 174. Roy. lugdb. 449.

Lychnis coronaria diofcoridis Cativa. Bauh. pin. 203.

Lychnis. Cam. epit. 560 .

Hubizat in Jtalia. o

Fitos jovis. 4. AGROSTEMMA tomentofa, peralis emarginatis.

Lychnis coronaria fylveltris. Baub. pin. 204. Morif. hift. $2 . p \cdot 540.5 \cdot 5 \cdot t \cdot 36 \cdot f: 2$.

Lychnis umbellifera montara helvetica. Zan. $j_{j} z_{\text {. }}$ I 28. t. 51. Rai. bift. 993 .

Habitat in Helvetia.

\section{LYCFNIS.}

chalcedonica 1. LYCHNIS floribus farciculatis fantigiatis. Hort. cliff. I 74. Hort. "up. I I s. Koy. lugrib. 449.

Idychnis hirfuta, fore coccineo, major. Baub. pin. 203. Flos conitantinopolitanus. Dod. peript. 178 .

Habitat in Tataria, is

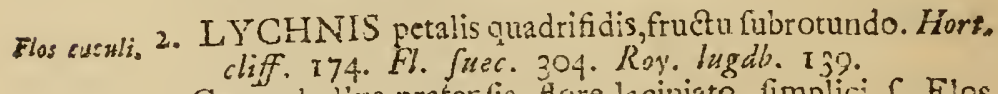

Caryophylius pratentis, Hore laciniato fimplici f. Flos cucali. Bawb. pin. 210.

3. Caryophyllus pratentis, fore pleno. Bauh. pin. 210. Odontites pliail. Chaf. bift. 1. f: 292. 293.

Habitat in partis Europe buiridiufiulis. 2

vifario, 3. LYCHNIS petalis integris.

Silene foribus pentagynis, capfulis quinquelocularibus. Hort. cliff. 172 . Fl. fucc. 364 . Koy. lugáh. 445

Lychnis fyiveftris vifcofa rubra angultifol:a. Basth. pir. 205.

Lychnis fylveftris V̈̈. Cluf. bitl. I. t. 289 .

Habitat is Europx feptentrionalis pratis ficcis. 2

sipına, 4. LYCHNIS petalis bifidis corymbolis.

Silene foribus corymboris, caule erecto, foliis lanceo. lato inearibus. Roy. lugd6. 447. 
Sileue lapponica alpina, facie vifcarix. Fl. lapp. 185. * Silcne tloribus in capitulum congettis. Halt. belv. 376 . t. 7 .

Halitat in Alpibus Lapponicis, Heiveticis, Sibiricis, Pyrenaicis, $2<3$

5. LYCHNIS petalis bifidis, caule dichotomo, folis fub-fibirica. hirtis.

Habitat in Sibiria. Ginclin. 2

Statura Silenes ravefris, Sod Radix perennis, Foliaminus glabra, ESTylis 5 difing zint plantam.

6. LYCHNIS thoribus dicicis. Hort. cliaf. 171. Fl. fuec, dioica. 361. Roy. lugalb. 478 .

Crucubalus caule compofito, calycibus oblongo-ovatis. Fl. lapp. 182.

Lychnis fylvcftris f. aquatica purpurea fimplex. Bash. pin. 204 .

Lychris fylveftris noctifora alba timplex, calyce amplisfimo. Till. pil. 1C5. t. 41. S. 1.

Melandrium plinii genuinum. Cluf. bift. r. p. 25,4. mas. B. Cucubaius floribus liermaphrcditis pentagynis, captulis unilocularibus. Hort. cliff. 190.

Lychnis fylvcitris alba fimplex. Bazh. pin. 204.

\%.Lychnis alba inultiplex. Baub. pin. 204.

Hiabitat in Europx frizida pratis fucculentis. \&

7. LYCHNIS calyce inflato, corolla calyce breviore, can- apctald. le fubunifioro.

Cucubalus caule fimpliciffimo unifloro, petalis calyce brevioribus. Fl. Jucc. 363 .

Cucubalus caule fimplicifimo unifloro, corolla inclufa. Fl. lapp. 181 , t. 12. $f .1$.

Habitat in Alpibus Lapponicis, Sibiricis.

In Sibiria plasta caule multifioro lesta eft.

\section{CERASTIUN. \\ * Capfulis oblongis.}

1. CERASTIUM follis commatis. Hort. cliff. 173 . Mort. perfoliultums. "t?. II 5. Ray. lugdb. 450.

Myolotis orientalis ferfoliata, lychnidis folio. Tournef. cor. I8. Dill. elth. 295. t. 217. f. 284.

Habitat in Græcia. $\odot$

2. CERASTIUM ereetum vilio 174. Fl. Suec. 379. Roy. lugdb. 450.

$\mathrm{E} \mathrm{e}_{3}$

Ce- 
Ceraftium corolla calyci æquali. Fl. lapp. I93.

Miyolotis hirfuta altcra vifcofa. Vaill. parif. 142. t. 30. . . I.

Alfine hirfuta altera vifcofa. Baub. pin. 257.

Habitat in Europæ pratis macilentis. $\odot$

semideran. 3. CERASTIUM tioribus pentandris, petalis emarginadrbit. 2. His. Hort. cliff. 173. Fl. Suec. 382. It. ol. 17. Roy. lagáb. 450. Gron. virg. 51. Gort. gelr. 90.

Ceraitium corolla calyce breviore. Fl. lapp. 193.

Ceraltium hirfutum minus, parvo Hore. Raj. angl. 3. p. 34 \%.t. $15 . f . \mathrm{I}$.

Myofotis arvenfis hirfuta minor. Vaill. perif. I 4 2. 3०. $f .2$.

Habitat in campis apricis fterilifimis Europæ borealis. $\odot$ Filamenta buic 5 fterilia, 5 antherifera.

fentandr:m. 4. CERASTIUM floribus pentandris, petalis integris. Lxall. defcr. 26.

Habitat in Hifpania.

Flanta minima, fimilis C. Semidecandro, a quo differt: colore viridi nec incano. Staminibus 5 fertilibus; nec 5 aliis anthera deftitutis. Petalis calyce longe brevioribus lanceolatis acutis; sec acute emarginatis.

arvense. 5. CERASTIUM foliis lineari-lanceolatis obtufis glabris, corollis calyce majoribus. Fl. Suec. $38 \mathrm{r}$.

Ceraftium foliis calycibusque hirfutis. Mort. cliff. 174 . Roy. Iugdb. 450 .

Myolotis arventis hirfuta, flore majore. Vaill. parif. If I. t. 30. f. 4 .

Caryophyllus arvenfis hirfutus, flore majore. Baub. pin. 210 ,

Habitat in Scania $\hat{O}$ anftraliori Europa. $\psi$

dichotomun 6. CERASTIUM foliis lanceolatis, caule dichotomo ramoliflimo, caplulis ercetis, Roy. lugdb. 450.

Lychnis fegetum ininor. Baub. pin. 204.

Alfine corniculata. Cles. bift. 2. p. 184.

Habitat inter fegetes Hilpanix. $\odot$

alpis:ati, 7. CERASTIUM foliis orato-lanceolatis, caule divif, capfulis oblongis.

Ceraflium foliis lanceolatis, curolfis calyce majoribus. ti. fítec. 380 .

Ceratlium follis lanceolato-ovatis, caule fubunifloro. K'oy. laigdb. 451 .

Cera- 
Ceraftium corolla calyce majore. Fl. lapp. 192.

Alfine myofotis facie, lychnis alpina, flore amplo niveo, repens. Rag. angl. 3. p. 349. t. I5. f. 2.

Habitat in Alpibus Europæ.

$$
\text { * Capfulis fubrotundis, }
$$

8. CERASTIUM foliis lanceolatis, pedunculis ramofis, rezens. caprulis fubrotundis.

Ccraftium caule perenni procumbente, foliis lanceolatis tomentofis. Roy. lugab. 450.

Ceraftiun perenne procumbens. Hort cliff. 174 .

Myofotis arvenfis, polygoni folio. Vaill. parif. I $41 . t$. jo. $f$. 5 .

Lychnis incana repens. Baub. pin. 206.

Habitat is Gallia, Italia. 2

9. CERASTIUM foliis linearibus acuminatis glabris, pe-firictum. dunculis uniforis fubcomentolis, capfulis globofis.

Myofotis caule hirfuto, foliis peranguftis glabris, flore calycem excedente. Hall. belv. 384 . t.5. f.i.

Alfine apina fubhirfuta, linaria folio. Scbeuch. alp. 2. p. I 30 .

Caryophyllus nolofteus alpinus, foliis ftrictifimis glabris acutis, flore magno. 3 urf. XI. I19.

Habitat in Alpibus Auftriacis, Helveticis.

10. CERASTIUM caule perenni procumbente, foliis fuffreticof. lineari-lanceolatis fubhirfutis.

Myofotis tenuifimo folio rigido. Tournef. inft. 205.

Habitat in Europa aixfrali. b

II. CERASTIUM foliis lanceolatis fcabris, petalis cre-maximin. natis, capfulis globofis.

Habitat in Sibiria. D. Gmelin.

I2. CERASTIUM foliis cordatis feffilibus, Aoribus fo- aquaticum. litariis; fruetibus pendulis."

Alfine major. Baub. pin. 250.

Aifine maxima folanifolia. Mentz. pug. 2. t. 1. f. 3 .

Habitat ad littora lacuwn Europæ. 2

13. CERASTIUM foliis nvatis fubtomentofis, ramisu-Intifolikm. nifforis, capfulis globofis.

Caryophyllus holofteus alpinus latifolius. Baub. pin.

211 . prids. IOt.

Habitat in Alpibus Helvetix. 2

$$
\mathrm{EC}_{4} \quad \text { 14. CE. }
$$


tomentofur. I4. CERESTIUM foliis oblongis tomentofis, pedunculis ramofis, capfulis globolis.

Ceraftium foliislanccolato-linearibus fubhirfutis, corolla calycern fuperante. Sauv. mon $\sqrt{t}, 142$.

Caryophyllus holofteus tomẹtofus latifolius. Baxb. piss. 210. prodr. 104.

B. Caryophyllus holofteus tomentofus anguftifolius. Bawh. pin. 210 prodr. 104.

Habitat in Granada. 2

\section{SPERGULA.}

arvents, I. SPERGULA foliis verticillatis, floribus decaudris. Hort. cliff. 173. Fl. Juec. 377. Roy. Iugdb. 451. Spergula fiuctu pendulo. Fl. lapp. Igo.

Spergula. Dod. permpt. 527.

Alfine Spergula dicta major, Bauh. pin. 251. Habitat in Europæagris. ()

pentandra, 2. SPERGUj,A foliis verticillațis, foribus pentandris. Leefl. defor. 23 .

Spergula foliis filiformibus verticillatis raris, reminibus nigris. Saut. monfp. 167.

Alfine fpergula facie minima, feninibus emarginatis. Tourner. infi. 244. Vaill. pirif. 8.

Alfine fpergula facie minima. Magn. mossp. I4.

Arenaria teretifolia verna, flore albo, femine limbo foliaceo cincto. Kupp. jen. Ior.

Spcrgula annua, femine foliaceo nigro circulo membranaceo albo cincto - - Morif. bifl. 2. p. $55 \mathrm{I}$, blej. 23. Dill. gif. 46. E. N. C. cent. r. 2 275 . t. 4 .

Habitat in Germania, Gallia. Anglia, Hifpania. $\odot$

3. SPER. SERULA foliis oppofitis fubulatis lævibus, caulibus fimplicibus:

Spergula foliis oppofitis, fedunculis fimplicibus. Hort. cliff. 173. Fl. fues. 378 . Roy. lugdb. 451.

Alfine nodofa germanica. Baub. pin. 251.

Alline paluftris, eric $x$ folio, polygonoides, articulis crebrioribus, fore albo pulchello, Pluk. alm. 23.t.7.f. 4 . polygonum, folìs gramincis, alterum. Isoef. praf. 204a t. 64.

Habitat in Furopa frigiäuris campis Jubhumidis. 2 
4. SPERGULA foliis oppolitis fubulatis ciliatis fafcicu-laricina. latis.

Habitat in Sibiria. D. Gmelin.

5. SPERGULA foliis oppofitis linearibus lavibus, pedun-fagiroides. culis iolitariis longifimis. caule repente.

Alline tenuifolia, pedunculis florum longifimis. Vaill. parif. 8. Sauv. monfp. 142.

Habitat in Gallia, Sibiria. D. Gmelin.

\section{DEGAG $R N I A$. \\ NEURADA.}

I. NEURADA. Hort. upf. II\%. Chamedrifolia tomentofi malcarienfis. Pluk. alm, 97.

t. $275 . \mathrm{f}^{\circ} 6$.

Habitat in Egypto, Arabia. $\odot$

\section{PHYTOLACEA.}

1. PHYTOLACCA foliis intergerrimis. Hort cliff. 177 . americana. Hort. ups. II7. Gron. virg. I6I. Roy. lugall. 222. Phytolacca vulgaris. Dill. elth. 3 IS. t. $239 . f: 309$. Solantim racemofum americanum. Plak. alma $353 . t$. $225 . \hat{3} 3$.

B. Phytolacca mexicana, baccis feffilibus. Dill. altk. 218 t. $239 . f .308$.

Habitat in Virginin, Mexicn. 2

2. PHYTOLACCA foliis ferratik. $\dagger$

Nalagu. Rbeed. mal. 2. p. 4j.t. 26. Raj. bift. 1635 ? mfotice, Havitat in Malrbaria. 


\section{Clafjis XY. DODECANDRIA}

Stamina inter $X I$ E $X I X$ inclufive

$M O N O G \Upsilon N I A$.

\section{ASARUM.}

rkropanm. I. ASARUM foliis reniformibus obtufis binis.

Afarum foliis fubcordatis petiolatis. Hort. cliff. I $78 . F \%$ Juec. 392. Mat. med. 219. Guett. ftamp. 198. Roy. lugáb. 207.

A farum. Baub. pin. 197. Cam. epit. 19.

Habitat in Europæ nemoribus. 2

canaderfe. 2. ASARUM foliis reniformibus mucronatis.

Afarum foliis fubcordatis petiolatis. Gron. virg. 52.

Afarum canadenfe, mucronato follo. Morif. bift. 3.p.

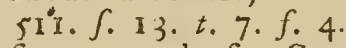

Afarum canadenfe. Corn. canad. 24. t. 25 .

Habitat in Canada. $*$

An varietas precedentis; for Suadent Folia bina; diffusdent alia.

sirginickn. 3. ASARUM foliis cordatis obtufis glabris petiolatis. Gron. virg. 162,

Afarum virginianum, piftolochiæ foliis fubrotundis, cyclaminis more maculatis. Pluk. alm. 53. t. 78.f.2. Morif. bift. 3. p. 511. f. 17. t. 7. f. 3.

Habivat in Virginia, terra Mariana, Carolina. 2

Hyporiffis. 4. ASARUM folis fefilibus imbricatis, floribus quadrifidis. Mat. med. 220.

A farum aphy!lum fquamofum. Sazv. monsp. 4.

Hypociftis. Bauh. pin. 465. Cam. epit. 96. 97. Clus. bift. I. p. 68. 79 .

Habitat in Hirpania, Lufitania parafitica cifti

\section{GETHYLLIS.}

ofra. GETHYLLIS. Hort. cliff. 493. * Habitat in Africa.

Statura Croci. 


\section{RHIZOPHORA.}

1. RHIZOPHORA foliis ovato-oblongis obtufufculis corjusta. integerrimis, calycibus feflibilibus, fruclibus cylindracco-fubulatis. Fl. zeyl. 181 . *

Habitat in India.

2. RHIZOFHORA foliis bvato-lanceolatis integerrimis, gymmovbize. radice terra fuperimporita.

Rhizophora calycum lacinits perffentibus patentibus verfus tiuctum incurvatis. Hactind. ult. 59.

Candel. Kbeed. mal. 6. p. 57. t. 31. 32. Kaj. bijl. 1760 .

Irabitat in Indix ripis Salfis. 3

5. RHIZOPHORA foliis obtufis,pedunculis bigeminatis Cande\% folio longioribus, fruetibus fubulatis.

Tfierou-Kandel. Rbeed. mal. 6. p. 63.t.35. Raj.bift.

1770 .

Habitat in Indix faljis. b

4. RHIZOI'HORA foliis acutis, fruetibus fubulato-cla- Mangic. vatis.

Rhizcohora fegmentis calycum perfiftentibus reflexis, fructu acuminato. Wach. ultr. 90 .

Magles aquatica, foliis fubrotundis \& punctatis. Plum.

gin. 13.

Mangle pyri foliis, cum filiquis longis, ficui indic $x$ aftinis. Bauh. hift. I. p. 4is. Sloan. jam. I5s. hift. 2. p. 63.

Pcckandel. Rbeed. mal. 66. p. 91. t. 34. Raj, bift. 1770.

I Haititat in paludibus Caribæarum, Malabariæ. ち

5. RHIZOPHG RA fructibus cylindricis obtufis.

Kari-Kandel. Kbeed. mal. 6. p. 59. t. 33. Kaj. bift.

cyimivica.

I 7 >0.

Habitat in uliginofis Malabarix. b

\section{SAMYDA.}

1. SAMYDA. Amon. acad. I. p. 40r.* Guilmibe. Guidonia, nlicis juglandis foilo, major. Plum. gen. 24. B Guidonia, nucis juglandis tolio, minor. Plum.ges. 24. liabitat in America calidiore. b

\section{GA R CINIA.}

I. GARCINIA. Hort. clifj. İ̈2. 
Mangoftalls. Garc. act. angl. 43 I. t. I. Bont.jav. II5. Mangoftana. Rumpf. amb. t. p. 132.t. 43 .

Laurifolia javanentis. Bazh. pin. 461. Raj. bift. 1662. Habitat in Java. is

\section{STYRAX.}

officinale. 1. STYRAX. Hort. cliff. 187. Hort. upf. 122. Mat. med. 227. Roy. lugab. 265. Sant. monsp. 305. Styrax folio mali cotonei. Baub. pin. 452 .

Styrax. Camz. cpit. $3^{8}$.

Hibitat in Syria, Judxa, Italia. to

\section{CRATEVA.}

Tapia, I. CRATEVA inermis. Fl. 2cyl. 2rr. Crateva. Hort. cliff. 484. Apiofcorodon 5 . Arbor americana triphyllos, allii odore, yoma ferens. Pluk. aim. 34. t. 137. S. 7 . Nisrvala. Rbeed. mal. 3. p. 49. t. 22. Habicat in India utraque. b

Maymzlos, 2. CRPTEVA finofa. Fl. zesl. 212.

Cucurbitifera tritolia pinofa nicdica, fruetu pulpa cydonii xmula. Pluk. alin. 125. t. 170. f. 5.

Cydonia cxotica. Bauls. tin. 435.

Covalan. Rheed. mal. $3 \cdot$ P. 37. t. 37 .

Hubitat in India. 5

\section{TRIUMFE'TTA.}

Lappnls. I. TRIUMFETTA. Hort. cliff. 210.* Hort.upS. 148. Roy. Imga'b. 476 .

Lappinla bermundenfis althioides fpicata, fruetu orbiculari majore. Platk. alin. 206. t. 245.f. 7.

Agrimonia lappacea inodora, folio fubratundo dentato. Sloan. jam. 92. bift. 1. P. 211. Raj. Srppl. 247. Habitat in Jamaica, Brafilia, Bermudis. 5

\section{PEGANUM.}

Favmala.

3. PEGANUM foliis multifisis. Hort. upf. 144. Peganum. Hort cliff. 206. Hurt.upfi 144 . Ruy. lugdb. 461.

Ruta fyiveftris, flore magno alto. Baub. pin. 336 , Harmala. Dod perngt. $12 \mathrm{I}$. 
Habitat in areni Madritii, Alcxandrix, Cappadocia, Galatid. 4

2. PEGANUM folis indivifis.

Harmala montana daurica perennis multicatilis, polyga-daurick. ix folio, flore albo. Amin. sistb. 9 т.

B. Harmala montaia, polygalx foliss, Horibus luteis. Amm. rush. 92 .

Habitat in Sibiria. $*$

\section{PORTULACA.}

1. PORTULACA foliis cuncitormibus, floribus fefili-oieracea, bus. Koy. lugdb. 473. Gron. virg. 59. Hort. upj. 146. Mat. med. 260. Dalib. parif. 158. Hall. kelv. 392. Sasz. manzos. 106.

Portulaca foliis cuneiformibus verticilatis fefilibus, toribus refflibus. Hort. cliff. 207.

Portulaca anguftifolia fylveltris, Bastb. pin. 288.

R. Portulaca latifulia lativa. Bash. pin. 288.

Portulaca domentica. Lob. ic. 338.

Habitat in Europa auftrali, India, Inj. Afcenfionis, America, (P)

2. PORTULACA foliis fubulatis alternis: axillis pilofis, piloso. fioribus festilibus.

Portulaca folis linearitus acutis, cauleprocumbente piloSo. Roy. lasgitb. 473 .

Portulaca curatiavica, angufo longo lucidoque fo'io, procumbeus. Comrr. bort. 1. p. 2. t. 5.

Portulaca coraffavica lanuginofa procunbens. Lerin. par. 215 . t. 215

Portulaca lamiginola procumbens, vermiculate foliis, ancricana. Pluk. alm. 304. t. 217. f. 7.5 .

B.Portulaca coraftavica lanuginofa, pitylii folio, creetior \& elacior, Hore dilutius rubente. Herm. par. $21 \%$ t. 214.

Portulaca curaffavica lamuginola, kali folio, erector \& clatior. Pluk. alsn. 303. t. 105. f. 4 .

Habitat in America meridionali. $\odot$

Folia alterna, fed terininalia f. Horalia octo in orbem digcfta. Flores felfiles, terminales, caiyce bitido, Strminibas quindecim, Stylo quinguefido.

3. PORTUIACA foliis ovatis gibbis, pedunculo multi- Ansasmpso. floro, caule fruticofo. 
Anacampferos foliis ovatis convexis acutiufculis. Hort. $x p \int .146$.

Anacampferos folis acuminatis. Hort. cliff. 20\%. Roy. $\operatorname{lugdb}$. $4 \mathrm{I} 2$.

Telephiaftrum folio globofo. Dill. elth. 375. t. $281 . f$. 363.

Pormlaca africana fempervirens, flote rubicundo. Conm. bort. 2. p. 177. t. 89. Raj. Suppl. 507.

Habitat ad Cap. b. fpei. b

Axille foliorum pilofie funt, EN Folia Jucculenta conjunzunt banc cum Portulacis, quanvis famina plurima Ẽ. Capfula apice debilcens.

fortsider 4. PORTULACA foliis lanceolatis convexis, peduncufrum. lis unifloris.

Portulaca curaffarica, angufto longo lucidoque folio. ilerm. par. 212 . t. 212.

Habitat in Curantao.

Calyx quinquefidus, Capsula borizontaliter difiliens.

\section{YTHRUM.}

Sajiceris. 1. J.TTHRUM foliis oppofitis cordato-lanceolatis, fioribus fipicatis dodccandris.

Lythrum foliis oppolitis. Hort. cliff. 178. Fl. Suec. 393. Roy. Ingib. 458. Guett. Jamp. 2. p. 122.

L.ythrum floribus verticillatis. Fl. lapp. 197.

Lytimachia fpicata purpurea. Basb. pin. 246.

Lyímachia purpurea communis major. Cluf. bift. 1. p. 51 .

B. Blattaria tubra fpicata major, folio fubrotundo. Morif. hift. 2. p. 490. f. 5. t. IO. f. II.

$\gamma$. Lylimachia trifolia lpicata purpurea. Bocc. mur. 167. 9. Ly limachia quadrifolia purpurea, mollioribus \& longioribus foliis. Bocc. muf. 167.

Habitat in Europa ad ripas aquarum. 2

serticillat

เมns.

2. LYTHRUM folis- oppofitis fubtus tomentofis fubpetiolatis, Horibus verticillatis lateralibus.

Lythrum foliis oppofitis, tioribus verticillatis. Gron. virg. 52.

Habitat in Virginis.

pesolatmm. 3. LYTHRUM foliis oppofitis linearibus petiolatis, floriaus dodecandris.

Lythrum foliis petiolatis. Gron. virg. 5z.

Hobitat in Virginia. 
4. LYTHRUM foliịs oppolitis linearibus, fnribus op-lircare. politis hexandris.

Lythrum foliis lirearibus, floribus hexandris Colitariis. Gran. vira. 162.

Habitat in Virginia.

Caulis filiformis ereetus angulatus Foliis oppofitis line. cribus, terininatus fpica vilajore Eु duabus lateralibus manoribus compofitis ex Floribus oppofitis remotis: Sub fingulis folio. Facies fequentis.

5. LYTHRUM follis alternis linearibus, foribus hexan- Fystopifolie, dris. Hort. upf. i 8 .

Lythrum foliis alternis. Hort. cliff. 178. Sauv. monjp.

53. Rov. Iugdb. 458. Gort. gelr. 271.

Salicaria hylfopi folio latiore. Hall. jess. 147, t. 2. $f .3$. Hyflopitolia. bauh. pin. 2 I8.

B. Lyfimachia rubra non tiliquofa. Baub. pin. 246

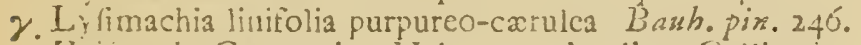
Habrtat in Germania, Helvetix, Anglix, Gallix inundatis. $\odot$

6. LYTHRUM foliis alternis linearibus, toribus tetra-kybnifolia. peralis.

Lythrum foliis linenribus. Sauv. monsp. 49.

Salicaria mituma tenuifolia. Tournef. inl?. 254.

Hylopifolia minor $f$. potius thy mifolia maritima. Bauh. bit. 3. p. 792.

Polygonum aquaticum minus. Barr. ic. 773. f. 2.

Habitat in Italix \& G. Narbonenfis uligix ofis. ()

Petala 4, ftunina 2, calyx qdentatus. Folia lineartlanceolata, alterna, ima oppofita. Flores jolitarii axillares. Calyx flipulis 2 lateralibus fulcitus. D. Sasvages.

7. LYTHRUM foliis alternis lanceolatis, panicula virgata, Horibus dodecandris.

Salicaria orientalis, falicis folio acutifimo \& glabro. Tournef. cor. 18 .

Salicaria glabra ramofiffima, longifimis \& auguftifinnis foliis. Arum. ruth. 89.

Salicaria glabra, longioribus \& anguttioribus foliis Amm. "wth. 88.

Habitat in Sibiria, Tiaturia, Dululis paniculatus Ramis alternis longis. Floses $2 f: 3$ pedicellati ex, Songula ala alterna raceini. 


\section{$D I G \Upsilon N I A$. \\ HELIOCARPUS.}

americenti 1. HELIOCARPUS. Hort. cliff. 211 * to 16. Habitat in America meridionali. 5

\section{AGRIMONIA.}

Eupatoyia, r. AGRIMONIA foliis caulinis pinnatis, fuctibus hifpidis. Hort. cliff. I79. Fl. Suec. 394. Hort saps. I18. Mat. med. 221. Gron. virg. 53. R9\%. lagdb. 240. Hall. belv. 407. Guett. Stakp. I. p.293. Delib. parif. 139 .

Eupatorium veterum r. Agrimonia. Larh. pir. $3^{2}$. Eupatorium. Fuchs. bijt. $24+4$ Cant. epit. 756 .

3. Agrimonia medio modo odotata. Morif. blief.

$\gamma$. Eupatorium vdoratum. Baub. pin. $32 x$.

Agrimonia oricntalis humilis, radice crafiflima repente.

Tozirnlef. cor. $2 \pi$.

Habitat in Europæ pratis apricis argillaceis. 2

Agrinmosi-2. AGRIMONIA foliis canlinis ternatis, fructibus glades. bris. Lart. rliff. 179: Roy. lugdb. 24x.

Agrimonia fimilis Baub. pin. $32 \mathrm{~T}$.

Agrimonoides, Cal. ecpiśr. I. p. 345. t. 144. Boerh. lugdt. 1. 17.179 .

Habitat in Italie nemoribus waicrofis bumeitibus.

\section{TRIGTNIA.}

\section{RESEDA.}

Lutrola. I, RESEDA foliis lanceoiris integris, calycibus quadrífidis:

Releda foliis fimplicibus lanceolatis integris. Hort. cliff. 212: Fir. cliff. 49. Fl. Succ. 439. Koy. lugab. 483. Dalib. parif. I60.

Luteola herba falicis folio. Baub. pir. 100.

Lutumi herba. Dod. perapt. 80.

Habitat in Europa ad was Ev pagos. ()

rarsosm, 2. RESEDA foliis fubulatis fparfis. Sazv. inonpp. 48. Refeda folis fumplicibus oblongis integris. Guett. fans?

1. p. 225 .

ReEda aiba minor. Bash. pix. soo. 


\section{DODECANDRA TRIGYNIA}

Selämoides folmanticum parvum i. Clar. hift. i. $f$. 296.5235.

Ih. abitut is Salmantica.

3. RESEDA foliis linearibus bali dentatis, foribus tetra-gimuca. gynis.

Refedil linaria foliis. Bauli pis. 10rs prodr. +1 . Burf. Il. 88.

Refeda, linaria folio, glaucum pyrenaicum, flore ha-

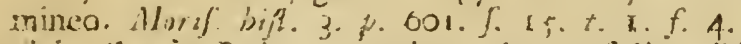

Rcleda, linarie folio, pyrenaica, glauco follo. Plak. alint 32\%. 1. 107. f 2. Raj. Juppl. Fil.

Luteola pumita pyrcraica, linaride tolio. Tosernef. ingl. $4 \geq 3$.

Inalsist in Pyrenzis.

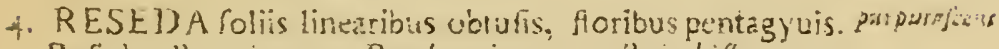

« Releda alba minor 1. Baub. piri. 100 Raj. hift. 10;4.

Sefamoides faimanticum parrum t. Clat. ra,ta p. 296.

Sefanioides foliis crafis, lloribus ex herbaceo purpura-

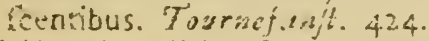

Ylatilat in collibus Salmanricis. Munipelii.

5. RESEDA foliis lancen!atis integrits, fructibus frellatis, Seintraci ies.

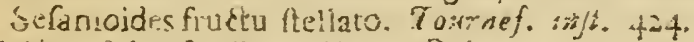

Itaintat Monfpelii in thorio Dei.

6. RESED I folis pinatis, Horibus tetragynis. Hort. upfo arba, I 4 Oด.

Refeda folis pinnatis integerrimis. Hyrt. vilft. 212

Refeda maxima. Eaub. Din. 10o. Lot. hifl. rao.

6. Refeda miror alba, foltiis dentatis. Barr. rar. 78, $t$. 58.

llab:fai Monfpelii. ()

7. KESEUA foliis omnibus rtifidis, inferioribus pinna. lu eu

tis. Hort. diț. 213. Hort. wh. 149. Kay. ingdo.

48.3.hall. Belv.315. Dalit.parif. 1,o. Gort. gelr. 310.

Reieda vulgaris. Barls. pin. soo. Ray. hifi. 1053.

Refedat lutea. Bazb. ki/. 3. p. 467 .

B. Reicua gallica crilpa. Bacr. fic. 77. ثै. 4r.f. 3 .

Refeda inaffilienfis, foliis latiorions crilpis. Plari. aim.

317. .5 .5 .9 .4 .

Itabitat in Europx auftralioris mostibas cretacris. $\odot$

8. RESEDA foliis integris trilobisque. calycibus maxi- Foverasen unis. Hort. clety. 4iz. Dalib. purif: Isig.

$$
\text { if }
$$


Refeda floribus trigynis, calycibus maximis hexaphyliis Hort. ups. 150 .

Refeda minor vulgaris. Tournef. inft. 423.

Refedx affinis Phyteuma. Bassb. pin. 100. prodr. 42. t. 42.

Erucago apula trifida \& quinquefolia. Col. expbr.267. t. 269 .

B. Refeda minor vulgaris, folio minus incifo. Toarnef. inft. 423 .

\%. Refeda minor vulgaris, foliis integris. Tournef. ixaft.42z, Pliyteuma. Baub. bift. 3. p. 386. fig.

Habitat in Gallia, Italia. ()

\section{E UPHORB!A.}

\section{* Fruticeja aculeate.}

antiguorm. I. EUPHORBIA aculeata fubnuda triangnlaris articulata: ramis patelitibus. Hort. cliff. 196. * Hort. upf. 138. Fl. zeyl. 199. Mat. med. 154 Roy. lugdb. 194. Diff. eup?. 1.*

Euphorbium antiquorum verum. Comm. bort. I p. 23. t. 12.

Schadidacalli. Rbeed. mal. 2. p. 81. t. 42.

ß. Tithymalus aizoides triangularis \& quadrangularis articulofus \& f́pinofus, ramis compreflis. Comm. pral 2r. t. 55 . f. 5 .

Hobitat in India. $\vdots$

rmarien/is 2. EUPHORBIA aculèta nuda fubquinquangularis, aculeis geminatis. Hort. cliff. 196. * Hort. ups. 138 . Roy. lugdh. 194. Difl; euph. 2.

Tithymalus aizoides fruticofus canarienfis aphyllus quadrangularis \& quinquaugularis, fpinis geminis aduncis atronitentibus armatus. Comm. bort. 2. p. 207 t. .104.

Tirhymalus aizoides lactituus $\mathbb{f}$. Euphorbia canarienfis quadrilatera \& quinquelatera, cereieffigie. $\mathrm{Pluk}$. alm. 370. t. 320 . f. 2.

Hatitat in Canariis. 5

beptngona. 3. EUPHORBIA aculcata nuda feptemangularis: fpints folitariis fubulatis Horiferis. Hort. cliff. 196. * Ryy. lugdb. T94. Difr. euph. $6 . *$

Euphorbium heptagonum, fpinis longiflimis in apice frugieris. Barb. lis $l^{\prime}$. 1 p. 258. t. $25^{8}$.

Habitat..... 
4. EUPHORBIA aculeata nuda: angelis tuberofis fipinis interftinctis. Diff. caph. 5 .

Euphorbium polygonum, aculeis longioribus ex tuberculorum internodiis prodeuntibus. 1 $n$. act. 1720. p. 386.

Tithyinalus aizoides africanus, validisfinis fpinis ex tuberculorum internodiis provenientibus. Comin. prel. 59. t. 9.

Habitat in Ethiopia. 5

Differt ab Heptagona angulis duplicntis torulolus; fpina folitariainter fingulatuberculalongtudinaliter digefta. Flores non vidi; an ex Jfinarsm apice, ut Scptagoin?

5. EUPHORBIA aculeata nuda muitangu'aris, fpiris ?o- cereiformis. litariis tuhulatis. Roy. lugdb. 195. Uilf. euph. 4.

Euphorbium polygonum fpinolium, cerei effigie. linard. act. 1720. p. 38 ,

Euphorbium cerei effigie, caulibus gracilioribus. Barh. lazkib. 1. 5.258.

Euphorbium aphyllum angulofum, forum coma denfistima. Bum. afr. 19. t. 9. f. 3 .

Tithymalus africanus 1pinolus, cereicftgie. Morif.hif. 3. p. 245. Pluk. alm. 370. t.: 231. j. 1 .

Habitat in Ethiopia. 5

6. EUPHORBIA aculeata nuda muitangularis: aculeis geminatis. Hort. cliff. ig6. * Fiort. upf. 139. Roy. ingatb. 195. Difl. exph. 3.

Euphorbium poiygomn ipinolum, cereiefigie. Ifnard. ast. 1720. p. 500. t. 10.

Euphorbium cerei cffigie, caulibus crasfioribus fpinis validioribus armatum. Coinm. bort. I. $p$. 21 . t. II. Sel. thef. 1. p. 29. t. I9. f. 2.

Euphorbium. Bash. pis. 357.

Hiabitat in Ethiopia E A Arica calidiore. 5

7 EUPHORBIA aculeata reminuda: angulis oblique tu- reriifolia, berculatis. Hort. cliff. 196. * Hos. nof. I 39. Fl. 2cyl. 300. Roy. lugdb. 194. Difl. expr. T

Euphorbiun atrum fpinofusn, folis latioribus non fpinofis. Seb. the 1. p. 18.t 9.fir.

Tithymalus aizoides arborefeens finofus, caudice angulari, nerii folio. Comm. prel. 22. 56. t. 6.

Tithymalus indicus fpinolus, nerii folio. Comm. bort. 1. P. 25.2 .13 . 
Ela Calli. Rbeed. mal. 2. 1. 83. t. 43. Habitat in India. 5

* Frutirofe inermes.

(Vel caulis nec dichotomssi, suei umbelliferus I3. 15.)

Caput medw-8. EUPHORBIA inermis imbricata tuberculis foliolo Sa lineari inftructis. Hort. cliff. 15,7. Hort. ups. I 39. Roy. lugdb. 195. Dij. enth. 8.

Planta lactaria africana. Comm bort. I. p. 33. t. 17. Tithymaius aizoides africanus, fimplici fquamato caule, chamancrii folio. Comm. prel. 58. t. 8. Eq p. 23. $57 . t . \%$

B. Euphorbium anacantum fquamorum, lobis florum tridentatis. Ifnard. ast. I720. p. 502. t. Ir.

y. Euphorbium erefum aphyllum, ramis rotundic, tuberculis terragonis. Burm. ufr. 16. t. $7 . f .2$.

8. Euphorbium humile procumbens, ramis fimplicibus co.. piofis, caule crafin fimo tuberofo.Burm.efr.20.2.10.f.1.

- Euphorbium procumbens, ramis plurimis fimplicibuz fquamolis, foliis deciduis. Burm. afr. 17. t. 8 .

$\zeta$ Euphorbium procumbers, ramis geminatis, caule glabro oblongo cinereo. Burm. afr. I8. t. 9. f. 1 .

Habitat in Astriovia. 5

Diftinctifima planta petalis palaratis. b

viminalis. 9. EUPHORBIA inermis nuda fruticofa filiformis vo* lubilis: cicatricibus oppofitis. Hort. coliff. 197. Hort. upf. 140. Diff. ezph. 9. *

Felfel Tavil. Alp. regipt. 1yo. t. Igo. Dill. elth. 368.

Habitat in Africe moritimis. 5

mantitanisa 10. EUPHORBIA inermis feminuda fruticofa filiformis flaccida, friliis ulternis. Hort. cliff. 19y. Lort. upf. 1 to. Roy.lugdo. 195. Diff. euph. 10.*

Tithymalus aphyllus mauritanix. Dill. elth. $384 . t$. 289. \& 373.

Habitat in Africa maritimis. 5

Tirucali. II. EUPHORBIA inermis libnuda fruticofa filiformis ercta, ramis patulis determinate confertis. Hort. cliff. x97. Hort ups. 139. Fl. zeyl, 197. Ry. lugdb. 195. Difr. euph. I1. *

Tithymalus indicus frutefcens. Comm. bort. x. p. 27. t. 14.

Tithymalus arbo:cicens, caule aphyllo. Pitk. pisyt. 399. f. 9 .

TiruCalli, Rbeed. mal. 8. p. - - t. 44

Llabisat in India. 5 
12. EUPHORBIA inermis fruticora, foliis dintiche Titbymaloi. alternis ovatis. Hort. iliff. 198. * Roy. Ingdb. 195. dos.

Diff. euph. 12. *

Tithymalus curatavicus myrtifolius, fore coccinen mel- mprtifolia. lituo. Ferm. pror. $234 . t, 234$.

Tithymalus curafivicus myrifolius, flore papilionaceo coccineo parvo Comm. bort. 1. D. 31. 1. 16. Mizk. alm. jón. t. 230. f. 2.

Q. Tithymaloides hurocerafi folio non ferrato. Dill.e eth. padifolia. 383.2 . 289. f. 372 .

Halitat in Curatio, at B. forte in India.

13. EUPFIORBIA incrmis, foliis ferratis petiolatis dif-haterophlla. formin ovais lanceolatis panduriformibus. Dif: cath. 33 .

Tithymalus curafavicus, falicis \& atriplicis folits va.rij, caulibus viridantibus. Plak. alm. 369.5 . 12. f.6.

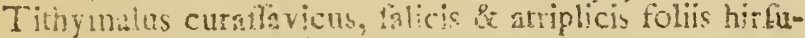
tis, callibus tubrubentious. hiorij. bift. $3 \cdot p \cdot 336$.

Habriat in America calidiore.

24. EUPHORBIA foliis oppolitis fubcoróatis petiolatis cotinifolin. cmarginatis integerrimis, caule fruticofo. $D: D$ : eaph. I5.

Euphorbia incrnis, cauic fruticoro, foliis oppontis jub. cordatis emarginatis, petiolis folia longioribus. Hort. cliff. 193. Kuy. Ing db. 196.

Tithymalus curaflavicus, folio cotini triphyllos, peta. lis Horum ierratis. Pluk. alm. 3t. t t. 230. f. 3 .

Tillymatus arboretis curaftavicus, cotmi folio. Seistore 1. p. 75. t. $46 . f .4$.

Tithymalus arborcus amencanus, cclini folio. Comm. hurt. I. p. 29. t. 15.

Havitut in Curacao. 5

15. EUPHORBIA incrmis herbacea ramofa, foilis fib-ocymoidea, cordatis integerrimis petiolo hrevioribus, toribus folitarifs. Diff. euph. 11.

Euphorbia inermis, folijs lubcordatis obutis integerrimis petiolatis, caule ramolo ereeto. Rog. lagdb. I9g.

Habital in Campechia. Unuft.

* Dickotomer (unbella bifida ant metllia).

r6. EUPHORJ3IA dichoroma, foliis ferru!atis ovatis ob-origanoiles. tufis trinerviis, panicula terminai, caulibus fimplicibus. Dif. expis. 17. 


\section{Habitat in Infula Afcenfionis. 2}

Plasta refert ita Origanum, ut primo intuitu nequeat non pro eo arnofai.

byp:ricifolis I7. EUPHORBIA dichotoma, foliis ferratis ovali-ob. longis glabris, corymbis terminaiibus, ramis divaricatis. Diff.euph. I6. *

Euphorbia inermis, foliis ovalibus oppoitis hine ferratis uniformibus, ramis alternis, caule ercetiufculo. Hort. chiff. 198. Hort. up $\int .143$ * $^{*}$ Roy.lugdb. 196. Gron. arg. 5 .

Tithymalus erectus, floribus rarioribus, foliis oblongis glabris integris. Burm. zcyl. 224. t. 105.f. 2.

Tithymalus erectus acris, parietarix foliis glabris, Horibus ad caulium nodos conglomeratis. Sloan. jam. 82. bit. 1. p. I.j7. t. 126.

Iiabitai in India. ()

hrta. 18. EUPHORBIA dichotoma, foliis ferrulatis ovatis acuminatis, pedunculis capitatis axillaribus, caulibus pilofis. Diff. cupb. 18 .

Euphurbiainermis, foliis oppofitis ovalibas ferratis uniformibus, pedunculis capitatis axillaribus. Fl. zeyl. 197.

Tithymalus botryoides zcylanicus, eauliculis villofis. Burn. z.cyl. 223. t. 104 .

Habitat in India. $\odot$

pilalifera. 19. EUPHORBIA dichotoma, foliis ferratis ovali-oblongis, pedunculis bicapitatis axillaribus, caule erecto. Diff. eupb. 19.

Tithymalus botryoides erectus, fiorum capitulis conjugatis \& longiori pediculo infidentibns. Burm, ze $l$. 224. t. 105. f. 1. Pet. gaz.t.82. f. It.

Habitat in India. $\odot$

tibnnifolia, 20. EUPI-IORBIA dichotoma, foliis rerratis ovali-oblongis, capitulis axillaribus glomeratis fubfeftilibus, caulibus procumbentibus. Diff. emph. 20.

Tithymalus foltis oppofitis oblique cordatis obtufis fer. ratis, pecunculis multiforis. Fi. zeyl. 198.

Tithymalus indicus annutas dulcis, floribus albis, caulibus viridantibes \& rubentibus. Pluk. aim. $372 . t .113$. f. 2 .

8. Tithymalus humilis ramofifimus hirfutus, foliis thymi ferratis. Burm. zeyl. 22j. t. 105. f. 3 .

Hónitut in India. $\odot$

21. EU. 
2r. EUPHORBIA dichotoma, foliis ferratis oblongis maculaia. píufis, floribus axillaribus folitariis, ramis patulis.

Tithymalus $f$. Chamælyce altera virginiana, foliis crenatis \& macula fufca eleganter notatis. Pluk. alm. 372 . t. 65. f. 8.

Habitat in America Septentrionali. $\odot$

Caulcs diçbotomi: Ramis alterais, patentibss, fuprapurpurafcentibus. Folia ovali-oblonga, trinervia, JutpiloSa, jerrata, altero latere maxima parte integerrima, tenera adbuc planta notata macsila fufca. Flores axillares, folitarii, parzi, caljce rufo.

22. EUPHORBIA dichotoma, foliis crenulatis fubro- Chamafyce. tundis, floribus folitariis axillaribus, caulibus procumbentibus. Difl. euph. 22.*

Euphorbia inermis, fotiis oblique cordatis ferrulatis uniformibus, ramis alternis, floribus folitariis. Hort. cliff. 198. * Roy. lugdb. 196. Gmel. fib. 2. p. 237.

Chamelyce. Baub. pin. 293. Cluf. hift. 2. p. 187.

Habitat in Europa auftrali, Sibiria. $\odot$

23. EUPHORBIA dichotoma, foliis integerrimis femi- $p_{\text {splis, }}$ cordatis, floribus folitariis axillaribus, caulibus procumbentibus. Diff. enph. 2r.

Euphurbia foliis fubrotundis obtufis, floribus foliiariis in foliorum alis. Guett. Stamp. 2. p. 420.

Peplis maritima, folio obtulo. Buzb. pin. 293.

Peplis. Cluf. bift. 2. p. 187. Cam. epit. 970.

Peplion. Dalech. bift. 970.

Habitat in Narbonx, Hifpaniz maritimis. $\odot$

24. EUPHORBIA foliis oppofitis integerrimis lanccola- polygonifolia tis obtufis, floribus folitariis axillaribus, caulibus procumbentibus. Diff: euph. 23. *

Euphorbia procumbens, ramulis alternis, foliis lanceolato-linearibus, floribus lolitariis. Giron. virz. $5^{8}$.

Euphorbia ininina ramofiffima anguitifolia. Raj. Suppl. 43 I.

Habitat in Canada, Virginia.

25. EUPHORBIA dichotoma, foliis integerrimis lance- Ip:racusst olatis, pedunculis axillaribus unifloris folia æquanti- bre bus, caule erecto. Dif: eupb. 21.

Tithymalus flore exiguo viridi apicibus flavis, antequam

folia emittit florens. Gron. virg. 58 .

Habitat in Virginia, Canada. 2

$$
\mathrm{Ff} 4 \quad \text { 26. F.U. }
$$


pertulazeiies.

Zeplxs.

falcato.

exigun.

Reutr.

rexura,

tuberofo.
26. EUPHORBIA dichotomia, folits integerrimis ovaibus retufis, pedunculis axillaribus uriforis folia $x-$ quantibus, caule ercto. Diff. emph. 25. *

Tithy malus perennis, portulaca folia. Few.peruv. 707. t. 2 ?

Habizat in Philadelphia. Kan. z

\section{*. Umbelta trifida.}

27. EUPHORBYA umbella trifia: dichotoma, invo, lucellis ovaris, foliis integerrimis obovatis petiolatis Dib. euph. 27. *

Euphorbia foliis obveric ovatis imegerrimis, umbella univerfali trifida triphytia. partialibas dichotomis di-

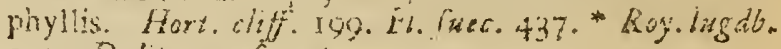
197. Daliv. partf. 150.

Pepins f. Elula rotunda. Baxh. pin. 202.

Peplus. Fosiof. hifl. 603. Dod. pempt-375.

liavus it. Eurcpx cults olcraveis. $\odot$

28. EUPHOKBIA umbella trifida: dichotoma, involucellis cordaio-fubfalcatis acutis, foliis lanceulatis obtulufculis. Diff. explo. 28.

Habisat in Europa ariftriti.

29.EUPHORBIA umbeila trifda: dichotoma, invalucellis lanccolatis, follis lincaribus. Diff. 2 kp. 20.*

Euphorbia inermis, folits atternis linearbus acaris, umbulla unverfali trifida, pitrialibus dichotomis diphyllis.

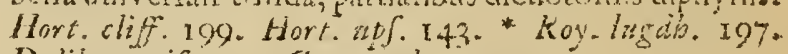
Dalib. parif. $15 \%$. Gort. gelr. 304.

Tithymalus f. Efula cxigua. Barh pin. 291.

Efula minima tragi. Davech. hift. I6gro.

B. Tithymalus 1. Efula exigna, folis obcufis. Bank. pis. 201 prodr. I32.

y. Tithymalus exiguts faxatilis. Bash. pint. 296. prodr. I32. Mrgn. ansp. 259. t. 258. Burf. XVI. 55.

Habitat sa Luatia, Gallia, Helyetia, Hifpania ister fegetes; is. Monfpelii in faxofs. \%. Padux é' Mafilix. $)$

30. EUPHORBIA umbella trifida, involucro tetraphyllo, caule nudo, foliis oblongis enarginats. Difl. euph. 26.

Euphorbia inermis, iolits oblongis obtutis emarginatis Rov. Izozdb. icg.

Tithynalus humilis, fulio lapathi. Busid cent. 2.p.2\%。 t. 23 .

Tithy- 
Tithymaius tisbcrofus acaulos, folis oblongis cucullatis \& planis. 33.urm. afr. 9. t. 4.

Tithymalus sficanus humilis, toliis latioribus ablongis, tuberola radice. Raj. Supp!. 923.

Habizat in AEgyto Eं Fithiona. 2

* Umbella quadrifida.

31. EUPHORBIA unbella quadrifida: dichotoma, fo- Lathym. liis oppoficis integerrimis. Diff. enpb. 30.*

Euphorbia inermis, foliis oppolitis lanceolatis intogerrimis, umbella univer ali quadrifida tetraphylla, viterioribus dichotomis. Hort. cliff. 140. Mat.med. 256 .

Euphorbia inernis, follis oppolstis lanceolatis, umbella miverfai trifida polyphyla, partialibus triphyilis, reiiquis diphyllis. Hort. cliff. 198. Roy. lugdt. Ig6. i) abi?. parij. 155 .

Lathy:es major. Bawh. piz. 293.

Lathyrus. Cam. epit. g68. Fuchj. hift. 454.

Hubitat in Gallia, Italia ad arrorum margines. $\delta$

* Unbella quinguefida.

32. EUPHORBIA umbella lúcquinquetida fimplici, in-foinos. volucellis ovatis: primariis triphy llis, folis oblotigis integerrimis, caule fruticolo. Diff cuph. 33. *

Euphorbia inermis fruticofa, foliis lanccolatis integerrimis, floribus folitariis terminalibus, involucris iriphyllis. Hart. cliff. zor. Ray. lugdb. 196.

Euphorbia incrmis iruticofa, rsmis ficcis pungens, foliis ad unbellas ternis fepius ovatis, floribus folitaris. Sauv. morjp. $\leq \mathbf{I}$.

Tithymalus maritimus fpinofus. Bauk, pir. 291.

Habilat is Creta. b

33. EUPHORBIA umbella quinquefida: bifida, involu-Apios. cellis obcordatis. Dif. culfh. 32.

Tithymalus ruberora pyriformi radice. Bauk. pin.292.

3 ithymalus tuberofa radice. Claf. bijt. 2. n. 190.

Habitut in Crera.

34. EUPFORBYA umbella quinquefida: bifida, involi-duicis. cellis fubovatis, foliis lanceolatis obtufis integerrimis.

Difl. euph. 35 .

Titlymalus montanus non acris. Baub. pin. 292.

l'ityula l. Liftia minor altera, tioribus rubris. Lob. is. 358 .

Habitat in Gallia Italia, Cermania.

$$
\text { F } f 5
$$


Pithysa. 35. EUPHORBIA umbella quinquefida: bifida, involucellis ovatis mucronatis, foliis lanceolatis: infunis involutis retrorfun imbricatis. Diff. euph. 36 .

Tithymalus foliis brevibus aculeatis. Bauh, pin 292.

Pithyufa. Dalech. bift. 1652 .

Habitat in arenofis Belgii, Hifpania, Italix. 2

portlandica. 36 . EUPHORBIA umbella quinquefida: dichotoma, involuccllis cordatis, foliis lineari-lanceolatis notufnfculis acuminatis reflexis.

Tithymalus maritimus minor. Raj. Syn. 3. p. $3^{1} \hat{\jmath} . t$. 24. $f$. 6 .

Habitat in Anglix Devonscbire. \&

Paralias. 37: EUPHORBIA umbella fubquinquefida: bifida, involucellis coratato-reniformibus, foliis furfum imbrica.. tis. Diff. euph. 53.

Euphorbia inermis, foliis fetaceo-linearibus confertis, umbella univerfali multifida, partialious ramofe bifidis. Hort. cliff. 200. Roy. lugdb. 193. Gort. getr. 306.

Tithymalus maritimus. Bash. pin. 291. Dod. pempt. 370. f. 1. 2.

Tithymalus paralios. Carn. epit. 962 .

Habitat in Europæ arena maritima. 2

alepica. 38. EUPHORBIA umbella quinquefida: dichotoma, involucellis ovato-lanceolatis mucronatis, foliis inferioribus retaceis. Diff. euph. 37.

Tithymalus foliis inferioribus capillaceis; finperioribus myrto fimilibus. Morif: bift. 3. p. $33^{8}$.

Tithymalus cyparifius. Alp. exot. 65. $t .64$.

Habitat in Creta, Aleppo. $z$

fegetnis. 39. EUFHORBIA umbella quinquefida: dichotoma, involucellis cordatis acutis, foliis lineari-lanceolatis, ramis Aoriferis. Diff. euph. 34.

Euphorbia inermis, toliis alternis linearibus acutis, partialibus umbella ovato-rhombeis, petalis bicornibus. Hort. up. 142. *

Euphorbia inermis, foliis linearibus acutis ad umbellain quinis ifocelibus, ad umbellulas ter dichotomas ovatotrigonis. Sauv. monlp. 46.

Tithymalus annuus, lunato flore, linaria folio longiore Morif. bift. 3: p. 339. $\int:$ 10. t. 2. f. 3 .

Tithymalus maritimo affinis, linariz folio. Baub. pin 291 ? 
Tithymalus icgetum longifolius. Rizj. angl. 2. p. jiz.* lictutat in Mauritania. $\odot$

40. EUPHORBIA umbella quinquefisat trifida: dichoto-Heliofcapla. ina, involucellis oburatis, foliis cunciformibus ferratis. Diff. esph. 42.

Euphorbia foliis crenatis, umbella univerfali quinquefda pentaphylla, partialibus tritidis, propriis ttiphyllis. Hort. cliff. I98. Fl. Jinec. 436. * Roy. lugaib. 197. Dalib. parts. 156.

Eupho:oia inermis, foliis fubrotundis crenatis. Fl. lnop. 220.

Tithmalus heliorcopius. Baub. pin. 29r. Fuchs, brjt. Sil.

Habivet in Europx cultis. ()

Limbella radii bis trifidi, dein dicbotomi iv Involucro finilia.

41. EUPHORBIA umbella quinquefida: trifida: dicho-serrata, toma, involuccilis diphyllis reniformibus, tolitis amplexicaulibus cordatis ferratis. Diff. exph. 43 .

Euphorbia inermis, foliis denticulatis: caulinis !anceolatis, umbellaruin cordatis. Hort.cliff. 200. Roj. lugbd. 197 .

Tithymalus characias, folio ferrato. Baub. piz. 290.

Tinymalus myrtites valentinus. Clas. bijt. 2. p. 189. Habitat in Narbona Hifpania. $\odot$

42. EUPHORBIA umbella quinquefida: rrifida: di-verrucosa. chotoma, involucellis inbovatis, roliis lanceolatis ferrulatis. caplulis verrucolis. Dif. esph. 32.

Euphorbiz inermis, foliis lincaribus, umbella univerfali trifida triphylla, partialibus trifidis, propriis dichotomis diphyllis, foliolis fubrotundis. Guett. ftamp. 269. Dalib. parij. 154 .

Tithymalus myrfinites, fruetu verrucx fimili. Banis. pin. 291.

Tithymalus foliis fubhirfutis ad cauiem cllipticis, fubfloribus binis fubrotundis. Hall. belv. 191.

Hatiat in Gallia, Helvetia.

43. EUPHORBIA umbella quinquefida: trifida: dicho-corollaro, toma, involucellis fuliisque oblongis obtulis, petalis membianaceis. Difl. euph. 38 .

Euphorbia inernis, toliis lancenlatis obtufis alternis, ramis floriferis dichotomis. petalis maximis fubrotuu. dis. Gron. rirg. 58.

Habitat its Virginia, Canada, 
corallioines. 44. EUPHORBIA vmbella quinquefida: trifida: dichotoma, involucellis ovatis, folitis lanceolatis, caplulis lanatis. Difr. exph. 39.

Euphorbia inemis fruticofa, foliis lanceolatis, involucro liniveriali quinquefío, partialibas tritidis, reli-

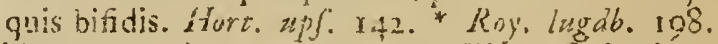

Tithymalus arborcus, caulc corallino, folio hyperici. pericarpio barbato. Bucri. lngah 1. p. 256.

Habitut in Sicilia, Manritania, Oriente. it

frinfa. 45. EUPHORBIA umbella quinquefida: trifida: bifida, involucris ovatis, petalis integris, foliis lanceolatis fubpilolis adice ferrulatis.

Euphorbia follis aiternis ex ovali-?anceclatis, umbellis diphyllis fubtritotis, capulis erectis murcatis, canle implici. Gnel. Jib. 2.p 226. t.93.

Tithymalus palcitris villofus molior eredus. Barr. rar, 41. t. $88 \%$.

Tithyrnalus inermis hirfutus. Bazb. pin. 292? prodr. 135 ? Mass. monfp. 255.

Habitat in Sibiria. 2

liabilus exase $\mathrm{E}$. paluftris, ut facile pro eadem fumerctur, codernate tempore furet, fauto tanen mator. IOlia latu-ionceolata, alterna stringe vix mukf fefe piLofa, apice ina terizilime Jerrate, ut vix objercientas" ferratura. Umbeila cam umbellulis lateralious itas coacervate, wi pimaria difficilius ersatur, later petalis of incilucris. Flores primarit majculi pentapetali; reliquibermaphroditi tetrapetali:petalis trassierfe ozalibus. Fructus verrucofi of yilis albis fubtiliblmis adjperfi. Rami fteriles ex alis foliorume inferiorum, at ex furrmis alis pedunculi mobellutifer:

rvientitu. 46. EUPHORBIA umbella quinquefida: quadrifida: dichoroma, involucclis fitorotundis acutis, foliis latceolatis. Difr. eupls. 40.

Euphorua incrinis, folis lanceolatis, invollicro univerfali quinquefido lanccolato, partiali tetraphyllo fubrotundo, propriis diphyllis. K'a'. lugdt. 198.

Tithymalus orientalis, falicis folio, caule purpureo, thore magno. Tournef. cor. 2.

Ilabitul in oriente.

pletyphylos. 4\%. EUPHORBIA umbella quinquefida: fubquadrifida. dichotoma, involucellis primariis tetraphyllis, foliis feratis lanceolatis fefilibus. Difl. euph. 41 . 


\section{DODECANDRIA TRIGYNIA. ¿G}

Euphorbia inermis, foliis altemis lanceolatis amplepicaulibus fubferratis, umbella univerfali quinquetida pertiphylla, partialibus bifiajs. ILert. upf. $4 \mathrm{r}$.

Euphorbia incinis, folitis lanceolatis, unbella univerfali partialiunque prima quinquefidis : fecunda trifica: reliquis bilidis. Roy. Jugdb. 198. Dalib. parif. 156.

Tithymaius arvenfis latifolius germanicus. Bash. pin. 201.

Tithymalus platyphyilos. Fuches. bift. $8 \mathrm{r} 3$.

Habitat in agris Gallix, Anglix, Germanix. $\odot$

* Umbelliz multifida.

48. EUPHORBIA umbella mulcifida: dicinotuma, in-Ejulw volucellis fibcurdatis, petalis lubbicornibus, ramis fterilious foliis unitornibus. Diff. euph. 48 .

Euphorbia incrmis, folis lanceolato-linearibus, involucri univeralis fultis quinis ovato-acuris, parrialis temorbiculatis. Hort. upf. I 4 I. Sauv. monjp. 47.

Euphorbia inermis, foliis ligulatis patalis ad umbe!lam quinis ovato-oblongis acutis, bracteis trignnis. Sauv. monsp. 51?

Tithymaius lithofpermi majoris folio. Magn. monsp. 304 ?

Efula minor. Dalech. hilt. I653. Dod. pempt. 374.

Habitat in Germania, Belgio, Gallia. 2

Flores omner fertiles: petala flavejicentia, 4. objoletebicornia? Fructus glaber. Umbella castis laterales dicbotoma.

49. EUPHORBIA umbella multifida: dichotoma, invo- Cyparifiar. lucellis fubcordatis, ramis terilibus foliis fetaceis, catinis lanceotatis. Diff. euph. 49.

Euphorbia inermis, foliis conjertis linearibus, umbelia univertali multida, partialibus dichotonis: foliolis fubrotundis. Hort. cliff. I99. * Hort. upf. 142.* Roy. lugdio. 197. Dalib. pasrif. iss. Gort.gelr. 105.

Tithymalus cyparifius. Baub. pin. 291. Dalech. bijt. 1644.

Tithymalus cyprefinus. Tabern. bift. 990.

Habitat in Mlinia, Bohemia, Helveria, G. Narbonenfi.

50. EUPHORBIA umbella fuborifida: bifida, imolu. Movirites. celiis fubovatis, tolis fathulatis patentibus carnoris mucronaris maraine leabits. Diff. euph. 5 2.

Euphorbia incrmis, fulie lupcrioribus reflex is iatoribus lanceulatis, umbella unirerlali trinda, pariaibus bisidis. Hort. chets. 159. Hors. Hefl. If1. Eu- 
Euphorbia inermis, foliis lignlatis fpinula terminatis, ad umbellam duodenis, bracteis trigonis ipinula terminatis. Sazu. monpp. $5 \mathrm{I}$.

Tithymalus myrlinites latifolius. Baub. pin. 296.

Tithymalns myrfinites legittimus. Clus. hijt. 2. p. 189. Habitat in Calabria, Monfpclii. 2

Caules multi, pedales, deflexi, virides, inferns a casu folior um cicatrifati. Folia alterna, pathulata, coriacea, concava, glauco-viridia, patentia, mucronata, margine foujcabra, superiura reflexa. Umbella 7-9 fida, radis semel bifiais. Involucrum univerfale foliolis 7-9, ovatis, tcruioribus, acutis; Involucella dipbylla, fubcordata, latiora, concava, acuta, m."gine fubfcabra. Flores inira involucella primaria so jecuidaria maficuli, religzi bermaphroditi. Calyces ore Jerrati. Petala 4 , flava, bicurnic apicibus teretibus nitentia. Capfulix glabre.

paluftris. 51. EUPHORBIA umbella multifida: fubtrifida: bifida, involucellis ovatis, foliis lanceolatis, ramis fterilibus. Diff. euph. 47.

Euphorbia foliis lanceolatis, umbella univerfali mulrifida polyphylla, partialibus trifidis triphyllis, propriis dichotomis. Hort cliff. 200. H\%. juec. 438. * Mat. med. 255. Roy. lagab. 198. Dalis. parif. 153 . Gort. gelr. 307.

Tithymalus paluitris fruticolus. Bash. pin. 292.

F.fula major. Dalech. bift. 16,3 .

Habitat in Succia aufrali, Germania, Belgio. *

byberna. 52. EUPHORBIA umbella fexfida: dichotoma, inyolu= cellis ovalibus, foliis integerrimis, ramis nullis, caprulis verrucolis. Diff. euph. 50 .

Tithymalus latifolius hifpanicus. Bauh. pin. 291. Tubern. bijt. $98 \%$.

Tithymalus hibernicus, valculis muricatis erectis. Dill. eltb. $387 . t$. 200 . f. 374 .

Habitat in Hibernia, Sibiria, Auftria, Pyrenæis. 2

Dendroider. 53. EUPHORBIA umbella multifida: dichotoma, invo lucellis fubcordatis: primariis triphyllis, caule arboteo. Dif: euph. 51 .

Tithymalus myrtifolius arboreus. Baxh. pin. 290.

Tithymalus dendroides. Cam. epit. $9^{1}, 5$.

Habitat in. Italia, Creta, Intulis Stæchadum. 
54. EUPHORBIA umbella multifida: dichotoma, invo-Amyzdaloslecellis perfoliatis orbiculatis, foliis obtufis. Diff. des. euph. 46.

Tithymalus characias amygdaloides. Bauh. pin. 290 Husitat in Gallia, Germania.

55. EUPHORBIA umbella multifida: dichotoma, invo-fyluntica. lucellis pertoliatis fubcordatis, foliis lanceolatis integerrimis. Diff.euph. 45 .

Tithymalus lylvaticus, lunato flore. Bauh. pin. 290. Murif: bijt. 3. p. 335.f. I0. t. 1.f. 3. Barr. ic.830. 839. 829.

Tithymalus lunato fore. Cal. ecphr. 2. p. 57. t. 57.

Habitat in Germania, Gallia, Hifpania, Italia. b

56. EUPHORBIA umbeila multifida: bifida, involucel-Characiat. lis perfoliatis enarginatis, foliis integerrimis, caule frutefcente. Dill: esph. 44.

Euphorbia inermis, foliis lanceolatis, umbella univerfali multifida, partialibus dichotomis, involucris femibifidis perfoliatis Hort. cliff. 199. Hort. up . 142. * Roy. lugdb. 197.

Tithymalus characias rubens peregrinus. Baub.pin.290.

Tithymalus characias I. Cluj. bijt. 2. p. I 88 .

Tithymalus foliis pini. Baub. pin. 292.

Habitat in Gallia, Hifpania, Italia. b

Caules quadripedales, frutico $f$, $\int e c u n d x m$ annos ramofi, crafjitie digiti. Rami annotini fuperne craffiores, fubzillofi, infra folia adjperfs cicatricibus transwerfis. Ramus florifer primo vere ex apice ramorum excrefcit, fruticat, perit, cum ad latera ba eos novi rami prodeunt. Folia lanceolsta, coriacea, Jubtomentofa, viridia, reflexa nervo wtrinque elevato, verfus flores latiora obtufara. Umbella parva, conferta, terminalis, fesfilis: Radiis numerojis femed bifidis. Involucrum universale polyphyllum, fublanceolatum, parvum, refie$x$ um; Involucella perfoliata, femibifida. Flores intra involucella primaria masculi, reliqui hermapbroditi; onnes Petalis 4, purpureis, humidis. Germina vil$\log a$

\section{PENTAGYNIA}

\section{GLINUS.}

I. GLINUS.

A.lfine lotoides ficula. Boc6.Ji6.21, t. I I. Morif. hift. 2.

lotoilles.

p. 552 .

Alfi- 


\section{DODECANDRIA DODECAGYNIA.}

Alfine heliutropio cognati. Cup. cath.

Portuiaca bxtica, luteo fiore, Spuria aquatica. Earr.rar. $4 \%$. t. 336.

Habitat in Sicilia, Hifpania ad folia.

\section{DODECAGTNIA.}

SEMPERYIVUNF.

mborsum. I. SEMPERVIVUM canle arborefcente laviramnfo. Sempervinum caule inferne nudo lavi ramofo. Hork. cliff. 179. Hort. up. 18 . Ry. lug dit. 4$)^{5}$. Sedum majus arbotelcens, Holculis candiais. Baut. pin. 282.

Seduin majus lecitimam. Claj. מaja. z. p. 43 . Habitai is Lafianis; Creta, Corryra, Zacintho. 5.

comatienfe, 2. SEMMERVIVUMV cauix foliorum ruderibus lacero, foliis retulis.

Sempervivum canle infra folio lacero, fuliis cuncitormibers: Cummis Cubrotundis. Hort. eliff. $17 y$. Ro\%. lugib. 457 .

Sedum canarium, foliis cmnium raximis. Comin.bort. 2. p. 180 . t. 95 .

Sedum majus calnariuni acrulon, pilis ad oras foliornm hifpidis. Pluk airn. 3.jo. t. 3I f.f. I. Raj. Juopl. 3 G2. Habitat in Canaris. 5

tectorur. 3. SEMPERVIV U R. folis ciliatis, proprginibus patentibu's.

Sempervivum folis andicalibus carnofis ciliatis, caulinis imbricatis mombranaceis, corymbo racemolo reficxo. Hort cliff. 179. Fl. juec. 375. What. mod. 222. Roy. lig6. 457.

Scmpervivum majus alterum C. Rarba jovis. Dol. feinpt. 127.

Seduin majus vulgare. Baub. pim. 2.93.

Habitat in Europis tectis ef collibus. 2

glebiferm. 4. SEMPERVIVUM foliis ciliatis, propaginitus globofis.

Sempervivum foliis radicalibus in globum congefis ci. ilatis, propagiaibus globolis. Hurt. cliff. 180. Roy. Inodib. $45 \%$.

Sedun majus vulgari finile, globulis decidentibus. Murij. bijt. 3. y. $472 . \int .12 .2 .7 . f . i 8$. 


\section{DODECANDRIA DODECAGYNIA. $\$ 6 s$}

Scdum vulgari magno fimile. Bawb. bift. 3.p. 688. Hobitat in Rutheno D. Ginelin. Z

5. SEMIPERVIVUM foliis pilis intertextis, propagini- aracinosnea bus globolis.

Sempervivum folils radicalibus in globum congeftis: vil lis reliculatim connexis. Hort. cliff. $180 . *$ Roy'. lugatb. 457.

Sempervivnm rubrum montanum gnaplialoides. Col. ecphr. I. p. 292 t. 291.

Scdum montanum tomentofum. Baub. pin. 28 .

Habitai in Alpibus Italia, Helvetix. $z$

6. SEMPERVIVUM foliis integerrimis, propaginibus montann?, patulis.

Sedum rofulis liberis, foliis levibus. Hall. belv. 393.

Sedum alpinum, rubro magno tlorc. Bash. pir. 284 .

Sedum inajus montanum, foliis non dentatis, Horibus rubentibus. Baub. pin, 283 .

Sedum minus, Hore ruberte. Befl. ey/t. vørn. 6. t, 8, f. 2 .

Habitat in rupibus Helveriz, 2 


\section{Claffis XII. ICOSANDR I A. MONOGXNIA. CACTUS. \\ Echino Melocadtifubrotundi.}

Y:amกiilla Yir.

т. CACIUS rubrotundus tedus tuberculis ovatis barba tis. Llart. cliff. 18I. Hort. un!. II ). R6y. lagdi. 278 Erhinollelocactus minor lacteficens, uheiculis 1 mam. millis inajoribus. Herm. par. 136. t. I 36.

Ficoides f. Welocactus mamirillaris giabra lulcis carens fructum fum undique fundens. Pluk. alms. $14^{\circ} .2$. 29. $f:$ I .

Ficoides $f$. Ficus amcricana fpharica tuberculata iactefcens, Hore albo. Cuinm. Burs. I. p. IC5. t. 55. Hibitat in Emerica caliaiois repibus. b

Melceatras. 2. CACTUS fubrotundus quatuordecim-angu'aris. Hort. cliff. I81. Hort. ups. Is Roy. lugdb. 297.

Melocastus india occidentalis. Baub. pin. 384.

Echinomielocactus. Cluj. cxot. 92.t.92.

Habitat in Jamaica, Amcrica calidiore. th

* Carei erecti julintes per lé.

hepsegonas. 3. CACTUS ereetus oblongus feptemangularis. Hort. cliff. 181. * Koy. lugdb. 279.

Habitat in America. 5

tetragonus. 4. CACTUS quadrangularis longus erectus: angulis compreflis. Hort. cliff. I8I. Hort. upf. I I9. Ray.lugdb. 380.

Cereus ereetus minor, fructu fpinn $\mathrm{fo}_{1}$ coftarum numero varians. Jlerm. par. 117.

llabitat in Cuiacao, Anterica calidiore. 5

hexngonss. 5. CACTUS erectus fexangularis longrus. Hort. clif. I 81. Hort. \#pj. II9. Roy. luzitb. 279.

Cereus furinamentis. Epb. N. C. 3. P. 394. t. 7. 8

Cereus crectus aitifimus furinam cnfis. Horm. par. Ir 6 Kaj. dendr. $2 \hat{3}$.

Liabitat Surinani. 5

6. CA. 
6. CACTUS libquinquangularis erekius longus articu-pertazonus.

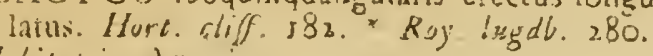

Ilatitat in America.

7. CACTTUS erectus iongus o tangularis: angulis com-reasnibus. prellis undatis, fpinis lana longioribus. Hort. clid. 132. Lisy. lugitb. 279.

Habitat ir America aslidiore. $b$

8. CACTUS erectus longus fubnovenanguiaris: angulis Inmyingus. obfoletis, fpinis iana bievioribus. Hoa l. cliff. 182. Kay. lixgdb. 279.

Cerens curaffavicus eręus maximus, fructu rubro non fpinolo, janagine fiavefcente /lerni. par. 115.t. 115. Habital in Curacao. क

9. CACTUS eredtus iongus lubodtangularis: angulis ob pernoinus. tulis. Hort cl:fi. 191. Hort. upf. 120. Roy. lugcib. 279. Cercus crectus, fructu rubro nun finino Ho Herm. par. 114.

Ccreus pervianus fpinofus, fruetu rubro nucis magnimedisie. Bakb. pin. 458 .

Euphorbii arbor cerei effigite, ${ }_{1}, 06$. ic. 2. p. 25.

Hainat in Jamaica, Feru aplicis aridis muritivis. \$

10. CACIUUS creerus articulatus lub-decanguiaris: ar-Royens. ticulis fubovatis, Ipinis ianam squantibus. Roy. lag sob. 279.

Habitat in America. D

* Ceren repentes radiculis laieraleious.

Ix. CACTLS repens fubquinquangularis.

Caetus icandens, angulis quinque piuribusque obtusis.

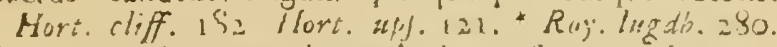

Cereus americanus major articulatus, fore maximono. cle le aperiente f. fiavifinmm udoren fpirante. Vuik. befp. i. p. !33.t. 234 .

İnoshio in Jamaica, veraCruce. t

12. CAC'TUS repens decemanzularis

Castus icandens. angulis deren obfoletis. Klort. "lf. grintifiurus: $32:$

Cereus minor lcandens polygonus fpinofifimus, thore purpureo Erbet. tat. 2. f. 2 .

Ficoides americanum $f$. Cereus minima ferpens americana Pluk. alm. 148 . 6. $158 . \% 6$.

labilai in America caldiore. b

$$
\mathrm{C}: 2 \text { 33. CA. }
$$


miangularis. I 3. CACTUS repens triangularis.

Cactus triangularis fcandens articulatus. Hort. cliff. 182. Hort. upf. 121. Roy.lugdb. 280.

Ficoides americanum, $f$. Cereus creEtus criftatus, fo= liis triangularibus profunde canaliculatis. Pluk. alm. 147. t. 29. f. 3 .

Hisbitat ia Brafilia, Jamaica.

* Opuntia comprefe articulis proliferis.

monilifor 14. CAC'TUS articulato-prolifer, articulis globofis fpimis. nofis glomeratis.

Melocactus, ex plurimis globuiis opuntix modo nafeentibus, fpinolifimus. Plum. Spec. 20.

Habitat in America calidiore. 5

conntia. 15. CACTUS articulato-prolifer, articulis ovatis, fpinis fetaceis.

Cactus compreffus articulatus ramofifimus, articulis o. valis: fpinis fetaceis. Hort. cliff. 183. Hort.up $\int .120$. Gron. virg. 54 Roy. lugdb. 280.

Opuntia vulgo herbariorum. Bash. bift. I. p. 154.

Ficus indica, folio fpinoso, fructu majorc.Bauh.pin.458. Habitat is Amerlca, Peru, Virginia, nunc in Hifpana, Lufitania. 5. 4 .

Ficus indica. 16. CACTUS an riculato-prolifer, articulis ovato-oblongis, fpinis fetaceis.

Cactus compreflus articulatus ramofus, articulis ovato- . oblongis: fpinis fetaceis Hort. cliff. 183 . Hort. $" p$ S. I 20. Koy. lizgdb. 280.

Habitat in America calidiore. 5

T*n: i7. CACTUS articulato: prolifer, articulis ovato-oblongis.: fpinis fubulatis.

Cactus compreflus articulatus ramorus, articulis ovatooblongis, fpinis fubulatis. Hort cliff. $18_{3}$. Hort.ups. 120. Rey. lugdb. 280.

Tuna major, fpinis validis flavicantibus, flore gibbo. Dill. elth. 396. t. 295 . $f .238$.

Opuntia major, folio oblongo rotundo: rpinis longis \& validifimis, flore luteo. Sloan. jam. 103. bift.2.p. I 49. $t .224 . f: I$.

Habitat in Jamaica Ẽ America calidiore. 5

cochenilifer 18. CACTUS articulato-prolifer:articulis ovato-oblongis fubinermibus.

Cackus compreffus articulatus ramofus, articulis ovato. oblongis fubinermibus. Hort. "pj". 121 .

Tu- 
Tuna mitior, flore fanguineo, cochinillitera. Dill. elth. 399. t. 297. f. 383 .

Ficus indica major lavis f. rpinofa vermiculos proferens. Plut alm. If o. t. $291 . f .3^{\$} 3$.

Opuntia maxima, toliu oblongo rotundo majore ipintlis nonnullis \& innocentibus abtito. Sloan. jain. 194. bift. 2. p. I52. z. 8. f. 1. 2.

Habitat in Jamnica Eo America calidiore. b

19. CACTUS articulato-proliter, articulis cylindrico.-curafostcus. ventricofis compreflis.

Caktus tereti-compreffus articulatus ramofins. Hort.cliff. 182. Hort. up. I20. Roy. Iugd6. 290.

Ficus indica i. Opuntia curaffavica minima. Comm.bort. I. $p .107 . t .56$.

Ficus indica l. Opuntia minor caulefeens arbufenlx in modum, ramis cincritiis fpinofifima. Pluk. alim. I 47. $\therefore=8 \mathrm{I} \cdot f .3$.

Habitat in Curacao. b.

20. CACTUS prolifer enfiformi-compreilus ferrato-rc-Phyllanthr. pandis.

Cactus foliis enfiformibus obture ferntis. Hort. cliff. I 83. Koy. lugath. 281.

Cereus ícolopendri folio brachiato. Dill. eltb. 73.t.64. f. 74 .

Phyllanthos americana, finuofis foliis longis. Plak.alm. 296. t. 247 . f. 5 .

Habitat in Bralilia, Surinamo, Americe meridionali. 5

2r. CACTUS caule tereti arboreo fpinofo, foliis lanceo-Perefkio. iato-ovatis. Hort. upf. 122.

Percicia. Hort. cliff. I 22. Roy. Iugdó. $28 \mathrm{~s}$.

Perefkia aculeata, Are albo, fructu flarefcente. Pism. gen. 37. Dill. elth. 305. t. 227. f. 294.

Millis americana fpinoia, portulace folio, fructu folioto, temine reniformi fiplendente. Cormm. bort. I. p. I35. t. 70 .

Portulaca americana latifolia ad foliorum ortum lanugine obdicta, longioribus aculeis horrida. Plak. alm. I $35 . t .215 \cdot f .6$.

Habitat in America calidiore, Jamaica, Margaretha. 5

22. CACIUS caule tercti arborco ipinofo, foliis cunci- portulacifo. formibas reculis.

Opuntia arbor fpinofifima, foliis portulaca cordatis. Pluk. Sper. 6 .

$$
\text { G ig } 3
$$

Ha. 
Hehitat in Arerica calidiore. 5

Iruitus bujous monine foliis adjperfus, uti procedentis.

\section{PHILADELPHUS.}

co\%oxirius. I. FHILADELPHUS foliis fubdentatis,

Philadelphus. Kort. cliff. 185. Hort. upf. 122.

Sjuinga albar. Philadelphus athenxi. Bauh. pin. 399.

iruter coronarms. Cinj: lirft. 1.p. 55 .

Hibbtal in - .. - b

Flos primarius quinquefidus calyce, corolla, frifillo, copjula. Pbil. bat. I $7 \delta$

inodotus. 2. PHILADELPHUS foliis integerrimis.

philadelphas fore albo majore inodoro Caiesb. car. 2. p. $8 .+.68_{4}$ Hibitat in Callolina.

Guanar. ₹. PSIDIUM.

\section{PSII IUM.}

Fidium ranis tetragonis. Hort: $z p$ f. $1 \geq 2$.

Pfidium caule quadrangulu. Hort. cliff. 184. Fl. zeyl. 192.

Guajava alba acida, fruetn rotundiore. Pluk. num. 181. t. $193 \cdot \hat{\jmath}^{\circ} .4$.

R. Guajava alba dulcis. Comm. bort. I. P. I2 I. t. Úz. Habitat in India. D

\section{EUGENIA.}

snatercents. I. FUGENIf foliis integerrimis, pedunculis ramofis latcralibus. Fl. zey'. I8\%.

Perlici officulo truetus malaccenfis rubens. Baub.pin.

Nati-fichambu Rhecd.mal. I.p. 20.t. 18. Raj. bift. I 479 . Habisat in India. b

'sumbs. 2. LUGENIA foliis integerrimis, pedunculis ramofis terminalibus. Fl. zeyl. 189

Perfici officulo fruetus malaccentis ex candido rubeícens. Baub. pin. 441 .

Mlalacca Cchambu Rbeed mal. I. p. 27. t. 17. Kaj. bifl. 1478

Habitat in India. 5

s:pifod 3. EUGENIA foliis integertimis, pedunculis unifloris lateralibus. Fl. zeyl. 189. 
Eugenia. Ruy. lugdb.265.

Engenia indica, myrti folio deciduo, flore albo, fruequ luaveruhenti molli leviter fulcato \& odoro. Mich. gen. 220. t. 10S.

Myrtus indica, toliis rigefecntibus latis ar recurvis parum odoratis. Till pij. I I 7. t. 44.

Habitat in India. t)

4. EUGENIA foliis c:enatis, pedunculis terminalibus, aeutangula. pomis oblongis acutangulis. Fl. zeyi. 19u.

Thieria-famftravadi. Kheed. mai. 4. p. 51. t. 7. Raj. bift. 1480 .

Habitat in India. $b$

5. EUGENIA foliis crenatis, racemis longiflumis, po-rasemnfa. Inis ovatis. Fl. z.e\%l. 191.

Saniftravadi f. Cabarfiumbu. Rbeed. Mal. 4.p. II. $t$. 10. Ra1. hift. 1479 .

Hebitat in India. to

\section{MYRTUS.}

1. MSRTUS fioribus folitariis: involucro diphyllo. Hort. commanis. cliff. 42.Hurt.up! I23.Mat.med.224. Rov.lugd6.269.

Myrtus communis italica. Bauh. pis 408 .

2. Mytrus batica latiolia 1. 2. Bash. pen. 469. Chuf. betica. bift. I. P. 65 .

$\gamma \cdot$ M y rtus minor vulgaris. Bauh. pin. 469 .

tarentina.

d. Mytus foliis minimis \& mucronatis. Baxh.pir. 469. mucronats.

E. Myrtus fylvettris, foliis acutiffmis. Bauh. pin. 469 .

$\hat{\imath}$. Myttus angultifolia bxtica. Baub. pin. 469 .

э. Myrtus latifolia belgicn. Baub. pin. 469.

9. Myrtus latifolia romana. Bash. pins. 468.

acueifolix. engurtifolia

belgica.

romana.

Habitat in Europa aufrali, Alia, Africa. 5

2. MYRTUS floribus folitariis, pedunculis nudis, peta- brafliana. lis lubciliatis.

Arbor brafiliana, myrti laurca foilis inodoris. Comm burt. I. P. 173 . t. 89.

Habitat in Bratilia. D. Hucbend. o

Folia ozta, obtula, petiolata, glabra, appofite. Flores fotitarii, axillares, pedunculati, pedzuculo ophyllo. Corolla petala 4. J. 5, lacero-ciliata, obverje ouata, concavia, reflexa. Stamina circiter 40.

3. MYRTUS pedunculis muitinoris, foliis lanccolato-emmini. ovatis. Fl. zey\%. ISs. Habitst in Zeylon. 4. MYR 
Zeylarien, 4. MYRTUS pedunculis multifloris, foliis ovatis fubpetiolatis.

Myrtus foliis ovatis acuminatis obtufiufculis, Fl, zeyl. 182 . *

Myrtus zeylanica odoratifima, baccis niveis monococcis. Herm. lugdb. 434. t. 435 .

Myrioides foliis ovatis. Hart. cliff. 489 . Roy.lugdb. 535.

Habitat in Zeylona. 5

androfaroi-5. MYRTUS pedunculis multifloris, foliis fubovalibus des. feflilibus. Fl. zeyl. 184.

Habitat in Zeylona. 5

iaryopbylla-6. MYRTUS pedunculis multiforis, foliis obovatis. Fl. ta. zeyl. 183. Mat. med. 225 .

Caryophyllus aromaticus ind. occid. foliis \& fructu rotundis. Pluk. alm. 188. t. $155 . \mathrm{f} .3$.

Habitat in Zeylona. 5

Pimenta. 7. MYRTUS foliis alternis. Fl. zeyl. 186. Mat. med. 225.

Myrtus calycibus absque appendiculis. Hort. cliff. 5or. Myrtus arborea aromatica, foliis laurinis. Sloan. jam. I6r, bift. 2. p. 76. t. I91. f. i.

Caryophyllus aromaticus americanus, lauri acuminatis foliis, fructu orbiculari. Pluk. alm. 88.t. 155.f. 4 . Habitat in India. $\hbar$

\section{PUNICA.}

Granatum. 1. PUNICA. Hort. cliff. 134. Hort. ups. 122. Mat. med. 223. Roy. lugdb. 267.

Malus punica fylveftris. Bazb. pin. 438.

Malus punica fativa. Boub. pin. $43^{8}$.

Malus punica. Cam. epit. 130. 13 1 .

B.Balauntia flore pleno najore \& minore. Baub.pin. $4 j 3$.

Habitat in Hifpania, Italia, Mauritania Solo cretaceo.

AMYGDALUS.

Werfica. AMYGDALUS foliorum ferraturis omnibus acutis. Hort. cliff. 189. Hort. wp. 123. Mat. med. 230. koy. lugdb. 267.

Perlica móli carne \& vulgaris. Eaub. pin. 440.

Perfics rubra. Cam. epit. 145 .

B. Nuciperfica, qux nucum juglandium faciem repra-

contat. Bazh. pin. 440. Raj. hift. I si6.

Haviout .... 方

2. A- 
2. AMYGDALUS foliis petiolatis: ferraturis intimis commmis.glandulolis. Hort. cliff. 186. Hort. ups. 123. Mat. med. 22\%. Roy. lugab. 267.

Amygdalus fylveftris. Bauh. pin. $44^{2}$.

B. Amygdalus iativa. Baub. pin. 441 . Amygdalus. Dod. pempt. 798.

$\gamma$.Amygdalus amara. Tournef. inft. 627. Habitat in Mauritanix Sepibus. $b$

3. AMYGDALUS foliis petiolatis bafiattenuatis. Hort. nma. cliff. I86. Hort. up. I 24. Roy. lugdt. 267. Amygdalus indica mana. Pluk. alm. 28. t. 11. f. 3. Armeniaca perfica foliis, fructu cxfucco. Amm. ruth. 273. t. 30?

Habitat in Afia Septentrionali?

\section{PRUNUS.}

I. PRUNUS floribus racemolis, foliis deciduis bafi fub- Padas. tus biglandulolis.

Padus glandulis duabus bafi foliorum fubjectis. Hort. cliff. 185. F\%. Suec. 395. Roy. lugsib. 269. Holl. helv. 397.

Padus foliis annuis. Fl. lapp. 198.

Cerafus racemola fylveftris, fructu nou eduli. Baub. pin. 451 .

Habitat in Europa. 5

2. PRUNUS floribus racemofis, foliis deciduis bafi anti- Eirginicno. ce glandulofis.

Cerafus fylveftris, fructu nigricante in racemis longis pendulis phytolaccx inltar congeltis. Gron. virg. S4. Roy. lingdi. 537.

Cerafi fimilis arburcula mariana, padi folio, flore albo parvo racemofo. Pluk. mant. 43. t. 339. Catcsó. car. I. p. 28: t. 28.

Habitat in Virginia. $b$

3. PRUNUS floribus racemofis, foliis fempervirentibus l:sitariea, eglanduIofis.

Padus foliis glandula defitutis. Vir. diff. 42 . Hort. upS. 120 . Ray. legdb. 26 n.

padus foliis feinpervirentibus ovatis. Hort. clif. 18r.

LauroCerafus lufitailica minor. Dill. elat. 193. 159. $f$ : 193.

Hulitat in Lufitania, Penfylrania. bु

$$
\text { C. } \text { g }^{\circ} \text { 4RL'- }
$$




\section{ICOSANDRIA MONOGYNIA.}

Latercera. 4. PRUNUS floribus racemolis, foliis fempervirentibus $\int$ H. doito bigiandulotis.

Padus giandulis duabus dorfo folionum innatis. Y Y ir clitf. 42. Llurt. aff. 126. Ray. lagdb. 26g.

Padus foliis fempervirentibus lanceolato-ovaris. Hlort siiff. 185 .

Cerafus folio laurino. Baub. pin. 450.

Lauroccralus. Cluf. hift. 1. p. 4. Cam. bort. t. 23. Habitat in Trapezunte unde s/s Europam verit 1576.5

Mabaleb. 5. PRUNUS foribus corymbofis, foliis ovatis.

Cerafus folis ovatis. Vir. cliff. 43. Wall. belv. 30 \%. Roy. luzdb. 268. crenatis. Hort. cliff. $48 \%$.

Cclafo affinis. Baub. pin. 451 .

Mahalen. Cain. epit. 91.

Habitat in Helvetia. 5

Ameniacr. 6. PRUNUS floribus reffilibus, foliis fubcordatis.

Primus folis ovato-cordatis. Hort. eliff. 186. Hort. upf. I24. Roy. lugdb. 263.

Mala Armeniaca majora. Baub. pin. 442.

Malas Ameniaca majora, nucleo dulci. Bash. pin. 442. Malus Armeniaca minor. Bauh. pin. 442. Habitat ... -

fibirica. 7 PRUNUS foribus feffilibus, foliis ovato-oblongis. Armeniaca betula folio \& facie, fructu exfucco. Ainm. ruth. $272 . t .29$.

Habitat in Sibiria

An baec Jatis diftincta a precedenti?

Cerafus.

8. PRUNUS pcdunculis fimplicibus, foliis ovato-lanceolatis conduplicatis.

Coraius foliis ovato-lanceolatis. Vir. sliff. 43. Hort. zpf. 125. Mat. med. 233. Roy. lugdib. 267. Hall. belv. 396.

caproniana a. Cerafus fativa rotunda rubra \& acida. Beub. pin. 449. rolea, B.Cerafus hortenfis, flore rofco. Bus, pin. 450.

plena, $\quad \gamma$. Ccrafus hortenfis, flore pleno. Bnuts. pin. 450.

dulcis, \&. Cerala alba dulcia. Baub. pis. 450.

juliana. $\varepsilon$. Cerafa carne tenera \& aquofa. Baub. pin. 450.

atiana. $\zeta$. Cerafus fylveftris ac major, fruetu iubdu!ci: nigro colore inficienre. Baub. pin. 450.

suftera. भ. Ceratus acidiffima fanguineo fucco. Baub. pin. 450.

pumila. 9. Cerafus pumila. Bash, pin. 450.

avium. Cerafus racemofa hortenfis. Bumb. pin. 450. 
y. Cerala fativa majora. Bash́p. pir. 450.

Bizarcll.

C. Cerafa craffa carne dura. Busb. pin. 450.

Duracina.

Fisbitat in Furopa. b.

9. PRUNUS pedunculis fimplicibus, foliis lanceolato-donefica. ovatis convolutis.

Prunus inermis, folis lanceolato-ovatis. Ilyrt. cliff. i 86. Hurt. ups. I 2.t. Mat. med. 232. Res. lugab. 268

Pruntis. Bazb. pin. 443 .

Q Pruna majora dulcia \& parva atro-carulea. Bauh. pin. Damafcena. 443. r. $^{2} 3$.

P. Pruni magna crafra fubacida. Baub. pin. 443 . hungarica.

j. Prusa oblonga carulea. Bash. pin. $443 . \quad$ julian.

ع. Pruna nigra: carne dura. Bauh. pin. 443 . pernicona.

Y. Pruna coloris cer ex candido in luteum palicfente. cerea. Bazb. pin. 443 .

*. Pruna magna tubra rotunda. Basb. pirz. 143 . acinaria. 9.Pruna rotunda fiava dulcia mali amplitudine. Bauh. inalicormis. pin. 443 .

1. Pruna angulto maturefcentia minora \& aufteriora. Baub. augurama. pis. 443 .

* Pruna parva precccia. Buah. pin. 443. precor.

ג. Pruna parva ex viridi Havécentia. Baub. pin. 443. cereola.

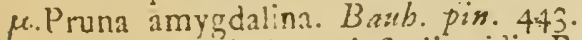

¿. Pruicoli albi oblongiufculi acidi. Baub. pin. 443 . galarenfis.

- Pruna ex flaro rufelcentia unixti faporis gratifima. Brignola. Bawh. pin. $44 j$.

$\xi$. Prunus fruau rotundo nigro-purpureo dulci, Bauh.pin. myrobalan.

Habitat in Europa auftralioris locis elevatis. 5

10. PRUNUS fpinofa, foliis lanceolatis. Hort. cliff. 186. Ipinosa.

Fl. fuec. 397 . Inat. med. 231. Roy.lugab. 265. Mall.

helw. 355 .

Prunus fylveftris. Baub. pin. 444. Tabern. is. 992. Huoitut in Europa collibus apricis. 5

\section{DIGTNIA. \\ CRATAGUS.}

1. CKAT 王GUS foliis ovatis inæqualiter ferratis fub-dris. fus tomentofis. Hort. cliff. $18 \%$. H\% Juer 39\%. J'ir.

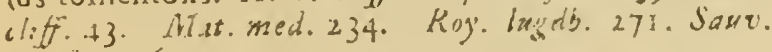
manjp. 30\%. 
Alni effigic, lanato folio, major, Baub. pis. 452.

Aria. Dalech. bilt. 202.

Sorbus alpina. Baub. bift. 1. p. 65.

fuecica. B. Cratægus incrmis foliis ellipticis ferratis transveraliter inuatis fubtus villofis. Fl. lapf. 199.

Sorbus fylseftris anglica Raj. bift, 1459.

Habitat in Europa, Hclvetiæ, frigidis: $\beta$. in Succia, Anglia. 5

serminalis.

2. CRAT \&GUS foliis cordatis feptangulis: lobis infimis divaricatis.

Cratægus foliis cordatis acutis: lacinulis acutis ferratis. Hort. cliff. $18 \%$. Koy. lugdb. 271 . Sauv. monsp. 286.

Sorbus torminalis \& Crategus theophrafti. Bauh. hift. I. p. 63 .

Sorbus torminalis. Carn. epit. 162.

Mefpilus, apii folio, fylveftris non fpinofa r. Sorbus torminalis. Baub. pin. 454.

Habitat in Anglia, Germania, Helvetia, Burgundia. 5

rensinea. 3. CRAT REGUS foliis ovatis repando-angulatis ferratis glabris. Hort. cliff. 187. Hort.ups. 126. Grom. virg. 54. Roy. lugdb. 272.

Meipilus, apii folio, virginiana (pinis horrida, fruetu amplo coccinco. Pluk. alm. 249. t. 4u. f. 4 .

Mefpilus fpinofa 1. Oxyacantha virginiana maxima. Angl. bort. 49.t. I3. f. 1 .

Habitat in Virginia, Canada. b

$V$ ariat cum valiais Spinis lateralibus $\mathcal{O}^{\circ}$ absque $\int p i n i s$.

Crus ga!ii. 4. CRAT FEGUS foliis lanccolato-ovatis ferratis glabris, ramis fpinotis.

Mefpilus aculeata pyrifolia denticulata fplendens, fruetu infioni rutilo, virginienfis. Pluk. alm. 249.t.40.f. I. Mefpilus pruni folis, fpinis longifimis fortibus, fruEtu rubro magno. Clayt. virg. 55 .

someniofa. 5. CRAT BEGUS foliis cuneiformi-ovatis ferratis fubangulatis fibtus villofis, ramis pinofis.

Mefpilus inermis, foliis orato oblongis ferratis fubtus tomentofis Gron. virg. 55 .

Hobitat in Virginia. b

viridis. 6. CRAT \#GUS foliis lanceolato-ovatis fubtrilobis fer. ratis glabris, caule inermi.

Mefpilus inermis, foliis oblongis integris acuminatis ferratis parvis utrinqne viridibus. Gron. virg. 163.

Habitat in Virginia. b

7. CRA- 
7. CRAT FEUS foliis lanceolatls ferratis, caule inermi, indicn. corymbis fquamolis.

Habitat in India. 5

Frutex ramis inermibsu. Folia lato-lanceolata, obtuls ferrasa, crafiufcula, petiolatu. Corymbi termisales pedunculis fquamofis, bracteis fubulatis.

8. CRAT ÆGUS fuliis obtulis bitrifidis ferratis Hort. Oxyasantra. cliff. 188. F7. furec. 399. Roy. lugdb. 272.

Mcipilus, apii folio, fylveftris fpinola f. Oxyacantha. Bash. pin. 454 .

Oxvacantha 1. Spisa acuta. Dod. pempt. 751

Hübitat in Europx pratis apricis duris. to

9. CRATAEGUS foliis obtufis bitrifidis fubdentatis. Azarolut, Meffilus apii folio laciniato. Baub. pin. 453 .

Metpins Aronia veterum. Baub. bift. I. p. 67.

(3. Metpilus orientalis, apii folio, fubtus hirfuto. Pock. Aronia. orient. 139.1 .85 .

Habitat Florentix, Monfpelii. 5

Differre videtur ab Oxyacantha Sola magnituaine, wt Jorbus domeftica a fylveftri; in bac quadruplo majora -mnia; Jpina in culta pauciores Es Sape nulle.

\section{TRIGTNIA.}

\section{SORBUS.}

1. SORBUS foliis pinnatis utrinque glabris. Hall. belv. nucupa:ta. 250.

Sorbus foliis pinnatis. Hort. cliff. 188. Fl. Suec. 400.

Mat. med. 235. Roy. lugdb. 274 .

Sorbus fylvefttis, foliis domefticx fimilis. Baub.pin. 415 .

Sorbus fylveftris. Cam. epit. 161.

Haéitat in Europx frigidioribus. क

2. SORBUS foliis pinnatis fubtus tomentolis. Hall. belv. demeffico. 351

Sorbus fativa. Bawb. pin. 415.

Sorbus legitima. Cluf. I. p. 10.

Habitat in Europac calidioribus. 5 


\section{$P E N T_{\alpha} A G Y N I A$}

MESPILUS.

germanicn. I. MESPILUS incrmis, foliis lanccolatis integerrimis fub. ius tomentofis, calycibus acuminatis. Hort. cliff. 139. Hol kPf. 129. Mat. med. 236. Roy. lugdb. 270. Bector lipj: r'74.

Melpilus germanica, fulio laurino non furato. Baub. pin. 453 .

Melpilus. Dod. pernpt. $80 \mathrm{r}$.

E. Mefpilus, folio laurino, major. Bars. pin. 453. Klicilat in Europa usiflruli. t,

Pyracantha. 2. MESPILUS fpinora, foliis lanceolato-ovatis crenatis, calycibus fructus obtulis. Hort. chef. 189 . Fr. cliff. 44. Roy. izgdb. 27 .

Oxyacantha diofcoridis 1: Spina acuta, pyrifolio. Bauid. timo +54 .

Yia urit. Dalech. bit?. I64.

Habitas in Galloprovincia, ltalie Jepibus. 5

mbutifolia. 3. MESPILUS inermis, folis lanccolatis crenatis fubtus tomentolts. Hog't. cisff. 189. Roy. lugdl. 271 :

Sorbus virginiana, folio arouti. Hern. hagdb. 578 . 1. 669.

Sorbus aucuparia virginiana, Coliis arbuti, Breva. proulr. i. p. 15 .

Habilat in Virginia. b

Airetonchier 4. MESPILUS inermis, foliis ovalibus ferratis, cauliculis hirfutis.

Mefpilus inermis, folits ovalibus ferratis acutis. Hort. rlif: 189. Roy. lus did. 271.

A ini a figic lanato folio, minor. Basb. pin. 452 .

Vitis idad III. Cluf. bifl. 1. p. 75 .

Habitat in Helvetia, Auftria, Galloprovincia. 5

Tenella adhuc berba ramis petiolis peduratis fulies fubtus villofo-tomentof $e^{\mathrm{e} t}$, adult ib fruttiferis glabra lanum exuit.

canadenfis. 5. MESPILUS inermis, folyis ovato-oblongis ghabris ierratis. Cauie inermi.

Mefpilus inermis, foliis fibtus glabris obverle-ovatis. Grun. virr. 54 .

Ilabotat in Virginia. Canada. b

6. $M E$ - 


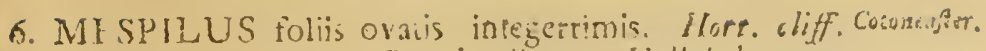
189. Fl. Jaes. 403. Roy. lugdb. 273 Hall, belu. 352. Cotoneafter folio rotundo non firrato. Bavio. pin. $45^{2 n}$ ChamxMefpilus getineri. Cllif. hift. 1. p. 60.

ChamaMcfpilus cordi. Bauh. pin. 452 .

llabitat in Luropa frigidioris collibus africis ingue $P_{Y}$ renteis, Ararar. 5

7. MESPILUS inerinis, foliis ovalibus ferratis glabris, Chnue Mefloribus cafinaris, bracteis deciduis linearibus.

Cratzgus foliis ovilibus utn inque glabris plicatis indivilis ferratis. Hurt. cliff. 497 . Vir.cliff. 43 . Roy. lugalb. 272. Hall. helw. 353 .

Cototieafter folio oblongo ferrato. Bauh. pin. $45^{2}$.

Cotonealier forte geineri. Cluf. bift. 1: p. 63 .

Habitat in alpibus Aultiacis, Pyrenaicis. $b$

Folia pruni argute ferrata lerraturis terfus apicem inflexis tensiffiris, utringue nuda. Stipule lireares, periclis longiores, decidur. Corymbus 'x alus pedunculatus, canglobitus in capitalum, pedunculo jubvillolo, foliis dimidio brevior. Bractea inter flure: limeares, flore loxgiures, coloratic, deciduat.

\section{PYRUS.}

1. PYRUS foliis rerratis, foliis bafi productis. Hort.cliff. communis. 190. Hort upf. 130. Fl. Juec. 401. Koy. lugdb. 266. Hall. bel'. 351 .

Pyrus fiviveftris. Baub. pin. 439. Dod. peinpt. 351. B Pyrus Beigansotta gallis. Bauh. hifl. x. p. 45 .

y. Pyrus boni chriltiani. Bauh. hift. 1. p. 44 .

¿. Pyrus jefi f. mofchatcllina rubra. Basb. bifl. $! p \cdot 44$.

ع. Yyra dorfalia eademque liberalia dieta. Baub bift. 1.p. Voloma.

Habitat in Europa. o

2. PYRU 5 foliis ferratis, pomis baficoncavis. Hort cliff. Malus.

189. Hort. upf. 130. 11. Juec. 402. Hat. med. 237.

Roy. bugd6. 260 . Hall. belw. 35t.

Malus lyitreftis. Baub. pin. 435. Dod. penept. 790 fylveftris.

B. Malus pumila, qua porius frutex quan arbor. bauh. pradilica.

Min. 433.

Malus pralomila. Bamb piz. 433.

piraforils.

i) Malus fativa, fruetu languinei coloi is ex auttero fub-rubelliara. dulci. Tournef: infl. 635 .

6. Mala curlipendula dic?a Buas. bijt. 1. p. 21.

celliaus. 
Eprrotica. そ. Poma orbiculats. Ruell. ftirp.

Habitat in Europa. 5

coronaria. 3. PYRUS foliis ferrato-angulofis.

Malus fylveftris, floribus odoratis. Gron. virg. sr. Habitat in Virginia. b

cyionia, 4. PYRUS foliis integerrimis. Hort. cliff. I60. Mat. med. 238. Roy. lugdb. 267.

Malus cotonea fylvettris. Baub. pin. 435.

B. Malus cotonea major. Bauh. pin. 434.

\%. Malus Cotonea minor. Baub. pin. 434.

Cotonca \& Cydonia. Lob. bift. 580 .

Hiabitat ad ripas petrofas Danubii.

\section{TETRAGONIA.}

fruticofi. 1. TETRA GONIA foliis linearibus. Roy. lugdb. 2 , 0. Tetragonia. Hort. cliff. 188. Hort. ups. 126.

Tetragonocarpus africana rutilans, foliis longis \& anguftis. Comm. hort. 2. p. 205. t. 103.

Evonymo affinis africana, portulaca folio. Seb. thef.2. p. I3.t. II. f. 8 .

Habitat is Athiopia. $\#$

herbores. 2. 'TETRAGONIA foliis ovatis. Rog. lagdb. 450

Tetragonocarpos africana, radice magna craffa \& caino.

12. Comm. bort. 2. p. 203. t. 102 .

Habitat in Ethiopia. $b$

\section{MESEMBRYANTH EMUM.}

* Albis coirollis.

nodiforam. I. MESEMBRTANTHEMUM foilis alternis tetetiufculis obtufis ciliatis. Hort. 2pe. I 29.

Kali crafulx minoris foliis. Baub. pin. 289. Morif, hift. 2. p. 6ro. . 5. t. 33. f. $\%$.

Kali neapolitanum aizoides repens. Col. exphr. z. p. 72. t. 73 .

Kali II. Alp.regypt. 125. t. 127.

Habitat in ZEypto, Neavoli. (-)

eryfallinm 2. MESEMBRYANTHEMUM foliis. alternis ovatis obrutis undulatis. Hort. cliff. 216 . Hort. 2 f. 127. Roy. lugdl. 28I.

Mefembryanthemum cryftallinum, plantaginis folio undulato. Dill. elth. 231. t. 180. f. 211 . 
Ficoides atricana, folio plantaginis undulato micis arzenteis adfperfo. T Bradl. Shicc. 5. t. Is. f. $4^{3}$.

Hoititat in Arica? (o)

3. MESEMBRYANTHEMUMI foliis femiteretibus gericsitio Horibus [cifilibus axillaribus.

$r \times m$.

Metembr. ramis undique papillofis folic cralioritus. Hort. clitf. 218 . Roy. lizgdio. 295.

Méremb. cipenie geniculiñorum ncapoittanum ereditum. Dill. elti. 271 . t 20 r f. $26 \pi$.

Ficoides ncapoiltana, forc candido. H. Brodl. fuce. 5. t. I7. f. 34 :

Ficoides caperile, folio tereti, frore albido, Pet. gaz. $\therefore 7^{\prime S}, y_{0} 3$.

Hutitut ad Cap. b. Spei. t

4. MESEMBRYANTHEMUM foliis iemicylinda-neatiorm ccis, floribus quadificis.

Mefemisr. (oliis tubulatis femicylindricis lavibus $1: x$ connatis apice recurvis. Hort.cly. 220. Koy lugdb 286

Niejembr. nottiforum, fore intus candido extus phae nicec odorntilimo. Dill. eith. $273 . t .206$ f. 262.

B. Melemb. noftillorum, flore intus candido extus lira. mineo odcratiffimo. Dill. ellh. 27.4. $t \cdot 205 . f \cdot 26 j$.

Hizbital in Africa. To

Caipd buic auadrifidus, ftyli is fruEtas quadribcuiaris.

5. MESEMBRYANTHEMUM foliis fubtrigonis IU- un:vel!nenn: bulatis, caule erefto, corymbu trichotomo.

Meiembr. frutefcens, Horibus albis umbellatis. Dill. cith. 277 . t. 208. f. $26 t$.

Ficoides africana erecta teretifolia, floribus albis unu.beliatis. Herm. par. 166. 2. 166. Bradl. füce. 4.p. I 2 t. 44 .

Habitat ad Caput b. Spei. b

6. MESEMBRYANTHEMUM acaule, foliis fubterc- calamiforme. tibus connatis, foribu; oftagynis.

Bicferribr. calamiforme. Dill. ellh. 239. t. 186.f. 238.

Ficoides capenfis humilis, cepar folio, forc famineo, Erradi. Jucc. 2. p. 10. f. 19.

Haustat ad Cap. b Spei. 2

7. MESEMBRYANTHEMUM foliis lanceoiatis pla- Tripolixw, nis crenulatis. Hort.eliff. 317 . Hort. ng. I2R. Rov. lug it 283 
Mefembr. tripolii folio, flore argenteo. Dill. eltb. 230 2. 179. f. 220 .

Ficoides africanum, Mefembryarithemum $\mathrm{f}$. Fic us aizoides major procumbens, tripolii folio magis luccllento denticulis fimbriato. Pluk.mant.77.t. $329 . f .4$. Hakizat in Africa. $\delta$

$$
\text { * Ribbirundis corollis. }
$$

bellidifforam 8. MESEMBRY ANTEIEMUM acaule, foliis triquett is linearibus apice trifarian centatis. Hort. sliff. 218.* Roy. luga'b. 233 .

Mefembr. bellidiforum. Dill. elth. 244. 2. 187, 2.233. Hizbitat in Africa zै

seltoidr. 9. MESEMBRY ANTHEMUM caulefeens, foltis deltoid.bus triquetris dentatis. Hor" c cliff. 218.* Roy.luggdb. 284.

Mefembr. deltoides \& dorfo \& lateribus muricstis. Bill. elth. 255 . t. 195 . f. 246 .

Ficus aizoides africana ercita, folio triangulari breviufculo fimbriato, thoribus roleis odoratis. Volk. befp. 223 . i. 224. f. 5 .

f3. Mefembr. deltoides, dorfo \& lateribus muricatis, maius. Dill. elth. 254. t. $195 . f .2+7$.

y. Mefembr. deltoides, non dorfo fed latcribus muricatis. Dill. elth. 253. t. 195. $f .243 \cdot 244$.

Habitat in Africa. 5

butbotsm, 10. MESEMBRYANTHEMUM foliis apice barbatis. Hort. cliff. 216. * Hort. upf. 127. Roy.lugdb. 282. Mefembr. radiatum, ramulis prolixis recumbertibus Dill. elth. 245. t. 190. f. 234 .

Ficoides capentis, tereti folio: apicibus hirtis. Pet. gaz. t. 77. f. 6 .

Ficoides capenfis frutefcens, folio tumido extremitate flellata, flore purpuren, Bradil. Succ. I. p. 6:1.5. Ë is. Ficus aizoides, folio tereti in villus radiatos abeunte, flo. re rubro. Vole. befp. 222. ¿. I 24. f. 6.

B. Melenbr. radiatum humile, foliis minoribus. Dill. elth. 245. t. 190. f. 235 .

$\gamma$ Mefembr. radiatum humile, foliis majoribus. Will. elth. 249. 2. 190. f. 236.

Habitat ad Cap. b. Spei. 古

whitsm, 16. MESEMBRY ANTHEMUM caule hifpido, folii 3 CY'indricis deflexis. 
Mefembr. caule hifpido.Hort.chff.217. *Rey.lugdb.282

Merembr. pilorum unicans, Hoie Caturate purpureo. Di:!. cisk. 289. t. 277 . f. 278.

Q. Mcicmor. pilofum micans., Hore purpureo fallidiore. Dill. cltb. 29c. t. 214. f. 280 . 270 .

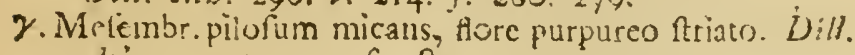
elin. 299. 2. $215 . f .29$ :

Ficoldes i. Ficus aizoides africana, folio longo renui, fole aurantio. Bradl. Facc. 4. p. 13. 2. $3 \%$.

Ficus aizoides reretitolia, foliis crytitino rore clegarmter confpertis, Horibus ditute roicis. t’olk. basp. 2.21. t. 224. f. 2.

Habial: ad Cap. b. Spei. 5

12. MIESEMBRY ANTHEMUM caulc foliisque pube- viliofun rcentibus. Ifort. cliff. $217 . *$ Roy. lazil6. 282.

Hubitat in Africa. 5

13. MESEMERY ANTHEMUM fotiis fubularis fub- fabmm us uidique fcabris. Hort oliff. L19 " Hurr. upf. 127.

Mefembr.purpureum icabrum, faminibus expanfis Dill. clith. 25\%. t. 197. f. 250.

Ficcides capensis, triangulari folio acuto, flote purpu. reo. Pet. gas. t. $77 . f .3$.

B. Melenbr. purpurcum ficabrim, ttaminibus colledtis. Dill. olth. 260. t. 197. f. 251 .

Habitat in Arica. b

14. MESEMBRY ANTHEMUMarticulis caulinis ter- meinntum minatis in folia acuminata fubtus clemeta. Hort.slif: 218. Ros. luzdb 28.

Mefembr. peroliatum, foliis monoribus diacamthis. Dill. clib 250. c. 193. $f$. 239.

r Ficoides afra folio triangulari giauco perfoliato brevislimo apice f́pinofo Bradl. fucc. 3. t. 27.

6. Mefembr. perfoliatum, foliis majoribus triacanthis. Dill. clth. $25 \%$ t. 133. $f .2\} 0$.

licoides africana frutefcens perfoliara, tolio trianguiati glauco puriclato. Bradl. jucc. 5. F. 13. t. 46.

Habitat in Atrica. b

15. MESEMIBR Y ANTHEMUM fpinis ramofis. Hort, finatwm. chot: $210 . *$ Roy. lugdb. 23 is.

Metembr. fruticefcens, ramis tracanthis Dill. elth. $276 . t .208 . f: 265$.

Ficoides atricaua, aculsis iongiffimis \& foliolis nafcend. $\mathrm{H} \mathrm{h}_{2}$ 
bus ex foliorum alis. Tournef. att. 1705. P. 316 Bradl. Juce. 4 !. t. 39 .

Habitat in Africa. 5

totherofum. 16. MESEMBRYANTHEMUM foliis fubulatis papillolis, radice capitata. Hort. cliff. $316 .{ }^{*}$ Roy.lug dib. 282. Mefembr. fruticefcens, radiceingenti tuderofa. Dill.eltb. 275 . t. $207 . f .264$.

Habstat in Africa. 5

kentifoliatm. I7. MESEMBRYANTHENIUM foliis fubulatis femiteretibus glabris internodio longioribus. Hort.cliff: 220 .

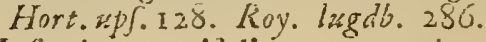

Mefembr. tenuifolitum proctmbens, folio tenuiore viridi, flore coccineo. Dill. cith. 264. t. 201. f. 256. Ficoides capenlis humilis terenfolia, fore coccineo. Bradl. Succ. 1. p. 13. t. ?.

Ficoides africana minor procurrbens, folio tenuiore viridi, flore coccineo. Morif. bift. 3. p. ro7. f. 12. t. 8. f. 6 .

Habitat in Africa. it

Aipuhcerm, I $\overline{8}$. MESEMBRYANTHEMUM folits fubulatis fubcylindraceis obfoicte papillofis diftinctis. Hort. cliff. 220. Roy. latgdh. 287.

Mcfembr. fiutefcens, tore purpureo rariore. Dill.elth. 279. t. 200 . f. 267.268.

Halitat in Africa. b

yrafifo:inm. 19. MESEMBRYANTHEMUM caule repente fem:cylindracco, foliis femicylindricis lævibus connatis a. pice triquetris. Hort. cliff. $21 \%{ }^{*}$ Roy. lugdb. 283. Mcfembr. crafififolium repens, tiore purpureo. Dill. ilth. 266. t. 201. f. 257.

Ficoides africana reptans, folio triangulari viridi, thore faturate furpurco. Bradl. fucc. 4. p. 16, t. $3^{8}$.

Habitat in Africa. 2

falcatm. 20. MESEMBRYANTHEMUM foliis acinaciformibus ditlinetis lævibus, ramis teretibus. Hort.cliff.219.* Roy. lugab. 2.85 .

Mefembr. falcatum minimum, flore purpureo parvo. Dill. elth. 288. t. $213 \cdot f .276$.

Ficoides afra, folio triangulari enfiformi brevifimo, flore dilute parpurafecnte filamentofo. Bradl. Sikc, Se $p$ - 1) $t .42$.

Habitat in Africa. b 
* Inteis corollis.

21. MESENIBRYANTHEMUM foliis acinaciformibus nsinaciforme conmatis: angulu carinali fcabris, tamis angulatis. Hort. cliff. 219. Roy. lizedb. 284.

Mefimbr. acinacitorme, fiore ampliffi mo purpureo. Dill, purpureun elth. 282 t. 211 . $f: 270$. Ev t. $212 . f .27 t$.

G. Metembr. fălcarum maius, thore amplo luteo. Dill. eleb. flarum. 283 . t. $212 . f .2 \% 2$.

Ficoides $r$. Ficus aizoides africana major procumbens, triangulari folio fruetu maximo eduli Herin. lazall. 244. t. 245. Murif. bift. 3. p. 506. S. 13. t. . f. .1.

y. Mefembr falcaturil majus, Hore purpureo mediocri. Dill. with. 285 . t. 211 . f. 273 .

Habitat ad Cap.b. Soei. 5

22. MESEMBRYANTHEMUM folits fubtriguetris bicolor. feabris, cerollis biccloribus.

Mefembr. tenuifolium fruticefcens, fore crocco. Dili. citb. 207 . t. 202. f. 258.

Ficoides 1 . Ficus aizoides africana minor eresta, triangulari folio visidi, fiore intus sureo; foris purpureo.

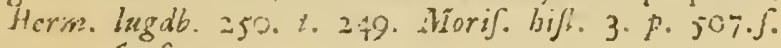
2. 2.6 .5 .4 .

Ficoides capenfis firutcicens, folio tcreti punetato, petalis luteis. Brail. Jis.c. 1. 7.8 . t. 7 .

fiabitat in Africa. ${ }^{\circ}$

Corolls extus purpures, intus fiazic.

23 MIESEMBRYANTHEMUTM foliis fubulatis tri-ferralum. quetris: angulo carinali retrorfum jeiratis. Hort.cliff. 219. Roy. lug $16.28+$.

Mclembr. ferratum, flore acetabuliformi luteo. Dill. elth. 249. t. 192. f: zis.

Fistitat in Africa. b

24. MESEMRRYANTHEMUM foliis fubulatis fub- misons. cylindraceis papillolis dininetis, caule icabro. Hort. iliff. 220. * Ro1. lugdb. $2 \$ 7$.

Nefembr. micans, thore phenicco: filamentis atris. Dill. elth. 292. t. 215. f. 282 .

Flcoides capenlis, tereti folio, thore croceo. Pet. gaz. t. $7 . f .9$.

Ficoides capenfis, folio tereti argenteo, petalis perplurimis aurantiacis. Bradl. fucc. I. p. 9. t. S.

Havitat ad Cap. b. Spei. b 
piemdens. 25. MESFMBRYANTHEMUM foliis linearibus obfolete triquetris diftindis: fummis imbriatis lavibus. Hort. cliff. 220.

Melembr. foliis confertis filendentibus, flore pailido. Dilleltb. 270, t. 204. 6.260 .

Ficoides capentis frutefcens, foliis terctibus confertis glaucis, dore albo. Bradl. Succ. 1. p. 7. t. 6.

B Mefembr. Foliis triquetris gibbis oppolitis imbricatis, ramis inferme nudis. Hort. cliff. 220. Roy. Ingdb. 286.

Habitat ad Lap. b. Spei. D

sof?ratкm 26. MESEMBRYANTHEMUM acaule, foliis remicylindricis comnatis externe tuborculatis. Hart. cliff. 219. Roy. lugdh. 285 .

Mefembr. roltrum arde referens. Dill. elth. 240. $t$. 186. f. $2>9$.

Habitut in Africa

Eerruculathm.

27. MESEMIBRYANTHEMUM foliis fübcylindricis acuris connatis arcuatis lavibus. Hort. chiff. 220. Hort. ups. 128. Roy.lug db. 285.

Mefembr. foliis verruculiformibus, floribus mellinis umbellatis. Dill. elth. 268. t. 203. f. 259 .

Hubitat in Africa. 5

3:писнm. 28, MESEMBRYANTHEMUM folits fubulatis triquetris ftrictis acutis: puntis pellucidis obfoletis fparfis. Hort. cliff. 220. Roy. lugdb. $2 \$_{3}$

Mcfembr. Icabrum, Hore fulphureo convexo. Dill, eith. 156: $t .196 . f .248$.

Ficoides africana frutefcens, folio triangulari breviore glauco. Morif. bift. 3. F. 507. f. 12. t. 5. f. 3.

Ficnides afra, caule lignofo, ereeta, folio triangularl enfiformi fatbro, hore lureo magno. Bridl. Suci. 4. p. $15 . t .32$.

Fícuides $r$. Ficus ainoides arricana minor erekta, folio triangulari glauco, flore luteo. Herin. lugdb. $247 . t$. 248 .

Hlabitat in A frica. 5

loreum. 29. MESEMBRYANTHEMUM caulcfcens, follis fubulatis fennicylinitricis recurvis connatis longis. Hor: aliff. 19. * Hort. upf: I2S. Roy. lugdb. $28 \%$.

Mefembr. Foliis corniculatis longioribus. Dill. elth 262. t. 199. f. 2.53. 254 .

Ficoides capenlis, folio trizngulati, Hore lutco intus pal. lido. Pet. gaz t. 77 f. 10. 
6. Mefernbr. foilis corniculatis becriuribus. Dill, eith. 261. t. 198. f.. 252 .

Ficoides africana reptans, folio triangulari craforo longisiino, fore intus luteo ertus aurauriaco. Brad!. Succ. 4. p. 18. t. 40 .

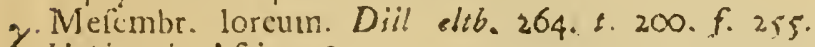

Habitat in Africa. Z

in. MESLMBRYANTIIEMUM foliis plantis oppofi-tortsofwm. tis ovatis a cuminatis connatis integerrimis. Hart. clitf. $217 . *$ Roy. lagdb. 2d 3.

Mefembr. tortuolum, ioliis fempervivi expanfis. Bill. eirh. 234. 5. 18: f:223.

Ficoides capenfis, folio lato acuto, Horc albo intus luter,

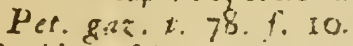

Ficoides africana procumbens, toliis planis conjugatıs lucidis. Bradl. Succ. 3. p. 7. t. 16 .

Q. Mefembr. tortuofum, fulits fempervivi congeftis. Dill. elth. 2.33.t. I83. f. 22 2.

Ficoides capenfis procumbens, olce folio, llore albo medio crocen . Bradl. fuic. 2. p. 7. 7. 16.

Habtius ad Cap. o Spei. $飞$

Petain exteriora albiua, inteliors fiava funt.

31. MESEMBRYANTHEMUM fubacan]e, foliis ci- -inerm. listo-dentatis. Hort. cliff. 218. * Roy lagdb. 2§3.

Mefembr. rietum caninum referens. Dill. elit. 241. $\mathrm{i}$. caninum. 185. $f .231$.

Ficoides capenfis humilis, folio triangulari prope fummitatem dentaio, Hure fuleo. Brsall. fucc. 2.p. 8.t 17.

B. Mefembr. rictum felinum reprefentans. Dill. eltb. 240. fel num. 2. 187. f. 230.

Ficoides afra, folio triangulari enfiformi craffo brevi ad margines laterales nuultis majoribus foinis aculea10. Mart. cent. 30. 1.30.

Ilabilat nd Cap. b. Spei. 2

32 MESEMBRYANTHEMUM foliis dolabrifornit detam form bus. Hort. cliff. 219 . Kov. lugdi. 287.

Melcmbr. folio dolabritormi. Dill. eltin. 248. t. I91 f. 237.

Ficoides capenfis humilis, foliis cornua cervi referentibus, petalis iuteis, noetitera. Bredl.jucc,1,p.11,t.10.

Habibat in Africa. 2

33. MESEMBR.YANTHEMUM foilis difformibus difformt. iscy. Ixyde. 28.7. 
Mefembryanth, foli:s difformibus, flore luteo. Dill, eith 252. t. 194. $f$ : 241. 242 .

Ficoides Mefembryanthenum crafifino \& valde fucculento folio nigris punctis notato. Pluk, alin. 148 . t. $225 . \mathrm{f} .4$.

Habitain in Ethiopia. to

inguifoime. 34. MFSEMIBR Y ANT HFM UTM acaule, foliis lin. guiformibus altero margine craftionibus. Hort. cliff. 219. Hort. ups. I28. Roy. lugdb. 292

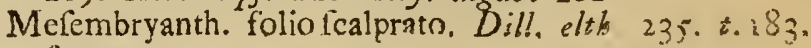
f. 224.

3. Matcmbr. folio linguiformi latiore. Dill. elth. $23 \mathrm{c}$. I 84. f. 224.

g. Mefembr. folio linguiformi anguftiore. Dill. elth. 238. t. 185. f. 226.

D. Mefcmbr. folio linguiformi longiore. Dill. elth. $23 . t$. $185 . f .227$.

Habitat in Africa. $\%$

Har Decagyna eft.

pusionifor: 35. MESEMBRYANTHEMUM foliis alternis fubume. latis triquetris longiflimis. Hort. cliff. 216. * Hort. upf. 129. Roy. lingdb. $28 \mathrm{I}$.

Mefembr. folio pugioniformi, flore amplo framineo. Dill. elth. $280 . t .210 . f .269$.

Ficus capenfis, caryophylli iolio, flore aureo fpeciofo. Bradl. Succ. 2. p. 5. t. 14.

Habitat ad Cap. b. Spei. 5

Hec polygyna eft.

\section{A I ZOOON}

eanarients. I. AIZOON foliis cunciformi-ovatis, floribus feffilibus. Hort. ups: 127.

Aizoon foliis obverfe ovatis. Hort. cliff. 4I, Roy. lug db. $22 \mathrm{I}$.

Ficoidea procumbens, portulacx folio. Niff. alt. I yx r. $p: 422 . t_{1} \mathrm{I}_{3}, f . \mathrm{s}$.

Kali aizoides canarienfis procumbens. Pluk. alrn. 202.

t. 304. f. 4. Volk.norib.236. t.236.

Habitat in Canariis. $\odot$

hifpmicum, 2. AIZOON foliis lanceolatis, floribus resfilibus.

Ficodea hilpanica annua, folio longiore. Dill. elth. 143. t. 117 . $f$. $143^{\circ}$.

Habitat in Hifpania. $\odot$

paniculatmi 3. AIZOON foliis lanceolatis, floribus paniculatis. 
Aizoon fol:is lanccolatis rubtus hirfutis. Roy. ing .13.22 . biabitat in Africis.

\section{SPIR AE.}

2. SPIR EA foliis lanceolatis obeufis ierratis mudis, fori-falitiolian bus duplicato-raccmolss. Hort. cliff. 121. Hort. ups.

131. Koy. lugdb. $27 \%$.

Spirza theophrafti firrte. Clus. bift. \&. p. 30.

Itretex fpicatus, ioliis ferratis falignis. Baub. tim $47 \%$ \%

Spiraa falicis folio ingiore ferrato, Horibus rubris. Airm. ruth. 26,

Halitat in Sibiria, Tataria. B

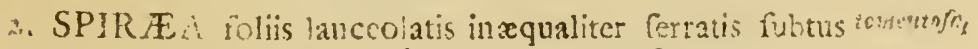
tomentolis, Horibus duplicato-raccmolis.

Uimaria pentacarpos, integris ferratis folis parvis fubtus incanis, virginiana. Pluk. alm. 393,t, 32I $f$. 5 .

Habitat in Philadelphia. Kalm. 5

Differt a precedent: Foliis magis profuncie io incequaliter ferratis; foliis fubtus zialde tomentolis adroque crafjis; racemo terminali compofito deidiosi longions.

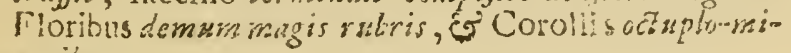
noribus.

3 SPIR EA toliis integerrimis, umbellis fesflibus. Hort brpericifolat spt. 13 .

Spirxa foliis integerrimis, pedunculis fimplicibus. Hor.

cliff 190. Roy. lugdb. 277.

Prumo fylveftri affinis camadentis. Baub. pin.517. Plak. glm. 30S. t. 218. $f .5$.

Habitat in Canada. 5

4. SPIR EA foliis ovatis incifo-ferratis ghoris, umbollis shamedryfs: pedunculatis.

Spiraa chamxdryos foliis. Amm. rnth. 269.

Habitat in Sibiria. D. Gmelin. b

5. SPIR EA follis oblongiufculis apice Terratis, corymbis rynata. latcralibus.

Spirxa hifpanica, hyperici folio crenato. Barr. rar. 1376.

$t, 56+$.

Spirea hyperici folio ampliore, modo integro modo dentato. Artm. ruth. 270.

Habitat in Sibiria, Hifpania. 5

6. SPIR 瓜A foliis lobatis ferratis, corymbisterminalibus. oy foito.

$$
\text { Hhs Spirea }
$$


Spiræa foliis incifis angulatis, floribus corymbofis. Hort. cliff. 130. Gron. virg. 55. Roy. iugdb. 277.

Evonymus virgriniana, ribelii folio, capinlis eleganter buliatis. Conm bort. 1. p. t60. $t .87$.

Hubitat in Virginia, Carradd. 5

farbifolia $\uparrow$. SPIR A: A foliis pinnatis, foliolis uniformious ferratis, caule iruticolo, Horibus paniculatis.

Spirxa foliis pinnatis. Aman. acad. 2. p. 352 . *

Spiraa forbi folio renniter crenato, thoribus iti thyrfoalbis. Jimm. rusth. $\mathbf{1} 86$.

Ilabitat in Sibiriz aliginofis. $b$

Aruncus, 8. SPIR EA foliis fupradecompofitis, fpicis paniculatis, floribus dioicis.

Aruncus. Hurt. cliff. 463. Roy. lugdh. 278. Gron. virg. I $2 \mathrm{~T}$.

Barba capre tioribas oblongis. 13auh. pin. 163.

Barta capra. Cam. bort. 26. t. 9.

Habitat in Auftria. Alvornia montanis. $z$

filipendul.t. 9. SPIR EA foliis pinnatis : foliolis uniformikus fertatis, canle herbacco, flaribus cymofls.

Filipendula foliis pinnatis: foliolis uniformibus. Flors. chaff. 191. Fl. fuec. 404. Mrat. med. 239. Roy.layguld. 277.

Filipendula vulgaris. Baub. pin. 163 .

Filipendula. Ciam. epst 5o8.

biabitat in Europz pajauis. \&

UH+anin, ro. SPIRZA foliis pinnatis: inpari majore lobato, fiosibus cymofis. Fl. lapp. 20i. Flart. cliff. 191. Fl. luec. 405. Mat. mett. 24I. Roy.lugdb. 2.77.

Barba capræ floribus compactis. Bazh. pim. 164.

Regina prati Dod. permpt. 57.

Habitat in Europre pratis uliginofis, umbrofis. Z

rifolinta. 11. SPIR EA foliis termatis ferratis fubaqualibus, nori. bus fubpaniculatia.

Filipendula tollis ternatis. Hort. cliff. 191. Hort. apf. 131. Roy. liggdb. 277. Gron. virg. 55.

Ulmaria major trifolia, flore arnplo pentapetalo, virginiana Pluk alin. 393. t. $236 . f$. . Kaj. Juppl. 330.

Ulmaria virginiana trifolia, foribus candidis aurplis longis \& acutis. Morif. bift. 3. p. $32 .:$.

Habitat in Virginia, Canada. 


\section{A IIBA.RDA}

- DALIBARDA

\section{IJalizat in Canadia. Kalm. 2}

Radiz repens. Stolones repeantes, berbacei. Folia corchata, obtufa, obtufe crenata, venoja, pilis raris adsperfa. Petiolipilol, foliss jenius longiores. Scapi nudi, pilori, longitudine petiolorim, unifiuri. Cali xquinquepartitus. Corolla alba. Semina 5, uhda, uvata. Diwarfis " Rubo feminibus nudis.

\section{POLYGTNIA. \\ ROSA.}

- ROSA inermis, calycis foliolis indivilis, fructu ob-cinnammen longo. Hall. beln' $34 \%$.

Rofa fivlveftris, odoratifimo rubro flore. Bash. pin 483

Habitat in Helvetia. 5

2. ROSA aculeata, foliis odoratis fubtus rubiginofis. Hall eglanteris a belv. 350. Dalib. parif: 145.

Rofa fylveftris, foliis odoratis. Baub. pirs. 483.

Rofa eglanteria. Tabern. is. 1087.

Habitat in Helvetia, anglia. b

3. ROSA foliis utrinque villofis, fruetu fpinofo. Hall. valiofn。 belv. 350 .

Rofa fylvcitris pomifera major. Baub. pin. 484.

Habitat in Furopa auftrali. o

4. RUSA caule aculcato, petiolis incrmibus, calycibus cminn femipinnatis. Fl. Jucc. 4ob.

Rofa fylveftis vulgaris, thore odorato incarnato. Bash.

pin. 4.3.

Hubitat in Europa. 5

5. ROSA caule petiolisque aculeatis, calycis foliolis in fpinofiffinn. divilis. Fl. Suec. 407.

Rofa campeftris fpinofifima, Hure albo odorato. Basb pin. 483 .

Habitat in Europa. 5

6. ROSA c:tulo aculeato, pedunculis hípidis, calycibus sentifoin. lemipinuatis glabris.

Rofa mulriplex media Bakb. pis. 483. 
Rora centifolia batavica rI. Cluf. biff. I. p. II 4 . linbitat is Europa. 5

alba \%OSA canle aculeato, pedunculis lavibus, calycis bus femipinnatis glabris.

Rofa alba vulgaris major. Banh. pir. 482 .

G.Rofa alba, tiore pleno. Be $l . c y^{\prime}$. vern. G.t.3. f. x. Habitas in Europa. 5

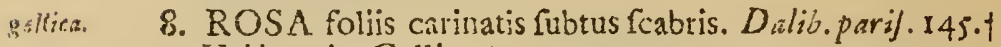
Habitat in Gallia. 方

irsic.s. 9. ROSA fubirermis, foliolis quinis fubtus tomentofis: impari majori, fipulis obfoletis.

Rofa chufan glabra, juniperi frueru. Pet. gaz. s6. $t$. 35: $f .11$.

Habitat in China, 5

Rami inermes; rarius armati una citerave fpina tenuisfima verfus folia vel in petiolis. Folia pinnata: Folioiis quinis, fubius tomentofis, fupra glabris, ferratis: extimo duplo majore. Pedunculi inngi, nudi, fimplices. Calyxincifus, levis. Fruetus magnitudine Sorbi aucuparia. Specics Kofarum difficile difingvuntur, difficilius determinaulur; mibi videtur naturam mifcussfeplures vellufuex unoplures formaffe; binc qui paucas vidit fpecies facilius eas difinguit, quariquiplusesexnininazit.

femperzi- 10. ROSA caule aculeato, foliolis quinis glabris perent rens. nantibus.

Rofa fempervirens jungermanni. Cluf. bift. 2. app. alt. Dill. elit. $326 . t .246 . t: 318$.

Rula molchata fempervirens. Bauh. pin. 482.

Mabitat in Germania. 5

ocndalina. Ix. ROSA fnetibus oblongis pendulis.

Rofa fangvirorbe majoris folio, fructu longo pendulo. Dill. elth. $325 . t .245 . f .317$.

Halistat in Europa. b

corolina- I2. ROSA foliis ferratis medio tenus integerrimis.

Rofa carolina fragrans, foliis medio tenus ferratis. Dill. elth. $325 \cdot t \cdot 245 \cdot f \cdot 316$.

Habitat in Carolina.

\section{RUBUS. \\ * Frutefientes.}

ilan: T. RUBUS foliis quinate-pinnatis ternatisque, caule aculca- 
culeato, petivlis canaliculatis, 17. Sesec fo8. Mat.med. 242.

Rubus caule erecto bifpido, foliis termatis. Fl.lapp.204. Hort. clitf. 192. Hort. upf. I 33. Rov. lugdt. 273

Rubus idaus frinolus. Bavb. piz. $47 \%$.

B. Rubus idaus fructu albo. Baul. pir. $47 \%$

$\gamma$. Rubus idaus lavis. Banb. pin. 47 .

llabitat in Europa lapidinfs. 2 - is

2. RUBUS foliis quinato-pinnatis terıatisque, caule a-ocoidentalis culeato, petiolis teretibus.

Rubus folijs loneinribus fubtus moll: hanugine obdaEtis \& incanis, Hore \& fructu minoribus. Sloan.jum. 173. bift. 2. p. 109. t. 213. f. 1. Ral. dendr. 70.

Rubus idcus, fructu nigro, virginianus. Dill.elth. 327 . t. $28 \%$. f. jig.

Habitat in Cunzada. Kalm.

Caulis teres, lirvis; aczleis recurvis. Petioli zeretes a* csleis recurvis. Folia ternatc, intermedio pedicellato, ovata, incifo-ferrata, fubtus albo-tomentofa. Raccinus terininalis. Fructus niger, variat ctiam frueturubro. magis acido quan $R$. idcei. Differt inprimis a $R$. idro, cui linillimus, peiclis ieretibus nec canaliculatis.

3. RUBUS foliis ternatis nudis, caulibus petiolisque hi-binidu. ipidis.

Habitat is Canada. Kalm. 5

Caules viticalis longis, procumbentibus, lignofis, una cum pet:ulis adlperfi fetis rigidis. Folia ternata, nudo, incifo-jerraba: intermedio pedicellato; pedinculi ctjaris bispiál.

4. RUBUS foliis ternatis nudis, caule aculeato: Hort. cafins: cliff. 192. Fl. Ja:c. 163. Gron. virg. 163. Roy. lugdb. 273. fall. beir. 344.

Rubus repens, fructu cxlio. Baub. pin. 479.

Rubus ninor. Dod. pempt. 7.42 .

Habitat in Europa dumetis. 5

Folia subtus non tomentofa, qramris sepe probecentia.

5. Rubus foliis quinato-digitutis ternatisquc, caule petiolis-fikt: ofus. que aculeatis. Fl. J jer. 409.

Rubus caule aculcato, foliis tcrnatis ac quinatis. Hort. cliff. 192. Grun. virg. 163. Ruy. lagelb. 273 :

Rubus vulgaris $f$. Rubus fruelu nigro. Baub. pir. 479 . Rubus. Carit epit. 751 .

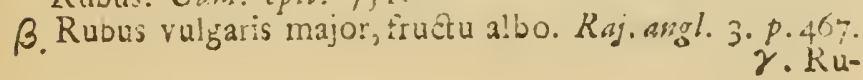


2. Rubus flore albo pleno. Magr, bort. I7. Hab:tat in Jeoitus profertim maritisnis Europa. b

annadanfis. 5. RUTBUS follis digitatis denis quinis ternatisyue, caule inetimi.

Itabilat in Canada. Kulm.

Caulis Jabpurpureus. Foliola lanceolata, utrinque nu. da, tcnuifina, argure Seriata. Bracteæ lanceolatie. Stipula lineares, acutc.

adaratas 7. RUBUS foliis rimplicibus palmatis, caule inermi multifolio multiloro. Hort. rliff. Ig2. * Hort, up. 133 Roy. Ingdi. 274 .

Rubus odorntus. Carn. canad. 149. $\$ 150$.

Llabitat in Canada. $\$-b$

* Herbacęi.

Saxntilis. 8. RUBUS folliis ternatis nudis, flagellis repratutibns herbaceis. Fil. Juec. 411.

Rubus caule repente annuo, foliis ternatis, Fl. lapp. 206. Roy. liggdb. 274. Hall. belv. 344. Roj. lngdb. 274 .

Chama Rubus faxatilis. Bawh. pin. IIo.

Habitat in Europa collibus lapidofis. \#

arfiers. 9 RUBUS fohis termatis, caule inermi unitoro. Fl.juse. 4I2. Mat. med 2.ft.

Rubus cavie unitioro, folìs ternatis. Fl. lapp. 20\%. $t$. 5.f. 2. Hort. rliff. 292. Roy. Jugdb. 274 .

Rubus humilis, fore parpureo. Buxb eent. $5 \cdot p$. I3. 1. 26. snalla.

Rubus trifolius humilis non fpinofus, rapore \& odore razaria, fruelu rubro polycocco. $4 \mathrm{~mm}$. rkth. I85. Habitat in Bothnia Suecix, Sibiria, Canada. \#

chamemo- 20. RUBUS foliis fimplicibus lobatis, caule unifloro. $F$. om. fuec. 413. nnt. med. 244.

Rubus caule bifolio unifloro, foliis fimplicibus. Fl. lapp. 209. t. $5 \cdot f$. 1. Hort cliff. 102. Roy. Iugáb. 279. Chama Rubus foliis ribes. Banh. pin. 4 80.

Morus norvegica. Till. aboenf. 47. h. 150.

Hatitat in Suecia paludibis uliginofis, twifojis fre guens. 2

\section{FRAGARIA.}

vifse.

FRAGARIA nagellis reptans. Hort. cliff. 192. Hort,

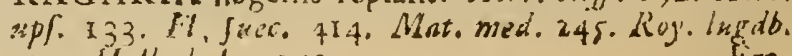
274. Hall. bicle. $2+3$. 
Fragaria vulgaris. Bash. pin. 326. Fl. lapp. 209. Gron. Fylreftris. vir.s. it.

Fragnilia fructu albo. Bazh. prs. 326.

B. Fragaria tructu parvi pruni magnitudine. Baub. pin fativa $3 \div 7$.

y. Fragraria chiloenfis, fruefu maximo, foliis carmofis hirfutis. chiloenfis. Dill. elth. I $45 . t$ i 20. f. I 46 .

Halitat in Eusopæ bnicalis ferslibus, duris, apricis. 26

2. FRACrARI it canlc erecto fufruticofo, foliis hirfutis. maricata. Fragaria arbarea, Hore herbaceo. nan. bift.

Fragiaria major velca, Horcherbaceo, Murif. bigl. 2. $p$ 186.

Ilab:lat in - . - b

Folia inter flores diffing unnt bawc a jiruma.

3. IRAGARIA caule decumbante repente. Roy. Ingib. Jierilis. 274. Dalib. paril. 147. Sauv. inonjp. 177.

B. Fragaria lterilis. Bauh. pin. 32.7.

Fragaria fterilis 5 : minime vefca hirfuta minime incana.

Mlorif. hift. 2. p. 196. f. 2. t. 19. f. 5.

Fiagaria iylveftris minine vefoa is Rerilis. Lob.ic. 698

Hanitat in Augliz. 2

Caules procumbentes, nullus reltus; Pedunculi axillares, uniflori; Fioliola orntia; Baccx exfucce.

\section{POTENTILLA \\ * Folits pinnatis.}

1. POTFNTILLA folis pinnatis, canle fruticofo. Hort. fruticso. cliff. 193. Fl. Suec. 416. Rov. Ingib. 275.

Pentaphylloides rectum fruticofum eboracenfe. Morif. hill. 2. p. 193. S. 2. 1. 23. f., 5. Hortsl. angl. 54 t. 54 .

Pentiphylloides reetum frutefcens. Wialth. bort.95.1.17 Pentaphvlloides fruticola elatior. Amm. rath. 88. t. 17. E $89 . t .18 . t .1$.

Habitat in Eboracn, Anglia, Oelandia auftrali, Sibiria. 5

2. POTENTILIA foliis pinnatis ferratis, canle repente. Anjerima Fl. lapp. 210. Fl. Juec. 415. Hort cliff. 193. MIIt. med. 246. Roy. lugdb. 275.

Potentilla, Baub. pin. 321. Cam. epit. 758.

Habitas in Europa pafeuis; in argillofis argented. 2

3. POTENTILI, folliis bipinnatis utrinque tomento- rerice tis: fegmenti, parallelis approximatis, cirulibus dicumbentibus. 
I'otentilla folins duplicato-pinnatis: pinnulis linearibus in. tegerrimis brevibus. Gmal. mil:

Habitat in Sibiria. $z$

Habitus foilorun P. anferine argenter, quamvis minima fant; canlis vero $E$ fructificationes $P$. vernac. Radis fquamis foliorsm ruderibus nigris vefita. Folia pinuata ex is circiter foliolis ovatis, tomunto.

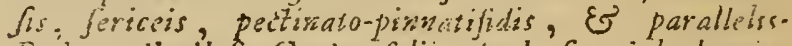
Pedunculi piloj. Caules folies dexplo $\int$. tritilo losigio. res, ciccumbintes absauc farmentis, nec repentes, in

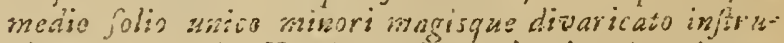
Et, teretes, cpicc Floribus aliquot luteis, alternis, pe. duaculatis.

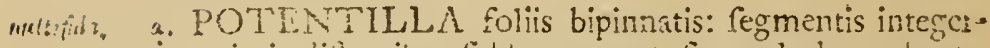
rimii ditantitus fubtus tomentolis, caule decumbente

Jentapiylloides fupinum ninus, follo glabro, non ferrs to. Hinw. rwth. 116.

Pertaphylloides repens, foliis pinnatis. Boub. cent. 1.p. 30. t. 4?. $f$. I.

B. Pentaphylioides fupina minor, foliis alatis hirfutis varie dificers. Amin. ratio. 117.

Habitat in Sibiris, Tataria, Cappaciocia. 2

Habitus multa indicat affinia cum $P$. argenien. Folio ex foptem foliolis, fogmenits linearious f. lanecolalis: quinis $\int$. Jurimuin $\int e p t e n i s$, alicrnis, at in impar: op: pofitis, a je invicern biantiüs $\sqrt{1}$ ve apice remutis, $\int u b$. tus toinentofis.

frgariaides. 5. POTENTILLA foliis pinnatis tematisque: extimis majoribus, flagellis reptantibus.

Potentilla foliis ternatis hirfutis utrinque viridious: iobatis accefforiis. Gmel. in/s.

Habitat iu Sibiria. 2

Facies Fragarice ferilis. Radix fubtuberofa. Folia fericer petiolis pilofis, pinnata ex 3. 5. vel 7. Follolis ozatis, oppofitis, ferratis, bafi quo propioribuseominorilizs. Stolones decumbentes.

myetis. 6. POTLN TILLA foliis pinnatis aiternis: foliolis quinis ovatis crenatis, caule ereeto. Hort. cliff. 193: It. wgath. 63. 76. Roy. lugdb. 275 .

Pentaphylloides erectum. Bauh. bift. 2. p. 30\%. Moris. biti. 2. p. Ig2. r. 2. t. 20. f. I.

Quinquefolium fragirerum. bauh. pin. 326. Clus. bifl. 2 5. $107 . n .5$. 
Ulaiblat ad latera vontium Wutrogothix, Sibirix, Germanix. 2

7. POTENTILLA foliis pinnatis fubequalibus: foliois bifures. obiongis fub-bifidis: extimis contluentibus.

Pentaphylloides orientaic fupinum, foliis alatis bifidis vel tritidis. Tosmefo cor. 2I.

Habitat in Sibiria. 2

8. POTENTILIA follis pinnatis: foliolis fubroturdis annginelloin dentatis zunalibis, caule erefto.

Pentaphylloikes orientale erectum, folio \& facie pinpi-

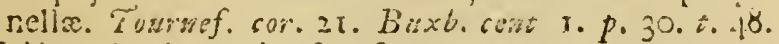

Habitat is Amenia faxoflis. is

9. POTENTILLA foliis pinnatis, caule dichotomo de-fopitan.

cumbente. Hort cilff. 193. Hert. upj. 133. Rü. lag $d 6.275$

Penieptiyllam alpinum minus fipinum. Plekk alm.29s. $\therefore$ soú. $f_{0} .7$.

Pentaphylium Expinum quorundam, potcrtilla facic. Clat. hitit. 2. $p \cdot 10 \%$.

Quinquefolio fragifero afinis. Baub pin. 326 .

liabitat ad Maguntian E' in Sibiria. 0

\section{* Foibis quinatis.}

:O. POTENTILLA foliis digitatis lanceo!atis ferratis retik, utrinque fubplofis, caule ere:to.

Potentilla Coliis digitatis, canle ereeto corymbolo. Hot: apS. 133. * Roj. luggdb. 275.

Quirquefolium rectun lutedm. Bark. pirs. 325.

Quinquefolium alterum vulgare /Jot. pempt. irs.

Habilat in Itaiia, Narbora, al agrorsm inargines. ()

folia utringue viridia, et aldulta fere sudia.

11. POTENTILLA folis quimatis cuneiformibus inci- argenta. fis fubtu; tomentofis, cauie erecto.

Potentilla foliis digitatis, caule crecto corymbofo. $I \%$. floce. 457 .

Potentilla foliis digitaris incifo-ferratis, caule erecto. Hort. cliff. [ 93 .

Quinquefolium folio argenteo, Bash. p:n. 325.

Pentaphyllum minus. Cam. epit. 760.

Habitat in Europer rederatis. 7

12. POTENTILLA foliis feptenis quinatisque cuneifor-birts. mbus incifis pilofis, caule adfrendente.

Ii Quin. 
Quinquefolium montanum rectum hirfutum. Baub.pin. 325. prodr. 139.

Habitat Montipelii D. Sauvages; inque Pyienxis. 2

Differt a priscedente Foliis radicalious Jefienis, \& Subtus longis dijtinatis pilis birfutis, nec tomentofis, apace argutizis furcatis. Pedunculi unifori, longi.

Segularis. 13. POTENTIILA foliis digitatis feffilihus ftipulæ infidentibus.

Potentilla foliis novenis ftipulis-infidentibus. Gmel. mif. Hobitat in Sibiria. 2

Civulis adfcendens, filiformis, levis, apice divifus. Stipula amplexicanies, folitarice, einarginater. Foliola 8. ad 9. lineuri-lanecolata, fiabjerrata, glabra, e.x emarginatura ftipule pendentia absque petiolo.

verna. 14. POTENTILLA foliis radicaibus quinatis acute ferratis, caulinis ternatis, caule duclinato. Fl. Suec. 419.

Potentilla foliis guinatis incifis, calle affurgente. Fl. lapp. 212. Hort. cliff. 194. Roy. lugdb. 276.

Poientilla foliis quinatis acute ferratis ora fericca, petalis maculitis. Hall. belv. 339. t. 6. f. 4 .

Quinquefolium minus repens alpinum aureum. Bauh. pin. 325 .

Habitat in Europæe pafcuis factis, frigidiuribus. 2

canadenfis. 15. POTENTILLA foliis quinatis villofis, caule adficendente hirfiuto.

Habitat in Canada. Kalm.

Habitus fragurice. Folia radicalia quinata: foliolis obverje ovatis, arute ferratis, Jupra pubefeentibus, fubtus villofis alto-fericeis, petiviis valde albo hirfutis. Caulis digitalis, ramofus, rarioribus fuli is. Corolla luter. Similis precedienti, a qua differt Foliis valde pilofs, argute Serratis, Jubrotundis E' C'aule valde hirlinto.

4:5\%. I\%. POTENTILLA foliis digitatis apice conniventi-ferratis, caulibus filiormibus procumbentibus, receptaculis hirlutis. Hort. cliff. ro4. Koy. Ingäb. 276.

Quinquefolium album. Hall. it. helv. 70.

Quircquefolium :lbum minus alterum. Baub. pin. 325

Pentaphyllumi majns, fore albo. Claf. bift. 2. p. 105. 6. Quiuquefolian s!tum majus. Babh. prodr. 325.

Quin- 
Quinquefolium alblin minus. Barb. pin. 325 prodr. 139.

Habitat in alpibus Stirix, Aufrix, Panoniz. 2

17. POTENTILLA foliis digitatis, caule repente, pe-reptans. dunculis unifloris. Fl. fuec. 418 . Mat. med. 247 .

Potentilla foliis digitatis longitudinalirer patenti-ferratis, caule repente. Hort.cliff. 194. Gron virg. 163.

Quinquefolium maịs repens. Eazh. pin. 325 .

Quinquefolium majus luteun. Futcbs. bift. 624.

Habitat in Europæ apricis argillofis. $\mathbb{E}$

\section{* Foliis ternatis.}

18. POTENTIL LA foliis ternatis, caulc ramoro ete- monfpelienfis eto, pedunculis fupra genicula enatis. Hort. ups. 134 .

Peritaphylloides majus ereEtum, flore luteo. Morif.hifl. 2. p. 193. f. t. 20. f. 2.

pentaphylloides trayaria tolio. Magn, monsp. 304.

Fragaria fterilis alpina caulefcerls. Boerh. ingdó, 1.p. 42. Hiabitat Montpelii. $\odot$

Foliola ovatu, obtufa, obtufe E requaliter ferrata.

19. POTENTILLA foliis ternatis, caule dichotomo, morvegico. pedunculis axiliaribus.

Potentilla foliis ternatis, caule corymboro ereeto. F\% fuec. 420 .

Potentilla foliis ternatis incifis, caule diffuro. Fl. lapp.

21. Hort. cliff. 193. Roj. lugdb. 27\%.

Quinquefolium hirfutum luteum paucioribus lacinis. Leelel. pruff. 118. t. 70.

IIabitat in Norvegix, Suecix, Borufix, Canadx agris. $\odot$

foliola lnnceolata, ferraia, deniata.

20. POT ENTILLA foliis ternatis incifis fubtus tomen- nives. tofis, caule adfcendente.

Fragari: fterilis, folitis fubtus incanis, magno flore albo. Vaill. parif. ss?

Habitat in Alpibur Lapponix, Sibitix.

Structura $P$. sernie, fed folia $P$. argentce, at ternaEs lutiora, magisque linj ritar, jubtus tomertofia nivicu. Corollia lutea.

21. POTENTILLA foliis ternatis dentatis utrinque groniligara. fubpilufis, caule erecto foliis longriose. 
l'otentilla foliis teruatis, petalis cordatis luteis. Hall belv. 342 . t. 6. $f .2$.

Fragatia fterilis, ampinfimo folio \& fore, petailis cor: datis. Vaill. parif. 55. $\therefore$ 10. f. 3.

llabitat in Helvetia, Sibiria. ()

Folia atraque pagina concoloria, nec inferiori argentea.

nenalis.

22. POTENTILLA foliis ternatis dentatis utrinque tcmentofis, eauie foliis oreviore.

Potentilla foliis ternatis mollibos incanis, caulibus vix uncialibus. Gmel. in f? $^{\circ}$.

Halitat in Sibiria. 2

Folia ternata, rugofa, tomentofa, pilofa, coriacea, cuncifurmia, dentata. Stipula late, acietie, piifofo. Caulis biflorus, $\int$. Scapus Seppe zniflorus, petiolis brevior. Corolla maxima, lutea: petalis emarginatis, bufi flavis. Stamina lutca.

\section{TORMENTILLA.}

merta 1. TORMENTILLA caule eredo.

Tormentilla. Cam. epit. 685. Fl. lapp. 21 3. Fl. fuec. 421. Mat. med. 249. Hort. cliff. 194. Roy. Iugdl, 276.

Tormentilla fylveftis. Baub. pin. 326.

Habitat in Europa pafcris factis. 2

reptans.

2. TORMENTILIA caule repente.

Pentaphyllum minus viricie, Aore aureo tetrapetalo, radiculas in tetram e geniculis dimittens. Morif. bifl. 2 . p. Igo.

Pentaphyllum reptans alatum, foliis profundius ferratis. Flot. oxf. 6. 0.7 . t. $9 . f$. 5 .

Habitat in Anglia. 2

\section{GEUM.}

sarginimen I. GEUM foribus erectis, fructu glcboro: ariatis uncinatis nudis, foliis ternatis. Huri. cliff. I25. Grox. virg. 56.

Caryophyllata virginiana, albo fore minore, radice inodora. Herm par. III. t. III.

Habitat in Virginia. $*$

Folia caulina inferiora ternata, fuperiora Simplicia; color corolla albus, nec ut in Jequesti ixiens; Stipule integre.

2. GE- 
2. GEUM floribus erectis, fruetu globofo: ariftis unci- uro.m:xm. matis nudis, foliis lyratis. Hort. cliff. 195. F\%. Surec. 423. Mat. med. 249 . Roy. lugdt. 276.

Caryophyilata vulgaris. Baxis. pir. 321 .

Caryophyllata. Dod. pempt. I 37.

Habirat in Europa zembrefis. 2:

Folia radicalia byrata is bac, EJ finula dentatic.

3. GEUM floribus nutantibus, frustu oblongo: arifis vivale. plumolis. Hort. cliff. 195. Fl. Suec. 424 . Roy. lugdb. 276.

Geum rivale, Fl. lapp. $2 \times 6$.

Caryophyllata aquatica, nutante flore. Baub. pis. 32 r.

Caryophyllata ieptentrionalium. Lob. ic. 604.

B. Carvophyllata aquatica altera. Baxh. pin. 322.

Habitat in Europx pratis Jubbumiais. 2'

4. GEUM tore erecto folitario, fructu oblongo: ari- armtamsm. this plumolis.

Caryophyllata pinnis confcrtioribus extrema fubrotunda, tubis reetis. Hall. belv. 3,6 .

Caryophyllata alpina lutea. Baub. pir. 322.

Caryophyllata montana. Cam. epit. 727.

B. Caryophyllata aipina minor. Baub. pirs. 322. prodr. I 39.

Caryophyllata alpina minima, flore aurco. Barr. rar. 588. 2.399.

Habilat in Alpibus Helvetix, Aufriæ, Delphinatus. 2

5. GEUM foliolis uniformibus incilis: alternis minori-tegtant, bus, cauie repente.

Caryophyllata alpina, apii folio. Baub. pin. 322.

Caryophyllata alpina tenuifolia incana, fore luteo longius radicata. Barr. rar. $5 \$ 9.400$. Boct. mas. 160. t. 128.

Habitat in Helvetia \& valle Barfilionenfi.

\section{DRYAS.}

1. DRYAS pentapetala, foliis pinnatis. Aman. scad. 2. piniapetala p. 353: Habitat in Camfchatka. 2

3. DRYAS octopetala, foliis fimplicibus.

o.topetsla.

Diyas. Fl. lapp. 215. Fl. Juce. 426. I!ort. cliff. 195. Roy. lugdb. 279. Hall. helv. 335. Sigu. ver. 512. 


\section{ICOSANDRIA POLYGYNIA.}

Chamedrys 3. r. inontans. Clus. bijt. 2. p. $35 \mathrm{r}$. Habutat in Aipibus Lapponicis, Helveticis, Auftriacis, Sabaudicis, Hibernicis, Sibiricis. 2

\section{COMARUM.}

qulufie. 1. COMARUM. Fl. lapp. 214. Fl.-Suec. 422. Hort. cliff: 195. 13.oy. iugdb. 276. Hall. belv. 337.

Quinquefoium faiutre rubrum. Bauk. pin. 325 .

Pentaphylluin paluitre. Cood. hif. 95.

Habitat in Europæ uliginojis. 2 
POLYANDRIA MONOGYNIA. 503

\section{Clajpis XIII. \\ POLYA NDR IA. MONOGRNIA.}

MARCGRAVIA.

1. MIARCGRAVIA.

น1ubellats.

Marcgravia fcandens, fructu radiation pofito. Pluk. gen. 7.

Habitat in America calidiore. b

Folia alterna, petislata, oveto-lanceolata, integerrima.

Umbella hisiplex pedunculis numerofis, in orbern pofitis, equabibus, birizontaliter patentibus. Flores adfcendentes, nudi; corolla coljceque caducis. Difcus umbella conftans glandulis nestariferis, felfilibus, fopius quinis, ercitis, forma corollic ringentis, galea $j$. Supreniz petali acositi, ore ambitsm rejpicientibus.

MORISONIA.

I. MORISONIA.

omericann.

Morilonia arbor nucis juglandis folio. Pluk. gen. $3^{6}$.

Hruita: in America callaiore. 5

Foila alierna, petiolata, ovata, obtura.

BREYNIA.

1. BPEYNIA foliis oblongo-ovalibus. Roy, lugdb. $476 \cdot$ indica. Breynia elangni foliis. Plum. gen. 40. Breyn. is. 13.

t, I3.

Ceratonix affinis arbor filiquola, olex folio, flore tetrapetalo albido; filiqua tereti ventricofa. Slonn. jam. I53. bift. 2. p. 60. Raj. dendr. 100.

Habitat in America calidiore. t)

\section{CAPPARIS.}

1. CAPPARIS aculeata. Hort. cliff. 203. Alat.med. 259. Pirofr. Roy. lugdb. 476 .

Capparis lpinola, fructu minore, folio rotundo $B a u b$. pin. 480.

B. Capparis folio acuto, Bash pin. 480.

Capparis ticula, duplicata fpina, fulio acuto. Bocc. fic 79. t. $42 . f .3$. 
y. Capparis aculeis geminis, foliis ovatis ersinque acutis. Fl. "reyl. 210 *

Mabitut in Europx as!fralis arenofis, ruderatis, t5

ennininaliothora.

Sulecsa.

2. CAPPARIS incrmis, "nlis ovalibus alternis perentantibus. Hot: clifi. 204 .

Hebitat iss Americat b

3. CAP'ARIS ne: tuis, foliis ovato-oblongis determinate confertis peremantibus. Hort. claff. 204.

Citpparis arborcfecus indica Baducea dicta. Kaj. bift. 630.

Baducen. Rbered. anal. G. p. 105. s. 57.

Wubitat in India. b

AC'TEA.

Aica:a. I. ACT RE A racemo orato, fruthibusque baccatis. A Eixa. Hart. ciff. 200. Fl. fuec. 431 . Hort. ups. 138 . Mat. med. 253. Koy. lugdio. 480. Datib. part. T5? A staa caule inermi. $F$. lapp. 2 r7.

nigra. Aconitum bacciferum. Bavb. pis. 182 . Chrifothoriana. Cluf. bijt. 2. p. So.

alba. B. Aconitum baccis niveis Corn. carad. 76. t. $7 \%$ Chiffophoriana americana racemora baccis niveis a rubris. Morif. bift. 2. t. 3. T 1. t. 2. f. 7. Habitat in nemoribms Eucpe; $\beta$. America. 2 Pecala rbombea. plantemembramarea.

rowinde. 2. ACT EA mcenis longiffmis, fruetibus nincapfularbus.

A exa racemis longifinis. Gron.sirg.59. Hat med. 253 . Chritophoriana americana procerior \& longias fpicata. Hort. elth. 79. t. 67. $f_{0}, 8$.

Chrifophorian facic herba fpicats. Amath. 54. $t$. $383 \cdot f: 3$.

Mabitat in Florida, Virginia, Canadz. z

Petalc craffa, gibbu, minima, pediccllata, acusine fetaceo acuminata, calycisfoliolis plura.

rimuctuma. 3. ACT AA racemis paniculatis, iruetibus quadricapla. laribus.

Cimicituga. Araur acad. 2. p. $35 \%$ *

Thalietroides iotidifimum, chrifophoriana facie. Amin. riath. $\mathrm{IO} 2$.

Habitat in Sibiria D. Krafbenrinnikof: 2

Petala 4. Sisbrotknda, calyse majore, teneriora. Styli 4 . BUC- 


\section{BOCCONIA}

1. BOCCONIA.

Bocconia ramora, fphondylii folio tomentofo. Plun frestens. gert. 55.

Chelidonium majus arboreum, foliis quercinis. Slan jam. 82. hifi. i. p. 195. t.125.

Habitat in Jamaica, Mexico. b

\section{SANGUINARIA.}

1. SANGUINARIA. Hort. clitf. 202. Grnn. virg. 57. smadentw. Sanguinaria minor, fore limplici. Dill. elth. 335 . t. $252 . f .326$.

Chelidonium majus canadenfe acaulon. Corm, canad. 212. Morif. bift. 2. p, 25\%. S. 3. t. 11. f. 1. Raj. hi:je. IS 87 .

B. Sanguinai major, tore fimplici. Dill. eltb. 335 . $252 . f_{0} 325$.

y. Sanguinaria majot, fore plena Dili. elth. $335 . t .252$. f. 326.

Hibitat in America feptentrionali. 24

\section{PODOPHYLLUM.}

7. PODDPHYLIUUM folits peitatis lobatis. Podophyllum. Hort. cliff. 202. Hort. "pis. 137. Grow. virg. 5\%. Roy. lugdb. 490 .

Anapodophyllum canadenfe. Catesb. cor. T.p. 2t.t.24. Aconitifolia humilis, fore albo unico campanalato, fruetu cynosbati. Mlyentz. p:g. t. II.

Habitat in America feptentrionali. $z$

1. PODOPHYLLUM foliis binatis femicordatis.

diplygllinnt:

Habitat in Virginia. Collinfors. 2

Folia radicalia, petiolata, binato ut in Hymenea, glatru, integerrima, Sernicordata, absane pedicellis. Scarus racicalis, unifiorus, firlin antecedentis. liks mihi nor: rifus.

\section{CHELIDONIUM.}

I. CHELIDONIUM pedunculis umbeliatis.

Chelidonium pedunculis inultihoris umbellatis. Fort.

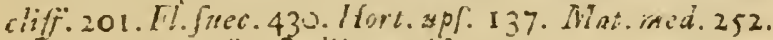
Ro\%. lugib. 478 . Dalib. purif. I5.

Chelidonium majus vulgare. Bazb. fin. 144.

Chelidonium rnajus. Firblo. bijk. 865. 
B. Chelidonium majus, foliis quernis. Bazh. pia. I 44 . Chelidonium majus. foljo laciniato. Cluf, bijt.2.p.203. Ilabitat in Europx rucicratss. 4

Giacium, 2. CHEITTONIUM pedunculis miforis, foliis annplexicaulibus tinuatis, canic glabro.

Chelidoniun glabrum, pedunculis unifioris. Hort. upf. I37. Roy. lugab. 479. Dalib. parif. is2.

Chelidonium pedunculis unithoris. Hort. cliff. $20 \mathrm{I}$. Gron. virg. 57.

Papaver cormiculatum luteum. Batb pin. I 7 I.

Papaver corriculatum, flavo Hore. Cluf. bift.2.j. 9 T. Habitat in Anglix, Helvetix. Gallix, Italix, Virginis arenofis. ( $($ ).

zomirnin- 3. CHELIDONIUM pedunculis unifioris, foliis forfitwat. Iibus pinnarifidis, caulc hifoijo.

Chelidonium hifpidum, pedunculis uniforis. Hort. upr. 137. Sauv, monsp. 2 S6.

Cilaucium hirintum, flore phoniceo. Tournef. inft. 254: Papaver cornutum, phonicco Hore Giluf bift.3. p.y1, llabitat in Hungaria, Bohemia, Minfpelii. $\odot$

bybridum, 4. CHELIDONIUM peduncriis unitoris, folis pinnatifidis linearihus, caule lavi.

Papaver caule ranofo, foliis linearibus pinnatifidis, cap-

fulis fulcatis. Hort. upf. I30. Sauq. monfp. $252 . \cdots$ Papaver corticulatum volaceum. Bauh. pin. 172 .

Papaver corniculatum, violaceo fiore. Cluf. hift.2.p.92. Habitat in Eusopa anfiraliurt. 9

Strymata 4.

\section{PAPAVER.}

* Capjulis bijpidis.

Aytridum. I, PAPAVER capiulis fabglobolis tarofis hifpidis, caule faliofa mulcitoro.

Papaver foliis ternato-pinnatifidis,capfulis fulcatis hifpidis. Hort. cliff. 20 r.

Papaver caule ramofo, foliis lineari-pinnatifidis, capfulis fulcatis hilpidis. Fort. upf. 136 .

Argemone capitulo breviore. Baub. pin. 172.

Argemone capitulo hirfuto rotundo torulis canaliculato. Moril: bijt. 2. p. 278. . 3. t. 14.f. 9. Lob. ic. 276. Habitut in Europa ouftraliore. (-

Arremone, 2. PAPAVER capfulis clavatis hifpidis, caule foliofo millifioro. 
Papaver capfulis hifpicis oblo:1go-turbinatis fulcatis. Fl. fisec. 429. Dalib porif. Isz.

Papaver foliis ternato-pinnatis, fruetu angulato. Hurt. cliff. 201. Roy. lngdb. 419. Saur. monip. 252.

Argemone capitulo longiurc. Bazab. pin. 172 . Lob.ic. 276.

Arge:none capitula tenuiore longiore hirfuto. Morif.bift. 2..p. 278. J. 3.t. 14 f 10 .

Habitat in Europx campis arenofis. Q

3. PAYAVER capfula hilpida, fcapa unifloro mido hi-alpinxm. fpido, follis bipinnatis.

Papaver perenne, pilis rigidifimis, foliis pinnatis, flore luteo hirfuto. Hall. helv. 304.

Papaver alpinum faxatile, coriandri folio. Segu. ver. I. p. 4 I6. t. 4. f. 4 .

Argemone alpina, foliis fcandicis, lutea. Bauh. pir. 172. prodr. 93. Burj. IX: 58 .

Argemone alpina, coriandri folio. Baub. pin. 1\%.

Argemone minor penæ. Dalech. bift. 17 I4.

Habitat in Helvetia, Sneeherg Aufrix. 2

Flores plente Burferiana apud $C$. Baukinum albi erant, nec lutes, afjerente Burfero.

4. PAPAVER capfulis hifpidis, fcapo unifioro nudo hi-mudicanle. fpido, foliis timplicibus pinnato-finuatis. Hort. up $\int .130$.

Papaver erraticum nudicaule, flore flavo odorato. Dill. elth. 302. t. 224. f. 29 r.

Papaver erraticum, luteo flore, capite oblongo hifpido. Amm. ruth. 61. n. 81.

Habitat in Sibiria. a

Stipula 8 ad 9 .

\section{* Caplulis glabris.}

5. PAPAVER capfulis glabris globofis, canlc piloro mul- Rheres, titloro, foliis pinnatitidis incifis.

Papaver foliis pinnatindis hilpidis, fructu ovato, Ilart. cliff: 201. Fl. Suec. 428. Mall. belv. 303. Mat. med. 25 1. Rov. lugdb. 478. Daib. parif is

Papaver caule multifloro foliofo hifpido, foliis pinnatifidis, capfulis lixvibus. . Hort. ups. I 3̧6. Sauv. monfe 252. Papaver erraticum majus. Bash. pin. 171.

Papaver rhoeas prius. Dalech. hift. 439.

(s) Papaver crraticum, pleno flore. Baub. pin. I7I,

- Papaver craticum minus, Baub. pin. I 11 .

$\gamma \cdot$ Habitat in Europa arvis, agris. $\odot$ 
fömifern:. ó. PAPAVER calycibus capfulisque glabris, foliis amplexicaulibus incifis.

Papaver caule multiforo, foliis limplicibus g!abris incilis caulinis. Hort. upf. 135 . Nat. med. 250.

Papaver foliis fimplicibus glabris incilis. Lort. cliff. 200. Hall. helv. 303. Roy. lugdio. 979.

Papaver hortenfe, femine albo. Bauh. pirs. I70. B. Papaver hortenfe, remine nigro. Baub. pin. 170. $\gamma$. Fapiver criftatum, floribus \& lemine album. Baub. fin. I TI.

¿.Papaver criftatum, Horibus rubris, femine nigro. Baub. pán. I I I.

๕. Popaver, fore pleno, album. Baub. pin. I7r. Habitat w Europs auffralioris ruderatis. $\odot$ Caulis, Folia, Calyes, Capjule glubra. Stigmata 10.

embricum

7. PAPAVER capfulis glabris oblongis, caule multiforo lavi, foliis pinnatis incifis.

Papaver foliis pinnatis, fructu acuminato. Hort. cliff: 201. Rog. lagdb. 479 .

Papaver cambricum perenne, flore fulphureo. Dill. elth. 300. t. 223 . f. 290.

Argemone cambro-britaniica lutea, capite longioreglaw bro. Morif. bift. 2. p. 297. f. 3. t. 14. f. I 2.

Papaver erraticum pyrenaicum, flore flavo. Basib. pix, I y r. prodr. 92. Burl. $I X: 45$.

Habitat in Cambrix icpientrivialis nemorofis. Z Sizgmata 5. . 6. diflinsta. Capfula oblongu, inferneasguffior.

orientale. 8. PAPAVER capfulis glabris, caulibus unifioris fcabris foliofis, foliis pinnatis ferratis. Lort. $u p \int .136$.

Papaver foliis pinnatis, fructu globoro. Roy. lugdb. 279. Papaver orientale hirfutifimum, flore magno. Tournef. cor. 17. itin. 3. p. 127. t. 127. Cornith rar. 34.t.34. Habitat in Oriente $\odot$

Stigmata I6. Sete in caule Sparfac, cauli adprefler, bafi prominula aspere. Capfulc bifpida."

\section{ARGEMONE.}

moxicnns. I. ARGEMONE caplulis quinquevalvibus, foliis fpino: fis.

Argemone. Hort. cliff. 201. Hort.upf. 135. Roy.lugdb 479.

Papaver fpinofum. Baub. pir. I.71. prodr. 93. t. 92. Clus. bift. 2. p. 93 . 


\section{POIYINDRIA MONOGYNIA. 509}

Paparer fpinofum luteum, foliis albis venis notaris. Morif. bift. 2. p. 277.f. 3. t. 14. f. .5.

Habitat in Mexico, Jamaica, Caribæis, nunc in Europa auftral:. o

2. ARGEMONT capfulis trivalvibus.

Papaver orientale, hypecoi folio, fruetu minimo. Tosr-

armetiaca, nef. cor. 17.

Habitat in Armenia.

3. ARGEMONI: capfulis quadrivalvibus, cauie nudo. pyrenaica.

Habitat in Pyreneis. Tournefort.

Hæc Semiquadrivalvis, uti jpecies fecunda Semitriculvis, fo prinu femiquinquevalvis; Hae fpecies wal fub diftineto genere final tradenda wel etjam at gexus papaverinum arrandande oinnes. Hujus babitus plurimum accedit Papaveri alpino.

\section{MUNTINGIA.}

I. MUNTINGIA.

Muntingia pedunculis uniloris. Hort. cliff. $203 .{ }^{*}$

Muntingia folio fericeo molli, fruetu majori. Plum. gin: 4 I.

Mépilus americana, alni vel coryli foliis, fruelu mucilaginolo albo. Counm. bort. 1.p. 155. i. $8 \mathrm{n}$.

Calabura alba. Pluk. alm. 75. mant. 34. t. 154. f. 4.

Loti arboris folio angultiure, rubi Hore, fructi poly permo umbilicato. Sloan. jair. IG2, bijt. 2. p. 80.t. I94. f. I. Raj. dendr. 32 .

Hatitat in jamaica.

\section{CLUSIA.}

1. CLUSIA foliis aveniis.

Clufia flore albo, fructu coccineo. Plam. gen. 21.

Cenchramidea arbor faxis aduaicens, obrotundo pingui folio, fruetu pomiformi. Pluk. alm. 92.t. 157.f.2. Terebinthus folso tingulari non alato rotundo liucculcuto, flore pallide lutco. Sioan. jam. 167. bift. 2. p. 97. t. 200.f. 1. Raj. dendr. 5!.

B. Clufia tlore rof co major, fruetu fubriridi. Plum.gen $2 \mathrm{r}$. $\gamma$. Clutia alia minor: Hore albo, fuctu virefcente. P/xm. geir. $2 \mathrm{I}$.

Habitat in Jamaice $\sigma^{2}$ Caribarum apricis. b Arbor foliis oppofotis, obvere ociatis, 13 petiolos defiren. ribris, integerrimis. Pedunculi axillures, jepisestriflori. 
minor. 2. CLUSIA foliis venofis, Clufra, flore rofeo, minor, fructu flavefcente, Plsm. gen. 21 . Habitat in America meridionali. b Arbor folits venofis. Racemus fiorum terminalis.

\section{SARRACENIA.}

purpures. I. SARRACENIA foliis gibbis. Hort. diff. $42 \%$ Gron, virg, 164 .

Sarracena toliis brevioribus latioribus. Catesb. car, 2. p. 70.7 .70$.

Collophyllum virginianum, breviore folio, flore purpuraficente. Marif. bift. 3.p. 533 .

Bucanepliyllum americanum, limonio congener dictum. Pluk. aim. $7 \mathrm{I}^{\circ}$ amalth. 46. t. 376. f. 6 .

Limonium peregrinum, foliis torma Horis arifolochiæ. Baub. pin. 192.

Habitat in Americæ Septentrionalis udis. 2

finci. 2. SARRACENIA foliis trictis.

barracena foliis reatis. Hort. cliff. 497. Grow. virg. I64. Sarracena foliis longioribus \& angultioribus. Cateth. car 2. p. 09. t. 09 .

Coilophyllum virginianum, longiore folio erecto, flore luteo. Norif. bift. 3. p. 533 .

Eucanephyllun clatius virginianum $\mathbf{r}$. Limonio congeneris alicra fpecies elatior, foliis triplo longioribus. Pluk. alm. 72. amaltb. 46. t. 152.f. 3. (mala) t. 376. f. 5. bona.

Thuris limpidi folium. Bauh. bift. I. p. 307. Dalech. bift. 1754. Lab. adv. 430.

Habitut in Americx Septentrivalis udis. 2

\section{NYMPH尼A.}

inse 2. 3. NYMIFH.A calice magno pentaphyllo. Fl.lapp. 218. Fl.fuer. 426. Hort. rliff. 203. Mat. med. 258. Kay. lag de. 480 . Dalib. parif. I 50.

Nymphea lutea major. Bath. pin. I93.

Nyinpiza lutea. Gam. epit. 635 .

liabitui ad Europa litura fut dulci aqua. Z

In Canada eariem foris magnitudine vix Caltba. Kalm.

alin. 2. NYMPHIEA foliis cordatis integerrimis, calyce quadrifido.

Nympháa calyce tetraphyilo, corolla multiplici. Fi. 
lapp. 219. Fl. Juec. 427. Hort. dliff 203. Roy. Iugalb. 480. Dalib. parif. I ro.

Nymphæa alba major. Bash. pin. 193.

Nimphxa alba. Cain. épit. 634.

Habitut in Europæ \& Americ nquis dulcibus. 4

3. NIMPH优A foliis cordatis dentanis. Fi. zeyl. I94.* Lotus.

Nymphrea indica, flore candiso, tolio in umbitu ferrato. jloan. jam. I20. bijt. I. p. 252. Kaj. Juppl. 630.

Lotus xigyptia. Alp. agypr 103 . exot. 214. t. 213. 216.218 .220 .222 .226$.

Ambel. Rheed. mal. 11. p. 5i. t. 26.

Hinbitat in calidis Indiz, Africæ, Amcricz. 2

4. NYMPHEA foliis undique integris. Hurt. cliff. 203. Nelanblo. H. zeyl. 193.

Nymphæa indica, Faba xgyptia dieta, Hore incarnato. llerm. par. 205. E. 205.

Nymphxa fabitera, indie paludibus gaudens, foliis umbilicatis amplis, pediculis f́pinofis, flore rofeo purpureu. Ptrk. alm. 267. t. 207.f. 5. EF t. 322. f. I. opt.

Tamara. Rheed. mal. II. p. 59. t. 30.

Bem-Tamara. Rbeed. mal. I . p. 6r.t. 31. Raj. Suppl. $\sigma_{32}$.

B. Nymphxx affinis glandifera virginiana, umbilicato folio, Hore lutco pleno. Morif. biff. 3. p. SI4. Raj. Supph. $0,32$.

Habitat in Indiis. 2

l'arietas $B$. differt Jeminibus duris, in reliquis convenit ut vix diftirgoveradu videatur.

\section{BOMBAX.}

I. BOMBAX foliis diginatis, caule aculeato.

$X$ ylon foliis digitatis, caule aculeato. Fl. zeyl. 221 Hort. Ceibas. «ps. $14^{8}$.

$X$ ylon caule aculcato. Hort. cliff: 75. Roy. lugdb. 437. Gorfypium arboreum, caule finofo. Baub. pin. 430. Mioul-elavou. Rbeed mal. 2. p. 61. t. 52.

Hobitat in India utraque. $b$

2. BOMBAX foliis digitatis, canle inermi.

X ylon toliis digitatis, cauic inerrit. F\% zeyl. 230. Hort. ${ }^{\text {pritandrum. }}$ spf. I 48 .

xylon caule inermi. Hort cliff. 175. Roy. lugd6. 437.

Gonlypium javanenfe, Ealicis folio. Baub. pin +30.

Ponja. Rheed. mal. 3. p. 59. 3. 49. 50. f. 5t.

Lahitat on Indiis. 5 
trligiosn, 3. BOMBAX foliis quirequelobis acuminatis fubns to. mentofis (Xylon). Fl. zeyl. 222.*

Gorfypium frutefcens annum, folio vitis ampliori guinquefido. Piak. alm. 172. t. I88. f. 2.

Hecisitat in India. D

\section{BIXA.}

oreltano. I BTXA. Hort. cliff. 2is. Mat. mat. 266. Roy.lugdt 477.

Orleana f. Orellana folliculis lappaceis. Plak. aim.272 t. 200 . . 4. Comm. bort. 1. p. ó 5 . f. 33.

Arbor mexiocana, fruetu caftantz, coccifcra. Bashs. pir. 419 .

Urucu. Jloan, jam. I 50. bift. 2. p. ร2, t. 181, f. 1. Habitat in America calidiore. 5

\section{SLOANEA.}

isn+ate. r. SLOANEA foliis cordato-ovatis denticuintis, fijulis fcrratis.

Sloanea amplis caftanea foliis, fructu echinato. Pism. gen. 49.

Apeiba. Marcgr. braf. 123. t. 123. Raj. bijt. $16,43$.

Habitat in Amcrica mericlionali. b

orrarginata. 2. SLOANEA foliis oblongis integerrimis emarginatis. Anona folis laurinis in fummitate incifis, fructu com* preifo fcabro fufco in medio acumine longo. Catesb. car. 2. p. 87.t. 87.

Habitat in Carolina. is

\section{MAMMEA.}

amerian:s. 1. MAMMEA faminibus flore brevioribus.

Maminei magno fructu, perfica fapore. Plum. ger. 44 Mamay. Baub. bift. 1.p. 172. Dalech. bifi. 1836 . Last. amer. 356 .

Malus perfica maxima, foliis rotundis fpiendentibus glabris, fructu maximo fcabro rugofo. Sloan. jam. 179. bif.. 2. p. [23. ᄂ. $217 . f .3$.

Arbor indica Mamei diota. Basib. pin. 417. Raj. bijz. 1665 .

Habitat in Hifpariola, Jamaica. 5 Raxi fabri; Fulia oblonga, obtufa.

ofintics. 2. MAMMEA faminibus flore long:oribus. Habisa: in Java. Osbeck. t) 
Arbor magna, fepius procumbens. Foliapedalia, cbovata foblunga, laria. Feduncuii xnifint. Calyx osistus, biparitizs. Petala of ovata, calyce triplo longiora, breai decidua, cum Staminibus corulia dat:lo longioribus, minerojis, fubulatis, ereftis. Autherx fuo rotundx, minima. Fructus tetragonus.

\section{OCHNA.}

1. OCHNA. Fl. $\approx 2 \%$ \%. 209.* Jabotapita cinnamomi folio, floribus fpicatis. Burm. Fabosagita $_{0}$ $\approx c y l . I=3 \cdot t \cdot 56$.

$\beta$. Arbor africalla, lubrotundo folio margine denticulis acutis arpero, floribus pentapetalis atropurpurcis. Fluk. aim. 4 1. t. $26_{3}$. f. I. 2 .

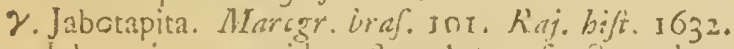
Jaborapita pyramidato flore luteo, fructu rubro. Plum. gen. 42 .

Havitet in India, B. in Africa, $\gamma$. in America.

Racemi perfiftunt Squarrofi injra folia a cnfü pedicelle. rumés fractificationum.

\section{CHRY SOBALANUS.}

i. CHRYSOBALANUS.

Myrobalanıs minor, folio fraxini alato, fruetu purpu-

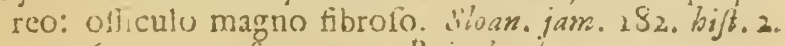
p. 126. t. 219. f. 3. 4. 5. Raj. dendr. 33 .

Prunus Inaco. Lab. itin. 3. p. $3^{0 .}$

Icaco froctu purpureo. P'luria. gex. 44.

B. Icaco truetu ex albo rubefcentc. Plans. gen. 440

$y$. Icaco truetu nigro. Pluin. gen. 44.

\&. Myrobalanus folio fraxini alato, fruetu luteo: officulo magno fibrofo. Sloan. jam. I8I. hifr. 2. p. I25. $t$. 219. S. 1. 2. Rai. ceeadr. +3.

Arbor indica juglandi timilis 5 , 5 . Hobos. Baub. pir. 417.

E. Myrobalanus 6. f. Myrobalanis tavis finilis fruetus. Bazib. pin. 446 .,

Condondum. Kumpf. amb. I. p. 161. t. 60.

Habitat in Jamaica, Brafilia, Barbiches, Surnamo. 占

\section{CALOPHYLLUM.}

i. CALOPHYLLUM folis ovaibus. $F$, ze1/. 201, * 1ropbyllum. Arbor indica, mali medica amplioribus folis. Pluk. alm. $41, t .147, f: 3$.
$\mathrm{k} k$
Bon- 
Ponna T. Ponna-maram. Khedd. mal. 4. p. 79. t. 38. Raj. biff. 1525 .

Habitat in India. 5

calabs. 2. CALOPHYLLUM foliis ovatis obtufis. Fl. zeyl. 202.

Calophyllum foliis ovatis obtufis: ftriis parallelis transverfis. Hort. cliff. 206. Roy. Lugdb. 476.

Thierou-ponna. Rbeed. mal. 4. p.81. t. 39.

Habitat in Indiis. $b$

TIL I A.

ewropen. I. TILIA floribus nectario deftitutis.

Tilia: Hort. cliff. 204. Fl. Suec. 432. Mat. med. 262. Roy. lugds. 477. Dalih. parif. 153.

Tilia femina, tolio majere. Baub. pin. 426.

Tilia urbata. Gefn. tab. III.

B. Tilia montana, maximo folio. Baub. pin. 426.

\%. Tilia femina, folio minore. Baub. pin. 426 .

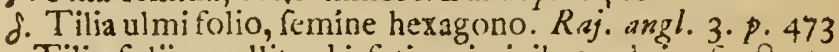

$\varepsilon$ Tilia foliis molliter hirfutis, viminibus rubris, fructu te-tragono. Raj. angl. 3. P. 473 .

$\zeta$. Tilia bohemica, folitis minoribus glabris, fruetu oblongo utrinque acuminato minime coltulato. Till. pif. 65. t. 49. $f .9$.

Habitat in Europæ pratis. 5

americman. 2. TILIA floribus ectario inftruetis. $\mathrm{Kalm}$.

Tilia foliis majoribus mucronatis. Gron. virg. 58.

Tilia, anplifimis glabris foliis, noftrati fimilis. P!uk. mant. 181 .

Haditat in Virginia Canada. 5

\section{MICROCOS.}

aniculatu. 1. MICROCOS panicula terminali. Fl. $z c y \%$. 20\%. * Microcos folis alternis oblongis acuminatis. Burm. zeyl. 159. t. 74 .

Schageri-Cottam. Rbeed. mall. r. p. I05. t. 56. Habitat in India. 5

aterifora 2. MICROCOS pedunculis axillaribus conferis dichc tomis, Fl. zeyl. 208 .

Hamdamanias. Herm. zeyl. 3

Habitat in Zeylona, 5 
POLYALDRIA MONOGYNIA. gNS

ELAOCARPUS.

ELIEOCARPUS. FI. z.e\%l. 206. *

jervatis

Liajocarpos foliis Lauri ferrato, floribus fpicatis. Barro. zeyl. 39. $t, 40$

Perin-Kara. Rheed. mal. 4. p. 5x. 2. 24. Raij. bijt. 1546. dendr. 42.

Halitat in India. $b$

\section{MESUA.}

I. MESUA folis lanceolatis. Fl. zeyl. 203. * ferren.

Naghas. Lerm. zeyl. 7.

Balutta-triampacam f. Caftanea rofce indica. Rbsed.mal. 3. P. 63. T. 53. Raj. bift. 1680 .

Habitat in India. b

\section{VATERIA}

1. VATERIA. Fl. zeyl. 204.

Pænoe. Rheed. mal. 4. p. 33. t. 15.

llabitat in India. $b$

\section{THEA.}

1. THEA. Hort. cliff. 204. Mat. med. 264. fin:this.

Thee. Kiempf. jap. 60,. t. 606.

Thee frutex. Bart. aft. 4. p. i. t. I. Bont. jav. 87. t. 88. Barr. rar. 128. t. yo4.

Thee finenfium. Breys, cest. IIT. t. II 3. i6. I7. t. 3. Bocc. muf. IIt. t. 94.

Chiaa. Baub. pin. 147.

Evonymo affinis arbor oricntalis nucifera, Hore rofeo. Pluk. alm. I39. t. S8. j. 6.

Habitat in Japonia, China. o

$V$ idi flores in aliis bexapetalos, in aliis erneapetalos; an ejusciem Speciei judicent, qui poffint vivam ixfpicere.

\section{CARYOPHYLLUS}

1. CARYOPHYLLUS. Hort cliff. 207. Mat med. 26. usmaticns. Caryophyllus aromaticus, fructu oblongo. Bass. piss. 410.

Caryophyllas aromaticus ind. orient, fruetu clavaro monopyreno. Fluk gim. 8S. t. 155 . f. I.

Caryophyllus. Ciaf. ¿xot. I6.

Habitat in Moluccis foily aridilomion

$$
\mathrm{K} k 2
$$




\section{MENTZELIA.}

apera. I. MENTZELIA. Mort. cliff. 492.

Mentzelia foliis \& fructibus afperis. Plum. gen. 4 t.

Onagra americana, folio betonic 2 , frustu hifpido. Tournef. inft. 302 .

Habitat in America.

Folia ferrata, alterna. Rami alterai. Flores axillares, folitarii, Sefiles.

\section{PLINIA.}

ginnats. I. PLINIA.

Plinia fructu croceo odurato. Plum. gen. $g$.

Habitat in America. $b$

Arbor Folia pinnata, abrupta; foliolis circiter 12, oulato-lanceolatis, integerrimis. Flores jefiles, fparfi per ramos mudos foriores. Fructus edules.

\section{MIMOSA. \\ * Foliis fimpliciter pinnatis.}

Lebbeck. 1. MIMOSA foliis pinnatis: foliolis oblongo-ellipticis, petiolis obverfe clavatis. Hajfelquift. act. upf. 1750 . p. 9.*

Haditat in Egypto fuperiore. 5

Inge 2. MIMOSA foliis pinnatis quinquejugis: petiolo articulato marginato.

Mimofa inermis, foliis pinnaris: petiolis membranaceis alatis. Hort. cliff. 209.

Arbor filiquofa bratilienfis, foliis pinnatis cofta media membranulis cxtantibus alata. Sloan.jam. 153. bift, 2. p. 58. t. 183 . f. I. Raj. bift. 1762.

Habitat in Brafilia, Jamaica, Surinamo b

fngtfokia. 3. MIMOSA foliis pinnatis bijugis; petiolo marginato. Arbor filiquofa, faginis foliis, americana, Hotibus comofis. Pluk. alm. 44. t. 141. f. 2.

Habitat in Barbados. $b$

uodosa. 4. MIMOSA foliis pinnatis bijugis: foliolis intcrionibus minoribus, petiolo lincari.

Mimofa inermis, foliis pinnatis: foliolis quaruor, glandula ovata inter infima minota. Vir. cliff. 49. Hort. cliff. 209. Roy. lugdb. 471 .

Phaleolus arboreus tetrapbyllos zeylanicus. Pluk. alirn. 294. t. $211 . f .5$.

Mabitat, in Leylona. \$

Fe. 
* Foliis, petiolo bipartito, non pinnais.

r. MIMOSA foliis bigeminis acuminatis. Fl. zeyl.218.* bigemina.

Katou-conna. Rbeed. mal. 6. p. 2i. t. Kaj. Lift. $174^{6}$.

Hibita: in India. o

6. MIMOSA foliis bigeminis obtufis. Hort. upf. 207. Ungnis cati. Roy. izgdb. 470.

Acacix quodammodo accedens $\mathrm{f}$. Ceratix \& Acacix, media jamaicentis fpinofa, ! igeminatis foliis. Pluk. ployt. r. f. 6 .

Acacia arborea major fpinofa, pinnis quatuor majoribus fubrotundis, filiquis varie intortis. Stoan. jam. 152 . bift. 2. p. 56 .

Habitat in Jamaica, Caribxis. 5

7. MIMIOSA foliis tergeminis.

Acacia frutefcens non aculeata, flore purpurafcente, alia. Plum. bifl. ml. Houft. mll.

Habitat in America meridionals. 5

Petiolus bifidus: pedicello fingulo terininato foliolis duobus; Jed infuper Foliola duo oppofita ad aivaricationem petioli communis.

* Foliis conjugatis f. Folia duo pinnata, communi petiolo annexa.

8. MIMOSA foliis conjugatis pinnatis: foliolis aquali-circinalis. bus, ftipulis Spinotis.

Acacia foliis amplioribus, filiquis circinatis. Plum. spei. 17.

Habitat is America calidiore. o

9. MIMOSA foliis conjugatis pinnatis: foliolis intimis purpuren. minoribus, caule inermi.

Acacia frutcicens non aculeata, flore purpurafcente.

Plum. Jjer. 17 .

Habitat in America meridionali. o

Io. MIMOSA folis conjugatis pinnatis: foliolis xquali-cineren. bus, caulc aculcis incurvis.

Mimola maderafpatana f́pinofa intfix accedens, cortice cinerco, ramis communi pediculo binis. Plak. alm. 4. $\therefore .2 . f .1$.

Habitut in India. b

I. MIMIOSA foliis conjugatis pinnatis: partialibus bi-viva. jugis lubrotundis, caule inermi herbaceo.

$$
i 1 \text { is } 3
$$


Mimafa herbacea non fpinofa minima repens. Sioan. jam. 153. hif.. 2. p. 58. t. 182.f.7. Raj.juppl.480. H. bitat is Iamaica fratis, 4

caga. 72. MIMOSA foliis conjugatis pinizatis: partialibus trijugis fubaqualibus, cavile aculeato.

Mimofa foliis conjugstis : foliolis pinnatis: pinnis fenis iibaqualibus. llort. upf. 145 .

Mimola undique aculcata, foliis geminatis pinatis : foliotis intimis minimis. Hort, cliff. 203.

Erchynomene fpincira latifolia i. Herba viva rei fpinota latifolia, pilofo \& fubrotundo folio. Comin. bort. 1. p: 55, t. 28.

Habitat in India: 5

Flares fpice inferiores decandri fieriles; juperiores decandiri fertiles.

Senfitiva, 3. MIMOSA foliis conjugatis pinnatis: partialibus bijugis: intimis minimis, caule aculeato,

Mimofa caule aculeato, foliis geminatis: partialibus tetraphylis, foliolis intimis mininsis. Roy, lugdh. 471 .

Mimofa fpinofia prima \&. brafiliana latiolia, filiquis radiatis. Breyn. cent. 3I. t. I6.

Hakitat in Brafilia, b

gradicas

14 MIMOSA foliis fubdigitatis pinuatis, caule aculeato hilpido.

Mimora foliis digitatis: foliolis pinnatis, caule aculeato hifpidoque, foliis pinnato-palmatis : ingulis numcrore pinnatis. Hort cliff. 208. Hart, upj. I 44 .

Mimora fpinofa 3, filiquis parvis echinatis. Breyn,cent. 40. $t .18$.

Fefchynomene foinofa, flore globofo albido, filiculis articulatis echinatis. Comm. bort. I, p. 57. t. 29.

Habitat in Braflia. b

Calyx infundibuliformis, trifidus: lobu attero. iatiore. Corolla mulla. Staninum frlament 4 , calyce fexies

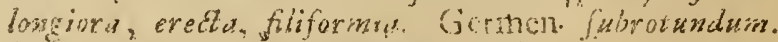
Stylus Jubulatus, firminibus paula bresor. Srigma acalitin.

* Folits digliare-pinatis, inermes.

Entak, 45. MIMOSA incrais, foliis bipinatis cirmo terminstis. F\% $20 \%=10$.

Entads. Rheed. mal.9. p: 151. t. 67.

Hultion ia wrayse ludia. b. 
16. MIMOSA inermis, foliis bipinnatis, fpicarum fori, plena. bus pentandris: inferioribus plenis. Hort. upf. 145.

Mimofa herbacea non finofa procumbens \& palultris, Hore luteo plerio. Houft. mls. $t$. I.

Habitat in Vera Cruce. $\odot$

17. MIMOSA inermis, foliis bipinnatis, fpicis cernuis, wirgata. floribus decandris: inferioribus caftratis apetalis. $1 \%$. zeyl. 505. Hort. up 145 .

Minofa inermis, foliis duplicato-pinnațis, filiquis linearibus glabris. Hort. cliff. 209.

Habitat in India. b

18. MIMOSA inermis decumbens, foliis bipinnatis, fpi- peinambucis cernuis, foribus pentandris: intcrioribus caftratis. cank. Hort. xps. 145 .*

Mimofa americana pigra, filiquis longis angultis allium olentibus. Pluk, alm. 552.t. 307. $f \cdot 3$.

Habitat in America. 5

19. MIMOSA inermis, foliis bipinnatis, leguminibus fpi- arboren. raliter circumvolutis, caule arboreo.

Acacia non fpinofa jamaicentis, foliis lata bafi in meta formam faitigiatis. Pluk. alin. 6. t. 25I. f. 2 .

Acacia arborea maxima non fpinora, ninnis majotibus, flure albo, filiqua contorta cuccinea ventricofa elegantifima. Sloan. jain. 157. bijt. 2. p. 54. t. 182.f. I. 2. Raj. Suppl. 477 ,

Habitat in Jamaicx E" Caribxarum humidis. 5

20. MIMOSA inermis folis bipinnatis: foliolis exterio- wass. ribus majoribus incurratis pubefcentibus. Hort. cliff. 209.

Mimofa non fpinofa ind. or; cantanex foliis, floribus ftanineis amplis, filiqua crulţacea placentæ in modum colorato. Pluk. maxt. $2 . p \cdot 33 ! . f .1$.

Arbor filiquola btafiliana, filiqua iortuofi, fintefcens. fraxinella folits. Breyn. cent. 1. ¿. I 5. an?

Habitat in India. 5

21. MLMOSA inermis, foliis bipinnatis : partialibus quin-Iatifitiqua. quejugis : propriis decemjugis.

Acacia non fpinofa, fiiquis latis compreffis, flore albo.

l'bem. fpec. 17.

Habizat in America calidiore.

Bractea dimidiato-coraata. Pedunculi terni; Flores capitati.

K. k. 4

22. $\mathrm{MI}$ - 
polyftochis. 22. MIMOSA inermis, folits bipinnatis: partialibus propriisque fexjugis oblongis.

Acrcia alia fcandens, ficica multiplici, filiquis latis. Plum. Spec. 7

Habitat in America calidiore.

Flores Spicati: Legrmina lata, longa, obtufa.

paregrina. 23. MIMOSA inermis, foliis bipinnatis: partialibus fedecemjugis : propriis quadragintajugis; glandula bafeos petiolari.

Mimofa inermis, foliis duplicato-pinnatis, glandula ad bafin petiolorum, filiquis ovato-oblongis planis. Hort cliff. 20\%.

Habitat in America. b

glume* 24. MIMOSA inermis, foliis bipinnatis: partialibus fexjugis, leguminibus membranaceis.

Mimofa inermis, foliis duplicato-pinnatis: partialibus utrinque fenis pluribusque, tiliquis planis membranaceis. Roy. lugdb. 472 .

Mimofa arborelcens non fpinofa, pinnis acacix latioribus inferne glaucis, flore albo. Breyn. cent. 1. p. 73 . Acacia fimilis americana non fpinofi, floribus globo.. fis albis ramofis. Kigg. beaum. 3 .

Habitat in America. 5

* Foliis duplicato-pinnatis, fpine aculei f. geminii $\int$. Solitar:i, nec fparfi.

eneres. 25. MIMOSA fpinis folitariis, foliis bipinnatis, floribus fpicatis. Fl. zeyl. 215 . $^{*}$

Acacia fpinola $\mathrm{cx}$ alis fpicata, foliis pennas avium referentibus. Burm. zeyl. 3. t. 2. bona.

Acacia maderafpatana, miuutiffimis foliis, aculeis ferocibus alternis frondofa, cortice cincreo. Pluk.alin. 3. t. I 2 I. $f$. 5 .

Habitat in India. 5

cornizern. 26. MIMOSA fpinis axillaribus geminis connatis, foliis bipinnatis. Hort. cliff. 208. Roy. lugdb. $4 \% 0$.

Acacia cornuta ind. orientalis. Seb. thes. $x . p$. I 3 . t. 70. f. 13 .

Acacia americana, grandibus aculeis ad ramulorum exortum cornua bovina referentibus, liliqua roftrata. Pluk. alm. 3. p: I22. f. I.

Acacix fimilis, fpinis corniformibus, mexicana. Comm. hort. 1. p. 209. t. 107.

Hatitat in Mexico, Cuba. b 
27. MIMOSA fpinis oppofitis longitudine foliorum, fo. horriln liis bipinnatis: partialibus bijugatis.

Acacia maderafpatana, foliis parvis, aculcis e regione binis pragrandibus horrida, cortice cincreo. Pluk. elim. 3. t. I2x. f. 4.

Mobitat in India. 5

28. MIMOSA fpinis geminis approximatis, foliis bipin-fcorpioites. natis: partialibus bijugatis. Hort. cliff. 208. Koy. lugdb. 470.

Acacia foliis fcorpioidis leguminofx. Baub. pin. 392. Acacia rgyptiaca. Hern. mex. 866. t. 866. bona.

Acacia vera f. Spina ægyptiaca, fubrotundis foliis, tlore luteo, filiqua brevi \& paucioribus ifthmis glabris \& cortice nigricantibus donata. Pluk. atm. 3. t. 123. f. I.

Habitat in Aigypto, Arabia. b

29. MIMOSA fpinis ternis: intermedio reflexo, foliis Senesal. bipinnatis, foribus fpicatis.

Mimola aculeata, foribus polyandris rpicatis, legumine compreifo lavi elliptico. Adanfon, ex B.'Yujfieu.

Mimofa fpinis geminis diftinetis, foliis dupiicato-pinnatis: partialibus utrinque quino-pluribus. Hort. cliff. 209. Hort. zipj. 146. Roy. lugdb. 411. Wat. med. 261.

Acacia. Baub. pin. 392. Alp. egypt. 9. t. 9.

Acacia altera vera, liliqua longa villola, corticc candicante donata. Pluk. alm. 3. p. 25I. f. I.

Habitat in Arabia. b

Cortice albo diftinguitur bec $\int p e c i e s p r i m o$ intuizu. Spi$n x$ ad foliz exortum tres.

30. MIMOSA fpinis geminis diltinelis, foliis bipinnatis : farmituma. partialibus octojugatis. Hort. $" p \int$. 146.

A cacia indica farneliana. Ald. farnej. 2. Raj. bift.977.

Habitat in Domingo. b

31. MIMOSA fpinis geminis patentibus, foliis bipinna- vilatica, tis: partialibus extimis glandula interitinctis.

Habitat in Ægypto, unde Seinina per D. Haflelyuift. D

Habitus $A$. Farnefiano $\sigma^{\circ}$ Senegal; differt a priore ramis absque punctis callofis, ut ab bor cortice mirime elto Seat purpurafcente; nec spikas babet ternas i.t j:nezal, jed binas easque longives anam farmejaina. Rami purparafcentes, leves. Loliabipionata, 5 circa-

$$
\mathrm{K} \text { a } \mathrm{s}
$$

ter 
ter parium foliorum partialiurs, inter duo paria partialium exterioruin glandula petiolo communi inferta efi.

* Folic duplicato-pinnatis: aculci fparfi.

ceis. 32. MIMOSA aculeata, foliis bipinnatis: foliolis oval. oblongis oblique acuminatis. $\mathrm{Fl} .2 \mathrm{cyl} .2 \mathrm{I} 7$.

Acacia pinofa, indix orientalis, foliis fubtus cxfis, floribus globofis luteis. Pluk. mant. 1. t.330. f. 3 . Habitat in India. $b$

persuta, 33. MIMOSA aculeata, foliis bipinnatis numerofffimis lineari-acerofis, panicula aculeata, capitulis globolis. Fl. $z e y ! .216$.

Acacia aculeata multiflora, folits pennas avium referentibus. Barm. zeyl. 2. $t$. I.

Habitat in Zeylona. $b$

inisia 34. MIMOSA aculcara, foliis bipinnatis, follolis incurvis, caule angulato.

Mimofa aculeis undique fparfis folitariis, foliis duplicato-pinnatis, caule angulato. Hort. cliff. 209. Gron. virg. 195.

Acacia maderafpatana fpinofa, pinnis veluti lunulatis:nervo pinnularum ad unicun latus vergente. Pluḱ. alm. 4. t. 122. f. 2.

Intfia. Rheed. mal. 4. p. ...t, 122., f:

Habitat in India. $\vdots$

femifinsfa. 35. MIMOSA aculcata, foliis bipinnatis, articulis caulinis luperne aculeatis.

Minofa aculeis ad fummitatem internodiorum confertis, foliis duplicato-pinnatis. Hort. cliff. 208.

Habitat in America. 5

quabrinleis 36. MIMOSA aculeata, foliis bipinnatis, caule quadrangulo, aculeis recurvis, leguminibus quadrivalvibus.

Mimofa undique aculeata, caule angula: 0 , foliis duplicaro-pinnatis: partialibus utriuqne ternis. Roy.lugdb. 471 . Mimola herbacca procumbens actipinofa, caule quadrangulo, iiliquis quadrivalvibus. Horft. mfl. fig. boz. Amm. berb. 50 a.

flabitat in Vera Cruce. 4

Aculei recurvi, $\int p a r / i$ in caule, petiolis, pedunculis. Folia portialio utrinque terizafoliolis platrimis. Pedunculi axillares, terminati Capisulo globofo. 
37. MIMOSA aculeata, foliis bipinnatis: partialibus viginti- tenvifo'is. jugatis: propriis inultijugatis.

A cacia rcpens aculeata, flore albo, foliis omnium miniinis. Plum. freci $1 \%$.

Hobizat in America colidiore.

Aculei recurvi in coml of Pedunculis commaniter. Flores cantati, interalce, plares.

38. MIMOSA aculeata, foliis bipinuatis: partialibus quin- ceratoniu. que-jugatis: proprifs tri-jugatis tiinervis.

Acrcia repens aculeata, flore abo, foliis filiqux, Plum. frec. 17.

Hibitat in America ealidiore.

Aculei rectrvi in cas!e Es petiolis. Peduncuil laternles, conferti. Fiores capitati. Legumina obtufa, futura acusciatu.

29. MIMOSA aculeata, foliis bipinnatis: partialibus quin - tamorind:fnque-jugatis: propriis decem-jugatis, periolis jner mibus. liv.

Acacia aculeata, tore albo, folis tamarindi. Plum. $\int p$ i 7 .

idabitat in Ainerica meridionali. b

Pedunculi ramofi. Flores fpicati,

\section{CISTUS.}

\section{* Expipulatia fiuticare.}

I. CISTUS arborefcens, foliis cordatis lavibus acumina- popsinglia. tis petiolatis. Hort. riff. 205. Roy. lugdt: 474.

C:\{us Ledon, foltis populi nigra, inajor. Basb. pin. 467.

Ledum iatitolium z, majus. Clus. bift. i. p. 78 .

B. Ciltus Ledon, lohis populi nigra, minor. Bauh. pin. 4a\%.

L.edum latifolium 2 minus. Cluf. bift. I. $p .79$.

Habitat in Luntania.

2. CISTUS arborefcens, folis ovatis petiolatis trincrviis lamifola,

flipra glabis: petiolis bafi connatis.

Citus Ledon, folits laurinis. Bamb gin. 467 .

Ledon 1 iatifolium. Clus. bijt. I. p. 77.

Habitut in Hifpania, b

3. ClSTUS aiborefcens, foliis ianceolatis fupra ?ævibus, isturifero. periolis bafi coalitis vaginantibus. Fort. cliff. 205 .

Sayz. mosion. I.1\% 15\%

Cith adanifera hifpanca incana. Bazh. pist. 467.

Cilus lednn angultifolius. Cluf. Hift. I. p. 77.

Hahtal in Hipanie, Lnitanix collives. b

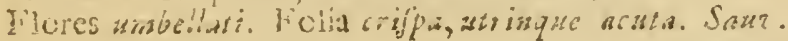


incras. 4. CISTUS arborefcens, foliis fefilibus utrinque villofis rugolis: inferioribus ovatis bafi connatis; fummis lanceolatis. Hort. cliff. 205. Hort. ups. 143. Roy. lugdú. 475 .

Ciftus inas anguftiolius, Baub. pin. 464.

Ciltus mas 2. Clas. bift. I. p. 69.

Habitat in Hifpania, G. Narbonenfi. 5

mon,pelien-

is.

5. CISTUS arborefcens, foliis lanceolatis fefflibus utrinqne villolis trinervius, alis nudis. Hort. cliff. 205. Hort. ups. 144. Ruy. lugdb. 1475. Sauv. monsp. 147. Ciftus ladanifera monpclienfium. Baub. pin. 467.

Ledum. Dalech. hijt. 230.

Q.Ciltus Ledon foliis olea, fed angutioribus.Baub.pin. 467.

Ledon s'. Cluf. bift. I. p. 79.

Habitat in Narbonenfi E' Regno Valentino. 5

mbida. 6. CISTUS arborefcens, foliis oblongis tomentofis incanis feflilibus fupra aveniís, alis nudis. Sauv.monifp. I50.

Ciltus mas, folio obiongo incano. Baub. pin. 464.

Cittus mas 1. Clus. bift. I. p. 68.

Ciltus mas 4. monf́pelienfis, folio oblongo albido. Baub. hift. 2. p. 3 .

Habicat in G. Narbonenf, Hifpania. क

Salvifoiia, 7. CISTUS arborelcens, foliis ovatis petiolatis utrinque hirfutis, alis nudis. Hort. cliff. 205. Roy. lagdb. 475. Saur. monsp. I 50.

Ciltus femina, folio falvix, Bauh. pir. 464.

Ciltus femina. Clus, hift. I. p. 60.

Habitas in Italia, Sicilia, Narbona. $b$

Pedunculi uriflori, diphylli. Corolla alba. D. Saxv.

erifps. 8. CISTUS arbarefcens, foliis lanccolatis hirfutis repandis, alis nudis. Hort. cliff. 206. Roy. lugdb. $475^{\circ}$ Sazz. Marafp. 147.

Ciftus mas, follis chamædryos. Baub. pin. 464.

Ciftus mas 5. Cluf. bijt. I. p. 69.

Habitat in Lufitania. $b$

Rawuli, pedunculi E calyces tenui lana adjperfi.

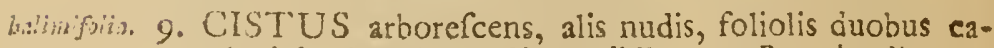
lycinis linearibus. Hort. cliff. 205. Roy. lugdb. 475 Sauv. mogl? 147 .

Ciftus femina, portulace marina folio latiore obtufo.

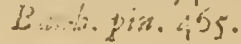

Ciltus 
Ciftus folio halimi r. Cluf. bift. r. $p$. $7 \mathrm{t}$.

B. Ciftus femina, portulacæ marinæ folio anguftiore mucronato. Baub. pin. 465 .

Ciftus halimi folio 2. Cluj. bift. 1. p. 7 r.

Habitat in Lutitanix maritimis. b

$$
\text { * Exfipulate, Juffrutisole. }
$$

ro. CISTUS fuffruticolus procumbens exftipulatus, fo-smbellazus. liis oppofitis, foribus umbellatis.

Ciftus folnis lincaribus non ttipulatis, canle forali umbellato lignofo. Guett. ftamp. 2. p. iso. Daliv. pa= rif. 158 .

Ciftus Ledon folis thymi. Baub. pin. 467.

Ledon X. Clus. bift. I. p. 81.

Habitat in Gallia, Hifpania. b

11. CISTUS fuftinticufus procumbcns cxitipulatus, foliis Fumans. aiternis linearibus, pedunculis mintoris.

Ciltus cauce proctimbente, foliis alternis. Fl. fater. 435. Gutet. ftamp. 157.

Ciftus fruticolus procumbens, foliis aciformibus nudis. Sauv. monsp. 45 .

Hclianthemum foliis linearibus fapius alternis non ftipulatis, pedunculis unifioris, caule lignofo. Guett. famp. 2. p. 18.

ChamaCitus, erica folio, luteus elatior. Baub. piz. 466.

Hclianthemum tenuifolium glabrum srectum, luteo tore. Bash. bift. 2. p. is.

B. Ciltus fruticolus procumbens, foliis aciformibus nudis, floribus auriculatis. Sauv. monfp. 4ú.

ChamæCiftus, ericæ folio, luteus humilior. Bazb. pin. 466.

Helianthemun tenuifolium glabrum, lutco Hore, per humum fparfum. Bawb. hift. 2. p. 18.

Hubitat in Gallia, Gotlandia, Helvetia. 5

Co, olla calyce $z i x$ major eft.

12. CISTUS fuffruticofus exftipularus procumbens, fo- catns. liis oppolitis villofis fubtus tomentolis.

Ciltus toliis ovatis tubrus incanis, alis uluis, caulc procumbente. Sis r. rionjp. 148 .

ChamxCiftus tolijs myrti minoris incanis. Bauh. fin. 406.

ChamxCiltus folii myrti tarentizx canis \& cincrcis. Baub. bift. 2. p. is. 
ChamæCiftus 3. Clus. bift. T. p. 74.

Habitat in G. Narbonenfi, Hilparia. b

marifolins, 3 . CISTUS fuffruticofus exftipulatus, foliis oppofitis ovatis petiolatis planis fubtus tomentofis.

Helianthemum luteum, thymi durioris folio, Bair. rar. 521. t. 44I.

Habitat Maffilix. b

Oelanicus, 14. CISTUS fuffruticofus procumbens exftipulatus, foliis oppofitis oblongis utrinque giabris, petiolis ciliatis, petalis emarginatis.

Ciltus caule procumbente, foliis oblongis utrinque glabris, ftipulis nullis. Fl. friec. 434 .

Habitat in rupibus apricis Oẹlandia. 5

\section{* Exftipulate, berbarere.}

Tuberaria. 55 . CISTUS exftipulatus perennis, foliis radicalibus ovatis trinerviis tomentofis: caulinis glabris lanceolatis: fummis alternis.

Ciftus perennis, foliis humi appreffis villofis; fummis glabris. Sauv. monfp. I 49.

Ciltus folio plantaginis. Bauh. pin. 465.

Tuberaria noltras. Basib. bift. 2. p. I 2.

Tuberaria major. Baub. hift. 2. p. 12.

Habitat in Galloprovincia, Hifpania, Pifis. $z$

gutatus. I6. CISTUS herbaceus exftipulatus, foliis oppolitis trinerviis, racemis ebracteatis.

Ciftus annuus, foliis radicalibus opporitis lanceolatis trinerviis, ramiferis ternntis linearibus. Sauv. mon $p$. 148.

Cifus foliis oblongo acuminatis non fipulatis, caule florali racemofo. Guett. ftamp. 2.p. 181. Dalib. parif. 158.

Ciftus flore pallido, punicante macula infignito. Baub. pin. 465 .

Helianthemum flore maculolo. Col. ecphr. 2. p. $78 . t .77$.

Habitat in G. Narbonenfi, Italia. $)$

Raccmi capillores omnino, absque ullis vel minimisbra: Eteis.

canadenis. 17. CISTUS herbaceus exftipulatus, foliis omnibus alternis lanceolatis, caule adfcendente.

Habitat in Canada. Kalm. 24

Facies C. Heliantbemi, Sed Folia alterna. 


\section{* Stipulata , berbacer.}

18. CISTUS herbaceus erectus glaber ftipulatus fioribus ledifoliws, folitariis fubfellibus, folio ternato oppolitis. Hort. upf. 144. Sauz. monjp. I 78.

Ciltus tipulis quaternib, foliis oblongis, caule erecto. Hort. cliff. 475 .

Cintus ledi tolio. Baub. pin. 465 .

Ciftus annuus, foliis ledi. Lob. ic. 2. p. 118.

Habitat Monfpelii. $\odot$

19. CISTUS herbaceus patulus villofus ftipulatus, ftoribus frabifoliss. folitariis fubfedilibus bractea triplici uppolitis. Hort. up. 144.

Ciftus ltipulis quaternis, foliis fubovatis fubtus tomentofis, caule procumbente. Hort. cliff. 206.

Ciftus folio falicis. Baub. pin. 465.

Ciflus annuus 1. Clul. hift. 1. p. 76.

Hahitat in Lufitania, Hifpania. ()

20. CISTUS herbaceus erectus ftipulatus, foliis lineari- gyptinsts. lanceulatis petiolatis, calycibus intlatis curolla majoribus.

Habitat in Egypto. B. Fufleus. (

Conf. CytiCintus foliis inferioribus confertis, fuperioribus oppolitis. Burm. zeyl. 85.t. $3^{6 .}$

$$
\text { * Stipulatie, fuffruticole. }
$$

21. CIST US fuffruticofus procumbens ftipulatus, foliis furrejanws. ovato-oblongis fubpilotis, petalis lanceolatis.

Helianthemum: vulgare, petalis Horum perangultis. Dill elth. 177. t. $145 . f .174$.

Ilabitat in Anglia comitatu Surrejano prope Croycion. 5

28. CISTUS fuffruticofus ftipulatus, foliis inferioribus or- nummulario biculatis, fuperioribus ovatis.

Ciltus humilis 1: ChamæCiftus nummulaxix folio. MIagn. monsp. 293.

Helianthemum ad nummulariam accedens. Baub. bift. 2.

ilabitat 20.

ilabitat Monfpelii. b

2.3. CISTUS luffruticolus fipulatus, toliis oblongis, ca-jovpillifolins lycibus lrevibus. Saur. nuon/p. I 48.

ChamæCittus repens ferpillifoliz lutea. Baub.pin. 460.

Cimma: Ciftus cerpylli folio nigricante \& hirturo, fore aurco odorato. Bauh, hijh. 2. P. I7. 
ChamxCiftus 2. Clisf. bift. r. D. 73 . Habitat in Alpibus Aulria, Stiria. b

thymifolius. 24. CISTUS fuffuticulofus ftipulatus procumbens, foliis ovali-linearibus oppolitis congeftis. Saur. non $\int p$. I 48 . $\dagger$

Heliauthemum folio thymi incano. Baub. bift. 2.p. 19

ChamæCiftus incanus, tragorigani folio, hifpanicus. Barr. rar. 512. t. 47 5.

Habitat in G. Narbonenf, Hifpania. b

plefies. 25. CISTUS fuffuticofus ftipulatis, foliis lineuricus fup. tus bifulcatis incanis, calycibus lavibus. Saum monf p. 147.

ChamæCintus foliis thymi incanis. Baxb. pix. $4 \in 6$

ChamaCiftus 4. Cluf. bift. I. p. 74.

Q. Ciltus ftipulis quaternis, foliis lineari-ovalibus incanis. calycibus tomentolis. Saur. monsp. 148 .

Helianthemum fore albo, folio angatto hirfuto Bauh. bift. 2. p. 17.

$y$. Ciftus folis villofis lanceolatis, axillis foliofis, fipulis fubulatis. Sauv. monsp. I48.

Helianthemum f. Ciftus humilis, folio fampluci, capitulis valde hirfutis. Bauh. bifz. 2. p. 20.

Habitat Monfpelii. 5

líne tres a. B. $\gamma$. vel varietates vel valde affines: cerw. ora determinent autopt.e.

Heliantise- 26. CISTUS fuffruticofus procumbens, ftipulis lanceo. мxแm. latis, foliis oblongis revnlutis fubpilofis.

Ciftus ftipulis quaternis, foliis oblongis utrinque nudis caule procumbente. Hort. cliff. 206. Roy. ligdb. 476. Fl. fuec. 433 .

Cham Ciftus vulgaris, fore luteo. Bamb. pira. 465. La!. prafl. 43. . 8.

Flos lolis, Panax chironium. Cam. epit. jor.

Habitat in Europæ pafcuis fircis b

Petalu fuborbiculata, integerrima, flava, antulo receptaculum aimbiente fopizs fulvo. Racemus ante florefcentiam uztans. Folia pilis raris adjper $\int a$.

birtus. 2\%. CISTUS fuffruticofus ftipulatus foliis ovatis, calyci. bus hifpidis.

Ciftus foliis oblongo-linearibus margine revolutis. Ls monier. Sauv. imansp. 148 .

Helianthemum rorismarini folio fubtus incano. $B$ ar. pir. 467. 
Helianhenum, angufto ferpilli folio, villofum, flore sureo, italicnun. Barr. rar. 511. t. 488.

Ledon 8. Cluf. bift. 1. p. 8.

Habitat in Hilpunia, Narbona. D

28. CISTUS fuffruticofus thipulatus erectus, foliis lance-apentinis. olatis hirtis.

Helianthemurn album gernanicum. Tabern. icon. rofiz. Helianthemum lixatile, foliis \& caulibus incanis obiongis, Horibus albis. Mentz.peg.8.f. 3. Dill.elth. I 70.

Habitat in Apenninis, italix muntibas. b

Cifforu in biftoria maxime ominium obfcura ob varietatum eppiam, illasfrabitur fi ietermikent autoptec in fingulis

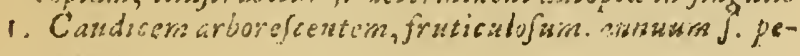
renuen.

2. Caslem eredum /. decusinbentem.

3. Folia oppofita f. alisrna: cum figura eorundem.

17. Sipulas $f$. nkllas.

5. Pedunculum unifiorum, multiflorkm: sudumfibran Eleatum.

5. Peialorism figaram.

7. Capjulas sloculares $\int$ jualies.

8. Galycen cqualim $\int$. incequalein.

\section{CORCHORUS.}

- CORCHORUS capfulis inearibus compreflis bivalvi- flizharyus. bus. Hort. aps. I 47 .

Corchoro affinis chamadryos folio, flote famineo, feminious atris quadrangulis duplici ferie difpolitis.

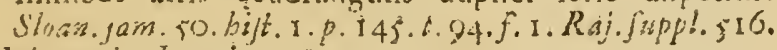

Habsiat in Jamaica. (\%)

2. CORCHORUS capfulis oblongis ventricofis, folio-nliternt: rum intimis iciraturis fetaceis rehexis. Fl, zeyl. 213. Hort. $n: 14.147$.

Corchorus foliorum infimis ferraturis maximis rettexis. Hort. cliff. 209. Roy. lugdb. 478 .

Corchorus plinii. Bants. pirs. 317 .

Corchortis. Cain. bort. 47. t. I 2.

C. Alcea cibaria f. Corchorus amcricana. Plikk. alm. I 7. t. $12 \%$ f. 3 .

y. Alcea cliroria f. Corchortis americana. Pluk: alm. 37

t. $\times 27.5 .4$.

Habitat in Alia, Africa, Anerica. O

3. CORCHORUS caplnhis fubrotundis depreflis rugo- arfulars. fis. Fl. zeyl. 214 . 
Corchorus foliorum infimis ferraturis minoribas. Hort. slitf. 2.10. Ray. Ixgdb. 478 .

Alcea olitorin $\mathrm{f}$. Corchorus annericunus, przlong is foliis, capfula thiata librotunda brevi. Plak. alm. 18. t. $255 \cdot f \cdot 4$.

Habitat in India. $\odot$

hirfutus. 4. CORCHORUS capfulis fubrotundis lanatis, folits ovatis obrulis tomentefis.

Corchorus americanus lanuginofus, folio chamadryos, filiqua tricapfulari lanuginofa \& fubaipera. Breysa. prodr. 3. p. 56.

Guazuma frutex chamadryfolia, fruetu lanuginofo, ma. jor E' minor. Plum. gen. 36 .

Habitat in America meridionali.

\section{DIGINIA.}

\section{P正ONIA.}

officinalis, 1. P正ONIA. Hort. diff. 2i2. Hort. upf. 149. Mat. med. 26\%. Siluz. monfr. 307.

feminea, a. Pxonia folis difformiter lobatis. Hall. belv. 311.

Paonia communis $f$ temina. Baub. pin. 323 .

Paonia femina. Fuchj. biff. 202. Lom. ic. 602.

inafrula, $\beta$. Fronia foliis lobatis ex ovato-lanceolatis. Hall. belq. 3 Ix.

Pxonia folio rigricante fplendido, mux mas. Baús. pir. 323 .

Pronia mas. Lob ic. 684 .

Habitat in Nemorihus monium Idx, Helvetix. 2

Limites inser flecies non reperi, binc conjunxs.

\section{CALLIGONUM.}

polygoroides 2. CALLIGONUN. Hort. cliff. 2 ז.

Polygonoides orientale, ephedì facic. Tournef. eer.

47. itin. 3. p. 214. t. 214 .

Habitat in mortio Ararat. 5

\section{TRIGTNIA. \\ DELPHINIUM. \\ * Unicapfulares.}

Ccufolide. I.DELPHINIUM nestaris monopinglis, esuie fubdivifo. Hort clift. 217 . Fl. Sasec. 440 . Mat. med. 263. Roy. ingulb. 482. Oalib. purif. 158.

Cors. 
Confolida regalis arvenfis. Baub. pin. $14^{2}$.

Confolida regalis. Cism. epit. i2r.

Habitut in agris Europx rejtivilibus. $\odot$

2. DELPHINIUM nectariis monophyllis, caule fimplici. Ajucir. Hort. cliff. 213 . Hort. "pf. I ja. Rog. lugdb. 482. Confolida regalis hortenlis, fore majore \& limplici. Baun. pin. 142.

Confolida regalic horten fis, fore minore. Bauh.piz. I 42. Confolida regalis fore inajure \& multiplici. Bash. pin. 142.

Flos regius. Dod. Demps. 252. Habirat ...- -

3. DILPHINIUN nectariis d:phyllis, capfulis folitariis, peregrinn. foliis multipartitis obtufis. Hort. cliff. 213 .

Confolida resalis latitolia, parvo forc. Buzh. pin. 142. prodi. 74.t.74. Morif. bift. 3. p. 406.f.12.t.4.f.3. Habitat in Italia, Sicilia, Melia.

$$
\text { * Ti icnpplutares }
$$

4. DELPHINI UM nectariis diphyllis labeliis integris, flo-gramdifloribus fublolitariis, foliis componitis lineari-mnultipartitis. Hort. upf. 150.

Delphiniuin lulitanicum glabrum, aconiri folio. Rolof. bert. 6I. $t .3$.

Delphinium elatius fubincanum perenne, floribus amplis azureis. Amin. ruth. 175 .

Habitat in Sibiria. \&

5. DELPHINIUM neetariis diphyllis: labellis bifidis a-eleturn pice barbatis, foliis incilis, caule erefto. Hort. ups. I5I.*

Delphinitim neexaris diphyllis, foliis peltatis multipartitis acuîis. Hort. cliff. 213 .

Aconitum cxruleum hirfutum, fore confolidz regalis. Baub. pin. I3T.

Acninitum lycoctonum, flote delphinii filefaci. Clus. bijt. 2. P. 94.

Habist in Sibiria. Zz

5. DELPHINIUM neetarïis dipbyllis; foliis palmatis: Srophafugia lobis interris. Hort. clitf. 21 i. Ifort. $x p l: 1$ yo. Mhat: med. 269. Roy. lugdb. 482. Snuv. monft. 214. Staphifagria. Baub. pin. 324. Dod. pempt. 366. Mabritat in Iltria, Dalinaria, Calabria, Apulid, Creta. Galloprovincia. 0

$$
\begin{aligned}
& \text { L } 12 \\
& \text { ACO. }
\end{aligned}
$$




\section{ACONITUM.}

lycottoxжm. I. ACONITUM foliis palmatis multindis villofis. Aconitum foliis pelatis mulrifidis, petalo lupremo cylizdraceo. Fl. lapp. 2 I1. Hort. clift. 213 . H\%. Juec. 441. Roy. lugdb. 482 . Hill. beiv. 312.

A conitum lycoctonum luteum. Bará. pin. 183 .

Aconitum Ifcoctonum, flore lureo: Bejl. eyjt. eff 25. f. 2.

Aconitum II. Cam. epit. 827 .

Hehitat in Alpibus Lapponiz, Helvetia, Auftix, Italix. 2

varieguthm, 2. ACONITUM foliis mutifidis: laciniis femipartitis: fuperne latis. Hort. cliff. 214. Hort. ups. 15i. Koy Ingab. 482.

A conitum cæruleum minus. ᄃ. Napeilus minor. Baиb pin. 183 .

Aconitum cxruleum parvum. Dod. pempt. 441. Daleck bift. 17.13 ..

Habitat in ltalia, Bohemiz montibus. 2

Nipellus. 3. ACONITUM foliorum laciniis linearibus fuperne la* tioribus linea exaratis. Hort. cliff. 214. Fl. Juec.442. Gron. visg. 165. Hall. belo. 312. Roy. lagd6. 483. A.t. fockb. 1739. p. 41. t. 2 .

Aconitum cxrulcum f. Napellus :. Bash. pin. 183. Napelius verus. Lob. bi/f. 387 .

Habitat in Helvetia, Bavara, Gallia. $z$

pyrenaicum. 4. ACONITUM foliis multipartitis: laciniis linearibus incumbentibus quarrofis. Hort. $x p \int$. 152.*

Aconitum prenaicum luteum, foicrum fegmentis 6 bi invicem incumbentibus. Kaj. exrop. 367 .

Habitat ia Sibiria, Tataria, lyrenæis. 2

Authoria. 5. ACONITUM Roribus pentagynis.

Aconitum foliorum lacinis linearibus dintinetis ubiegue ejusdem latitudinis. Hort. cliff. 214. Hort. $2 p \int .252$ Mat. med. 27o. Hell. hel:. 313. Roy. lugdu. 483. Aconitum falutiforum r. Anthors. Bauh. pin. 184 . Anthora f. Antithora. Garn. epit. 337.

Habstat in Alpitus Yyrenais, Helveticis, Taurinis, A? lobrogicis. \& 


\section{TETRAAGNIA.}

TE.TRA GER A.

1. TETRACERA. Hor:. clill. 21 .

volubilis.

Petraca tloribus fpicatis, fabris lauri foliis. Amm. berb. SSI.

Fagus anericanus, ulmi ampliffmis foliis, capfulis bigemellis. Pluk. arrali. S7.

Arbor americana convolvulacea platyphyllos barbadenfibus dice follis ferratis. Plak. alim. 48. t. I $46 . f .1$. Habitat in Barbados, Vera Cruce, Marilandia. 5

\section{$P E N T A G T N I A$}

\section{AQUILEGIA.}

I. AQUILEGIA nectariis incurvis. Hort. apf. 152. Mat valgavis. med. 272.

Aquilegia. Hort. cliff. 215. Roy. Isgdb. 4\$2. Dalib. parif. 160.

Aquilegia fylveltris. l3auh. pin. Iff.

B. Aquilegia hortentis fimplcs. Banb. pin. 144:

$\gamma$. Aquilegia hortentis multiplex, flore magno C. B. I44.

- Aquilegiahortentis multiplex, flore inverfo. C. B. 144.

ع. Aquilcgia fiore rofeo multiplici. C.B. 147

Y. Aquilegia degencr virclcens. Baub. pin. 144.

- Hibitat in Europa nemoriuus faxofis. 22. AQUILEGIA ncetariis rectis petalo lanceolato brevi- nlpina.
Oribus.

Aguilegia moutata, magno florc. Baub.pin. I 44.prodr. 7). Burf. VIl: 108. Baub. bift. 3.p.484. Raj. bift.

707.

Habitat in Helvetia. $\delta$

Folia duplicato-ternata, parva: foliolis multifidis: lobis fubliracaribus, obtufis, facic Ẽ tcneritudine lequentis; Nectarii cornicala ereetiuf cula, brezica, petals dimidio breaiora. Petala lanccolut a, longifirina.

3. AQUILEGIA neetaris rectis, Itaminibus corolla lon- cnuderfis. gioribus. Llort. up i. 153:

Aquilegia corolla implici, nectariis icre rectis. Gron. virg. 59.

A quilegia pumila prxcox carladentis. Corn. canad. 60. t. 60. Lob. ic. 26. 
Aquilegia præcox canadenfis, fore externe rubicund? medio luteo. Morif. bift. 3. p. 457 . J. I2.t.2. f. 4 . Habitat in Virginia, Canada. 2

\section{NIGELLA. \\ * Pentagyna.}

Iamafenn. I. NIGELLA fioribus involucro foliofo cinstis. Hort. cliff. 215 . Hort uts. 153 . Roy. lugdb. $48 \mathrm{t}$.

Nigelia anguftifolia, flore majore fimplici caruleo. Bauh. pin. 145.

Mclanthium fylveitre. Matth. dinfc. 529 .

B. Nigella tlore majore pleno caruleo. Baab. pin. 145 .

Habitat inter fegetes Europa auftralis. ()

fativa. 2. NIGELILA petalis fubtricufpiciatis foliis fubpilofis. Hort. upf. 15.4. Mat. med. 27I. Boehn. lipl. I 73.

Nigella fore minore fimplici candido. Baub. pin. 145 . Melanthium fativum. Cam. epit. $55 \mathrm{x}$.

Nigella flore minore pleno \& albo. Baub.pin. 146.

Habitat in Ægypto, Creta. $\odot$

arenss. 3- NIGELLA pittillis quinis, petalis integris, capfulis turbinatis.

Nigella fiore follis nudo, pintillis corollam æquantibus. Hort. cliff. 215. Roy. lugdb. 481. Hall. belv. 316. Dalib. parts. ióo. Bachm. lipf. 174.

Nigella arventis cornuta. Bauh. pin. 145.

Melanthium fylveitre alterum. Cam. epit. 553 .

Hujus Capjula infernc anguftior, preccacnis inferne ventricofior, Superne utraque contra.

* Decazjina.

bijgrrica. 4. NIGELLA piftillis denis corollam rquantibus. Hort. upf: I54. Sauv. monlp. 253 .

Nigclla latifolia, tore inajore fimplici caruleo. Baub.pin. I45.prodr. 75 . Morif bift. 2. p. 5I6. J.I2.t.18.f.8. Habitat in Hifpania, Monfpclii. ()

-rientalis. r. NIGELLA piftillis denis corolla longioribus. Hort. rlift. 215. "Hort. apf. 153 - Roy. lazdb. 431 .

Nigella chalepenfis lutea, corniculis longioribus. Morif: buft. 3. p. 5x6. f. 12. t. is. f. 10. Rai. app. 525.

Ilabibat. carcan Alepum. () 


\section{$H E X A G \Upsilon N I A$.}

STRATIOTES.

1. STRATIOTES foliis enfiformi-triangulis ciliato-2-Aloides. culcatis.

Stratiotes. Fl. lapp. 222. Fl. Suec. 444. Hort. cliff. 22 I. kiny. lingdb. 10. Gort. gelr. 3 I3.

Stratotes militaris aizoides, Lob. biff. 904 .

Aloë paiuftris, Paub: pin. 286.

Ilabitra in Europx jeptentrionalis aquis pigris. \#

2. STRATIOTES foliis cordatis. Fl. zeyl 223 .

Oel-ambel. Rbeed. mal. II. p. 95. t. 46 .

Habizat in India. 2

\section{POLTGRNIA.}

\section{DILLENIA.}

8. DILLENIA. Hort. cliff. 221.

Syalita. Rbued. mal. 3.p. 39. t. $3^{8} .39$.

Alifmoides.

Habitat in Malabaria. $b$

\section{LIRIODENDRON.}

1. LIRIODENDRON. Hort. cliff. 223. Hort. "pf. I 54. Tulipifera.

Gron. virg. 60. Roy. lugalb. 494.

Tulipifera atbor virginiana. Herrn. lugdb. 612. t. 6r3.

Tulipifera virginiana, tripartito aceris folio: media laci-

nia velut abfcifra. Pluk. alm. 37y. t. 117. f. 5. Et.

249. f. 7. Catesb: car. I. p. 48. t. 48.

ß. Tulipifera caraliniana, foliis.productioribus magis an-

gulolis. Pluk alm. 379. t. 68. f. 3 .

Habitat in America Septentrionali. 5

1. MAGNOLIA.

\section{MAGNOLIA.}

Magnolia foliis ovato-lanceolatis. Hort. clift: 222 . Ciron.

indica, virg. 61. Ray. Iugdb. 493.

a. Magnolia foliis ovato-lanceolatis fubtus glauois. Anmn. glauca. Magnolia lauri folio fubtis albicante. Catesá. car 1. p 39. t.39. Dill. elth. 207. t. IGS. f. 205.

Tulipifera virginiana, laurinis foliis averfa parte tors cæruleo cinctis, cuni-baccifera. Plak. alm. 379.t.68. f. 4 . 


\section{6}

\section{POLYANDRIA POLYGYNIA.}

Laurus tulipifera, baccis calyculatis. Raj. bift. I 690 . Foetida, B.Magnolia foliis ovato-oblongis fubtus viridibus. Anon: Magnolia altifima, flore ingenti candido. Catesb.ior. 2. p. 61. t. 61. Ehrct. pidt.

Magnolia amplifimo folio, fructu cærulco. Phum.gen. 38.

Mngnolia fore maximo albo fatido, foliis decidais amplis, florum ad ramulorum fericm fpherice cirgent:bus, fructu majori. Gron. virg. 6i.

griea. $\quad \gamma$.Magnolia foliis ovato-oblongis fubtus grifeis. Aizon.

Lautus tulipifera, folits fubtus ex cinereo aut argente." purpurafecntibus. Raj. hift. 1718.

sripetala. D. Magnolit amplifimo flore albo. fruetu coccineo. Ca tesb. car. 2. p. 80 . t. 80.

beumirata. E. Magnolia flore albo, folio majore acumniato haud albicante. Catesb. car. 2. p. 15. t. 15, Cron. virg. 6r. Habitat in Virginia, Carolina. $b$

Utrum ba: a. B. \%. \&. \&. fist diftincter, determinent axtopta in folo naturali? harum.

8. Petalis tribus exterioribus reficxis.

$\varepsilon$. Foliis ovntis acurninatis.

B. Flore masizino Ẽ longiore in diametro quane foliorum losgitudo $\mathrm{S}^{\circ}$ Folits fubtus grifeis.

\section{MICHELIA.}

Chompacs. 1. MJCHELIA. Fl. zeyl. I44. Champacarn. Kbeed. mal. т. p. 3т.t. 19. Raj. hif.roat. Habitat in India. 5

\section{UVARIA.}

zcylantcr. I UVARIA foliis integerrimis.

Uvaria. Fl. zeyl. 224.

Narum-panel. Rbeed. mal. 2. p. I:. . . 9.Raj. bif. 1636. Habitat in India.

ingoniean 2. UVVARIA foliis ferratis.

Frutex vifcofus procumbcns, folio telephii vulgaris mulo, fructu racemolo. Kasinpf. amass. $476 . t .477$. Habita: in Japonia. $b$

\section{ANNONA.}

musccts. r. ANNONA folits ovali-lanceolatis glabris nitidis planis. pomis muricatis. Hort. sliff. 222.* Grow. zire 6i. Koy. lugab. 494. Anno 
Anona indica latifolis, fruetu fquamofo afpero. Plak. alm. 31. t. 134. f. 2 .

Anona indica fruciu conoide viridi fquamis veluti aculeato. Pluk. alm, 32. t. 135.5 .2$.

Anona maxima, foliis latis Splendentibus, fruetu maximo viridi conoide: tuberculis $f$. fpinnulis innocen. tibus afpero. Sloax. jam. 203. bift. 2. p. 196.t,225.

Anona. Cormm. bart. I. P. 133. t. 69 .

Guanabanus fruetu e viridi lutefcente molliter aculeato. Plum. gen. 43

Habitas is America calidione. "

2. ANNONA foliis oblongis, fructibus obtufe fubfqua- fantamofa. matis.

Anona foliis adoratis minoribus, fruetu conoide fqua. mofo parvo dulci. Slom. jam. 205. kijt. 2. p. 168. t. 237. Raj. dendr. 77.

Habitat is America meridionali. 5

3. ANNONA foliis lanceolatis, fructibus nvatis reticu- reticulats. lato-areolatis.

Anona maxima foliis oblongis anguftis, fructu maximo luteo conoide: cortice glabro in areolas angulares diltincto. Sloan. jam, 264. bi/t, 2. p. i67.t.226. Catesb. car. 2. p. 62. t. 62. Raj. dendr. 77.

Habitat in America meridionali. 5

1. ANNONA foliis lanceolato-ovatis, fructibus conoi glabra dibus glabris.

Anona maxima, foliis latis, fructu maximo luteo conoide: cortice glabro. Catesh. sar. 2. p. 64. t. 64.

Habitat in Carolina. I

f. ANNONA foliis lanceolatis, fructibus trifiơrs.

trilobs.

Anona fructu lutefcente levi ferotum atietis referente.

Catesb. car. 2. $p .85 .2 .85$.

Habitni in Carolina. b

6. A.NNONA foliis lanceolalis glabris nitidis fecundum afuntico. nervos fulcatis. Hert. cliff. 222. * H. zejl. 225. " Roy. lugdb. 494.

Annona fyiveftis. Burm. zeyl. 2.?

Habita: in Zeylona. क

7. ANNON A folis lancolatis pubeferer cibus. Hort. sliff. ofricana. 222. Roy. lug $d b .494$.

Habitat in JEthiodia. 万 
\%. Anemone alpina aiba minor. Baub. pir. 176. prod I94. Burf. IX: 81.

Habitat in Alpibus Styriacis, Helveticis. 2

Confer: Puifatilla lutea, fainicara fyiveftris folio. C.B.

177. quice vix videtur ab bac diversa.

bortenys. 9. ANEMONE foliis digitatis.

Pulfatilla foliis digitatis. Hort eliff. 224.

Anemone, geranii rotundo folio, purpurafcens. Basb. pin. 173 .

Anemone hortenfis latifolia 3. Claf. bift. I. F. 249.

Anemone 1. Dod. pempt. 434.

Habitat ad Rhemum E' in Italia. 2

* Anemonoide flore nudo, reminibus ecandatis.

Fiveris. 10. ANEMONE peduncula nudo, feminibus fubrotundis hirfutis.

Ancmone feminibus hirfutis. It. oel. I I 2. Fl. Juec. 449. Anemone leminibus feta plumola terminatis. Hort. cliff. 224. Roy. lugdb. 224.

Anemone fylvettris alba malor. Baub. pin. гү6. Anemone fylveftris 1. Cluj. bift. 1. p. 244 .

B. Ancmone fylveftris alba minor. Baub. pis. 176. prodr. Hailitar in Germania. 20

virginama. II. ANEMONE pedunculis alternis longiffimis, fructbus cylindricis, feminibus hirfutis muticıs.

Anemone caule ramofo, petalis lanceolatis. Roy. lugdb. 488. Grow. airg. I65:

Anemone virginiana tertie fimilis, flore parvo. Herm. lugdb. 645. parad. 18.2. 18.

Habitat in Virginia. 2:

Caulis nudus, terminatus Foliis ternis, ternatis: medio trilovo, acuto, ferrato, lateralibus bipartitis, lobato-ferratis. Pedunculus exize centro petiolurum, longus, nudus. Flos parvus petalis ovatis, viriditus, inftar calycis cujusdam. Pintilorum capitulum elongatum, cylindricum, refolvitur in Semina birfuta. Juxta pedunculi bafin exit coulis wlterins, terminatus pedunculo florifero of folis dicobus oppofit is of fic ulterius.

tichaseme. 12. ANEMONE caule dichotomo, foliis feffilibus amplexicaulibus palmatis. Amms. accid. I. p. 155.*

Habitat in Canada, Sibiria. 2

evfolia. 13. ANEMONE foliis sermatis ovatis integris ferratis. caule 
caule uniforo. Hort. upf. I s5. Hort. rliff. 224 . Roy. lugdb. 488. Dalib. parif. Íri.

Anemone trifoila, fiore albo. Basb. bif. 3. p. 412.

Anemone trifolia. Dou. pempt. 430 .

Habitai is Gallia. $\#$

4. ANEMONE foliis quinatis ovalibus ferratis, calle gninquefotis unifioro.

Ranuncuius nemorum, fragaria foliis, virginianus. $P$ /sk. alm. $310 . t$. rs. $f .3$.

Habitat in Virginia, Canada. Kalm. z

15. ANEMONE feminibus acutis, foliolis incifis, cau-rentorofs, le unitloro. Hort. cliff. 224. Fl.jucc. 450 . Roy. ikg db. 488. Mat. med. 275. Datib. parif. I6I.

Anemone nemorofa, ilore majore. Bash. pin. I 76.

Ranunculus fylvarum. Clasf: bifl. 247.

Habitat in Europx afperis, duris, memoribus. *

6. ANEMONE feminibus acutis, foliolis incifis, pe- aperninn. talis lancerlatis numerolis.

Ranunculvs nemorolus, flore carulso, apennini montis. Mcntz. fug. t. 8. f: 2.

Rádunculus neinuroíus, fore purpuro-caruleo. Park. theatr. 325 . Rei. angl. 3. p. 259.

Anemone, geranii robertiani folio, carulea. Balk. pin. 174 ?

Habitat in Apenninis, Anglia. 2

17. ANEMONE fominibus acutis, foliolis incifis, peta- -annuculoi: lis fubrotundis, caule fub-bifioro. Hort. cliff. I 25 . Fl. Juer. 451. Roy. lugab. 488. Dalib. porif. 161.

Ranunculus nemorofus luteus. Baub. pin. I 78 .

Ranunculus phragmites luteus nemorolus. Barb. bift. 3 . p. 413.

Habitat in Europa borealis pratis nemerefis. 2

15. ANEMONE calle uniforo, involucro foliofo ob-Sisirice. tufor.

Habivat in Sibiria. D. Gmelin. 2

Folia radicalia digicata, mulsifuda, marginibus proferiim hirfuta: peisolis pilufis bafi vaginantious. Scapus nuáus, pulofus. Involucrum $\int$ ú fiore tripartitum, lobatum: laciniis lanceolatis. Flos patens: pctains $6, j u b-$ rotundis, fulass. Siaminibus favis. Pittillorum capitula fubrotunda, muricata. 
Harciffifolis. 19. ANEMONE foribus vmbellatis, feminibus depresLo-ovalibus nudis.

Anemone multifora, femine lævi latiffimo, petalis fenis ex rotundo-acutis. Hall. belv. 330 .

Ranunculus montanus hirfutus humilior, narcili flore. Baub. jin. 182 .

Rawunculus montani 2 tpecies altera. Cluf. bijt. I. p. 235 .

Hubitat an Alfibus Aultria, Helvetix, Sibiriz. \#

forciculista. 20. ANEMONE fioribus umbellatis congeltis, foliis thultifidis. $t$

Ramunculus orientalis, aconiti lycoctoni folio, flore nagno albo. Tournef. cor. 20. isin. 3. p. 92.t. 92.

Habitat in Orientc.

Dbfure adbuc difirina a procedente, (cui fimillima) quaradiu bujus femino non deforipta funt.

Tistiftroi-21. FNEMONE folis caulinis fimplicibus verticillatis, Lies. radicalibus duplicato ternatis.

Ranunculus nemorolus aquilegix foliis . virginianus, aiphodeli radice. Plak. alm. 3IO. $t$. $106 . f .4$.

B. Thalietrum caule uniftoro, ex eodem puncto foliis quatuor fimplicibus inftucto. Grom, virg. 62.

Hativat in Virginia, Canada.

Caradconfis plante o, a D. Kalmio lecter, Radix tuberola. Folia radicalia petiolis longis, duplicato-terna. ta: folioits fubcordatis, angulatis. Scapus foliis pruslo strior, terminatus foliss quatsor fimplicibus, foliolis n $^{-1}$ dicalibus finilibus, peticits longis infirdentibus. Pedunculi terminales, conferti f. fafriculati $\mathrm{I}, 2,3 . \int 5$, fimplices, zuifiori, cequales. Corolla albe : petalis uzatis, obtufts, patentibus. Stamina Alsvefcentia. Pifitili safitulum ovatum, muricatum.

\section{ATRAGENE.}

acylnica. I. ATRAGENE cirthis diphyllis. Fl. zeyl. 226.* Atragene. Amun acad. t. $p .405$.

Clematis zeylunica, floribus obloletis parvis. Hern. $2 e \%$. 35.

Mabitizi in Zeylonan 3

Ulyan, 2. ATPAGENE foliis duplieato-termatis ferratis. Clematis foliis cordatis crenatis indivilis trilobis terua tisque. Roy. lugdb. 437 . 
Clematis alpina geranifolia. Bauk.p 23.300 prodr. $\times 35$. Pluk. alm. 109. t. 84. f. 7 .

Clematis crucrata alpina. Pon. bald. 335 .

Anemone, tubis caudatis, tetrapetala, pinnis latifimis. Hall. belv. 332.

Mabitat in Helvetia, Baldo, Sibiria. क

3. ATR A GENE foliis ternatis: foliolis tripartitis fubfer-fikivics. ratis.

Habitat in Sibirixe Subbumidss robique.

Caulis farmentofuts. Folia oppofiza, ternata, fubferrata; foliolis trifidis: lobo exteriore frofundiore. Flores paniculati, rubri, plepi. Facies Aquilegice follata.

4. ATRAGENE foliis ternatis : foliolis incilis laceris. capensa. Pulfatilla foliis trifidis dentatis, flore incarnato pleno.

Burm. afric. 148

Pulfatilla apii folio rigido, fore magno. Herm. afr. 18. Habitat ad Cap. b. Spei. 2

\section{CLEMATIS.}

\section{* Coandentes.}

I. CLEMATIS foliis compofitis decompohtisque: folio-Irticelit. lis ovatis integerrimis. Hort. cliff. 225 . Roy. trgdth. 486.

Clematitis cxrulca vel purpurea repens. Batib pira. 300 .

Clematis altera. Clzzs. hifit. 1. p. 122 .

Clematitis cærulea, flore pleno. Buabh. pin. 360.

Habizut in Italiae, Hiipanix fepibres.

2. CLEMATIS foliis compolitis decompontisque: fo. Viorna. liolis quibusdam trifidis. Gron. virg. 62.

Flammila fandens, flore yiolaceo claufo. Dill. eltb. 144. t. 118. f. 444.

Clematis purpurea repens, petalis florum coriaceis. $R_{a j}$. bift. I928.

Scandenis caroliniana planta, viornæ folio. Pet.fisc. 27. Ilabitat in Virginia, Carolina.

3. CLEMATIS foliis simplicibus ternatisque: foliolls ith-krifpas tegris trilubisve.

Clematis flore crifpo. Dill. clth. 86. t, 73, f. 84 .

Habitat an Carolina.

4. CLEMATIS folits compofitis: foliolis incius angu-orientation latis lobaris cuncitormibus.

Cle. 
Clematis orientalis, apii folio, fore e viridi-flavefiente pofterius retlexo. Tourwef. cor. 20.

Flammuia feandens, apii folio glauco. Dill. eltb. Iat t. I19. $f$. I 45.

Habiat in Oriente.

vitalba. s. CLEMATIS folitis pinnaris. foliolis cordatis fcandentibus. Hort. cliff. 225. Roy lugdh. 4\% C. Hall.belv. 334. Gron wirg. 62. Saxv. monst. 2, Gort. gelr. 315

Clematitis latiroiz integra. Basb. bifl. 2. p. 125.

Clematis tertia. Cam. opit. 097.

B. Clematis latifolia dentata. Bauh. hift. 2.p. 125

Vitalba. Dod. pempt. 404.

7. Clematis fylveltris latifolia.3aub. pin.300. Slaar jam.84. Hatitat in fepibus Europx auftralis, Virginix, Janraica.

tirtbara. 6. CLEMATIS cirhis fcandens. Hort. cliff. 226. Roy lugab. 487 .

Clematitis peregrina, follis pyri incifis. Baub.pin. 300.

Ciematis altera batica. Cluf. bifl. 1. p. 123.

Clematis peregrina, foliis pyri incifis: nunc fingularibus, nuinc ternis. Toursef. ror. 20.

Habitat in Batica, arbores operiens $E$ defrintms.

Flampinia, 7. CLFMATIS foliis inferioribus pinnatis iaciniatis: iummis fimplicibus integerrimis lanceolatis. Hort. cliff. 225. Roy. lugdb. 486. Hall. belv. 334. Sazev. monfp. 249 .

Clematitis f. Flammula repens. Baub. pin. joo. Raj, bijt. 621.

Flammula. Dod. pempt. 404. Dalecls. bift. 1 I 7

B Clematitis maritima repens. Baub. pin. $3 \mathrm{co}$. prodr. 135 . Uabitat Monfpelii, Jenæ, inque Khetia Cepibus

\section{* erects}

8. CLEMATIS foliis pinnatis: foliolis ovato-lanceolatis intercrrimis, caule erceko. Hort cliff. 225 . Horl. itf. 155. Ro\%. liegd6. 486. Sauv. mones. 249.

Flammula recta. Baub. pin. 300.

Flammula. Cam. epit. 698. Clmf. bijt. 1. p. 124 Habitat in collicus Auftrix, Pannonix, Tararix, Mon. fpelii. $z$

witegrifolia. 9. CLEM ATIS foliis fimplicibus ovato-lanceolatis. Hort. cliff. 225. Hort. upi. ₹ 56. Roy. luga'b 486

Clematitis carulea erecta. Baub. pin. joo. 
Clematis cxrulen pannonica. Claf. bijt. x. p. I.3.

Habitat in Hungarial, Tataria. ?

\section{THAIICTRUM.}

1. THALICTRUM caule fimplicitimo fubnudo, race-nlainum. mo fimplicitermiuali. Hort. cliff 22.7. F\%. Suec, 455 . koy. lugdb. 45 i.

Thalictrum caule tubnudo fimplici, foliolis obtufis. Fl. lapp. 225.

Thalictrum montanum minimum præcor, foliis fplen. dentibus. Mors. hift. 3. p. 325. j. 9. t. 20. f. 17. Habitat is Alpobus Lapponiz, Arvonia. 2

Petala 4, Stamina 12, Piftilla $8, K$ Kacemus fomplex fio. ribu: cernuss.

2. TH.ALICTRUM caule paniculato ramofifimo fo-fctitum. lioro.

Thalikirum caule filiformi ramofiflimo in paniculam difperlo fubjectis folio is. Hort cliff: 227. ${ }^{*}$ Royliggab. 45, Saur. monfp. 251.

Thalikrum minimum foridifimum. Basb. pin. 337. prodr. 147. Bauk. bifl. 3. p. 489. Morif. bift. 3.

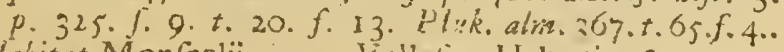
ilabitat MonSpelii, inque Valletia, Helvetia. 2

3. THA LICTRUM floribus pentapcualis, radice tubero- tuberofam. Ia Lfort. cliff. 227. Roy. lugab. 480 .

Thalictrum minus, alphodeli radice, magno flore. Tour. nefi: inft. 271 .

Ranuncplus thalictri folio, afphodeli andice. Morif. bift 2. p. 43 S. 5.4 . 28 . f. 13.

Oenahtine folio hederx, Bauk. pin. 163.

ftabite: in Hifpania. 2,

4 THALICTRUM roribus pentapetalis, radice fibrora. cornne. Ko). lag th. 480 .

Thalicirum canadenfe. Corn. canad. 186.

Thalietrum americanum. Pork. theatr. 205.

Thalietrum majus, foliis aquilegim, flore aibo. Morif.bift. 3. p. 3. 325.

Habilat in Canada. \#

THALICTRUM toribus dioicis.

Habitat in Canada. Kalm.

dioner?t.

Alritudo vix pedalis. Caulis restus. Flores tetrapeial, curollis fr faminibus 40 albis. Antherx flavefcextes. M $\mathrm{m}$

Folio- 
Foliola rerpua fust, qua roia difinerifima evidit flanta ex haisou.

minits. ¿. THALICTRUM foliis rexpartitis, fioribus cernuis. Tinalictrum caule foliofo, foliclis cauinis acutis, panicula divaricata, foribus rutantibus. Fl. Suec. 454 . It . roti. 180. * Dalib. paris. 454 .

Thalicirum minus. Baub. pin. 337. Dod. pempt. 5 S. Ruta pratenfis minor. Tabcrn. ic. 55 .

Ilabitat in Europx pratis. \#

sibiricm. 7. THALICTRUM foliis tripartitis divaricatis, doribus cernuis.

Halitat in Sibiria D. Grselin.

Habitus, Semina EF omnia aniecedentis, ai Folia baf? tansum tripartita, ES foliola ienella, glauca, parwa, uti in Fumaria.

prilurajcens 8. THALIC'T RUTM fuliis tripartitis, caule foliis duplo alriore, floribns cernuis.

Itabiat in Canada.? 4

Habitus Thaizzri mivoris, at vix pevilis eradit, ubiildo tripedalis. Caiyces purpurafcentes, Iaminibus iuteis. Caulis eijam purparafcens.

angufifoli- 9. THALICTRLM foliolis lanceolato-linearibus inteuns.

gerimis. Hort . liff. 226. $\%$ l. bybrid. 28. Kay.lagdb. 487. Hall. belv. 308. Sauv. monjp. 25:.

Thalictrum pratenfe, anguftifimo folio. Baub. pin, 357 prodr. $14 \%$ t. I46. 1,luk. alm. 364.t. 65. f. 6.

Habitat in Germania rarixs. 2\%

Peialia 4, ftamina $x 6$. Pifrilla 7.

- Mavuis. ro. THALICTRUM caule foliofo fulcato, panicula multiplici erecta. Hort. cliff. 226 . Fl. fusc. 453 . Roy. luadb. 455. Hall. beiv. 308. Dasib. parif. I62.

Thalisirum pratenie. Fl. lapp. 224.

Thalictrum majus, filiqua anguiofa $\mathrm{f}$. ftriata. Baub. pin $33 \%$.

Chalictrum magnum. Dod. pempt. 58.

fpeciofun $\beta$. Thabietrum majus Havum, floribus luteis 1. glauso folio. Bauh. pin. 336. jiaminibus fuivis.

Habitat in Europa jeptentrionalioris $\sqrt{ }$ uburnidis; $\beta$.in $\mathrm{HH}$ fiania. 2

Petala 4, Stamina 24, Pifilla! ro... I6.

bycid:un.

:4. TITALICTR UM cavie foliofo fulcato, foliis linea ribus carnolis. Labib. fary. I6z. $t$ 
Thalictrum minus lucidum, libanotidis coronarix foliis. P!uk. airn. 363. t. 6, $f$. .

Thalictrum minus alterum parifienfium, foliis crafioribus \& lucidis. Tournef. inft. 271.

Thalikrum I, vel pratenfe 2. Clas. bift. I. p. $23+$.

Habitat Parifis of in Hifpanin.

Planta, an fatis dif?inc? a, a T. flavo? videtue temporis filia.

12. THALICTRUM fruetibus pendulis trianguiarous aquilegifoli restis, caule tereti.

sim.

Thalitrum feminibus triangularibus pendulis, ftipulis saulinis. Hort. cliff. 226. Fl. jzec. 452 . Roy. lugdb. 285. Hall. helv. 309.

Thalictrum majus . florum ftaminibus purpurafeentibus. Bash. pin. 337.

Thalictrum majus, foliculis angulofis, caule lavi. Bawh. bift. 3. P. 487.

Habitat in Scania. Helveria $\$$

Petcila 4, Starnista 60, Piftiltu 16 :

13. THALICTRUM fruEtibus pendulis triangulatibus comterzum. contortis, canle fubancipiri.

Thalictrum hyobidum feminibus contortis. Fl. bvarid. 27. *

Habitat in Sibiria. G. Dersidaff. $z$

Petala 4 Stamina oo, Pijtilla 8. antecedenti jimilite, fed humitior floribus allis.

\section{NIS.}

1. ADONIS fioribus oftopetalis, fruetibus iubcylindri- antur. cis. llort. up $\int$. is 6 .

Adonis radice annua. Hort. cliff. 321. Ray. Ingáb.

489. Dalib. parif. 162. Sauv. muntp. 253 .

a. Adonis lylventis, tore phourceo ejusque toliis longio-phenicea. ribus. Bauli. pin. -8

Adonis fore pallido Cum. epit. 648.

6. Adonis horrcnfis dore minore atro-rubente. Bawb. pin. a:rorubens. 178.

Flos adonis. Clee. bift. 1. p. $33^{6}$.

Habitat inter jegetes Europe au'tralis. ค

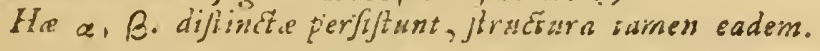

2. ADONIS fore dodecapetalo, fruetu ovato. Adonis radice perenni. Hort. cliff. 231 . Fi. firec. 450 . 1t. al. 73. Koy. lagdb 488. Sauv. munlp. 253: 
Helleborus niger tenuifolius, buphthalmi flore. Bauto pin. 186.

Buphthalmum. Dod. pempt. 261.

Habitat in Oclandix, Boruffix, Bohemix collibus api's cis. 2 .

apinina. 3. ADONI3 fioribus pentdecapetalis, frudu ovato.

Helleborus niger ferulaceus, caule geniculato, hore magno tulipæ minotis inftar. Mentz.prg. t. 3.f. I. Habitat in Siburia, Apenninis. 2

Difficillime diltingrantur plante 2. 3. fimillima. Caulis 2 adjperfus pilis; 3 pundtis farinofis pellucidis. Ra. $\mathrm{mi} 2$ ex caulis partc inferiore; $36 x$ alis $\int u p e r$ oribus Pedunculus 2 brevifimus; 3 longior. Folia in 2 mio mus pinnata; 3 magis divila. latiora, nitidiora. Calyx in 2 grifeus friutus villojus concavus; 3 luteo rirefcens, glaber, avenius, planus. Perala in 2] lancerlata, Japius duodecim; 3 ovata, imbricata, fupius quindecim. Flos in 2 unicus; in 3 plures. Stamins in 3 valde reflexa. Planta 3 . diutius allate durat: vero vernalis eft.

caperis. 4. ADONIS fruetibus depreffis, foliis duplicato-ternatis ovatis ferratis.

A ctæa trifoliata hirfuta, toliis fcabris, tlore fulphureo rariore Burm. afr. I $47 . t$. SI.

Chriltophoriana africana ranunculoides, foliis rigidis. Boert. lagdt. 2. p. 62,

Ranunculus athiopicus, toliis rigidis, floribus ex luteo. virefenribus. Comm bort. I. p. 1.t. I.

Imperatoria ranunculoides africana enneaphyllos, lafer. pitii lobatis foliis rigidis margine fpinotis. Pluk.alm. 198. t. 95 . f. 2 .

Habitat and Cap. b. Spei. "

\section{RANUNCULUS. \\ * Folus fimplicibus.}

Fismmula. I. RANUNCULUS foliis ovato-lanceolatis petiolatis. caule declinato. Hort. cliff. 228. Hl. Suec. $45^{8}$. Ruy. lugaú. 489. Hall. betv. 322. Dalib. parif. I63.

Rauunculus foliis ovato-oblongis integerrimis, caule procumbente. Fl. lapp. 325 :

Rannnculns longitolius paluftris minor. Basb. pin. 180 Flammula Ranunculus. Dod. pempt. 432.

B. Ranunculus paluftris, foliis Cerratis. Baxh. pin, 180 . Habitut in Europie pajcriss udis. 2 
2. RANUNCULUS foliis lincruibus, caule repente. reptons

\section{Fl. lapp. 236. t. 3. f. 5. Fl. Juec. 459}

Ranunculus tianmeus minimus, fpergulæ folio. B*xb. cent 5 . app. 4 r.

Ranunculus repens, gramineis folis, efingulis geniculis radices agens. Amm. rutb. 80. $t$. 13. f 1 .

Habitat in Succia. Ruffia ad ripas lacusion antecedenti valde atfines io foric varictis.

3 RANUNCULUS toliis lanceolatis, caule erecto. Lingua. Hurt. cliff. 228. H\%. fuec. 457 Roy. luggdb +59 . D.ilib. p.rif. 163.

Kanunculus inngifoliur paluteris major. Baub. fir. 34 . Ranuncuitus lanceolatuvinajor. Tabern.ic. 48 .

Halitat in Europe bsecalioris fofles, aquis limofis. 2

4. R.ANUNCULUS foliis oratis petiolatis, finribus fes-nodifinas. filibus. Hort cliff : 29 . Dalib. pari. 164.

Ranunculus parificulis pumilus, pintaginellx folio. I'et.gaz. 40.t.25.j. +. labll. ad. $1719 . p \cdot 52 . t$ 4. f. 4 .

$\beta$ Ranunculis ficulus, folin rotundo vix ferrato. Pet.

Hatstat Parifis ${ }^{2} f \cdot 9$. Sicilia locis paluciofs

r. R.ANLNCULUS foliis lanceolaro-lincaribus feftili-grenirem bus, caule ereeto, radice bulbota. Ho:t. cliff. 258 . Roy. liggio. 489 . Dalib. parif. 163 . Jawr manfp. ij. Rantinculus, ramineo tolio, bulbolus, Bauh. pins. 150. kamunculus pumilus, gramiucis toliis. Baxis. hift. j. p 806.

Hydropiper lanceoi:Itum. Daelch. hijt. $103^{8}$.

Habitat an Pyrenæis E Galize pratis aridis. 2

6. R.ANUNCUIUUS foliis fuboratis nervolis integer-parnafifalum rimis petiolatis

Rananculus montanus, gramiuis parnafti-folio. Tourncf. in:ft. 286.

Haivitat in Europa anjtrait.

7. RANUNCULUS foliis ovatis acuminatis amplexi- nmplexicar:caulibus, caule fubunilloro, radice faciculata. Hort. lis. clift. 229. Koy. lagdb. $4^{5} 4$. Saur. mon/p. 76.

Rananculus muntanus, folio plantaginis. Bash pin. 80 . Alorif. bi/t. 2. p $4+4 . \int .4$. 6.30 f. 30 .

Ranunculus dulcis, foliis latis rapinti perfoliatis, floribus albis. Menz.pug. t. S. j 6. 
B. Ranunculus montanus, folio gramineo. Baub.pin, 181 . Morif. bift. 2, p. 441. . . 4.t. 30. f. 38.

Hebitat in Pyrenæis, Apcnninis. 2

willats, 8. RANUNCULUS foliis ovatis ferratis, feapo nudo uniforo. Hort. cliff. 220 .

Ranunculıs latifolius buîlatus, afphodeli rndice. Baxb. pin. ISi.

Raninculus lufitanicus. Dod.pempt. 429.

Ranunculus grumora radice 1. Claf. b.ft. โ. p. 238 .

B. Ranunculus latifolins bulbatus autumnalis, flore pleno $\&$ prolifero. Morif. $h_{2}: A .2 . p \cdot 447 . \Gamma \cdot 4 \cdot t \cdot 3^{1} \cdot f \cdot 49 \cdot$ so. $5 \mathrm{x}$.

Habitat in Lufitania, Creta. $\%$

ficatin. Q. RANUUNCULUS foliis cordatis angulatis peticlatis Fl. juec 460 . Hort. ciiff: 228. Hat. med. 274 . Koy lugd6. 490. Dalib parif: $10 \%$.

Chelidonia rotundifo'ia minot. Baubs piz. 167.

Chelidonium minus. Fucbf. hifi. 866 .

Chelidonia rotmindifolia major. Baub. pia. 167. prodr 137.

Habitut in Furopæ ruderatis, umbrofis. Spongiofis. $z$

Tho: 10. RANUNCULUS foiiis reniformibus fubtrilobis crenatis, canlino îcfili, Horalibus lanccolais, caulc fub-bithöo.

Aconitum pardalianches $\mathrm{r}, \mathrm{r}$. Thora majo: Bavi.pir. 184.

Thora major. Cam. epit. 825.

Ptora valdenfum. Lob. i. . 604. Cluf. hilt. i. p. 2y).

B. Aconitum pardalianches alterum, t. Thora minor. Baub. pin. I $\delta_{4}$.

Thora minur. Gam. epit. 826.

Limeum pardaiianches genus, uno tantum folio. Dalecb. bift. 1738.

Raifunculus foliis radicalibus cordato fubrotundis, cau.. linis fefilibus lanceolatis integerrimis. Hall. belv. 327 .

Irabitat in Alpibus Helveticis, Pycenaicis. 2

$$
\text { * Tolive differtis Eo dinufis. }
$$

retiens. II. RANUNCULUS foliis radicalibus reniformibus crenatis fublobatis, caulinis iripartitis lanceolatis integerrinis, caule multilloro.

Ranunculus foliis radicallbus cordato-fubrotundis, cau- 
liris tripartitis lesfilibus lanccolatis integerrimis. Roy. lagg do. 49o.

Ranunculus, afphodeli mdice, creticus. Bauh.pin. $x$ \&. R.munculus creticus latifolius. Cluf. hift. r. p. 2.39.

linabirat in Creta. 2

5. 2. RANUNCUL, U S foliis radicallbus fibrotundo-corcoffuticus, datis crenatis; caulinis digitatis dentatis, caule muiti floro.

R.anunculus rotundifolius vernus fylvaticus major vel caffubicus, folio thore calthx. Breym. prodr. 1.p. 45

Ilabitat in Caffuida, Siniria. $z$

13. RANUNCULUS foliis radicalibus reniformibus surjeomi's. crenatis incifis; caulinis digitatis linenitus. caule multitoro. Hort. aliff. 229. Fi. fate. 452. Ray. lugdh. 490. Hall. belv. 32.7. Dalib. paril. 167.

Rammeu'us nemorolus f. Sylvaticus, folio fubrotunda. Busb. pin. I7.

Ramurculus 1. fylvetris. Dalech. biff. IO2s.

Hubutu in Europx palcuis bumidiufculis. 2

14. RANUNCULUS foliis radicalibus cordatis crena-abortivus. tis; caulinis tematis angulatis, caule lubtrifloto.

Ranunculus folis radicalibus crenatis, caulinis digitatis petiolat:s. Roy. lugdb. 490.

Ranuncu!us foilis radicalibus renitormibus crenatis petiolatis: caulinis paucis digitatis filfilibus. Gron. virg. I66.

Ranunculus virginanus, Aore parvo, molliori folio. Herm. lag dis. 514.

Habitat in Virgioja, Canada.

15. RANUNCLLUS follis inferioribus palma' is; fum- felernes. mis digitatis, filiet ous ublungis. Mort. cliff. $23 a$. F\%. fuec. 4G3. Roy. lag dì. 490. Hall. belw. 323 . Gron. virg. 63. Dalib. parif. 167.

Ranunculus paluftris, apii fulio, lavis. Baub. pim. 580 , Kanunculus lylventris 1. Doi. vempt. 425 . Habitat ad Europa fifias es paludes. ()

16. RANUNCULUS foliis ommibus quinatis lancenla- monitifolius tis incifo-ferratis. Hor: cliff. 229. Hort. upf. 156. Ro\%. lugdb. 4\%0. Hall. belu. 325 .

Ranuículus montanis, aconiti tolio, albus: Bore majore. Bash. pir. $1 \$ 2$.

$$
\text { Min } 4 \quad B \cdot R_{2}
$$


G. Ranunculus montanus, aconiti folio, albus fore nino.

re. Boub. pin. 182

Kanunculus moit!nus 4. Cluf. bi/t. I. p. 236 .

$\gamma$. Ranunculus folio aconiti, thore albo multiplici. Baub. pin. I79.

Ranunculus plens tiore albo. Clus. bift. I. p. 236.

Habitat in Alpibus Helveticis, Auftriacis. 2

illyricus.

37. RANUNCULUS foliis ternatis integerrimis lanceclazis. It. xl. 7r. Fl. Jues 47 T.

Ranunculus folis tripartitis: laciniis linearibus, caulc multitoro, radice ruberofa. Hort. cliff. 230. Ray. iugd3. 491. Sauv. monfp. $18 \mathrm{r}$.

Ranunculus lamuginofus anguftifolins, grumofa radice, major Go minor. Baub. pin. I8i.

Ranunculus grumofa radice 4. Clus. bilt a. p. 240.

Habitat in Oelandia, Hungaria, Narboma, !talia. 4

sinticus, 18. RANUNCULUS foliis ternatis hiternatisque, folinI: trifidis incifis, caule inferne ramofo.

Ranunculus foliis tripartitis lacinatis, caulc inferne ramolo, radice tuberor. Hort cliff. 23c. Hort. $4 \%$. 756. Roy. lugdi. 490.

Ranunculus, grumofa radice, ramofus. Binh. pin. isi. Ranunculus afiaticus polyclonos $f$ grumofa radice. 2. Claf. bift. 1. p. $24 \mathrm{r}$.

$\beta \cdot$ Ranunculus grumofa radice, fiore flava vario. $\mathbb{B} a$ b. pin. 181 .

\%. Ranunculus grumofa radice, fore alho. Rauh. pis. 18 r. 8. Ranunculus gramofa radice, flore àbo ieniter crenato. Baub. pin. I8I.

E. Ranunculus grumofa radice, flore niveo. Baut. pin. $18 \mathrm{r}$.

$\zeta$. Ranunculus grnmofa radice, flore phoniceo minima fimplici. Bauh. pin. I 8 r.

ฑ. Ranunculus afphodeli radice, flore fangvinco. Baub. pin. 181 .

9. Kanunculus afphodeli radice, fiore fubphneniceo ruben* te. Baseb. piz. 181 .

6. Ranunculus, afphodeli radice, prolifer miniatus. Basts pin. 181 .

Habitat in Afia vel Mauritania. 2"

rmafoliss. 19. RANUNCULUS foliis fupradecompofitis, caule fimpticiftimo unifolio, radice tuberofa. Hort. aliff: 230. Koy. ingdb. $49 I$. 
Ranunculus rutace folio fore fusve rubente. Banh. pin. 18r. Marif. bift. $\therefore$ p. 448, . 4. t. 31 . f. i4.

Ranunculus pracox i, ruta folio. Cluf. Lijt. 1. p.232.

Halatat in Alpiba: Auftrix, Delphinstus. 2 .

20. RANUNCULUS calycibus hirfutis, caule bitloro, glacialis. folits multifidis. $F$ \% $\int u \cdot 6$. 464.

Ranunculus caule bifloru, calyce hirfinto. Fl. lapp. 233. t. 3. f. . .

Ranunculus moutanus purpureus, calycevillofo. Bawb. bift. 3. 2. 868. Sobeuch. alp. 33\%. t. 20. f. I.

Habitat is Alpilus Lapponia. Heiveriz $\therefore$

3. RANUNCULUS calyce hiffuro, auic uniforo, nirgise foliis radicalibus palmatis; caulinis inulipartitis fe Bilibus. Fl. lapp. 232. t. 3. f. 2. H! Jat 46 r. Llall. belv. 326.

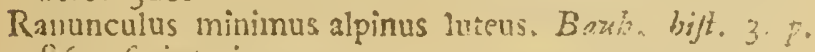
Sós. f. interior.

B. Ranunculus idem pygmaus. Fl. lapp. $232 . t .3 . f .3$.

Habitat in Alpiom Lapponia. Helvetia. 2

22. RANUNCULUS foliis radicalibus fubcordatis ot, atrefris, tufis tripartitis: lobis trilobatis; caulino hanccolato integerrimo, caule linitor(s.

Ranunculus caule aphyllo uniforo, foliis fubrumusis femitrifidis. Hall. belw. 326. Sauv. ranlp. 205.

Ranunculus alpinus humilis rotundifolius, fore majore \& minore. Baub. pin. 181 .

Ranunculus alpinus humilis albus, rolio iubrosurda, $S_{e}$ *. ier. I. F. 489 t. 12. \%. I.

Ranunculi montani 1. ifecies i. \& 2. Cluf. bift. I. p. $2 \hat{34}$.

Habitat in Alpibas Aufriacis, Helveticis. 2

23. RANUNCULUS oliis tripartitis lobatis obtufis, Lipponicas. caule fubnudo unittoro. Fl. Suec. 46r.

Ranunculus caule unifolio unitoro, foliis tripartitis. Fl. lapp. 23 I. t. $3 . f .4$.

Habitat in Alpibus Lapponicis.

24. RANUNCULUS foliis tripartitis crenatis, caule mor:Selizen. fimplici villofo fubuto unifloro. Sass. monfp. 1si.

Ranunculus faratilis, magno tore, Bawb. pir. $1 S_{2}$. prudr. 96.

Huoitat Monfpelii. 
bulbofus. 25. RANUNCULUS calycibus retroflexis, pedunculis iulcatis, caule erefto, foliis compofitis $F \%$. $u c c .469$. Dolib. parif. 10;.

Ranunculus radice fimpici globoria. Hort. cliff. 230 Ray. Lughb. 49r. Hall. helu. 323.

Rannnculus bulbolus. Joob ic. 666 . Fl. latp. 229.

Ranuteculus pratentis, radice verticilli modo rotunda. Baxh. pin. I79.

Habivat in Europa pratis. pafruis. 2

repens. 26. RANUNCUi.US calycious patulis, pedunculis fulcatis, itolowious repentibus, foliis compotits. $F$. frec. $\triangle 68$

Rununculus foliis ternytis, foliolis petiolatis trifidis: medio productiore, caule multifoio. Hort. clilf 230 Gro\%. Virs. I G6. Roy. Iugdb. $49 \mathrm{I}$.

Ranunculus pratenfis repeis hirfutas Bakh. pin. I79. 1\%. Lapp. 2.30 .

Rallunculus hortenfis x. Dá. pempt. 425 .

Habitat in Europa cu!tis. 2

polyanto. 27. RANUNCUI,US calycibus patuis, pedunculis fulintss. caris, caule erecto, foliis multipartitis. $H$. fuec. 467.

Ranuncultis polyanthemos fimpiex. Lab. ic. 666.

Ranunculus fvlveftris. Tabern. ir 42 . bjft. II 7 .

Hebital in Europd borealis graminofis. 2

aris. 28. RANUNCULUS calycibus patulis, pedunculis teretibus, foliis cripartiro-multitidis: lummis linearibus. Fl. fHec 466. Dalib. paris 164 .

Ranunculus foliis peltatis quiquangularibus multipartitis: laciniis linearibus, caule inultifloro. Hort. cliff. 221. Ruy. lugdb. 492 .

Ranunculus prateufis erectus acris. Baub. pim. I78. Fl. lapp. 228.

Ranunculus hartenfis. Dod. tempt. 420 .

3. Ranunculus hortenfis ercetus, tlore plena. Baub.pin. I $7 \%$.

Habitat in Europe pratis, pafcuis. it

anuirofus. 20). RANUNCULUS foliis tripartitis acute. finuatis romentofis.

Ranuriculus folis sxdicalibus pinnatis. Sauv. inosagp. 227.

Kannuculus montamus lanuginoíus, foliis ranunculi pratentis repentis. Baub. pin. 182. prodr. 96. 
Ranuncuius inagnus valde hirfutus, fiore luteo $B$ ank. bift. 3. p. 477 .

Halitat Montpelii. 2

Caulis altus, ereizus. Folia Aconitif Ran. acris, fed magris incifa. Senina arzera. comprefja.

30. RANUNCULUS caly cibus tetrofexis, pedunculis cherophyllus fulcatis, caule erefto, foliis compofitss. meice granulofa. Guett. ftamp. 275 Dalis. pari. 100.

Ranunculus charophyllos, arphodeli iadice Barsis. pron. $18 r . B a r r .86 \cdot 5 \delta$.

Ranunculus montanus leptophyllos, atphodeli aadice. Col. exphr. 1. p. 312, t. 311 .

Habitat in Gailia. Italia.

3I. RANUNCULUS feminibus acukeats, follis fupc-arqenfis. rioribus decompotitis linearibus. Hor: cleff. 229. Fl. Suec. 470. It. el. 104. *. Rog. Ingib. 49I. Dnlib. parif. 166.

Ranuncolus arvenfis echinatus. Baub. pis. Iyg.

Ramunculus fylveitris 3. Dod. pempt. $42 \%$.

Habitat in Europx asftralioris egris. $\odot$

32. RANUNCULUS feminibus acuicatis, foliis lim- mmicatus picibus palmatis licilis. Thari. cliff. 229. Hort usp. 157. Roy. lugdh. 49r. Saze. Marasp. 204.

Ranunculus palmetris cchinatus. Bast. pin. $180 . p r o d r$. 95.

3. Ranunculus rotundifolius repens echinatus. Bauls. pin. 180. prodr. 95.

y. Ranunculus ftellatus echinatus creticus, Basb. pin. 180.

d. Ranunculus hirfutus anıuus, tore minimo. Raj. cimgl. 3. p. 248. t. 12. f. 1. Pluk. alm. 3I. t. 55. f. 1.

Ranunculus arventis anmus hirfutus, fore omnium ninimo. Morif. bift. 2. p. 470 . $\int$. 4. t. 28. f. 21.

Habitat in Europw anferalis fogis \&o bumentibus. ()

ij. RANUNCULUS feminibus fpinofo-fubuiatis re-arientalis curvis, calycibus reflexis, foliis multiais.

Habitat in Oriente.

34 RANUNCULUS caule erecto bitolio, folijs mul- gramliporm rifidis; caulinis alternis refrilibus. Roy. lisgib. 492.

Ranunculus crientalis, aconiti folio, forc maximu. "Tossinef. cor. 22.

llabisat in Orientc. 2 
falcatus. 35. RANUNCULUS foliis filiform!-ramofis, calycibus appendiculatis. Hort. up $\int$. 1 57 . Sakz. monfp. 205. M yofuros tuilis ramolis. Hort.cliff. in . Roy.ingab. 492

Melampyrum: luteum minimum. B.7sb. pin. 234 .

Ramuncu'us ceratocephalus, feminibus falcatis in tpicam a uactis. Morif. bift. 2 p. 440. . 4 t. 28 . f. 22.

Habitat inter fegeics Europa aufiralis. (-)

isciraceur. 36. RANUNCULUS foliis fubrotundis trilobis intcherrimis, caule repente. Hort. cliff. 231. Roy. lightb. 492. Dalit. parif. 167. Gort. gelr. 325

Ranunculis aquaticis hederaceus iuteus. Baub pir ISo Morf. bift. 2. $p \cdot 44$ T. f. 4. t. 29. f. 29.

Habitat in aquis viadofs Anglix, belgii.

ugatilis. 377. RANUNCULUS foliis \{ubmerfis capillaceis, cmeris peltatis.

Ranunculus foliis inferioribus capillaceis, fupcrioribus peltatis. Fi. Ho. 234. Roy.izy th. 422 . Hall. belv. 328 .

Ranuaculus aquaticus, falio rotundu \& capillaceo. $B$ avón. pin. 180.

Ranunculus aquailis. Dod. pempt. 39\%.

B. Ranunculus foliis fubmersis capillaceis. $F \%$. juec. +72 . Dalib. parif. I 8 .

Ranunculus tolis onmihus capillaceis circumferintione rutumcis Hort. cliff. 231. Rey. Ingdb 492. Hall. bela. 32.8

Ranunculus aquaticus albus, circinnatis tenuifine divilis foliis. Pulk. alm. 3:1. t. $52 . f .2$.

Millefoliun aquaticum cornutuin majus. Babs.pin $1+1$. 2. Ranunculus foliis capillaceis circumfcriptione vaga brevioribus. Hall. belw. 328 .

Ranunculus aquaticus capillaceus. Bcuh. pin. 180.

Kanunculus trichophyllos aquaticus medio luteus. Col. ecpbr. I. p. 31\%.t. 316.

d. Ranunculus foliis omnibus capillaceis circumferiptione cblongis. Roy. lugdb. 492.

Ranunculus albus thuitans, peucedani foliis. Herm. lugdb. 517.

Habitut is Europa aquis undofts, fojits, rivulis.

\section{TROLLIUS.}

earcpens. 1. TROLLIUS corollis conniventibus, neetariis longiludine ftaminum.

Ilelleborus flore claufo erecto petiolato, caule finipliciflimo. Fl. Suec. 474 . 
Helleborus foliis angulatis multifidis, flore gioboio. Hort. clitf. 227. Kuy. lugdb. 484.

Helleboius caule fimplici, Hore pedunculato. Fl. lapp. 220.

Ranunculus hore globoro. Dod pempt. 430.

Habiant in Alpibus \& $\int$ ubalpins Sueciz, Germanix, Anglix. 2

2. TROLLIUS corollis patentilus, neetaris longitudine afnticus. petalorum.

Trollius humilis, flore patulo. Buxb.cent. I. p. 15.6.2.2.

Helleborus niger oricntalis, ranunculi folio, Hore neçuit. quam globofo. Tournef. tor. 20.

Helleborus aconiti folio, Hore globofo croceo. Amm rsth. 101.

Ilabitat in Sibiria, Cappadocia. 2

\section{ISOPYRUM.}

6. ISOPYRUM Itipulis fubulatis, petalis acutis. Hort.ymariois ups. 157 .

Helleborus fumarix foliis. Amm. ruth. 74. t. i2.

Habilust in nemeribus Sibirix. $\odot$

2. ISOPYRUM Atipulis ovatis, peralis obtufis.

thalictroides

Thalietrum batrachioides, fore albo, inalicum. Bocc. mif. 84. t. 79. f. : *

Kanunculus nemorolus, thalietrifolio. Bash. pin. 178 . Raj. bift. 584. Niorif. bifi. 2. p. 437 . . + t.t. $28 . f .12$

Ranunculus pracox 11 , thalietrifolio. Clri bift. : p.2.33.

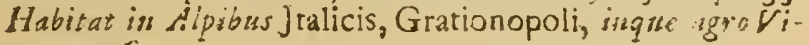
enmenjs.

3. ISOPYRUM Ripulis obfoletis.

Aquilegia montana, flore parvo. thalictri tolio. Basis. nquilegrioides pin. 144. prucir. 75. Bauh. hif. 3.p.434. Ray. hift. 707. Moril. befl. 3. P. 458 . f. 12. t. 11. f. 5. Hall. belv. 310 .

Habitat in Alpitus Helveticis, Tridentinis, Apeuninis.

\section{HEL LEBORLS:}

2. HELLEBORUS flore folio in idente. Horl. cliff. 22\% hemalis.

Hort. upj: 158 Kuy. lagydb, $48+$

Helleborus ranunculoides præcox cubcrofus, flore lutio.

Mor 2. bift. 3. p. 459. J: 12. t. 2. f. 4.

Acunitum unifolium bulbolum. Baub. pin. 183 .

Ilabitat in Lombardid, Iraila, Apenninis. if 
¿. HEIILEBORUS fcapo fub-unitoro fubnudo, foliis pedatis. Hort. mpl. 1, 7. Ruy.lugdb. 484. Mat. med. 273. Helleborus Capo tiorifero fubnuda. pitiolo commu. ni bipartito. Hort rliff. 227.

Hellevorus niger, finore rofeo. B.ash. pn. 186.

Elloburus niger lezitimus. Claf. bifl. 1. p. 275.

Habitat in Auftria, Hetruria, Apenninis. 4

vivias.

3. HELLEBORTIS caule multitoro folloto foliis digitatis.

Hellesoru canle equali folioio, foliis radicalibus raulem candem iuperantibus. Hort. clift. $22 \%$. Surt. upl: r.8. Roy. lugdi. 434.

Heileborus niger hortenfs, flore viridi, Bawb.tis. 185. Filleborum nigrum alterum. Cam. egit. 941.

Habitat in montibus Vicrnenfibus, Lugancis. Z

fatta\%s. 4. HE LLEBORUS caule mulritloro foliofo, foliis pedatis. Hellejorus caule inferne anguttato multiolio multificro, foliis canle brevioribus. Hort. witt 22\%. Roy.lugdb.

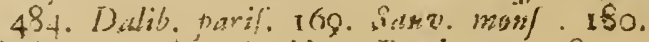

Hieliborus niger roetidus. Bazh. p1m. 185.

Heileborafter naximus. Lob. 26. 679

Hclleboras femina. Sterb. fun's. 372. 2. 36. f. C.

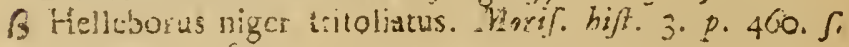
I 2. t. 4. $f .7$.

Habitat in Germania; Helvetia Gallia.

erifoius. 5. HFLLEBQR 13 S folis ternatis, foape unitoro. Ancen. acad. 2. t. $35^{-6}$ t. $f$ f. 18 .

Habitat in Canada, Sibiria. 4

\section{CALTIA.}

palufiss, I CALTHA. Fl. lapp. 227. Fl. fuec. 473. Hort cliff:

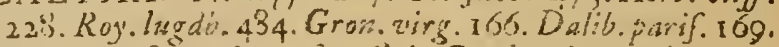
Caitha paluftris, tore fimpiici. Bauk. pin. $2 \rightarrow 6$. Populago major. Tabers. ic. 7 ro.

B. Populago minor Tabern. is. 750 . Calcha palultris, fore pleno. Baub fin. 276.

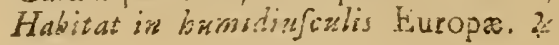

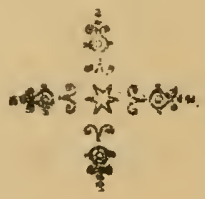




\section{$A D D E N D A$}

\section{Pag. 158. pol. Gridian.}

\section{STFILIERA.}

1. STELLFRA foliis !irearibus, foribus quadrifidis pajperino.

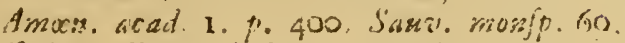

Palferina. Bants. bift. 2. p. 456.

Lithofpermum, linaria folio, germanicum. Baub.jin. 259

Linaria aliera botryoider montana. Col.ecphr. I.p.S2.8.80.

Habitat in Europa artis, campis, apricis, aridis. म

2. STELLERA foliis lanceolatis, corollis quinquefidis. Chamena Amon. acad. P. p. 400.

Cliamejafme radice mandragoræe Amin, rusk. 10. i. 2. Habitat in Sibiria. D. Gmelin. 2

\section{PASSERINA.}

1. PASSERINA follis linearibus convexis quadrifariam filformis, imbricatis, ramis tomentolis.

Patterina foliis linearibus. Morl. cliff. 246. t. In. Roy. lug db. 208 ,

Thymel:a anhiopica truticora, folits in lontrum ftratis, lurculis vaide tomentulis. Plak. mant. 180.

Thymeiza whiopica, pafferina follis. Breya, sent.ro.t.6.

Thinelxa foliis oppofitis cruciatis angultis, floribus tubralotis in fica modurs e foliorum alis ercets. Burin. afr. 27. t. 47 . f. 1.

Hibisat in Ethiopis b

2. PASSERINA folitis carnofis extuc glabris, caulibus tom hivfinta. mentofis.

Thymelaz tomentoia, folis fedi minoris. Baub. pise. 453 .

Sallamunda 3. Clug: hift. h. p. 80 .

Sefamcides parvum dalechampii. Bahl. bift. x. p. 59s. Inbitut in Hilpauia. b

3. PASSERINA foliis janceolatis iubciliatis ereetis, ramis cilintn. nudis.

Pafferina Eoliis lanceolatis. Hori.cliff. I 4 6. Roy lugelb. 208.

Thy nelad foliis chamelar minoribus hirfutis. Bauh. pin. 463

Thynelara foliis oblongo-acutis ad oxas fimbriatis Batm. afr. 129, t, 47 . f. 2 .

Sanainunda I Cluf. hijt. i. p. 88.

Esim 
Frica africana, rufci folio. Seb.thef.2.p.15,t.12,f. 9 Habitat in Ethiopia, Hifpania. b

"nujurs. 4 PASSFRINA foliis lincaribus oppofitis, floribus terminalibus folitariis, ramis glabris.

Thymclar foliis triquetris cruciatim oppofitis, fore fericeo. Barm. afr. 132, t. 48. f. 2 .

Thymelæa ramofa, lincaribus foliis angultis, flore folitario. Burme afr. I $3 x$. 2.48 . f. x.

Ilubitat is Hithopia. 万

\section{LACHN $\mathrm{EA}$.}

crisceplonin. 3. LACHNIEA capirulis Sulitariis lanatis, foliis quadriialiain imbricatis.

Lulitat in Rithiopia. 5

Folia trigona, gibor. Capitula terminalia, folitaria, tomentufa, cineta lasa canáta.

cong! im:rsia.

LACHN E A capitwlis confertis, folis laxis.

Thymelara śricana, polii anguftioribus folis, floribus in capitulis fummo caule glomeratis. Pluk. neant. 179. Kaj. dendr. 54.

Sanamunda 3 . clufii affinis, polii folio. Breyn.cent.18.t.7. Habitut ad Cap. b. Spei. 5

\section{Pag. 35. inter Melotbriam Eं Laflingiam. ORTEGA.}

bifpanics. 2. ORTEGA. 1, nfl. epif. YIII: 43.

Rubia linifolia afpera. Bash. pin. 333.

Incaria Ialmatica. Cluf. bifi. 1. 1.174.

Habitat ir Caftilia Misumt. Batical elez, Salmantica. 0

$$
\text { P.xg. } 79 .
$$

nembrami-

4. STIPA pedicellis dilatatis membranaceis.

sed

Habitat in Hifpania. Loening.

Gri. vix pedaiz, habitu Arience. Panicula frmplex, vis fubdivifa, laxa, drbilis Pedicelli membranacei, ancip:tes, obtufiufculi. Calycis arifta longitudinse arifto on rollina

$$
\text { Pag. 84. }
$$

Hyîrix. 0 . EL YMUS fpiculis involucro deftitutis.

Giamen arenaceum, locuntis arifatis, paniculis echinum referentibus. Gronoz.

Halitas in - - -

Spica compofita ex Spiculis duabus ad frugulum deratem.

Spiculx quadriflore; arifis; long is. Injolucra nulla. Sed buram boco Calle diso.
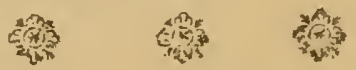

